University of New Hampshire

University of New Hampshire Scholars' Repository

\title{
Seasonal Changes in Sediment Grain Size of New Hampshire Atlantic Beaches
}

\author{
Larry G. Ward \\ University of New Hampshire CCOM, Durham, Igward@ad.unh.edu \\ Nathan W. Corcoran \\ University of New Hampshire, Department of Earth Sciences, Durham \\ Zachary S. McAvoy \\ University of New Hampshire CCOM, Durham \\ Rachel C. Morrison \\ University of New Hampshire CCOM, Durham
}

Follow this and additional works at: https://scholars.unh.edu/ccom

Part of the Geology Commons, and the Sedimentology Commons

\section{Recommended Citation}

Ward, L.G., Corcoran, N.W., McAvoy, Z.S., and Morrison, R.C., 2021, Seasonal Changes in Sediment Grain Size of New Hampshire Atlantic Beaches: BOEM/New Hampshire Cooperative Agreement (Contract M14AC00010) Technical Report, Department of Interior, Bureau of Ocean Energy Management, Marine Minerals Division, 45600 Woodland Road, Sterling, VA, 20166, 208 pp. https://dx.doi.org/10.34051/p/ 2021.33

This Report is brought to you for free and open access by the Center for Coastal and Ocean Mapping at University of New Hampshire Scholars' Repository. It has been accepted for inclusion in Center for Coastal and Ocean Mapping by an authorized administrator of University of New Hampshire Scholars' Repository. For more information, please contact Scholarly.Communication@unh.edu. 

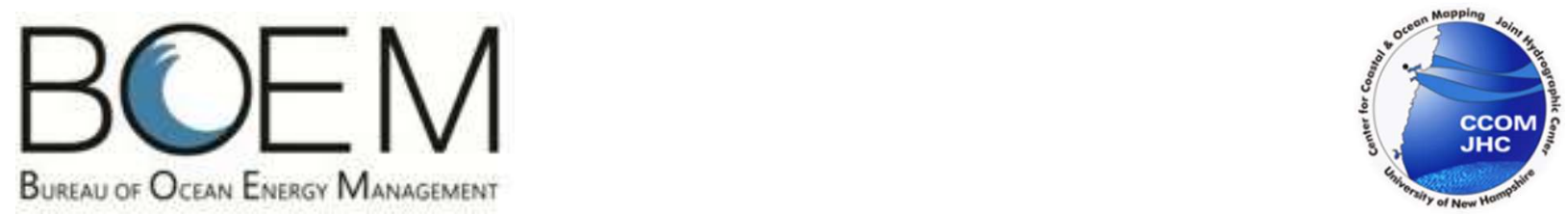

BOEM/New Hampshire Cooperative Agreement (Contract M14ACO0010) Technical Report

\section{Seasonal Changes in Sediment Grain Size of New Hampshire Atlantic Beaches}

By Ward, L.G., Corcoran, N.W., McAvoy, Z.S., and Morrison, R.C.

University of New Hampshire Center for Coastal and Ocean Mapping/Joint Hydrographic Center 24 Colovos Road, Durham, NH 03824
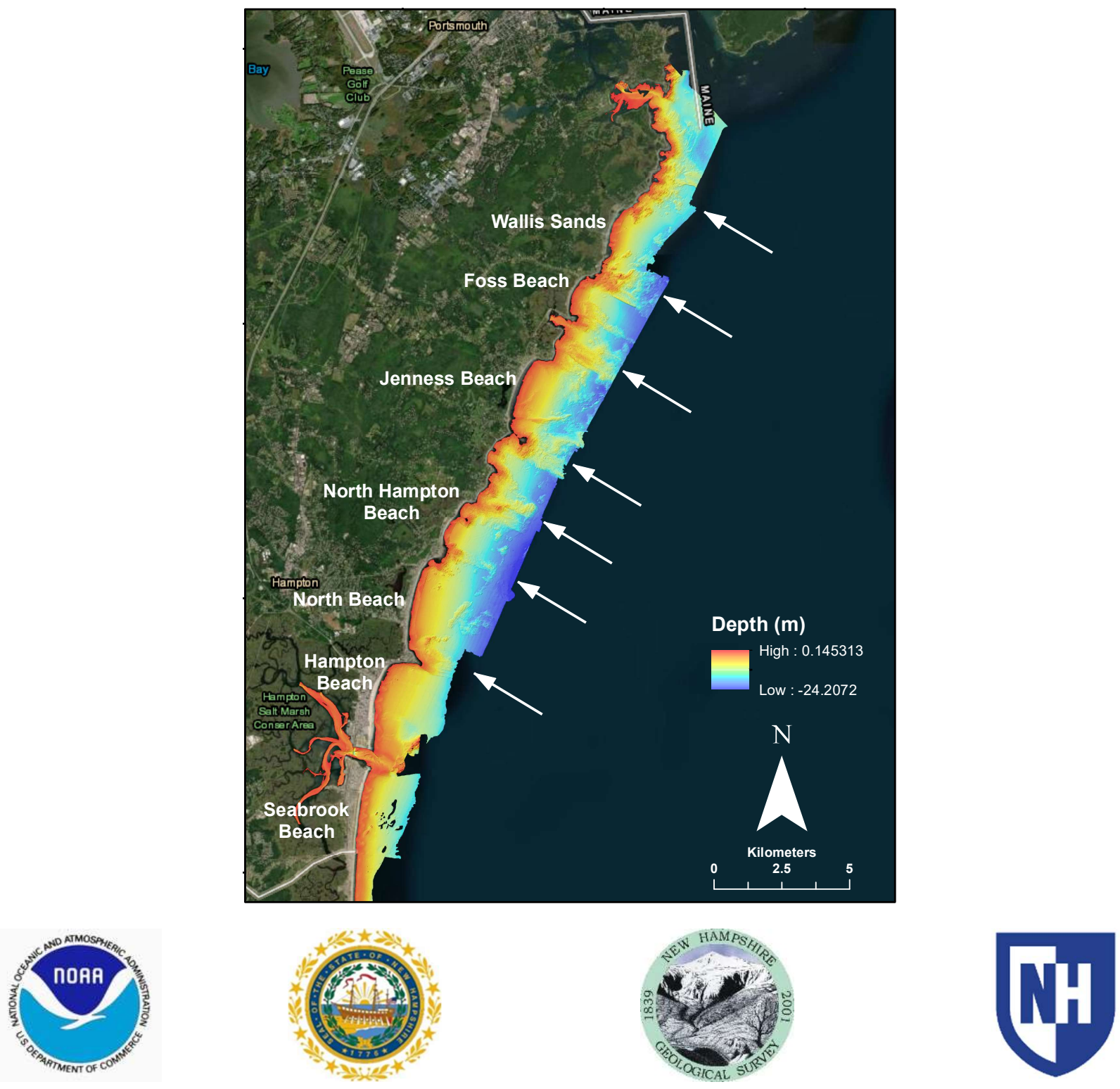


\section{Acknowledgements}

The development of the "Seasonal Changes in Sediment Grain Size of New Hampshire Atlantic Beaches" report was supported by the Bureau of Ocean Energy Management (BOEM) Award Number M14AC00010. The project was managed at the University of New Hampshire (UNH) Center for Coastal and Ocean Mapping and /Joint Hydrographic Center (CCOM/JHC) (NOAA Joint Hydrographic Center Award Number NA10NOS4000073). UNH CCOM/JHC also provided office and laboratory space and computer support.

We gratefully acknowledge Dr. Thomas Lippmann for the use of the GNSS Rover and accessories, as well as helping to process and verify the data. A number of colleagues at UNH CCOM/JHC provided scientific and technical support, advice, and insight including the IT Group (Will Fessenden) and Data Management (Paul Johnson). Jon Hunt provided valuable help with the use of the GNSS rover and processing the data. Liam Kenefic, Emily Wilcox, Shawn Case, Sarah Linder, and Stephanie Ward provided help in the field and laboratory. Their efforts are greatly appreciated.

\section{Map Coordinate System, Projection and Datums}

Coordinate System: WGS 1984 UTM Zone 19N

Projection: Transverse Mercator

Horizontal Datum: WGS 1984

Vertical Datum: MLLW

\section{Recommended Citation}

Ward, L.G., Corcoran, N.W., McAvoy, Z.S., and Morrison, R.C., 2021, Seasonal Changes in Sediment Grain Size of New Hampshire Atlantic Beaches: BOEM/New Hampshire Cooperative Agreement (Contract M14ACO0010) Technical Report, Department of Interior, Bureau of Ocean Energy Management, Marine Minerals Division, 45600 Woodland Road, Sterling, VA, 20166, 208 pp.

https://dx.doi.org/10.34051/p/2021.33

June 1, 2021 


\section{Table of Contents}

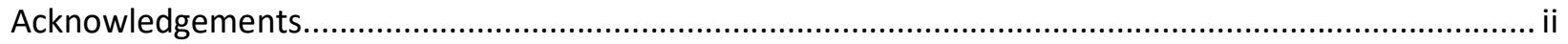

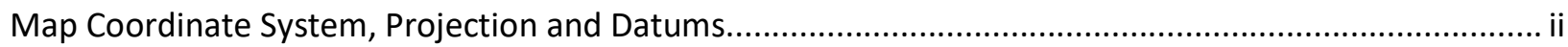

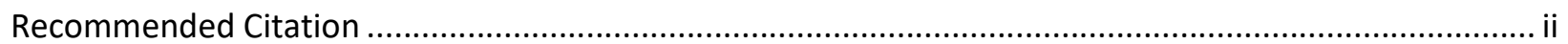

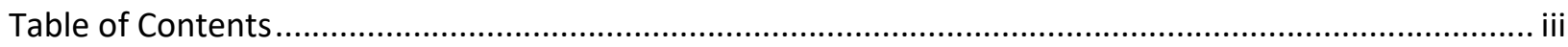

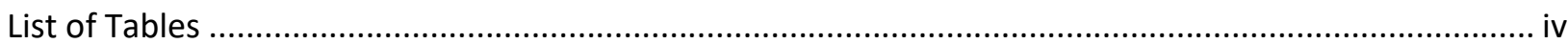

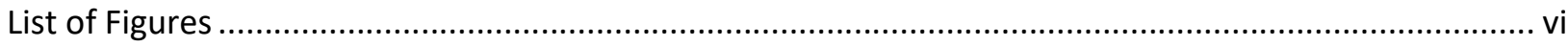

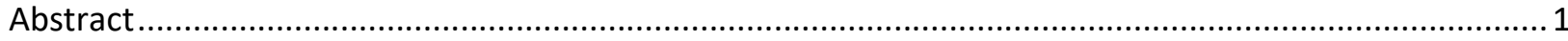

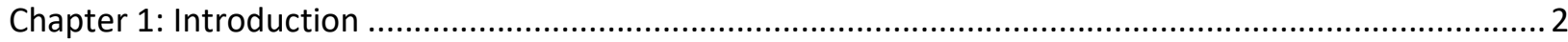

Availability of Reports and Database for the NH Coast ..................................................................... 3

Chapter 2: Geology of the New Hampshire Coast ................................................................................... 5

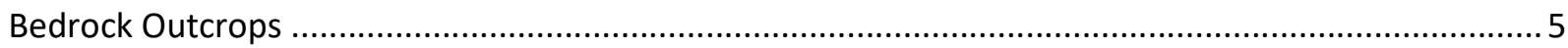

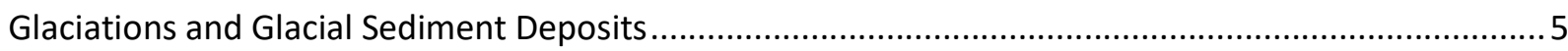

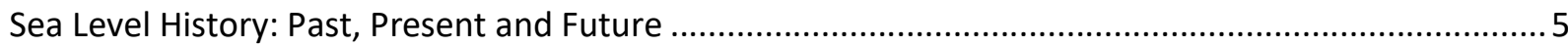

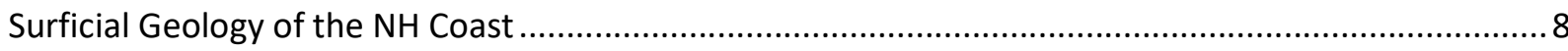

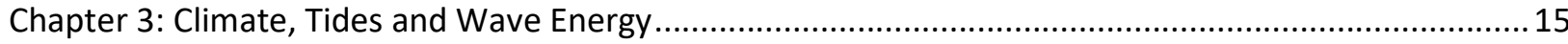

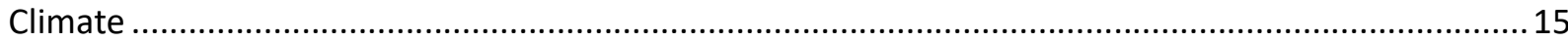

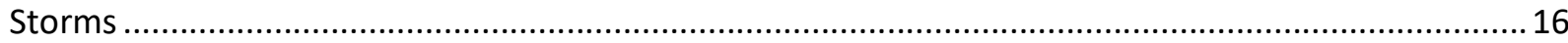

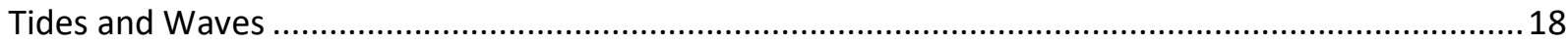

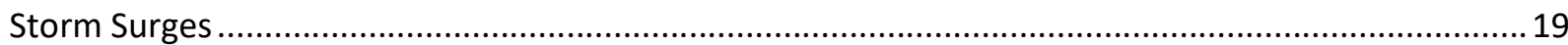

Chapter 4: Previous Studies on the New Hampshire Coast..................................................................2

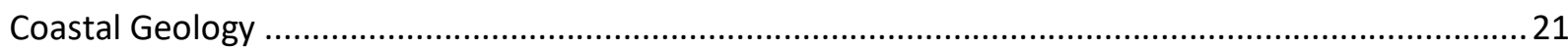

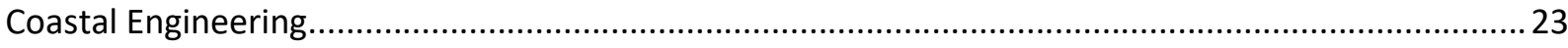

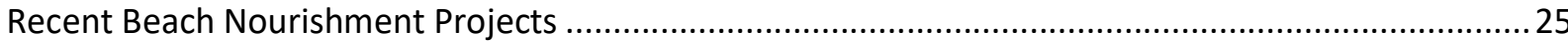

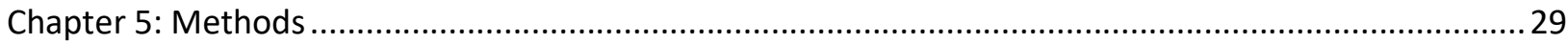

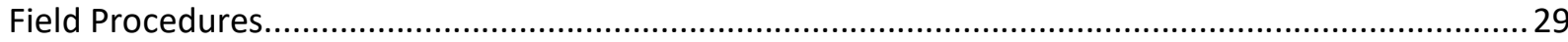

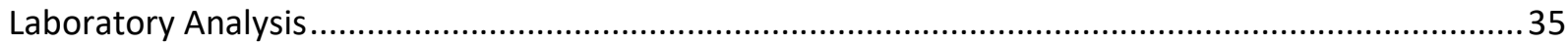

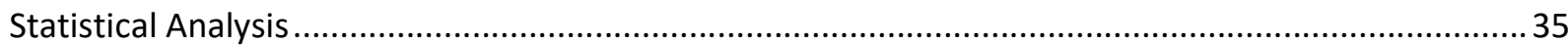

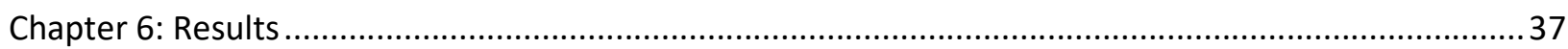

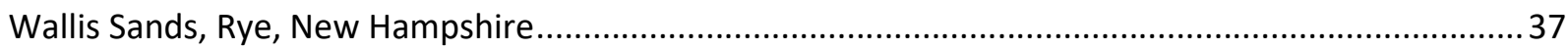

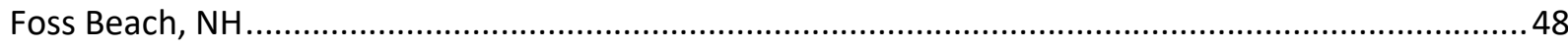

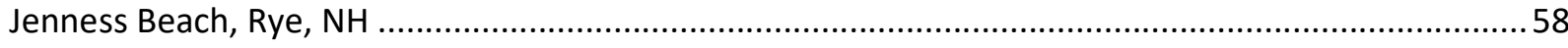

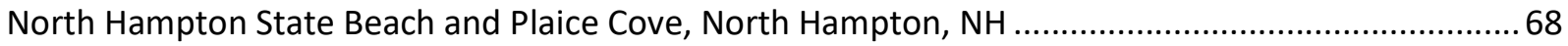




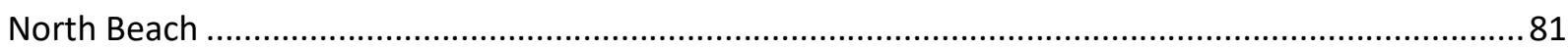

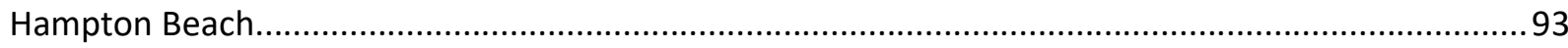

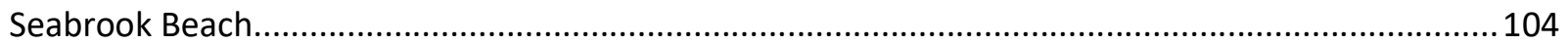

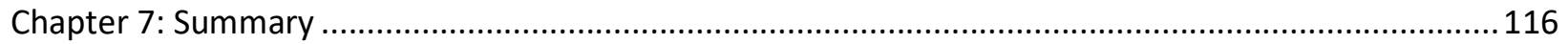

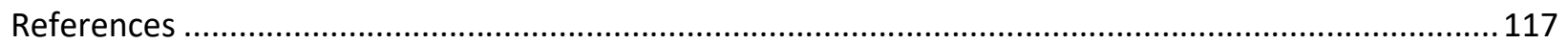

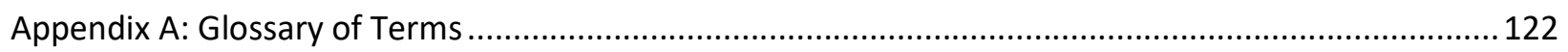

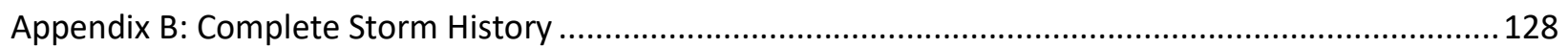

Appendix C: Relationship Between Grain Size, Phi Size, Wentworth Classification and Gradistat

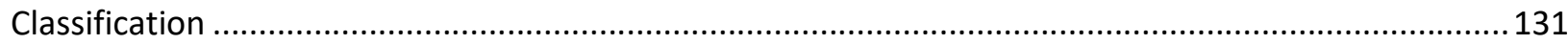

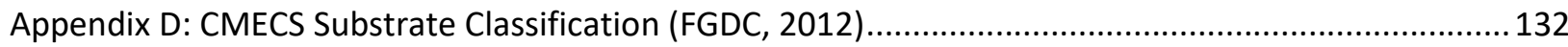

Appendix E: Complete Grain Size Data for Beach Sediment Samples ................................................133

Section 1(a): Wallis Sands (Winter/Spring 2017 Sampling Period) ..................................................... 134

Section 1(b): Wallis Sands (Summer/Fall 2017 Sampling Period) .....................................................139

Section 2(a): Foss Beach (Winter/Spring 2017 Sampling Period) ...................................................... 144

Section 2(b): Foss Beach (Summer/Fall 2017 Sampling Period) ..................................................... 149

Section 3(a): Jenness Beach (Winter/Spring 2017 Sampling Period)................................................ 152

Section 3(b): Jenness Beach (Summer/Fall 2017 Sampling Period).................................................. 157

Section 4(a): North Hampton Beach (Winter/Spring 2017 Sampling Period).................................... 162

Section 4(b): North Hampton Beach (Summer/Fall 2017 Sampling Period)...................................... 167

Section 5(a): North Beach (Winter/Spring 2017 Sampling Period) ....................................................172

Section 5(b): North Beach (Summer/Fall 2017 Sampling Period) ...................................................... 177

Section 6(a): Hampton Beach (Winter/Spring 2017 Sampling Period) .............................................. 180

Section 6(b): Hampton Beach (Summer/Fall 2017 Sampling Period) ............................................... 185

Section 7(a): Seabrook Beach (Winter/Spring 2017 Sampling Period) ............................................. 190

Section 7(b): Seabrook Beach (Summer/Fall 2017 Sampling Period) .............................................. 195

\section{List of Tables}

Table 3-1. Summary of air temperature, wind speed, and precipitation ...............................................16

Table 3-2. Storms impacting the NH coast during the study period ....................................................17

Table 3-3. Mean and maximum significant wave heights (Hs) for the wave buoy off Cape Elizabeth, Maine for the time period between 1982 and 2008 and for the buoy at Jeffreys Ledge for 2017, 2018, and 2019 
Table 3-4. The twelve highest storm surge events each year in 2017, 2018, and 2019 at the NOS tide

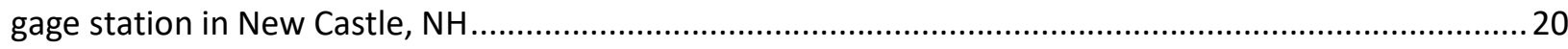

Table 4-1. Summary of known beach nourishment projects on the New Hampshire coast .....................27

Table 5-1. Location and elevation of the station markers for the beach sediment grain size study..........30

Table WS-1. Sediment grain size data for samples taken at Wallis Sands ............................................. 41

Table WS-2. Comparison of average grain size statistics for each of the cross-beach transects at Wallis

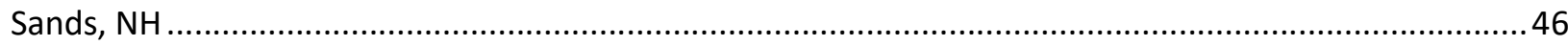

Table WS-3. Comparison of average grain size statistics for Wallis Sands, NH sediment samples grouped

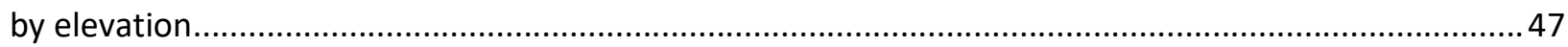

Table FB-1. Grain size statistics for the samples collected at Foss Beach, NH in 2017 ..........................56

Table FB-2. Comparison of average grain size statistics for each of the cross-beach transects at Foss

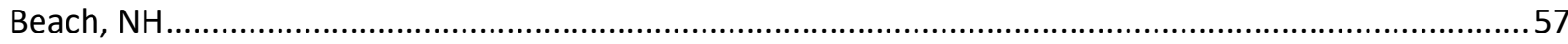

Table JB-1. Grain size statistics for all samples collected at Jenness Beach, NH in 2017 .......................65

Table JB-2. Average grain size statistics for the pooled sediment samples for each of the cross-beach transects at Jenness Beach in March and September 2017 ..................................................................66

Table JB-3. Comparison of average grain size statistics for the samples from Jenness Beach grouped by elevation 67

Table NHB-1. Grain size statistics for samples collected at North Hampton Beach, NH .78

Table NHB-2. Comparison of average grain size statistics for each of the cross-beach transects at North Hampton Beach, $\mathrm{NH}$

Table NHB-3. Comparison of average grain size statistics for North Hampton Beach, NH sediment samples grouped by elevation .80

Table NB-1. Grain size statistics for samples collected at North Beach, NH in 2017. .90

Table NB-2. Comparison of average grain size statistics for each of the cross-beach transects at North Beach, $\mathrm{NH}$

Table NB-3. Comparison of average grain size statistics for North Beach, NH sediment samples grouped by elevation 92

Table HB-1. Grain size statistics for samples collected at Hampton Beach, NH... 101

Table HB-2. Comparison of average grain size statistics for each of the cross-beach transects at Hampton Beach, NH. 102

Table HB-3. Comparison of average grain size statistics for Hampton Beach, NH sediment samples grouped by elevation 103

Table SB-1. Grain size statistics for all samples collected at Seabrook Beach, NH in 2017 113

Table SB-2. Comparison of average grain size statistics for each of the cross-beach transects at Seabrook Beach, $\mathrm{NH}$.

Table SB-3. Comparison of average grain size statistics for Seabrook Beach, NH sediment samples grouped by elevation 


\section{List of Figures}

Figure 1-1. The study area in relation to the Western Gulf of Maine is shown on the left and the NH coast is shown on the right

Figure 2-1. Approximate location of the NH shoreline (seaward edge of brown area) during the last sealevel lowstand at $-60 \mathrm{~m}$ based on Kelley et al. (2010) ...................................................................... 7

Figure 2-2. Surficial geology map of the NH coastal upland ............................................................... 10

Figure 2-3.Surficial Geology of the inner continental shelf off the coast of NH (modified from Ward et al.,

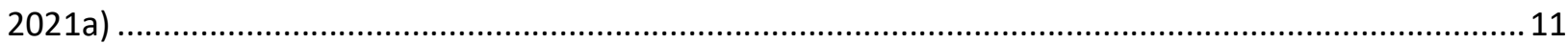

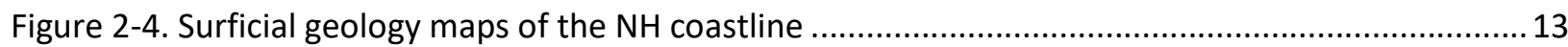

Figure 2-5. Bathymetric imagery of the NH nearshore shelf ................................................................. 14

Figure 4-1. Coastal engineering structures along the NH coastline (from Blondin, 2016) ...................... 26

Figure 4-2. Beach nourishment at Seabrook Beach using dredged material from Hampton-Seabrook

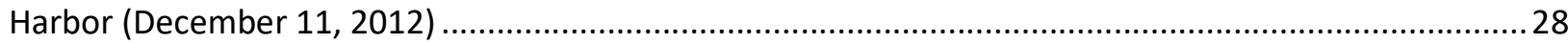

Figure 4-3. Beach nourishment at Hampton Beach State Park using dredged material from Hampton-

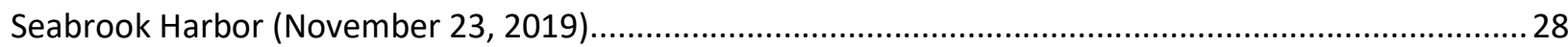

Figure 5-1. GNSS rover used to measure beach elevation profiles and locate sediment sampling stations

Figure 5-2. Collection of a beach sediment core at Wallis Sands station WS01 on September 5, 2017 ....32 Figure 5-3. Sediment core from Wallis Sands station WS02 on September 5, 2017 ............................32

Figure 5-4. Collection of a large sediment sample at North Beach station NB04 on April 24, 2017......... 33

Figure 5-5. Running a beach elevation profile using the GNSS rover on the gravel ramp at Foss Beach

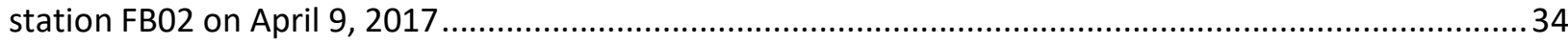

Figure 5-6. Gravel sample from the upper beach at Foss Beach station FB02 on April 9, 2017 ...............34

Figure WS-1. Station locations and shoreline structures (from Blondin, 2016) (left) and surficial geology of the upland (modified from NHGS digital series) and nearshore shelf (modified from Ward et al.,

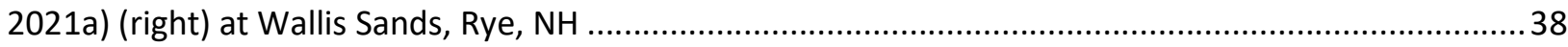

Figure WS-2. Wallis Sands looking south from the northern headland on November 4, 2012 ...............39

Figure WS-3. Southern headland at Wallis Sands from station WS05 on May 4, 2017 ...........................39

Figure WS-4a. Beach profiles and sediment sample locations from winter and late summer 2017 for stations WSO1 and WSO2 at Wallis Sands, NH.

Figure WS-4b. Beach profiles and sediment sample locations from winter and late summer 2017 for

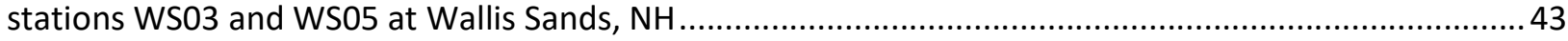

Figure WS-5. Wallis Sands at station WS02 on February 23, 2017 after significant winter erosion .......... 44 Figure WS-6. Wallis Sands station WS02 on September 5, 2017 after an extended period of accretion .. 44 Figure WS-7. Average grain size distribution for the February/March (blue) and September (red) sediment samples at Wallis Sands, pooled for a station for each time period .46 
Figure WS-8. Average grain size distribution for the February/March (blue) and September (red) sediment samples at Wallis Sands, pooled by elevation for each time period

Figure FS-1. Station locations and shoreline structures (from Blondin, 2016) (left) and surficial geology of the upland (modified from NHGS digital series) and nearshore shelf (modified from Ward et al., 2021a) (right) at Foss Beach, Rye, $\mathrm{NH}$

Figure FB-2. Foss Beach, NH looking north from station FB01 (left photograph), and the megaclast platform that extends seaward and forms the northern end of the beach (right photograph) .50

Figure FB-3. Foss Beach, NH looking south from station FB02 (left photograph), and the large megaclast platform located at the southern end of the beach (right photograph)

Figure FB-4. Tree stumps exposed in the lower intertidal at station FB04 at Foss Beach on April 10, 2017 after a period of erosion

Figure FB-5a. Beach profiles and sediment sample locations from winter and late summer 2017 for stations FB01 and FB02 at Foss Beach, NH.

Figure FB-5b. Beach profiles and sediment sample locations from winter and late summer 2017 for stations FBO3 and FBO4 at Foss Beach, NH.

Figure FB-6. Foss Beach looking south from FB01 on April 9, 2017 (left photograph) after a period of erosion and on September 15, 2017 (right photograph) after a period of accretion

Figure FB-7. Foss Beach looking south from FB03 on April 10, 2017 (left photograph) after a period of erosion and on September 15, 2017 (right photograph) after a period of accretion

Figure FB-8. Average grain size distributions for each of the Foss Beach stations in April (blue) and September (red) 2017, pooled for a station for each time period

Figure JB-1. Station locations and shoreline structures (from Blondin, 2016) (left) and surficial geology of the upland (modified from NHGS digital series) and nearshore shelf (modified from Ward et al., 2021a) (right) at Jenness Beach, Rye, NH 59

Figure JB-2. Jenness Beach looking north (left photograph) and looking south (right photograph) from station JB04 on September 11, 2017.

Figure JB-3. Jenness Beach looking north on March 28 (left photograph) and on September 9, 2017 (right photograph) from station JB01. 60

Figure JB-4a. Beach profiles and sediment sample locations from winter and late summer 2017 for stations JB01 and JB02 at Jenness Beach, NH.

Figure JB-4b. Beach profiles and sediment sample locations from winter and late summer 2017 for stations JB03 and JB04 at Jenness Beach, NH

Figure JB-5. Jenness Beach looking south from station JB03 on March 29 (left photograph) and September 11, 2017 (right photograph)

Figure JB-6. Jenness Beach looking north from station JB03 on March 29 (left photograph) and September 11, 2017 (right photograph)

Figure JB-7. Average grain size distributions for each of the Jenness Beach stations in March (blue) and September (red) 2017, pooled for a station for each time period 
Figure JB-8. Average grain size distribution for the March (blue) and September (red) sediment samples at Jenness Beach, pooled by elevation for each time period 67

Figure NHB-1. Station locations and shoreline structures (from Blondin, 2016) (left) and surficial geology of the upland (modified from NHGS digital series) and nearshore shelf (from Ward et al., 2021a) (right) at North Hampton Beach, $\mathrm{NH}$

Figure NHB-2. Little Boars Head, which forms the northern extent of North Hampton Beach ................ 70

Figure NHB-3. Godfreys Ledge tombolo on February 17, 2019 following a stormy period ......................70

Figure NHB-4. Exposed tree roots uncovered by erosion on Godfreys Ledge tombolo on April 11, 201870 Figure NHB-5. Plaice Cove beach looking south from station NHB02 on September 14, 2017 ...............71

Figure NHB-6. Cement seawall with riprap armoring near station NHB03 ...........................................71

Figure NHB-7a. Beach profiles and sediment sample locations from winter and late summer 2017 for stations NHB01 and NHB02 at Jenness Beach, NH .72

Figure NHB-7b. Beach profiles and sediment sample locations from winter and late summer 2017 for station NHBO3 at North Hampton Beach, NH.

Figure NHB-8. North Hampton State Beach looking north from station NHB01 on March 31 (left photograph) and on September 13, 2017 (right photograph)

Figure NHB-9. North Hampton State Beach looking north from the southern end on March 31 (left photograph) and on September 13, 2017 (right photograph) .74

Figure NHB-10. Plaice Cove beach looking south from station NHB02 on March 30 (left photograph) and on September 13, 2017 (right photograph). 74

Figure NHB-11. Plaice Cove beach looking south from NHB03 on March 30 (left photograph) and on September 13, 2017 (right photograph)

Figure NHB-12. Plaice Cove beach at station NHB03 near the seawall on March 30 (upper photograph) and on September 13, 2017 (lower photograph) 75

Figure NHB-13. Low tide terrace at station NHB01 looking north near the water line in 2018................77

Figure NHB-14. Average grain size distributions for stations NHB01, NHB02, and NHBO3 in March (blue) and September (red) 2017, pooled for a station for each time period. .79

Figure NHB-15. Average grain size distributions for stations NHBO2 and NHBO3 in March (blue) and September (red) 2017, pooled by elevation for each time period

Figure NB-1. Station locations and shoreline structures (from Blondin, 2016) (left) and surficial geology of the upland (modified from NHGS digital series) and nearshore shelf (from Ward et al., 2021a) (right) North Beach, Hampton, $\mathrm{NH}$

Figure NB-2. Photograph of the northern headland at North Beach taken on March 18, 2017 from station NB01.

Figure NB-3. North Beach looking south on June 6, 2019 83

Figure NB-4. Cobble and boulder or megaclast platform outcropping on the southern end of North Beach on August 5, 2020 
Figure NB-5. During storm conditions waves push gravel up the beach and often form gravel ramps as shown in this photograph taken on September 5, 2016

Figure NB-6. During storms, sand can be eroded from the lower beach and transported landward building a sand ramp against the seawall as seen here at North Beach on April 7, 2018 following three severe nor'easters

Figure NB-7. Storm waves following the nor'easter Riley at North Beach

Figure NB-8a. Beach profiles and sediment sample locations from winter and late summer 2017 for stations NB01 and NB02 at North Beach, NH

Figure NB-8b. Beach profiles and sediment sample locations from winter and late summer 2017 for stations NB03 and NB04 at North Beach, NH

Figure NB-9. North Beach looking north from station NB01 on April 24 (left photograph) and September 19, 2017 (right photograph)

Figure NB-10. North Beach looking south from station NB03 on April 11 (left photograph) and on a foggy day in September 19, 2017 (right photograph).

Figure NB-11. North Beach looking north from station NB02 on April 11 (upper photograph) and September 19, 2017 (lower photograph)

Figure NB-12. Average grain size distributions for stations NB01, NB02, and NB03 in April (blue) and September (red) 2017, pooled for a station for each time period

Figure NB-13. Average grain size distributions for stations NB01, NB02 and NB03 in April (blue) and September (red) 2017, pooled by elevation for each time period

Figure HB-1. Station locations and shoreline structures (from Blondin, 2016) (left) and surficial geology of the upland (modified from NHGS digital series) and nearshore shelf (from Ward et al., 2021a) (right) Hampton Beach, Hampton, NH

Figure HB-2. Great Boars Head, seen from station HB01 on February 2, 2017.

Figure HB-3. The northern jetty at Hampton Inlet (arrow), seen from the dunes at station HBO4 on October 27, 2017

Figure HB-4. In contrast to northern Hampton Beach, the southern end near the jetty has a welldeveloped and vegetated dune system (left photograph) and the intertidal beach is wide and relatively

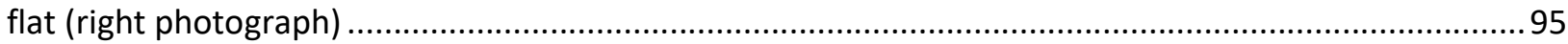

Figure HB-5. Hampton Beach, which is somewhat unusual for NH beaches .96

Figure HB-6a. Beach profiles and sediment sample locations from winter and late summer 2017 for stations HBO1 and HBO2 at Hampton Beach, $\mathrm{NH}$ 98

Figure HB-6b. Beach profile and sediment sample locations from late summer 2017 for station HB03 at Hampton Beach, $\mathrm{NH}$. 99

Figure HB-7. Station HBO2 on February 3, 2017 looking north from the berm crest. 100

Figure HB-8. Average grain size distributions for all stations at Hampton Beach, NH in February-March (blue) and September (red) 2017, pooled for a station for each time period. 102 
Figure HB-9. Average grain size distributions for stations HB01, HBO2 and HBO3 in February (blue) and September (red) 2017, pooled by elevation for each time period 103

Figure SB-1. Station locations and shoreline structures (from Blondin, 2016) (left) and surficial geology of the upland (modified from NHGS digital series) and nearshore shelf (from Ward et al., 2021a) (right) for Seabrook Beach, Seabrook, NH 105

Figure SB-2. The photograph is looking north from station SB04 on November 1, 2017 and shows the well-established, extensive dune system ..... 106

Figure SB-3. Homes north of the major dunes on Seabrook Beach are typically protected by a seawall (arrow) as shown in this photograph from February 4, 2020............................................................ 106

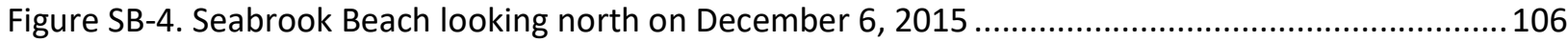

Figure SB-5. Bedrock outcropping on Seabrook Beach close to station SB01 on March 10, 2017 .......... 107

Figure SB-6. Seabrook Beach on September 5, 2016 looking south from near station SB02 _.................107

Figure SB-7. Beach nourishment on Seabrook Beach on October 26, 2019. 107

Figure SB-8a. Beach profiles and sediment sample locations from winter and late summer 2017 for stations SB01 and SB02 at Seabrook Beach, NH

Figure SB-8b. Beach profiles and sediment sample locations from winter and late summer 2017 for stations SBO3 and SBO4 at Seabrook Beach, NH...

Figure SB-9. Seabrook Beach looking south from station SB04 on March 18, 2017

Figure SB-10. Sand overwash deposits in the dunes at station SB04 on March 18, 2017 at Seabrook Beach, $\mathrm{NH}$ 112

Figure SB-11. Average grain size distributions for all stations at Seabrook Beach, NH from March (blue), May (orange), and September (red) 2017, polled for a station for each time period 114

Figure SB-12. Average grain size distributions for stations SB02 and SB04 in March (blue) and September (red) 2017 , pooled by elevation for each time period. 


\section{Seasonal Changes in Sediment Grain Size of New Hampshire Atlantic Beaches}

By Ward, L.G., Corcoran, N.W., McAvoy, Z.S., and Morrison, R.C. University of New Hampshire Center for Coastal and Ocean Mapping/Joint Hydrographic Center 24 Colovos Road, Durham, NH 03824

\section{Abstract}

The beaches along the New Hampshire Atlantic coast are essential to the local and regional economy and are one of the major attractions of the seacoast. Beyond their economic importance, the beaches also have great aesthetic and ecological value that are vital to the character and history of New Hampshire. Unfortunately, climate change and an acceleration in sea-level rise, coupled with a major reduction in sediment supply and extensive development (including engineering structures along the coast), has led to loss of elevation and narrowing of many of the beaches. The forecast is that these trends will continue and likely become worse. It is also very likely that engineering solutions will be sought to reduce the impact of sea-level rise and coastal erosion in the near future as the loss of the beaches become more critical and coastal flooding becomes a more frequent threat.

An option that will undoubtedly play an important role in efforts to mitigate the impacts of beach erosion, flooding, and storm damage is beach nourishment. Essential to beach nourishment success is a thorough understanding of the natural sediments that compose the beach. This includes studying the grain size distribution under low energy conditions (typically summer) when the beaches tend to be accretional, and under higher energy conditions (typically winter and stormy periods), when the beaches erode and finer sediments are winnowed.

A preliminary inventory of the grain size of the natural sediment composing the major New Hampshire beaches was carried out by Ward et al. (2016). However, this study was conducted in summer 2015 after a prolonged period of accretional or stable conditions. In addition, samples were taken only in the upper ten centimeters of the sediment column. Here, a seasonal study (completed in 2017) of sediment grain size from seven major New Hampshire beaches is presented. A total of twenty-eight elevation profiles were measured and one hundred forty sediment samples collected at cross-shore transects in late winter - early spring following an extended period of beach erosion. In late summer twenty-two of the profiles were rerun and ninety-seven sediment samples collected following an extended period of accretion. Six stations were not rerun due to a late summer storm which eroded the beach. The samples were collected along shore-normal transects from the seawall or foredunes to the low tide swash. Large samples were typically collected ( $1 \mathrm{~kg}$ to $24 \mathrm{~kg}$ ) from the upper 20 to $30 \mathrm{~cm}$ of the sediment column.

Results of cross-shore elevation profiles at each beach verified that all locations sampled in late winter early spring 2017 had been eroded by winter storms and often had sediment lag deposits. Conversely, all the beaches sampled following the summer accretional period had recovered and gained elevation. Along with the deposition of sediment there was a general fining of grain size, especially at bimodal beaches. This decrease in grain size by late summer was related to the deposition of fine to medium sand that migrated onshore, often in ridge and runnel systems. The bimodal beaches tended to show the largest change in grain size overall due to scattered pebbles or pebble lag deposits being buried by the sandy accretional wedge. 


\section{Chapter 1: Introduction}

The New Hampshire (NH) seacoast region (including all tidal areas) is a major driver of the state's economy and home to a large portion of its population. The coastal communities made up approximately 11 percent of $\mathrm{NH}^{\prime}$ s population in 2016 and accounted for $\$ 11$ billion of the gross regional product (summarized in New Hampshire Coastal Risk and Hazards Commission, 2016). Tourism in NH is important to the economy of the seacoast and the beaches are the main attraction. Improving and maximizing coastal resiliency and preserving the beaches are a major concern to the people of $\mathrm{NH}$.

Historically, the position of the $\mathrm{NH}$ coastline has undergone a slow retreat or has been relatively stable as a result of an overall low rate of relative sea-level rise prior to this century, headlands composed of bedrock and glacial deposits that anchor the shoreline, and extensive engineering structures (Tuttle, 1960; Ward and Adams, 2001; Himmelstoss et al., 2010; Kelley et al., 2010; Blondin, 2016; Olson and Chormann, 2016). Nevertheless, the beaches have narrowed in width in many areas and have lost elevation over time, making them more susceptible to erosion and flooding (Olson and Chormann, 2016). This is especially true of the beaches north of Great Boars Head which are smaller and lower in elevation than the beaches to the south (Ward et al., 2021b). The outlook for the future indicates that all of the beaches will be threatened by an acceleration in the rate of sea-level rise and an increase in the frequency and intensity of coastal storms, which will cause more intense erosion, flooding, and eventual landward migration (New Hampshire Coastal Risk and Hazards Commission, 2016). A major challenge lies in building coastal resiliency and adapting to changing climatic conditions.

To maintain the beaches in $\mathrm{NH}$, federal, state, and local government agencies and private individuals have invested in extensive shoreline engineering structures (Blondin, 2016) and ad hoc beach sand replenishment projects in response to storm damage and more frequent nuisance flooding. However, an important component of the strategies for increasing coastal resiliency now and in the future is the use of large-scale beach nourishment projects to restore beaches and enhance their buffering capacity to protect local infrastructure. Beach nourishment requires a knowledge of the equilibrium elevation profile and sediment grain size of the beach in order to identify suitable sources of material to use as fill (Massachusetts Department of Environmental Protection, 2007). The placement of sediment with too fine of a grain size can lead to rapid loss or erosion, while too large a grain size can change the equilibrium profile. Therefore, a thorough understanding of the sediment grain size dictates that observations should be made following periods of beach accretion, normally associated with fair weather conditions, and also following extended stormy periods when beaches are eroded.

The grain size of the sediment composing the major NH beaches was described by Ward et al. (2016) and McPherran (2017). However, both studies were conducted in summer after a prolonged period of accretional or stable conditions. In addition, samples were taken only in the upper $10 \mathrm{~cm}$ of sediment and avoided large gravel. Little is known of the mineralogy, sediment grain size distribution, or how the grain size varies over the year from the calmer summer conditions to the stormier winter periods. The study presented here was designed to begin to fill this gap. Seven major beaches along the NH coast representing the breadth of morphologic and sedimentologic types were sampled along multiple transects as well as at multiple locations along those transects (Figure 1-1). Large sediment samples were collected ( 1 to $24 \mathrm{~kg}$ ) from the upper 20 to $30 \mathrm{~cm}$ of the sediment column. The field sampling was done following a period of erosion in late winter-early spring 2017 and then again after a period of fair weather and accretional conditions in late summer-early fall 2017. Collectively, this work provides baseline data to help determine the grain size of sediment needed for beach nourishment in $\mathrm{NH}$. 
Included here are an extensive sediment grain size database (classification and statistics) from the 2017 field campaign; beach elevation profiles; new surficial geology maps of the New Hampshire coast and beaches made from a combination of field observations, satellite images, nearshore lidar, and the incorporation of existing onshore and offshore surficial geology maps (Bennet et al., 2004 and Ward et al., 2021a); photographs of the beaches; and a glossary of terms used in this report.

\section{Availability of Reports and Database for the NH Coast}

The appendices from this report, as well as additional sediment and field photographs from the 2017 sampling period, are available from the University of New Hampshire Scholars Repository (https://scholars.unh.edu/):

Ward, L.G., Corcoran, N.W., McAvoy, Z.S., and Morrison, R.C., 2021, New Hampshire Atlantic Beaches: 2017 Field Campaign Database - Field and Sample Photographs and Sediment Data: University of New Hampshire Center for Coastal and Ocean Mapping/Joint Hydrographic Center. UNH Scholars Repository. https://dx.doi.org/10.34051/d/2021.6

The report and database presented here are part of a comprehensive series of reports developed and supported by BOEM, UNH Center for Coastal and Ocean Mapping/Joint Hydrographic Center (CCOM/JHC), UNH Department of Earth Sciences, and the NH Geological Survey for the NH Atlantic Coast. In addition to this report, other major reports include the following.

1. Ward, L.G., McPherran, K.A., McAvoy, Z.S., and Vallee-Anziani, M., 2016, New Hampshire Beaches: Sediment Characterization: BOEM/New Hampshire Cooperative Agreement (Contract M14ACO0010) Technical Report, Department of Interior, Bureau of Ocean Energy Management, Marine Minerals Division, 45600 Woodland Road, Sterling, VA, 20166, 37 pp. https://dx.doi.org/10.34051/p/2021.29

2. Olson, N.F. and Chormann, F.H., 2016, New Hampshire Beaches: Shoreline Movement and Volumetric Change: BOEM/New Hampshire Cooperative Agreement (ContractM14ACO0010) Technical Report Department of Interior, Bureau of Ocean Energy Management, Marine Minerals Division, 45600 Woodland Road, Sterling, VA, 20166, 15 pp. ftp://ftp.granit.sr.unh.edu/pub/GRANIT Data/Vector Data/Oceans and Coasts/dbeachshorelinechange/BOEM Rept Change Analysis Olson D20160129 NFO final.pdf

3. McPherran, K.A., 2017, Seasonal Changes in Geomorphology and Sediment Volume of New Hampshire Beaches: Insights into a Highly-Engineered, Paraglacial, Bedrock Influenced Mixed Sand and Gravel Coastal System: Unpublished MS Thesis, University of New Hampshire, Durham, 149 pp. https://scholars.unh.edu/thesis/1105 

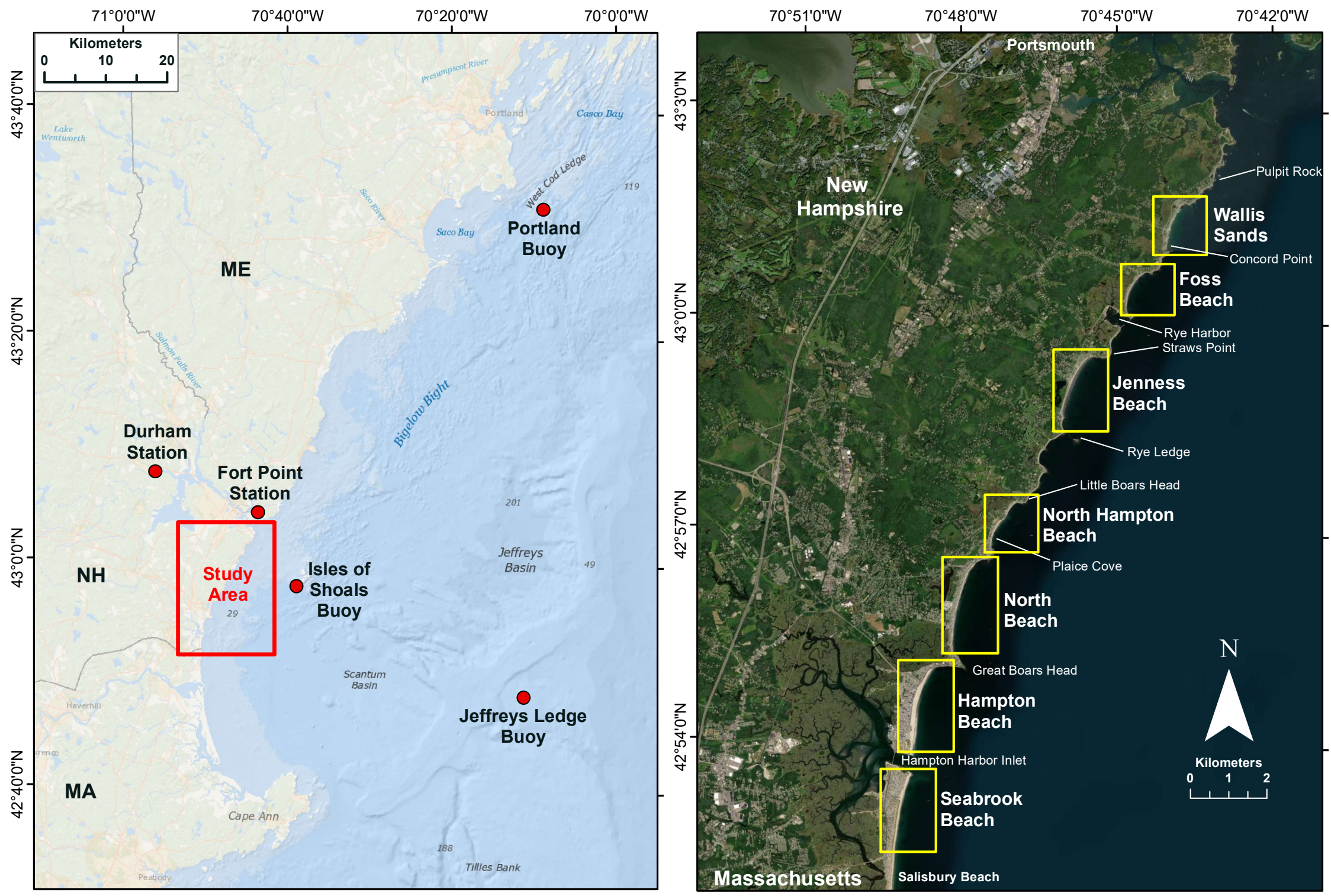

Figure 1-1. The study area in relation to the Western Gulf of Maine is shown on the left and the NH coast is shown on the right. The NH beaches where elevation profiles were measured and sediment samples were collected are outlined in yellow. 


\section{Chapter 2: Geology of the New Hampshire Coast}

The morphology and sedimentology of the beaches along the NH coast are a product of the local bedrock geology, sea-level rise, glaciations, and coastal engineering. Each of these controls are discussed here and their contribution to the beaches considered. A glossary is provided in Appendix A which provides definitions for many of the terms used in this report.

\section{Bedrock Outcrops}

The NH coast (Figure 1-1) is strongly influenced by the local bedrock geology and glacial deposits. Many of the beaches north of Great Boars Head (a glacial drumlin) are separated by headlands that are composed of bedrock or, more frequently, till covering bedrock. Bedrock also outcrops on the beaches and in the nearshore region along most of the coast, but especially north of Great Boars Head. The bedrock is dominated by metasedimentary and plutonic igneous rocks and has been described by Novotny (1969), Lyons et al. (1997), and Bennett et al. (2006), and summarized in McPherran (2017). The headlands and bedrock outcrops offshore strongly effect the beaches due to wave refraction and redistribution of wave energy. In addition, bedrock at the headlands and nearshore helps anchor the position of the shoreline.

\section{Glaciations and Glacial Sediment Deposits}

The glacial deposits along the NH seacoast are largely the result of the last major glaciation. The Laurentide Ice Sheet (LIS) covered New England and the Gulf of Maine during the Wisconsin glacial period reaching its maximum $\sim 24,000$ yrs B.P. when it extended to Long Island and Georges Bank (Balco and Schaefer, 2006). Although the NH seacoast has not been studied well enough to constrain the timing of deglaciation, Sinclair et al. (2018) estimated from work further south that ice receded from the coastal region by 15,000 yrs B.P. Maximum ice thickness in the seacoast area, also largely estimated from earlier studies done in Maine, was on the order of 1,500 m (Moore, 1987)

The NH coastal region and nearshore shelf was heavily eroded by the advancing ice sheet, exposing bedrock in many areas. The glaciation also left extensive sediment deposits along the coast and on the adjacent continental shelf including moraines, drumlins, eskers, glaciomarine deltas, submarine grounding line fans, kettles, tills, and stratified drift (Birch, 1984; Sinclair et al., 2018). These deposits, along with eroded offshore glacial deposits from similar features, are extremely important to the coastal system and are the major source of sediments to the beaches in NH (USACE, 1954; Tuttle, 1960).

\section{Sea Level History: Past, Present and Future}

Past Sea-Level Fluctuations. The formation of the Wisconsin ice sheet caused a lowering of eustatic (global) sea level as water was tied up in ice. In the northern latitudes the weight of the ice caused crustal subsidence and isostatic adjustments. As a result of both eustatic sea level changes and isostatic adjustments of the crust, the relative (local) sea level history in most paraglacial environments is complex.

In the western Gulf of Maine (WGOM), relative sea level has undergone a transgression, a regression (causing a seaward migration of the coast), and finally a second transgression (causing a landward migration of the coast), which is continuing today and accelerating (Kelley et al., 2010). The first transgression occurred during deglaciation when the glacier's terminus was receding and the ice was in contact with the ocean, resulting in a marine incursion landward of the present coast (late Pleistocene transgression). The magnitude of the highstand (most landward inundation of the ocean) varies along the coast from Maine to Massachusetts due to the different ice thicknesses and levels of isostatic depression. 
Around 14,000 yrs B.P., the highstand extended to approximately $30 \mathrm{~m}$ above present in northern Massachusetts and approximately $75 \mathrm{~m}$ above present in southern Maine. Birch (1988) estimated the highstand elevation in coastal $\mathrm{NH}$ to be $\sim 45 \mathrm{~m}$, which is reasonable when considering the Maine and Massachusetts levels.

Following the transgression, isostatic uplift of the crust due to the removal of the weight of the ice as it melted led to a major lowering of relative sea level (or a marine regression) despite the rapidly rising eustatic sea level. Essentially, the crust in the WGOM rebounded at a rate that exceeded eustatic sealevel rise. Therefore, at approximately $12,500 \mathrm{yrs}$ B.P. the relative or local sea level lowered to $\sim 55-60 \mathrm{~m}$ below current sea level in southern Maine (Figure 2-1), and $\sim 45 \mathrm{~m}$ below current sea level in Massachusetts (Oldale et al., 1993; Kelley et al., 2010). As isostatic uplift began to slow, eustatic sea-level rise overtook crustal rebound leading to a relative sea-level rise of $\sim 40 \mathrm{~m}$ above the lowstand in Maine between $\sim 12,500$ and 11,500 yrs B.P. The rate of sea-level rise during this period was $\sim 22 \mathrm{~mm} / \mathrm{yr}$.

Between 11,500 and 7,500 yrs B.P. a "slowstand" occurred in Maine, with a sea-level rise of less than 5 $\mathrm{m}$ at a rate of $\sim 2 \mathrm{~mm} / \mathrm{yr}$. From $\sim 4,000$ to 1,000 yrs B.P. relative sea level was nearly at a standstill, decreasing to as little as $0.2 \mathrm{~mm} / \mathrm{yr}$ by $1000 \mathrm{yrs}$ B.P. At the time of the slowing of sea-level rise, the shoreline was approximately in its present location (Ward and Adams, 2001). The very slow sea-level rise of the past 4,000 years has allowed for the formation of beaches, marshes, and barrier systems in New England (Ward et al., 2008; Hapke et al., 2010; Kelley et al., 2010). The remains of a drowned forest which are present in the intertidal zone at Odiorne Point, Rye, $\mathrm{NH}$ have radiocarbon age dates that show the tree stumps were killed by rising sea-level approximately 3,660 to 3,490 yrs B.P. (Lyon and Harrison, 1960; Harrison and Lyon, 1963; Kelley et al., 2010), which is consistent with the slow transgression of the past 4,000 years. Tree stumps associated with the sea-level transgression are exposed in the lower intertidal following erosional periods, and have been observed at several other beaches along the $\mathrm{NH}$ coast including Foss Beach, North Hampton Beach, and North Beach (see Chapter 5).

Due to the magnitude of the changes in relative sea-level rise in the Gulf of Maine, the position of the NH shoreline migrated $\sim 40 \mathrm{~km}$ (Ward and Adams, 2001). During the maximum transgression with ice retreat, the ocean flooded inland approximately $25 \mathrm{~km}$, and during the maximum regression, the coastline was $\sim 15 \mathrm{~km}$ seaward of its present position.

Present Sea-level Changes. Relative sea-level rise determined by NOAA CO-OPS (accessed January 2020) for the period from 1926-2018 measured at the tide station at Fort Point in New Castle, NH was 2.01 \pm 0.19 $\mathrm{mm} / \mathrm{yr}$. The tide station located a short distance away $(\sim 3 \mathrm{~km})$ at Seavey Island, Maine, was $1.76 \pm 0.30$ $\mathrm{mm} / \mathrm{yr}$ for the period from 1926-2001. Unfortunately, both locations have several extended gaps in their records. The tide station in Portland, Maine (located $75 \mathrm{~km}$ to the north) has a complete tide record for the time period from 1912-2018. The rate of sea-level rise at the Portland station was $1.88 \pm 0.14 \mathrm{~mm} / \mathrm{yr}$. The similarity in rates of the three stations and proximity gives confidence that the rate of relative sealevel rise along the New Hampshire coast was $\sim 1.8$ to $2.0 \mathrm{~mm} / \mathrm{yr}$ for most of the twentieth century.

Comparison of the relative sea level history at other stations along the east coast of the US demonstrates the rate of sea-level rise in $\mathrm{NH}$ was low in comparison to further south. The rate of relative sea-level rise in Boston (located $\sim 85 \mathrm{~km}$ to the south) was slightly higher (2.82 $\pm 0.15 \mathrm{~mm} / \mathrm{yr}$ from 1921-2018), but in general agreement. However, the rate of sea-level rise for Montauk, New York $(3.32 \pm 0.26 \mathrm{~mm} / \mathrm{yr}$ from 1947-2018), Portsmouth, Virginia (3.76 $\pm 0.45 \mathrm{~mm} / \mathrm{yr}$ from 1935-1987), Sewells Point, Virginia (4.66 \pm 0.22 $\mathrm{mm} / \mathrm{yr}$ from 1927-2018), Duck, North Carolina (4.62 $\pm 0.68 \mathrm{~mm} / \mathrm{yr}$ from 1978-2018), and Charleston, South Carolina (3.26 $\pm 0.19 \mathrm{~mm} / \mathrm{yr}$ from 1901-2018) are substantially higher. Kirshen et al. (2014) attributes the increasing rates of sea-level rise from Boston to the mid-Atlantic to crustal subsidence. 
For a long period of time, New Hampshire had the benefit of a very slow sea-level rise. Unfortunately for the coastal region, the rate of sea-level rise is now increasing largely due to climate change. This is apparent in the tide station record at Portland, Maine that shows an increase in the rate within the 19122016 period. The rate of sea-level rise at this station increased from $1.7-1.8 \mathrm{~mm} / \mathrm{yr}$ during the 1912-1980 period to $2.3 \mathrm{~mm} / \mathrm{yr}$ during the period from 1980-2016 (McPherran, 2017). This trend is seen elsewhere along the US East Coast (Wake et al., 2011; NOAA CO-OPS, accessed 2020).

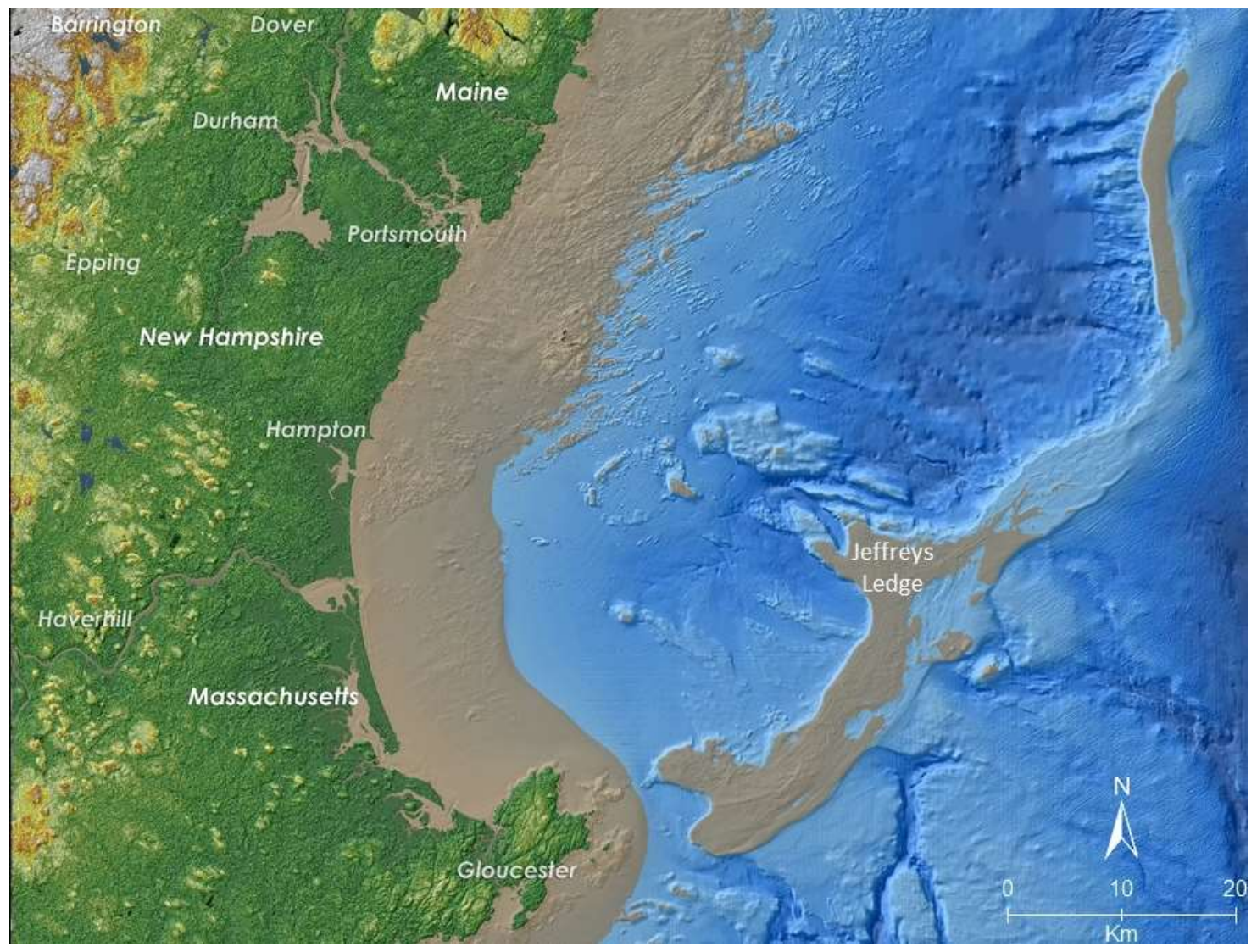

Figure 2-1. Approximate location of the $\mathrm{NH}$ shoreline (seaward edge of brown area) during the last sea-level lowstand at $-60 \mathrm{~m}$ based on Kelley et al. (2010). During the late Holocene transgression, the shoreline migrated landward reaching its present position about 4,000 B.P. (Ward and Adams, 2001).

Future Acceleration in Rate of Sea-Level Rise. As a result of climate change, eustatic sea-level rise has been accelerating in most areas and will continue to do so in this century. The tide gauge records for the $\mathrm{NH}$ seacoast and vicinity discussed above show that the rate of relative sea-level rise in $\mathrm{NH}$ is very close to eustatic or global sea-level rise. Wake et al. (2011) estimated the difference between eustatic and relative sea-level rise for Portland, Maine (which has a similar history to the gauges in New Castle, $\mathrm{NH}$ and Seavey's Island, Maine) to be only $\sim 0.05 \mathrm{~mm} / \mathrm{yr}$. The slightly higher rate of the relative (local) sea-level rise over eustatic sea-level rise is likely due to minor crustal subsidence. Therefore, predictions for future eustatic sea-level rise scenarios are likely valid for the $\mathrm{NH}$ seacoast region without adjustment for crustal movement (uplift or subsidence) (Kirshen et al., 2014). 
Mean eustatic sea-level rise (the average for the world's oceans) was $1.7 \pm 0.2 \mathrm{~mm} / \mathrm{yr}$ between 1901 and 2010 (IPCC, 2014). However, the mean eustatic rate of sea-level rise increased significantly to $3.3 \pm 0.4$ $\mathrm{mm} / \mathrm{yr}$ during the period from 1993 to 2010. This increase was primarily caused by ocean thermal expansion and inputs from terrestrial ice sheets and land water storage. The IPCC (2014) predicted that the rate of eustatic mean sea-level rise will increase significantly in the coming century due to climate change and anthropogenic greenhouse gas emissions. Kirshen et al. (2014) points out that projections of increases in sea level into the future are based on probabilities and as such have a wide range. At this time, it is not possible to give an estimate with certainty, but it is clear that sea level will increase significantly. The IPCC (2014) indicated that the mean rate of eustatic sea-level rise for the most extreme scenario would be between 8 and $16 \mathrm{~mm} / \mathrm{yr}$ for the period from 2081-2100, a major increase over the 1971-2010 period of $2.0 \pm 0.3 \mathrm{~mm} / \mathrm{yr}$. Relative sea-level rise in many regions will be more or less severe than eustatic sea-level rise due to fluctuations in ocean circulation, regional tectonics, etc. However, and important to this study, Sallenger et al. (2012) identified the northern half of the US east coast as a sealevel rise hotspot, with higher rates of sea-level rise.

\section{Surficial Geology of the NH Coast}

The sediments composing the $\mathrm{NH}$ beaches, their morphologic characteristics, and their stability are strongly influenced by the surficial geology of the coastal upland (including the headlands) and the inner continental shelf. In the past, during the last sea-level transgression, glacial deposits on the coastal upland and the headlands along the coast were important sources of sediment to the $\mathrm{NH}$ beaches. However, over the last century the slow rate of sea-level rise and the construction of extensive coastal engineering structures including seawalls, riprap armament, and berms have cut off much of the upland and headland sediment sources, resulting in a major loss to the beaches. The offshore glacial deposits on the inner continental shelf were also an important source of sediment to the beaches and likely are today. Therefore, knowledge of the surficial geology of the region from the upland to the inner shelf is essential to understanding the sediment composition of the beaches.

Surficial Geology of the NH Coastal Upland. Surficial geology maps of the NH seacoast published by the NH Geological Survey (NH Geological Survey digital map series; https://www.granit.unh.edu/, accessed January 2021; see Bennet et al., 2004) show that the major features and deposits within approximately five kilometers of the shoreline include bedrock outcrops, glacial tills, glaciomarine sediment, and Holocene (recent) deposits (saltmarshes, freshwater wetlands, and beaches) (Figure 2-2).

The glaciomarine deposits, which were the main source of sediment to the beaches (along with glacial tills), include wave-modified marine deltas composed of sand and gravel, and three facies of the Presumpscot Formation. The glacial till deposits, which are extensive, include eroded remains of drumlins, eskers, and moraines, and also appear as thin veneers draping over the underlying bedrock. Bedrock is also prominent, especially near the coast, where it has been exposed by marine erosion.

Glacial tills are important to the characteristics of the NH coast and frequently intersect the shoreline. Till is typically composed of unsorted sediment ranging in size from clay to boulders. Along the NH seacoast, tills are comprised primarily of smaller sediment such as poorly sorted sand and silt with pebbles and cobbles (Bradley, 1964). Erosion of the till deposits provided sand to the beaches and formed megaclast platforms which front the headlands and border and outcrop on many of the beaches (i.e., Foss Beach, Jenness Beach, North Hampton Beach, and North Beach). The glaciomarine deposits associated with the Presumpscot Formation found along the $\mathrm{NH}$ seacoast include proximal facies (sandy), distal facies (silt and clay), and undifferentiated mixtures (sand, silt, and clay). The sandy and undifferentiated sediments from the Presumpscot Formation were clearly important sources of sand to the beaches, as well as 
glaciomarine sediments deposited as wave-modified deltas or wave-formed features. The glaciomarine deltas were formed by glacial streams or tunnels bringing sand and gravel to the ice margin. Several large wave-modified marine deltas are found along the $\mathrm{NH}$ coast. These deposits are also very important to the beaches when considering long time frames (e.g. Holocene transgression).

The surficial geology varies along the coast which is reflected in the sediment composition of the beaches. Extensive bedrock outcrops mixed with the Presumpscot undifferentiated sand, silt, and clay deposits dominate the area from Portsmouth Harbor southward to Wallis Sands. The bedrock is more limited south of Wallis Sands, occurring intermittently on headlands where the glacial sediment has been eroded, on beaches, and in the nearshore. From Wallis Sands to Rye Harbor the upland is predominantly made up of undifferentiated sand, silt, and clay deposits and to a lesser extent, glacial tills. However, till deposits are the dominant feature from Rye Harbor to Little Boars Head. Southward, tills remain important, but wavemodified marine deltas composed of sand and gravel, and the fine-grained facies of the Presumpscot Formation become the major nearshore deposits. Keene (1970 and 1971) indicated that both the Presumpscot Formation fine-grained facies and sand facies occur in Hampton-Seabrook Harbor. The headlands separating the beaches along the $\mathrm{NH}$ coast are composed of glacial till or till overlying bedrock.

Surficial Geology of the Nearshore Shelf. The surficial geology of the inner continental shelf off the coast of $\mathrm{NH}$ has been mapped by Ward et al. (2021a). The maps include details of the major geoforms (or physiographic features) and surficial sediments of the seafloor extending from the $\mathrm{NH}$ coast to Jeffreys Ledge, located $\sim 50 \mathrm{~km}$ offshore. The nearshore shelf within $\sim 10 \mathrm{~km}$ of the $\mathrm{NH}$ coast is composed of extensive megaclast platforms, many of which extend offshore from the headlands along the coast; sandy nearshore ramps which extend from the beaches; bedrock outcrops offshore and along the coast; and seafloor plains composed of sand, gravel mixes, and gravel (Figure 2-3). The gravel and megaclast plains are extensive.

Based on the morphology of the seafloor geoforms and the sediment composition (grain size), glacial history, and the glacial features mapped onshore, Ward et al. (2021a) interpreted many of the physiographic features as marine-modified glacial deposits which include drumlins, eskers, and moraines. The sandy plain deposits found offshore are likely reworked marine-modified glaciomarine delta deposits or proximal sandy glaciomarine deposits. Many of the features mapped on the continental shelf also continue onshore. For example, all of the headlands from Great Boars Head to Portsmouth Harbor have subtidal megaclast platforms that extend offshore up to two kilometers and were formed as the coastline retreated (Figure 2-3). These offshore extensions essentially isolate each beach along the coast, interrupting longshore sediment transport and the exchange of sediment between the beaches. Also, an apparent esker that originates on the inner shelf crosses the southern end of Jenness Beach (appearing as a megaclast platform), and continues on land as a linear ridge that can be traced with Lidar topography (see Chapter 6: Jenness Beach). 


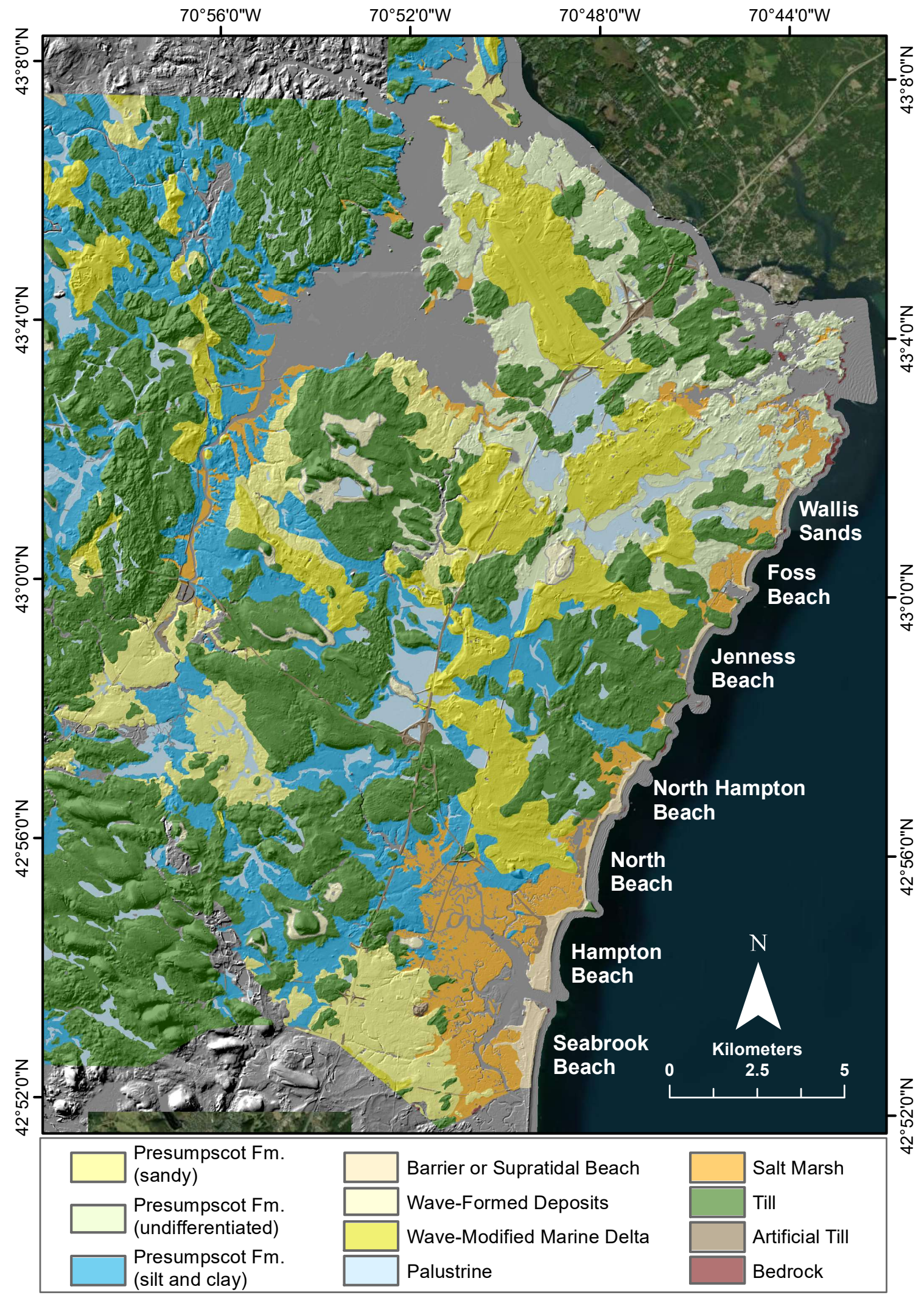

Figure 2-2. Surficial geology map of the NH coastal upland (modified from the NH Geological Survey digital map series; Bennet et al., 2004). 


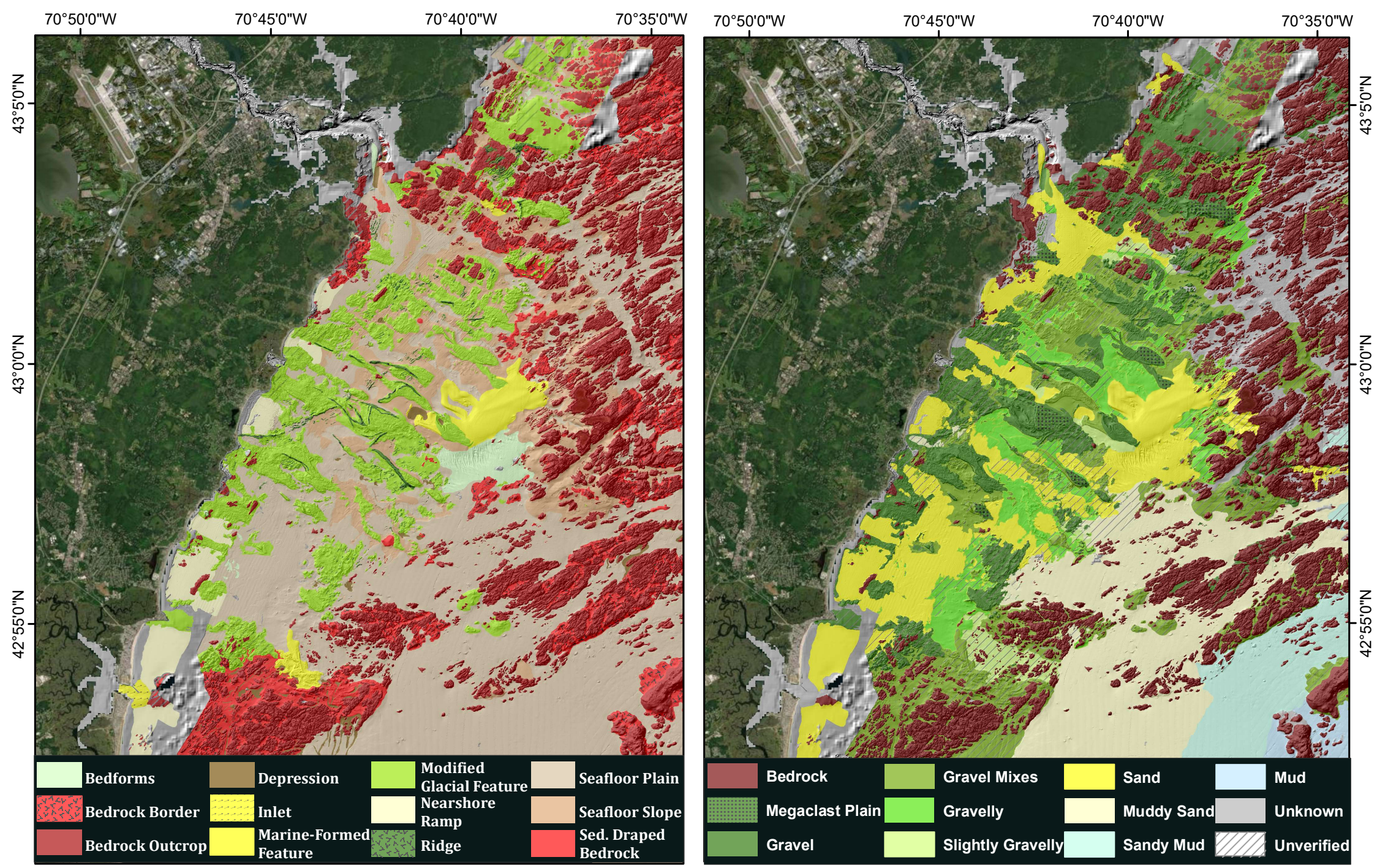

Figure 2-3.Surficial Geology of the inner continental shelf off the coast of NH (modified from Ward et al., 2021a). The major geoforms (or physiographic features) are shown on the left and the surficial sediments classification (based on CMECS) is shown on the right. The nearshore shelf within $\sim 10 \mathrm{~km}$ of the NH coast is composed of: extensive megaclast platforms, many of which extend offshore from the headlands along the coast; sandy nearshore ramps which extend from the beaches; bedrock outcrops offshore and along the coast; and extensive seafloor plains composed of sand, gravel mixes, and gravel. 
Surficial Geology of $\mathbf{N H}$ Beaches. NH has the shortest ocean coastline in the United States (29.5 km or 18.3 miles). Nevertheless, the shoreline is highly variable and has distinct changes in morphology and sediment composition from the northern boundary at Portsmouth Harbor to the southern boundary at Seabrook Beach (Figure 1-1). The NH coast forms a transitional zone between the rocky Maine coast to the north and the sandier barriers to the south in Massachusetts. The surficial geology of New Hampshire's beaches and nearshore region was mapped through a combination of field observations, satellite images, nearshore lidar, and the incorporation of regional onshore (modified from the NH Geological Survey digital map series) and offshore (modified from Ward et al., 2021a) surficial geology. The maps include the nearshore geology (extending up to $3.5 \mathrm{~km}$ offshore) including the typical sediment type (sandy, bimodal, gravel), the distribution of megaclast platforms, and exposed bedrock.

At the northern end of the coast north of Wallis Sands, the shoreline is extremely rocky with bedrock outcrops, megaclast platforms, and several small, narrow bimodal (sand and gravel) or gravel beaches (e.g., Odiorne Point) (Figure 2-4). From Wallis Sands south to Great Boars Head there are five attached or welded barrier beaches (Wallis Sands, Foss Beach, Jenness Beach, North Hampton Beach and North Beach) ranging in length from $\sim 1.2$ to $2.4 \mathrm{~km}$ and separated by bedrock and till-covered headlands. These beaches are largely sandy with a significant pebble content with two notable exceptions: Foss Beach and North Hampton State Beach which are sand and cobble or mixed sediment beaches. In addition, megaclast platforms and bedrock outcrops are common at all locations. Saltmarshes or coastal ponds are located landward of the barriers. The attached barrier beaches are separated by headlands fronted by rocky outcrops, megaclast platforms, and cobble beaches.

South of Great Boars Head, the beaches include an attached barrier spit (Hampton Beach) and a barrier island (Seabrook Beach). These beaches form the northern half of a barrier system that extends $\sim 7.9 \mathrm{~km}$ between Hampton Inlet and the Merrimack River (Figure 1-1). Salisbury Beach, MA forms the southern half of the barrier system. Hampton Beach and Seabrook Beach are separated by Hampton Inlet which delivers the tidal prism to a large backbarrier saltmarsh system. Unlike the beaches north of Great Boars Head, Hampton Beach has aeolian dunes at the southern end (locally referred to as South Beach) and Seabrook Beach is backed by aeolian dunes over much of its length.

The headlands separating the beaches are composed of bedrock and, more frequently, glacial till or a thin veneer of till overlying bedrock (Figure 2-4). For example, Great Boars Head is a glacial drumlin that once extended offshore but has since been significantly eroded. The till composing the headlands has been eroded by waves, removing the finer sediments (mud, sand, and fine gravel) and leaving behind coarse gravel (e.g., cobbles and boulders). This ultimately forms large megaclast platforms which extend offshore. The headlands interrupt longshore sediment transport between the beaches, limiting sediment transport to onshore-offshore (Figure 2-5). Once formed, the megaclast platforms act as a natural barrier, reducing the wave energy that can impact the headlands (McPherran, 2017).

The sediments that comprise the $\mathrm{NH}$ beaches were derived from adjacent headlands, the upland where the sediments have a pathway to the beaches (Hampton Beach and Seabrook Beach), and the offshore. 

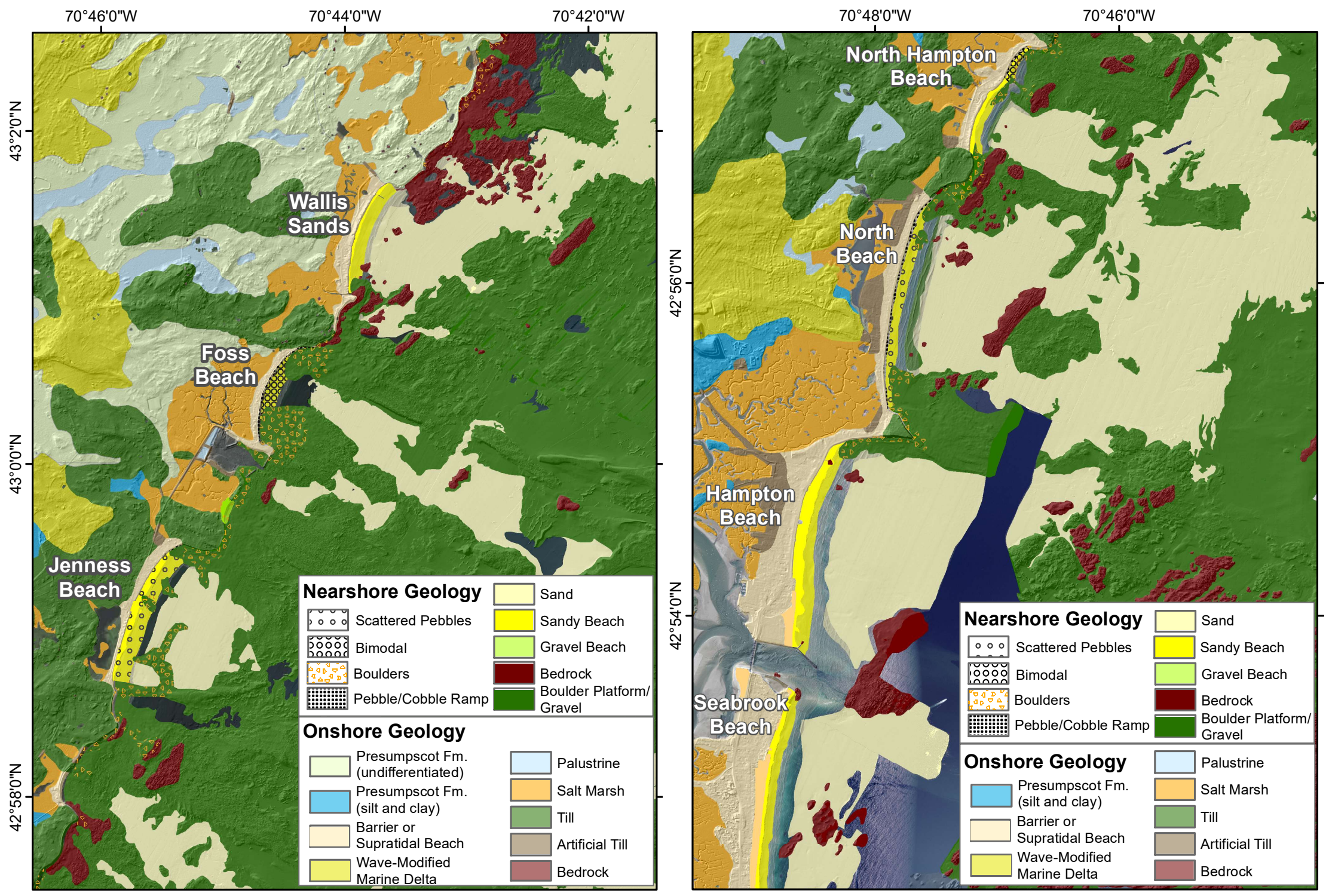

Figure 2-4. Surficial geology maps of the NH coastline (the northern half of the coast is on the left; the southern half is on the right). The upland is modified from the NH Geological Survey digital map series, the offshore is from Ward et al. (2021a), and the beaches were mapped for this study. 


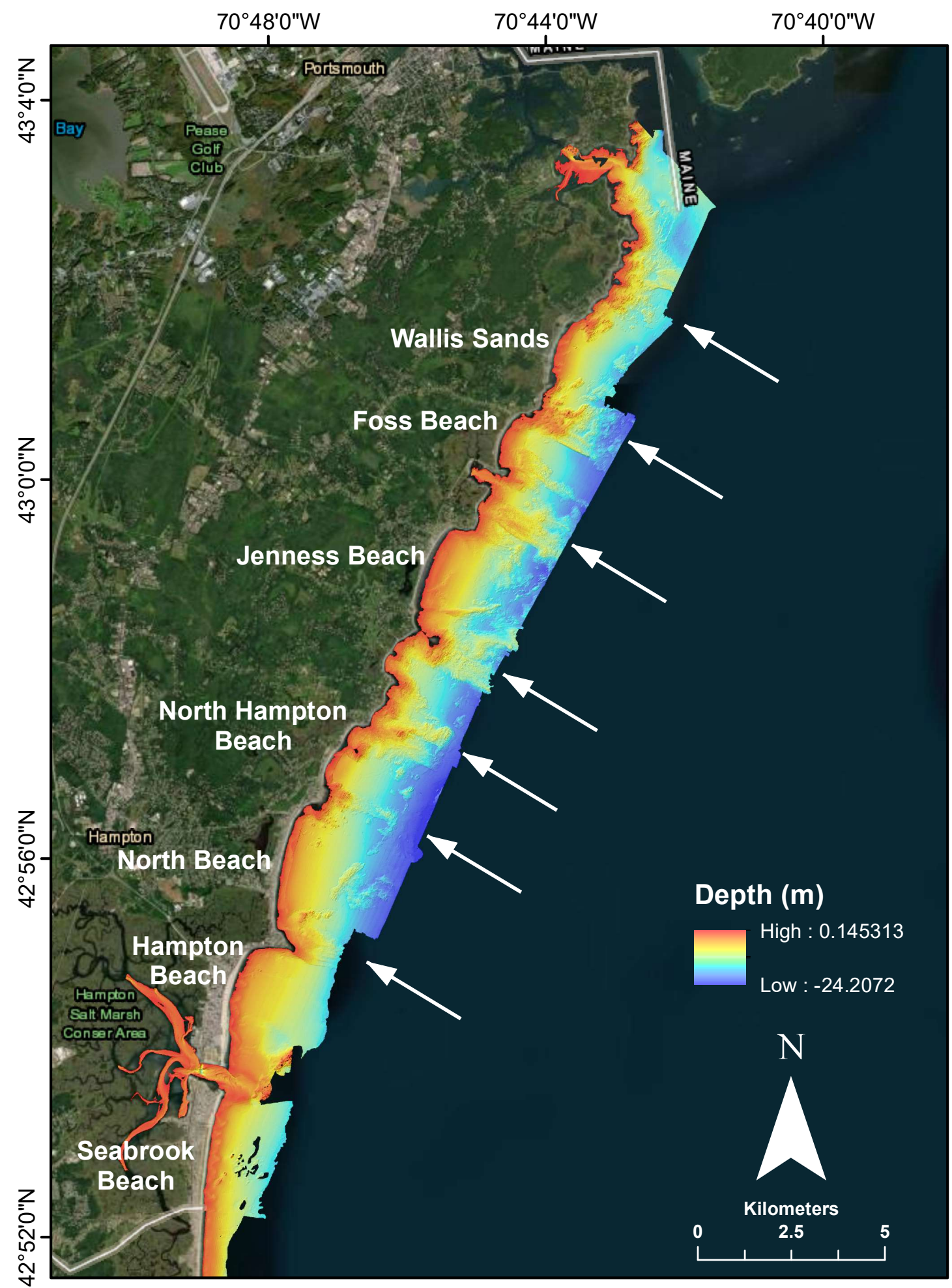

Figure 2-5. Bathymetric imagery of the NH nearshore shelf. Note the bathymetric highs offshore of the headlands which limit or prohibit longshore sediment transport between the beaches north of Hampton Beach. 


\section{Chapter 3: Climate, Tides and Wave Energy}

The major physical processes effecting $\mathrm{NH}$ beaches are largely controlled by climate, extratropical storms, and tidal range. $\mathrm{NH}$ has large seasonal temperature and precipitation variations, freezing conditions in winter, and storm-driven waves and coastal flooding. An overview of climate, storms, and an analysis of the wave climate is important for understanding beach morphology, erosion, and depositional processes, as well as sediment composition and grain size characteristics.

\section{Climate}

New England has a continental climate with four distinct seasons (winter, spring, summer, and fall) (Kottek et al., 2006). The coastal areas are influenced by the colder Gulf of Maine waters in the north and the warmer Gulf Stream to the south (NERA Group, 2001). In NH, the summers are typically warm and humid (June to September), while winters are cold with frequent snowstorms (December to March). The transitions between seasons are linked to regional climate changes (Betts, 2011). However, the weather is highly variable over short distances and time scales due to its latitudinal position where cold and warm air meet, forming frontal systems. These airflow patterns and high temporal and seasonal variability give New England, along with the Maritime Provinces of Canada to the north (despite their name) a predominantly continental rather than maritime climate (NERA Group, 2001).

The meteorological station at the Isle of Shoals, NH (Station IOSN3 - Isles of Shoals, NH; $42.967 \mathrm{~N} 70.623$ W; NOAA NDBC, accessed January 2020) was used to characterize the air temperature and winds for the $\mathrm{NH}$ coast due to its proximity ( $10 \mathrm{~km}$ or 6.2 miles offshore) and long-term records (Figure 1-1). The mean monthly average air temperature at the Isles of Shoals for the $1996-2008$ period was $8.9^{\circ} \mathrm{C}\left(48.0^{\circ} \mathrm{F}\right)$ but had a wide range (Table 3-1). Mean summer temperatures (June to September) averaged $17.9^{\circ} \mathrm{C}\left(64.2^{\circ} \mathrm{F}\right.$ ), while winter averaged $0.3^{\circ} \mathrm{C}\left(32.5^{\circ} \mathrm{F}\right)$. However, these averages can be deceiving as air temperatures can be both very warm and very cold within a season. Wind speeds at the Isles of Shoals over the same period averaged $25.9 \mathrm{~km} / \mathrm{hr}(16.1 \mathrm{mph})$ with higher averages in winter months. Similar to temperature, the average wind speeds are deceptive as very strong winds can occur during storm events in any season.

Precipitation in the form of rainfall and snow was obtained from the National Weather Service station in Durham, NH which was the closest location to the coast with a long-term, continuous record (NOAA NWS, accessed January 2020) (Figure 1-1). The average precipitation over three time periods (1996-2008, 20092019, and 2017) shows both longer-term averages and more recent conditions (Table 3-1). The annual precipitation averages for all three time periods ranged from 107.6 to $116.6 \mathrm{~cm}$ (42.4 to 45.9") with small differences between summer ( 32.4 to $41.6 \mathrm{~cm}$, or 12.8 to $16.3^{\prime \prime}$ ) and winter periods ( 33.7 to $35.1 \mathrm{~cm}$, or 13.3 to $\left.13.8^{\prime \prime}\right)$. Snowfall did increase over time with the most recent period (2017) having the highest average (35.1 cm or $\left.13.8^{\prime \prime}\right)$.

Mean annual precipitation in $\mathrm{NH}$ (whole state) increased 10\% or 12.7 cm (5") from 1895 to 2011, likely due to climate change (Kirshen et al., 2014). Extreme annual precipitation increased as well over the last century. The northeastern US, in general, has experienced a $53 \%$ increase in extreme precipitation since 1996 (Huang et al., 2017). This has primarily been due to an increase in frequency of tropical cyclones, extratropical cyclones, and fronts, occurring mostly in the months of September and October (Huang et al., 2017). Recent tropical cyclone activity accounts for about half of this observed increase in extreme precipitation. The mean annual precipitation and extreme precipitation events in $\mathrm{NH}$ are projected to increase by $20 \%$ for the period from 2071-2099 (Kirshen et al., 2014). 
Table 3-1. Summary of air temperature, wind speed, and precipitation. (Top) Average, minimum, and maximum air temperature and wind speed for the meteorological station at the Isles of Shoals located $10 \mathrm{~km}$ (6.2 miles) of the NH coast between 1996 and 2008 (Station IOSN3 - Isles of Shoals, NH; 42.967 N 70.623 W; NOAA NDBC, accessed January 2020). (Bottom) Yearly, summer, and winter precipitation and snowfall totals for the station in Durham, NH for the period between 1996 and 2008, for the last decade (2009-2019), and for the year of this study (2017) (NOAA NWS, 2020).

\begin{tabular}{|l|l|l|l|}
\hline Isles of Shoals, NH & \multicolumn{3}{c|}{ 1996-2008 } \\
\hline Air Temperature & Average & Minimum & Maximum \\
\hline Mean Monthly & $8.9^{\circ} \mathrm{C}\left(48.0^{\circ} \mathrm{F}\right)$ & $-1.7^{\circ} \mathrm{C}\left(28.9^{\circ} \mathrm{F}\right)$ (Jan) & $19.3^{\circ} \mathrm{C}\left(66.7^{\circ} \mathrm{F}\right)$ (Jul \& Aug) \\
Summer (Jun - Sept) & $17.9^{\circ} \mathrm{C}\left(64.2^{\circ} \mathrm{F}\right)$ & $5.3^{\circ} \mathrm{C}\left(41.5^{\circ} \mathrm{F}\right)$ & $33.3^{\circ} \mathrm{C}\left(91.9^{\circ} \mathrm{F}\right)$ \\
Winter (Dec - Mar) & $0.3^{\circ} \mathrm{C}\left(32.5^{\circ} \mathrm{F}\right)$ & $-22.5^{\circ} \mathrm{C}\left(8.5^{\circ} \mathrm{F}\right)$ & $22.9^{\circ} \mathrm{C}\left(73.2^{\circ} \mathrm{F}\right)$ \\
\hline Wind Speed & Average & Minimum & Maximum \\
\hline Mean Monthly & $25.9 \mathrm{kph}(16.1 \mathrm{mph})$ & $20.0 \mathrm{kph}(12.4 \mathrm{mph})$ (Aug) & $31.3 \mathrm{kph}(19.3 \mathrm{mph})$ (Jan) \\
Summer (Jun - Sept) & $21.4 \mathrm{kph}(13.3 \mathrm{mph})$ & 0 & $122.4 \mathrm{kph}(76.1 \mathrm{mph})$ \\
Winter (Dec - Mar) & $30.1 \mathrm{kph}(18.7 \mathrm{mph})$ & 0 & $93.2 \mathrm{kph}(57.9 \mathrm{mph})$ \\
\hline
\end{tabular}

Taken from Station IOSN3 data (https://www.ndbc.noaa.gov/station_page.php?station=iosn3)

Mean monthly average is the average of all values over the 12 year period

Mean monthly minimum is the month with the lowest mean values

Mean monthly maximum is the month with the highest mean values

Wind speed is averaged over a two-minute period and is reported hourly

\begin{tabular}{|c|c|c|c|}
\hline Durham, NH & 1996-2008 & 2009-2019 & 2017 \\
\hline Precipitation Totals & Average & Average & Totals \\
\hline Annual (over time interval) & $116.6 \mathrm{~cm}(45.9 \mathrm{in})$ & $114.6 \mathrm{~cm}(45.1 \mathrm{in})$ & $107.6 \mathrm{~cm}(42.4 \mathrm{in})$ \\
\hline Summer (Jun - Sept) & $40.7 \mathrm{~cm}(16.0 \mathrm{in})$ & $41.6 \mathrm{~cm}(16.3 \mathrm{in})$ & $32.4 \mathrm{~cm}$ (12.8 in) \\
\hline Winter (Dec - Mar) & $34.4 \mathrm{~cm}(13.5 \mathrm{in})$ & $33.7 \mathrm{~cm}$ (13.3 in) & $35.1 \mathrm{~cm}(13.8 \mathrm{in})$ \\
\hline Snowfall Totals & Average & Average & Totals \\
\hline Annual (over time interval) & $103.6 \mathrm{~cm}$ (40.8 in) & $120.4 \mathrm{~cm}(47.4 \mathrm{in})$ & $112.3 \mathrm{~cm}(44.2 \mathrm{in})$ \\
\hline Winter (Dec - Mar) & $93.5 \mathrm{~cm}$ (36.8 in) & $113.5 \mathrm{~cm}(44.7 \mathrm{in})$ & $93.7 \mathrm{~cm}$ (36.9 in) \\
\hline
\end{tabular}

Calculated from data from the National Weather Service (https://w2.weather.gov/climate/xmacis.php?wfo=gyx)

Annual precipitation/snowfall is the total of the mean monthly precipitation totals over the specified time interval

\section{Storms}

The major storms impacting the $\mathrm{NH}$ coast are tropical storms and, far more frequently, extratropical storms or cyclones (Kirshen et al., 2014). Tropical cyclones include tropical depressions (with maximum sustained surface winds less than $63 \mathrm{kph}$ or $39 \mathrm{mph}$ ), tropical storms (less than $119 \mathrm{kph}$ or $74 \mathrm{mph}$ ), and hurricanes (greater than $119 \mathrm{kph}$ or $74 \mathrm{mph}$ ) (NOAA NOS, accessed December 2020).

Severe storms are most common during the fall and winter in New England and are dominated by nor'easters which can produce long periods of heavy snowfall or rain and strong winds. Tropical storms (e.g., hurricanes) are much stronger than extratropical storms, but occur far less frequently in New England. However, periodically the northern New England coast is impacted by hurricanes. At least five intense hurricanes have occurred in southern New England since the early 1600's, as recorded in overwash fan deposits (Donnelly et al., 2001). Notable examples include the 1938 New England Hurricane, 
the 1944 Great Atlantic Hurricane, Hurricane Carol (1954), Hurricanes Donna and Edna (1960), Hurricane Gloria (1985), Hurricane Bob (1991), and Hurricane/Tropical Storm Irene (2011).

Over the period of this study (2017) twelve named storms (including three nor'easters) and a large wave event occurred (Table 3-2). The most significant was the nor'easter Stella, with an average sustained wind speed of $19.5 \mathrm{~m} / \mathrm{s}$ (43.7 mph; measured between 13:00 on March 14 and 4:00 on March 15) and gusts up to $30.7 \mathrm{~m} / \mathrm{s}$ (67.7 mph). The peak sustained significant wave height during Stella was $6.3 \mathrm{~m}$ (measured between 20:00 on March 14 and 2:00 on March 15), with an average height of $4.6 \mathrm{~m}$ and a maximum of $7.1 \mathrm{~m}$ ) (see Appendix B). The average wave period was 8.2 seconds. All major storms during the study period occurred prior to the end of May 2017. This allowed for sediment accretion from that time through September 19, 2017, when the remnant effects of Hurricane José hit the coast of NH and ended the period of accretion.

Table 3-2. Storms impacting the NH coast during the study period. Wind and snow data is from NWS station in Durham, NH. The wave data is from the NOAA NDBC buoy located $53 \mathrm{~km}$ offshore of NH at Jeffreys Ledge. Additional information gven in Appendix B.

\begin{tabular}{|c|c|c|c|c|c|}
\hline $2016-17$ & Name & Type & Snow & \begin{tabular}{|l|} 
Average \\
Wind Speed
\end{tabular} & \begin{tabular}{|l} 
Average \\
Significant Wave Height
\end{tabular} \\
\hline Dec $28-30$ & Fortis & Winter Storm & $<5 \mathrm{~cm}\left(<2^{\prime \prime}\right)$ & $13.8 \mathrm{~m} / \mathrm{s}(30.9 \mathrm{mph})$ & $2.8 \mathrm{~m}(\mathrm{SE}$, then $\mathrm{W})$ \\
\hline Jan 3-5 & & & & $13.4 \mathrm{~m} / \mathrm{s}$ (30 mph) & $4.0 \mathrm{~m}$ (ESE) \\
\hline Jan 7-8 & Helena & Nor'easter & & $11.4 \mathrm{~m} / \mathrm{s}(25.5 \mathrm{mph})$ & $2.8 \mathrm{~m}(\mathrm{E})$ \\
\hline Jan 17-19 & Jupiter & Winter Storm & $13-20 \mathrm{~cm}\left(5-8^{\prime \prime}\right)$ & $10.8 \mathrm{~m} / \mathrm{s}(24.1 \mathrm{mph})$ & \\
\hline Feb 5-7 & Maya & Winter Storm & $15 \mathrm{~cm}\left(6^{\prime \prime}\right)$ & $11.6 \mathrm{~m} / \mathrm{s}(26.0 \mathrm{mph})$ & $1.6 \mathrm{~m}$ (WSW) \\
\hline Feb 7-9 & Niko & Nor'easter & $25-38 \mathrm{~cm}\left(10-15^{\prime \prime}\right)$ & $13.6 \mathrm{~m} / \mathrm{s}(30.4 \mathrm{mph})$ & $3.1 \mathrm{~m}$ (WSW) \\
\hline Feb 9-10 & & & & $14.1 \mathrm{~m} / \mathrm{s}(31.5 \mathrm{mph})$ & $3.4 \mathrm{~m}$ (NE, then WNW) \\
\hline Feb $12-13$ & Orson & Winter Storm & $15-41$ cm (6-16") & $14.0 \mathrm{~m} / \mathrm{s}(31.4 \mathrm{mph})$ & $3.6 m(E)$ \\
\hline Feb 15-16 & Pluto & Winter Storm & & $10.3 \mathrm{~m} / \mathrm{s}(23.0 \mathrm{mph})$ & $2.8 \mathrm{~m}(\mathrm{E})$ \\
\hline Mar 14-15 & Stella & Nor'easter & $30-51 \mathrm{~cm}(12-20 ")$ & $19.5 \mathrm{~m} / \mathrm{s}(43.7 \mathrm{mph})$ & $4.6 \mathrm{~m}$ (ESE) \\
\hline Mar 19-21 & & & & $10.1 \mathrm{~m} / \mathrm{s}(22.6 \mathrm{mph})$ & $3.1 \mathrm{~m}$ (ESE) \\
\hline Mar 31-Apr 2 & Theseus & Winter Storm & $15 \mathrm{~cm}\left(6^{\prime \prime}\right)$ & $12.5 \mathrm{~m} / \mathrm{s}(27.9 \mathrm{mph})$ & $3.3 \mathrm{~m}$ (ESE) \\
\hline May $14-15$ & & & & $11.7 \mathrm{~m} / \mathrm{s}(26.2 \mathrm{mph})$ & $2.6 \mathrm{~m}(\mathrm{E})$ \\
\hline May 25 & & Coastal Flood & & $12.3 \mathrm{~m} / \mathrm{s}(27.6 \mathrm{mph})$ & $2.2 \mathrm{~m}(\mathrm{E})$ \\
\hline Jun 5-7 & & & & $12.2 \mathrm{~m} / \mathrm{s}(27.3 \mathrm{mph})$ & $2.9 \mathrm{~m}(\mathrm{E})$ \\
\hline Sept 19-22 & Jose & Hurricane & & $11.1 \mathrm{~m} / \mathrm{s}(24.9 \mathrm{mph})$ & $3.6 \mathrm{~m}(\mathrm{E})$ \\
\hline Oct $29-30$ & Philippe & Tropical Storm & & $16.4 \mathrm{~m} / \mathrm{s}(36.6 \mathrm{mph})$ & $3.9 \mathrm{~m}$ (SE) \\
\hline Dec 5-6 & & & & $13.5 \mathrm{~m} / \mathrm{s}(30.2 \mathrm{mph})$ & $2.8 \mathrm{~m}(\mathrm{SE})$ \\
\hline Dec 23-24 & Dylan & Winter Storm & 3-10 cm (1-4") & $8.2 \mathrm{~m} / \mathrm{s}(18.4 \mathrm{mph})$ & $1.9 \mathrm{~m}$ (ESE, then WNW) \\
\hline Dec 25-26 & & & & $13.4 \mathrm{~m} / \mathrm{s}(30.0 \mathrm{mph})$ & $2.9 \mathrm{~m}$ (ENE, then WSW) \\
\hline
\end{tabular}




\section{Tides and Waves}

Tides. The $\mathrm{NH}$ coast has semidiurnal tides with a strong diurnal component. Mean tidal range at the Fort Point, New Castle, NH tide level station for the 1983-2001 epoch was $2.63 \mathrm{~m}$ (8.63') (Station 8423898 Fort Point, NH; 43.072 N 70.71 W; NOAA CO-OPS, accessed January 2020). The great diurnal range calculated as the difference between MHHW (mean higher high water) and MLLW (mean lower low water) was $2.86 \mathrm{~m}\left(9.38^{\prime}\right)$. Tidal heights and times often vary from predicted due to storm effects as described previously in Storm Surges.

Waves. Unfortunately, there are no long-term wave gages located close to shore off the NH coast. Therefore, wave data was obtained from the two nearest wave gages with extended periods of record: Cape Elizabeth, Maine located $\sim 70 \mathrm{~km}$ ( 43.5 miles) northeast of Portsmouth Harbor, and Jeffreys Ledge located $\sim 53 \mathrm{~km}$ ( $\sim 32.9$ miles) offshore of the NH coast (Figure 1-1). The wage gage near Cape Elizabeth is $\sim 6 \mathrm{~km}$ (3.7 miles) offshore in $26.5 \mathrm{~m}$ (86.9') of water (Station 44007 - Portland; 43.525 N 70.141 W; NOAA NDBC, accessed January 2020). The wage gage located just seaward of Jeffreys Ledge is in $76.5 \mathrm{~m}\left(251.0^{\prime}\right)$ of water (Station 44098 - Jeffreys Ledge; 42.798 N 70.168 W; NOAA NDBC, accessed January 2020). It is likely that wave conditions along the $\mathrm{NH}$ coast are most similar to those in Portland, Maine. Therefore, long-term averages and maximum wave heights available for the Portland gage provide an overview of monthly, seasonal, and extreme wave conditions (Table 3-3). Waves measured at Jeffreys Ledge are likely larger than those close to the coast as shoaling would reduce the wave energy. However, Jeffreys Ledge is provided as a comparison and has data that provides insights to more recent events that occurred during the study period.

Mean monthly significant wave heights ( $H s$; average height of the highest one-third of all wave heights during a 20-minute sampling period, reported every half hour) for the period from 1982-2008 at the Cape Elizabeth, Maine wave gage ranged from 0.7 to $1.1 \mathrm{~m}$ (2.3 to 3.6') with an annual average of $0.9 \mathrm{~m}\left(3.0^{\prime}\right)$ (NOAA NDBC, 2009). However, there was a strong seasonal signal (e.g., higher means and maximum wave heights in winter) (Table 3-3). Maximum significant wave heights (single highest 20-minute average that occurred during a given month) ranged from 2.6 to $9.6 \mathrm{~m}$ (8.5 to $\left.31.5^{\prime}\right)$. As expected, monthly means for

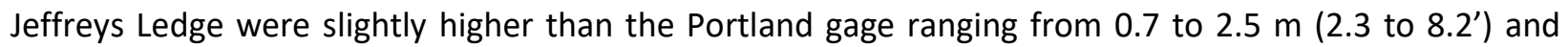
averaging $1.3 \mathrm{~m}$ (4.3') for the entire 2017-2019 period (Table 3-3). The maximum wave heights at Jeffreys Ledge ranged from 1.5 to $8.4 \mathrm{~m}$ (4.9 to $\left.27.6^{\prime}\right)$ for the 2017-2019 period. During the study period (2017) monthly mean significant wave height ranged from 0.8 to $1.8 \mathrm{~m}$ ( 2.6 to $\left.5.9^{\prime}\right)$ and the maximum significant wave height ranged from 2.7 to $7.1 \mathrm{~m}$ (8.9 to $\left.23.3^{\prime}\right)$. 
Table 3-3. Mean and maximum significant wave heights (Hs) for the wave buoy off Cape Elizabeth, Maine for the time period between 1982 and 2008 and for the buoy at Jeffreys Ledge for 2017, 2018, and 2019.

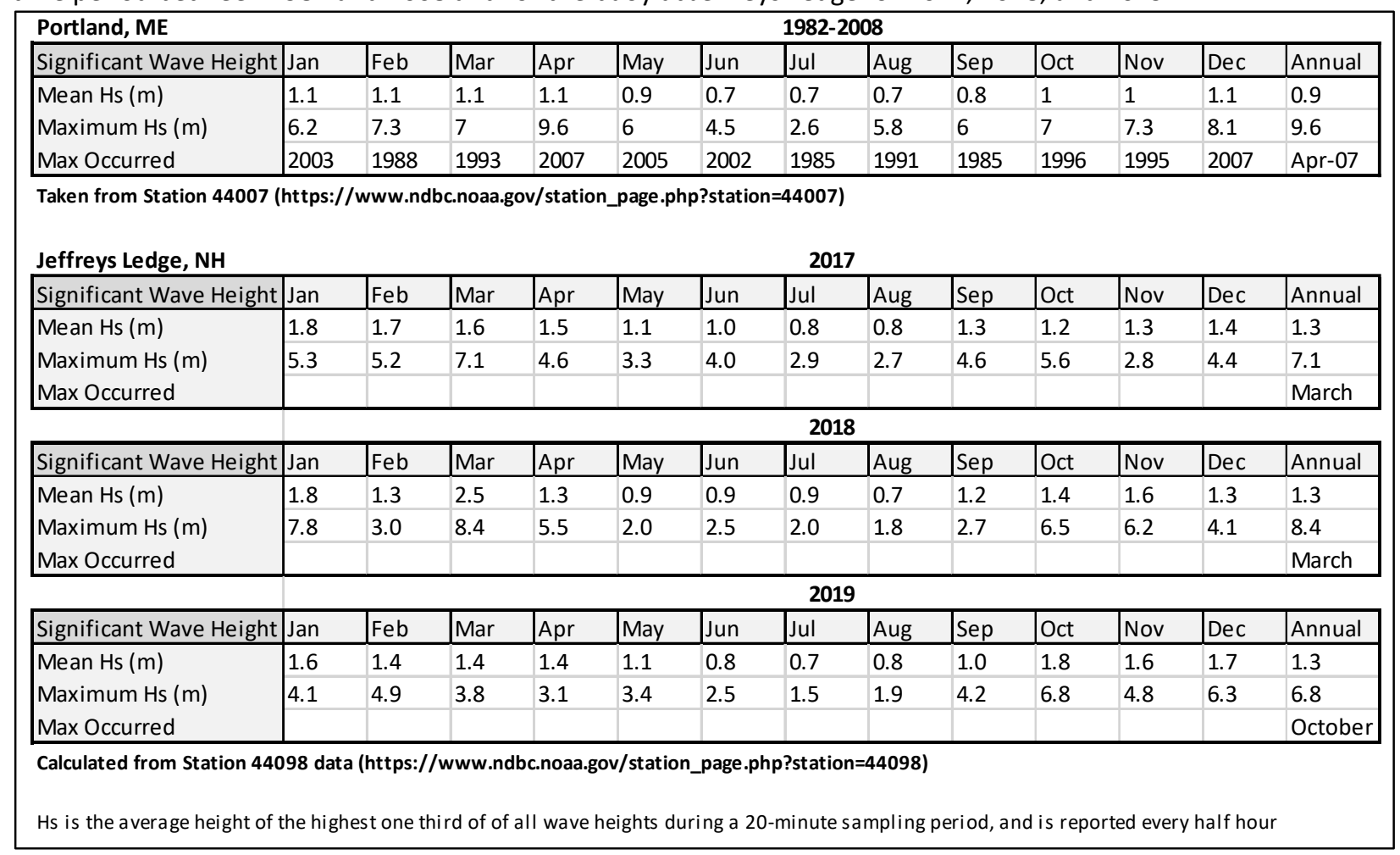

\section{Storm Surges}

Strong easterly winds associated with storms often create storm surges (difference in the predicted highwater level versus the actual measured water level); however, the magnitude of the storm surges (at least in $\mathrm{NH}$ ) tend to be much less than a meter. For example, the ten largest storm surges at Fort Point, New Castle, NH between 2003 and 2012 ranged from 0.25 to $0.62 \mathrm{~m}$ (0.82 to 2.02') (Kirshen et al., 2014). However, as discussed previously, the "Blizzard of 78" storm surge at high tide on February 7, 1978 at Seavey Island, Maine (Station 8419870; NOAA CO-OPS, accessed January 2020) was $0.82 \mathrm{~m}$ (2.69'). In addition, this blizzard and storm surge occurred during a spring tide, resulting in the flooding of broad areas of the NH coast. At the tide gage in Boston, Massachusetts (Station 8443970), the maximum storm surge for the "Blizzard of 78" on February 7 was $1.28 \mathrm{~m}\left(4.20^{\prime}\right)$.

The storm surge at Fort Point, NH ( $3 \mathrm{~km}$ or 1.8 miles from Seavey Island) was determined for the 20172019 period (Table 3-4). During March 2018 three severe nor'easters occurred (Riley, Quinn and Skylar). During Quinn the storm surge reached as high as $0.80 \mathrm{~m}$ (2.62') on March 8, 2018. Fortunately, this was not during a spring tide, so the overall tide level was not as high as during the Blizzard of 78 . The impact of storm surges is strongly affected by the phase of the tide (spring versus neap tide). 
Table 3-4. The twelve highest storm surge events each year in 2017, 2018, and 2019 at the NOS tide gage station in New Castle, NH.

\begin{tabular}{|c|c|c|c|c|c|}
\hline \multicolumn{6}{|c|}{ Highest Storm Surges 2017} \\
\hline Date & Time (GMT) & Predicted $(\mathrm{m})$ & Verified $(\mathrm{m})$ & Difference $(\mathrm{m})$ & Storm Event \\
\hline $1 / 4 / 2017$ & $8: 00$ & 1.108 & 1.609 & 0.501 & (Not named) \\
\hline $1 / 24 / 2017$ & 13:42 & 1.101 & 1.748 & 0.647 & \\
\hline $1 / 25 / 2017$ & $2: 12$ & 0.819 & 1.329 & 0.51 & \\
\hline $2 / 13 / 2017$ & $5: 36$ & 1.351 & 1.866 & 0.515 & Winter Storm Orson \\
\hline 2/14/2017 & $6: 18$ & 1.304 & 1.731 & 0.427 & Winter Storm Orson \\
\hline $2 / 15 / 2017$ & 19:06 & 1.182 & 1.585 & 0.403 & Winter Storm Pluto \\
\hline $2 / 16 / 2017$ & 7:30 & 1.16 & 1.783 & 0.623 & Winter Storm Pluto \\
\hline $3 / 14 / 2017$ & $17: 42$ & 1.359 & 1.775 & 0.416 & Winter Storm Stella \\
\hline $4 / 4 / 2017$ & $22: 30$ & 1.109 & 1.527 & 0.418 & \\
\hline $4 / 7 / 2017$ & 1:00 & 1.177 & 1.599 & 0.422 & \\
\hline $10 / 30 / 2017$ & $11: 18$ & 0.995 & 1.621 & 0.626 & Tropical Storm Philippe \\
\hline $11 / 19 / 2017$ & $16: 24$ & 1.357 & 1.78 & 0.423 & \\
\hline \multicolumn{6}{|c|}{ Highest Storm Surges 2018} \\
\hline Date & Time (GMT) & Predicted $(\mathrm{m})$ & Verified $(\mathrm{m})$ & Difference $(\mathrm{m})$ & Storm Event \\
\hline $3 / 3 / 2018$ & $4: 48$ & 1.556 & 2.133 & 0.577 & Winter Storm Riley \\
\hline $3 / 4 / 2018$ & $5: 36$ & 1.552 & 2.072 & 0.52 & Winter Storm Riley \\
\hline $3 / 5 / 2018$ & $6: 18$ & 1.496 & 2.007 & 0.511 & Winter Storm Riley \\
\hline $3 / 6 / 2018$ & 7:00 & 1.401 & 1.922 & 0.521 & Winter Storm Quinn \\
\hline $3 / 7 / 2018$ & $20: 30$ & 1.053 & 1.647 & 0.594 & Winter Storm Quinn \\
\hline $3 / 8 / 2018$ & $8: 36$ & 1.164 & 1.967 & 0.803 & Winter Storm Quinn \\
\hline $3 / 13 / 2018$ & $13: 24$ & 1.018 & 1.601 & 0.583 & Winter Storm Skylar \\
\hline $3 / 22 / 2018$ & $7: 12$ & 1.429 & 1.986 & 0.557 & (Not named) \\
\hline $11 / 25 / 2018$ & 17:06 & 1.643 & 2.143 & 0.5 & \\
\hline $11 / 27 / 2018$ & 7:06 & 1.183 & 1.89 & 0.707 & Coastal Flood \\
\hline $11 / 27 / 2018$ & $18: 42$ & 1.551 & 2.051 & 0.5 & Coastal Flood \\
\hline $11 / 28 / 2018$ & 7:48 & 1.193 & 1.735 & 0.542 & Coastal Flood \\
\hline \multicolumn{6}{|c|}{ Highest Storm Surges 2019* } \\
\hline Date & Time (GMT) & Predicted $(\mathrm{m})$ & Verified $(\mathrm{m})$ & Difference $(\mathrm{m})$ & Storm Event \\
\hline $1 / 4 / 2019$ & $2: 42$ & 1.015 & 1.299 & 0.284 & \\
\hline $1 / 5 / 2019$ & $15: 42$ & 1.342 & 1.696 & 0.354 & \\
\hline $1 / 6 / 2019$ & $4: 12$ & 0.965 & 1.301 & 0.336 & \\
\hline $2 / 16 / 2019$ & $0: 24$ & 0.898 & 1.217 & 0.319 & \\
\hline $2 / 24 / 2019$ & $20: 12$ & 1.382 & 1.841 & 0.459 & High wind event \\
\hline $3 / 22 / 2019$ & $17: 00$ & 1.785 & 2.134 & 0.349 & \\
\hline $4 / 27 / 2019$ & $10: 18$ & 0.994 & 1.553 & 0.559 & (Not named) \\
\hline $4 / 27 / 2019$ & $22: 42$ & 0.822 & 1.111 & 0.289 & (Not named) \\
\hline $5 / 14 / 2019$ & 11:54 & 1.372 & 1.68 & 0.308 & (Not named) \\
\hline $5 / 15 / 2019$ & $0: 30$ & 1.388 & 1.671 & 0.283 & (Not named) \\
\hline $9 / 7 / 2019$ & $10: 36$ & 1.004 & 1.417 & 0.413 & Dorian \\
\hline $10 / 12 / 2019$ & $3: 12$ & 1.193 & 1.608 & 0.415 & Melissa \\
\hline \multicolumn{6}{|c|}{ Calculated from Fort Point, NH Station data (https://tidesandcurrents.noaa.gov/waterlevels.html?id=8423898) } \\
\hline \multicolumn{6}{|c|}{ Datum used was NAVD88 } \\
\hline \multicolumn{6}{|c|}{ *2019 had no data for Nov and Dec } \\
\hline
\end{tabular}




\section{Chapter 4: Previous Studies on the New Hampshire Coast}

\section{Coastal Geology}

One of the earliest systematic geologic studies of the NH coast was done by Tuttle (1960) as part of dissertation research at Harvard University completed in 1952. Many of the observations made by Tuttle remain valid today. Tuttle (1960) noted most of the headlands along the NH coast are composed of bedrock covered by till to varying extents. In addition, the seacoast in general has extensive glaciallyderived deposits found in ground moraines and drumlins, outwash deposits (stratified drift), and glacial marine sediments. According to Tuttle (1960), the till is a mixture of mud, sand, and gravel including cobbles and boulders; the stratified drift (outwash) is mostly sand and finer gravel with varying amounts of mud; and the glacial marine sediments are composed of mud and sand.

A U.S. Army Corps of Engineers (USACE, 1954) report noted that there is no viable riverine source of sediments to the NH coast. Tuttle (1960) added that the Piscataqua River has very low sediment discharge as most sediments are trapped within the estuary. Both of these studies recognized that glacial deposits likely constituted the major source of sediments to NH beaches. Tuttle (1960) hypothesized that the size of the barriers and beaches decreased from south to north along the $\mathrm{NH}$ coast due to the decrease in glacial drift deposits and the dominance of bedrock headlands in the north. Tuttle (1960) also observed that the $\mathrm{NH}$ beaches which transgressed into glacially-derived deposits resulted in a variety of beach types (with respect to sediment grain size). Recent work by Venti et al. (2016) along the Massachusetts coast (including Salisbury Beach, which is part of the same barrier island as Seabrook Beach, NH) showed that beach sediment grain size is strongly related to the sediment source. Venti et al. (2016) further observed that beaches which eroded into glacial drift (outwash) are dominated by sand, while beaches which eroded into till deposits associated with glacial moraines, drumlins, or eskers are bimodal and composed of sand and gravel or are gravel beaches.

As discussed in the Sea Level History: Past, Present and Future section in Chapter 2, Ward and Adams (2001) assessed the long-term movement of the NH coast based on the topography of the upland, the bathymetry of the continental shelf, and the relative sea-level curve for the WGOM by Kelley et al. (2010). Ward and Adams' results show that during the Holocene, the NH coast has migrated over $40 \mathrm{~km}$ ( $25 \mathrm{~km}$ inland during the highstand, and $\sim 15 \mathrm{~km}$ seaward during the lowstand) before arriving at or close to its modern-day position $\sim 4,000$ years before present. Evidence of the $\mathrm{NH}$ seacoast stabilizing at its present position are the tree stumps in the intertidal zone of the beaches along the NH coast (see Chapter 6: Jenness Beach or North Hampton Beach). Goldthwait (1925) noted tree stumps exposed on the northern end of Jenness Beach, south of Straws Point, and at Odiorne Point. Lyon and Harrison (1960) described the Pinus strobus stumps rooted in woodland peat at Odiorne Point. Bulk ${ }^{14} \mathrm{C}$ dating of the stumps indicated inundation by the sea between $4,190 \pm 170$ to 3,215 \pm 130 yrs B.P. Goldthwait (1925), Lyon and Harrison (1960), and Harrison and Lyon (1963) all used the drowned forests as evidence of the Holocene transgression and computed some of the first submergence rates for the $\mathrm{NH}$ coast. Redfield and Rubin (1962) incorporated the dates from Odiorne Point with other sites to evaluate sea-level rise in Massachusetts.

Olson and Chormann (2016) assessed the stability (shoreline position) of the NH beaches using charts, orthophotographs, and lidar surveys to determine both short-term (years: 2000-2014) and long-term trends (decades: 1855-2015). Changes in shoreline positions were determined using the Digital Shoreline Analysis System (DSAS) (Thieler et al., 2009). Although there was a great deal of variability depending on the time period and location, some general trends emerged. Seabrook Beach and Hampton Beach showed seaward growth, while the beaches north of Great Boars Head migrated landward with Plaice Cove 
(southern end of North Hampton Beach) having the highest transgression rates. Olson and Chormann (2016) also assessed volumetric or vertical changes based on the Lidar surveys for the period from 20002014. The results of the volumetric analysis were consistent with the shoreline change analysis. Hampton Beach and Seabrook Beach varied a good deal between surveys, but in general showed a trend of accretion. The beaches north of Great Boars Head also showed a great deal of variability, but by contrast lost sediment over the same period.

The first systematic field study of seasonal and storm-related erosion-accretion cycles of $\mathrm{NH}$ beaches was conducted by Leo (2000) in 1997-1998. Relative elevation changes of beach profiles were measured at three locations in NH (Jenness Beach, North Beach, and Hampton Beach) and two locations in southern Maine (Seapoint Beach and Crescent Beach). Jenness Beach eroded fairly steadily throughout the study period, while Hampton Beach suffered major erosion during several storms, but recovered relatively quickly. Leo (2000) also suggested that a maximum erosional downcut limit was reached at Jenness Beach, but not at Hampton Beach (likely due to the larger sand volume). A downcut limit is a critical elevation below which there is little to no vertical erosion (Fucella and Dolan, 1996). This is evidenced by a decrease in erosion of a beach despite increasing or continued high wave energy as the stormy season progresses, and is determined by wave energy, beach profile shape, sediment grain size, and pre-existing beach sediment volume. Although an interesting notion, whether Jenness Beach or any other NH beach has reached their downcut limit remains to be determined by long-term studies that extend over multiple years.

A comprehensive field study was carried out by McPherran (2017) who assessed the morphology of NH beaches, seasonal changes in morphology, sediment volume, and sediment grain size, and response of the beaches to storms (erosion and accretion). McPherran monitored twenty-four sites distributed over six major New Hampshire beaches from July 2015 to August 2016. A GNSS rover beach profiling system (described here in Chapter 5: Methods) was utilized to measure beach elevation profiles multiple times during the study period. A major finding of the study was a change in the morphologic and sedimentologic characteristics of the beaches along the coast. The three northern beaches studied (Wallis Sands, Foss Beach, and Jenness Beach) were bimodal, granular to pebbly fine to medium sand, dissipative beaches. These beaches tended to have relatively little relief and were bound by bedrock or glacial headlands. The northern beaches underwent vertical erosion and accretion on the scale of weeks to months across the entire width of the beach. Conversely, the two southernmost beaches studied (Hampton Beach and Seabrook Beach) were primarily unimodal, granular to pebbly medium to coarse sand, intermediate to reflective beaches. The southern beaches were wide in comparison to the more northern barriers and had well-developed berms and large sediment volumes. These beaches tended to undergo major erosion and accretion of the berm, including berm crest retreat and advance on the scale of weeks to months. However, similar to the findings of Leo (2000), Hampton Beach and Seabrook Beach tended to recover relatively rapidly in this study. McPherran's (2017) results also support Tuttle's (1960) observation that $\mathrm{NH}$ beaches tended to diminish in size north of Great Boars Head.

Based on the results from the earlier work by McPherran (2017), a long-term beach elevation profile monitoring program was established in late 2016 on six of the major beaches in NH (Ward et al., 2021b). The study is part of a cooperative program between UNH, NHGS, the NH Coastal Program, and citizen scientists. Monitoring was initiated at three stations in December 2016 and ten additional stations were added in 2018. It is anticipated that the profiling will continue through at least June 2021. Based on beach elevation profiles and volumetric calculations, there are considerable differences in how $\mathrm{NH}$ beaches respond to storm events at a single station over time and between different stations during the same profiling period. Therefore, trends in erosion or accretion, as well as losses or gains in elevation, must be based on the overall changes over several months when beach elevation and sediment volume gains or 
losses become clearer. Also, beach profile elevations averaged over all profiles between January 2018 and March 2020 show that, in general, beach profiles located north of Great Boars Head have lower elevations than the barriers to the south, making them more susceptible to erosion, flooding, and storm damage.

Ward et al. (2016) and McPherran (2017) assessed the grain size of the natural sediment composing the major New Hampshire beaches under summer equilibrium conditions as a first step in assessing the optimal sediment size that would be needed for beach nourishment. In summer 2015, seven major beaches including Wallis Sands, Foss Beach, Jenness Beach, North Hampton Beach, North Beach, Hampton Beach, and Seabrook Beach were sampled along three to five transects extending from the dunes or engineering structures (e.g., seawalls) to the low water line. Results indicated that during the low energy conditions of summer 2015, many of the sandy beaches appeared to vary between fine to medium sands with granular sediments and scattered pebbles. Two of the beaches (North Hampton and Seabrook) were coarser, composed of medium to coarse sands with granular material and scattered pebbles. However, the gravel fractions tended to be under-sampled. To date, no detailed analyses (known to the authors) have been performed on the mineralogy of the NH beach sediments. Tuttle (1960) noted that the sand deposits on the beaches largely reflected the sediment source and were composed of quartz, feldspar, mica, and metamorphic fragments (slate, schist, phyllite, and quartzite).

The most comprehensive study to date of seasonal changes in sediment grain size in the northeast was carried out by Venti et al. (2016) in Massachusetts with the purpose of determining the sediment size distribution that would be needed for beach nourishment. The project was part of the Bureau of Ocean Energy Management Cooperative Agreement with the Massachusetts Geological Survey/University of Massachusetts Amherst. Beach elevation and grain size were measured in winter and summer on eighteen Massachusetts beaches located from Salisbury Beach at the NH border to south of Cape Cod including Nantucket and Martha's Vineyard. The study showed that higher wave activity during winter eroded sand from the intertidal zone at almost all of the beaches. At cobble beaches removal of a veneer of sand in winter exposed gravel. However, little appreciable change in the beach profiles occurred. On finer-grained sandy beaches the berm was eroded and the sediment became coarser.

There have been no published sediment transport or modeling studies (known to the authors) conducted on $\mathrm{NH}$ beaches to date. However, insights into controls of sediment transport pathways can be developed by examining high-resolution bathymetry and surficial geology maps developed by Ward et al. (2021a). The bathymetry and surficial geology maps revealed that the headlands, or the erosional remnants of the headlands, extend offshore and essentially separate the beaches. McPherran (2017) indicated that the presence of the headlands and the separation of the beaches would limit or prohibit longshore transport between them, leading to onshore-offshore being the dominant sediment transport pathway. USACE (1962) also noted the apparent lack of longshore drift along the NH coast north of Great Boars Head based on morphologic observations. However, Hampton Beach and Seabrook Beach tend to move sediment southward, based on the presence of sand built up on the northern jetty at Hampton Inlet. In the past, erosion of the upland would have been a major source of glacial sediments, but that source is now cut off by engineering structures (Blondin, 2016).

\section{Coastal Engineering}

Some of the earliest studies along the $\mathrm{NH}$ coast addressing beach erosion, storm surge flooding, and damage to coastal infrastructure were performed by the U.S. Army Corps of Engineers (USACE). An unpublished report in 1932 by the USACE Beach Erosion Board (BEB) (Original Beach Erosion Study of Hampton Beach, N.H.; described in USACE, 1954) presented the results of a study requested by the New Hampshire Shore and Beach Preservation Commission (NHSBPC) to review severe erosion problems at the 
southern end of Hampton Beach. The BEB concluded the erosion was due to the migration of Hampton Inlet and recommended the construction of a jetty on the northern side of the inlet and the placement of landfill adjacent to the jetty which would be supplied by dredging Hampton Harbor. The BEB also recommended the construction of a jetty on the southern side of the inlet. From 1934-1935 two stone jetties were constructed by the NH State Highway Department at Hampton Inlet. The northern jetty extended $\sim 450 \mathrm{~m}\left(\sim 1300^{\prime}\right)$ seaward, while the southern jetty extended $\sim 300 \mathrm{~m}\left(1000^{\prime}\right)$ (Sargent and Bottin, 1989). In addition, $\sim 0.2 \mathrm{~km}^{2}$ ( $\sim 50$ acres) of land was reclaimed adjacent to the northern jetty. In 1966 the federal government extended the northern jetty by $300 \mathrm{~m}\left(1000^{\prime}\right)$ with a crown elevation of +3.7 $\mathrm{m}\left(12^{\prime}\right)$. A landward spur was also included. The outer $\sim 91.5 \mathrm{~m}\left(300^{\prime}\right)$ of the southern jetty was repaired and the crown elevation increased to $+5.5 \mathrm{~m}\left(18^{\prime}\right)$. A $\sim 55 \mathrm{~m}\left(180^{\prime}\right)$ landward-perpendicular spur was added to the southern jetty at the same time (Sargent and Bottin, 1989). Additional repairs were made to the northern jetty from 1973-1974 and again in 1981.

An unpublished report in 1942 by the BEB (Continuing Study of Hampton and Seabrook Beaches and Hampton River and Harbor, N.H.; cited in USACE, 1954) indicated that the jetties, dikes and sand fill at the mouth of Hampton River had successfully stabilized the inlet and protected the southern end of Hampton Beach. However, Hampton Harbor had extensively shoaled since 1935. In addition, beach erosion and storm damage occurred in the "business district", presumably the northern half of Hampton Beach. The $B E B$ recommended the construction of a seawall and spur groins. Between 1946 and 1954 seawalls were constructed along the entire business district of Hampton Beach, extending up to Great Boars Head (USACE, 1954). Despite these efforts, the beach fronting the seawall was badly eroding and was on the order of $\sim 20$ to $25 \mathrm{~m}$ ( $\sim 60$ to $85^{\prime}$ ) wide. Furthermore, the sandy beach at the very northern end of Hampton Beach was entirely missing and was composed of pebbles, cobbles, and boulders. In contrast, the beach

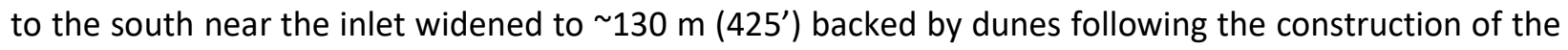
jetties. USACE (1954) recommended beach nourishment as a solution, widening the northern half of the barrier beach to $\sim 46 \mathrm{~m}\left(150^{\prime}\right)$ and $\sim 53 \mathrm{~m}\left(175^{\prime}\right)$ closer to Great Boars Head. The beach nourishment was completed by 1955 with $77,220 \mathrm{~m}^{3}\left(101,000 \mathrm{yd}^{3}\right)$ of material placed north of Haverhill Street. It is not clear from the earlier USACE reports whether the beach extends from the seawall to the low water line or if it is just the supratidal portion of the beach. However, it appears that USACE refers to the backshore landward of the berm as the beach.

The magnitude of erosion of Hampton Beach (northern $~ 70 \%$ ) is illustrated by calculations of changes in sand volumes based on a series of shore-normal profiles measured in 1940 and 1952 by the USACE that included the beach (presumably backshore), foreshore (presumably intertidal), and offshore to -5.5 $\mathrm{m}$ ($18^{\prime}$ ) (USACE, 1954). During this period, the beach and nearshore lost a yearly average of $\sim 11,700 \mathrm{~m}^{3}$ $\left(\sim 15,300 \mathrm{yd}^{3}\right)$. However, $96 \%$ of the volume lost was below mean low water to a depth of $\sim 5.5 \mathrm{~m}$. In contrast, the southern $\sim 30 \%$ of Hampton Beach gained a yearly average of $\sim 75 \mathrm{~m}^{3}\left(\sim 97 \mathrm{yd}^{3}\right)$, but this included a large increase on the upper and intertidal beach $\left(\sim 1,412 \mathrm{~m}^{3}\right.$ or $\left.1,847 \mathrm{yd}^{3}\right)$ offset by losses offshore $\left(1,337 \mathrm{~m}^{3}\right.$ or $\left.1,750 \mathrm{yd}^{3}\right)$. Similar sand volume calculations were made for Seabrook Beach for the 1940 to 1952 period. Seabrook Beach gained a yearly average of $\sim 975 \mathrm{~m}^{3}\left(1,275 \mathrm{yd}^{3}\right)$ on the beach, but lost $6,916 \mathrm{~m}^{3}\left(9,047 \mathrm{yd}^{3}\right)$ below mean low water to a depth of $\sim 5.5 \mathrm{~m}$. USACE (1962) again computed changes in sand volumes on Hampton Beach for the period from 1955 to 1959. The results showed considerable loss of sand occurred in the northern and middle reaches of Hampton Beach following the beach nourishment completed in 1955, while the southern end of the beach accreted. Although these estimates must be considered very approximate, it does show the large changes that can occur. Visual inspection indicated the entire amount of material placed on the northern half of Hampton Beach had been eroded or transported to the southern end. Importantly, a Rockingham Planning Commission (RPC) report (RPC, 1986) noted in a later study that the sediment placed on the northern end of Hampton Beach drifted south and back into Hampton Harbor. 
The USACE (1962) recommended North Hampton Beach be widened along $487 \mathrm{~m}\left(1600^{\prime}\right)$ of its length to

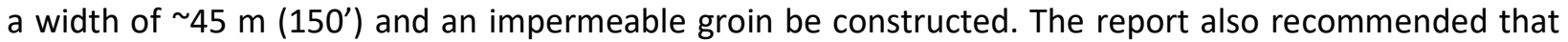
Wallis Sands should be widened to $\sim 45 \mathrm{~m}\left(150^{\prime}\right)$ along $244 \mathrm{~m}\left(800^{\prime}\right)$ of its length at the State Beach. An impermeable groin was recommended as well. As a result of the USACE recommendations, the beach at Wallis Sands State Beach was widened to $\sim 45 \mathrm{~m}\left(150^{\prime}\right)$ and a $107 \mathrm{~m}$ (350') groin constructed. These modifications were completed in October 1963. Additionally, Hampton Beach was once again widened from Haverhill Street to near Great Boars Head (a length of $\sim 1,580 \mathrm{~m}$ or $\sim 5,200^{\prime}$ ) to a width of $\sim 46 \mathrm{~m}$ $\left(150^{\prime}\right)$. A $58 \mathrm{~m}\left(190^{\prime}\right)$ groin connecting to a bedrock outcrop was also constructed near the northern end of the beach. These projects were completed in November 1965 (USACE, 1977). In response to a major storm in 1972 (i.e. Tropical Storm Carrie) much of the NH coastline was declared a National Disaster Area, and as a result, the USACE nourished Hampton Beach.

The RPC conducted a review of shoreline changes along the NH coast in 1978 with an update in 1986 (RPC, 1986). The focus of the 1986 report was to identify the most critical erosion problems along NH's tidal shoreline. Foss Beach, North Beach, the northern end of Hampton Beach, and the dunes at the northern and southern ends of Seabrook Beach were identified as critical erosion areas. Also identified were some of the headlands extending seaward between the beaches in Rye (Figure 1-1).

The RPC (1986) also noted that the stabilization of Great Boars Head with riprap slowed the rate of erosion but removed a source of sediment that the headland provided to Hampton Beach and North Beach. Erosion of these glacial deposits such as Great Boars Head were once the major source of sediments for the beaches along the entire $\mathrm{NH}$ coast. In addition, the near-continuous engineering structures have largely eliminated the upland as a source of sediment to the $\mathrm{NH}$ beaches.

In response to storms and shoreline erosion the $\mathrm{NH}$ coastline has been extensively modified with a variety of coastal engineering structures including seawalls, riprap, gravel berms, groins, and jetties. Blondin (2016) inventoried the NH Atlantic coast and found that $70 \%(23.2 \mathrm{~km}$ or $14.4 \mathrm{mi})$ of the $34.0 \mathrm{~km}(21.1 \mathrm{mi})$ shoreline had some form of armor (Figure 4-1). With few exceptions, the only parts of the NH coast left without engineering structures are the southern $\sim 600 \mathrm{~m}$ of Hampton Beach State Park and the southern $\sim 1500 \mathrm{~m}$ of Seabrook Beach, both of which have well-developed dunes providing valuable habitat and protection against flooding and infrastructure damage.

\section{Recent Beach Nourishment Projects}

Periodically, beach nourishment projects have been carried out in NH (Table 4-1), where sand is brought in from other areas or pumped onto the beach during dredging operations in order to alleviate erosion, increase elevation, or to extend the intertidal area. For example, Seabrook Beach and the southern end of Hampton Beach was nourished in 2012 and again in 2019 with sand from dredging Hampton Harbor for navigation purposes (Figures 4-2 and 4-3). The placement of the sand on Seabrook Beach and Hampton Beach was driven by convenience and cost. The sand dredged from Hampton and Seabrook Harbors was pumped directly on the beaches, mitigating transportation costs. A more complete history of beach nourishment in $\mathrm{NH}$ is difficult to assemble as record-keeping in the past appears to be incomplete at best. Also, it is likely that smaller projects were conducted ad hoc and not carefully documented. Nevertheless, several efforts to assemble what is known about beach nourishment in NH have been made including Haddad and Pilkey (1998), Olson and Chormann (2016), USACE (2016a and 2016b), and McPherran (2017). An updated version of the NH beach nourishment projects between 1935 and 2020 is given in Table 4-1. 


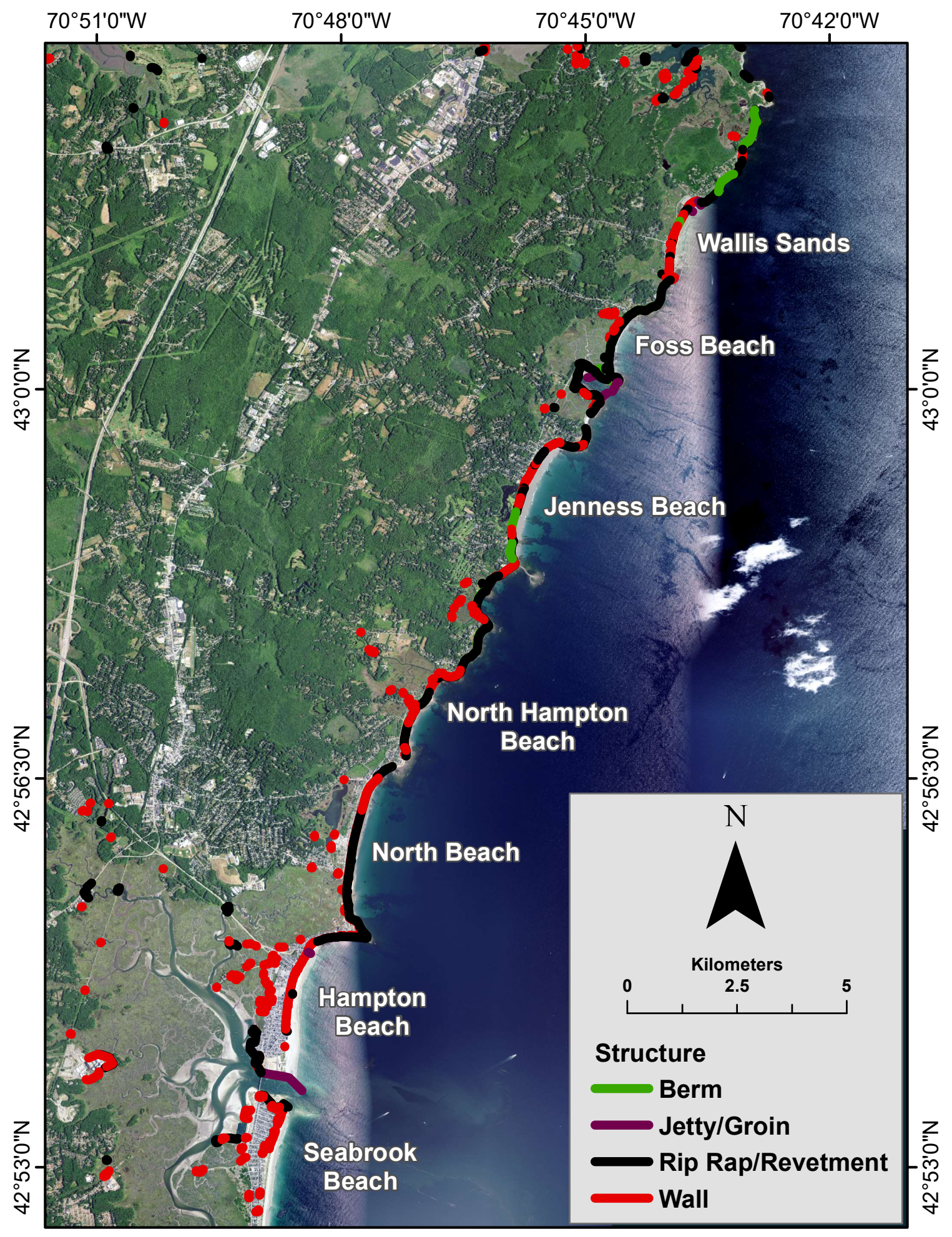

Figure 4-1. Coastal engineering structures along the NH coastline (from Blondin, 2016); downloaded from https://granit.unh.edu, accessed January 2021. 
Table 4-1. Summary of known beach nourishment projects on the New Hampshire coast. Modified (updated) from McKenna (2013) and McPherran (2017).

\begin{tabular}{|c|c|c|c|c|c|c|}
\hline Location & Organization & Date & $\begin{array}{c}\text { Nourishment } \\
\left(\mathrm{m}^{3}\right)\end{array}$ & Placement Location & Structure & Other \\
\hline $\begin{array}{l}\text { Wallis Sands } \\
\text { Beach }\end{array}$ & $\begin{array}{l}\text { USACE NH Shore and } \\
\text { Bank Protection } \\
\text { Projects (NHSBPP) }\end{array}$ & 1963 & 153,000 & $\begin{array}{c}\text { Northernmost } 800 \text { feet of } \\
\text { beach; } \\
\text { direct placement of sand }\end{array}$ & $\begin{array}{l}107 \text { m long } \\
\text { stone groin } \\
\text { emplaced }\end{array}$ & $\begin{array}{l}\text { Widened northernmost } 244 \\
\mathrm{~m} \text { of beach to } 46 \mathrm{~m} \text { width }\end{array}$ \\
\hline $\begin{array}{l}\text { Wallis Sands } \\
\text { Beach }\end{array}$ & USACE NHSBPP & 1973 & 7,700 & & & $\begin{array}{c}\text { Part of restoration effort after } \\
\text { major storm in February } \\
1972 ; \\
\text { groin repaired }\end{array}$ \\
\hline $\begin{array}{c}\text { Wallis Sands } \\
\text { Beach }\end{array}$ & Unknown & 1983 & $\begin{array}{l}\text { Unknown } \\
\text { volume }\end{array}$ & & & \\
\hline $\begin{array}{c}\text { Wallis Sands } \\
\text { Beach }\end{array}$ & USACE & 1994 & 4,100 & $\begin{array}{c}\text { Wallis Sands State Park (900 } \\
\text { feet off the beach) }\end{array}$ & & $\begin{array}{c}\text { Material dredged from Little } \\
\text { Harbor entrance channel; } \\
\text { used to create a nearshore } \\
\text { "feeder berm" }\end{array}$ \\
\hline $\begin{array}{l}\text { Wallis Sands } \\
\text { Beach }\end{array}$ & USACE & 2001 & 31,000 & $\begin{array}{c}\text { Wallis Sands State Park (900 } \\
\text { feet off the beach) }\end{array}$ & & $\begin{array}{l}\text { Material dredged from Little } \\
\text { Harbor entrance channel and } \\
\text { anchorage; used to create a } \\
\text { nearshore "feeder berm" }\end{array}$ \\
\hline $\begin{array}{l}\text { Wallis Sands } \\
\text { Beach }\end{array}$ & USACE & 2017 & 3,100 & $\begin{array}{c}\text { Wallis Sands State Park (900 } \\
\text { feet off the beach) }\end{array}$ & & $\begin{array}{c}\text { Material dredged from } \\
\text { Sagamore Creek; used to } \\
\text { create a nearshore "feeder } \\
\text { berm" }\end{array}$ \\
\hline $\begin{array}{c}\text { Hampton } \\
\text { Beach }\end{array}$ & State of $\mathrm{NH}$ & 1935 & 765,000 & & & \\
\hline $\begin{array}{l}\text { Hampton } \\
\text { Beach }\end{array}$ & USACE NHSBPP & 1955 & 306,000 & $\begin{array}{c}\text { From Haverhill Ave to the } \\
\text { north (northern and middle } \\
\text { part of beach); } \\
\text { direct placement of sand }\end{array}$ & & $\begin{array}{c}\text { Widened northern } 1981 \mathrm{~m} \text { of } \\
\text { beach }\end{array}$ \\
\hline $\begin{array}{l}\text { Hampton } \\
\text { Beach }\end{array}$ & USACE NHSBPP & 1965 & 130,000 & $\begin{array}{l}\text { From Church St to the north } \\
\text { (northern 2,200 feet of the } \\
\text { beach); sand dredged from } \\
\text { channel at Hampton Harbor }\end{array}$ & $\begin{array}{c}58 \mathrm{~m} \text { stone } \\
\text { groin emplaced }\end{array}$ & $\begin{array}{c}\text { Widened northern } 671 \text { m of } \\
\text { beach with Hampton Harbor } \\
\text { dredge material }\end{array}$ \\
\hline $\begin{array}{c}\text { Hampton } \\
\text { Beach }\end{array}$ & USACE & 1973 & 313,000 & & & \begin{tabular}{|l} 
Part of restoration effort after \\
major storm in February 1972 \\
\end{tabular} \\
\hline $\begin{array}{l}\text { Hampton } \\
\text { Beach }\end{array}$ & Unknown & 1987 & 16,000 & & & \\
\hline $\begin{array}{l}\text { Hampton } \\
\text { Beach }\end{array}$ & USACE & $2012 / 2013$ & 40,000 & & & $\begin{array}{c}\text { Maintenance dredging } \\
\text { project at Hampton-Seabrook } \\
\text { Harbor }\end{array}$ \\
\hline $\begin{array}{l}\text { Hampton } \\
\text { Beach }\end{array}$ & USACE & 2018/2019 & 24,500 & $\begin{array}{l}\text { Southern end adjacent to } \\
\text { the jetty; } \\
\text { direct placement of sand }\end{array}$ & & $\begin{array}{c}\text { Maintenance dredging } \\
\text { project at Hampton-Seabrook } \\
\text { Harbor }\end{array}$ \\
\hline $\begin{array}{c}\text { Seabrook } \\
\text { Beach }\end{array}$ & Unknown & 2005 & $\begin{array}{l}\text { Unknown } \\
\text { volume }\end{array}$ & & & \\
\hline $\begin{array}{c}\text { Seabrook } \\
\text { Beach }\end{array}$ & USACE & $2012 / 2013$ & 92,000 & $\begin{array}{l}\text { Northern end of the beach; } \\
\text { direct placement of sand }\end{array}$ & & $\begin{array}{c}\text { Maintenance dredging } \\
\text { project at Hampton-Seabrook } \\
\text { Harbor }\end{array}$ \\
\hline $\begin{array}{c}\text { Seabrook } \\
\text { Beach }\end{array}$ & USACE & 2018/2019 & 91,700 & $\begin{array}{l}\text { Northern end of the beach; } \\
\text { direct placement of sand }\end{array}$ & & $\begin{array}{c}\text { Maintenance dredging } \\
\text { project at Hampton-Seabrook } \\
\text { Harbor }\end{array}$ \\
\hline
\end{tabular}



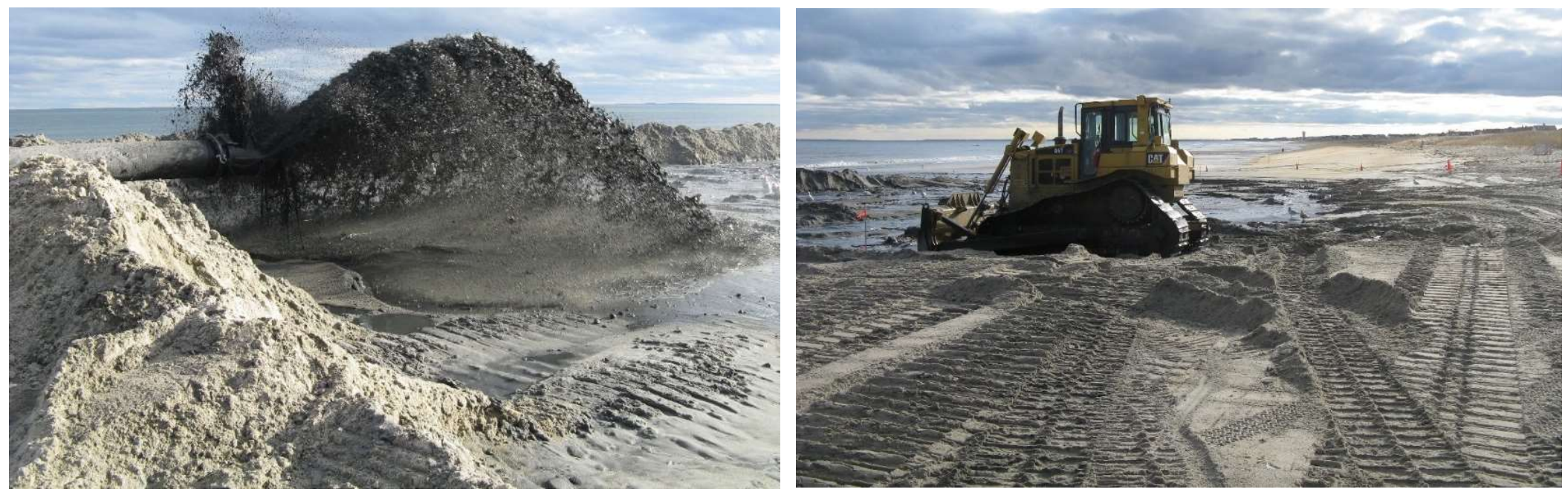

Figure 4-2. Beach nourishment at Seabrook Beach using dredged material from Hampton-Seabrook Harbor (December 11, 2012). The sand was pumped onto the beach via a pipeline (left photograph) and then graded with a bulldozer (right photograph).
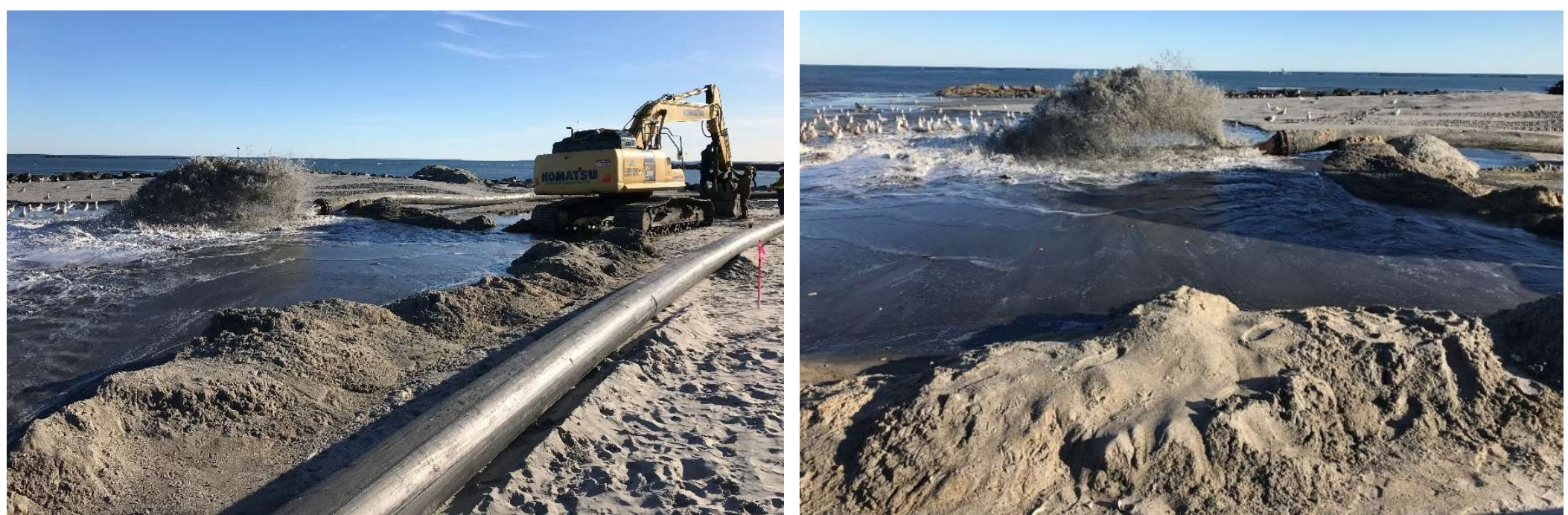

Figure 4-3. Beach nourishment at Hampton Beach State Park using dredged material from Hampton-Seabrook Harbor (November 23, 2019). The sand was pumped onto the beach via a pipeline (left photograph). Photograph on the right is a close-up of sand discharged from the pipe. 


\section{Chapter 5: Methods}

\section{Field Procedures}

Sampling Network and Strategy. The station network established along the NH coast in 2015 during the initial beach studies by McPherran (2017) was also used during this study with some small modifications. The seven major beaches (Wallis Sands, Foss Beach, Jenness Beach, North Hampton Beach, North Beach, Hampton Beach, and Seabrook Beach) were sampled in late winter - early spring 2017 and again in late summer-early fall 2017. The sampling windows were chosen to represent both a period of extended erosion (late winter - early spring) and a period of extended accretion (late summer). During each sampling period, three to five profile transects were run at each beach and three to six samples collected on each transect (Table 5-1).

In the late winter - early spring sampling period, twenty-eight stations were profiled to determine elevation and one hundred forty sediment samples collected. The bulk of the field work was done between February 2 and April 24, 2017. Two stations had to be rerun on May 2 and May 4 due to problems with the GNSS receiver during the earlier sampling. Between January 7 and April 2, twelve high-energy wave events occurred that included eight winter storms and two nor'easters. As a result, the beaches were significantly eroded and representative of extended high energy, erosive conditions during the late winter - early spring period. During the late summer 2017 sampling period, twenty-two profile transects were run and ninety-seven sediment samples collected between September 5 and 19, 2017. There were no storm or high-energy events from late May to September 19, 2017 and the beaches were representative of extended accretional conditions (Table 3-2). Six stations were not re-sampled during the late summer accretional period due to an unexpected storm. Hurricane Jose moved up the U.S. East Coast, degrading to a tropical storm as it drifted off the New England coast on September 20 causing significant erosion, ending the late summer sampling period prematurely.

The number and spacing of profile stations was based on alongshore variability in the beach morphology and sediments, tempered by practical limits in the number of stations that could be sampled within a sampling window. The sampling locations on each transect were chosen with the intent of capturing the major morphologic features and sediment changes. Although practical limits were imposed on the sampling scheme, the major environments present were profiled and sampled at a reconnaissance level. In addition, the sampling was successful in that the late winter - early spring field sampling did follow an extended stormy period when the beach was eroded, and the late summer window followed an extended accretional period when the beach elevation had built upward (late summer-early fall).

Beach Elevation Profiles. At each field station a shore-perpendicular topographic profile was measured along the sampling transect prior to sediment sampling. The profiles were run in the same locations using the same methodology as McPherran (2017), thus extending the period of coverage. Beach elevation profiles were run using a GNSS Rover which consisted of a three-wheeled dolly with a central fixed-height antenna and water-resistant housing with an Ashtech receiver (Proflex 500) (Figure 5-1). The raw GNSS data were post-processed with Continuously Operating Reference Stations (CORS) differential correction data using Precise Differential GPS Navigation and Surveying (PNAV) software (Ashtech, 1988) or RTKLIB (an open source program package; http://www.rtklib.com/; accessed January 2020). The CORS located in Salisbury, Massachusetts or Durham, New Hampshire were used. The elevations were determined in reference to the ellipsoid (WGS84) and adjusted to NAVD88 and Mean Water Level (MWL) referenced to NAD83 (1986) using VDatum 3.9 (NOAA NOS; http://vdatum.noaa.gov/; downloaded May 2019). 
Table 5-1. Location and elevation of the station markers for the beach sediment grain size study.

\begin{tabular}{|c|c|c|c|c|c|c|c|c|}
\hline Beach & Station & $\begin{array}{c}\text { WGS84 } \\
\text { Latitude }\end{array}$ & $\begin{array}{c}\text { WGS84 } \\
\text { Longitude }\end{array}$ & $\begin{array}{c}\text { Elevation } \\
\text { WGS84 } \\
\text { (meters) }\end{array}$ & $\begin{array}{l}\text { Elevation } \\
\text { NAVD88 } \\
\text { (meters) }\end{array}$ & $\begin{array}{c}\text { Sampling } \\
\text { season (if } \\
\text { applicable) }\end{array}$ & $\begin{array}{c}\text { Date } \\
\text { Leveled or } \\
\text { Sampled }\end{array}$ & Notes on Location \\
\hline Wallis Sands & WS01 & 43.027703 & -70.728421 & -23.81 & 2.92 & N/A & $6 / 20 / 2017$ & Seawall \\
\hline Wallis Sands & WSO2 & 43.024811 & -70.730853 & -22.51 & 5.32 & N/A & $7 / 22 / 2016$ & Seawall \\
\hline Wallis Sands & WSO3 & 43.022898 & -70.731935 & -21.61 & 6.22 & N/A & $7 / 22 / 2016$ & Seawall \\
\hline Wallis Sands & WS05 & 43.020684 & -70.732485 & -23.84 & 4.00 & N/A & $7 / 22 / 2016$ & Seawall \\
\hline Foss Beach & FB01 & 43.010426 & -70.741677 & -25.72 & 2.14 & N/A & $7 / 26 / 2016$ & Riprap Seawall \\
\hline Foss Beach & FB02 & 43.007890 & -70.743799 & -25.32 & 0.61 & Summer & 9/15/2017 & Landward-most sediment sampling location \\
\hline Foss Beach & FB03 & 43.005794 & -70.744873 & -25.61 & 2.25 & N/A & $7 / 26 / 2016$ & Riprap Seawall \\
\hline Foss Beach & FB04 & 43.003387 & -70.744998 & -27.45 & 0.41 & Winter & $4 / 10 / 2017$ & Landward-most sediment sampling location \\
\hline Jenness Beach & JB01 & 42.988737 & -70.760207 & -23.96 & 3.94 & N/A & $12 / 6 / 2017$ & Seawall \\
\hline Jenness Beach & JB02 & 42.985772 & -70.762434 & -23.97 & 3.93 & N/A & $6 / 13 / 2017$ & Seawall \\
\hline Jenness Beach & $\mathrm{JB} 03$ & 42.982859 & -70.763490 & -25.96 & 1.95 & N/A & $7 / 25 / 2016$ & Riprap Seawall \\
\hline \multirow{2}{*}{ Jenness Beach } & \multirow{2}{*}{ JB04 } & 42.980488 & -70.764507 & -26.10 & 1.80 & Winter & $3 / 29 / 2017$ & Landward-most sediment sampling location \\
\hline & & 42.980508 & -70.764479 & -25.88 & 2.03 & Summer & 9/11/2017 & Landward-most sediment sampling location \\
\hline North Hampton Beach & NHB01 & 42.955718 & -70.781270 & -23.55 & 4.40 & N/A & $6 / 20 / 2017$ & Seawall \\
\hline \multirow{2}{*}{ North Hampton Beach } & \multirow{2}{*}{$\mathrm{NHBO2}$} & 42.952370 & -70.784663 & N/A & $\mathrm{N} / \mathrm{A}$ & Winter & $3 / 31 / 2017$ & Landward-most sediment sampling location \\
\hline & & 42.952330 & -70.784395 & -25.06 & 2.89 & Summer & $9 / 13 / 2017$ & Landward-most sediment sampling location \\
\hline North Hampton Beach & $\mathrm{NHB03}$ & 42.950581 & -70.785804 & -25.64 & 2.32 & N/A & $8 / 8 / 2016$ & Riprap by Seawall \\
\hline North Beach & NB01 & 42.939494 & -70.794637 & -24.97 & 3.01 & N/A & $6 / 19 / 2017$ & Seawall \\
\hline North Beach & NB02 & 42.934373 & -70.796721 & -23.77 & 4.21 & N/A & $12 / 6 / 2017$ & Riprap by Seawall \\
\hline North Beach & NB03 & 42.928584 & -70.798199 & -25.28 & 2.70 & N/A & $7 / 26 / 2016$ & Riprap by Seawall \\
\hline North Beach & NB04 & 42.925031 & -70.798758 & -26.05 & 1.93 & Winter & $4 / 24 / 2017$ & Landward-most sediment sampling location \\
\hline Hampton Beach & HB01 & 42.913075 & -70.808819 & -23.27 & 4.75 & N/A & $6 / 19 / 2017$ & Seawall \\
\hline Hampton Beach & HB02 & 42.909014 & -70.810574 & -23.55 & 4.47 & N/A & N/A & Seawall \\
\hline Hampton Beach & HB03 & 42.905537 & -70.811223 & -23.52 & 4.50 & N/A & $12 / 15 / 2017$ & Seawall \\
\hline Hampton Beach & $\mathrm{HB} 04$ & 42.900096 & -70.811336 & -23.91 & 4.10 & Winter & $3 / 8 / 2017$ & Landward-most sediment sampling location \\
\hline Seabrook Beach & SB01 & 42.887581 & -70.814044 & N/A & $\mathrm{N} / \mathrm{A}$ & $\mathrm{N} / \mathrm{A}$ & $\mathrm{N} / \mathrm{A}$ & Seawall \\
\hline \multirow{2}{*}{ Seabrook Beach } & \multirow{2}{*}{ SB02 } & 42.884902 & -70.814562 & -22.83 & 5.20 & Winter & $3 / 10 / 2017$ & Landward-most sediment sampling location \\
\hline & & 42.884958 & -70.814448 & -23.85 & 4.18 & Summer & 9/18/2017 & Landward-most sediment sampling location \\
\hline Seabrook Beach & SB03 & 42.882888 & -70.814862 & -24.05 & 3.98 & Winter & $5 / 2 / 2017$ & Landward-most sediment sampling location \\
\hline \multirow{2}{*}{ Seabrook Beach } & \multirow{2}{*}{ SB04 } & 42.879766 & -70.815632 & -23.12 & 4.92 & Winter & $3 / 18 / 2017$ & Landward-most sediment sampling location \\
\hline & & 42.879767 & -70.815555 & -23.81 & $\mathrm{~N} / \mathrm{A}$ & Summer & 9/18/2017 & Landward-most sediment sampling location \\
\hline Seabrook Beach & SB05 & 42.874375 & -70.816350 & -22.74 & 5.30 & Winter & $3 / 20 / 2017$ & Landward-most sediment sampling Iocation \\
\hline
\end{tabular}

'Where summer and winter transects were not the same, the landward-most transect stations from both seasons were listed - see 'Notes on Location' 
Sediment Sampling. The beach sediment sampling was guided by earlier studies and experience working on the NH coast (Ward et al., 2016; McPherran, 2017). NH beaches cover a wide range of sediment sizes from fine sand to cobbles and boulders. Therefore, any sampling plan must be scaled to obtain adequate samples for sand as well as gravel (granule, pebbles, and cobbles). In addition, the sample should represent the upper $\sim 20$ to $30 \mathrm{~cm}$ of the sediment column.

Sediment sampling station locations were determined with a GNSS rover system by hovering over the sample location for five to ten minutes (Figure 5-1). In instances where the GNSS unit failed, the position of each sampled site was determined with a Garmin 76Cx hand-held GPS unit with an accuracy of $<10 \mathrm{~m}$. This only occurred on three occasions: Wallis Sands Station WSO5 on March 8; North Hampton Station NHBO2 (one sample) on March 31; and Hampton Beach Stations HB01 and HBO2 on September 17.

Samples that were predominantly sand and/or fine gravel mixtures were collected using a common drain spade ( 40 by $15 \mathrm{~cm}$ ) that was completely inserted into the sediment or until refusal, typically between 20 to $30 \mathrm{~cm}$ deep (Figure 5-2). The sample was removed by rotating the spade, and if necessary, digging the spade out so that the sediment column could be extracted relatively undisturbed. Subsequently, the sample was trimmed with a trowel to the desired size, photographed with a scale, measured, and placed into a plastic sample bag for transport to the laboratory and storage until analyzed (Figure 5-3).

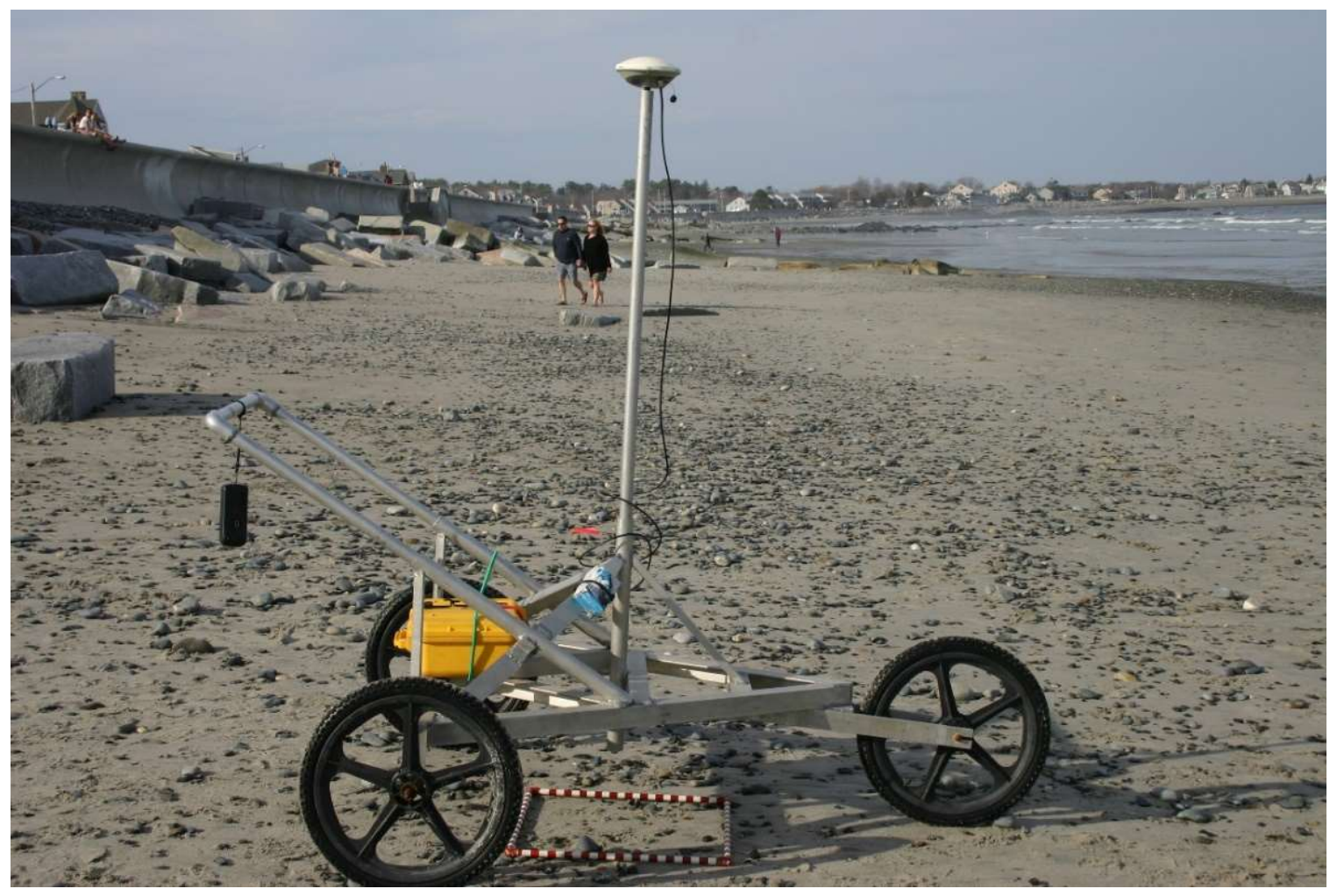

Figure 5-1. GNSS rover used to measure beach elevation profiles and locate sediment sampling stations. The photograph is looking north from station NBO2 at North Beach on April 11, 2017. 


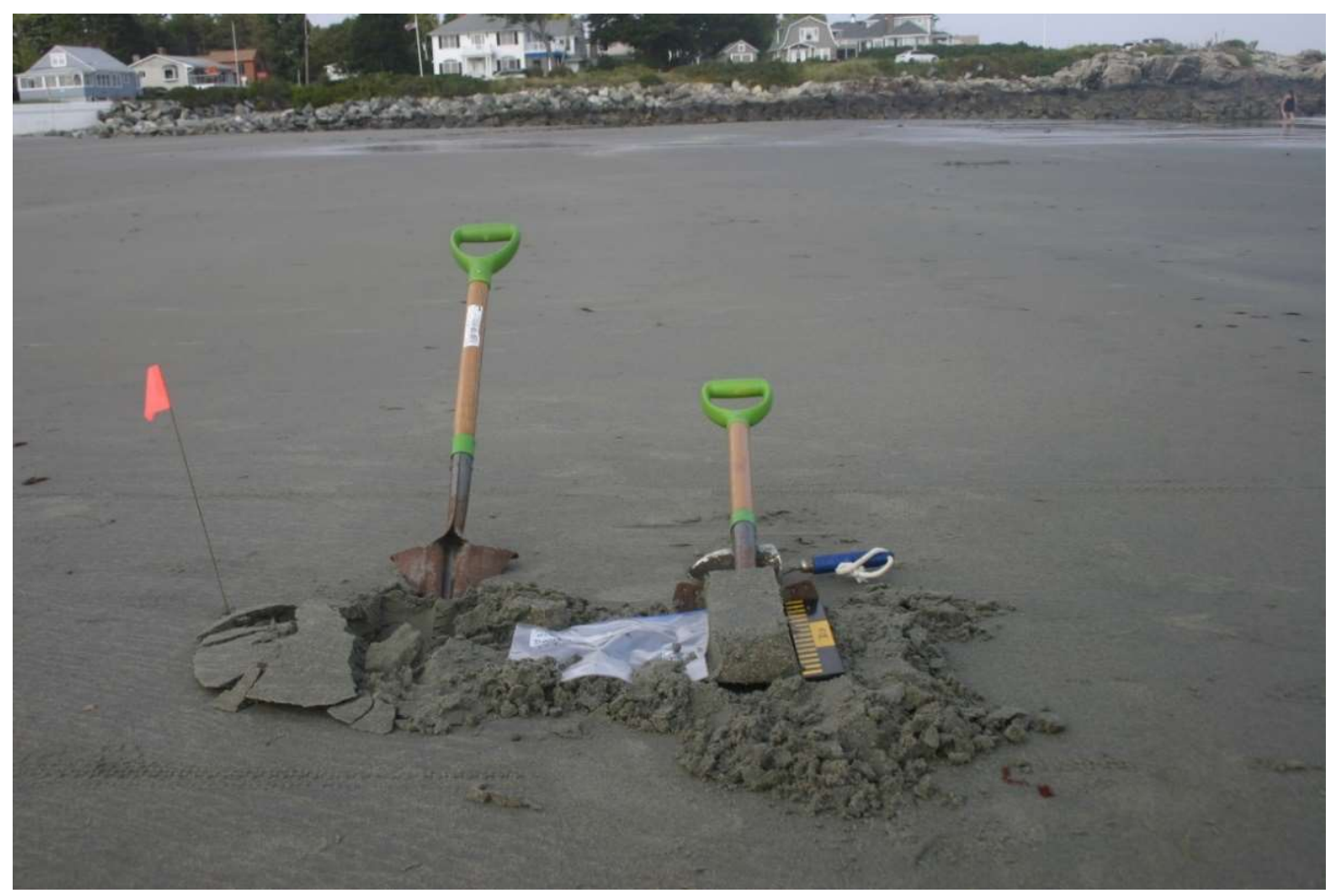

Figure 5-2. Collection of a beach sediment core at Wallis Sands station WSO1 on September 5, 2017.

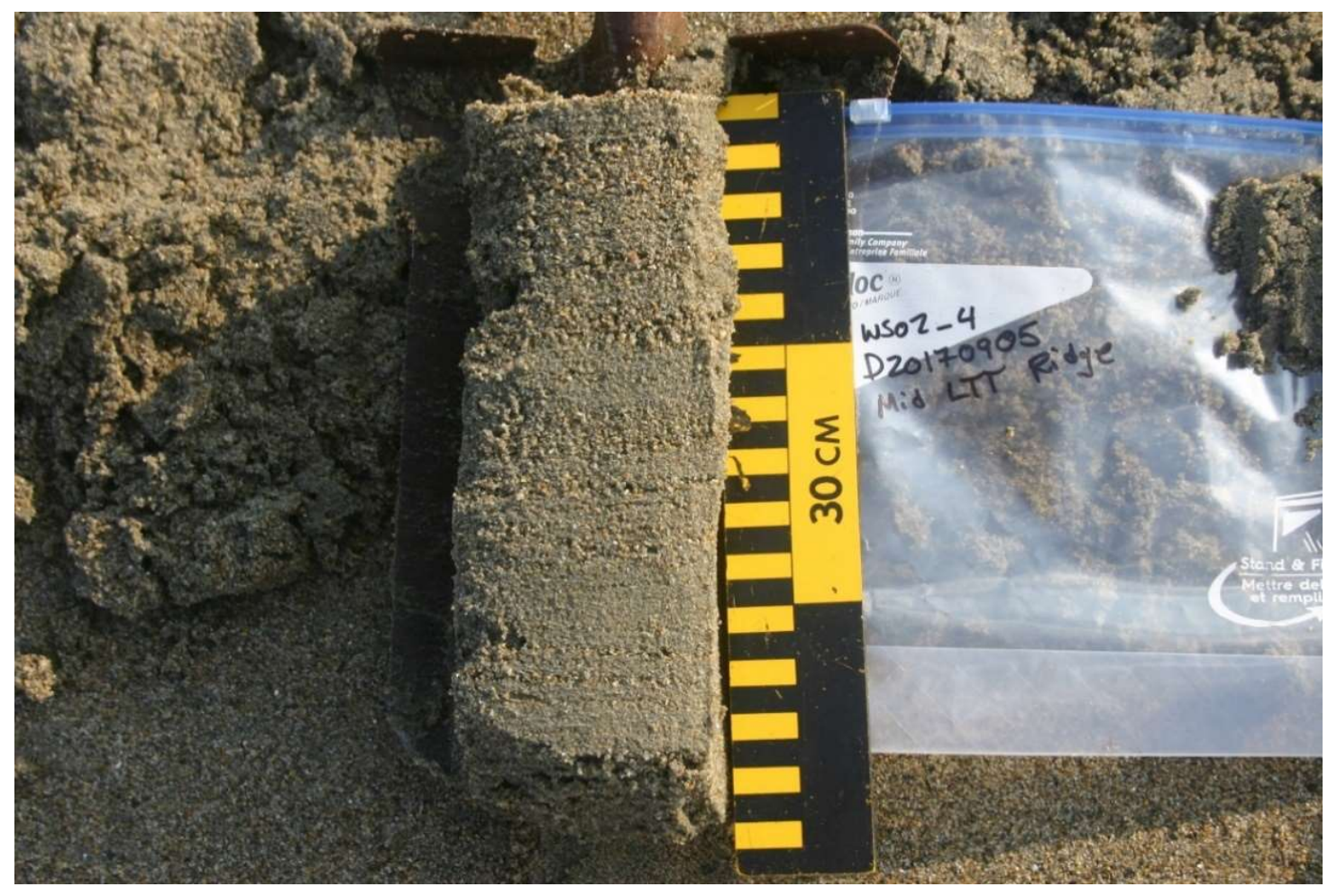

Figure 5-3. Sediment core from Wallis Sands station WSO2 on September 5, 2017. 
Coarser samples that had a large gravel fraction or that contained cobbles were sampled by excavating a pit in the sediment that was 20 to $30 \mathrm{~cm}$ deep and removing an adequate sample volume from the side of the hole. Care was taken to obtain near-equal volumes from the entire depth of the pit. The depth of the hole was also measured, and the samples were placed in a five-gallon bucket (Figure 5-4). Two hundred thirty-seven sediment samples were collected, ranging in size from 180 to $24,100 \mathrm{gm}$. Overall, $98 \%$ were greater than $1,000 \mathrm{gm}, 28 \%$ were greater than 5,000 gm, and $13 \%$ were greater than 10,000 gm. In special circumstances, shallower sampling depths were used at locations where the sediment was patchy or extremely coarse (e.g., pebbles and cobbles). Here, only a $5 \mathrm{~cm}$ layer was removed for analysis.

At several beaches, pebble and cobble ramps occurred at the landward extreme of the beach against the seawalls or anthropogenic berms (Figures 5-5 and 5-6). The gravel ramps were typically the result of major storms and in some instances (e.g., Foss Beach) became permanent features. Although the gravel ramps were an important component of the beach system, determination of their grain size distribution is problematic. Extremely large samples are needed (often requiring a truck or small backhoe on the beach) for complete grain size distribution measurements. Pebble counts can be made in situ but can be ambiguous unless very large samples are counted. Furthermore, and importantly, combing the results of cobble analysis with the grain size distribution can skew the results and statistics if measurements are made by weight (as in this study). Therefore, cobbles (and boulders) were noted and locations mapped for this study, but no direct measurements were made.

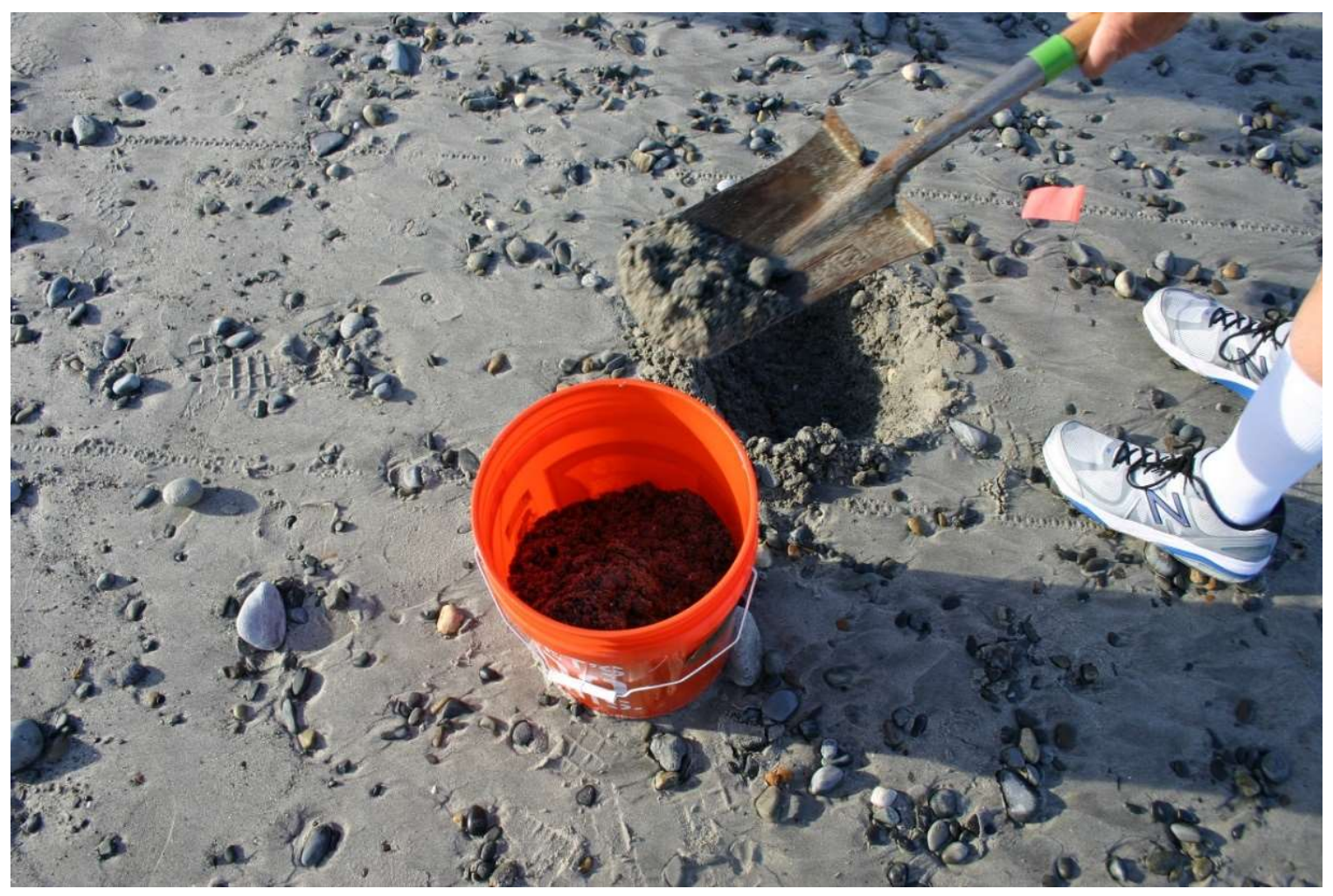

Figure 5-4. Collection of a large sediment sample at North Beach station NBO4 on April 24, 2017. 


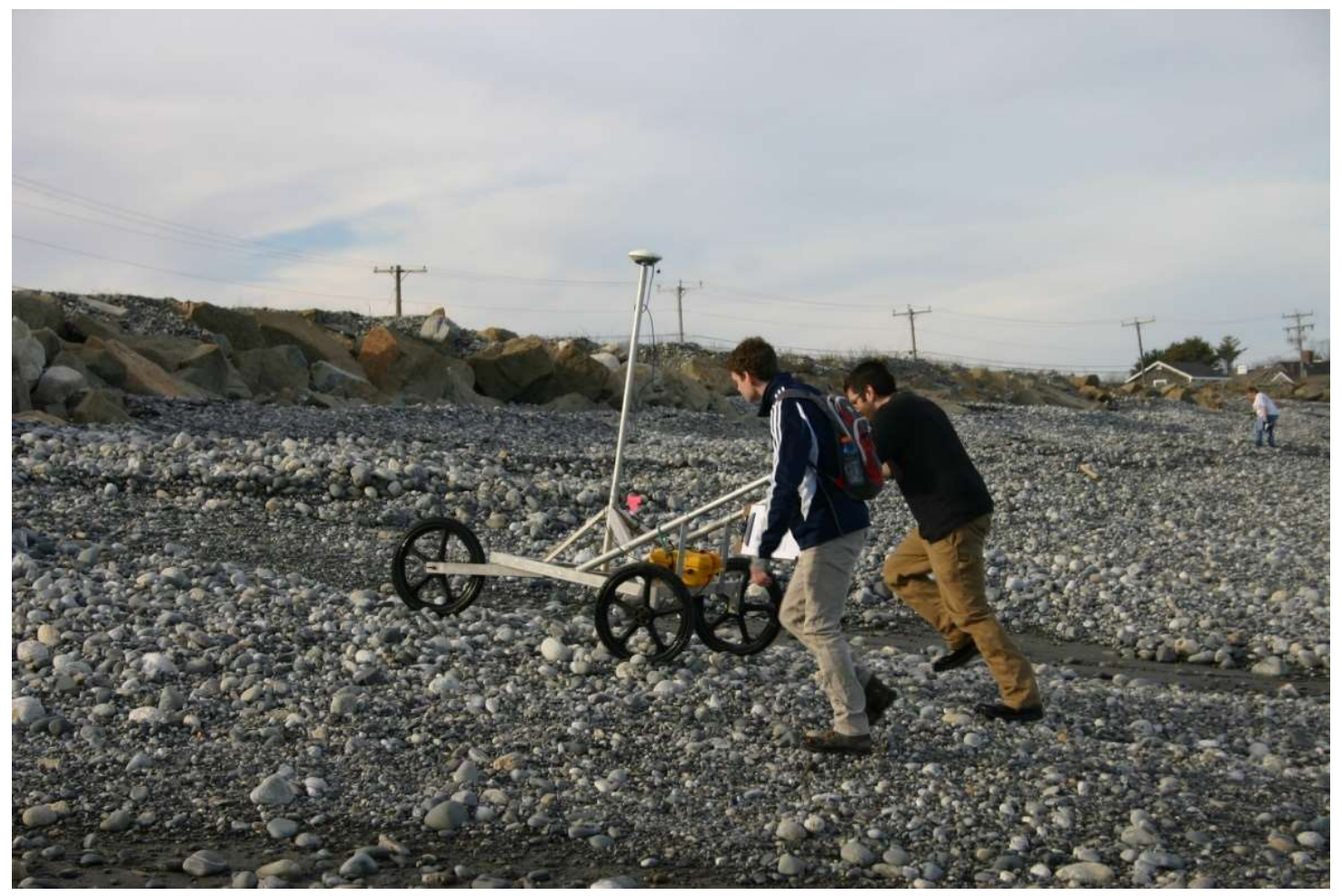

Figure 5-5. Running a beach elevation profile using the GNSS rover on the gravel ramp at Foss Beach station FBO2 on April 9, 2017.

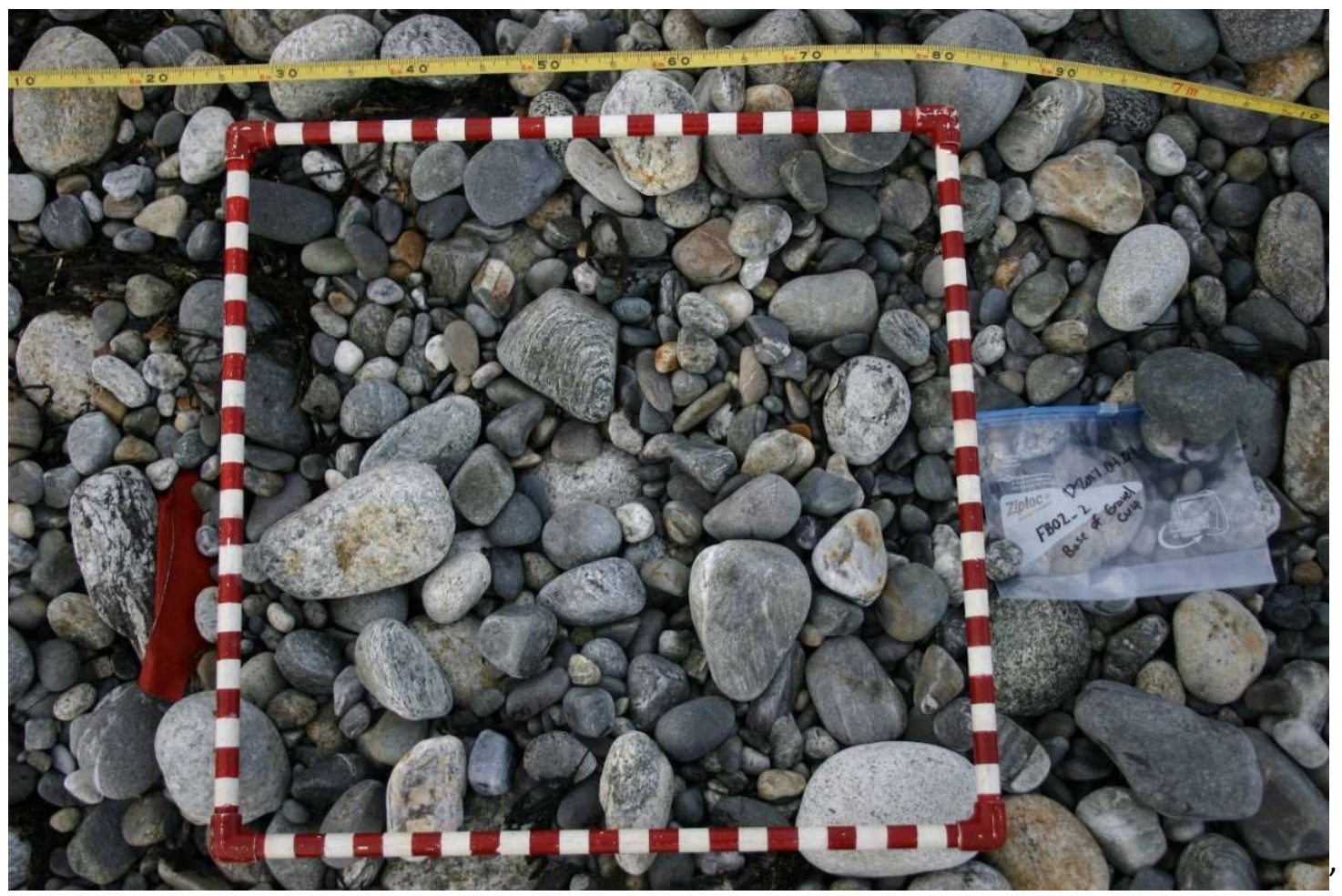

Figure 5-6. Gravel sample from the upper beach at Foss Beach station FBO2 on April 9, 2017. 


\section{Laboratory Analysis}

In order to determine the grain size of samples that included pebbles, very large volumes of sediment are needed in order to obtain representative size distributions. Furthermore, samples that are dominantly sand and pebbles occasionally have isolated cobbles. To address the issue of the amount of sediment to analyze and the presence of cobbles, the following guidelines were followed. For samples containing sand and pebbles, the entire sample was analyzed for grain size (even if only a few pebbles were present). If no pebbles were present, then the total sample was weighed and split down to 75 to $100 \mathrm{~g}$ subsamples and processed (replicates were frequently done for sand samples). When cobbles were present in a sample, they were measured and removed (unless the sample was dominantly cobbles). Isolated cobbles were not included in the bulk analysis, as a single cobble would dramatically bias the size distribution. Rather, the presence, size, and abundance of cobbles were noted in the sample descriptions. If a sample was primarily large pebbles and cobbles it was simply classified as cobbles.

The beach sediment samples were analyzed using the following protocol. The bulk sample was transferred to a single tub or divided between multiple tubs (depending on the size). The sediment in each tub was washed four times (twice with tap water and twice with deionized water) by submerging, stirring, and waiting twenty minutes to allow time for fine sediment to settle. After each rinsing the sample was then decanted through a $0.062 \mathrm{~mm}$ sieve. Any sediment on the sieve was washed back into the sample with deionized water. The effluent was examined and periodically checked to ensure that no or only an insignificant amount of mud (less than $0.062 \mathrm{~mm}$ ) was lost. However, it was assumed the sediment did not contain significant amounts of mud, which was supported by analyses. The final step in the procedure was to thoroughly dry the sample in an oven at $\sim 50$ to $70^{\circ} \mathrm{C}$ (usually for several days). The total weight of each washed and dried bulk sample was determined. It was then dry sieved into sand, granule, and pebble fractions. If the original sample had been separated into multiple bins for washing, each bin was processed separately and the results combined into a composite or pooled dataset for that sample. This was the case for most samples. Sieving was done by hand, agitating the sample through sieves $30 \mathrm{~cm}(12$ ") in diameter with $0.062 \mathrm{~mm}$ and $2.00 \mathrm{~mm}$ openings. Each fraction was weighed and the percent of the total weight determined. This had to be within $5 \%$ of the original bulk weight or the sieving process was repeated. The percent difference was always within $1 \%$ except when a component was extremely small.

Upon successful completion of bulk analysis, the sample was separated into size classes at 0.5 phi intervals using standard sieve analytical techniques using $20.3 \mathrm{~cm}\left(8^{\prime \prime}\right)$ diameter sieves and a mechanical sieve shaker (after Folk, 1980). The entire pebble fraction was sieved from -1.0 phi $(2.0 \mathrm{~mm})$ to -5.5 phi $(45.3$ $\mathrm{mm}$ ). Larger sieve sizes were available but were not required. Any material passing through the $-1.0 \mathrm{phi}$ $(2.0 \mathrm{~mm})$ sieve was added to the sand fraction (and the bulk weight adjusted). This was normally split to $\sim 75$ to $100 \mathrm{~g}$ subsamples, the split factor determined, and the sample then sieved from $-1.5 \mathrm{phi}$ ( $2.83 \mathrm{~mm})$ to $4.0 \mathrm{phi}(0.62 \mathrm{~mm})$. Any sediment passing through the 4.0 phi sieve was captured and weighed (but was always negligible). The sand weights were adjusted using the splitting factor and the entire sediment size intervals from 4.0 phi $(2.0 \mathrm{~mm})$ to $-5.5 \mathrm{phi}(45.3 \mathrm{~mm})$ were determined. The total calculated weight had to be within $5 \%$ of the original or the entire sample was rerun. All samples were within a few percent and usually around $1 \%$. The final step was to pool the class size data (by weight) for the entire sample if it had been divided into subsamples. Replicas of all the processing stages were run with excellent results.

\section{Statistical Analysis}

The grain size data was analyzed in Gradistat (Blott and Pye, 2001), with major statistics based on the lognormal distribution of phi sizes as recommended in Folk (1954; 1980). The Coastal and Marine Ecological Classification Standard (CMECS) sediment size classification was also determined (FGDC, 2012). The grain 
size parameters are expressed in phi units, a geometric conversion used in geologic studies to place equal importance on small differences in fine-grained sediments and large differences in coarse-grained sediments (Blott and Pye, 2001). The Wentworth scale is used which separates size classes by a factor of two (doubling as size increases or halving as size decreases). The transformation between phi $(\phi)$ units and $\mathrm{mm}$ is calculated by: $\phi=-\log _{2} d_{\mathrm{mm}}$ or $d_{\mathrm{mm}}=2^{-\phi}$ where $d_{\mathrm{mm}}$ is the diameter of a particle in $\mathrm{mm}$. Sorting is a measure of the spread of the sizes around mean or standard deviation of the sample, and is also expressed in phi units. Skewness and kurtosis are dimensionless. Skewness is a measure of the symmetry around the mean, with positive values indicating skewing towards fine sediment and negative values skewing towards coarse sediments. Kurtosis is the peakedness of the graphic representation of a statistical distribution (see Blott and Pye, 2001; or Folk, 1980 for further information). The relationship between grain size, phi units, and the Wentworth and Gradistat size classifications are given in Appendix $C$ and the CMECS substrate classification is given Appendix D.

In order to determine trends in sediment grain size statistics for each beach, all samples from each individual station were pooled and averaged for that station from the late winter - early spring and the late summer sampling period. Comparison of the averages for a station from each period allowed an assessment of alongshore variations in grain size as well as changes in the sediment at a station after a prolonged period of erosion (late winter - early spring) and an extended period of accretion (late summer). The average grain size for a station is determined by pooling the individual sample size distributions for all of the samples from a transect and recalculating the statistics for each sampling period. Subsequently, cross-shore variations in sediment grain size were assessed by pooling the grain size data for all appropriate samples from multiple transects from a beach by elevation into upper tidal beach (>1.5 $\mathrm{m} \mathrm{MTL}$ ), mid tidal beach (0.0-1.5 m MTL), and lower tidal beach $(<0.0 \mathrm{~m} \mathrm{MTL})$, pooling the individual sample size distributions, recalculating the statistics for each sampling period, and comparing erosional versus accretional conditions. The comparison for elevations was only made for those beaches where comparison of the average grain size for a station showed that the longshore differences in sediment grain size were small and pooling data by elevation was reasonable. The elevation-based grouping was based on analysis of total water level changes at three locations either in or nearby the study area including Salisbury Beach, Hampton Beach, and Wallis Sands. Total water level changes were determined for the thirty highest water levels (excluding major storms) that occurred during the study period (January 1 to September 20, 2017) using the USGS's Total Water Level and Coastal Change Forecast Viewer (https://coastal.er.usgs.gov/hurricanes/research/twlviewer/; accessed January 2018). The model combines tidal level, storm surge, and wave run-up to compute total water level changes at specific locations along the coast. For this study, the average total water levels for the three locations ranged from +3.0 to $-1.5 \mathrm{~m}$ with respect to mean tidal level (MTL). Samples that were within the vertical uncertainty of the sample elevation $( \pm 20 \mathrm{~cm}$ ) were assigned to a group by a trained geologist based on morphology of the beach. 


\section{Chapter 6: Results}

The results of the beach elevation profiling and sediment grain size analysis is presented in this chapter. Each beach is considered separately. The elevation profiles reveal the beach morphology, location of sediment samples with respect to the morphology and elevation, and confirm the condition of the beach (erosional or accretional). In this chapter, the sediment grain size classification, statistics, and size distribution are given for each station for all sampling periods in an abbreviated table. More compete descriptions are given in Appendix E. Also presented in this chapter, when appropriate, are comparisons of the average sediment grain size for a station for erosional (late winter - early spring 2017) versus accretional conditions (late summer 2017). Additionally, comparisons are available for cross-shore variations in sediment grain for the upper tidal beach (>1.5 m MTL), mid tidal beach (0.0-1.5 m MTL), and lower intertidal beach $(<0.0 \mathrm{~m} \mathrm{MTL})$. The methods and approaches used are described in Chapter 5 : Methods in Statistical Analysis.

\section{Wallis Sands, Rye, New Hampshire}

Wallis Sands is a small attached barrier that extends $\sim 1.3 \mathrm{~km}$ between two headlands (Seal Rocks and Pulpit Rock to the north and Concord Point to the south) (Figures WS-1, WS-2 and WS-3). The barrier is $\sim 200$ to $250 \mathrm{~m}$ in width from the edge of the back-barrier marsh (Parson's Creek Saltmarsh) to the lower intertidal zone. The dune system that once existed has been completely removed and replaced with private homes and infrastructure. Wallis Sands is separated from Concord Point by a small, shallow inlet (Parson's Creek, about 20-25 m wide) that facilitates the tidal exchange with the back-barrier marsh. The northern headland is composed of extensive bedrock outcrops fronted by wave-eroded cobbles and boulders. The upland behind the attached barrier is glacial marine sediments largely composed of undifferentiated sand, silt, and clay. The rocky headland at Concord Point forming the southern boundary of Wallis Sands is exposed bedrock intermixed with glacial tills which also form the adjacent upland. The till has been eroded in the intertidal region leaving behind cobble and boulder lag deposits (megaclast platforms) on the southern end of the beach. The glacial deposits extend offshore forming a boundary between Wallis Sands and the beaches to the south (Figure WS-1). Bedrock outcrops on the beach and in the nearshore zone near Concord Point (Figure WS-3). Wallis Sands State Beach forms the northern 200 $\mathrm{m}$ of the barrier and is separated by a stone groin that extends $\sim 100 \mathrm{~m}$ seaward, and is backed by a cement seawall (Figures WS-1 and WS-2). The area south of Wallis Sands State Beach is a town beach and is backed by primarily residential homes or rentals with a variety of engineering structures including vertical seawalls, riprap, and in a few locations a combination of hard structures and dune grasses. 


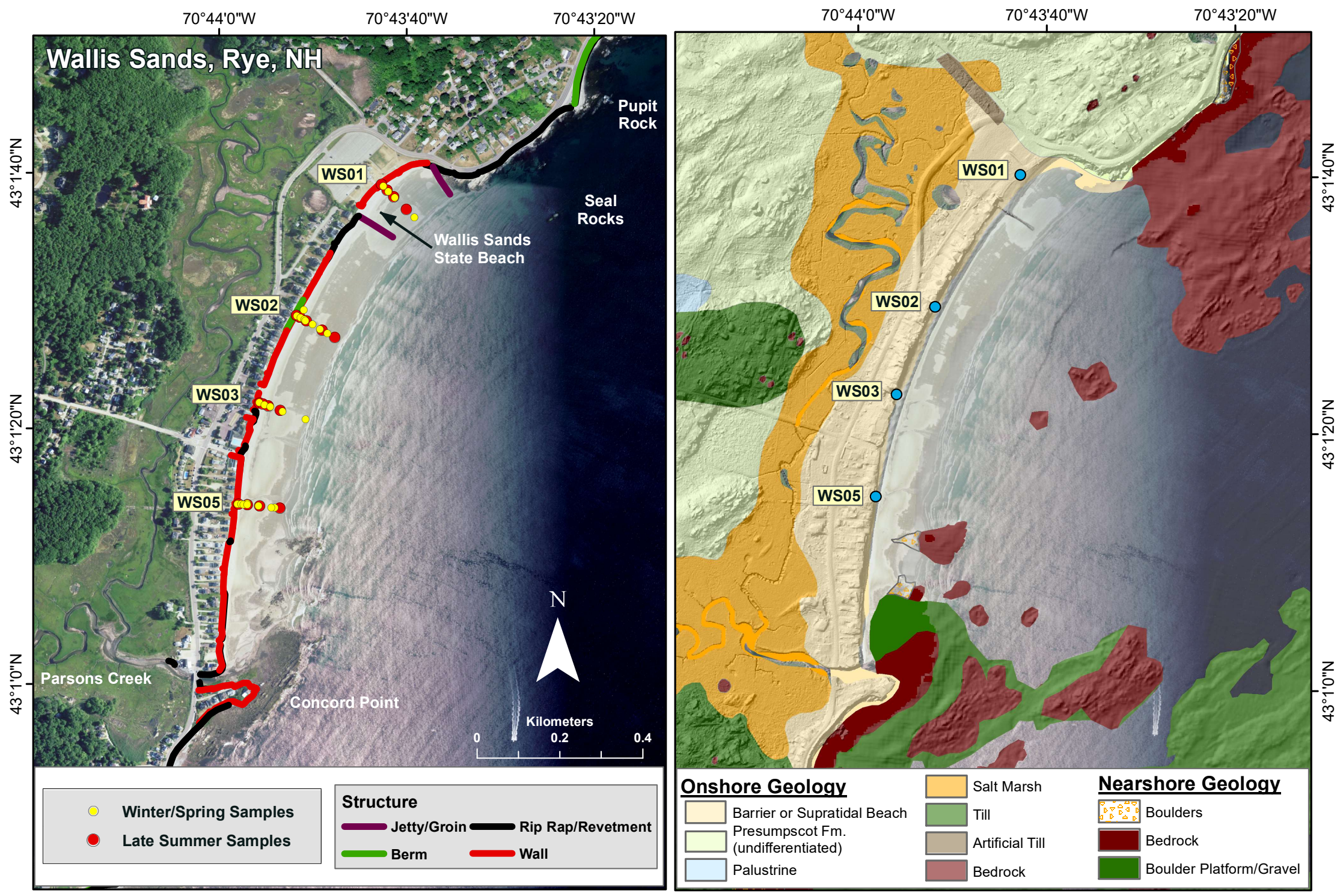

Figure WS-1. Station locations and shoreline structures (from Blondin, 2016) (left) and surficial geology of the upland (modified from NHGS digital series) and nearshore shelf (modified from Ward et al., 2021a) (right) at Wallis Sands, Rye, NH. The nearshore seafloor not mapped (satellite imagery) is predominantly sand (right). 


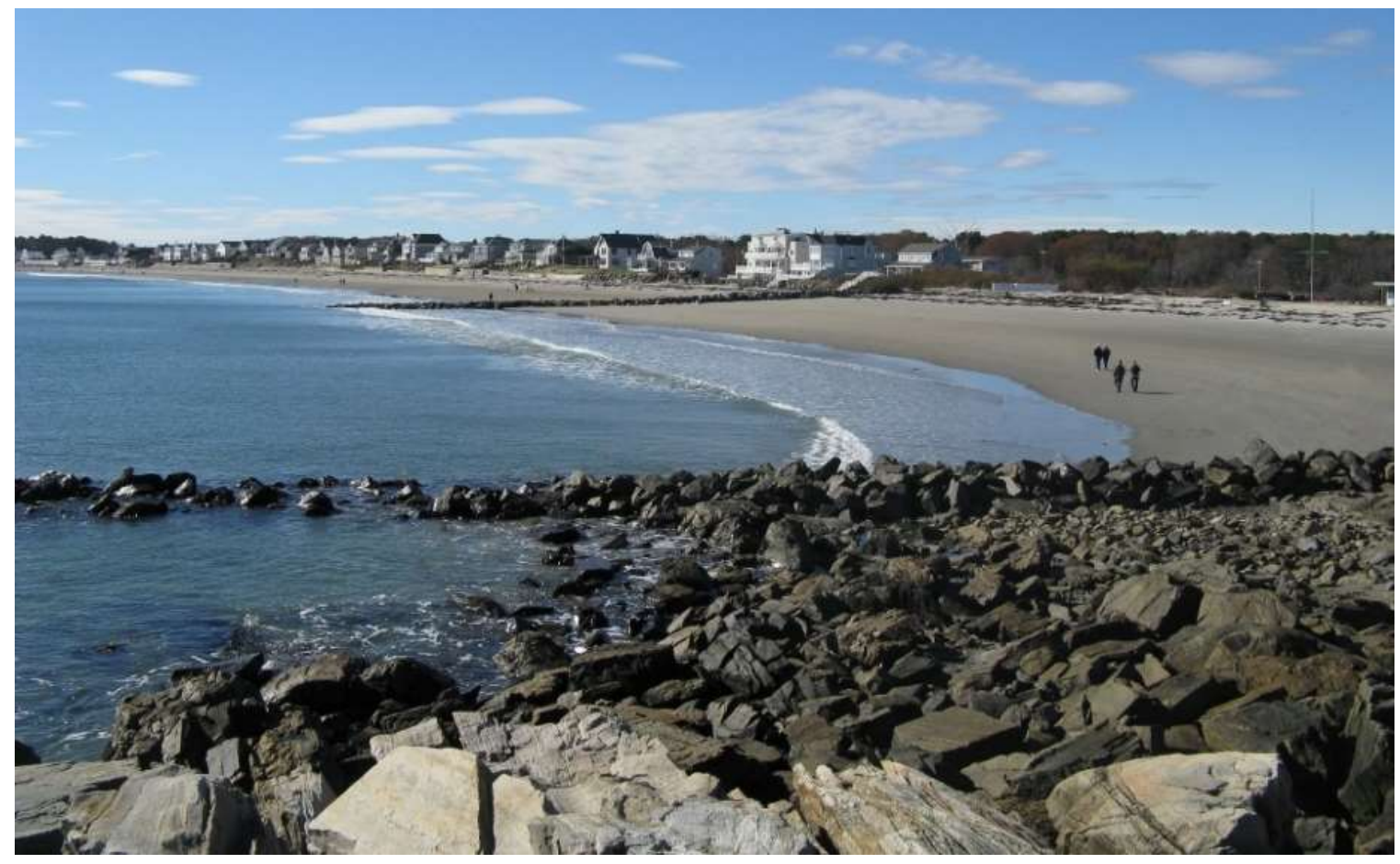

Figure WS-2. Wallis Sands looking south from the northern headland on November 4, 2012.

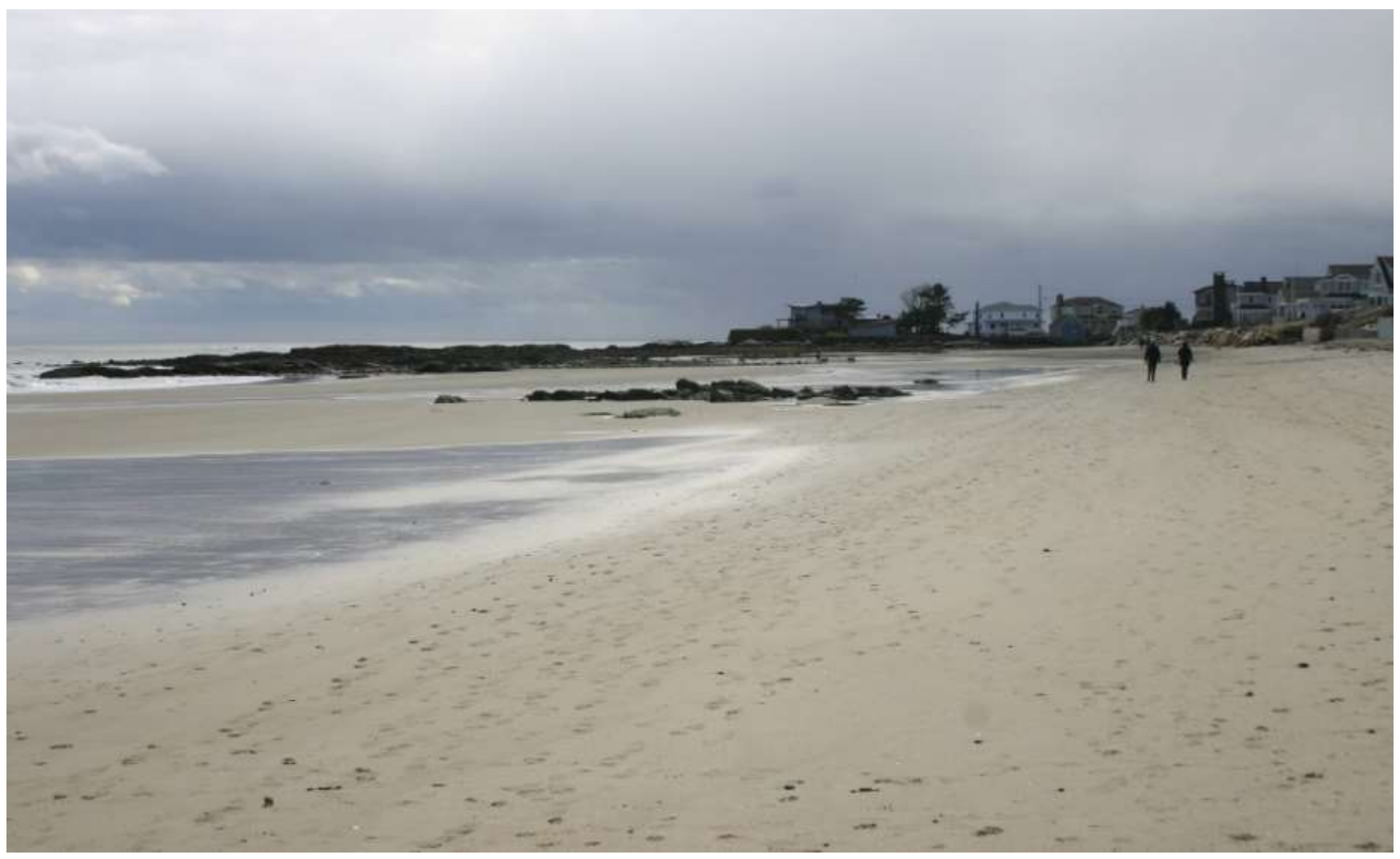

Figure WS-3. Southern headland at Wallis Sands from station WS05 on May 4, 2017. Note bedrock outcropping on the mid beach. 
Field Surveys. Beach elevation profiles were measured and sediment samples collected at Wallis Sands on February 22 (WSO1), February 23 (WS02), March 7 (WS03), and March 8, 2017 (WS05) to represent the erosional winter beach (Figure WS-1 and Table WS-1). Unfortunately, the GNSS data collected on March 8 at WS05 was faulty, which was not determined until the records were post-processed. Therefore, the beach was sampled again on May 4. Between March 8 and May 4 there were two major storms including the nor'easter Stella (March 14-15) and winter storm Theseus (March 31 to April 2), and a period of large waves between March 19-21 (Table 3-2). Consequently, Wallis Sands still had an erosional profile on May 4. Although results for both periods are included in the database, only the February-March data are used in comparisons between winter and the late summer. The profile at WSO3 also had numerous intermittent losses in elevation, but enough of the data points were recovered to allow the profile to be defined. The beach elevation profiles were again measured and sediment samples collected in late summer on September 5 (WSO1 and WSO2) and September 7 (WSO3 and WSO5) to evaluate the beach following an extended period of accretion.

Beach Elevation Profiles. The beach elevation profiles (Figures WS-4a and WS-4b) measured in the late winter - early spring period at WS01, WSO2, WS03, and WS05 are characteristic of the beach after an extended period of erosion. The lower beach was flat and featureless, typical of dissipative beaches. Landward of the low tide terrace a sand ramp extended to the seawalls (Figure WS-5). A sand ramp is defined here as a continuous increase in slope from approximately the low tide terrace to the seawall that forms under high-energy conditions and replaces the berm. The beach profile at WSO5 indicates the beach had started to accrete in the May 4 profile with a large ridge and runnel on the low tide terrace. However, examination of the overall morphology shows the upper beach had not accreted and maintained the sand ramp that is commonly present in winter.

The profiles measured in the late summer period show the beach accreted significantly, increasing in elevation and developing berms at WSO2 and WS03. The maximum elevation increase was $0.8 \mathrm{~m}$, measured at WSO2. The sand ramp previously seen under winter erosional conditions became covered by an accretional sediment wedge, and a small berm formed as seen at WS02 (Figures WS-5 and WS-6). All of the stations in late summer were representative of an accretional beach at Wallis Sands. 
Table WS-1. Sediment grain size data for samples taken at Wallis Sands. More complete summaries of the samples are given in Appendix E.

\begin{tabular}{|c|c|c|c|c|c|c|c|c|c|c|c|c|c|c|c|c|c|c|c|c|c|}
\hline $\begin{array}{c}\text { Sample } \\
\text { ID }\end{array}$ & $\begin{array}{c}\text { Latitude } \\
\text { WGS84 }\end{array}$ & $\begin{array}{c}\text { Longitude } \\
\text { WGS84 }\end{array}$ & $\begin{array}{c}\text { Sample } \\
\text { Collected }\end{array}$ & $\begin{array}{c}\text { Sample } \\
\text { Wt. (gms) }\end{array}$ & $\begin{array}{c}\text { Morphologic } \\
\text { Feature }\end{array}$ & $\begin{array}{l}\text { Sediment } \\
\text { Name }\end{array}$ & $\begin{array}{c}\text { Sediment } \\
\text { Classification }\end{array}$ & Sorting & \begin{tabular}{|c|} 
Gravel \\
$\%$
\end{tabular} & $\begin{array}{c}\text { Pebble } \\
\%\end{array}$ & $\begin{array}{c}\text { Granule } \\
\% \\
\end{array}$ & $\begin{array}{c}\text { Sand } \\
\%\end{array}$ & $\begin{array}{c}\text { Mud } \\
\%\end{array}$ & $\begin{array}{c}\text { Mode } \\
\text { Abbrev. }\end{array}$ & $\begin{array}{l}\text { Mode } \\
1 \text { (phi) } \\
\end{array}$ & $\begin{array}{l}\text { Mode } \\
2 \text { (phi) }\end{array}$ & $\begin{array}{c}\mathrm{D}_{10} \\
\text { (phi) }\end{array}$ & $\begin{array}{c}D_{50} \\
\text { (phi) }\end{array}$ & $\begin{array}{c}\text { Mean } \\
\text { (phi) }\end{array}$ & \begin{tabular}{|c|}
$\begin{array}{c}\text { Sorting } \\
\text { (phi) }\end{array}$ \\
\end{tabular} & $\begin{array}{c}\text { Skew- } \\
\text { ness }\end{array}$ \\
\hline WS01-1 & 43.027640 & -70.728328 & 22-Feb-17 & $2,563.0$ & S. Ramp or Berm & Sl. Granular Fine Sand & Med. Sand & MWS & 0.34 & 0.08 & 0.26 & 99.62 & 0.04 & u & 2.24 & N/A & 1.11 & 2.04 & 1.97 & 0.58 & -0.23 \\
\hline WS01-2 & 27534 & -70.728175 & 22-Feb-17 & $3,646.5$ & T: Landward & Sl. Pebbly Fine Sand & ne Sand & MWS & 23 & 1.15 & .08 & 98.76 & 0.01 & u & 24 & N/A & 1.15 & 2.12 & .06 & 61 & -0.20 \\
\hline Ws01-3 & 027400 & -70.727988 & 22-Feb-17 & $4,050.3$ & LT:Mid & Sl. Granular Fine Sand & Med. Sand & MS & 36 & 1.43 & 0.94 & 97.60 & 0.04 & u & .24 & N/A & 0.56 & 2.19 & .98 & .90 & -0.42 \\
\hline WS01-4 & 026983 & -70.727395 & 22-Feb-17 & $4,501.3$ & LT; Swash Zone & Sl. Granular Fine Sand & Med. Sand & MS & 0.98 & 0.33 & 0.66 & 99.00 & 0.02 & u & .24 & N/A & 0.54 & 1.93 & 1.78 & 0.87 & -0.27 \\
\hline WS01-1 & 43.027680 & -70.728386 & 5-Sep-17 & $2,798.3$ & S. Ramp & Sl. Granular Fine Sand & ne Sand & MWS & 0.68 & 0.29 & 0.40 & 99.24 & 0.08 & u & 24 & N/A & 1.19 & 2.10 & 2.05 & 1.58 & -0.22 \\
\hline WS01-2 & 43.027563 & -70.728218 & 5-Sep-17 & $2,371.3$ & Ramp; LHTS & Sl. Granular Fine Sand & e Sand & WS & 0.01 & 00 & .01 & 99.96 & 0.03 & u & 24 & N/A & 1.84 & 2.34 & 2.38 & 39 & 0.05 \\
\hline WS01-3 & 43.027420 & -70.728016 & 5-Sep-17 & $2,801.8$ & T; Mid & SI. Granular Fin & ee Sand & MWs & 0.49 & 0.09 & 0.40 & 99.48 & 0.03 & u & 2.24 & N/A & 1.10 & 2.22 & 2.15 & 0.66 & 0.26 \\
\hline Ws01-4 & 43.027153 & -70.727633 & 5-Sep-17 & $2,862.0$ & ; Lower & SI. Gr & e Sand & MS & 39 & 22 & 67 & 99.08 & 0.03 & u & 24 & N/A & 0.91 & 2.18 & 2.06 & .75 & .31 \\
\hline VSO2-nr1 & 43.024916 & -70.730610 & 23-Feb-17 & 841.7 & lamp or Berm; G. Patch & ebble Gravel & bble Gravel & PS & 99.10 & 89.77 & 34 & 89 & - & & 74 & /A & -4.84 & -3.61 & 3.54 & 1.09 & 14 \\
\hline WSO2-1 & 43.024792 & -70.730806 & 23-Feb-17 & $4,715.6$ & S. Ramp or Berm & SI. Granular Med. Sand & Med. Sand & MS & 1.57 & 0.62 & 0.96 & 98.40 & 0.03 & u & .75 & N/A & 0.11 & 1.15 & 16 & .81 & 0.05 \\
\hline WS02-2 & 024749 & -70.730699 & 23-Feb-17 & $4,886.8$ & S. Ramp or Berm & Granular Coarse Sand & V. Coarse Sand & PS & 17.51 & 10.77 & 6.74 & 82.47 & 0.02 & U & 0.25 & N/A & -2.17 & 0.03 & -0.05 & 39 & 0.20 \\
\hline Ws02-3 & 43.024704 & -70.730588 & 23-Feb-17 & 117.3 & Ramp or Berm Toe & Sandy Pebble Gravel & Granule Gravel & PS & 75.78 & 51.46 & 24.32 & 24.21 & 0.01 & u & -2.24 & N/A & -3.43 & -2.04 & -1.84 & 1.40 & 0.21 \\
\hline WS02-4 & 43.024693 & -70.730554 & 23-Feb-17 & $19,112.3$ & rm Toe Runnel & Sandy Granule Gravel & Coarse Sand & VPS & 42.07 & 28.62 & 13.45 & 57.92 & 0.01 & B & 1.75 & 5.74 & -4.24 & -0.43 & -0.91 & 2.12 & 0.38 \\
\hline WS02-5 & 43.024606 & -70.730338 & 23-Feb-17 & 22.6 & ; Landward to Mid & SI. Granular Med. Sand & d. Sand & MS & 2.61 & 0.9 & 63 & 97.3 & 0.0 & u & 4 & N/A & 0.11 & 1.7 & 56 & 97 & -0.33 \\
\hline WS02-6 & 4516 & -70.730112 & 23-Feb-17 & $4,214.0$ & LT; Mid & Sand & Sand & PS & 9.06 & 6.7 & 2.27 & 90. & 0.6 & B & 5 & -0.74 & -0.8 & 2.39 & 24 & 1.47 & -0.49 \\
\hline WS02-7 & 24429 & -70.729894 & 23-Feb-17 & $4,583.5$ & LTT; Swash Zone & Sl. Granular M & Sand & MS & 14 & 0.7 & 1.39 & 97.84 & 0.0 & u & 1.75 & N/A & 0.3 & 1.6 & 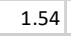 & 0.86 & -0.21 \\
\hline WS02-1 & 43.024799 & -70.730819 & 5-Sep-17 & 366.0 & Ramp; Ba & SI. Gra & Sand & MWS & 22 & 0.02 & 20 & 99.76 & 0. & u & 75 & $\mathrm{~N} / \mathrm{A}$ & 0.23 & 1.07 & 1.12 & 0.67 & 0.08 \\
\hline WS02-2 & 43.024760 & -70.730721 & 5-Sep-17 & 512.9 & Berm Crest; LHTS & SI. Granular Me & d. Sand & Mws & 06 & 01 & 04 & 99.92 & 0.02 & u & 24 & /A & 1.0 & 92 & 1.84 & 59 & 0.22 \\
\hline WS02-3 & 43.024683 & -70.730527 & ep-17 & 906.6 & ; LT & S. Pet & Sand & MWs & 22 & 18 & 04 & 99.76 & 0.02 & $\mathrm{u}$ & 24 & /A & 1.52 & 2.26 & 23 & .53 & 0.15 \\
\hline WS02-4 & 4 & -70.730056 & ep-17 & 2,86 & T; Mid & Sl. Gr & and & MS & 17 & 25 & 92 & .81 & 0.02 & u & 24 & /A & 0.38 & 73 & 60 & 86 & -0.23 \\
\hline WS02-5 & 43.024339 & -70.729667 & ep-17 & 270.9 & ; Swash Zone & lar Med. Sand & nd & MS & 0.65 & 0.10 & 55 & 33 & 0.02 & u & 24 & N/A & 0.44 & 56 & .55 & 84 & .11 \\
\hline WS03-1 & 22884 & -70.731868 & har-17 & 2.0 & Berm & Sl. Gra & and & MWS & 77 & 01 & 06 & 9.9 & 0.00 & & & N/A & 0.3 & 1.1 & .15 & 0.61 & 0 \\
\hline WS03-2 & 022844 & -70.731715 & har-17 & 220.8 & Berm & SI. Pebbly Med. Sand & ed. Sand & MWS & 0.08 & 0.05 & 0.03 & 99.92 & 0.00 & & 15 & N/A & 0.70 & 1.6 & .57 & 161 & 0.11 \\
\hline WS03-3 & 99 & -70.73 & 17 & 8 , & rd & Gra & id & PS & 15 & 7 & 01 & 8 & 0.01 & & 24 & 0.75 & 79 & 0.83 & 6 & 9 & 28 \\
\hline WS03-4 & 7 & 731179 & lar-17 & 0 & lid & Sl. Granular Fine Sand & nd & MS & 3. & 1.87 & 4 & 9 & 0.01 & U & 4 & /A & .54 & 1.83 & 0 & 35 & .31 \\
\hline WS03-5 & 43.022542 & -70.730492 & 7-Mar-17 & $3,170.8$ & Zone & Granular Med. Sand & Sand & PS & 36 & 2.85 & 1 & 94.13 & 0.01 & u & 24 & N/A & -0.19 & 1. & 46 & 11 & 0.34 \\
\hline WS03-1 & 43.022880 & -70.731864 & ep-17 & .6 & ishore & $r$ Med. Sand & Sand & Mws & 02 & 0.00 & 22 & 99.9 & 0.0 & U & 75 & /A & 0.5 & 1.4 & 1 & .64 & -0.05 \\
\hline WS03-2 & 43.022854 & -70.731760 & 7-Sep-17 & $1,958.7$ & Berm Crest; LHTS & S. Pebbly Med. Sand & Med. Sand & w & 0.18 & 0.13 & 0.04 & 99.80 & 0.02 & u & 2.24 & N/A & 1.28 & 2.03 & .98 & 0.48 & 0.13 \\
\hline Ws03-3 & 2814 & -70.731598 & 7-Sep-17 & $9,594.7$ & ; Berm Toe & nule Gravel & Coarse Sand & S & 31.52 & 18.59 & 12.93 & 68.47 & 0.01 & B & 24 & -0.74 & -2.73 & 0.47 & 0.23 & 09 & -0.19 \\
\hline WS03-4 & 43.022725 & -70.731244 & 7-Sep-17 & $3,004.4$ & T; Mid & Sl. Granular Fine Sand & ne Sand & Mws & 0.17 & 0.03 & 0.14 & 99.81 & 0.02 & $u$ & 24 & N/A & 1.15 & 2.17 & 2.11 & .62 & 0.23 \\
\hline WS05-1 & 2671 & 12 & -17 & & & Med. Sand & sand & $\mathrm{M}$ & & 2.6 & 6 & 97 & $0 . c^{-}$ & & & N/A & 0.5 & 1. & $1.5 \mathrm{~S}$ & 0.74 & 0.26 \\
\hline WS05-2 & 2 & 6 & -17 & $4,066.6$ & np Toe; Edg & Gra & a & $P$ & & 3.84 & 3 & 9 & 0.02 & U & & N/A & $0.0 \varepsilon$ & 1.4 & 1.40 & 1.02 & .29 \\
\hline WS05-3 & 0642 & -70.731830 & $r-17$ & 3.8 & & ly Med. Sand & Sand & MWs & & 0.7 & 31 & 98. & 0.01 & u & 75 & /A & 0.81 & 1. & 75 & 0.64 & 0.19 \\
\hline WS05-4 & 20617 & -70.731348 & $\mathrm{r}-17$ & 09.5 & Swash Zone & SI. Granular Med. Sand & Sand & vS & 53 & & 3 & 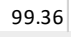 & 0.0 & $u$ & 24 & /A & 93 & 1.87 & 81 & 64 & .18 \\
\hline WS05-1 & 43.020677 & -70.732452 & 1ay-17 & 75.5 & Ramp; Near Seawall & SI. Granular Med. Sand & d. Sand & MWs & 0.05 & 0.00 & 5 & 99.94 & 0.01 & u & 75 & /A & 0.66 & 59 & 52 & 61 & 0.16 \\
\hline WS05-2 & 43.020673 & -70.732341 & 4-May-17 & $3,308.9$ & S. Ramp & Pebbly Med. Sand & Med. Sand & PS & 32 & 5.22 & 10 & 93.67 & 0.01 & u & 75 & N/A & -0.11 & .40 & .29 & 16 & 0.37 \\
\hline WS05-3 & 43.020669 & -70.732279 & 4-May-17 & $4,252.9 \mathrm{~S}$ & Toe; Edge of Runnel & Granular Coarse Sand & Coarse Sand & PS & 13.33 & 9.02 & 31 & 86.66 & 0.01 & u & 75 & N/A & -1.77 & 0.83 & 0.69 & 41 & 0.31 \\
\hline WS05-4 & 43.020663 & -70.732167 & $y-17$ & 28.0 & idward & ar Med. Sand & Med. Sand & MWS & .25 & 0.67 & 58 & 98.74 & 0.01 & U & .75 & N/A & 0.58 & .55 & 1.51 & 70 & 0.13 \\
\hline WS05-5 & 43.020611 & -70.731455 & 4-May-17 & $3,038.4$ & Seaward & Sl. Granular Fine Sand & Med. Sand & MS & 0.73 & 0.18 & .56 & 99.26 & 0.01 & u & 2.24 & N/A & 0.50 & 1.83 & 1.68 & .87 & 0.24 \\
\hline WS05-1 & 2674 & -70.732422 & ep-17 & 5.5 & LHTS & Sl. Grar & Sand & MWS & . & .01 & .05 & 99.9 & 0.01 & u & 2.24 & /A & 1.10 & 1.95 & .88 & 56 & 0.19 \\
\hline Ws05-2 & 43.020660 & -70.732155 & ep-17 & 7.2 & ; Landward & SI. Grar & nd & MWs & 0.54 & 0.34 & 9 & 99.43 & 0.0 & U & 2.24 & N/A & 0.93 & 2.06 & 1.93 & 68 & 0.29 \\
\hline $5-3$ & 41 & -70.7 & & & & & Sand & $\mathrm{M}$ & 0.99 & 0.56 & .43 & 8.99 & 0.02 & U & 24 & N/A & 0.68 & 1.82 & 1.72 & .74 & 0.18 \\
\hline & & & & & & anular Fine Sand & d. Sand & Ws & 0.32 & 0.10 & 0.23 & 9.67 & 0.01 & & 2.24 & N/A & 0.96 & 2.05 & 1.94 & .68 & 0.25 \\
\hline
\end{tabular}



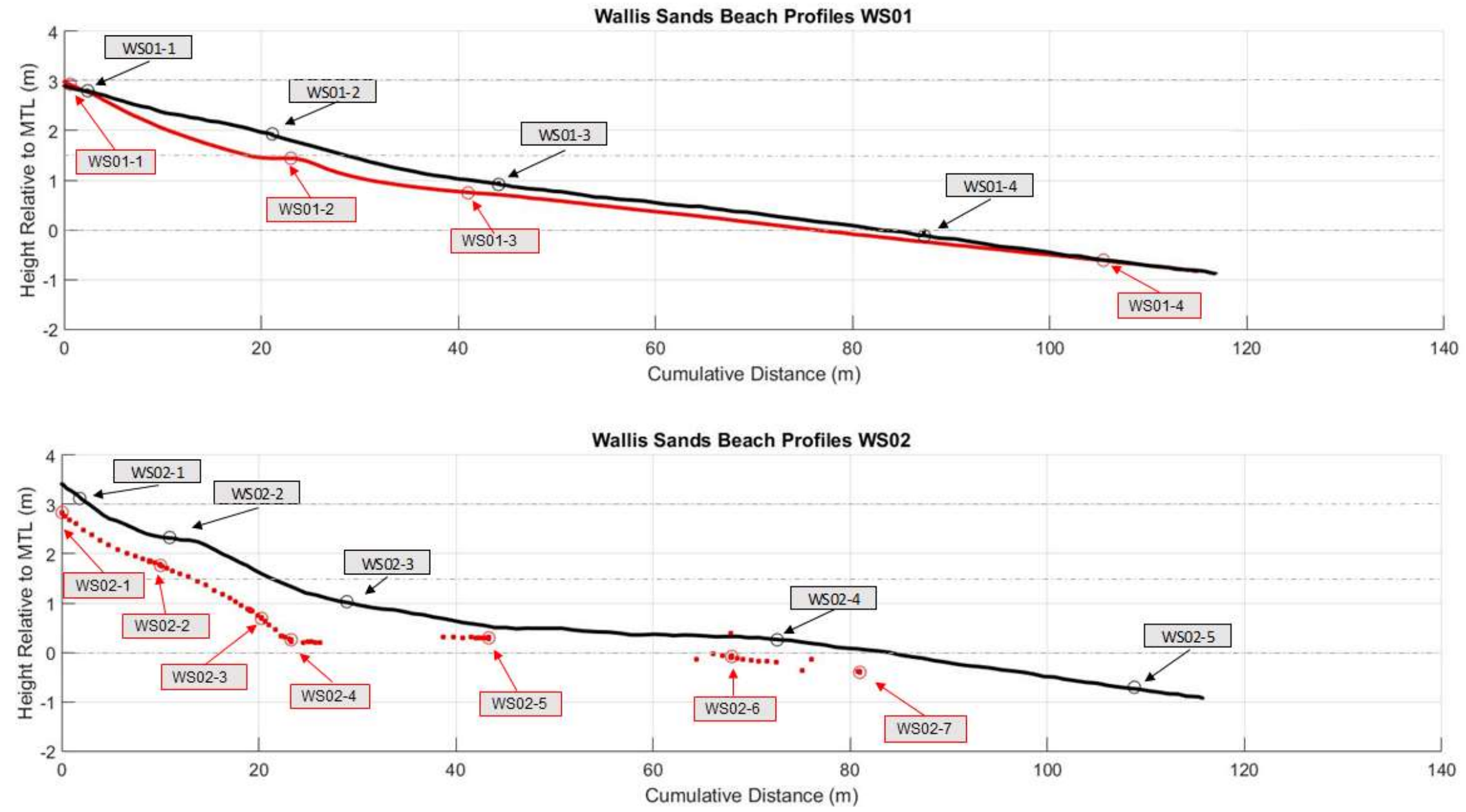

Figure WS-4a. Beach profiles and sediment sample locations from winter and late summer 2017 for stations WSO1 and WSO2 at Wallis Sands, NH. Profile WSO1 was run and sediment sampled on February 22 (red line/circles/boxes) and on September 5 (black line/circles/boxes). Profile WSO2 was run on February 23 (red) and on September 5 (black). Part of the GNSS record was corrupted and the entire profile was not recovered for WSO2 on February 23. However, enough of the profile was recovered to define the profile. Also, all sediment sampling stations positions and elevations were determined. 

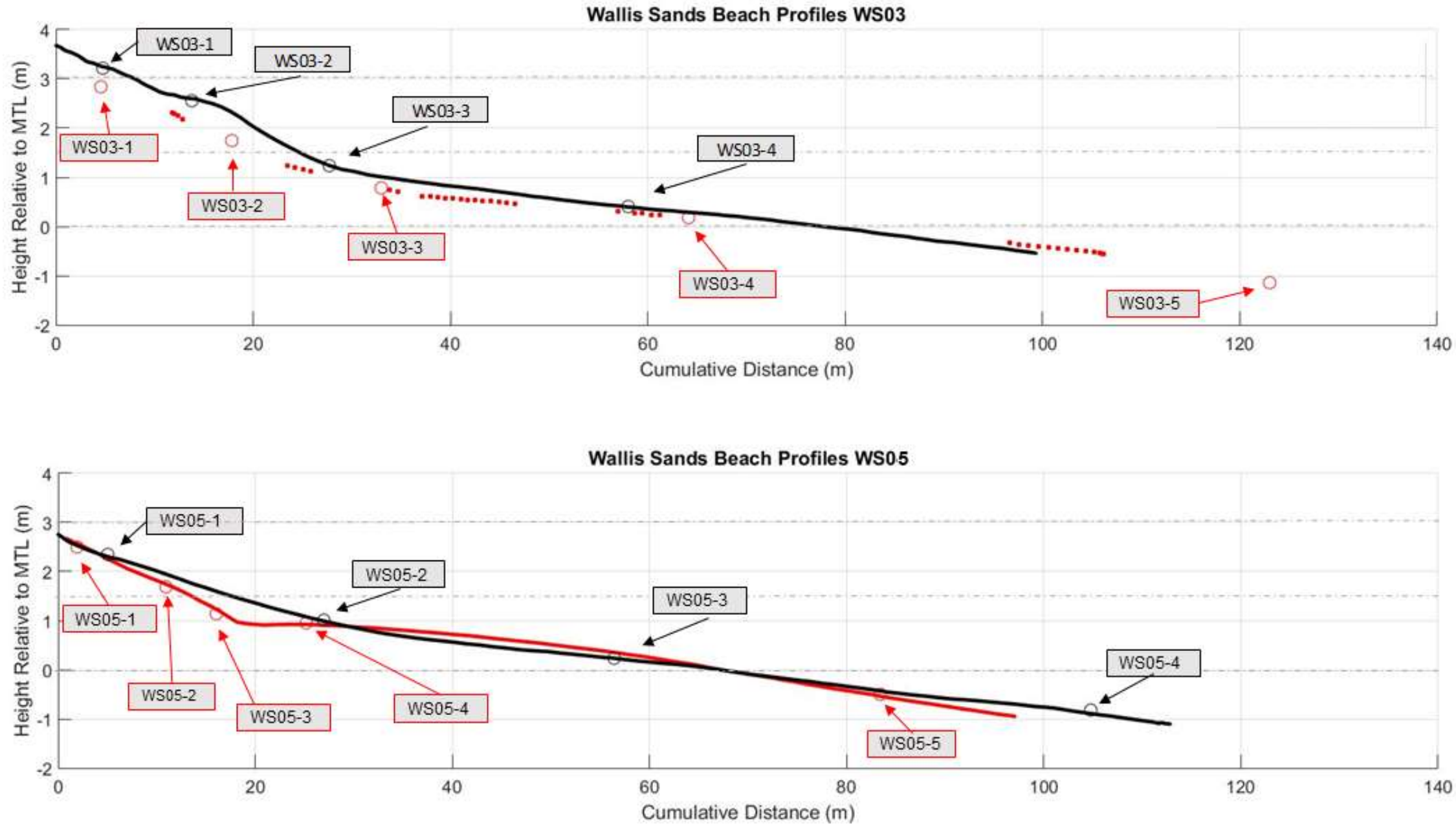

Figure WS-4b. Beach profiles and sediment sample locations from winter and late summer 2017 for stations WSO3 and WS05 at Wallis Sands, NH. Profile WS03 was run and sediment sampled on March 8 (red line/circles/boxes) and on September 7 (black line/circles/boxes). Profile WSO5 was run on May 4 (red) and on September 7 (black). Part of the GNSS record for station WSO3 was corrupted and the entire profile was not recovered on March 8 (top). However, enough of the profile was recovered to determine changes to the profile. Also, all sediment sampling stations positions and elevation were determined. 

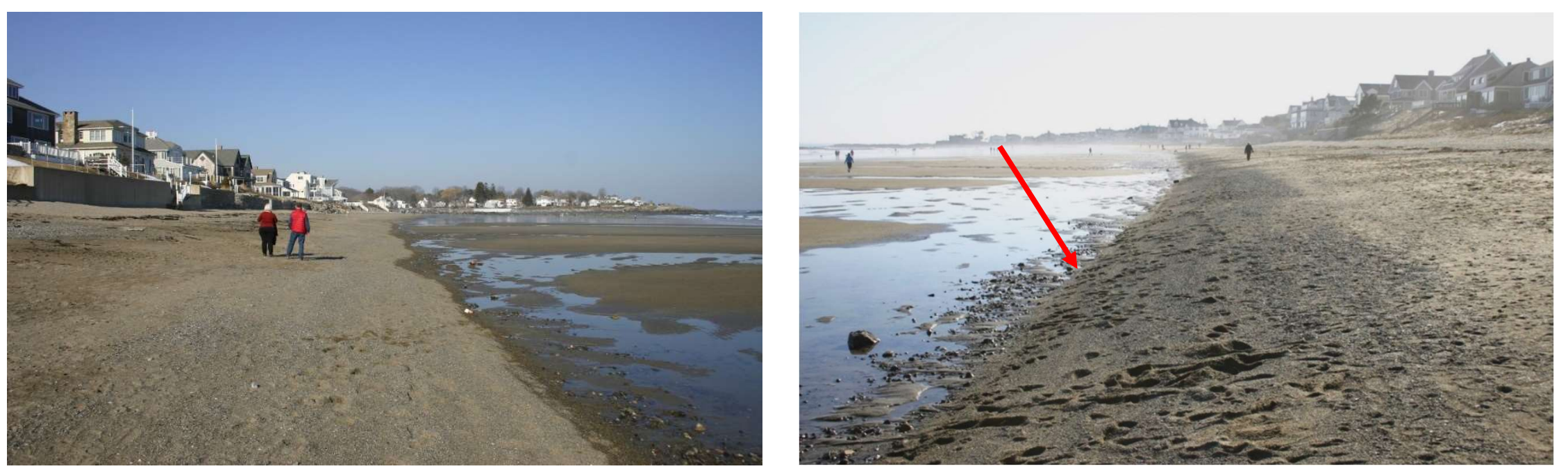

Figure WS-5. Wallis Sands at station WSO2 on February 23, 2017 after significant winter erosion. The photograph on the left is looking north and the photograph on the right is looking south from station WSO2. Note the coarse sand and gravel at the intersection of the sand ramp (arrow), and the exposed low tide terrace.
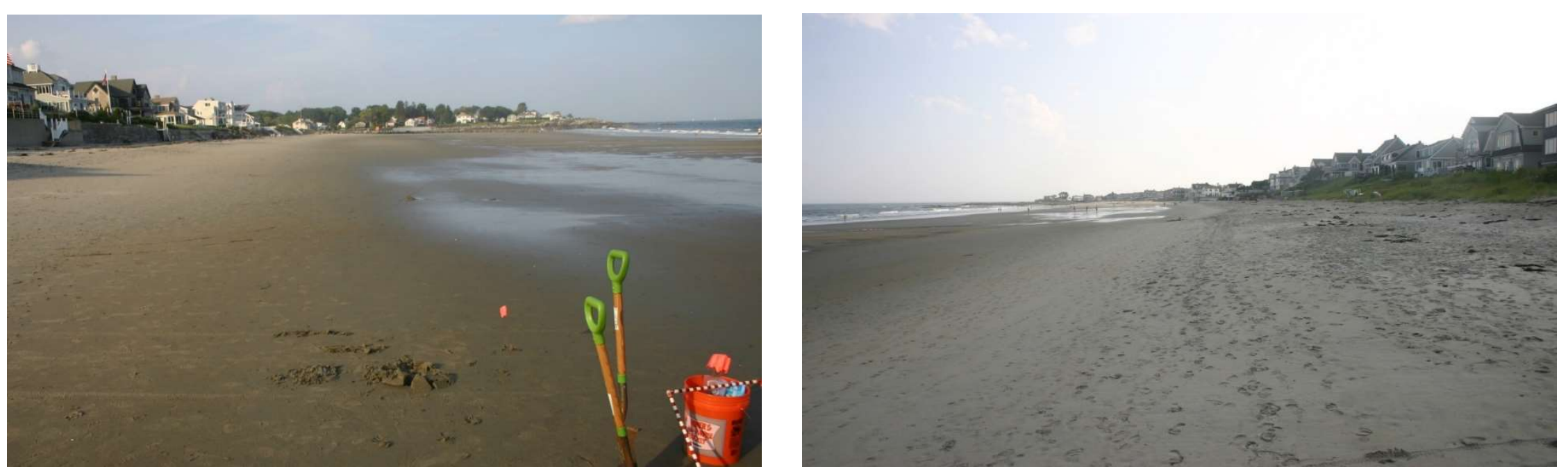

Figure WS-6. Wallis Sands station WSO2 on September 5, 2017 after an extended period of accretion looking at similar areas as shown above in Figure WS-5. The photograph on the left is looking north and the photograph on the right is looking south. Note how the low tide terrace is now buried by the accretionary wedge. 
Beach Sediments. The sediments at Wallis Sands ranged from slightly granuley fine sand to pebble gravel following the extended erosional period in winter 2017. However, most samples were slightly granuley to slightly pebbly medium sand with scattered pebbles (Table WS-1). Following the extended period of accretion, samples ranged from slightly granuley fine sand to sandy granule gravel, but most samples were slightly granuley fine to medium sand, because a fine-grained accretionary sediment wedge was deposited. This layering was observed in core samples along the base of the sand ramp during summerearly fall 2017.

To examine the overall trends of the entire beach from the erosional to the accretional period, the mean grain size statistics were examined using two approaches: first, by averaging the data by station and comparing the winter versus the late summer sampling periods (Figure WS-7 and Table WS-2); and, two, by pooling all of the sample statistics by elevation and examining the upper tidal beach, middle tidal beach, and the lower tidal beach for each time period (Figure WS-8 and Table WS-3). The mean statistics for each of the stations at Wallis Sands showed a distinctive fining from the winter period (following the extended period of erosion) to the late summer sampling (following an extended accretional period). However, except for station WSO2, the increase in mean grain size was small. At WSO2 significant erosion and exposure of pebbles occurred at the base of the sand ramp where pebble gravel was observed during the winter 2017 sampling (Figure WS-5). However, the coarser sediment was buried by finer sediment in the late summer sampling period (Figure WS-6). The shift in grain size distribution is more apparent when examining histograms of the pooled samples at each station (Figure WS-7 and Table WS-2). The modes shifted to finer sizes and the sediment became better sorted at all stations. This is especially true at stations WSO2 and WSO3 which had the largest coarse fraction.

Although there was a measurable fining of the sediment composing Wallis Sands between summer and winter, the variability between stations was relatively small. This gives confidence to pooling the grain size data for all of the stations by elevation in order to look at general changes from the upper to the lower beach (Figure WS-8 and Table WS-3). Overall, Wallis Sands sediment tended to vary cross-shore, while being relatively uniform alongshore between the four sampling stations. The upper tidal beach median and mean grain size increased by $0.6 \mathrm{phi}$ and the sorting increased from poorly to moderately well sorted. This shift is clearly visible in the histogram which shows a narrowing of the distribution and an increase in the median values. Also apparent is the loss of coarser fractions, especially in the mid tidal beach as the coarser clasts became buried by the accretionary sediment wedge composed of finer sediments. The lower tidal beach had a more moderate change in grain size and sorting. 

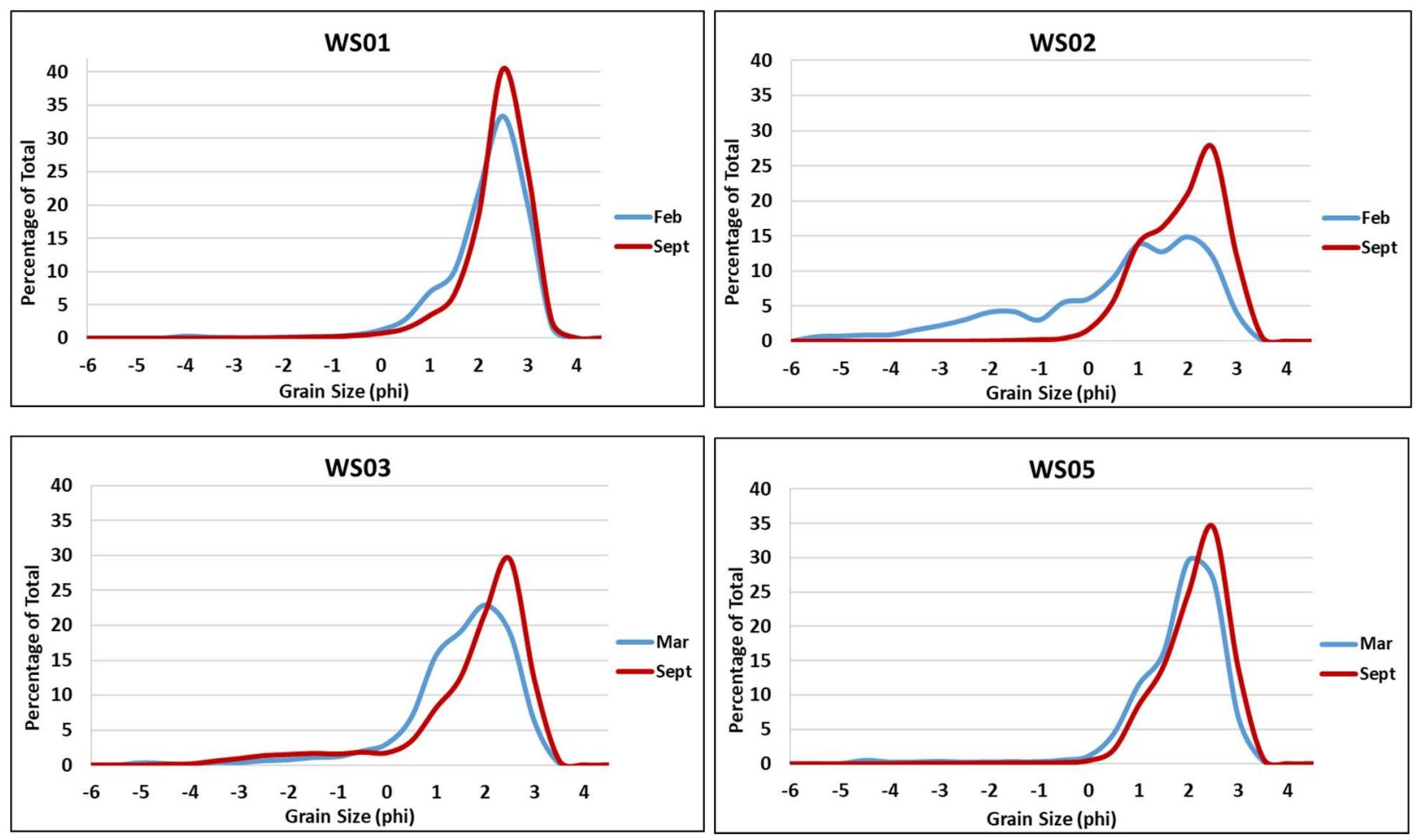

Figure WS-7. Average grain size distribution for the February/March (blue) and September (red) sediment samples at Wallis Sands, pooled for a station for each time period. Note the shift to better sorted and finer sediment after the summer accretion period. For the winter averaging, only February and March sampling results were used.

Table WS-2. Comparison of average grain size statistics for each of the cross-beach transects at Wallis Sands, NH. The average for each beach and season (winter erosive beach and summer accretional beach) is based on pooling all data from that station (n). For the winter averaging, only February and March sampling results were used (WSO5 samples from May were excluded).

\begin{tabular}{|c|c|c|c|c|c|c|c|c|}
\hline & \multicolumn{2}{|c|}{ WS01 } & \multicolumn{2}{|c|}{ WSO2 } & \multicolumn{2}{|c|}{ WSO3 } & \multicolumn{2}{|c|}{ WS05 } \\
\hline & Winter & Summer & Winter & Summer & Winter & Summer & Winter & Summer \\
\hline & $n=4$ & $n=4$ & $n=7$ & $n=5$ & $n=5$ & $n=4$ & $n=4$ & $n=4$ \\
\hline Gravel \% & 1.2 & 0.5 & 21.5 & 0.5 & 5.0 & 8.0 & 2.5 & 0.5 \\
\hline Pebble \% & 0.7 & 0.2 & 14.3 & 0.1 & 2.7 & 4.7 & 1.9 & 0.3 \\
\hline Granule \% & 0.5 & 0.4 & 7.3 & 0.4 & 2.3 & 3.3 & 0.6 & 0.2 \\
\hline Sand \% & 98.7 & 99.4 & 78.4 & 99.5 & 95.0 & 92.0 & 97.5 & 99.5 \\
\hline Mud \% & 0.0 & 0.0 & 0.0 & 0.0 & 0.0 & 0.0 & 0.0 & 0.0 \\
\hline Mode 1 (phi) & 2.2 & 2.2 & 1.7 & 2.2 & 1.7 & 2.2 & 1.7 & 2.2 \\
\hline$D_{10}$ (phi) & 0.8 & 1.3 & -2.5 & 0.6 & 0.0 & -0.4 & 0.6 & 0.9 \\
\hline $\mathrm{D}_{10}(\mathrm{~mm})$ & 0.6 & 0.4 & 5.7 & 0.7 & 1.0 & 1.4 & 0.7 & 0.5 \\
\hline $\mathrm{D}_{50}$ median (phi) & 2.1 & 2.2 & 0.8 & 1.8 & 1.4 & 1.8 & 1.7 & 2.0 \\
\hline $\mathrm{D}_{50}$ median $(\mathrm{mm})$ & 0.2 & 0.2 & 0.6 & 0.3 & 0.4 & 0.3 & 0.3 & 0.3 \\
\hline Mean (phi) & 2.0 & 2.2 & 0.3 & 1.7 & 1.4 & 1.6 & 1.6 & 1.9 \\
\hline Mean $(\mathrm{mm})$ & 0.26 & 0.22 & 0.79 & 0.32 & 0.39 & 0.33 & 0.32 & 0.27 \\
\hline Sorting (phi) & 0.76 & 0.62 & 1.84 & 0.81 & 1.00 & 1.18 & 0.76 & 0.67 \\
\hline Skewness (phi) & -0.30 & -0.22 & -0.39 & -0.21 & -0.25 & -0.47 & -0.25 & -0.26 \\
\hline Kurtosis (phi) & 1.19 & 1.25 & 1.01 & 0.90 & 1.17 & 1.60 & 1.04 & 1.05 \\
\hline
\end{tabular}



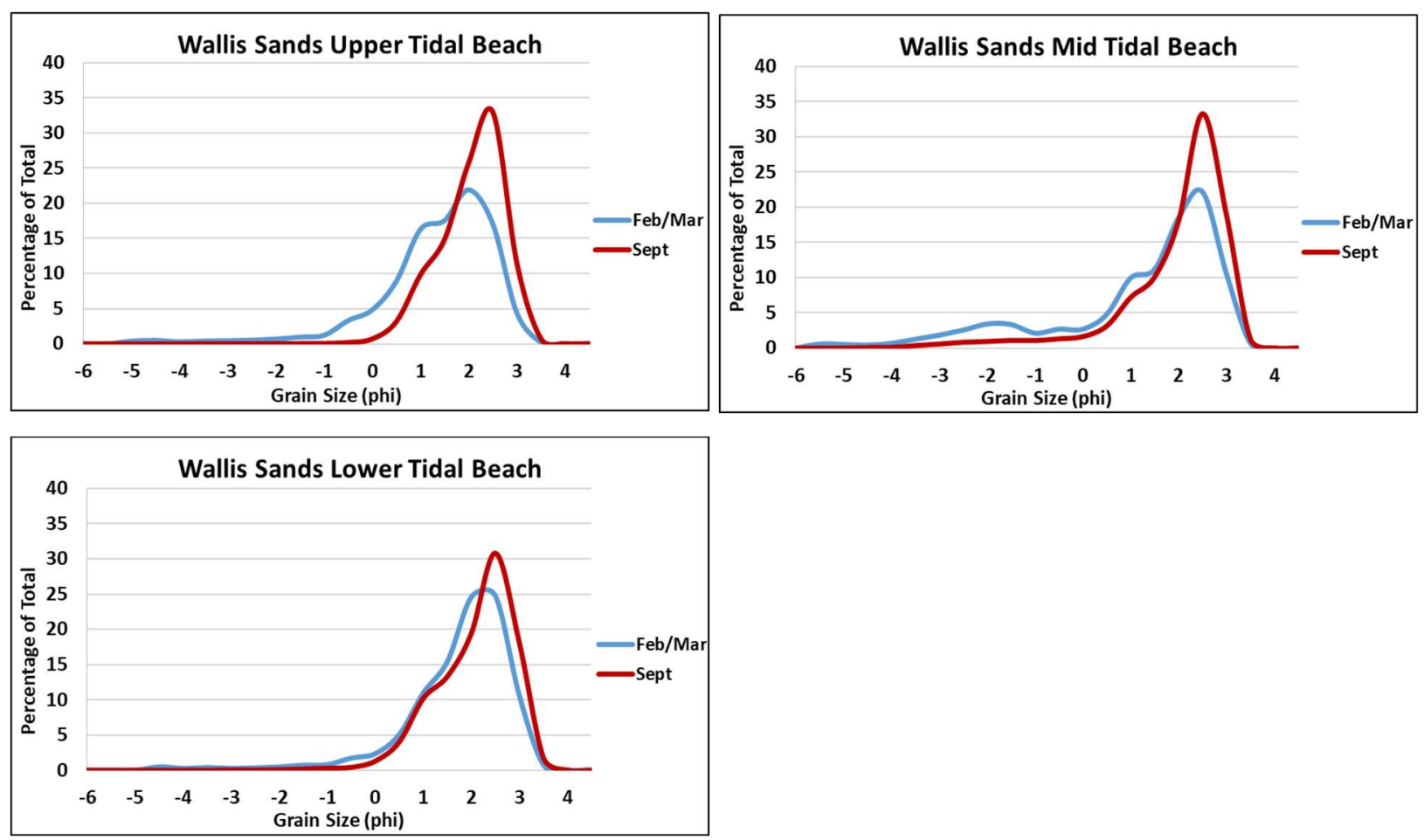

Figure WS-8. Average grain size distribution for the February/March (blue) and September (red) sediment samples at Wallis Sands, pooled by elevation for each time period. Note the shift to better sorted and finer sediment after the summer accretion period. For the winter averaging, only February and March sampling results were used.

Table WS-3. Comparison of average grain size statistics for Wallis Sands, NH sediment samples grouped by elevation into Upper Tidal Beach (UTB), Mid Tidal Beach (MTB), and Lower tidal Beach (LTB), and also separated into late winter (erosive beach) and late summer (accretional beach). For the winter averaging, only February and March sampling results were used (WSO5 samples from May were excluded).

\begin{tabular}{|rrr|rr|rr|}
\cline { 2 - 7 } & \multicolumn{2}{|c|}{ UTB } & \multicolumn{2}{c|}{ MTB } & \multicolumn{2}{c|}{ LTB } \\
& Winter & Summer & Winter & Summer & Winter & Summer \\
\cline { 2 - 7 } Gravel \% & $\mathrm{n}=7$ & $\mathrm{n}=7$ & $\mathrm{n}=8$ & $\mathrm{n}=7$ & $\mathrm{n}=5$ & $\mathrm{n}=3$ \\
\hline Pebble \% & 5.4 & 0.2 & 16.7 & 5.0 & 3.7 & 0.6 \\
Granule \% & 3.3 & 0.1 & 11.3 & 2.9 & 2.2 & 0.1 \\
Sand \% & 2.2 & 0.1 & 5.5 & 2.2 & 1.5 & 0.5 \\
Mud \% & 94.5 & 99.8 & 83.3 & 95.0 & 96.3 & 99.4 \\
Mode 1 (phi) & 0.0 & 0.0 & 0.0 & 0.0 & 0.0 & 0.0 \\
$\mathbf{D}_{10}$ (phi) & 1.7 & 2.2 & 2.2 & 2.2 & 2.2 & 2.2 \\
$\mathbf{D}_{10}$ (mm) & -0.4 & 0.8 & -2.2 & 0.3 & 0.2 & 0.7 \\
$\mathbf{D}_{50}$ median (phi) & 1.3 & 0.6 & 4.5 & 0.8 & 0.9 & 0.6 \\
D $_{50}$ median (mm) & 1.3 & 1.9 & 1.5 & 2.0 & 1.7 & 2.0 \\
Mean (phi) & 0.4 & 0.3 & 0.3 & 0.2 & 0.3 & 0.2 \\
Mean (mm) & 1.2 & 1.8 & 0.9 & 1.8 & 1.6 & 1.9 \\
Sorting (phi) & 0.43 & 0.29 & 0.53 & 0.28 & 0.34 & 0.28 \\
Skewness (phi) & 1.06 & 0.68 & 1.77 & 1.03 & 0.95 & 0.79 \\
Kurtosis (phi) & -0.27 & -0.23 & -0.56 & -0.47 & -0.30 & -0.30 \\
\hline
\end{tabular}




\section{Foss Beach, NH}

Foss Beach is a small attached barrier that extends $\sim 1.2 \mathrm{~km}$ between two headlands (Concord Point to the north and Rye Harbor State Park to the south) (Figures FB-1, FB-2, and FB-3). Both headlands are primarily composed of glacial till intermixed with bedrock. The till has been highly eroded, leaving behind extensive megaclast platforms that extend seaward and onto the margins of Foss Beach, controlling much of its character. The megaclast platform to the north is exposed and extends over one third of the barrier (Figure FB-2). The platform to the south is also extensive but is frequently covered with a thin veneer of sand during accretional periods (Figure FB-3). However, during erosional periods the thin veneer of sand is removed and the platform is exposed. Tree stumps were exposed in the intertidal area of the southern platform as a result of the landward migration of the barrier over the upland during the Holocene transgression (Figure FB-4). The landward boundary of Foss Beach is formed by a large manmade berm ( $\sim \mathrm{m}$ in height) that now separates the beach from the backshore (Figure FB-3). The intertidal beach is narrow ( 50-70 m depending on tidal phase) and normally lacks a backshore. A cobble ramp replaces the backshore and extends over much of the upper beach (Figure FB-2). The cobble ramp is present throughout the year and during the summer the toe of the ramp is covered by an accretionary wedge of fine sand with scattered pebbles. Overall, it is apparent that a major sediment source to Foss Beach is the eroding glacial headlands which have provided abundant pebbles, cobbles, and boulders leading to the bimodality of the beach. However, the source of sand is limited at present due to the offshore extension of the headlands interrupting or prohibiting longshore transport. Therefore, the movement of sand is likely onshore-offshore. The mapping of the adjacent continental shelf indicates a narrow sand ramp extends offshore but is limited in size (Figure FB-1).

Field Surveys. Beach elevation profiles were measured and sediment samples collected in early spring 2017 on April 9 (FB01 and FB02) and April 10 (FB03 and FB04) following winter storms and sediment loss from the beach. Stations FB01, FB02, and FB03 were profiled and sampled again in late summer on September 15, 2017 to assess the sediment characteristics after a period of accretion. The stations were positioned so that the major environments were sampled including the sand veneers covering the northern megaclast platform (FB01) and the southern megaclast platform (FB04). FB02 and FB03 were located on the interior of Foss Beach covering the cobble ramp and the sandy intertidal region. FB04 was not re-sampled in fall 2017 because the sand covering was absent. However, the April 10 data from station FB04 are included here and in Appendix E, but are not used in the comparisons between the erosional versus the accretional beach. The same argument holds true for station FB01 which was sampled in the spring and the fall, but was not included in the spring versus late summer comparison. 


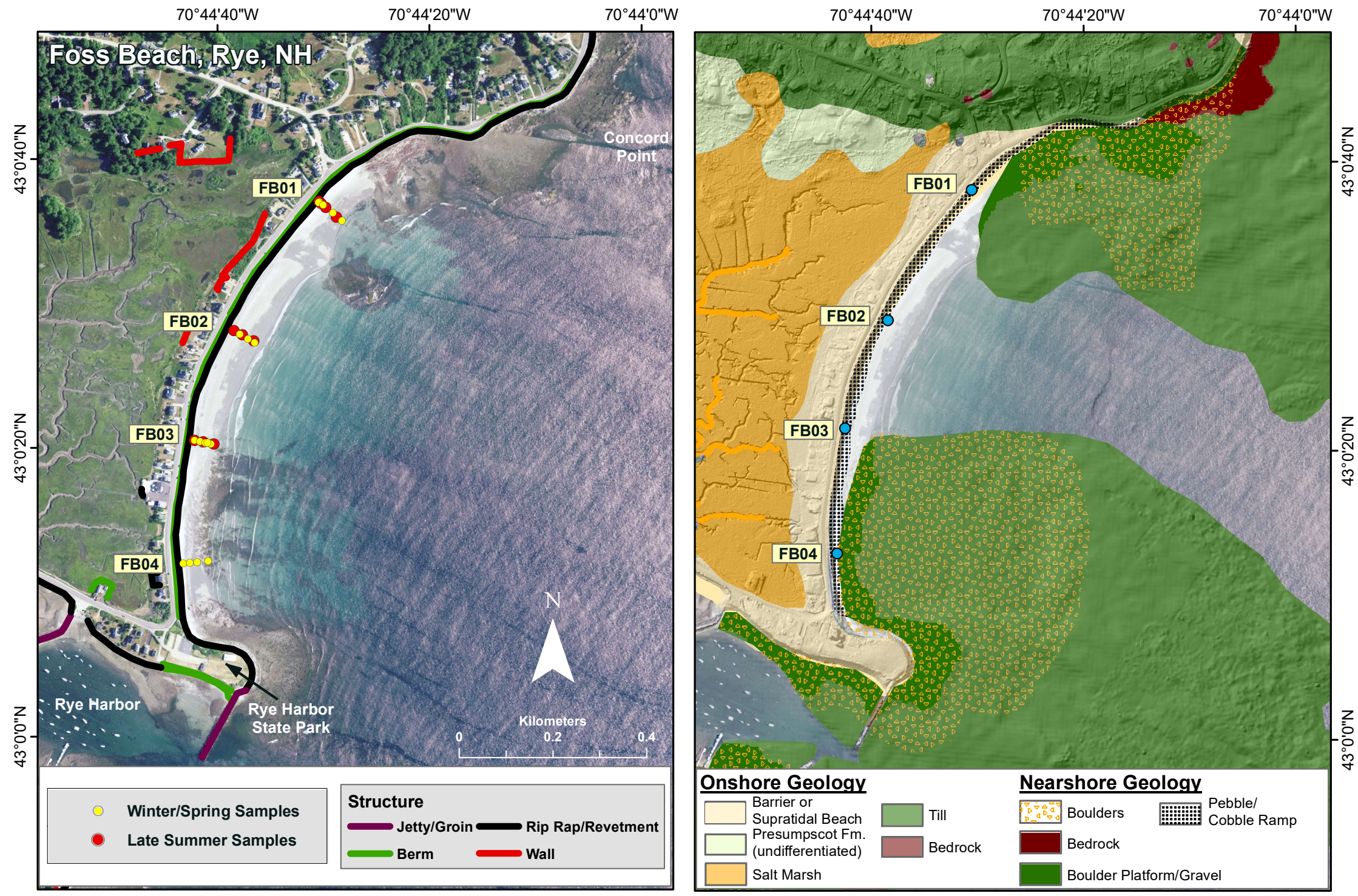

Figure FS-1. Station locations and shoreline structures (from Blondin, 2016) (left) and surficial geology of the upland (modified from NHGS digital series) and nearshore shelf (modified from Ward et al., 2021a) (right) at Foss Beach, Rye, NH. The nearshore seafloor not mapped (satellite imagery) is predominantly sand (right). 

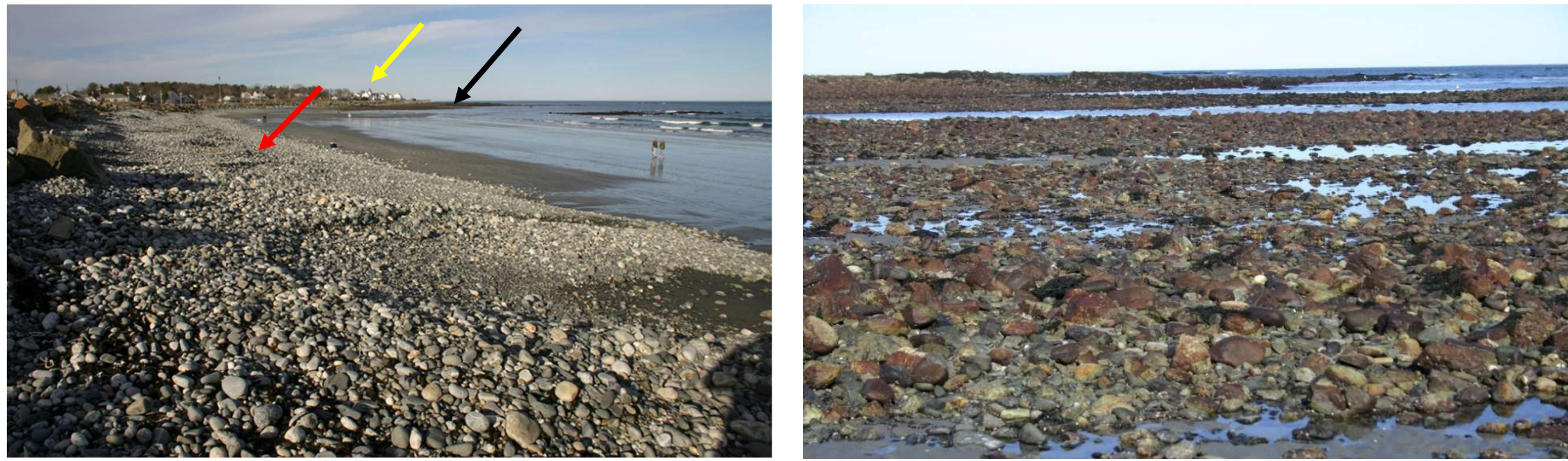

Figure FB-2. Foss Beach, NH looking north from station FB01 (left photograph), and the megaclast platform that extends seaward and forms the northern end of the beach (right photograph). Note the northern headland (Concord Point) (yellow arrow), the extensive gravel ramp composed of pebbles and cobbles running nearly the entire length of the beach (red arrow), and the megaclast platforms near the headland (black arrow). Photographs were taken on April 9, 2017.
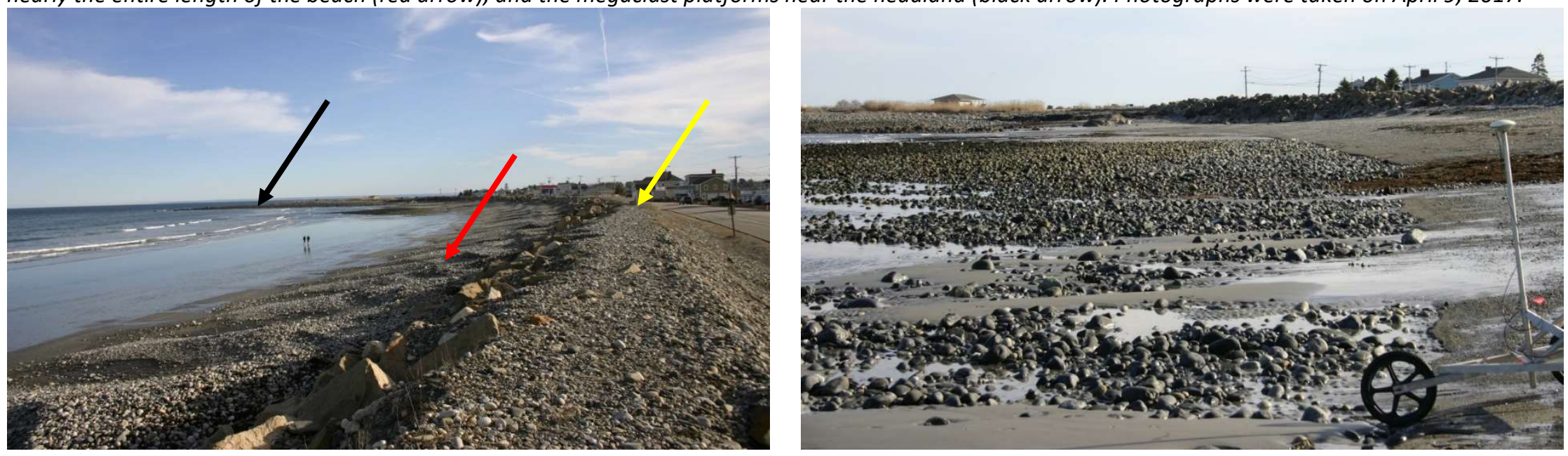

Figure FB-3. Foss Beach, NH looking south from station FBO2 (left photograph), and the large megaclast platform located at the southern end of the beach (right photograph). Note the manmade berm lined with boulders at the landward margin of the beach (yellow arrow), the extensive gravel ramp on the seaward margin of the berm with large cusps (red arrow), and the southern headland (Rye Harbor State Park) (black arrow). Photographs were taken on April 9, 2017. 

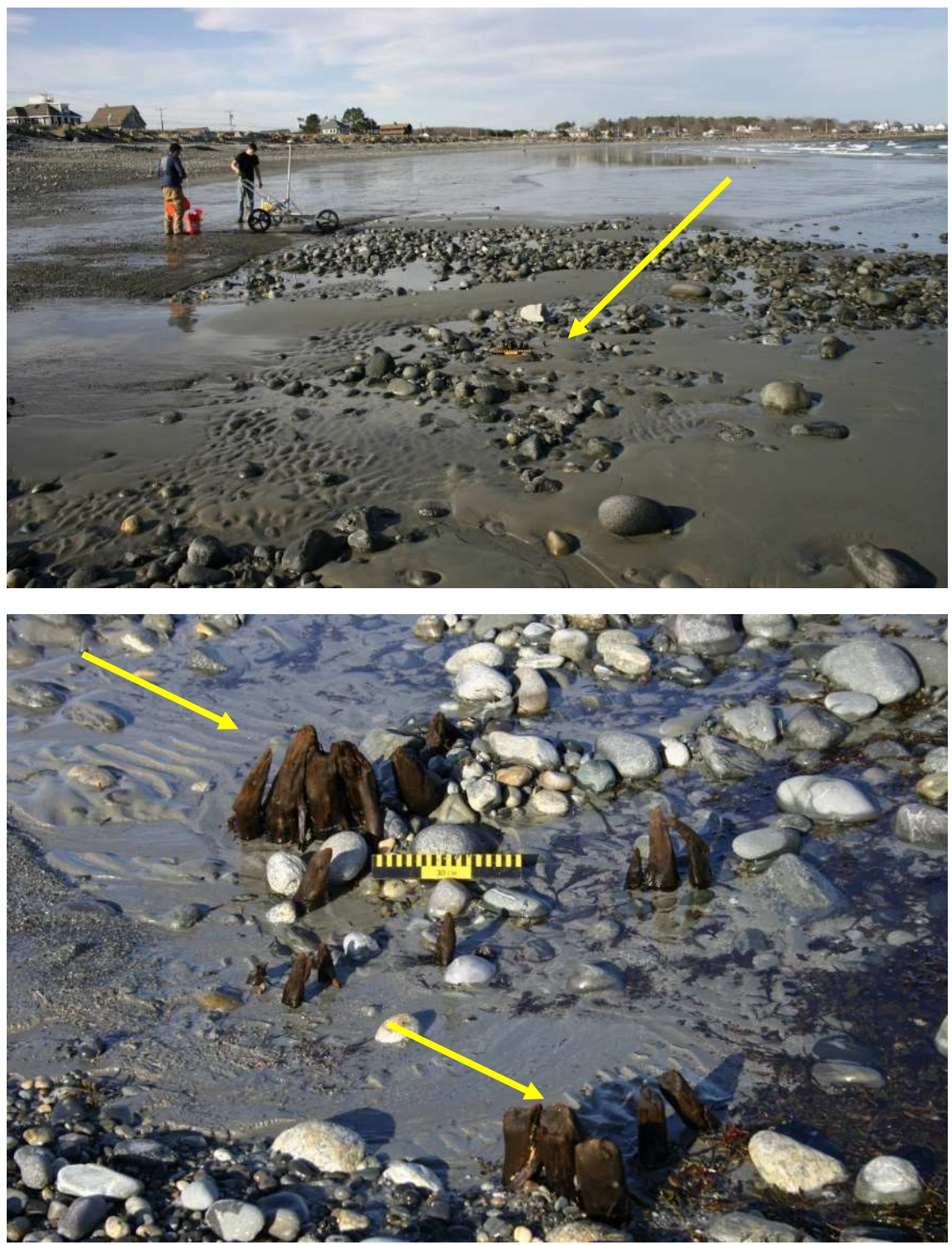

Figure FB-4. Tree stumps exposed in the lower intertidal at station FB04 at Foss Beach on April 10, 2017 after a period of erosion. The thin veneer of sediment was removed exposing a megaclast platform and tree stumps (arrows).

Beach Profiles. Foss Beach's morphology and sediment composition is highly variable with megaclast platforms, cobble ramps and sand veneers of variable thicknesses. This variability is reflected in the beach profiles (Figures FB-5a and 5b). The profiles located on or adjacent to the megaclast platforms (FB01 and FB04) had a lower slope than the beach elevation profiles located in the interior (FB02 and FB03), which were backed by the cobble ramp that persisted throughout the sampling period. The beach elevation profiles at stations FB01, FB02 and FB03 all significantly change from spring to the late summer. All four stations had erosional profiles in spring following the winter stormy period. In fall 2017 station FB01 had a veneer of sand over the megaclast platform that reached $\sim 0.5 \mathrm{~m}$ in thickness. Stations FB02 and FB03 showed major accretion in the lower and mid beach sections. At FB03 the accretional sand wedge reached $\sim 1.0 \mathrm{~m}$ in thickness. Accretion at both stations was most significant in the mid beach sections of the profiles at the base of the gravel ramp (Figures FB-6 and FB-7). 

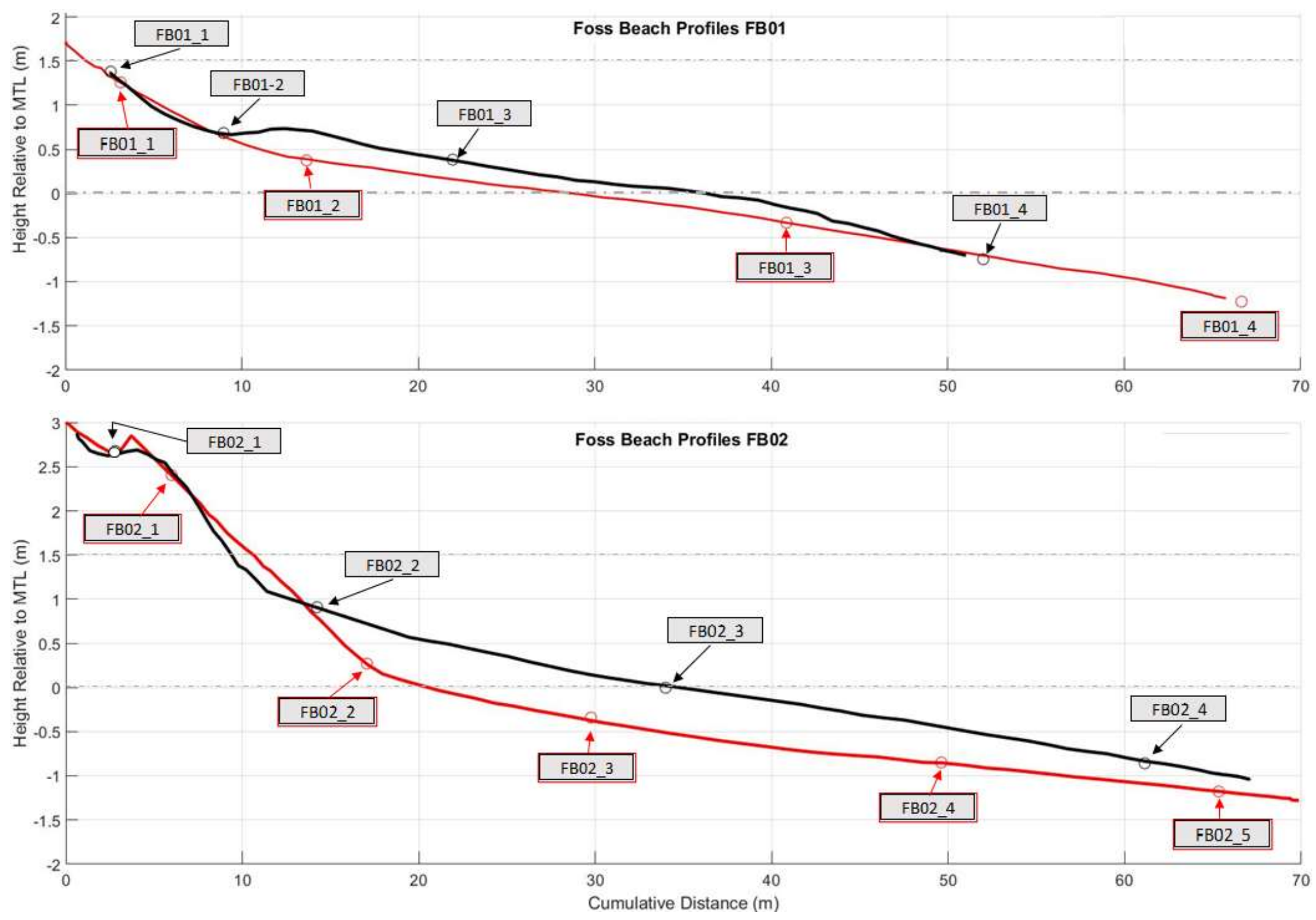

Figure FB-5a. Beach profiles and sediment sample locations from winter and late summer 2017 for stations FB01 and FB02 at Foss Beach, NH. Profile FB01 was run and sediment sampled on March 8 (red line/circles/boxes) and on September 7 (black line/circles/boxes). Profile FBO2 was run on May 4 (red) and on September 7 (black). 

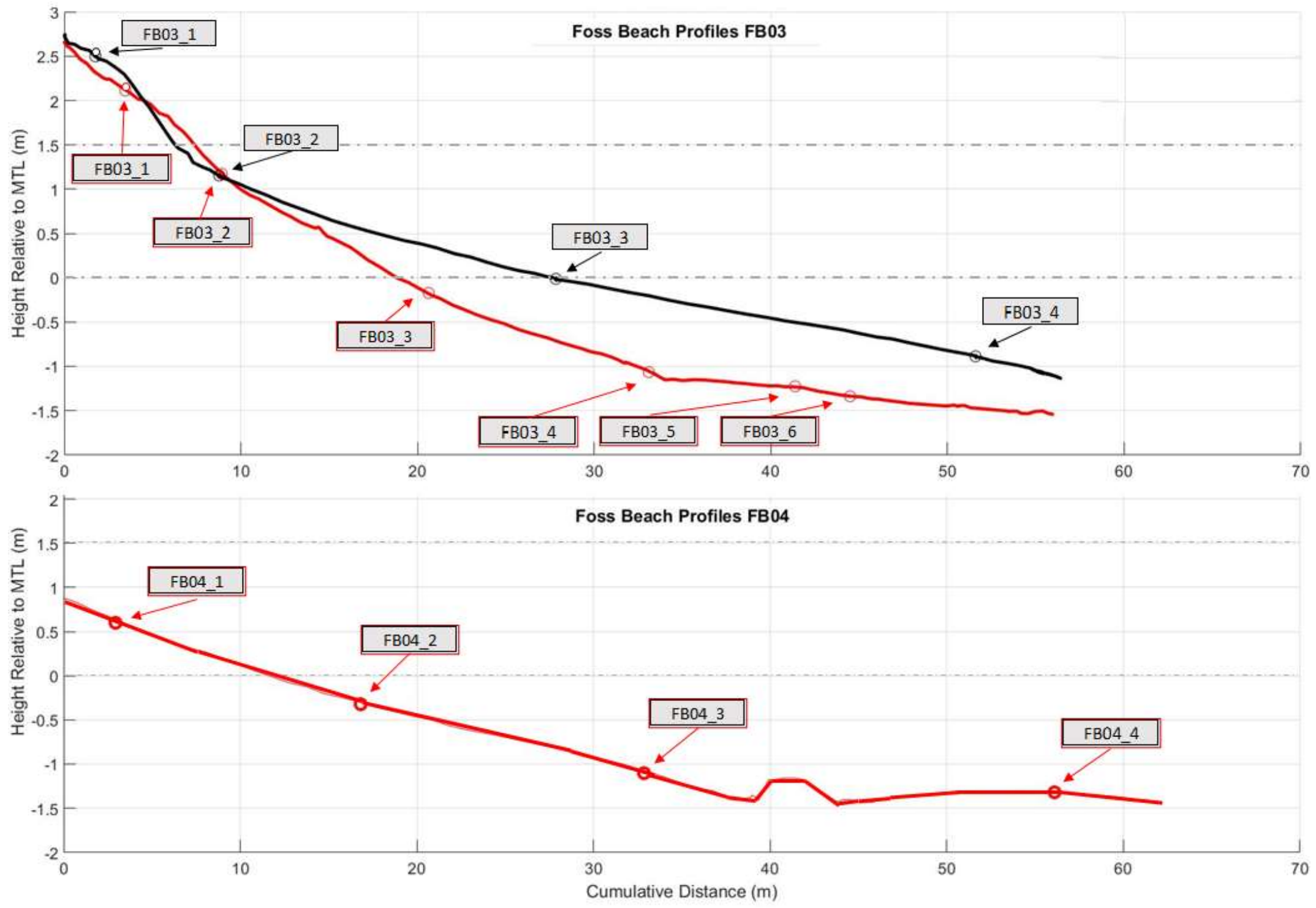

Figure FB-5b. Beach profiles and sediment sample locations from winter and late summer 2017 for stations FB03 and FB04 at Foss Beach, NH. Profile FB03 was run and sediment sampled on April 10 (red line/circles/boxes) and on September 5 (black line/circles/boxes). Profile FB04 was run on April 10 (red) only. 

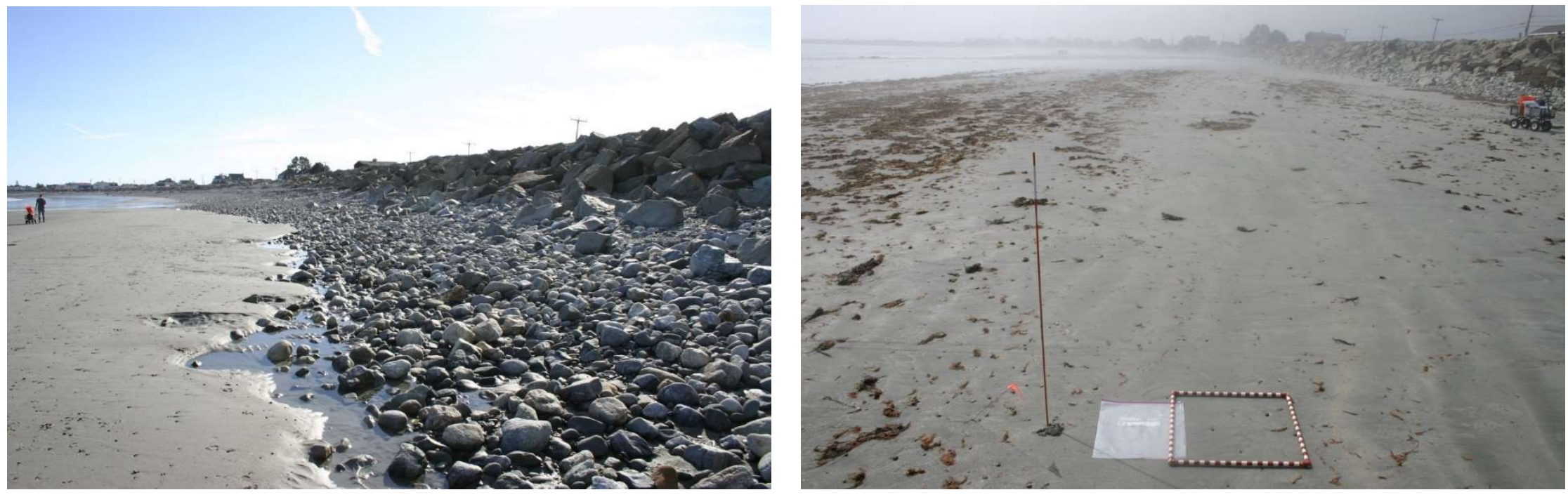

Figure FB-6. Foss Beach looking south from FB01 on April 9, 2017 (left photograph) after a period of erosion and on September 15, 2017 (right photograph) after a period of accretion. Note much of the lower gravel ramp exposed in April is buried by an accretional sand wedge in September.
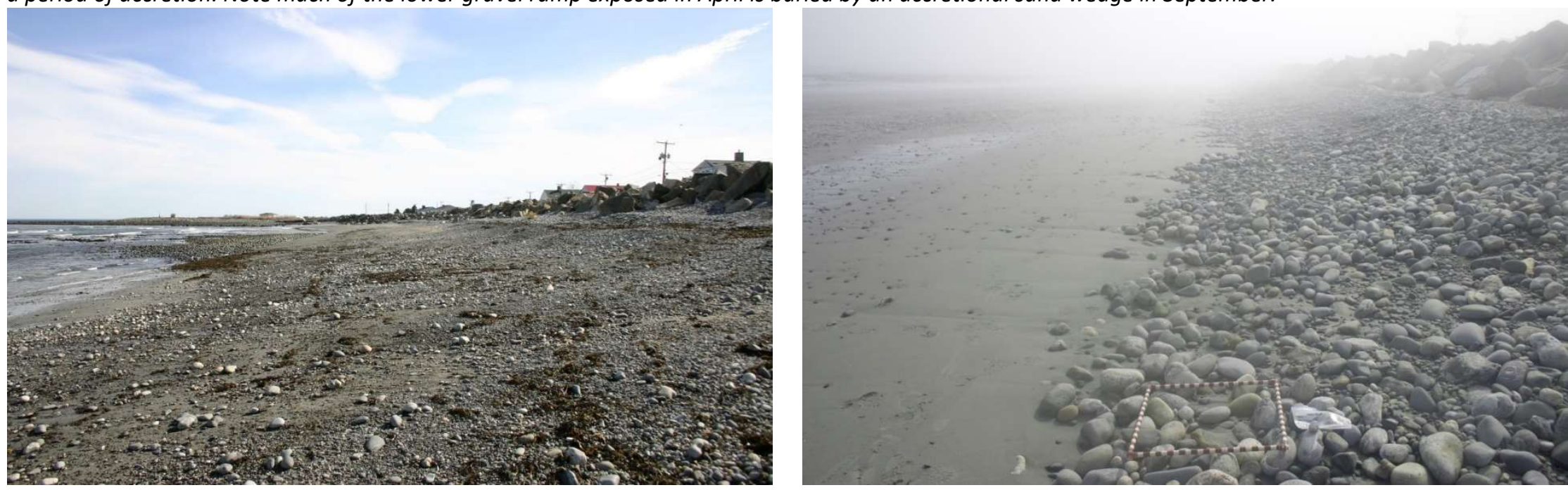

Figure FB-7. Foss Beach looking south from FB03 on April 10, 2017 (left photograph) after a period of erosion and on September 15, 2017 (right photograph) after a period of accretion. Note the lower and mid beach exposed in April is buried by an accretional sand wedge in September. Heavy fog occurred on this day. 
Beach Sediments. The sediment sampling stations reflect the variability in morphology and depositional environments at Foss Beach related to the glacial till-covered headlands and megaclast platforms. FB01 is located adjacent to the northern megaclast platform that extends seaward from the headland and likely underlies the station (Figures FS-1 and FS-2). The sediments at FB01 had a very large gravel fraction both in April and September. On April 9 following the winter erosional period the sediments composing the top 20-25 cm of the beach were poorly to very poorly sorted bimodal sandy granule gravel to sandy pebble gravels in the upper and mid beach, and gravelly fine sand in the lower beach (Table FB-1). On September 15 following the summer accretional period, the sediment compositions were very similar to the early spring period and only showed a small amount of fining. This pattern is visible in the grain size distribution of the samples from station FB01 (Figure FB-8). Station FB04 at the southern margin of Foss Beach was clearly on the megaclast platform and was covered by a thin veneer of finer sediment in the late winter. The sediment was composed of bimodal slightly granular fine sand to a pebbly fine sand, except adjacent to the manmade berm which was a sandy pebble gravel. This site was not sampled again in late fall.

The two interior stations, FB02 and FB03, had a wedge of fine sand over the mid and lower intertidal areas. FB02 was a moderately to poorly sorted granuley to pebbly fine sand in both the spring and in the late fall sampling periods. The mean grain size did show a fining trend as additional fine sand accumulated in the late summer sampling (Table FB-2). FB03 was located adjacent to the southern megaclast platform and was characterized by sandy pebble to pebble gravel in the mid and upper beach, and slightly granuley fine sand on the lower beach. During the late summer sampling period the fine sands extended landward and covered much of the gravel and cobble on the mid and upper beach (Figure FB-7).

FB03 was the only station at Foss Beach that showed a major change in grain size statistics and distribution (Table FB-2 and Figure FB-8). The changes were minimal at FB01 and FB02 and were on the order of 0.6 phi. This lack of change following months of calm conditions is attributed to the beach having a very limited supply of fine-grained or sandy sediment, with the eroded glacial till being the main source of sediment (resulting in a dominance of pebbles, cobbles, and boulders).

No comparisons were made which examined the upper tidal beach, mid tidal beach, and lower tidal beach by pooling the grain size statistics from all of the stations together and separating samples by elevation. The variability of the morphology and sediment grain size characteristics was too great between stations alongshore to justify pooling the data. 
Table FB-1. Grain size statistics for the samples collected at Foss Beach, NH in 2017. More complete summaries of the samples are given in Appendix E.

\begin{tabular}{|c|c|c|c|c|c|c|c|c|c|c|c|c|c|c|c|c|c|c|c|c|c|}
\hline $\begin{array}{c}\text { Sample } \\
\text { ID }\end{array}$ & $\begin{array}{c}\text { Latitude } \\
\text { WGS84 }\end{array}$ & $\begin{array}{c}\text { Longitude } \\
\text { WGS84 }\end{array}$ & $\begin{array}{c}\text { Sample } \\
\text { Collected }\end{array}$ & $\begin{array}{c}\text { Sample } \\
\text { Wt. (gms) }\end{array}$ & $\begin{array}{c}\text { Morphologic } \\
\text { Feature }\end{array}$ & $\begin{array}{l}\text { Sediment } \\
\text { Name }\end{array}$ & $\begin{array}{c}\text { Sediment } \\
\text { Classification }\end{array}$ & g & $\begin{array}{c}\text { Gravel } \\
\%\end{array}$ & $\begin{array}{c}\text { Pebble } \\
\%\end{array}$ & $\begin{array}{c}\text { Granule } \\
\%\end{array}$ & $\begin{array}{c}\text { Sand } \\
\%\end{array}$ & $\begin{array}{c}\text { Mud } \\
\%\end{array}$ & $\begin{array}{c}\text { Mode } \\
\text { Abbrev. }\end{array}$ & $\begin{array}{l}\text { Mode } \\
1 \text { (phi) }\end{array}$ & $\begin{array}{l}\text { Mode } \\
2 \text { (phi) }\end{array}$ & $\begin{array}{c}D_{10} \\
\text { (phi) }\end{array}$ & $\begin{array}{c}\text { D } 50 \\
\text { (phi) }\end{array}$ & $\begin{array}{c}\text { Mean } \\
\text { (phi) }\end{array}$ & $\begin{array}{c}\text { Sorting } \\
\text { (phi) }\end{array}$ & $\begin{array}{c}\text { Skew- } \\
\text { ness }\end{array}$ \\
\hline B01-1A & 43.010404 & -70.741635 & Apr-17 & $20,071.0$ & Anth. Berm Toe: Cusp Horn & andy Pebble Gravel & V. Coarse Sand & VPS & 32.28 & 25.15 & 7.13 & 67.71 & 0.01 & B & 0.75 & -3.24 & -3.67 & 0.11 & -0.52 & 2.11 & -0.38 \\
\hline B01-1B & 390 & 0.741647 & Apr-17 & 7.0 & Anth. Berm Toe: Cusp Trough & Pebble Gravel & Pebb & PS & 8.35 & 84.72 & 3.63 & 11.63 & .02 & $B_{2}-2$ & 3.74 & 2.24 & -4.94 & -3.61 & .44 & 74 & .36 \\
\hline FB01-2 & .010346 & 0.741532 & -Apr-17 & 750.8 & LTT: Landward & Sandy Granule Gravel & V. Coarse Sand & VPS & 6.37 & 27.41 & 18.96 & 53.62 & 0.01 & 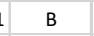 & 2.24 & -0.74 & -3.43 & -0.82 & -0.51 & .23 & 0.13 \\
\hline FB01-3 & 43.010194 & -70.741271 & 9-Apr-17 & 502.5 & LTT: Mid & Sandy Granule Gravel & V. Coarse Sand & VPS & 37.99 & 21.92 & 16.07 & 62.00 & 0.01 & B & 2.24 & -1.74 & -2.81 & -0.12 & -0.10 & 104 & .02 \\
\hline FB01-4 & 43.010051 & -70.741022 & 9-Apr-17 & $5,126.5$ & Swash Zone & ranular Fine Sand & Medium Sand & PS & 16.02 & 9.51 & 6.51 & 83.96 & 0.02 & 2 & 2.74 & N/A & -1.93 & 2.25 & 1.34 & .81 & -0.73 \\
\hline FB01-1 & 43.010407 & -70.741639 & 15 -Sep-17 & 867.9 & G. Ramp: Base & Sandy Pebble Gravel & Granule Gravel & VPS & 61.79 & 51.78 & 10.01 & 38.20 & 0.01 & & -3.74 & 2.24 & -4.76 & -2.15 & -1.58 & 2.56 & 0.25 \\
\hline FB01-2 & 43.010370 & -70.741579 & -Sep-17 & 067.7 & m: Backshore & andy Pebble Gravel & V. Coarse Sand & VPS & 46.57 & 37.48 & 9.09 & 53.39 & 0.04 & & 2.24 & -3.24 & -4.22 & -0.38 & -0.54 & .67 & -0.12 \\
\hline FB01-3 & 292 & -70.741458 & -Sep-17 & 989.3 & : Mid & Sand & Sand & VPS & 8.27 & 14.94 & 3.34 & 81.70 & 0.0 & & .24 & N/A & -3.02 & 2.13 & .04 & 11 & -0.75 \\
\hline FB01-4 & 43.010114 & -70.741180 & 15 -Sep-17 & 787.1 & LTT:Swash & Granular Fine Sand & Medium Sand & PS & 21.19 & 12.49 & 8.70 & 78.76 & 0.05 & u & 2.24 & N/A & -2.29 & 2.03 & 1.03 & 1.98 & -0.65 \\
\hline FBO2-3 & .007819 & -70.743638 & -Apr-17 & 990.4 & indward & Sand & e Sand & M & 5.19 & 4.42 & 0.77 & 94.78 & 0.0 & & .26 & N/A & 1.57 & 2.37 & 2.3 & 0.8 & -0.3 \\
\hline FBO2-4 & 07734 & -70.743424 & 9-Apr-17 & 430.2 & T: Mid & Granular Fine Sand & Medium Sand & $\mathrm{P}$ & 20.86 & 11.64 & 9.22 & 79.12 & 0.02 & 1 & .24 & N/A & -2.19 & 2.10 & 1.09 & 1.94 & -0.71 \\
\hline FBO2-5 & 43.007667 & -70.743254 & 9-Apr-17 & $4,879.5$ & r: Swash Zone & Granular Fine Sand & ledium Sand & $P$ & 19.18 & 11.11 & 8.07 & 80.80 & 0.02 & & 24 & -0.24 & -2.15 & 1.83 & 1.03 & .90 & -0.6 \\
\hline FBO2-2 & & -70.743799 & 15-Sep-17 & 2,20 & ore: Upper; Ba & St Pobbly & Fine Sand & ws & 25 & 25 & 0 & .73 & 02 & 2 & 24 & /A & 05 & 49 & .50 & 37 & .06 \\
\hline $\mathrm{FB} 02-3$ & & -70.7 & Sep-17 & & & sand & Fine Sand & PS & 3.08 & 11.85 & 1.23 & 86.48 & 0.44 & 4 & .74 & N/A & -3.00 & 2.42 & 2.12 & 54 & .65 \\
\hline $\mathrm{FB} 02-4$ & .007702 & -70.743272 & Sep-17 & 288.6 & T: Lower & ebbly Fine Sand & oarse Sand & VPS & 25.84 & 21.10 & 4.75 & 74.12 & 0.04 & & .74 & 3.74 & -3.61 & 2.03 & 0.62 & .51 & 0.7 \\
\hline FB03-1 & 005 & 0.744772 & Apr-17 & 1 & per & oble Gravel & le Gravel & & 9.80 & 99.69 & 0.10 & 0.20 & .00 & & 73 & 1/A & -5.53 & -4.51 & -4.47 & 84 & .0 \\
\hline FB03-2 & 005748 & -70.744631 & Apr-17 & 14 & S./G. Ramp: Mid & Pebble Gravel & Pebble Gravel & 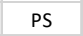 & 2.90 & 78.21 & 14.70 & 7.10 & 0.00 & & -3.24 & $\mathrm{~N} / \mathrm{A}$ & -4.10 & -2.96 & 2.85 & 29 & .27 \\
\hline FB03-3 & 43.005725 & -70.744481 & Apr-17 & 13,03 & S./G. Ramp: Lower; Upper LTT & Sandy Pebble Gravel & Pebble Gravel & VPS & 5.46 & 66.91 & 8.55 & 24.53 & 0.0 & & -3.24 & 2.24 & -5.22 & -3.11 & .04 & 86 & 0.43 \\
\hline FB03-4 & .005711 & -70.744381 & Apr-17 & 87.7 & in S. Ridge Over C./B. Field: Start & Sandy Pebbl & Coarse Sand & VP & 30.22 & 21.60 & 2 & 69.75 & 0.0 & & 2.74 & -2.24 & -3.0 & 2.33 & .89 & 34 & -0.8 \\
\hline FB03-5 & 43.005707 & -70.744344 & -Apr-17 & 528 & Thin S. Ridge Over C./B. Field: Mid & Sl. Granular Fine Sand & e Sand & $\mathrm{vW}$ & 0.45 & 0.12 & 33 & 99.50 & 0.05 & & .74 & N/A & 12 & 2.64 & 2.60 & 34 & -0.15 \\
\hline FBO3-6 & 43.005721 & -70.744426 & -Apr-17 & 202.6 & Thin S. Ridge Over C/BF: Swash & Sl. Granular Fine Sand & e Sand & w & .02 & 0.00 & 0.02 & 99.96 & 0.02 & 2 & 2.74 & N/A & .04 & 2.54 & 2.52 & .36 & -0.15 \\
\hline FBO3-2 & 43.005768 & -70.744776 & 15-Sep-17 & $2,931.6$ & reshore: Upper; Base of G. Ramp & Sl. Granular Fine Sand & e Sand & w & 1.18 & 0.33 & .85 & 98.79 & 03 & u & 24 & N/A & 65 & 2.28 & .31 & 48 & 0.11 \\
\hline FB03-3 & 43.005738 & -70.7 & -Sep-17 & $7,089.2$ & Mid & Sand & Coarse Sand & VPS & 29.78 & 26.24 & 3.54 & 70.19 & .03 & 3 & 2.24 & -5.73 & -4.73 & 2.12 & 0.30 & 97 & 0.82 \\
\hline FB03-4 & 55700 & -70.744259 & Sep-17 & & T: Lower & Sand & Sand & 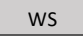 & 0.91 & 0.76 & 0.15 & 99.04 & .05 & & 2.74 & //A & 2.05 & 2.55 & .53 & 40 & \\
\hline FB04-1 & 43.00338 & -70.744998 & Apr-17 & 2 & /G. Ramp: Upper & Sandy Pebble Gravel & Gravel & . & 7.64 & 70.71 & 93 & 22.35 & 0.01 & & -4.73 & 2.24 & -5.36 & -3.56 & 2.31 & .93 & 0.52 \\
\hline FB04-2 & .003405 & -70.744829 & Apr-17 & $5,219.0$ & Ramp: Mid & e Sand & Coarse Sand & VP & 26.64 & 19.38 & 7.2 & 73.32 & 0.04 & 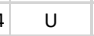 & 2.2 & N/A & -3.05 & 2.19 & 8.86 & 32 & -0.77 \\
\hline FB04-3 & & -70 & pr-17 & 33.2 & d. to C./B. Field & $\operatorname{san}$ & and & $y$ & & & 0. & 7.11 & 0.1. & 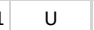 & & I/A & & 2.67 & .62 & .42 & 0.1 \\
\hline FB04-4 & 43.003453 & -70.744352 & -Apr-17 & 491.7 & Water Line - Low Tide & Granular Fine Sand & ine Sand & $\mathrm{vw}$ & 0.12 & 0.03 & 0.10 & 99.85 & 0.0 & & 2.74 & N/A & 2.05 & 2.50 & 2.50 & 0.34 & $0.04-04-5$ \\
\hline
\end{tabular}



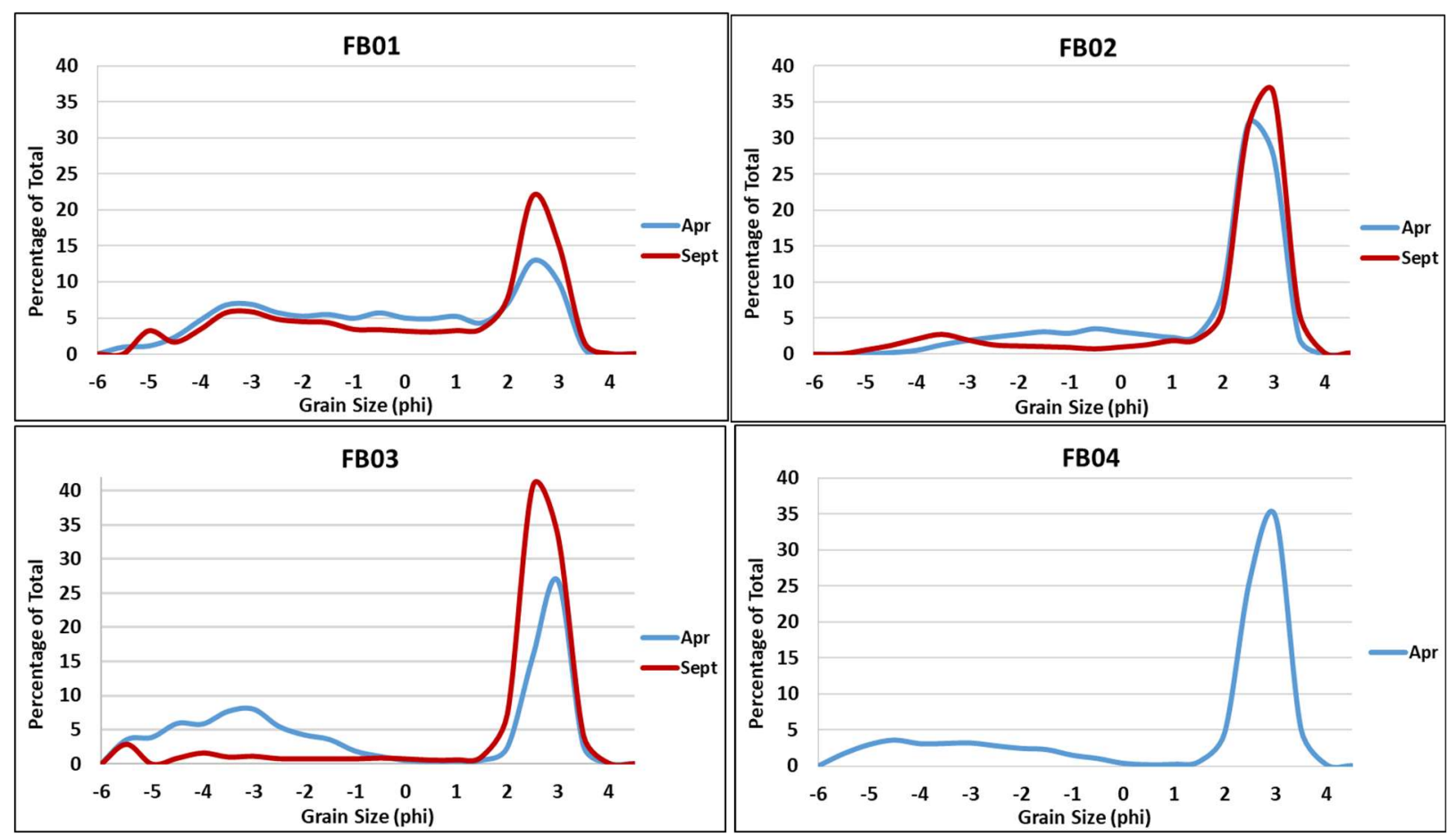

Figure FB-8. Average grain size distributions for each of the Foss Beach stations in April (blue) and September (red) 2017, pooled for a station for each time period.

Table FB-2. Comparison of average grain size statistics for each of the cross-beach transects at Foss Beach, NH. The average for each beach and season (winter erosive beach and summer accretional beach) is based on pooling all data from that station (n).

\begin{tabular}{|c|c|c|c|c|c|c|c|}
\hline & \multicolumn{2}{|c|}{ FB01 } & \multicolumn{2}{|c|}{ FBO2 } & \multicolumn{2}{|c|}{ FB03 } & \multirow{2}{*}{$\begin{array}{r}\text { FBO } \\
\text { Winte }\end{array}$} \\
\hline & Winter & Summer & Winter & Summer & Winter & Summer & \\
\hline & $n=5$ & $n=4$ & $n=3$ & $n=3$ & $n=6$ & $n=4$ & $n=4$ \\
\hline Gravel \% & 44.2 & 37.0 & 15.1 & 13.1 & 49.8 & 10.6 & 26.8 \\
\hline Pebble \% & 33.7 & 29.2 & 9.1 & 11.1 & 44.4 & 9.1 & 23.0 \\
\hline Granule \% & 10.5 & 7.8 & 6.0 & 2.0 & 5.4 & 1.5 & 3.8 \\
\hline Sand \% & 55.8 & 63.0 & 84.9 & 86.8 & 50.2 & 89.3 & 73.2 \\
\hline Mud \% & 0.0 & 0.0 & 0.0 & 0.2 & 0.0 & 0.0 & 0.0 \\
\hline Mode 1 (phi) & 2.2 & 2.2 & 2.2 & 2.7 & 2.7 & 2.2 & 2.7 \\
\hline$D_{10}$ (phi) & -3.9 & -3.8 & -1.8 & -2.5 & -4.8 & -1.4 & -4.2 \\
\hline $\mathrm{D}_{10}(\mathrm{~mm})$ & 15.2 & 14.4 & 3.6 & 5.5 & 27.1 & 2.6 & 18.6 \\
\hline $\mathrm{D}_{50}$ median (phi) & -0.5 & 1.0 & 2.2 & 2.4 & -0.9 & 2.3 & 2.3 \\
\hline $\mathrm{D}_{50}$ median $(\mathrm{mm})$ & 1.4 & 0.5 & 0.2 & 0.2 & 1.9 & 0.2 & 0.2 \\
\hline Mean (phi) & -0.6 & 0.1 & 1.4 & 1.9 & -0.8 & 2.2 & 0.6 \\
\hline Mean $(\mathrm{mm})$ & 1.47 & 0.95 & 0.39 & 0.27 & 1.75 & 0.21 & 0.65 \\
\hline Sorting (phi) & 2.53 & 2.57 & 1.77 & 1.64 & 3.00 & 1.38 & 2.73 \\
\hline Skewness (phi) & -0.07 & -0.49 & -0.71 & -0.69 & -0.01 & -0.51 & -0.82 \\
\hline Kurtosis (phi) & 0.63 & 0.63 & 1.20 & 3.47 & 0.55 & 4.57 & 0.77 \\
\hline
\end{tabular}


Jenness Beach extends $\sim 1.8 \mathrm{~km}$ between two headlands primarily composed of glacial till: Straws Point (also called Castle Neck) to the north and an unnamed headland to the south (Figures JB-1, JB-2, and JB3). Locally, Jenness Beach is referred to as Cable Beach (northern end), Jenness State Beach (middle section), and Sawyers Beach (southern end). It is likely that Jenness Beach was a barrier spit extending from Straws Point but has migrated landward and is now a mainland beach, at least on the northern half. A variety of engineering structures separate the beach from the upland along the entire length of Jenness Beach (Figure JB-1). Dunes are now absent at the landward edge of almost the entire beach system.

Important to understanding the morphology and sediment composition of Jenness Beach is the local glacial geology. Jenness Beach is bordered entirely by glacial till deposits, including the offshore region (Figure JB-1). The northern end of the beach (Cable Beach) abuts Straws Point which is fronted by a cobble and boulder platform (megaclast platform) that extends offshore. The megaclast platform formed as the headland was eroded by wave action. However, cobbles and boulders now afford some protection to the headland from further erosion, diminishing a former sediment supply (Figure JB-2). Similarly, the southern boundary of Jenness Beach (Sawyers Beach) has megaclast deposits at the headland, as well as an eskerlike feature that originates on the shelf and traverses the beach (Figure JB-1). The megaclast platforms are particularly visible after storm activity when the beach has been eroded and the sand veneer removed. During periods when the beach has been eroded, pebbles are scattered over the sand (Figure JB-3). A tombolo extends from the southern headland, which formed behind an offshore topographic high composed of bedrock covered with till. At one time the eroded sediment likely supplied sand to the beaches, but this source is likely no longer available.

Field Surveys. The beach elevation profiles were measured and sediment samples collected in 2017 on March 28 (JB01 and JB02) and March 29 (JB03 and JB04) following the winter erosional period. The stations were sampled again on September 9 (JB01 and JB02) and September 11 (JB03 and JB04) to assess the sediment characteristics after a period of accretion. The morphology and sedimentology of Jenness Beach was similar alongshore, allowing the four stations to reflect the characteristics of the beach system.

Beach Elevation Profiles. Jenness Beach is typically wide, but with an overall low elevation. The upper beach at JB01 and JB02 has a sand ramp that slopes up to the near-continuous seawalls (Figures JB-4a and 4b). At JBO4 the sand is replaced by a gravel ramp in the upper beach. The low tide terrace is wide and flat. As a result of its overall low elevation, Jenness Beach is very susceptible to inundation during spring tides and storm surges. It is also very susceptible to erosion which alters the sediment characteristics. However, the elevation does not change dramatically during most erosive events. The beach elevation profiles for all four stations transitioned from erosional to accretional profiles between March and September 2017. The stations at JB01 and JB02 showed accretion on the low tide terrace, and a berm formed on the upper beach at JB02. Conversely, stations JB03 and JB04 increased in elevation over the entire beach with an accretionary wedge of sand building over the summer and fall. This was most prevalent at JB03 where the cobble ramp adjacent to the riprap border at the upland (normally exposed during winter erosional periods) was covered with sand during the accretional period (Figures JB-5 and JB-6). 


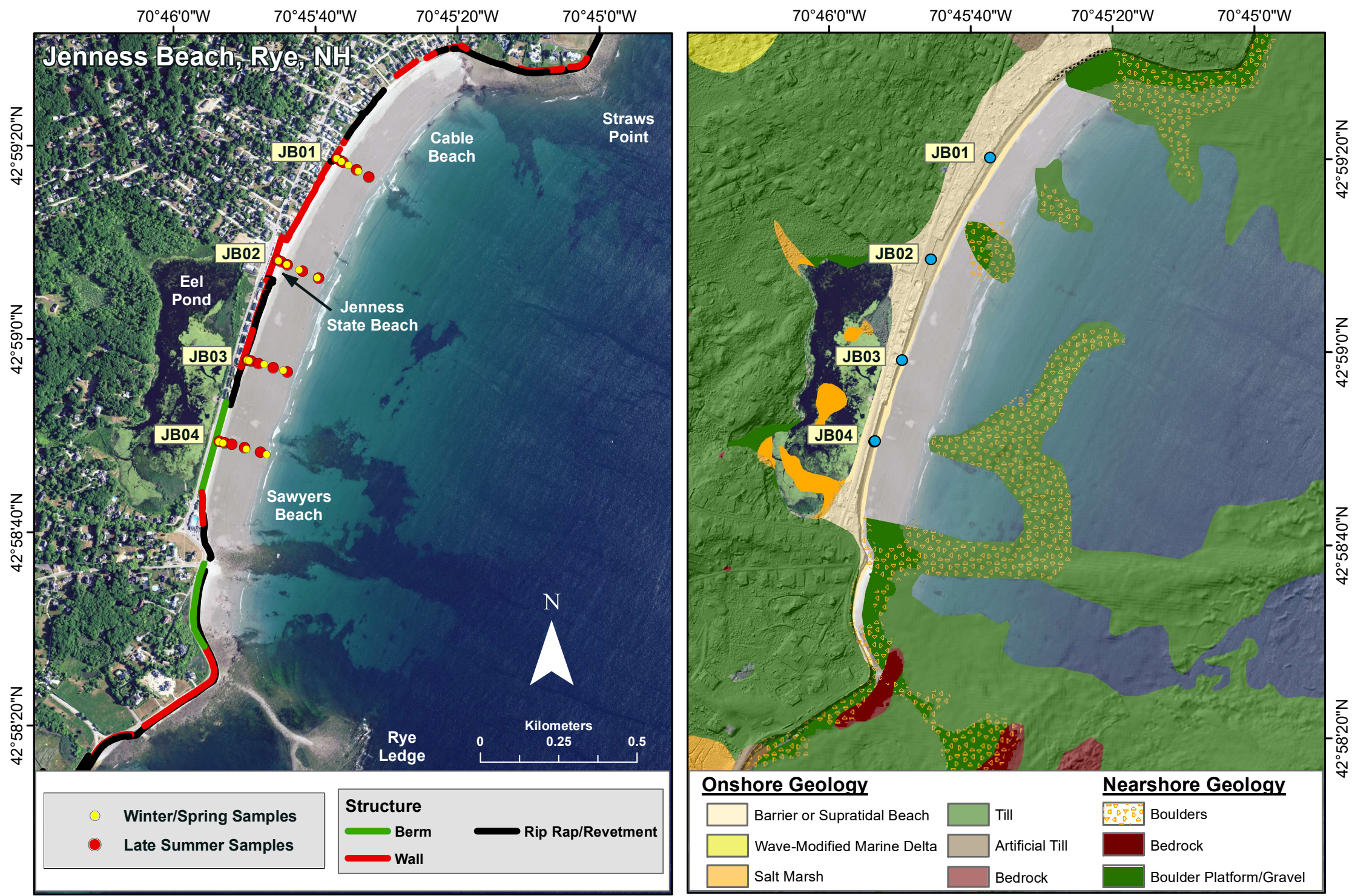

Figure JB-1. Station locations and shoreline structures (from Blondin, 2016) (left) and surficial geology of the upland (modified from NHGS digital series) and nearshore shelf (modified from Ward et al., 2021a) (right) at Jenness Beach, Rye, NH. The nearshore seafloor not mapped (satellite imagery) is predominantly sand (right). 

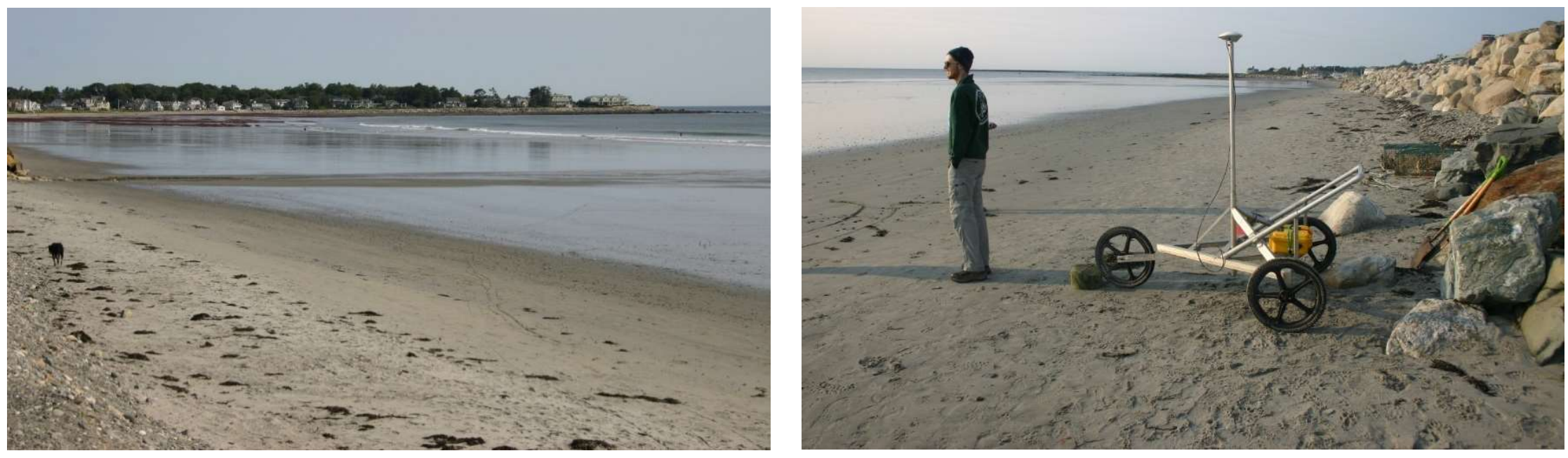

Figure JB-2. Jenness Beach looking north (left photograph) and looking south (right photograph) from station JB04 on September 11, 2017. The headlands at both ends of Jenness Beach interrupt longshore sediment transport, restricting sediment movement to onshore and offshore.

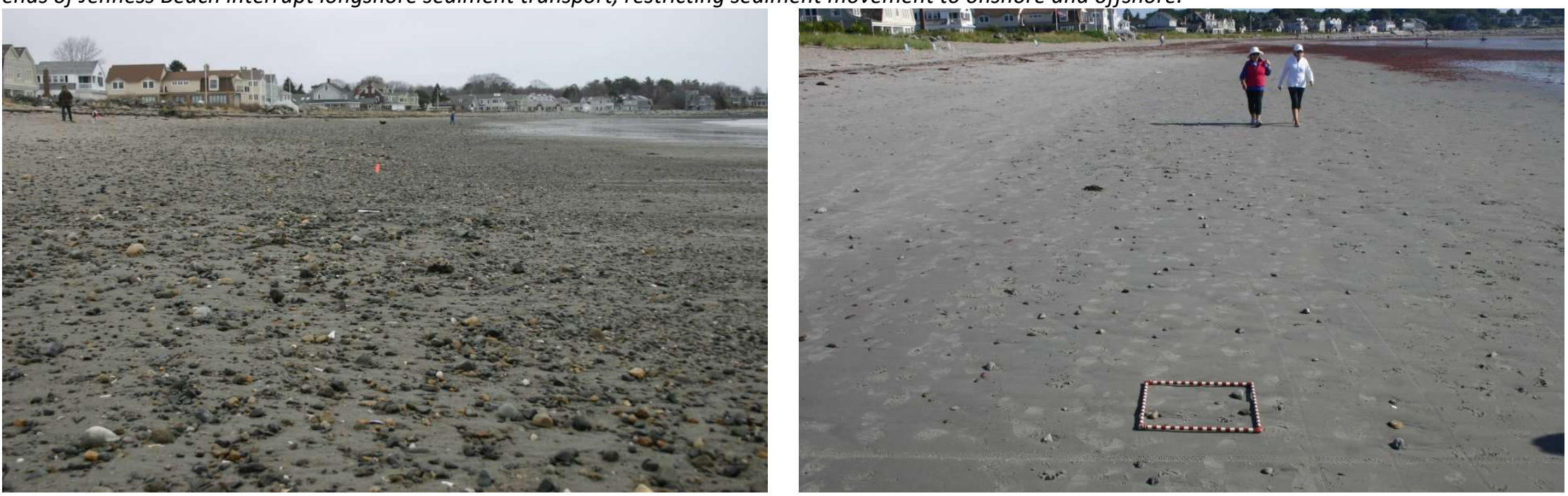

Figure JB-3. Jenness Beach looking north on March 28 (left photograph) and on September 9, 2017 (right photograph) from station JB01. Note the coarse pebble gravel lag deposit on the beach following a series of winter storms in March. The gravel lag was buried with sand at the end of the summer accretional period in September. 

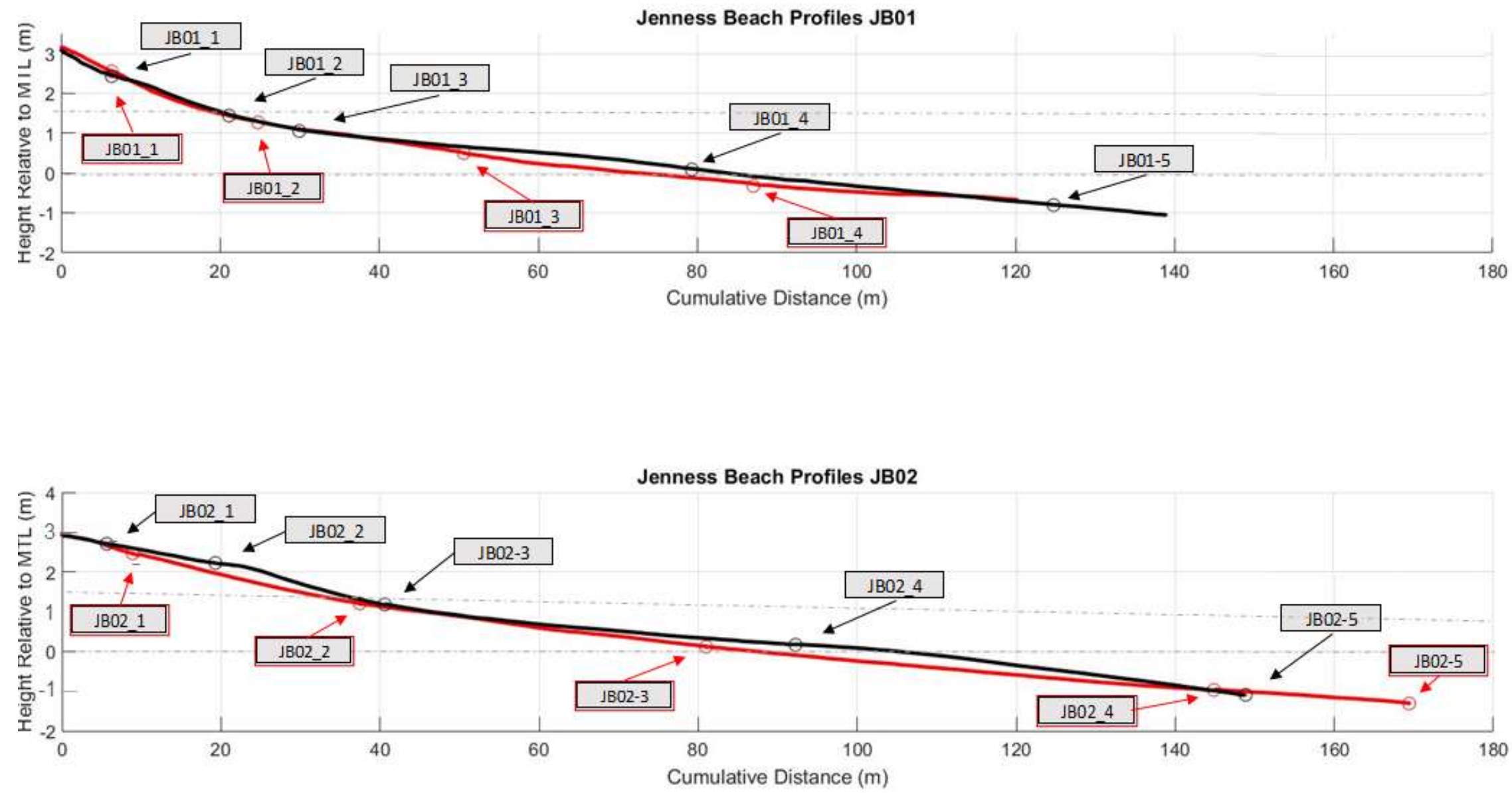

Figure JB-4a. Beach profiles and sediment sample locations from winter and late summer 2017 for stations JB01 and JBO2 at Jenness Beach, NH. Both profiles were run and sediment sampled on March 28 (red lines/circles/boxes) and September 9 (black lines/circles/boxes). 

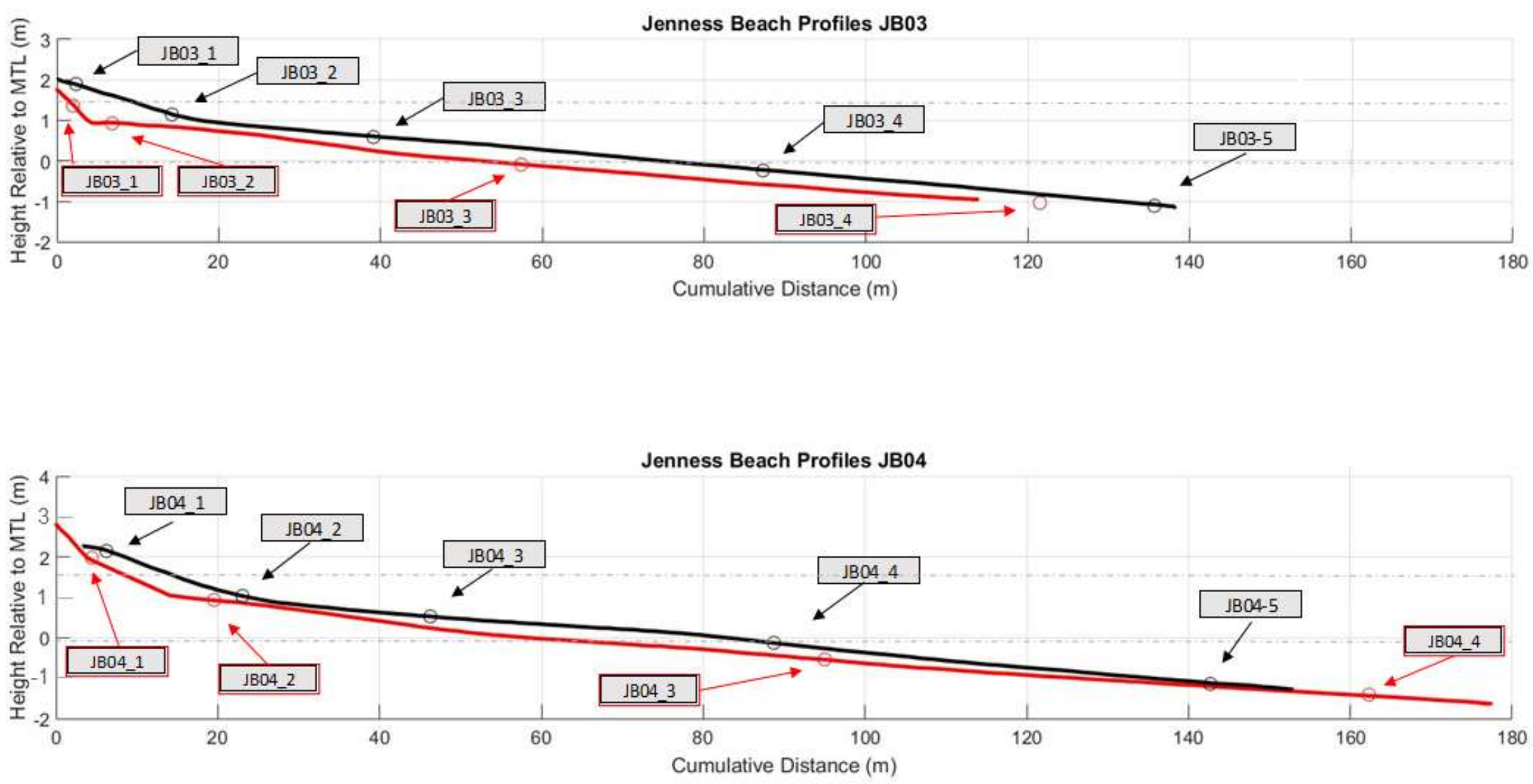

Figure JB-4b. Beach profiles and sediment sample locations from winter and late summer 2017 for stations JB03 and JB04 at Jenness Beach, NH. Both profiles were run and sediment sampled on March 29 (red lines/circles/boxes) and September 11 (black lines/circles/boxes). 

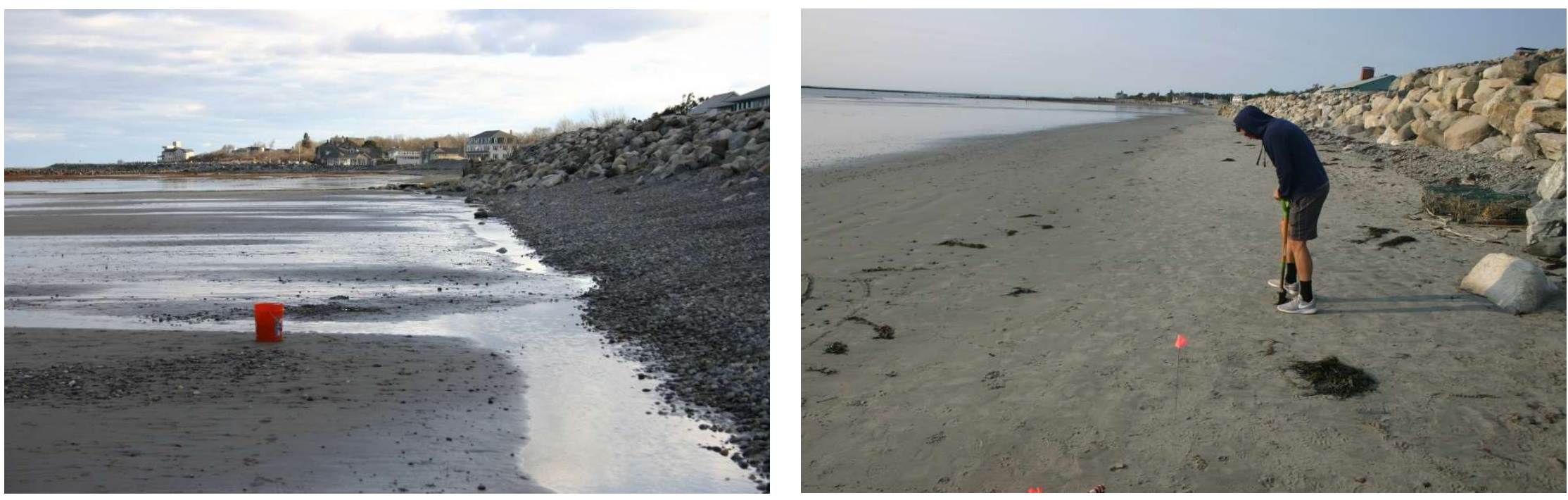

Figure JB-5. Jenness Beach looking south from station JB03 on March 29 (left photograph) and September 11, 2017 (right photograph). Note the gravel ramp exposed after erosion in March is buried with sand at the end of the summer.
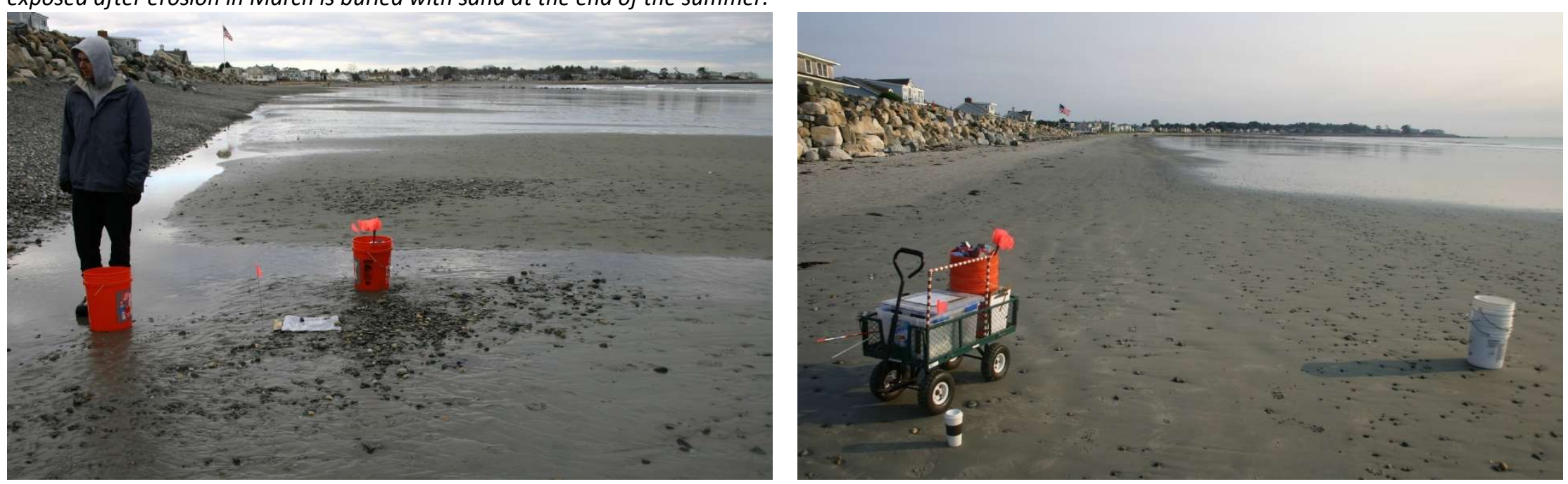

Figure JB-6. Jenness Beach looking north from station JB03 on March 29 (left photograph) and September 11, 2017 (right photograph). Note the gravel ramp exposed after erosion in March is buried with sand at the end of the summer. 
Beach Sediments. The sediment at Jenness Beach was relatively uniform alongshore between stations, but varied at individual stations between the upper beach landward of the low terrace and the mid and lower beach. The upper beach sediments ranged from very poorly sorted bimodal slightly pebbly medium sand to sandy pebble gravel during the March 2017 sampling period (Table JB-1). The mid and lower beach ranged from unimodal poorly to very poorly sorted granuley fine sand to pebbly fine sand, reflecting the general transition to finer-grained sediment on the low tide terrace. Following the summer and early fall accretional period the sediment was finer overall, but still showed differences between the upper and lower beach. In September 2017, most sediments in the upper beach ranged from medium to well sorted unimodal slightly pebbly fine sand, to slightly granuley medium sand. The lower beach ranged from slightly granuley fine sand to slightly pebbly fine sand.

The similarity in sediment characteristics alongshore and across-shore allowed the grain size statistics to be pooled and analyzed to look at changes between winter and summer periods at a station, as well as across-shore trends based on elevation (upper tidal beach, mid tidal beach, and the lower tidal beach).

Comparing the average grain statistics by station for all samples collected in March to those collected in September showed a major fining (Table JB-2). The increase at each station ranged from 1.2 phi (JB02) to 2.2 phi (JB03). This significant shift was due to a thin accretional layer of fine-grained sand being deposited across the entire beach. The decrease in grain size is obvious when examining the grain size distribution (Figure JB-7). All four stations showed a shift from a wide distribution with modes ranging from sand to gravel in March, to a more uniform distribution with a single mode in the fine sand range in September. Nevertheless, the size distribution still extended into the gravel range as a significant pebble population remained.

Overall, the large decrease in grain size was largely driven by the deposition of fine sand on the mid and upper beach. Comparison of the change in grain size between sampling periods showed that the upper tidal beach increased by $0.9 \mathrm{phi}$, the mid tidal beach increased by $0.8 \mathrm{phi}$, and the lower tidal beach by only 0.3 phi (Table JB-3). In addition, the sorting improved significantly at each elevation. This is also obvious in the grain size distributions for the pooled samples (Figure JB-8). The upper tidal and mid tidal beach both have a large gravel population in March with clasts in the -5 to -6 phi range. This population was greatly reduced in September and a more uniform distribution emerged due to the fine-grained sand wedge that developed. The lower beach showed only a modest change.

In summary, Jenness Beach is composed of bimodal sediment. Typically, fine to medium sand covers the beach surface during accretional periods. However, after storms when the beach has been eroded and the veneer of sand removed, the beach is frequently characterized by pebble lag deposits, especially on the mid and lower beach. The source of coarse material is likely the headlands that bound Jenness Beach, which are composed of eroded glacial tills and provide abundant gravel. 
Table JB-1. Grain size statistics for all samples collected at Jenness Beach, NH in 2017. More complete summaries of samples are given in Appendix E.

\begin{tabular}{|c|c|c|c|c|c|c|c|c|c|c|c|c|c|c|c|c|c|c|c|c|c|}
\hline $\begin{array}{c}\text { Sample } \\
\text { ID } \\
\end{array}$ & $\begin{array}{c}\text { Latitude } \\
\text { WGS84 }\end{array}$ & $\begin{array}{c}\text { Longitude } \\
\text { WGS84 }\end{array}$ & $\begin{array}{c}\text { Sample } \\
\text { Collected }\end{array}$ & $\begin{array}{c}\text { Sample } \\
\text { Wt. (gms) }\end{array}$ & $\begin{array}{c}\text { Morphologic } \\
\text { Feature } \\
\end{array}$ & $\begin{array}{c}\text { Sediment } \\
\text { Name }\end{array}$ & $\begin{array}{c}\text { Sediment } \\
\text { Classification }\end{array}$ & Sorting & $\begin{array}{c}\text { Gravel } \\
\%\end{array}$ & \begin{tabular}{|c|}
$\begin{array}{c}\text { Pebble } \\
\%\end{array}$ \\
\end{tabular} & $\begin{array}{c}\begin{array}{c}\text { Granule } \\
\%\end{array} \\
\end{array}$ & $\begin{array}{c}\text { Sand } \\
\%\end{array}$ & $\begin{array}{c}\text { Mud } \\
\%\end{array}$ & $\begin{array}{c}\text { Mode } \\
\text { Abbrev. }\end{array}$ & $\begin{array}{c}\text { Mode } \\
1 \text { (phi) } \\
\end{array}$ & $\begin{array}{l}\text { Mode } \\
2 \text { (phi) } \\
\end{array}$ & $\begin{array}{c}D_{10} \\
\text { (phi) }\end{array}$ & $\begin{array}{c}\mathrm{D}_{50} \\
\text { (phi) } \\
\end{array}$ & $\begin{array}{l}\text { Mean } \\
\text { (phi) }\end{array}$ & $\begin{array}{c}\text { Sorting } \\
\text { (phi) }\end{array}$ & $\begin{array}{c}\text { Skew- } \\
\text { ness }\end{array}$ \\
\hline JB01-1 & 42.988705 & -70.760126 & 28-Mar-17 & $14,751.00$ & S. Ramp; LHTS & Pebbly Medium Sand & Coarse Sand & VPS & 16.62 & 16.15 & 0.47 & 83.36 & 0.02 & B & 1.75 & -5.74 & -5.56 & 1.41 & 0.36 & 2.41 & -0.71 \\
\hline JB01-2 & .988624 & 0.759929 & 28-Mar-17 & $16,064.50$ & S.-P. Ramp: Lower & Sandy Pebble Gravel & Granule Gravel & VPS & 0.08 & 41.58 & 8.49 & 49.90 & 0.02 & B & 1.75 & -3.24 & -4.92 & -1.01 & -1.22 & 2.69 & -0.12 \\
\hline JB01-3 & .988511 & 70.759652 & 28-Mar-17 & $6,257.00$ & LT; Upper & Granular Fine Sand & Coarse Sand & VPS & 29.58 & 18.13 & 11.45 & 70.40 & .02 & u & 24 & $N / A$ & -2.93 & 0.46 & 0.13 & .05 & -0.26 \\
\hline JB01-4 & 988352 & 0.759260 & 28-Mar-17 & $4,448.70$ & LTT; Mid & ranular Fine Sand & Medium Sand & PS & 4.14 & 7.96 & 6.18 & 85.81 & 0.05 & u & 24 & $N / A$ & -1.65 & 1.42 & 1.08 & .67 & -0.38 \\
\hline JB01-1 & 38702 & 22 & ep-17 & 638.9 & Ramp; LHTS & . Pebbly $\mathrm{F}$ & ne Sand & $\mathrm{M}$ & .66 & 1.57 & .09 & 98.33 & 0.01 & & .74 & $\mathrm{~N} / \mathrm{A}$ & 1.05 & 2.12 & 2.06 & 0.73 & -0.18 \\
\hline JB01-2 & .988638 & -70.759962 & 9-Sep-17 & $15,845.7$ & Ramp; Lower & Pebbly Fine Sand & Coarse Sand & VPS & 27.52 & 22.69 & 4.84 & 72.45 & 0.03 & B & 2.74 & -3.24 & -3.84 & 1.35 & 0.37 & 2.64 & -0.53 \\
\hline JB01-3 & .988599 & -70.759867 & 9-Sep-17 & $4,963.7$ & ᄂTT: Upper & Sandy Pebble Gravel & V. Coarse Sand & VPS & 35.86 & 27.30 & 8.57 & 64.11 & 0.03 & B & 2.74 & -3.24 & -3.64 & 0.32 & -0.04 & 2.54 & -0.23 \\
\hline JB01-4 & 988385 & -70.759338 & 9-Sep-17 & $3,156.1$ & LTT: Mid & SI. Granular Fine Sand & Fine Sand & MS & 1.92 & 0.65 & 1.27 & 98.04 & 0.04 & u & 74 & N/A & 0.87 & 2.53 & 2.26 & .86 & -0.52 \\
\hline JB01-5 & 88184 & -70.758851 & 9-Sep-17 & $2,835.0$ & LTT: Lower & Sand & ne Sand & PS & 4.04 & 1.50 & 2.54 & 95.92 & 0.04 & u & 74 & N/A & 0.09 & 2.51 & 2.07 & 19 & -0.5 \\
\hline$J B 02-1$ & 35737 & 0.762319 & 28-Mar-17 & $2,850.20$ & S. Ramp; LHTS & Pebbly Me & Medium Sand & $\mathrm{MW}$ & .08 & 0.0 & 0.01 & 99.9 & 0.02 & 4 & 1.15 & N/A & 1.1 & 1.84 & 1.84 & $0.3=$ & 0.05 \\
\hline JBO2-2 & 885639 & -70.7 & 28-Mar-17 & $19,525.80$ & $\mathrm{mp}$ : Bound. with LTT & Sandy Pebble Gravel & V. Coarse Sand & VPS & 43.79 & 40.48 & 3.31 & 56.18 & $0 . c$ & 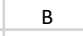 & 1.75 & -4.73 & -4 & 0.54 & -0. & 2.8 & -0.5 \\
\hline JB02-3 & 42.985485 & -70.761503 & 28-Mar-17 & $10,381.10$ & LTT; Mid & Pebbly Medium Sand & Coarse Sand & VPS & 26.81 & 22.28 & 4.54 & 73.16 & 0.0 & E & 1.25 & -3.74 & -3 . & 1.02 & 0.08 & 2.44 & -0.5 \\
\hline JB02-4 & .985264 & -70.760780 & 28-Mar-17 & $3,779.60$ & LTT; Lower & SI. Granular Fine Sand & Medium Sand & PS & 2.87 & 1.55 & 1.32 & 97.09 & 0.0 & u & 74 & N/A & 0.54 & 2.20 & 1.99 & 1.03 & -0.35 \\
\hline JB02-1 & 748 & 356 & $5 \quad 9$-Sep-17 & 65.8 & S. Ramp & I. Granula & ledium Sand & MWS & 0.03 & 0.00 & р3 & 9.93 & 0.0 & $u$ & 75 & $\mathrm{~N} / \mathrm{A}$ & 1.23 & 1.97 & 1.9 & .54 & 0.0 \\
\hline JBO2-2 & .985700 & -70.762202 & 9-Sep-17 & $2,370.7$ & erm Crest; LHTS & Pebb & Fine Sand & ws & 0.09 & 0.07 & 0.01 & 99.85 & 0.0 & $u$ & 2.74 & N/A & 2.03 & .54 & 2.52 & 40 & -0.15 \\
\hline JB02-3 & 1.985626 & -70.761961 & 9-Sep-17 & $5,339.7$ & erm Toe; $L T$ & Sandy Pebble Gravel & V. Coarse Sand & VPS & 32.75 & 31.10 & 1.64 & 67.22 & 0.03 & B & .74 & -3.24 & -4.36 & 1.10 & -0.01 & .80 & -0.52 \\
\hline JBO2-4 & .985449 & -70.761375 & 9-Sep-17 & $3,419.3$ & LTT: Mid & SI. Pebbly Fine Sand & Fine Sand & MS & 4.41 & 3.54 & 0.87 & 95.55 & 0.04 & 6 & 74 & N/A & 1.06 & 2.43 & 2.29 & .88 & -0.47 \\
\hline JBO2-5 & .985254 & -70.760734 & 9-Sep-17 & $4,393.9$ & LTT: Lower & Granular Fine Sand & Medium Sand & PS & 9.29 & 5.28 & 4.01 & 90.69 & 0.02 & u & 2.74 & N/A & -0.85 & 1.93 & 1.61 & .43 & -0.4 \\
\hline JB03-1 & 82856 & -70.763455 & 29-Mar-17 & $16,145.10$ & Ramp & Pebble Gravel & Pebble Gravel & $P$ & 6.19 & 83.6 & 2.57 & 13.80 & 0. & e & 3.74 & N/A & -4.75 & -3.59 & -3.3 & 1.8 & 0.4 \\
\hline JB03-2 & 982844 & -70.763397 & 29-Mar-17 & $16,159.50$ & Start LTT - Low Tide & Pebbly Fine Sand & Coarse Sand & VPS & 23.69 & 22.48 & 1.21 & 76.2 & 0.0 & the & 2.2 & -3.24 & -3.58 & 2.1 & 0.6 & 2.52 & $-0.7 \mathrm{~s}-\mathrm{x}=\mathrm{x}$ \\
\hline JB03-3 & .982734 & -70.762795 & 29-Mar-17 & $6,627.10$ & Mid LTT - Low Tide & Pebbly Fine Sand & Medium Sand & PS & 4.78 & 13.6 & 1.16 & 85.1 & 0.0 & $u$ & 2.24 & N/A & -3.1 & 2.1 & 1.7 & 1.62 & -0.6 \\
\hline JB03-4 & 2581 & 0.762037 & 29-Mar-17 & $3,656.80$ & ater Line - & Pebt & and & VPS & 22.50 & 18.7 & 3.75 & 77.4 & 0.0 & $u$ & 2.24 & N/A & -3.5 & 1.9 & 0.69 & 2.39 & -0.71 \\
\hline JB03-1 & 982855 & -70.763449 & 7) $11-$ Sep-17 & $2,719.9$ & S. Ramp; LHTS & SI. Pebbly & Sand & W & 31 & 0. & 0.00 & 99.66 & 0.03 & $\mathrm{c}$ & .24 & N/A & 1.88 & $.4 C$ & .43 & 0.41 & -0.02 \\
\hline JB03-2 & .982827 & -70.763307 & 11-Sep-17 & $5,623.0$ & Ramp Toe; ПT: Upper & SI. Pebbly Fine Sand & ne Sand & MS & 3.60 & 2.80 & 80 & 96.35 & 0.0 & $\mathrm{u}$ & 2.74 & $\mathrm{~N} / \mathrm{A}$ & 1.38 & 2.56 & 2.43 & .72 & -0.4 \\
\hline JB03-3 & 982768 & -70.763013 & 3 11-Sep-17 & $3,143.2$ & LTT: Upper to Mid & SI. Granular Fine Sand & ine Sand & ws & 0.18 & 0.08 & 0.10 & 99.79 & 0.03 & 4 & 74 & N/A & 1.81 & 2.51 & 2.48 & .46 & -0.15 \\
\hline JB03-4 & 982653 & -70.762443 & 3 11-Sep-17 & , 050.8 & T: Mid & SI. Pebbly Fine Sand & e Sand & MWS & 1.29 & .90 & 39 & 98.69 & 0.02 & 4 & 74 & N/A & 1.66 & 2.48 & 2.44 & .53 & $-0.2 C$ \\
\hline JB03-5 & 2538 & 761872 & -Sep-17 & 191.9 & LTT: Lower & sand & and & $\mathrm{N}$ & 30 & 4.10 & 20 & 4.68 & 0.02 & & & N/A & 1.09 & 36 & 2.26 & .00 & -0.4 \\
\hline JB04-1 & 0488 & 07 & $r-17$ & & G. Ramp & Sandy Pebble Gravel & Gravel & VPS & 3.59 & 5 & 96 & 3 & 0.0 & 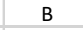 & $-4.8 \quad \gamma$ & 1.15 & -4.53 & -2.59 & -1.14 & 2.Jo & 0.3 \\
\hline JB04-2 & 80456 & -70.764327 & 7 29-Mar-17 & $11,899.60$ & Start LTT - Low Tide & andy Pebble Gravel & Coarse Sand & VPS & 34.75 & 32.87 & 1.88 & 65.2 & 0.0 & t & 2.24 & -3.24 & -4.03 & 1.95 & 0.30 & 2.65 & $-0.7 \varepsilon$ \\
\hline JB04-3 & 0306 & 63425 & 29-Mar-17 & 2.60 & Mid LTT - Low Tide & $P^{P}$ & Sand & PS & 12.99 & 11. & 1.83 & 86.97 & 0.0 & 4 & 2.14 & N/A & -2.46 & 2.44 & .12 & .60 & -0.6 \\
\hline JB04-4 & 3 & 23 & 29-Mar-17 & $3,567.50$ & Vater Line - 1 & & sand & $P$ & & & & & 0.0 & & & $\mathrm{~N} / \mathrm{A}$ & 1. & .49 & 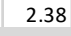 & U1 & -0 \\
\hline $\mathrm{JB}$ & & & 91 & 3.0 & S. Ra & nd & & w & & & & 99. & & & & N/A & 1.75 & 38 & 41 & 3 & -0.02 \\
\hline JB04-2 & 475 & -70.7 & ep-17 & $4,888.5$ & S. Ramp Toe; LTT: Upper & nd & and & PS & 66 & 5.59 & & 31 & 0.03 & $\iota$ & & I/A & 1.69 & 2.59 & 2.53 & 26 & -0.51 \\
\hline JB04-3 & 26 & -70.76 & -17 & & nid & nd & nd & v & & & & 12 & 0.03 & $u$ & & /A & 1.78 & 2.54 & 2.49 & 46 & -0.21 \\
\hline $\mathrm{JB}$ & & -70 & & & Mid & & & MWS & & 62 & & & 0.03 & 4 & & I/A & 1.66 & 2.46 & 2.43 & .52 & -0.17 \\
\hline JB04-5 & 223 & 0.762853 & ep-17 & 3.6 & wer & Sand & e Sand & MS & 86 & 3.64 & 1.2 & 95.11 & 0.03 & u & 2.24 & J/A & 1.04 & 2.25 & 2.19 & 0.93 & -0.37 \\
\hline
\end{tabular}



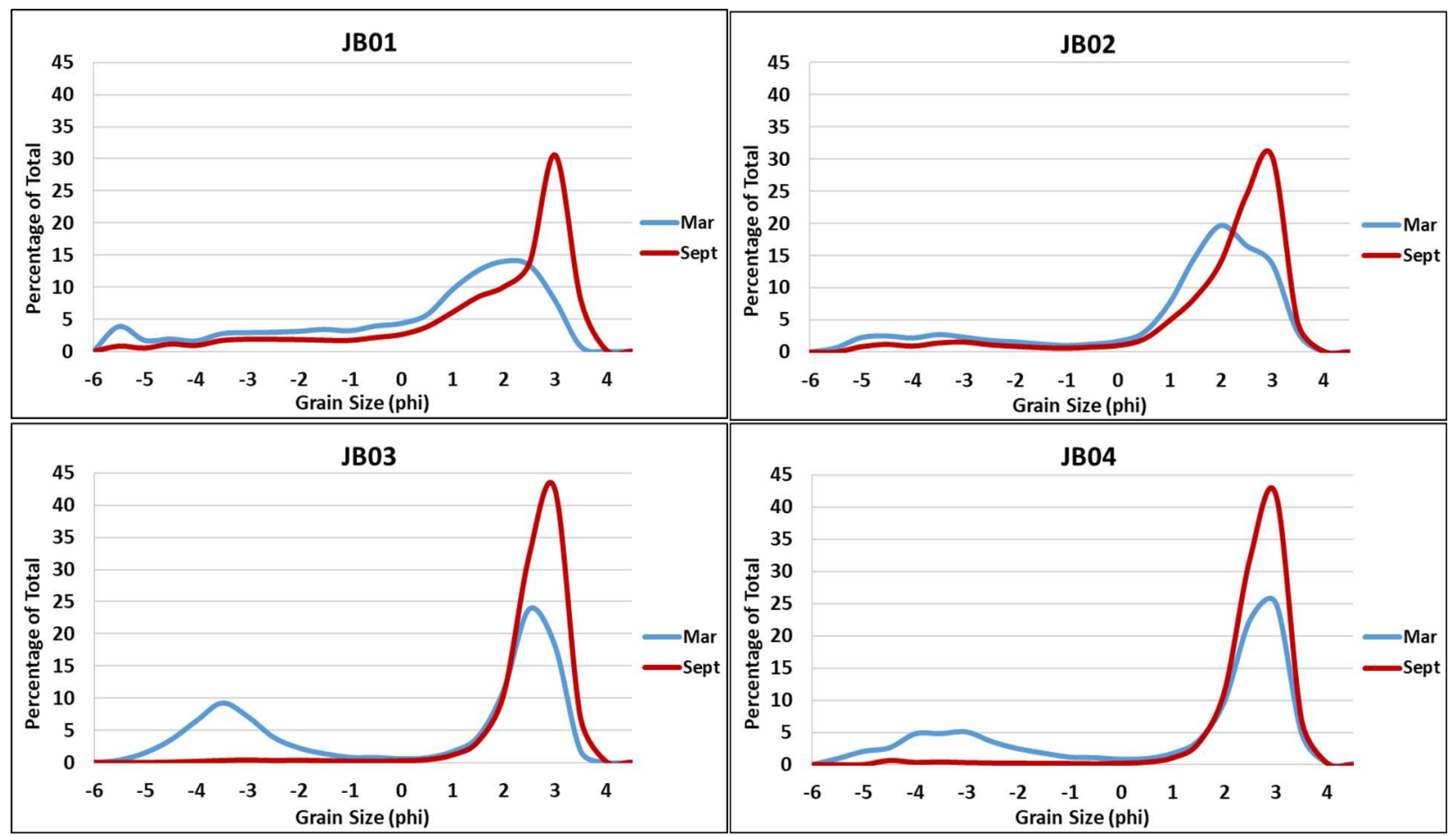

Figure JB-7. Average grain size distributions for each of the Jenness Beach stations in March (blue) and September (red) 2017, pooled for a station for each time period.

Table JB-2. Average grain size statistics for the pooled sediment samples for each of the cross-beach transects at Jenness Beach in March and September 2017. The average for each beach and season (winter erosive beach and summer accretional beach) is based on pooling all data from that station ( $n$ ).

\begin{tabular}{|c|c|c|c|c|c|c|c|c|}
\hline & \multicolumn{2}{|c|}{ JB01 } & \multicolumn{2}{|c|}{ JB02 } & \multicolumn{2}{|c|}{$\mathrm{JB} 03$} & \multicolumn{2}{|c|}{ JB04 } \\
\hline & Winter & Summer & Winter & Summer & Winter & Summer & Winter & Summer \\
\hline & $n=4$ & $n=5$ & $n=4$ & $n=5$ & $n=4$ & $n=5$ & $n=4$ & $n=5$ \\
\hline Gravel \% & 27.6 & 14.2 & 18.4 & 9.3 & 36.8 & 2.1 & 29.2 & 2.5 \\
\hline Pebble \% & 21.0 & 10.7 & 16.1 & 8.0 & 34.6 & 1.6 & 26.3 & 2.2 \\
\hline Granule \% & 6.6 & 3.5 & 2.3 & 1.3 & 2.2 & 0.5 & 2.9 & 0.4 \\
\hline Sand \% & 72.4 & 85.8 & 81.6 & 90.6 & 63.2 & 97.8 & 70.8 & 97.4 \\
\hline Mud \% & 0.0 & 0.0 & 0.0 & 0.0 & 0.0 & 0.0 & 0.0 & 0.0 \\
\hline Mode 1 (phi) & 2.2 & 2.7 & 1.7 & 2.7 & 2.2 & 2.7 & 2.7 & 2.7 \\
\hline$D_{10}(p h i)$ & -3.8 & -2.2 & -3.6 & -0.5 & -4.2 & 1.6 & -4.0 & 1.6 \\
\hline $\mathrm{D}_{10}(\mathrm{~mm})$ & 14.4 & 4.6 & 11.7 & 1.5 & 17.8 & 0.3 & 16.4 & 0.3 \\
\hline$D_{50}$ median (phi) & 0.9 & 2.1 & 1.6 & 2.2 & 1.7 & 2.5 & 2.1 & 2.5 \\
\hline $\mathrm{D}_{50}$ median $(\mathrm{mm})$ & 0.5 & 0.2 & 0.3 & 0.2 & 0.3 & 0.2 & 0.2 & 0.2 \\
\hline Mean (phi) & 0.1 & 1.5 & 0.7 & 1.9 & 0.2 & 2.4 & 0.5 & 2.4 \\
\hline Mean $(\mathrm{mm})$ & 0.92 & 0.36 & 0.62 & 0.26 & 0.88 & 0.19 & 0.72 & 0.19 \\
\hline Sorting (phi) & 2.45 & 1.88 & 2.27 & 1.46 & 2.72 & 0.56 & 2.70 & 0.56 \\
\hline Skewness (phi) & -0.52 & -0.61 & -0.61 & -0.56 & -0.71 & -0.24 & -0.76 & -0.24 \\
\hline Kurtosis (phi) & 0.98 & 1.35 & 1.80 & 2.08 & 0.55 & 1.23 & 0.64 & 1.22 \\
\hline
\end{tabular}



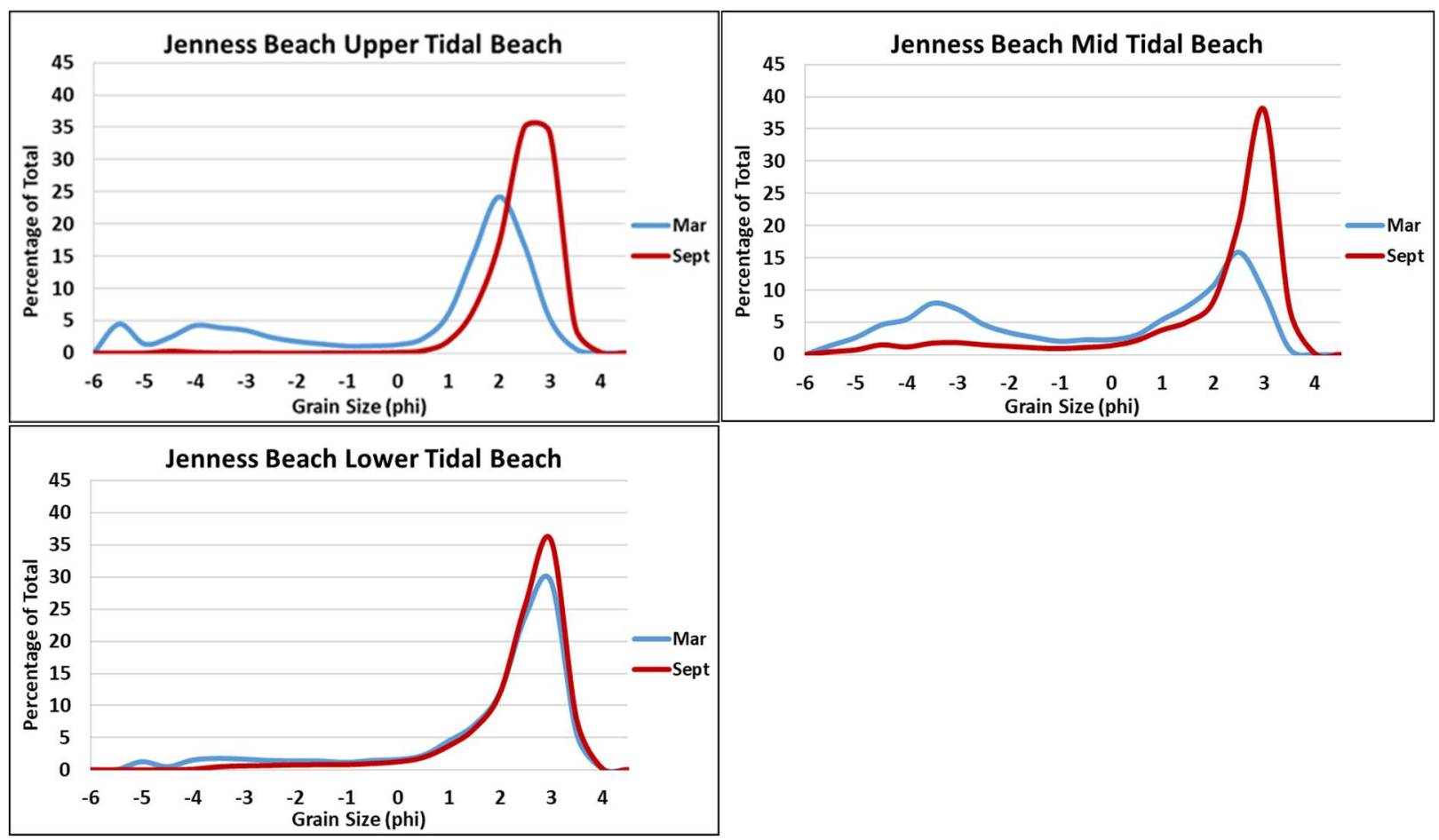

Figure JB-8. Average grain size distribution for the March (blue) and September (red) sediment samples at Jenness Beach, pooled by elevation for each time period. Note the shift to better sorted and finer sediment after the summer accretion period in the upper tidal and mid tidal beach.

Table JB-3. Comparison of average grain size statistics for the samples from Jenness Beach grouped by elevation into Upper Tidal Beach (UTB), Mid Tidal Beach (MTB), and Lower tidal Beach (LTB), and also by late winter (erosive beach) and late summer (accretional beach).

\begin{tabular}{|r|rr|rr|rr|}
\cline { 2 - 7 } & \multicolumn{2}{|c|}{ UTB } & \multicolumn{2}{c|}{ MTB } & \multicolumn{2}{c|}{ LTB } \\
& Winter & Summer & Winter & Summer & Winter & Summer \\
\cline { 2 - 7 } & $\mathrm{n}=3$ & $\mathrm{n}=5$ & $\mathrm{n}=7$ & $\mathrm{n}=9$ & $\mathrm{n}=6$ & $\mathrm{n}=6$ \\
\hline Gravel \% & 26.8 & 0.5 & 42.1 & 12.5 & 12.1 & 4.3 \\
Pebble \% & 24.3 & 0.4 & 37.4 & 10.5 & 9.6 & 2.7 \\
Granule \% & 2.5 & 0.0 & 4.8 & 2.0 & 2.5 & 1.6 \\
Sand \% & 73.2 & 99.5 & 57.8 & 87.4 & 87.8 & 95.7 \\
Mud \% & 0.0 & 0.0 & 0.0 & 0.0 & 0.0 & 0.0 \\
Mode 1 (phi) & 1.7 & 2.2 & 2.2 & 2.7 & 2.7 & 2.7 \\
$\mathbf{D}_{10}$ (phi) & -4.3 & 1.5 & -4.4 & -2.2 & -1.8 & 0.7 \\
$\mathbf{D}_{10}$ (mm) & 19.6 & 0.4 & 20.7 & 4.5 & 3.6 & 0.6 \\
$\mathbf{D}_{50}$ median (phi) & 1.4 & 2.3 & 0.5 & 2.4 & 2.2 & 2.4 \\
D $_{50}$ median (mm) & 0.4 & 0.2 & 0.7 & 0.2 & 0.2 & 0.2 \\
Mean (phi) & 0.0 & 2.3 & -0.4 & 1.8 & 1.7 & 2.2 \\
Mean (mm) & 0.99 & 0.21 & 1.28 & 0.28 & 0.30 & 0.22 \\
Sorting (phi) & 2.63 & 0.56 & 2.71 & 1.71 & 1.66 & 0.97 \\
Skewness (phi) & -0.71 & -0.19 & -0.41 & -0.69 & -0.62 & -0.45 \\
Kurtosis (phi) & 0.88 & 1.03 & 0.59 & 2.04 & 1.87 & 1.59 \\
\hline
\end{tabular}




\section{North Hampton State Beach and Plaice Cove, North Hampton, NH}

North Hampton Beach and Plaice Cove form an attached or welded barrier that extends $1.4 \mathrm{~km}$ from Little Boars Head southward to the headland at the southern extent of Plaice Cove (Figure NHB-1). Although the system is presently a single barrier, it is composed of three very different components including North Hampton State Beach to the north, a tombolo extending from the mid-beach area to Godfreys Ledge, and Plaice Cove to the south. Tuttle (1960) hypothesized that North Hampton State Beach and Plaice Cove were formed further seaward as limbs of a tombolo that connected Godfreys Ledge to the mainland. Over time, the sediment supply provided by the till at Godfreys Ledge diminished and the beach system migrated landward to its present position. North Hampton State Beach (and the small section of beach at the northern end) is $\sim 0.3 \mathrm{~km}$ in length and is strongly influenced by Little Boars Head to the north (Figure NHB-2) and Godfreys Ledge tombolo to the south (Figure NHB-3). Little Boars Head, which is largely composed of unconsolidated glacial till covering bedrock, has been heavily eroded by wave action as evidenced by cobble-boulder or megaclast platforms that surround the headland and extend southward onto North Hampton State Beach (Figures NHB-1 and NHB-2). Overall, much of North Hampton State Beach is adjacent to or is underlain by eroded glacial till deposits, providing an abundant source of cobbles and boulders (Figures NHB-2 and NHB-3).

The sandy beach behind Godfreys Ledge tombolo is also $\sim 0.3 \mathrm{~km}$ in length and bulges seaward (Figures NHB-1 and NHB-3). Most of the beach and tombolo are composed of pebbles, cobbles, and boulders and forms a platform that is exposed at low tide. Under accretional conditions the landward portion of the tombolo and the beach are covered with sand. During periods when the tombolo has been eroded, tree stumps are exposed in the intertidal zone (Figure NHB-4). Plaice Cove beach extends $\sim 0.7 \mathrm{~km}$ from the town boundary separating Hampton and North Hampton to the headland in the south (Figures NHB-1 and NHB-5), which is also composed of glacial till overlying bedrock. Similar to Little Boars Head, the eroded glacial deposits off the southern headland have formed a cobble-boulder platform that makes up the southern end of the beach. Eroded glacial deposits and some bedrock are exposed in the lower intertidal, as well as offshore of Plaice Cove (Figure NHB-1). Unlike North Hampton Beach, which is bimodal with extensive cobble and boulder deposits, Plaice Cove beach is largely sandy with patches of gravel (Figure NHB-5). However, the sand supply appears to be very limited as Plaice Cove is narrow with extensive engineering structures on the landward margin (Figures NHB-1). The entire length of Plaice Cove beach is either riprap revetments or high cement seawalls (Figure NHB-6).

Field Surveys. Three stations were established at North Hampton Beach (Figure NHB-1). Station NHB01 was located in North Hampton State Beach, and NHBO2 and NHBO3 were located in Plaice Cove. North Hampton State Beach is composed of a mixture of pebbles, cobbles, and sand, resulting in very different morphologic and sedimentologic characteristics from Plaice Cove. Stations at Plaice Cove are more uniform and largely composed of sand. Therefore, NHB01 was considered separately from NHB02 and NHB03. Elevation profiles were measured and sediment samples collected at North Hampton Beach on March 31, 2017 at all three stations (NHB01, NHB02, and NHB03) following the winter erosional period. These three stations were sampled again on September 14 to assess the sediment characteristics after a period of accretion. 

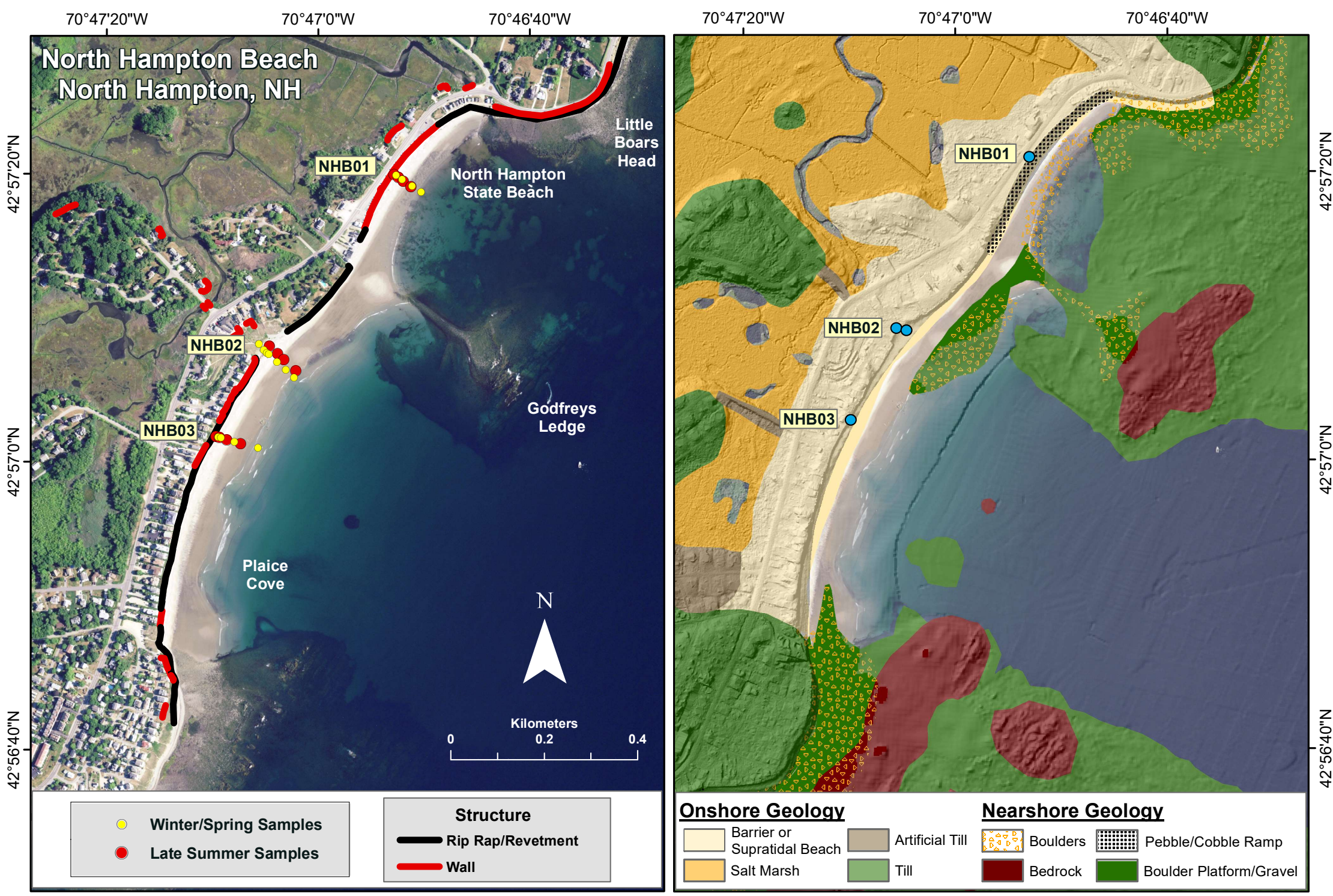

Figure NHB-1. Station locations and shoreline structures (from Blondin, 2016) (left) and surficial geology of the upland (modified from NHGS digital series) and nearshore shelf (from Ward et al., 2021a) (right) at North Hampton Beach, NH. The nearshore seafloor not mapped (satellite imagery) is predominantly sand (right). 


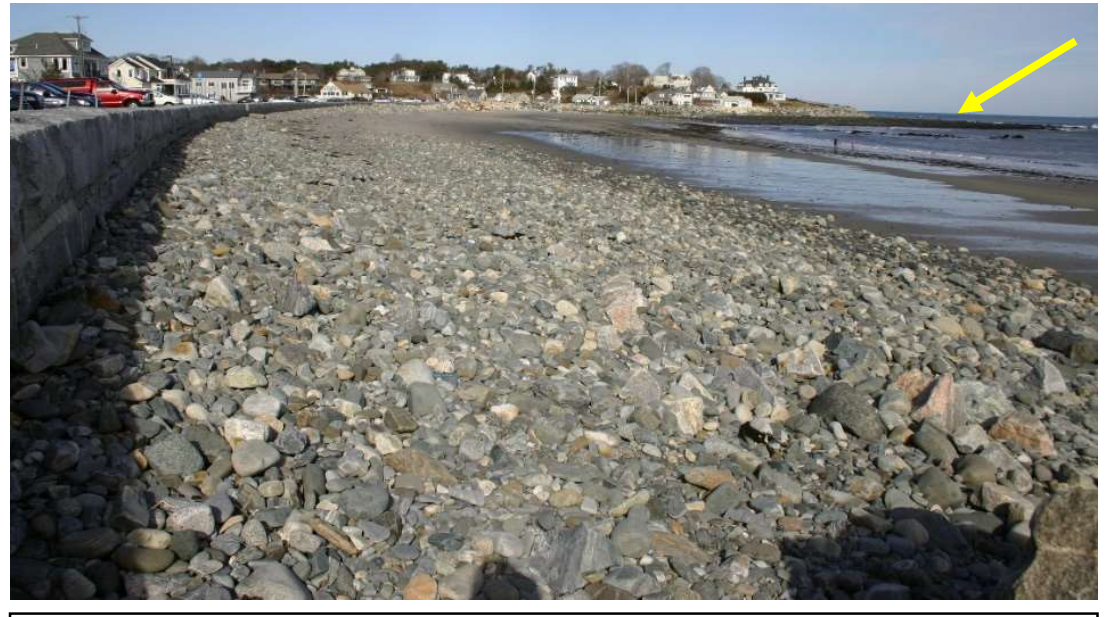

Figure NHB-2. Little Boars Head, which forms the northern extent of North Hampton Beach. The photograph is looking north from North Hampton State Beach on February 26, 2018. Note the pebble and cobble platform extending from the headland (arrow).

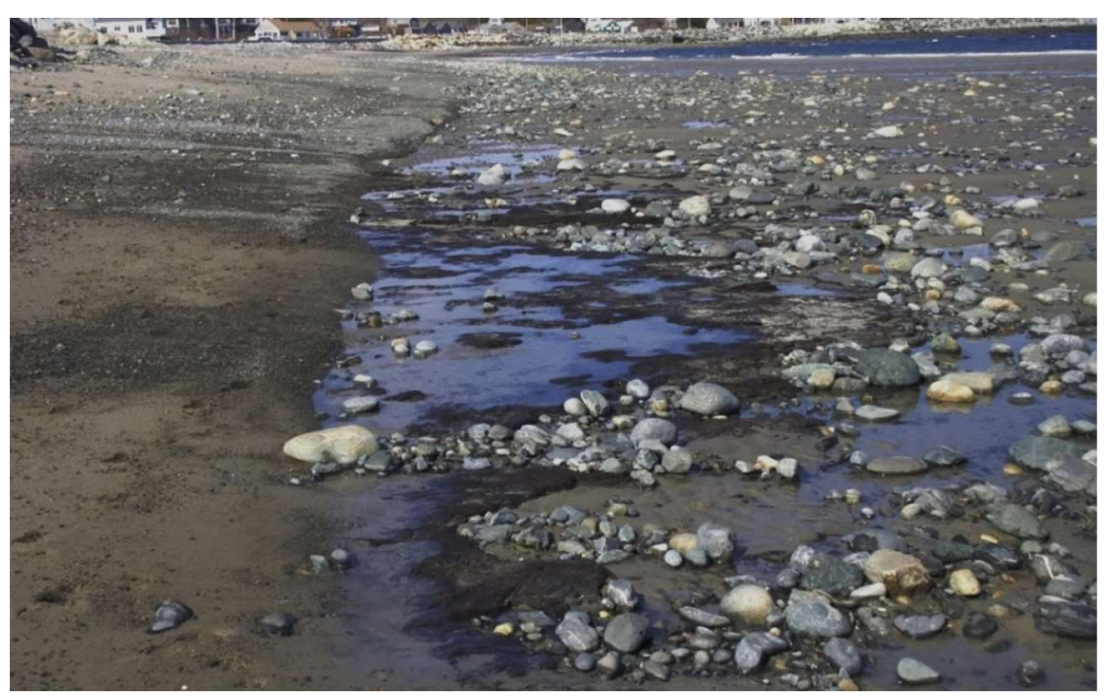

Figure NHB-4. Exposed tree roots uncovered by erosion on Godfreys Ledge tombolo on April 11, 2018. Note sample of the tree stump shown in the inset. 


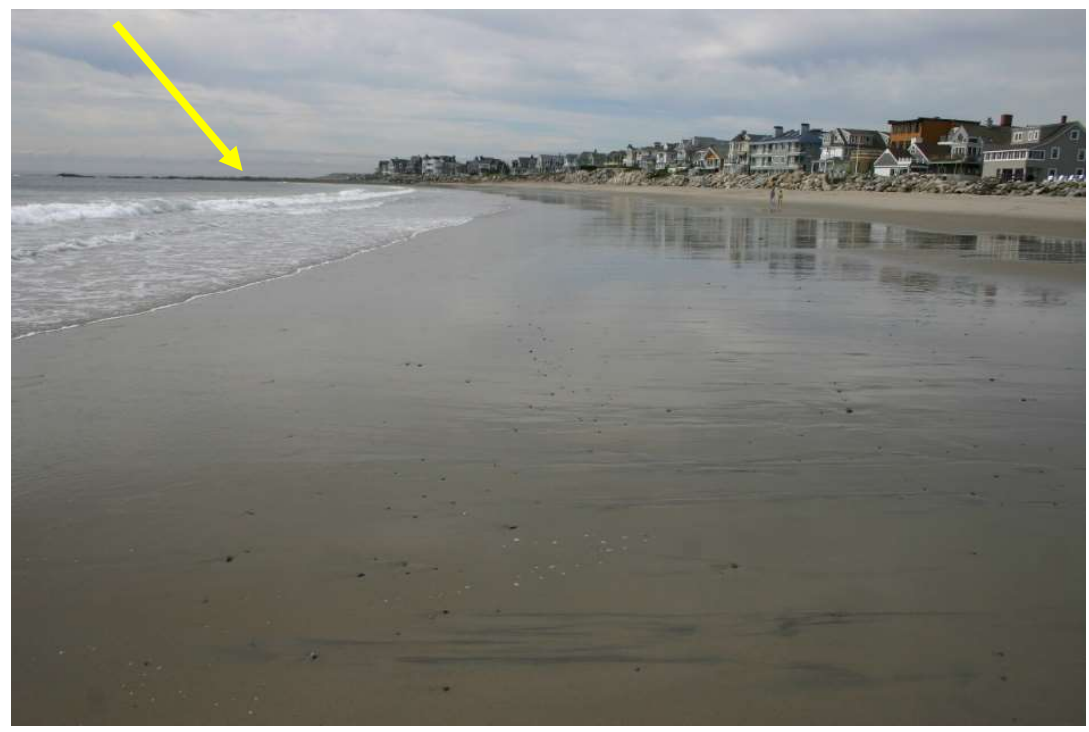

Figure NHB-5. Plaice Cove beach looking south from station NHBO2 on September 14, 2017. The southern headland (arrow) extends seaward prohibiting longshore sediment transport between beaches.

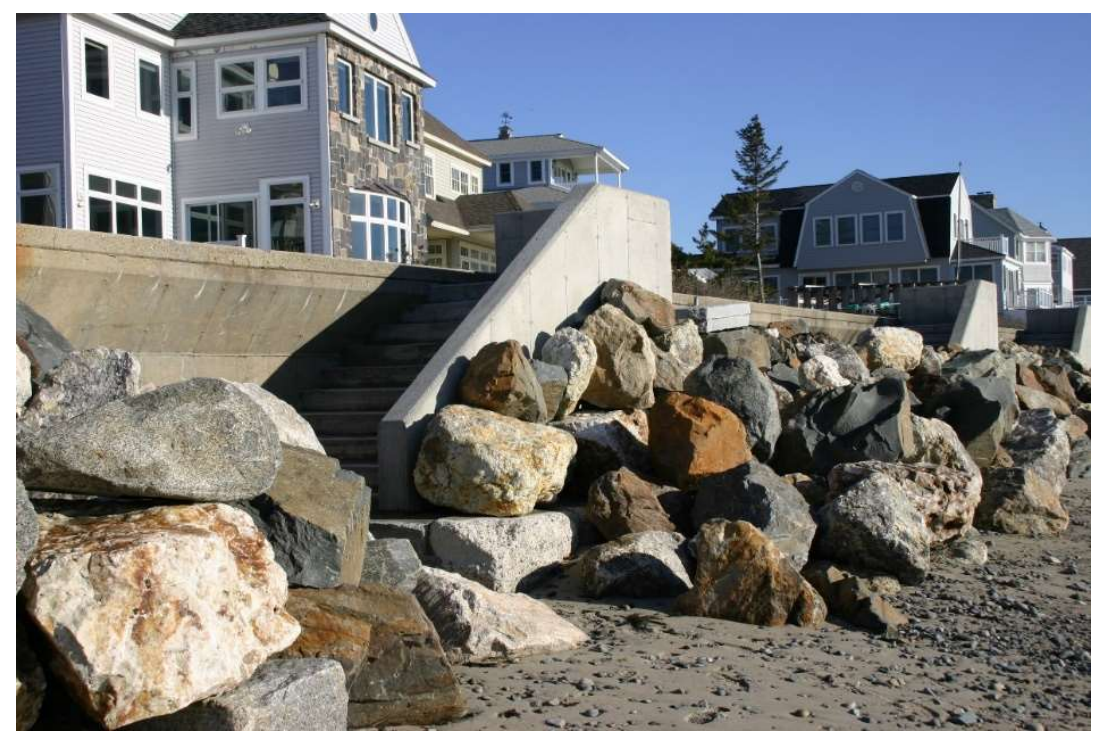

Figure NHB-6. Cement seawall with riprap armoring near station NHBO3. The photograph was taken on March 30, 2017.

Beach Elevation Profiles. All three beach elevation profiles were similar in that they were steep and relatively narrow (Figures NHB-7a and NHB-7b). NHB01 was eroded in March 2017 due to the winter and early spring storms which exposed the gravel underneath. Over a meter of sand was deposited on the upper and mid beach by September (Figures NHB-8 and NHB-9). North Hampton State Beach frequently changes from a gravel to a sandy beach after extended periods of accretion. However, this is typically in the form of a thin veneer of sand that is quickly eroded.

The beach elevation profiles from the two locations on Plaice Cove were eroded on March 31, but rebuilt by the end of the summer. NHBO2 had built a large berm with over a meter of deposition (Figure NHB10). Similarly, NHBO3 was badly eroded in March, but had recovered by fall with over a meter of accretion as well (Figures NHB-11 and NHB-12). The beach elevation profile from NHB03 on September 14 has large gaps in the profile due to loss of satellite signal. However, enough of the profile was recovered to define the elevation and morphology of the beach. 

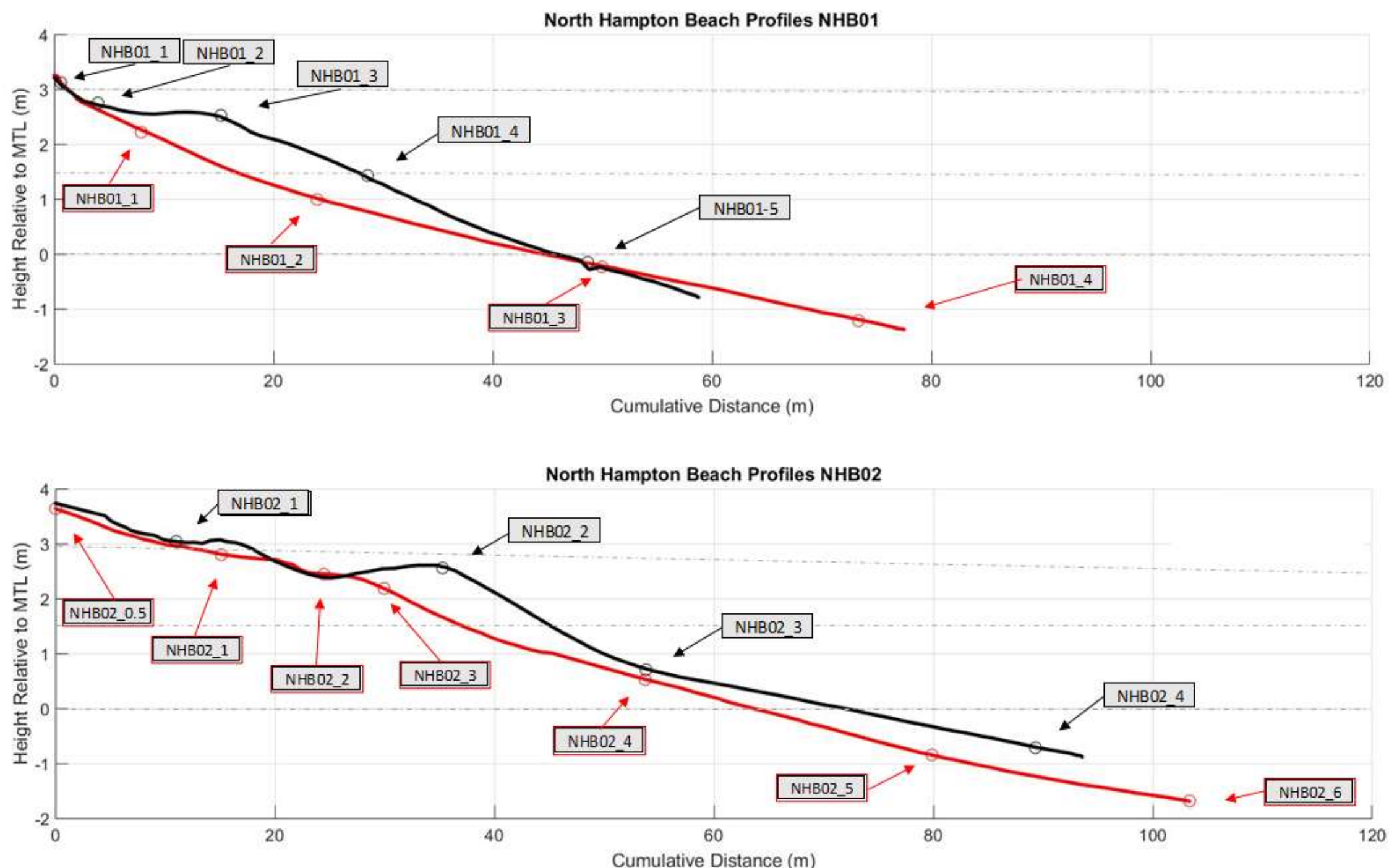

Figure NHB-7a. Beach profiles and sediment sample locations from winter and late summer 2017 for stations NHB01 and NHB02 at Jenness Beach, NH. Both profiles were run and sediment sampled on March 31 (red lines/circles/boxes) and September 13 (black lines/circles/boxes). 


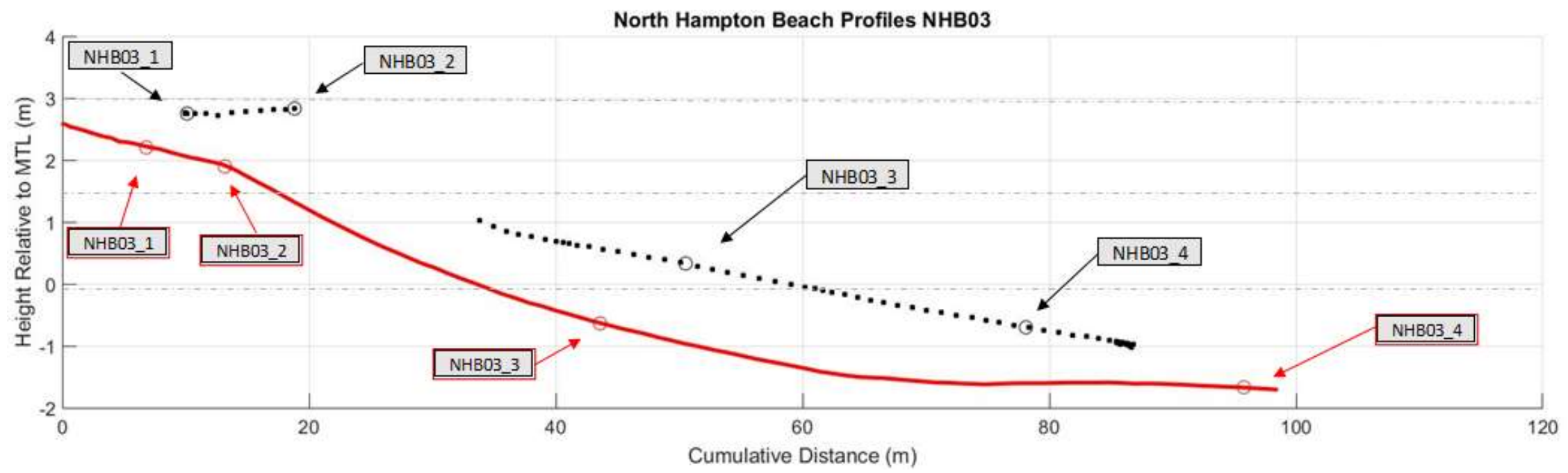

Figure NHB-7b. Beach profiles and sediment sample locations from winter and late summer 2017 for station NHBO3 at North Hampton Beach, NH. The profiles were run and sediment sampled on March 30 (red line/circles/boxes) and September 14 (black dots/circles/boxes). Part of the GNSS record was corrupted and the entire profile was not recovered on September 14. However, enough of the profile was recovered to determine changes to the profile. Also, all sediment sampling stations positions and elevation were determined.
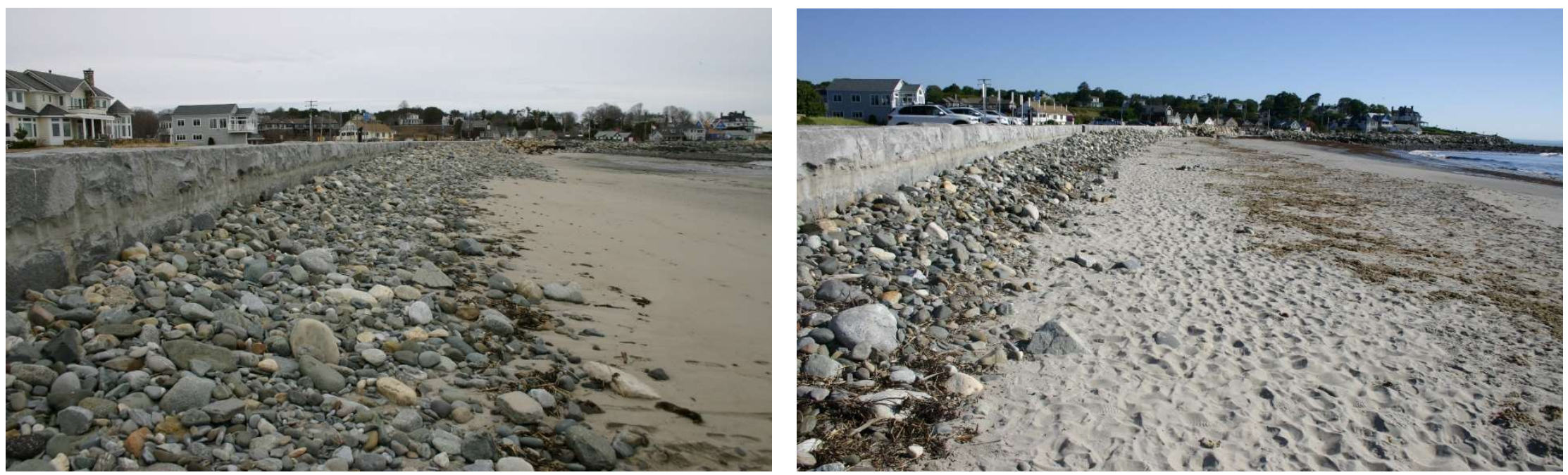

Figure NHB-8. North Hampton State Beach looking north from station NHB01 on March 31 (left photograph) and on September 13, 2017 (right photograph). Note the cobble ramp present formed by winter storms. Most of the cobble ramp was buried by sand at the end of the summer accretional period. 

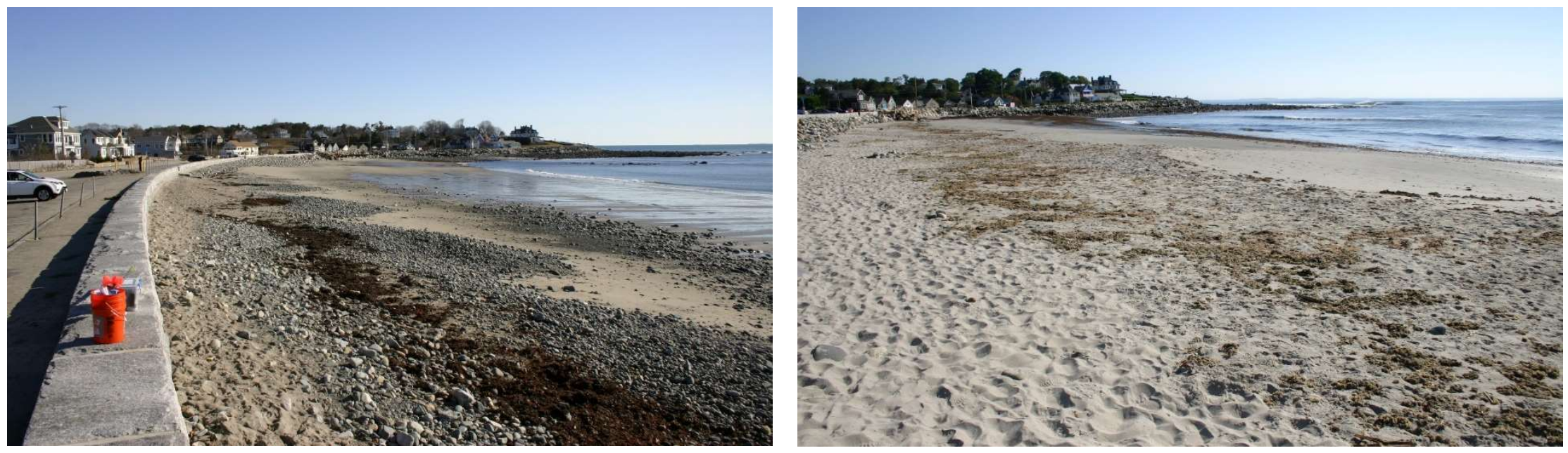

Figure NHB-9. North Hampton State Beach looking north from the southern end on March 31 (left photograph) and on September 13, 2017 (right photograph). Note the gravel cusps and exposed cobbles on the mid beach following a series of winter storms on March 31. Most of the gravel was buried by sand at the end of the summer accretional period on September 13.
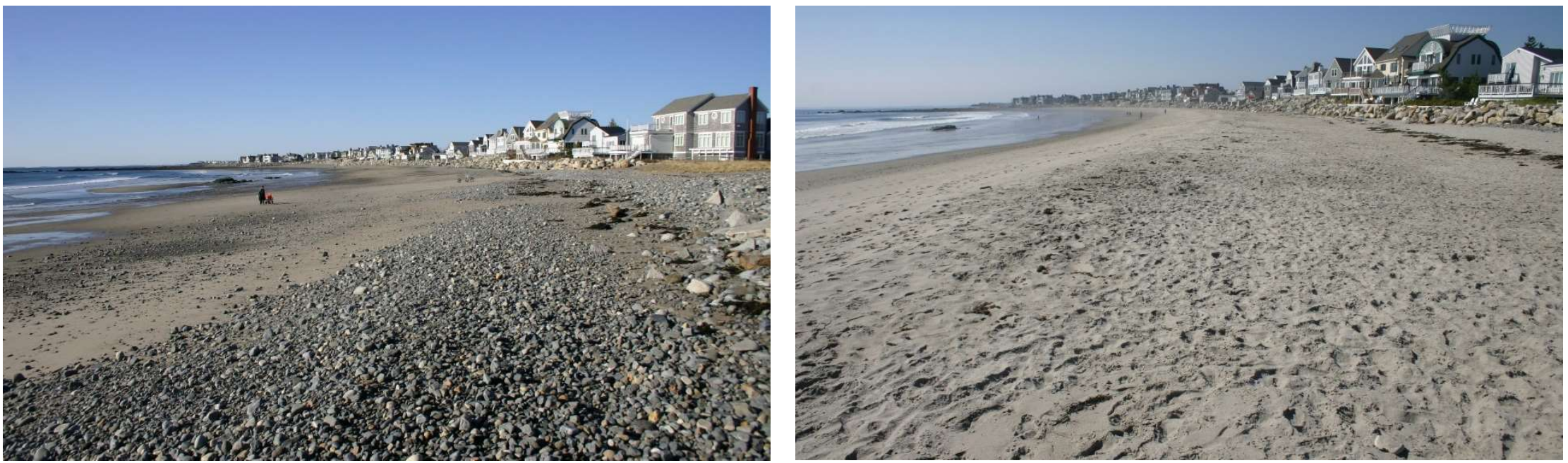

Figure NHB-10. Plaice Cove beach looking south from station NHBO2 on March 30 (left photograph) and on September 13, 2017 (right photograph). Note the gravel scattered over much of the beach, often in patches. Most of the gravel was buried by sand at the end of the summer accretional period on September 13 . 

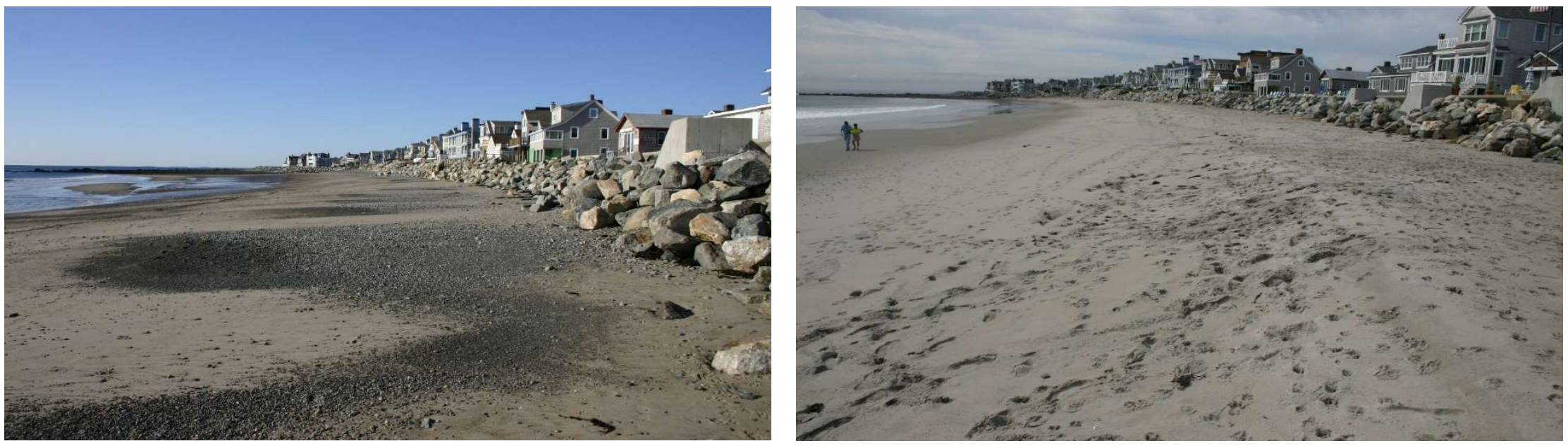

Figure NHB-11. Plaice Cove beach looking south from NHB03 on March 30 (left photograph) and on September 13, 2017 (right photograph). Note the gravel scattered over much of the beach, often in patches. Most of the gravel was buried by sand at the end of the summer accretional period on September 13.
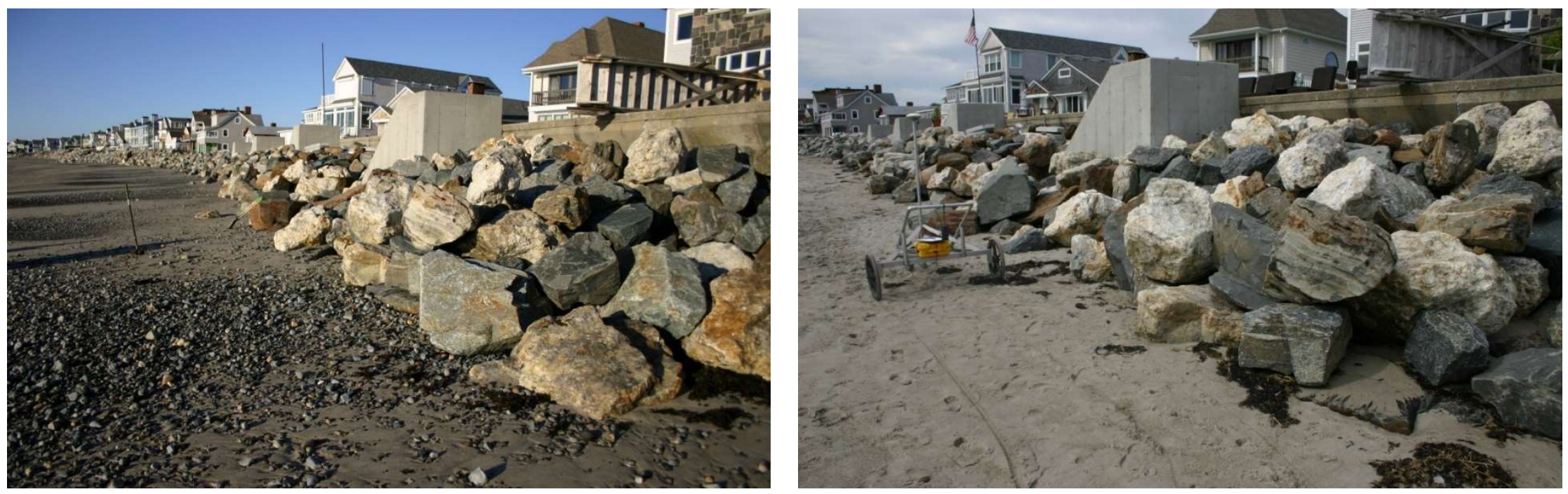

Figure NHB-12. Plaice Cove beach at station NHB03 near the seawall on March 30 (upper photograph) and on September 13, 2017 (lower photograph). The beach was significantly eroded by winter storms on March 30, but had recovered by September 13. 
Beach Sediment. North Hampton Beach (North Hampton State Beach and Plaice Cove) is extremely complex and heterogeneous due to the influence of Little Boars Head, Godfreys Ledge, and the southern headland which form its boundaries. Originally, erosion of these features provided sand and gravel to the beaches. However, with time the finer sediment was eventually removed by wave action, leaving extensive cobbles and boulders and megaclast platforms, as well as sandy sediments.

North Hampton State Beach is bimodal with extensive pebble and cobble deposits and megaclast platforms. Sand is somewhat patchy and temporally variable. The sediments vary dramatically alongshore and across-shore. The lower intertidal and nearshore has a cobble and boulder lag deposit that is periodically exposed (Figure NHB-13). The mid and upper beach are bimodal with extensive cobble deposits that are intermittently (spatially and temporally) covered with a veneer of sand (Figures NHB-8 and NHB-9). As a result of the across-shore and alongshore variability in sediment grain size at North Hampton Beach, trends are difficult to quantify from a single station (NHB01). However, it is likely NHB01 does represent general trends. The sediments at station NHB01 varied from pebbly medium sand to sandy pebble gravel in March 2017. In September sediments ranged from medium sand to sandy pebble gravel, but most were medium to slightly granular medium sand (Table NHB-1). Comparing the average grain size statistics of all the samples from NHB01 in March to the average from September shows a moderate decrease in grain size (Figure NHB-14 and Table NHB-2). However, this is misleading because the beach changes dramatically over short periods and as result it is not reasonable to define seasonal sediment changes at NHBO1.

South of Godfreys Ledge, Plaice Cove is largely sandy with a significant pebble population, outcropping bedrock, and a megaclast platform at the southern margin. The grain size of the sediments at stations $\mathrm{NHBO2}$ and $\mathrm{NHBO} 3$ ranged from medium sand to pebble gravel in March following the winter storms, and medium sand to pebbly medium sand in September following the summer accretional period. To examine this trend further, the samples were pooled to look at changes in averages for the summer from March to September at a station, as well as across-shore trends based on elevation.

NHBO2 and NHBO3 reflect the accumulation of finer-grained sediments during the summer period. The average statistics for each station increased by over two phi from March to September (Figure NHB-14 and Table NHB-2). The loss of the gravel fraction was a result of deposition of a fine sand layer over the coarser sediments. Pooling of the grain size data by elevation for NHB02 and NHB03 shows that gravel was a major component of the sediment in March, but was greatly reduced by September in the upper tidal beach and the mid tidal beach (Figure NHB-15 and Table NHB-3). The lower tidal beach also followed this pattern, but was less pronounced. 

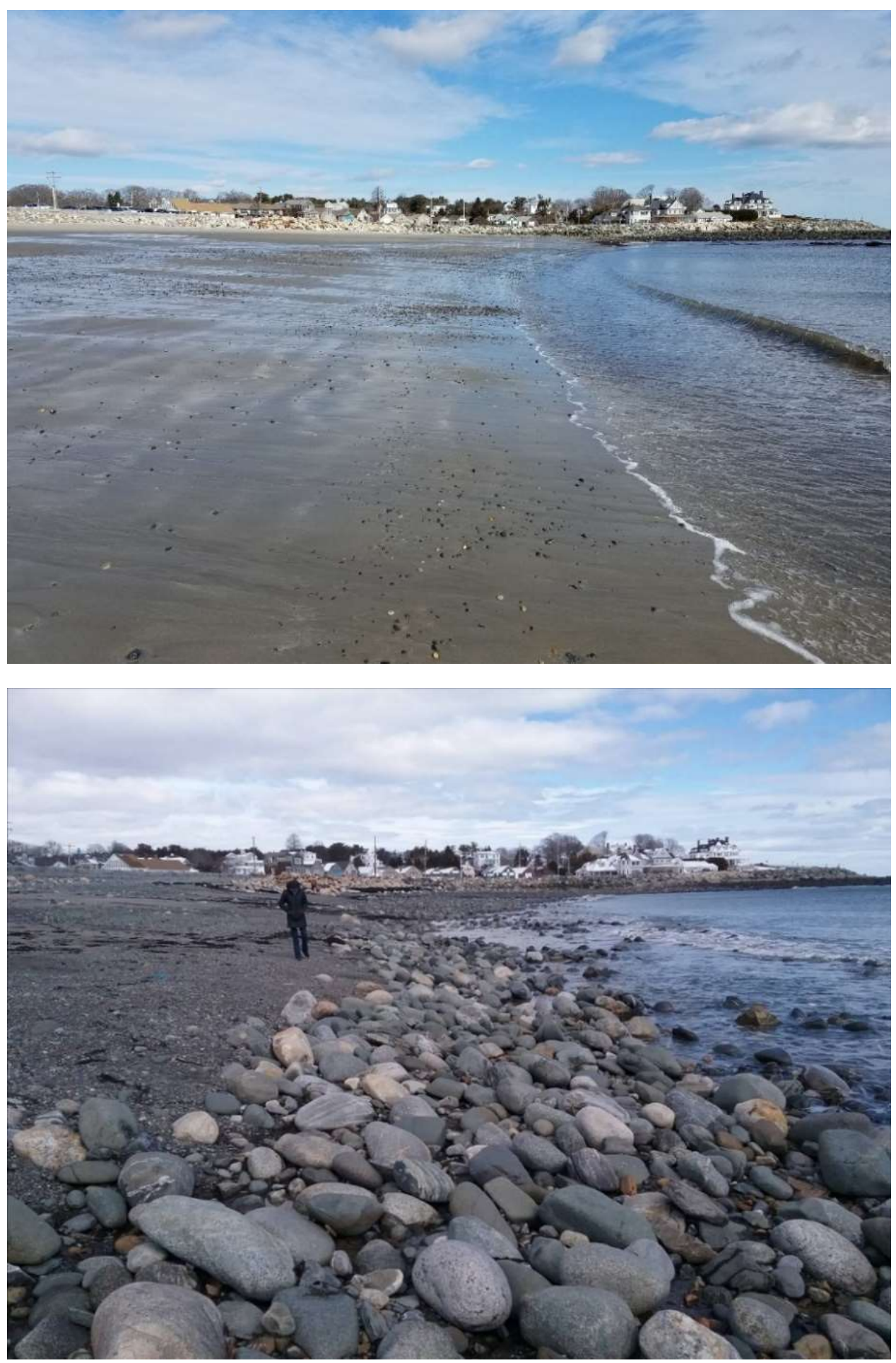

Figure NHB-13. Low tide terrace at station NHB01 looking north near the water line in 2018. Even though these photographs were taken the year after this study, they show clearly how the sediment can change at North Hampton State Beach and therefore are included. The upper photograph was taken on February 24, 2018 before the late winter 2018 storms when sand covered the cobbles and boulders that are located in the lower beach. The lower photograph was taken on March 10, 2018 after the megaclast platform was exposed due to severe erosion during the March 2018 nor'easters. 
Table NHB-1. Grain size statistics for samples collected at North Hampton Beach, NH. More complete summaries of the samples are given in Appendix E.

\begin{tabular}{|c|c|c|c|c|c|c|c|c|c|c|c|c|c|c|c|c|c|c|c|c|c|}
\hline $\begin{array}{l}\text { Sample } \\
\text { ID } \\
\end{array}$ & $\begin{array}{l}\text { Latitude } \\
\text { WGS84 }\end{array}$ & $\begin{array}{c}\text { Longitude } \\
\text { WGS84 }\end{array}$ & $\begin{array}{c}\text { Sample } \\
\text { Collected }\end{array}$ & $\begin{array}{c}\text { Sample } \\
\text { Wt. (gms) }\end{array}$ & $\begin{array}{c}\text { Morphologic } \\
\text { Feature }\end{array}$ & $\begin{array}{c}\text { Sediment } \\
\text { Name }\end{array}$ & $\begin{array}{c}\text { Sediment } \\
\text { Classification }\end{array}$ & Sorting & $\begin{array}{c}\text { Gravel } \\
\%\end{array}$ & $\begin{array}{c}\text { Pebble } \\
\%\end{array}$ & $\begin{array}{c}\text { Granule } \\
\%\end{array}$ & $\begin{array}{c}\text { Sand } \\
\%\end{array}$ & $\begin{array}{c}\text { Mud } \\
\%\end{array}$ & $\begin{array}{c}\text { Mode } \\
\text { Abbrev. }\end{array}$ & $\begin{array}{l}\text { Mode } \\
1 \text { (phi) } 2 \\
\end{array}$ & $\begin{array}{l}\text { Mode } \\
2 \text { (phi) }\end{array}$ & $\begin{array}{c}\mathrm{D}_{10} \\
\text { (phi) }\end{array}$ & $\begin{array}{c}\text { Dso } \\
\text { (phi) }\end{array}$ & $\begin{array}{c}\text { Mean } \\
\text { (phi) }\end{array}$ & $\begin{array}{c}\begin{array}{c}\text { Sorting } \\
\text { (phi) }\end{array} \\
\end{array}$ & $\begin{array}{c}\begin{array}{c}\text { Skew- } \\
\text { ness }\end{array} \\
\end{array}$ \\
\hline NHB01-1 & 42.955679 & \begin{tabular}{|l|}
-70.781161 \\
\end{tabular} & 31-Mar-17 & $4,014.9$ & Sand at Base of C.-B. Ramp & Pebbly Medium Sand & Medium Sand & PS & 7.17 & 6.54 & 0.63 & 92.82 & 0.0 & $u$ & 1.75 & N/A & 0.51 & 1.67 & 1.61 & 1.13 & -0.45 \\
\hline NHBO1-2 & 42.955598 & -70.780998 & 31-Mar-17 & $17,816.4$ & T: Upper & Sandy Pebble Gravel & Granule Gravel & VPS & 48.68 & 41.12 & 7.55 & 51.31 & 0.0 & D & 1.75 & -3.74 & -4.93 & -0.80 & -1.08 & 2.74 & -0.16 \\
\hline NHBO1-3 & 955468 & -70.780733 & Mar-17 & 0 & LTT:Mid & Pebbly Medium Sand & Coarse Sand & VPS & 86 & 17.90 & 3.97 & 12 & 0.0 & u & 75 & N/A & -3.45 & 70 & 55 & 27 & 74 \\
\hline HHBO1-4 & .955353 & -70.780493 & 31-Mar-17 & $4,441.5$ & LTT: Swash & Pebbly Medium Sand & Medium Sand & PS & 12.61 & 8.71 & 3.89 & 87.35 & 0.0 & $u$ & 1.75 & N/A & -1.70 & 1.79 & 1.37 & 1.42 & -0.61 \\
\hline 1B01-2 & 955690 & -70.781211 & $13-S e p-17$ & $1,802.50$ & rm; Sand Over Cobble & Medium Sand & Medium Sand & ws & 00 & 0.00 & 0.00 & 99.98 & 0.02 & c & .75 & N/A & 1.39 & 1.92 & 94 & 45 & 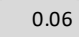 \\
\hline BB01-3 & 955632 & -70.781100 & 13-Sep-17 & 449.30 & st HT Swash & SI. Granular Medium Sand & Medium Sand & ws & 20 & 0.09 & 0.11 & 99.78 & 0.02 & u & 1.75 & N/A & 1.20 & 85 & 87 & 0.47 & 00 \\
\hline BB01-4 & 42.955564 & -70.780964 & 13-Sep-17 & $2,679.70$ & erm Face & SI. Granular Medium Sand & Mediur & MWS & 1.33 & 0.76 & 0.57 & 98.66 & 0.01 & u & 1.75 & N/A & 0.95 & 1.79 & 1.76 & 61 & -0.15 \\
\hline BB01-5 & 955461 & -70.780761 & 13-Sep-17 & $8,358.80$ & LTT:Mid & Sandy Pebble Gravel & Granule Gravel & VPS & 60.22 & 52.69 & 7.54 & 39.74 & 0.03 & B & 1.75 & -3.24 & -4.76 & -2.23 & -1.51 & 78 & 0.28 \\
\hline 302-05 & .952370 & -70.784663 & 31-Mar-17 & $2,808.7$ & Dune & Medium Sand & Sand & MwS & 00 & 0.00 & 0.00 & 99.97 & 0.0 & $\mathrm{c}$ & 1.75 & $\mathrm{~N} / \mathrm{A}$ & 0.63 & 1.46 & 1.43 & 61 & -0.03 \\
\hline NHBO2-1 & 952257 & -70.784540 & 31-Mar-17 & $3,053.2$ & -G. Ramp: Landward & Granular Medium Sand & Medium Sand & MWS & 0.14 & 0.03 & 0.11 & 99.85 & 0.0 & u & 1.25 & N/A & 0.55 & 1.26 & 1.26 & 0.59 & .02 \\
\hline NHBO2-2 & 952201 & -70.784457 & 31-Mar-17 & $15,781.9$ & S.-G. Ramp: Mid & Pebble Gravel & Pebble Gravel & VPS & 84.17 & 83.40 & 0.78 & 15.82 & 0.0 & B & -5.23 & 0.75 & -5.75 & -4.84 & -3.88 & .17 & 0.68 \\
\hline NHBO2-3 & .952169 & -70.784405 & 31-Mar-17 & $7,439.5$ & mp: Seaward Edge & Pebbly Medium Sand & V. Coarse Sand & VPS & 29.33 & 28.84 & 0.48 & 70.66 & 0.0 & B & 1.75 & -4.73 & -5.23 & 1.50 & -0.43 & 2.91 & -0.82 \\
\hline NHBO2-4 & 952027 & -70.784186 & 31-Mar-17 & $15,118.5$ & LTT: Upper & Sandy Pebble Gravel & V. Coarse Sand & VPS & 43.59 & 40.05 & 3.54 & 56.40 & 0.0 & B & 1.75 & -3.74 & -4.87 & 0.53 & -0.68 & 2.70 & -0.58 \\
\hline NHBO2-5 & 951873 & -70.783945 & 31-Mar-17 & 38.2 & LTT:Mid & Sandy Pebble Gravel & Granule Gravel & VPS & 1.69 & 42.32 & 9.37 & 48.29 & 0.0 & B & 1.75 & -5.23 & -5.02 & -1.19 & -1.27 & 65 & -0.07 \\
\hline HBO2-6 & 951731 & -70.783728 & 31-Mar-17 & 19.3 & LTT: Swash & Pebbly Medium Sand & V. Coarse Sand & VPS & 7.05 & 20.02 & 7.03 & 72.93 & 0.0 & B & 1.75 & -5.73 & -4.67 & 0.53 & -0.17 & .37 & -0.50 \\
\hline NHBO2-1 & 42.952330 & -70.784395 & 13 -Sep-17 & $1,169.10$ & ore: Edge of C. Ramp & Pebbly Medium Sand & Coarse Sand & PS & 11.00 & 10.74 & 0.26 & 88.98 & 0.02 & 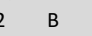 & 1.25 & -4.73 & -4.50 & 1.00 & 0.92 & .42 & -0.42 \\
\hline NHBO2-2 & 42.952186 & -70.784171 & 13-Sep-17 & $2,855.40$ & Berm Crest & Medium Sand & Medium Sand & ws & 00 & 0.00 & 0.00 & 99.98 & 0.02 & $u$ & 1.75 & N/A & 1.26 & 1.82 & 1.86 & .44 & 0.07 \\
\hline NHBO2-3 & 42.952073 & -70.784002 & 13-Sep-17 & $4,652.90$ & T: Landward & Pebbly Medium Sand & Medium Sand & PS & 11.27 & 9.24 & 2.03 & 88.71 & 0.02 & $u$ & 1.75 & N/A & -1.62 & 1.75 & 1.56 & 1.47 & -0.52 \\
\hline $\mathrm{HHBO2-4}$ & 42.951860 & -70.783679 & 13-Sep-17 & $5,956.20$ & LTT: Swash & Pebbly Medium Sand & Medium Sand & PS & 8.90 & 6.75 & 2.15 & 91.08 & 0.01 & u & 1.75 & N/A & -0.48 & 1.62 & 1.46 & 1.27 & -0.46 \\
\hline ABO3-1 & 556 & -70.7 & nar-17 & 3.2 & vel Cusp & ndy Pebl & ivel & $V_{1}$ & .15 & 72 & 43 & 04 & & ( & -3.74 & 1.75 & -4.89 & -3.19 & -2.23 & .46 & 45 \\
\hline NHBO3-2 & 42.950541 & -70.785614 & 30-Mar-17 & $17,929.2$ & G. Ramp; Base of Cusp & Pebble Gravel & Pebble Gravel & VPS & 2.60 & 71.25 & 11.35 & 17.39 & 0.0 & B & -4.73 & -2.24 & -5.31 & -3.67 & -3.20 & 1.13 & 0.41 \\
\hline NHBO3-3 & 42.950473 & -70.785252 & 30-Mar-17 & $5,329.5$ & S. Ramp; Start of LTT & Granular Medium Sand & parse Sand & PS & 19.49 & 10.57 & 8.93 & 80.49 & 0.0 & u & 1.75 & N/A & -2.13 & 1.06 & 0.55 & 1.71 & -0.51 \\
\hline NHBO3-4 & 42.950357 & -70.784633 & 30-Mar-17 & 42.2 & LTT: Swash & SI. Pebbly Medium Sand & ledium Sand & MWS & 26 & 0.91 & 35 & 98.73 & 0.0 & 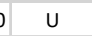 & .75 & N/A & .04 & .72 & 70 & .52 & -0.12 \\
\hline NHB03-1 & 42.950567 & -70.785743 & 14-Sep-17 & $2,458.60$ & ackshore & SI. Granular Medium Sand & Medium Sand & MWS & 32 & 0.01 & 0.31 & 99.67 & 0.01 & $u$ & 1.25 & N/A & 0.43 & 1.32 & 1.28 & 0.65 & -0.11 \\
\hline NHBO3-2 & 42.950550 & -70.785652 & 14-Sep-17 & $2,514.40$ & Berm Crest & SI. Granular Medium Sand & Medium Sand & ws & 0.02 & 0.00 & 0.02 & 99.97 & 0.01 & u & 1.75 & N/A & 1.02 & 1.68 & 1.65 & 0.50 & -0.12 \\
\hline NHBO3-3 & 42.950511 & -70.785458 & 14-Sep-17 & $2,985.70$ & I: Mid & Pebbly Medic & Medium Sand & PS & 49 & 9.24 & 0.24 & .50 & 0.02 & 2 & 24 & N/A & 0.50 & 1.90 & 1.81 & .41 & -0.49 \\
\hline 3-4 & 950436 & 0.785092 & Sep-17 & 5.80 & Swash & Sand & Sand & PS & 15.48 & 2.16 & 3.32 & 4.51 & 0.01 & U & 1.75 & N/A & -2.66 & 1.54 & 0.93 & 1.75 & -0.68 \\
\hline
\end{tabular}




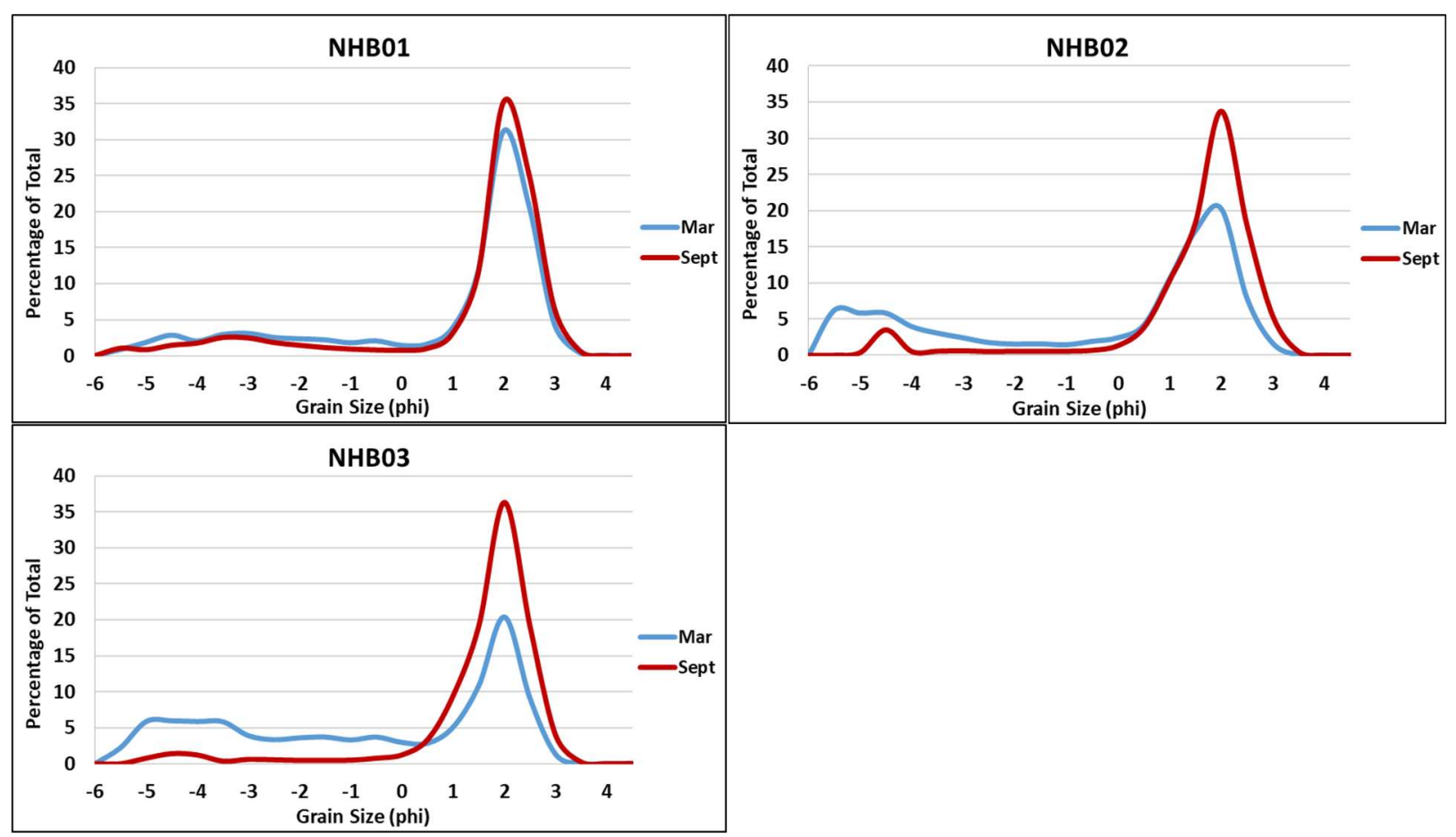

Figure NHB-14. Average grain size distributions for stations NHBO1, NHBO2, and NHBO3 in March (blue) and September (red) 2017, pooled for a station for each time period.

Table NHB-2. Comparison of average grain size statistics for each of the cross-beach transects at North Hampton Beach, NH. The average for each beach and season (winter erosive beach and summer accretional beach) is based on pooling all data from that station (n).

\begin{tabular}{|rrr|rr|rr|}
\cline { 2 - 7 } \multicolumn{1}{c|}{} & \multicolumn{2}{c|}{ NHB01 } & \multicolumn{2}{c|}{ NHB02 } & \multicolumn{2}{c|}{ NHB03 } \\
\cline { 2 - 7 } & Winter & Summer & Winter & Summer & Winter & Summer \\
\hline Gravel \% & $n=4$ & $n=4$ & $n=7$ & $n=4$ & $n=4$ & $n=4$ \\
Pebble \% & 22.6 & 15.4 & 33.7 & 7.8 & 43.6 & 6.3 \\
Granule \% & 18.6 & 13.4 & 30.7 & 6.7 & 36.6 & 5.4 \\
Sand \% & 4.0 & 2.1 & 3.0 & 1.1 & 7.0 & 1.0 \\
Mud \% & 77.4 & 84.5 & 66.3 & 92.2 & 56.4 & 93.7 \\
Mode 1 (phi) & 0.0 & 0.0 & 0.0 & 0.0 & 0.0 & 0.0 \\
$\mathbf{D}_{10}$ (phi) & 1.7 & 1.7 & 1.7 & 1.7 & 1.7 & 1.7 \\
$\mathbf{D}_{10}$ (mm) & -3.6 & -3.0 & -5.2 & 0.0 & -4.8 & 0.2 \\
D $_{50}$ median (phi) & 12.0 & 8.1 & 35.7 & 1.0 & 28.3 & 0.8 \\
D5 $_{50}$ median (mm) & 1.6 & 1.7 & 0.9 & 1.6 & 0.0 & 1.6 \\
Mean (phi) & 0.3 & 0.3 & 0.5 & 0.3 & 1.0 & 0.3 \\
Mean (mm) & 0.4 & 1.1 & -0.6 & 1.5 & -0.8 & 1.5 \\
Sorting (phi) & 0.74 & 0.45 & 1.57 & 0.36 & 1.79 & 0.35 \\
Skewness (phi) & 2.26 & 1.75 & 2.81 & 1.31 & 2.69 & 1.10 \\
Kurtosis (phi) & -0.75 & -0.67 & -0.67 & -0.47 & -0.38 & -0.45 \\
& 1.21 & 2.83 & 0.63 & 2.59 & 0.59 & 2.25 \\
\hline
\end{tabular}



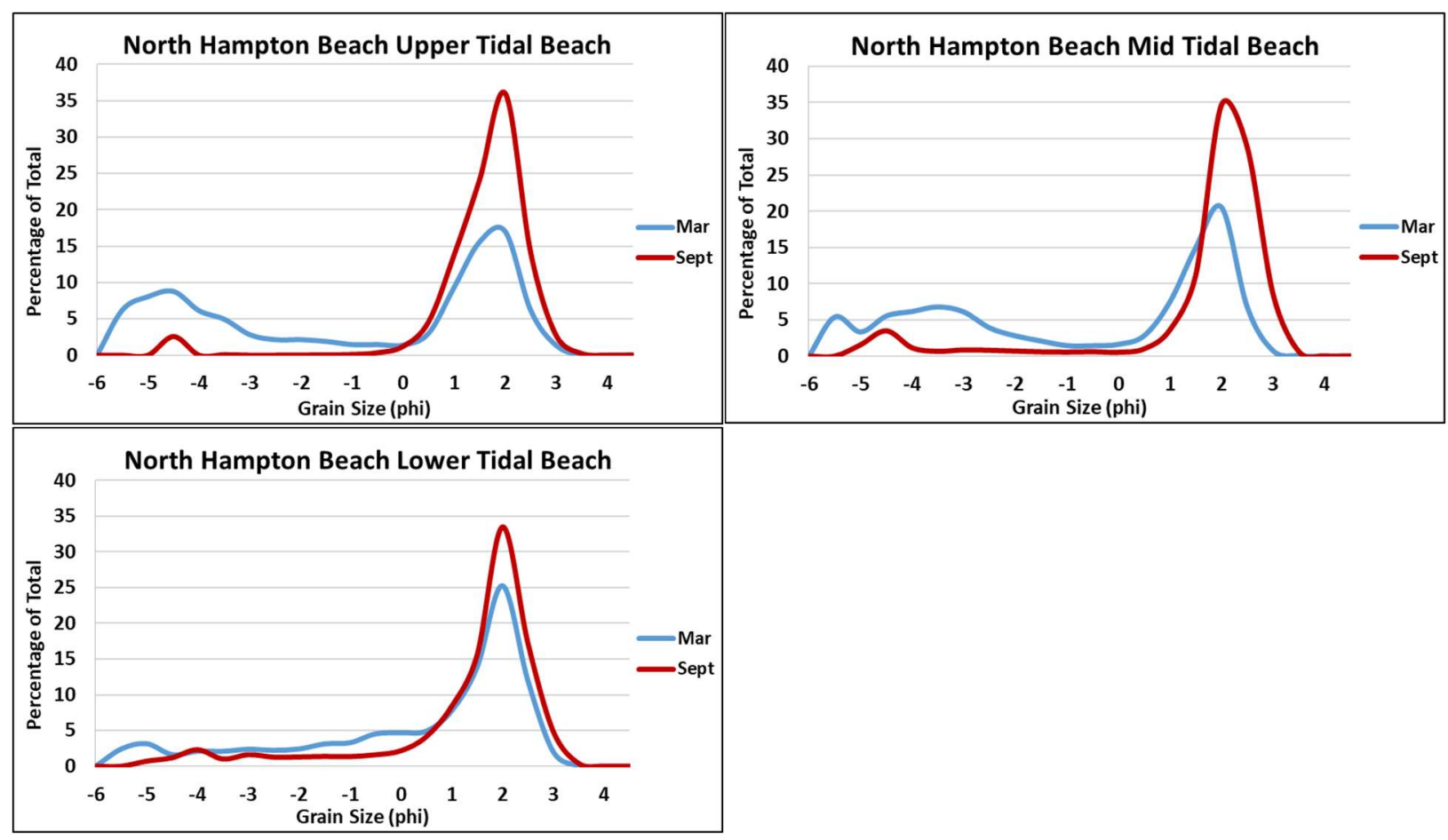

Figure NHB-15. Average grain size distributions for stations NHBO2 and NHBO3 in March (blue) and September (red) 2017, pooled by elevation for each time period.

Table NHB-3. Comparison of average grain size statistics for North Hampton Beach, NH sediment samples grouped by elevation into Upper Tidal Beach (UTB), Mid Tidal Beach (MTB), and Lower tidal Beach (LTB), and also separated into late winter (erosive beach) and late summer (accretional beach).

\begin{tabular}{|rrr|rr|rr|}
\cline { 2 - 7 } & \multicolumn{2}{|c|}{ UTB } & \multicolumn{2}{c|}{ MTB } & \multicolumn{2}{c|}{ LTB } \\
& Winter & Summer & Winter & Summer & Winter & Summer \\
\cline { 2 - 7 } & $\mathrm{n}=6$ & $\mathrm{n}=4$ & $\mathrm{n}=1$ & $\mathrm{n}=2$ & $\mathrm{n}=4$ & $\mathrm{n}=2$ \\
\hline Gravel \% & 44.6 & 2.8 & 43.6 & 10.4 & 24.9 & 12.2 \\
Pebble \% & 41.2 & 2.7 & 40.1 & 9.2 & 18.5 & 9.5 \\
Granule \% & 3.4 & 0.1 & 3.5 & 1.1 & 6.4 & 2.7 \\
Sand \% & 55.4 & 97.2 & 56.4 & 89.6 & 75.1 & 87.8 \\
Mud \% & 0.0 & 0.0 & 0.0 & 0.0 & 0.0 & 0.0 \\
Mode 1 (phi) & 1.7 & 1.7 & 1.7 & 1.7 & 1.7 & 1.7 \\
$\mathbf{D}_{10}$ (phi) & -5.3 & 0.5 & -4.9 & -1.3 & -3.8 & -1.8 \\
$\mathbf{D}_{10}$ (mm) & 38.1 & 0.7 & 29.2 & 2.5 & 14.2 & 3.5 \\
D $_{50}$ median (phi) & 0.4 & 1.5 & 0.5 & 1.8 & 1.1 & 1.6 \\
D $_{50}$ median (mm) & 0.7 & 0.3 & 0.7 & 0.3 & 0.5 & 0.3 \\
Mean (phi) & -0.9 & 1.4 & -0.7 & 1.7 & 0.2 & 1.3 \\
Mean (mm) & 1.87 & 0.37 & 1.60 & 0.30 & 0.87 & 0.42 \\
Sorting (phi) & 2.84 & 0.68 & 2.70 & 1.44 & 2.24 & 1.47 \\
Skewness (phi) & -0.57 & -0.24 & -0.58 & -0.49 & -0.64 & -0.58 \\
Kurtosis (phi) & 0.55 & 1.14 & 0.60 & 3.60 & 1.10 & 2.14 \\
\hline
\end{tabular}




\section{North Beach}

North Beach is an attached barrier located in Hampton, $\mathrm{NH}$, extending $\sim 2.7 \mathrm{~km}$ from the northern headland southward to Great Boars Head (Figure NB-1). The back-barrier landward of North Beach is composed of a small lagoon surrounded by fringing marshes to the north (Meadow Pond) and extensive saltmarshes to the south (Hampton Salt Marsh Conservation Area). A large cement seawall several meters in elevation extends nearly the entire length of North Beach. Large stone blocks are located at the base of the seawall for protection against wave damage (Figures NB-2 and NB-3). Both headlands bracketing North Beach are composed of glacial till that has been eroded, leaving behind megaclast platforms which extend seaward on the order of 1 to $1.5 \mathrm{~km}$ (Figures NB-1, NB-2 and NB-3). In addition, the megaclast platforms extend onto the beach at the northern and southern ends (Figure NB-4). The headlands cut off longshore transport of sediment to North Beach from either the north or south. Both headlands were likely a significance source of sand to North Beach in the past; however, the presence of megaclast platforms around the headlands and engineering structures has stopped or slowed present-day erosion and cut off a valuable source of sand. North Beach has a relatively low overall elevation and tends to lack large physiographic features such as berms. However, during storms, sand and gravel are eroded from the beach and pushed landward to form gravel ramps or sand ramps against the seawall (Figures NB-5 and NB-6). Due to its overall very low elevation, North Beach frequently becomes totally inundated with water during large spring tides and storm surges (Figure NB-7).

Field Work. The beach elevation profiles were measured and sediment samples collected in early spring 2017 on April 11 (NB02 and NB03) and April 24 (NB01 and NB04) following the winter erosional period. Three stations were sampled again on September 19 (NB01, NB02 and NB03). Unfortunately, NB04 was not sampled in the fall due to an early storm which eroded the beach. The morphology and sedimentology of North Beach was similar alongshore, allowing for pooling and averaging of the grain size data from stations NB01, NB02 and NB03. 


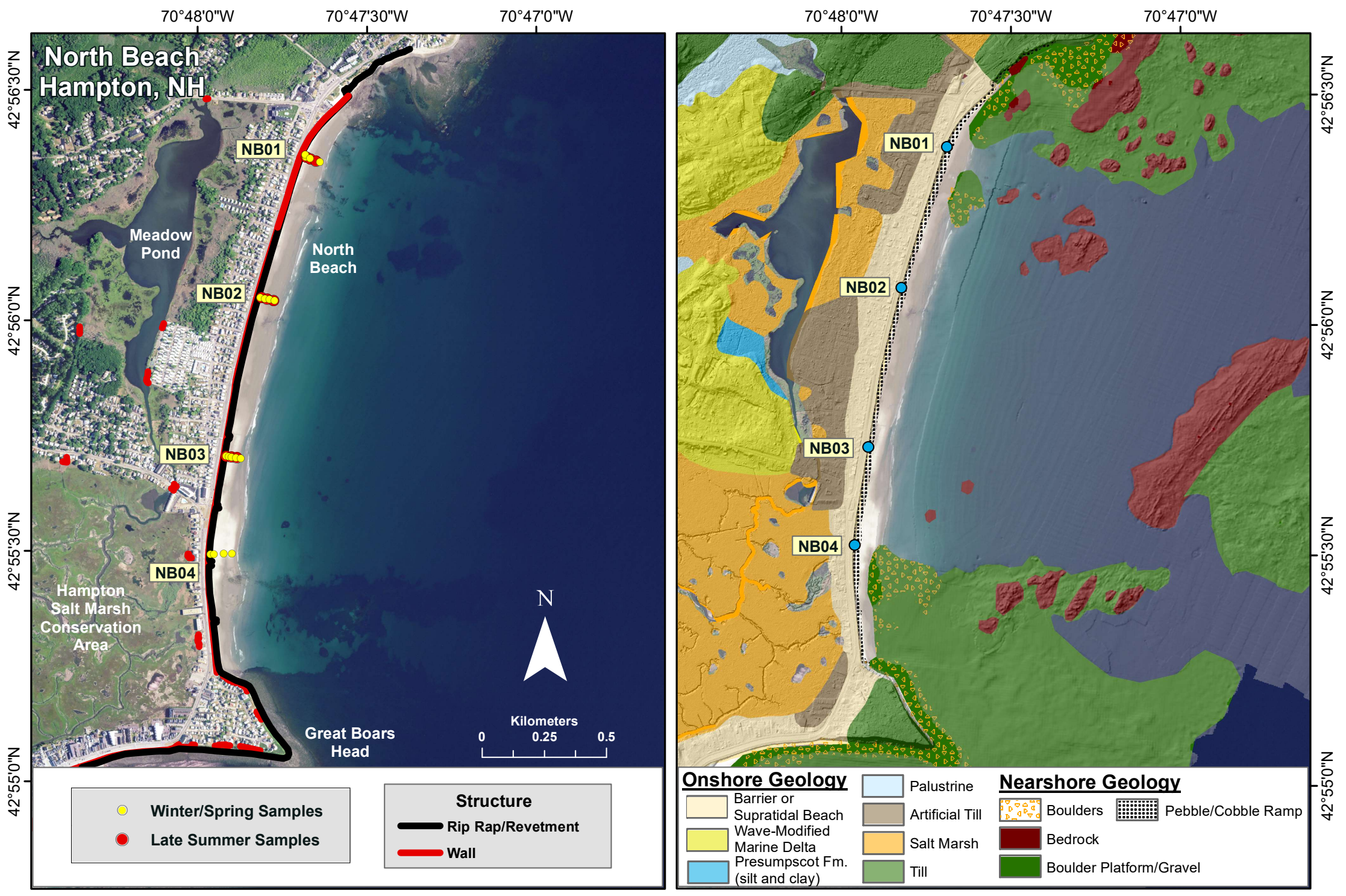

Figure NB-1. Station locations and shoreline structures (from Blondin, 2016) (left) and surficial geology of the upland (modified from NHGS digital series) and nearshore shelf (from Ward et al., 2021a) (right) North Beach, Hampton, NH. The nearshore seafloor not mapped (satellite imagery) is predominantly sand (right). 

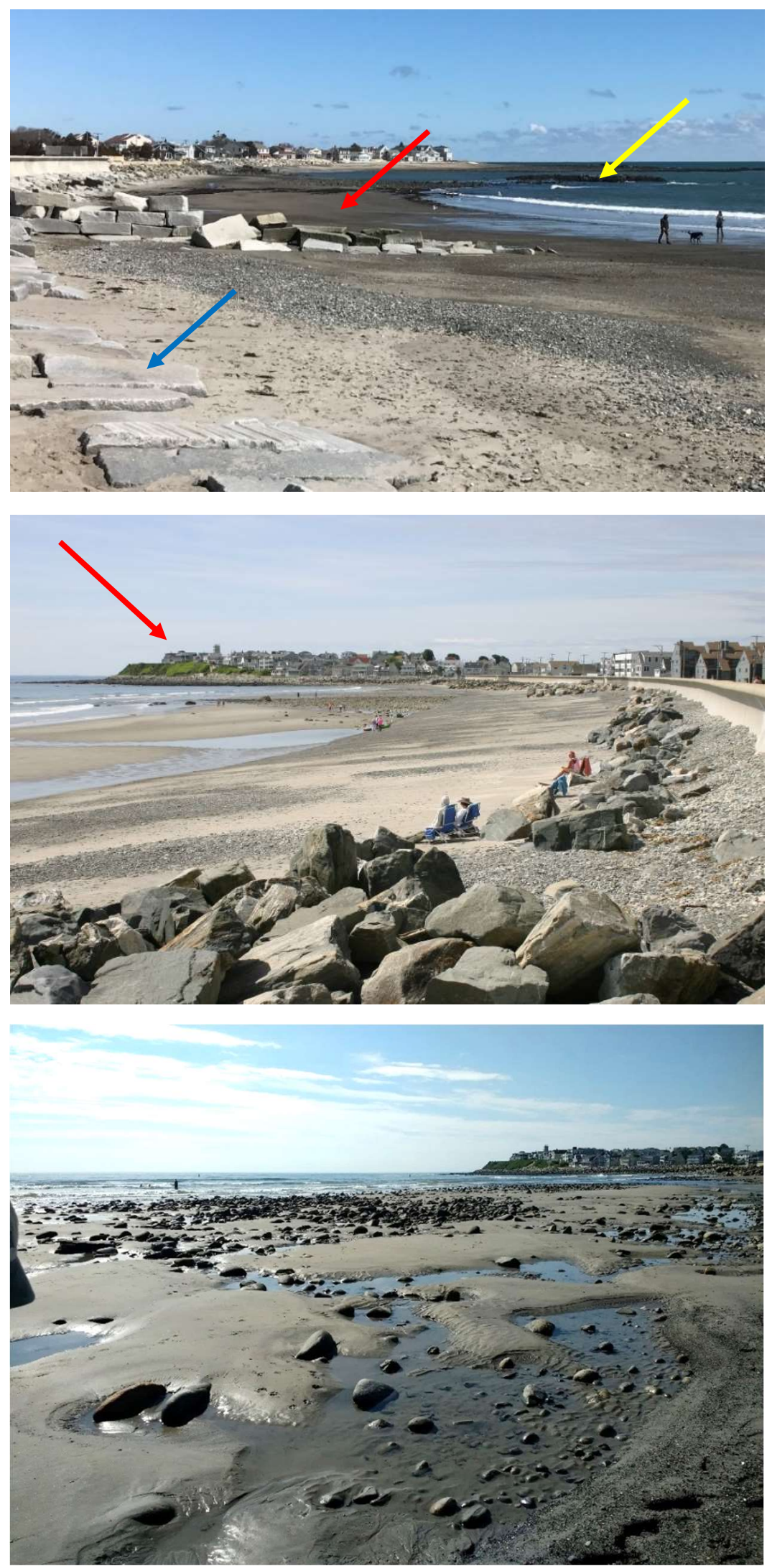

Figure NB-2. Photograph of the northern headland at North Beach taken on March 18, 2017 from station NB01. Note the stone groin in the foreground (red arrow), stone blocks at the base of the seawall (blue arrow), and a megaclast platform at the northern end of the beach (yellow arrow).
Figure NB-3. North Beach looking south on June 6, 2019. Great Boars Head (arrow) forms its southern boundary. A cement seawall extends the entire length of the beach. Note the riprap at the base of the seawall placed to diminish wave impact and the megaclast platform.
Figure NB-4. Cobble and boulder or megaclast platform outcropping on the southern end of North Beach on August 5, 2020. Great Boars Head is in the background and is surrounded by a megaclast apron. 


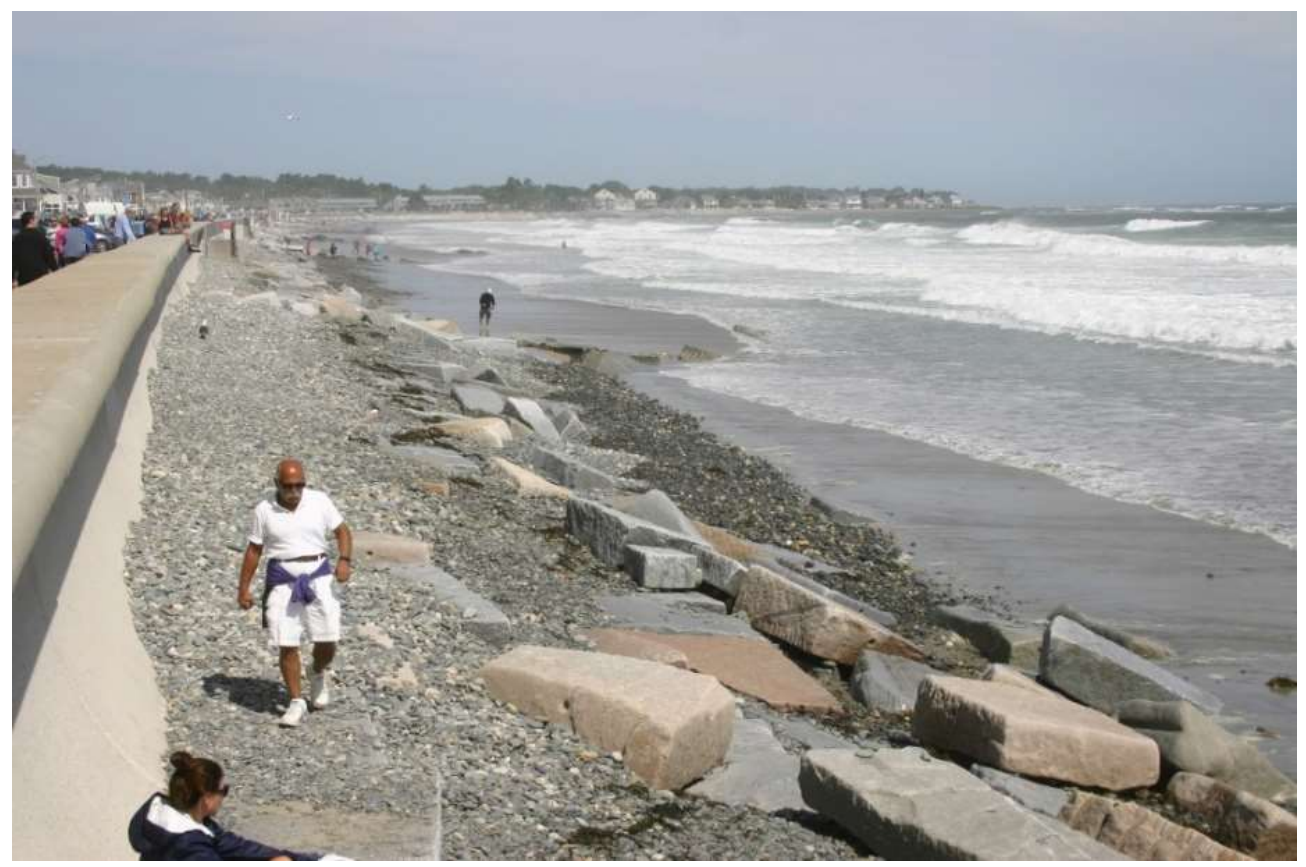

Figure NB-5. During storm conditions waves push gravel up the beach and often form gravel ramps as shown in this photograph taken on September 5, 2016.

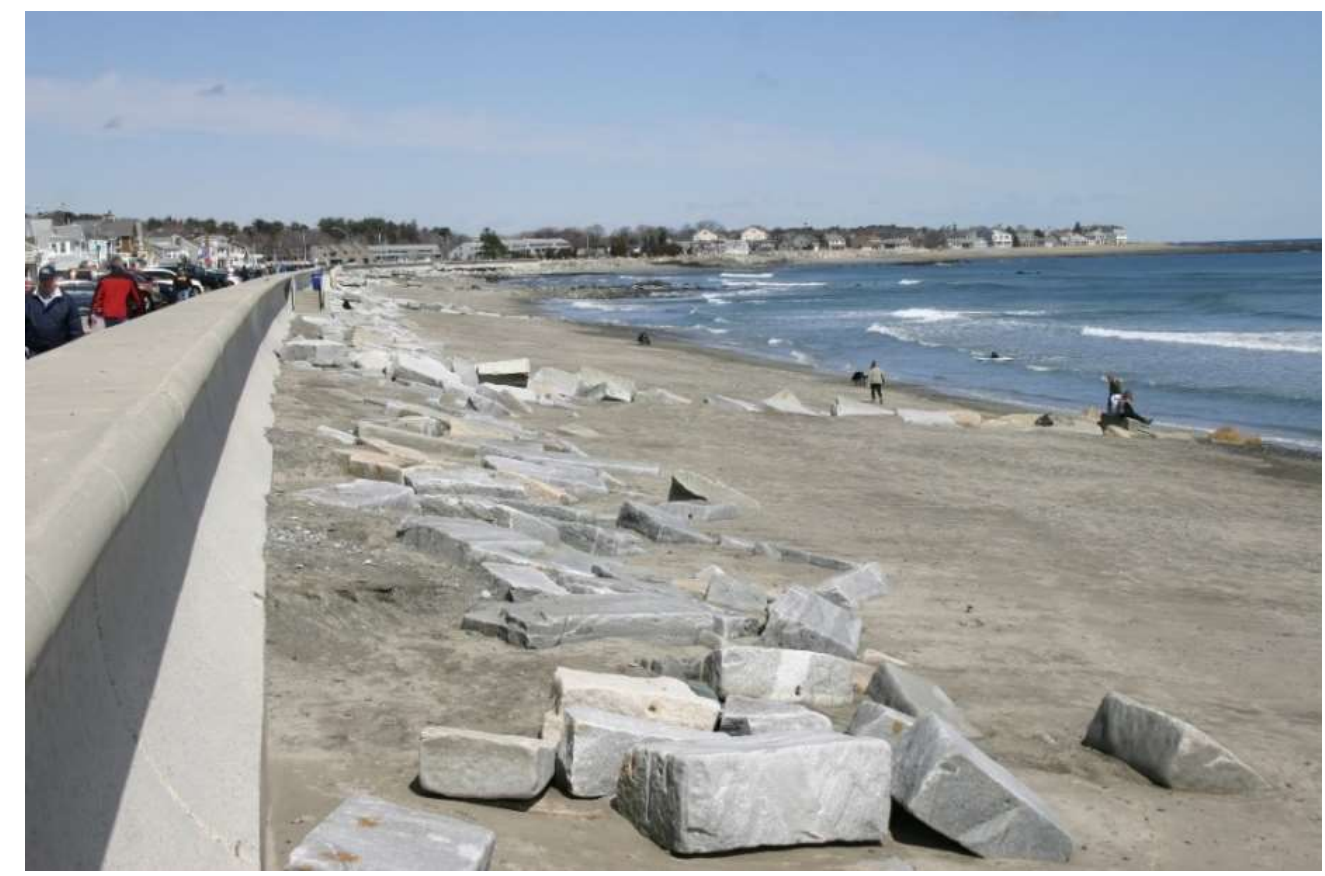

Figure NB-6. During storms, sand can be eroded from the lower beach and transported landward building a sand ramp against the seawall as seen here at North Beach on April 7, 2018 following three severe nor'easters. During this event, the sand extends from mid beach to the seawall. 
Beach Elevation Profiles. North Beach is relatively narrow and usually measures less than $100 \mathrm{~m}$ in width. Most importantly, North Beach has one of the lowest average elevations of all the beaches in $\mathrm{NH}$, resulting in the beach being inundated to the seawall during spring tides and minor storms (Figure NB-7). Consequently, North Beach is very susceptible to erosion and storm damage. The beach elevation profiles at all North Beach stations were highly eroded during the April 2017 monitoring period (Figures NB-8a and NB-8b). The mid and lower beach was scoured at each site and at least part of the sediment pushed landward to the seawall forming sand or gravel ramps. At station NB01, sand eroded from the lower and mid beach in April buried the large stone blocks adjacent to the seawall (Figure NB-9). In September, following an extended period of calm conditions, an accretionary wedge had developed on the mid and lower beach at NB01 as a result of landward migration of sand. In addition, some of the sand covering the stone blocks adjacent to the seawall deposited in April was removed. A similar pattern of erosion and accretion occurred at NB03, although riprap adjacent to the wall was not buried (Figure 10). Nearly a meter and half of accretion occurred at the base of the sand ramp at NB03 burying a pebble lag deposit (Figure NB-8b). At station NB02, the gravel ramp seen in September is covered with sand in April, which is atypical for NH beaches (Figure NB-11). Normally, the gravel ramps are more exposed in winter. However, this does not represent accretion of the beach. Rather the lower beach was scoured by winter storms in April and the sand pushed up to the seawall (see Figure 8a). NB02 had over a meter accretion in the mid beach area.

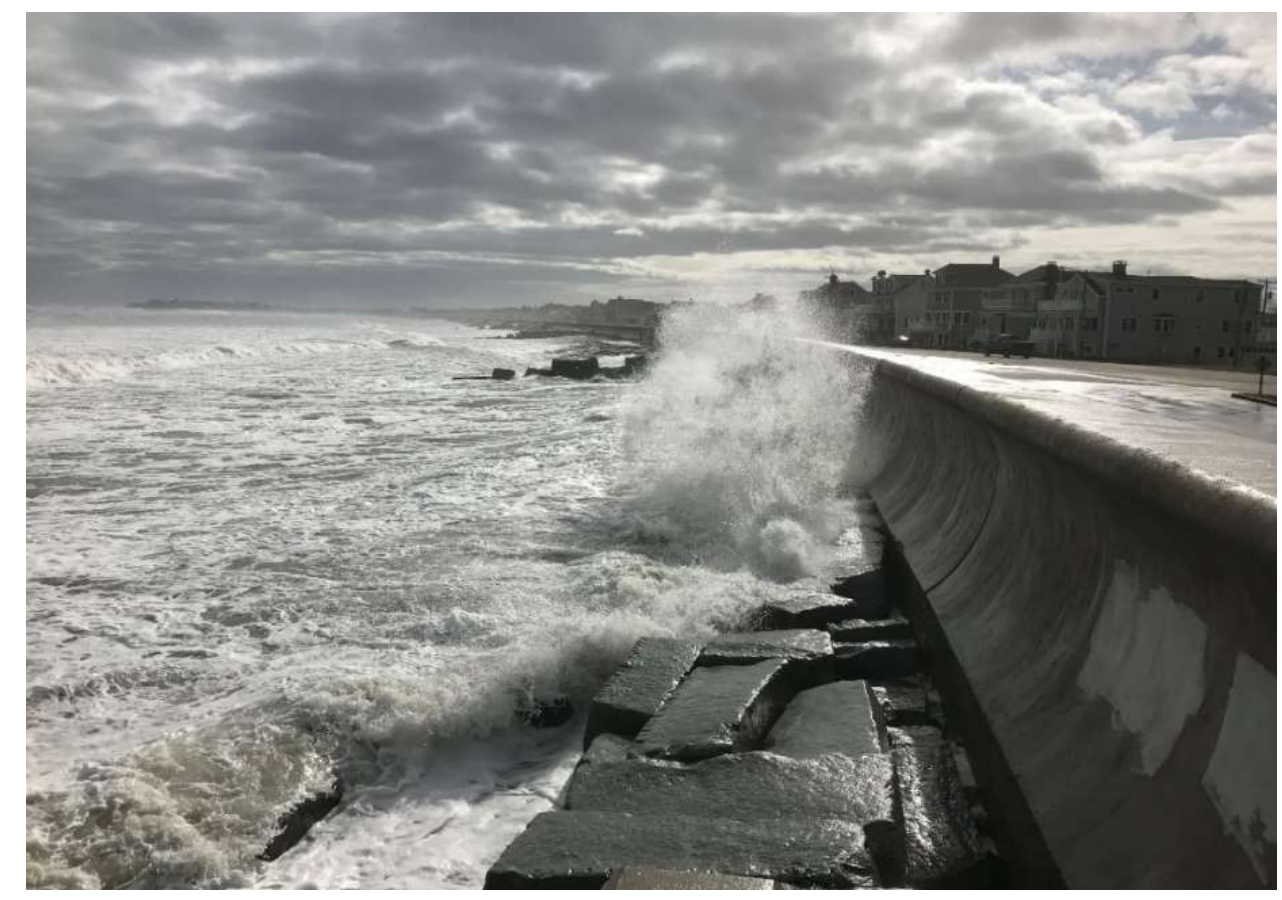

Figure NB-7. Storm waves following the nor'easter Riley at North Beach. The low elevation of the beach along with the storm conditions resulted in the seawall being impacted by waves. The photograph was taken on March 3, 2018 after the peak of the storm and the largest waves. 

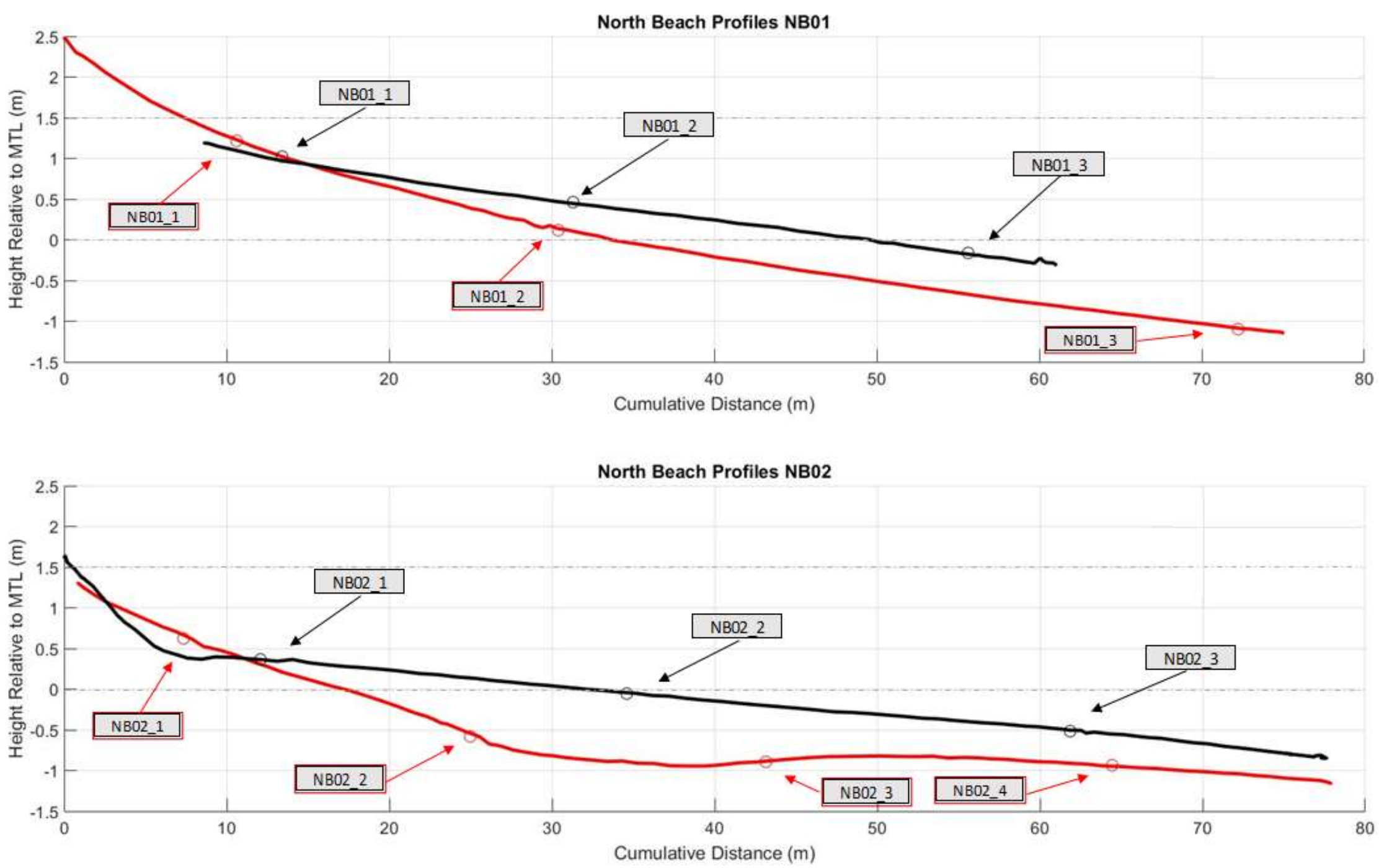

Figure NB-8a. Beach profiles and sediment sample locations from winter and late summer 2017 for stations NB01 and NB02 at North Beach, NH. Profile NB01 was run and sediment sampled on April 24 (red line/circles/boxes) and on September 19 (black line/circles/boxes). Profile NB02 was run on April 11 (red) and on September 19 (black). 

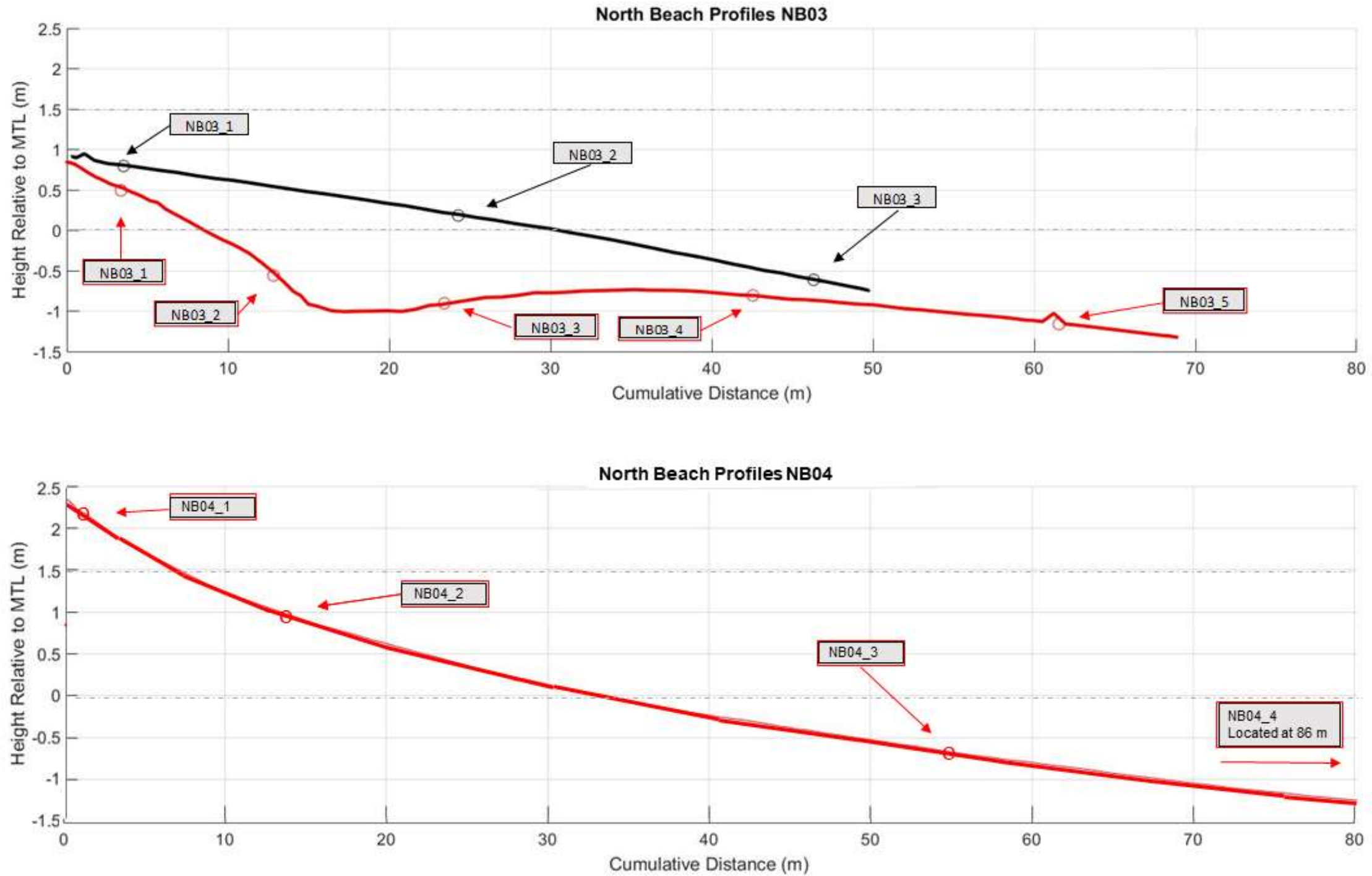

Figure NB-8b. Beach profiles and sediment sample locations from winter and late summer 2017 for stations NB03 and NB04 at North Beach, NH. Profile NB03 was run and sediment sampled on April 11 (red line/circles/boxes) and on September 19 (black line/circles/boxes). Profile NBO2 was run on April 24 (red). Note sample NB04-4 was taken at $86 \mathrm{~m}$. 

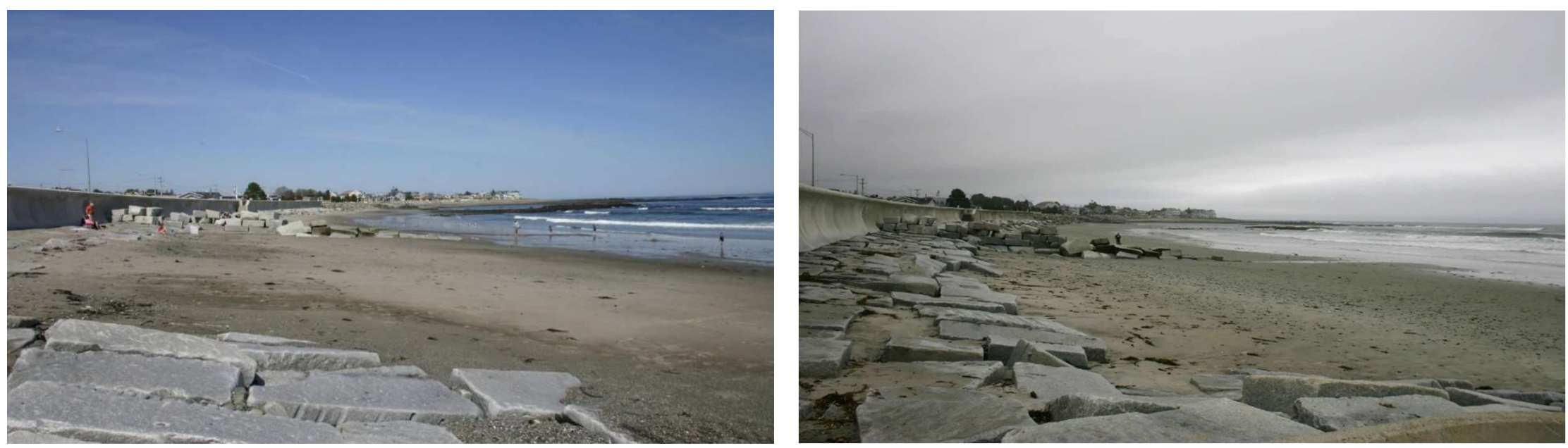

Figure NB-9. North Beach looking north from station NB01 on April 24 (left photograph) and September 19, 2017 (right photograph). Note the significant accretion on the lower beach following the summer season.
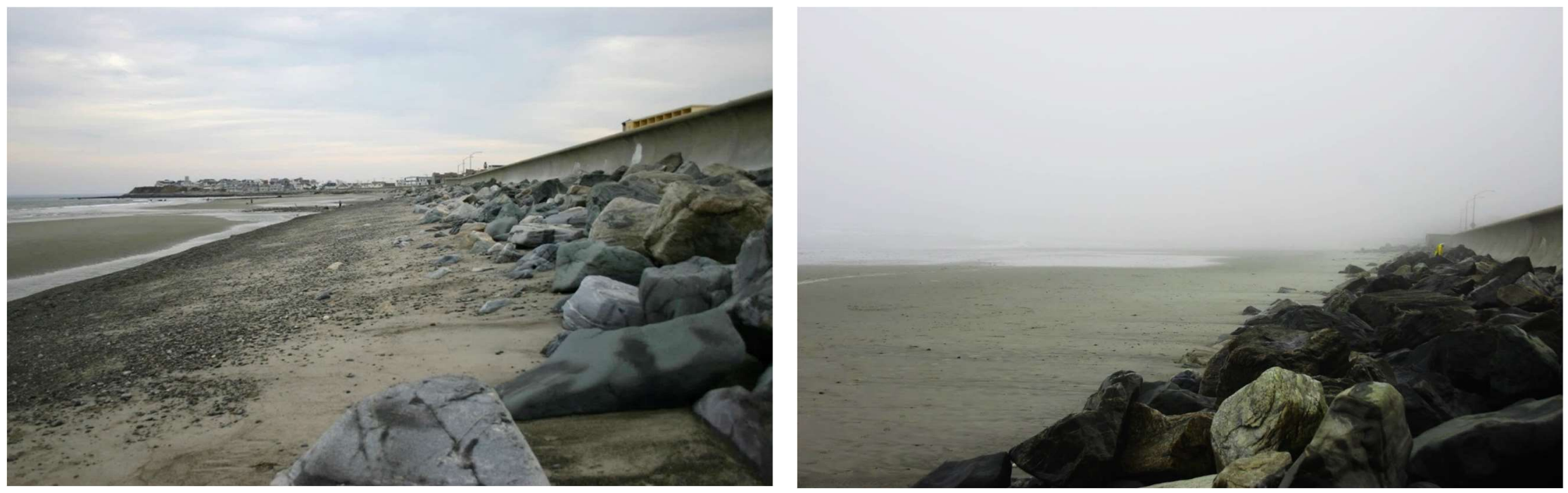

Figure NB-10. North Beach looking south from station NB03 on April 11 (left photograph) and on a foggy day in September 19, 2017 (right photograph). In April the beach was highly eroded and the low tide terrace (lower beach) elevation was much lower than September. A sand ramp is also visible in April adjacent to the seawall, which can form during storms by scouring the lower beach and transporting the sand landward. In September the beach had regained elevation through deposition of a sand wedge that buried the pebble lag seen in April. 


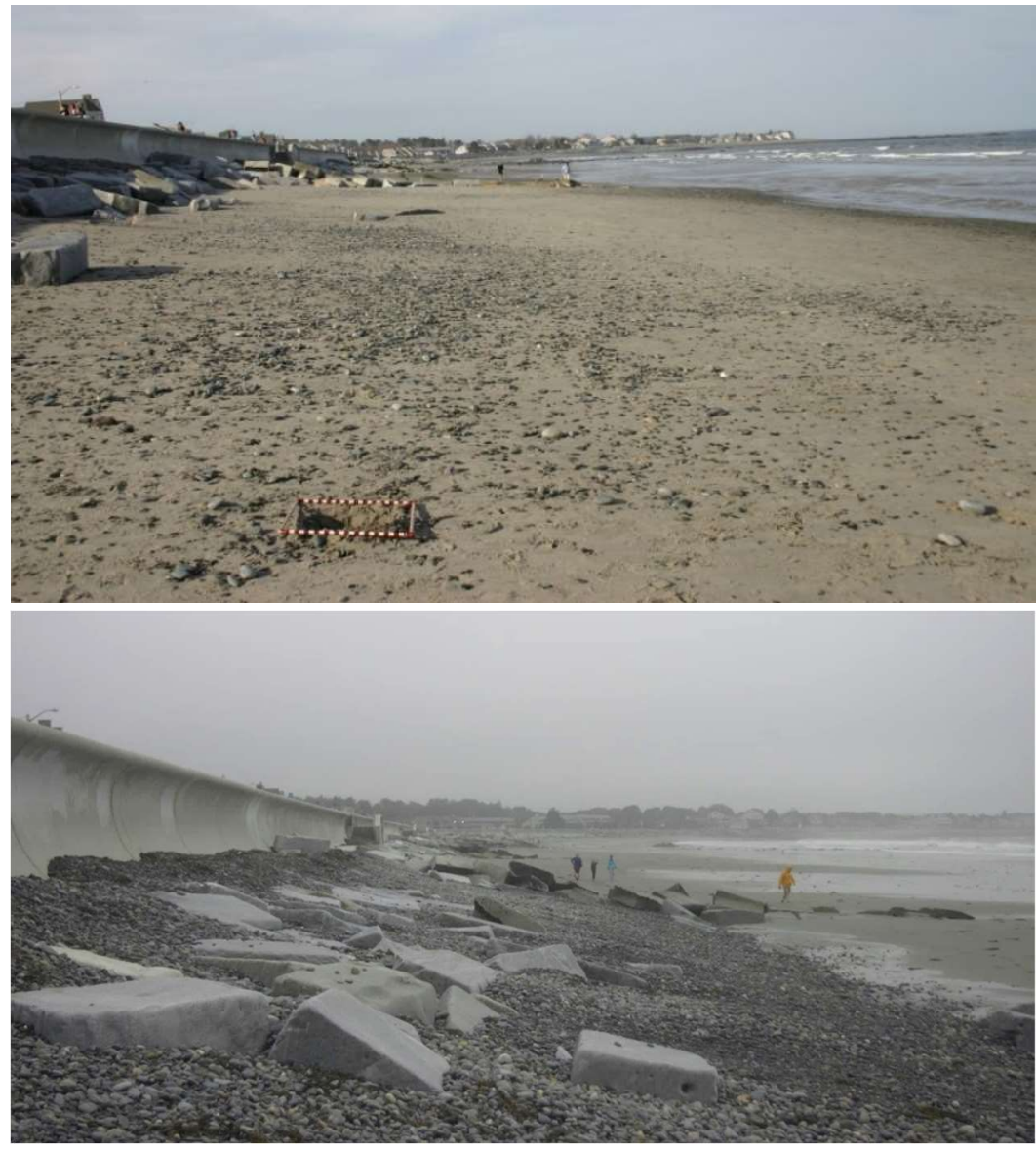

Figure NB-11. North Beach looking north from station NBO2 on April 11 (upper photograph) and September 19, 2017 (lower photograph).

The gravel ramp seen in September is covered with sand in April which is atypical for $\mathrm{NH}$ beaches. Normally, the gravel ramps are more exposed in winter. However, this does not represent accretion of the beach. Rather the lower beach was scoured by winter storms in April and the sand pushed up to the seawall (see Figure NB-8a).

Beach Sediments. The sediment characteristics at North Beach in April 2017 (following an extended period of erosion) ranged from slightly granuley fine sand on the lower intertidal beach to pebble gravels near the seawall (Table NB-1). However, most samples were sandy granule to sandy pebble gravel on the upper beach to granuley to pebbly fine sand on the mid and lower beach. In September (following an extended period of accretion) the sediment ranged from slightly granuley fine sand to sandy pebbly gravel, but pebbly fine sand was most common, which reflects the deposition of fine-grained sediment in summer and early fall.

Determination of the average grain size statistics for each station demonstrates the general overall fining of the sediments from April to September at stations NB01 and NB02, with means increasing 1.4 phi and 1.7 phi, respectively. The size distributions clearly show this trend, especially at station NB01 (Figure NB12 and Table NB-2). However, station NB03 remained relatively constant despite major accretion having occurred. The cause of this is not clear. Although there are differences in the behavior of the stations, pooling of the data into mid tidal beach and lower tidal beach is instructive. Only stations NB01, NB02 and NB03 were used to determine the averages, as NB04 was not resampled in September due to an early storm eroding the beach (and therefore no longer representing accretional conditions). The elevations of the beach were also too low to include the upper tidal beach. The mid and lower tidal elevation both reflected the deposition of a sand layer resulting in a fining of the beach. The mid beach average increased by $1.7 \mathrm{phi}$ and the lower beach by 1.0 phi (Figure NB-13 and Table NB-3). 
Table NB-1. Grain size statistics for samples collected at North Beach, NH in 2017. More complete summaries of the samples are given in Appendix E.

\begin{tabular}{|c|c|c|c|c|c|c|c|c|c|c|c|c|c|c|c|c|c|c|c|c|c|}
\hline $\begin{array}{l}\text { Sample } \\
\text { ID }\end{array}$ & $\begin{array}{l}\text { Latitude } \\
\text { WGS84 }\end{array}$ & $\begin{array}{c}\text { Longitude } \\
\text { WGS84 }\end{array}$ & $\begin{array}{c}\text { Sample } \\
\text { Collected }\end{array}$ & $\begin{array}{c}\text { Sample } \\
\text { Wt. (gms) }\end{array}$ & $\begin{array}{l}\text { Morphologic } \\
\text { Feature }\end{array}$ & $\begin{array}{c}\text { Sediment } \\
\text { Name }\end{array}$ & $\begin{array}{c}\text { Sediment } \\
\text { Classification }\end{array}$ & Sorting & $\begin{array}{c}\text { Gravel P } \\
\%\end{array}$ & $\begin{array}{c}\text { Pebble } \\
\%\end{array}$ & $\begin{array}{c}\text { Granule } \\
\%\end{array}$ & $\begin{array}{c}\text { Sand } \\
\%\end{array}$ & $\begin{array}{c}\text { Mud } \\
\%\end{array}$ & $\begin{array}{c}\text { Mode } \\
\text { Abbrev. }\end{array}$ & $\begin{array}{l}\text { Mode } \\
1 \text { (phi) }\end{array}$ & $\begin{array}{l}\text { Mode } \\
2 \text { (phi) }\end{array}$ & $\begin{array}{c}\mathrm{D}_{10} \\
\text { (phi) }\end{array}$ & $\begin{array}{c}\mathrm{D}_{50} \\
\text { (phi) }\end{array}$ & $\begin{array}{c}\text { Mean } \\
\text { (phi) }\end{array}$ & $\begin{array}{c}\text { Sorting } \\
\text { (phi) }\end{array}$ & $\begin{array}{c}\text { Skew- } \\
\text { ness }\end{array}$ \\
\hline NB01-1A & 42.939459 & -70.794499 & 24-Apr-17 & 101.7 & S. Ramp & Granular Coarse Sand & Coarse Sand & PS & 12.65 & 6.66 & 5.99 & 87.34 & 0.01 & $u$ & 0.75 & N/A & -1.35 & 0.26 & 0.20 & 1.18 & -0.18 \\
\hline NB01-1B_Top & 939519 & -70.794515 & Apr-17 & & $p$ of G. Cusp & ebble Gravel & Pebble Gravel & MS & .75 & 74.22 & 18.53 & 7.25 & 0.00 & u & -2.24 & $r$ & -3.38 & -2.45 & -2.42 & 2 & 14 \\
\hline 301-1B_Bottom & 39519 & 0.794515 & 24-Apr-17 & 4 & Bottom of G. Cusp & iravel & avel & MWS & 5.49 & 7.04 & 39.44 & 3.51 & 0.0 & $u$ & 1.24 & N/A & -2.92 & 2.12 & -2.13 & 3 & -0.01 \\
\hline NB01-2 & 939402 & -70.794269 & 24-Apr-17 & $12,021.1$ & S. Ramp Base -LTT Bound. & Sandy Granule Gravel & V. Coarse Sand & VPS & 35.11 & 1.22 & 13.89 & 64.88 & 0.01 & E & 2.24 & -0.74 & -3.06 & 0.21 & -0.20 & .05 & -0.06 \\
\hline NB01-3 & 939279 & -70.793785 & 24-Apr-17 & 41.6 & LTT: Lower & Granular Fine Sand & Medium Sand & PS & 6.09 & 62 & 3.47 & 93.88 & 03 & & .24 & N/A & -0.49 & 1.83 & 1.49 & 24 & -0.45 \\
\hline NB01-1 & 42.939449 & -70.794467 & 19-Sep-17 & $16,752.2$ & Ramp: Upper & Sandy Pebble Gravel & V. Coarse Sand & VPS & 42.28 & 37.64 & 4.64 & 57.71 & 0.01 & & 2.24 & -4.73 & -4.84 & 0.43 & -0.53 & 1.92 & -0.42 \\
\hline NB01-2 & 42.939394 & -70.794261 & 19-Sep-17 & 318.5 & П: Upper & Pebbly Fine Sand & Medium Sand & PS & 12.07 & 77 & 2.30 & 87.90 & 0.03 & $u$ & 2.24 & N/A & -1.89 & 2.05 & 1.59 & .67 & -0.6 \\
\hline NB01-3 & 42.939321 & -70.793980 & 19-Sep-17 & $5,651.1$ & LTT:Swash & SI. Granular Fine Sand & Medium Sand & MS & 2.56 & 29 & 1.27 & 97.42 & 0.02 & 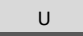 & 2.24 & N/A & 0.55 & 2.10 & 1.96 & 0.89 & -0.3 \\
\hline $02-1$ & 934344 & -70.796565 & 11-Apr-17 & 66.5 & S.P. Ramp & Indy Pebble Gravel & Pebble Gravel & VPS & \begin{tabular}{|l|}
73.14 \\
\end{tabular} & 69.03 & 4.11 & 26.84 & 0.0 & & 5.23 & 2.24 & -5.42 & -3.99 & -2.48 & 2.96 & 0.61 \\
\hline NBO2-2 & 34309 & -70.796354 & Apr-17 & 1 & Ramp - LTT Boundary & Pebbly Fine Sand & arse Sand & VPS & 26.74 & 20.43 & 6.31 & 73.23 & 0.0 & & 2.24 & N/A & -3.76 & 1.89 & 0. & 2.45 & -0.75 \\
\hline NBO2-3 & 42.934273 & -70.796137 & 11-Apr-17 & 367.6 & டПT: Upper; Ridge & SI. Granular Fine Sand & Medium Sand & MS & 4.43 & 2.19 & 2.25 & 95.47 & 0.1 & L & 2.24 & N/A & 0.70 & 2.11 & 1.99 & 0.91 & -0.40 \\
\hline NBO2-4 & 934233 & -70.795881 & 11-Apr-17 & 82.5 & LT: Upper & Granular Fine Sand & Medium Sand & MS & 6.04 & 71 & 2.33 & 93.93 & 0.03 & & 2.24 & N/A & 0.35 & 2.02 & 86 & .00 & -0.48 \\
\hline NB02-1 & 4 & -70.7 & 19-Sep-17 & 13,4 & т: Upper & Sand & oarse Sand & VPS & 27.77 & 25 & 39 & 72.21 & 0.02 & 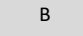 & .24 & -4.73 & -4.45 & 2.12 & 31 & 84 & -0.80 \\
\hline NBO2-3 & 42.934291 & -70.796237 & 19-Sep-17 & $5,401.3$ & LTT:Mid & Pebbly Fine Sand & Fine Sand & PS & 5.99 & 4.75 & 1.23 & 93.99 & 0.02 & $\iota$ & 2.24 & N/A & 1.07 & 2.16 & 2.13 & 1.00 & -0.38 \\
\hline NBO2-4 & 42.934236 & -70.795912 & 19-Sep-17 & $3,218.0$ & LTT: Lower & SI. Granular Fine Sand & Medium Sand & MS & 0.68 & 0.36 & 0.32 & 99.30 & 0.02 & u & 2.24 & N/A & 0.72 & 1.94 & 1.88 & 0.80 & -0.1 \\
\hline NB03-1 & 28573 & -70.798077 & 11-Apr-17 & $\mid 17,157.1$ & Ramp: Upper & Sandy Granule Gravel & Granule Gravel & VPS & 57.57 & 38.96 & 18.61 & 42.42 & 0.0 & & -0.74 & -3.24 & -4.62 & -1.41 & -1. & .37 & -0.05 \\
\hline NB03-2 & 42.928563 & -70.797962 & 11-Apr-17 & $11,148.0$ & p: Lower; Bound. to Runnel & Pebble Gravel & Pebble Gravel & PS & 89.30 & 66.28 & 23.02 & 10.69 & 0.0 & $\mathrm{l}$ & -2.24 & N/A & -3.86 & -2.44 & -2 & .46 & 0.20 \\
\hline NBO3-3 & 928552 & -70.797833 & 11-Apr-17 & 5.8 & LT: Upper; Ridge & Granular Fine Sand & ledium Sand & PS & 9.77 & 6.12 & 3.65 & 90.19 & 0.0 & 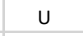 & 2.24 & N/A & -0.94 & 2.09 & 1.8 & 18 & -0.56 \\
\hline NBO3-4 & 42.928531 & -70.797600 & 11-Apr-17 & 90.6 & T: Mid; Ridge & Pebbly Fine Sand & ne Sand & MS & 5.78 & .67 & 11 & 94.20 & 0.02 & $\mathrm{u}$ & 2.24 & N/A & 1.03 & 2.12 & 2.05 & 89 & -0.43 \\
\hline NB03-5 & 42.928511 & -70.797369 & 11-Apr-17 & $2,837.2$ & LTT:Swash & Pebbly Fine Sand & Medium Sand & PS & 42 & 86 & 56 & 90.57 & 0.01 & $u$ & 2.24 & N/A & -0.77 & 1.97 & 1.81 & .19 & -0.52 \\
\hline NB03-1 & 42.928572 & -70.798080 & 19-Sep-17 & 12,79 & Іт: Upper & Sandy Pebble Gravel & V. Coarse Sand & VPS & 50.82 & 44.60 & 3 & 49.17 & .01 & $E_{2}$ & 2.24 & -3.24 & -4.17 & -1.19 & -0.90 & 60 & 0.10 \\
\hline NBO3-2 & 551 & 828 & p-17 & & Mid & SI. Pet & sand & MS & 4.77 & & 1.00 & 95.22 & 0.01 & 4 & .24 & N/A & $1.21 \mathrm{H}$ & 2.02 & 99 & .74 & -0.33 \\
\hline NBO3-3 & 42.928527 & -70.797559 & 19-Sep-17 & $7,651.0$ & LTT:Swash & Pebbly Fine Sand & dium Sand & PS & 11.14 & 20 & 3.95 & 88.84 & 0.02 & $u$ & 2.24 & /A & -1.29 & 1.97 & 1.66 & 1.26 & \\
\hline & & & & & & avel & & W & & & & & & & & Tot & -5.61 & -4.97 & -4 . & 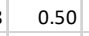 & 00 \\
\hline $\mathrm{Ne}$ & & & -17 & & ver & ravel & vel & $V_{F}$ & 38 & & 6.42 & & & & 2.24 & -4.2. & -4.63 & -2.74 & -1. & .68 & .45 \\
\hline & & & & & & & & VPS & 22.88 & & 4.15 & 09 & 0.03 & & 2.24 & N/A & -3.28 & 1.76 & 0.55 & 11 & -0.75 \\
\hline $4-4$ & 42.925048 & $70.197 / 108$ & 1-Apr-17 & 595.4 & T: Swash & Pebbly Fine Sano & edium Sand & & 13.91 & 1.3. & $2.6 \mathrm{C}-\mathrm{s}$ & 0.0 & 0.0 & & 2.24 & & 2.4 & .9 & .5 & .4 & \\
\hline
\end{tabular}



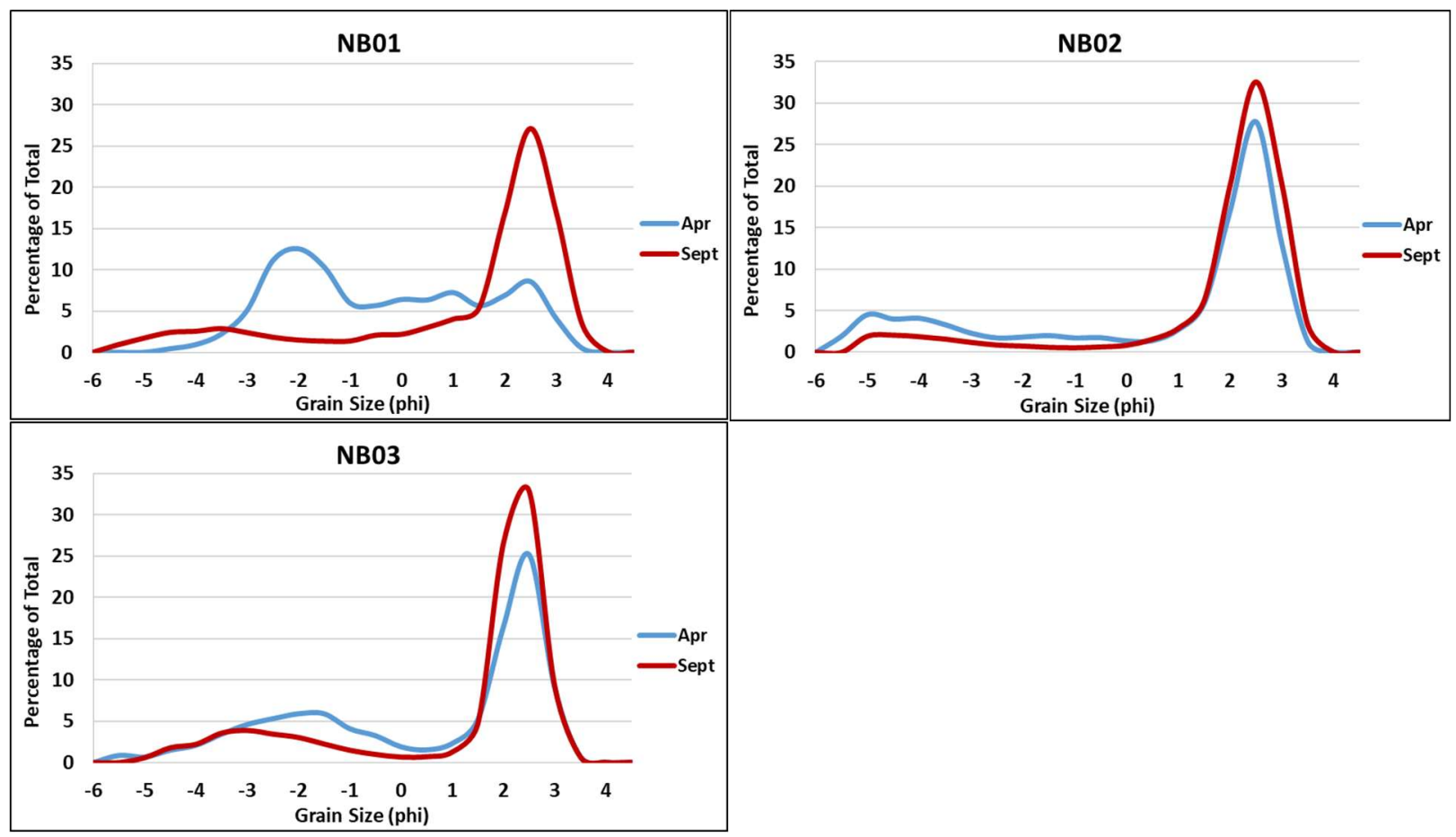

Figure NB-12. Average grain size distributions for stations NBO1, NBO2, and NBO3 in April (blue) and September (red) 2017, pooled for a station for each time period.

Table NB-2. Comparison of average grain size statistics for each of the cross-beach transects at North Beach, NH. The average for each beach and season (winter erosive beach and summer accretional beach) is based on pooling all data from that station (n). NBO4 was not included in averages as it was not re-sampled in September.

\begin{tabular}{|c|c|c|c|c|c|c|}
\hline & \multicolumn{2}{|c|}{ NB01 } & \multicolumn{2}{|c|}{ NB02 } & \multicolumn{2}{|c|}{ NB03 } \\
\hline & Winter & Summer & Winter & Summer & Winter & Summer \\
\hline & $n=5$ & $n=3$ & $n=4$ & $n=3$ & $n=5$ & $n=3$ \\
\hline Gravel \% & 48.6 & 19.0 & 27.6 & 11.5 & 34.4 & 22.2 \\
\hline Pebble \% & 32.4 & 16.2 & 23.8 & 10.3 & 24.4 & 18.5 \\
\hline Granule \% & 16.3 & 2.7 & 3.8 & 1.1 & 10.0 & 3.7 \\
\hline Sand \% & 51.4 & 81.0 & 72.4 & 88.5 & 65.6 & 77.7 \\
\hline Mud \% & 0.0 & 0.0 & 0.0 & 0.0 & 0.0 & 0.0 \\
\hline Mode 1 (phi) & -2.2 & 2.2 & 2.2 & 2.2 & 2.2 & 2.2 \\
\hline$D_{10}$ (phi) & -2.9 & -3.6 & -4.5 & -2.2 & -3.3 & -3.3 \\
\hline $\mathrm{D}_{10}(\mathrm{~mm})$ & 7.7 & 11.9 & 23.4 & 4.6 & 10.1 & 9.6 \\
\hline $\mathrm{D}_{50}$ median (phi) & -0.9 & 1.9 & 1.8 & 2.1 & 1.5 & 1.9 \\
\hline $\mathrm{D}_{50}$ median $(\mathrm{mm})$ & 1.8 & 0.3 & 0.3 & 0.2 & 0.3 & 0.3 \\
\hline Mean (phi) & -0.6 & 0.8 & 0.1 & 1.8 & 0.4 & 0.6 \\
\hline Mean $(\mathrm{mm})$ & 1.50 & 0.57 & 0.90 & 0.28 & 0.76 & 0.65 \\
\hline Sorting (phi) & 1.99 & 2.30 & 2.77 & 1.57 & 2.30 & 2.21 \\
\hline Skewness (phi) & 0.17 & -0.72 & -0.76 & -0.58 & -0.66 & -0.76 \\
\hline Kurtosis (phi) & 0.71 & 1.45 & 0.82 & 3.18 & 0.67 & 1.71 \\
\hline
\end{tabular}




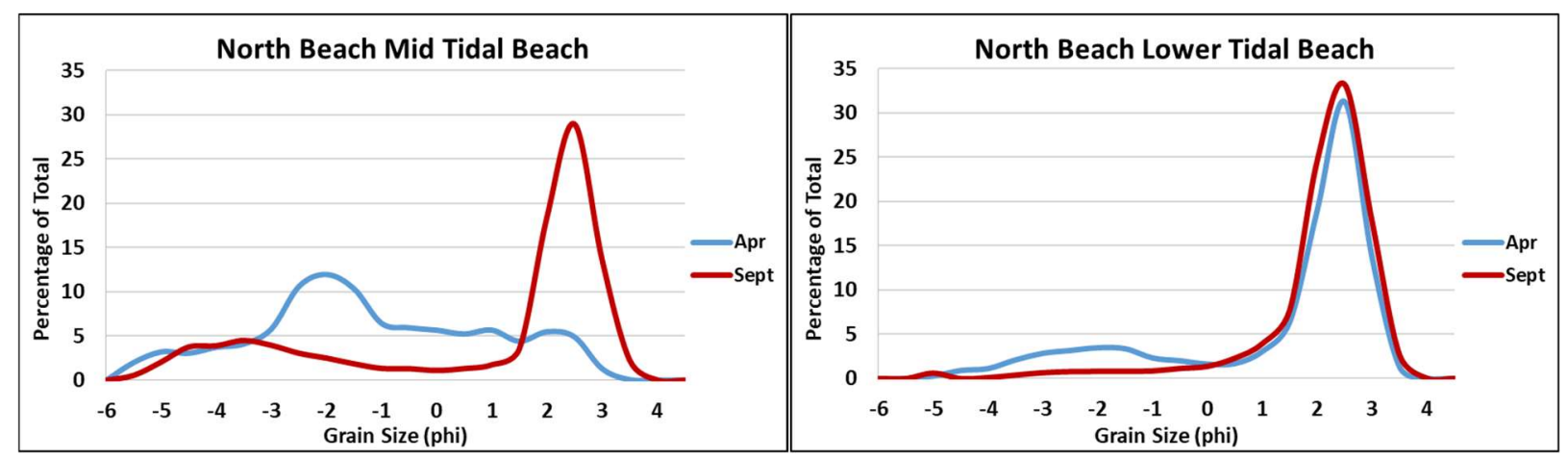

Figure NB-13. Average grain size distributions for stations NB01, NBO2 and NBO3 in April (blue) and September (red) 2017, pooled by elevation for each time period. Only the results for mid tidal beach and lower tidal beach samples are presented here, because the elevations of the beach were too low to include the upper tidal beach NBO4 was not included in averages as it was not re-sampled in September.

Table NB-3. Comparison of average grain size statistics for North Beach, NH sediment samples grouped by elevation into Mid Tidal Beach (MTB) and Lower tidal Beach (LTB), and also separated into late winter (erosive beach) and late summer (accretional beach).

\begin{tabular}{|c|c|c|c|c|}
\hline & \multicolumn{2}{|c|}{ MTB } & \multicolumn{2}{|c|}{ LTB } \\
\hline & Winter & Summer & Winter & Summer \\
\hline & $n=6$ & $n=5$ & $n=8$ & $n=4$ \\
\hline Gravel \% & 61.3 & 27.5 & 19.7 & 5.1 \\
\hline Pebble \% & 44.5 & 24.3 & 14.0 & 3.4 \\
\hline Granule \% & 16.8 & 3.2 & 5.7 & 1.7 \\
\hline Sand \% & 38.7 & 72.4 & 80.3 & 94.9 \\
\hline Mud \% & 0.0 & 0.0 & 0.0 & 0.0 \\
\hline Mode 1 (phi) & -2.2 & 2.2 & 2.2 & 2.2 \\
\hline$D_{10}(p h i)$ & -4.3 & -4.0 & -2.6 & 0.5 \\
\hline$D_{10}(\mathrm{~mm})$ & 19.2 & 16.4 & 5.9 & 0.7 \\
\hline$D_{50}$ median (phi) & -1.7 & 1.9 & 1.9 & 2.1 \\
\hline $\mathrm{D}_{50}$ median $(\mathrm{mm})$ & 3.3 & 0.3 & 0.3 & 0.2 \\
\hline Mean (phi) & -1.4 & 0.3 & 0.9 & 1.9 \\
\hline Mean $(\mathrm{mm})$ & 2.64 & 0.79 & 0.54 & 0.26 \\
\hline Sorting (phi) & 2.21 & 2.60 & 1.99 & 0.97 \\
\hline Skewness (phi) & 0.15 & -0.76 & -0.71 & -0.40 \\
\hline Kurtosis (phi) & 0.96 & 0.75 & 1.39 & 1.93 \\
\hline
\end{tabular}




\section{Hampton Beach}

Hampton Beach is a moderately-sized, mesotidal barrier spit $\sim 2.7 \mathrm{~km}$ in length bounded by a glacial drumlin to the north (Great Boars Head) and a tidal inlet (Hampton Inlet) to the south (Figures HB-1, HB2 and HB-3). The barrier is $\sim 0.6 \mathrm{~km}$ in width at its widest location from the Atlantic Ocean to the seaward edge of the extensive back-barrier marshes. Hampton Beach is very dynamic, having frequent overwash events, typically in winter, and nuisance flooding. Hampton Beach is heavily developed with a thriving business district geared towards tourism, numerous vacation homes, and permanent dwellings. Much of Hampton Beach is a NH State Beach and a favorite tourist destination.

The northern $0.3 \mathrm{~km}$ of Hampton Beach is a megaclast platform composed of cobbles and boulders formed by the erosion of Great Boars Head. The rest of the barrier spit is largely sandy. The southern $0.4 \mathrm{~km}$ adjacent to the jetty has a large dune system (Figure HB-3). At this end of Hampton Beach where the dunes are located, the beach is wider and flatter than the mid and northern end, largely due to sediment trapping by the large stone jetty at Hampton Inlet (Figure HB-4). In contrast, mid and northern Hampton Beach has a very wide upper beach (backshore), a steep, well-defined berm, and a wide lower beach or low tide terrace (Figure HB-5). The buildup of sediment at the southern end of the barrier indicates the net longshore drift is towards the south at Hampton Beach. This contrasts with the NH beaches north of Great Boars Head which tend not to have a net longshore drift direction, likely due to the headlands.

Hampton Beach has been extensively modified by man over the last three-quarters of a century. Presently, a continuous series of seawalls extend $\sim 2.0 \mathrm{~km}$ from near Great Boars Head southward to a series of private homes (Figures HB-1 and HB-5). The large dune system adjacent to the jetty was created with dredged sediment from Hampton Harbor in 1934-1935 (Figures HB-3 and HB-4). Hampton Inlet jetty was built in 1934-1935 and was extended in 1966. Hampton Beach has also been nourished a number of times. In November 2019 the southern end of Hampton Beach adjacent to the jetty was nourished with sand dredged from Hampton Harbor. Approximately 24,500 $\mathrm{m}^{3}$ of sand was placed near the jetty and spread northward with a bulldozer. During the late spring and summer months from approximately May to September, much of the beach area is mechanically groomed daily (Figure HB-5; top photograph).

Field Work. The beach elevation profiles were measured and sediment samples collected in 2017 on February 2 (HB01), February 3 (HB02), February 21 (HB03), and March 8 (HB04) following the winter erosional period. Three stations were sampled again on September 17 (HB01, HB02, and HB03). Unfortunately, HBO4 was not sampled in the fall due to an early fall storm causing beach erosion which negated the possibility of sampling accretional conditions. 


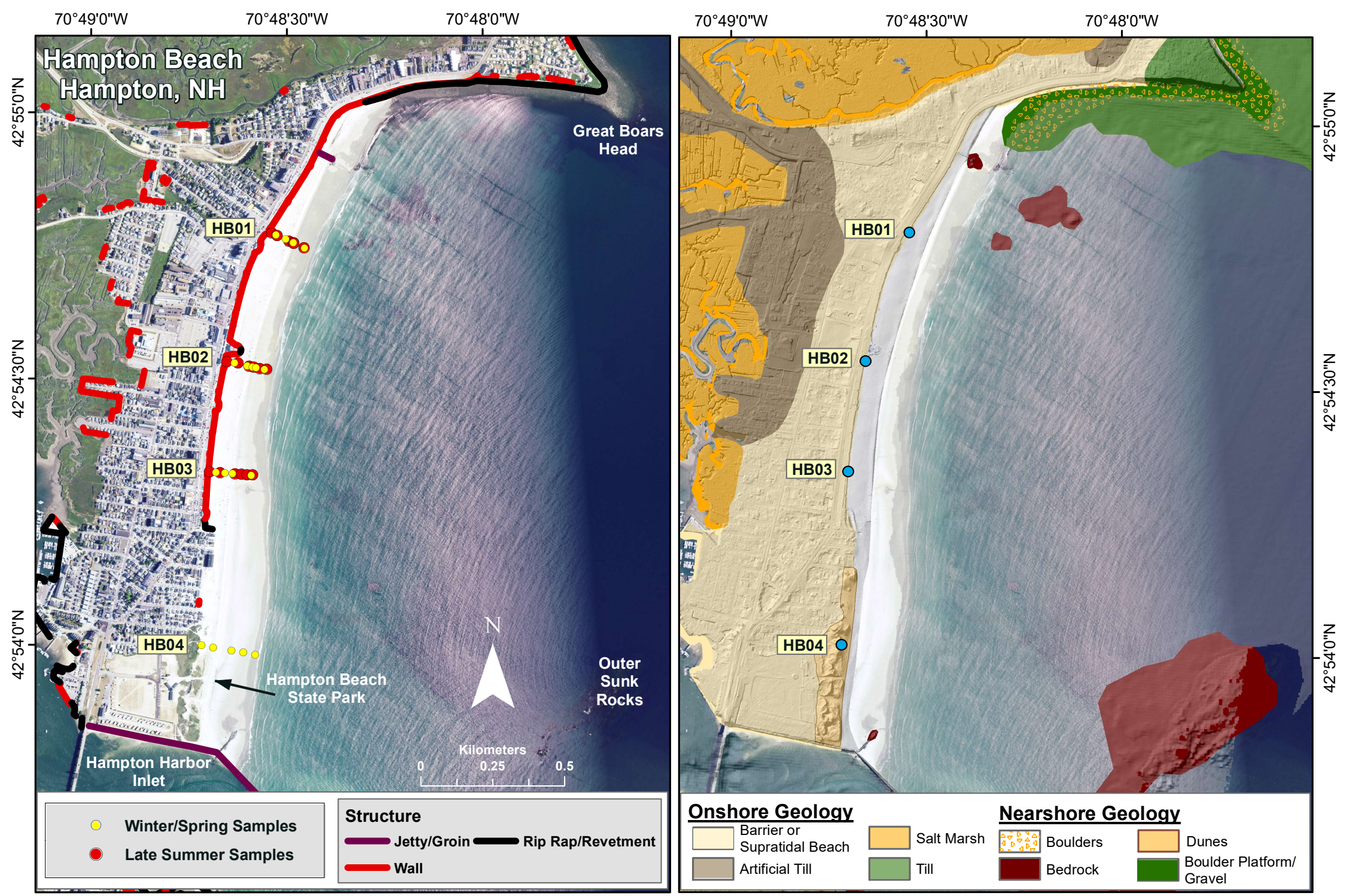

Figure HB-1. Station locations and shoreline structures (from Blondin, 2016) (left) and surficial geology of the upland (from NHGS digital series) and nearshore shelf (from Ward et al., 2021a) (right) for Hampton Beach, NH. The nearshore seafloor not mapped (satellite imagery) is predominantly sand (right). 


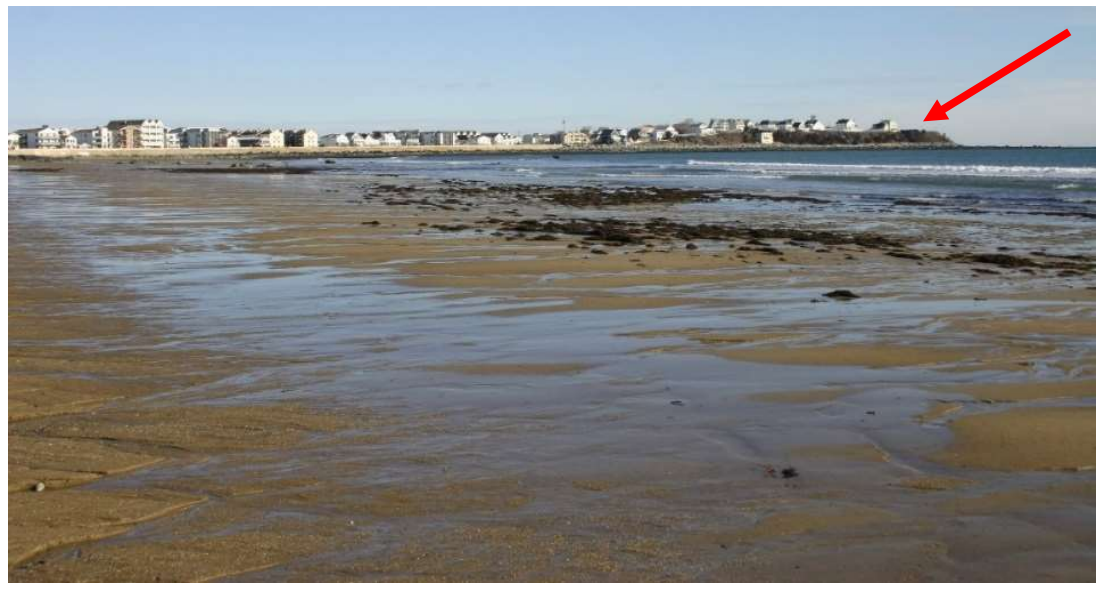

Figure HB-2. Great Boars Head, seen from station HBO1 on February 2, 2017 (arrow), is a glacial drumlin composed of till. Erosion of the headland has led to the development of a large megaclast platform that extends over a kilometer offshore and limits or prohibits the exchange of sediment with the northern $\mathrm{NH}$ beaches.

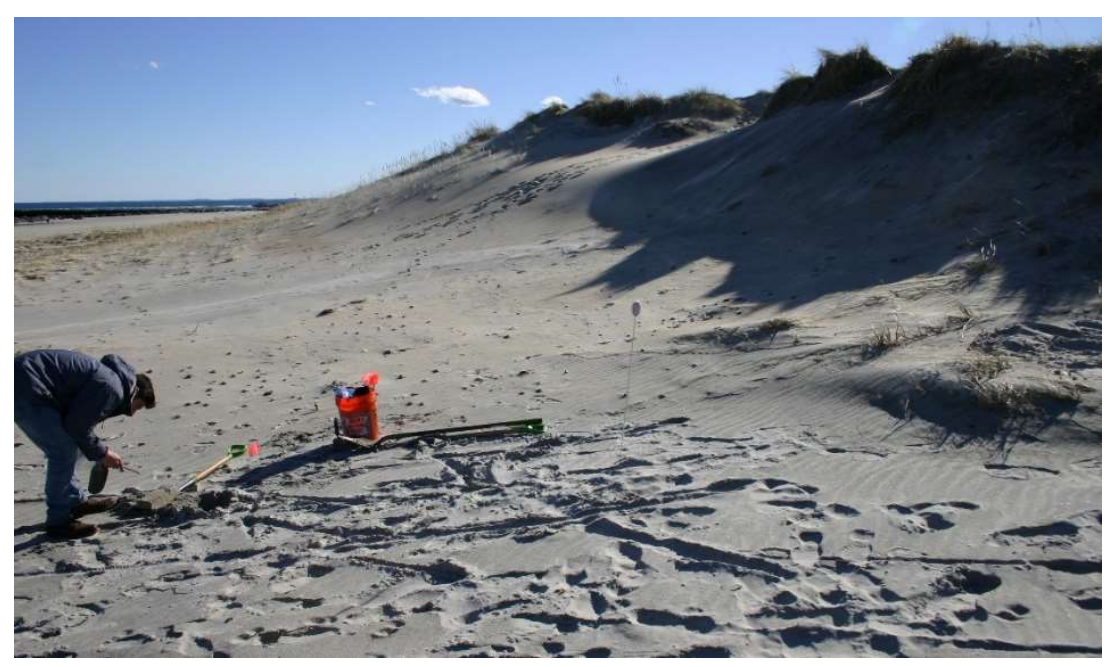

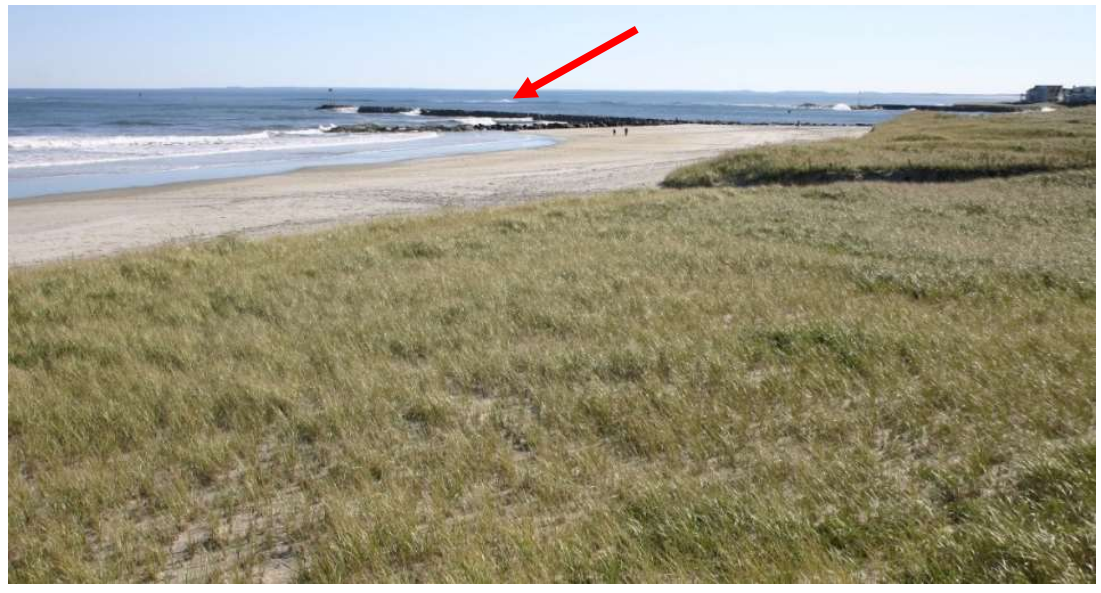

Figure HB-3. The northern jetty at Hampton Inlet (arrow), seen from the dunes at station HBO4 on October 27, 2017, forms the southern boundary of Hampton Beach.

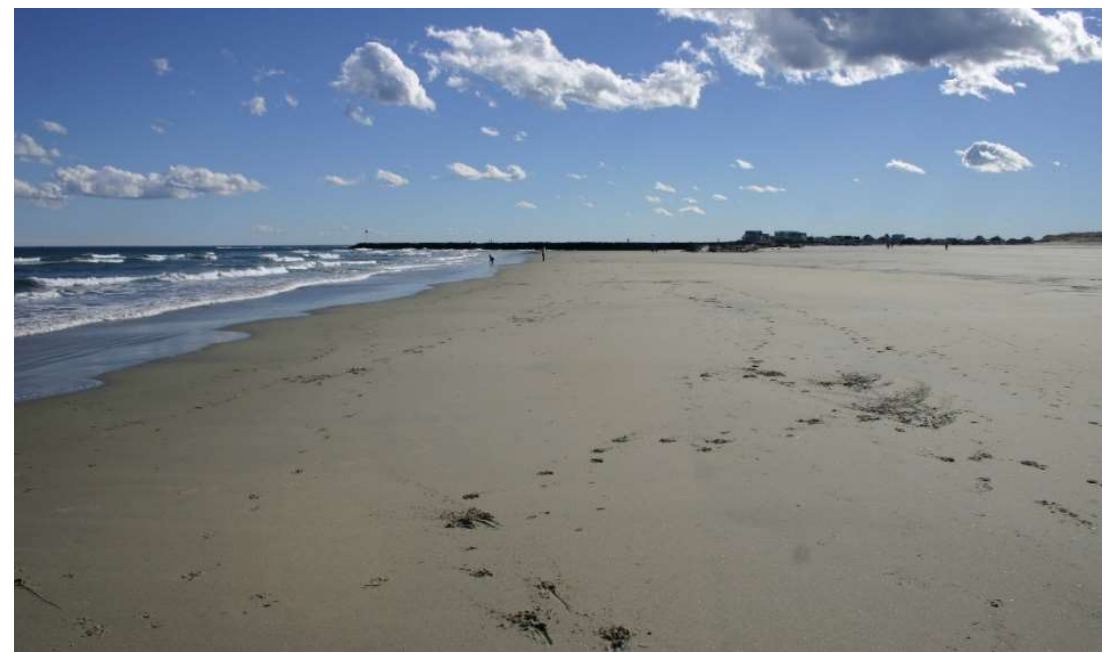

Figure HB-4. In contrast to northern Hampton Beach, the southern end near the jetty has a well-developed and vegetated dune system (left photograph) and the intertidal beach is wide and relatively flat (right photograph). The photographs are looking south from station HBO4 on March 8, 2017. 

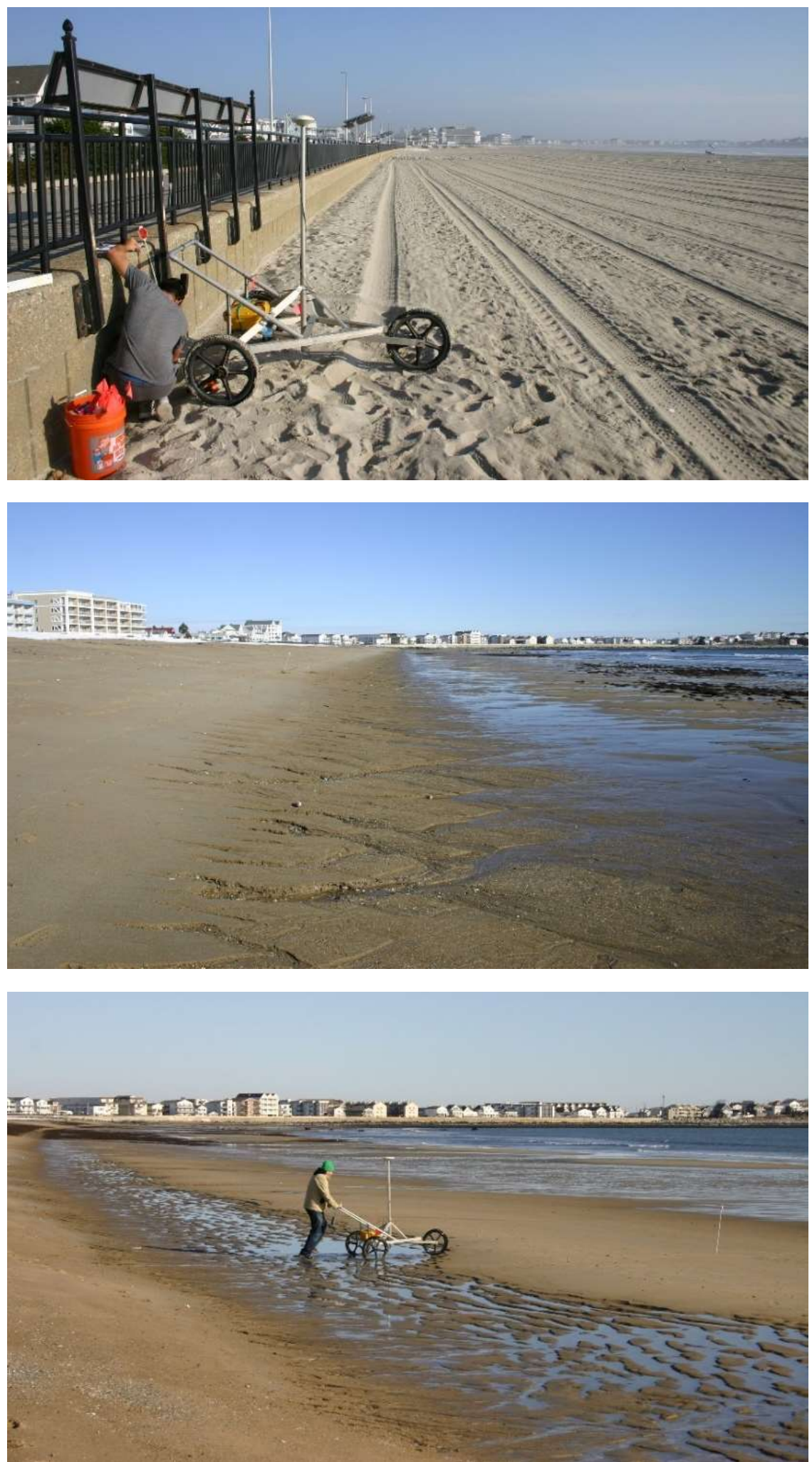

Figure HB-5. Hampton Beach, which is somewhat unusual for NH beaches, has a wide backshore that is frequently groomed (top photograph taken from HBO3 on September 25, 2017), steep berm (middle photograph taken from station HBO1 on February 22, 2017), and a wide, flat low tide terrace that has frequent ridge and runnel systems migrating landward (bottom photograph taken from station HBO2 on February 3, 2017). 
Beach Elevation Profiles. The elevation profiles at Hampton Beach reflect the change in beach morphology from the northern to the southern end of the barrier spit. The northern half of Hampton Beach closer to Great Boars Head is wide with a large, steep berm and a wide low tide terrace (stations HBO1 and HB02; Figures HB-6a and HB-6b). The relief of the beach becomes more subdued and relatively flat at the southern end close to the northern jetty of Hampton Inlet (station HBO4).

Comparison of the February-March and September elevation profiles at HBO1 and HBO2 show conflicting results. At HB01 the February profile indicates the beach was eroded on the lower beach and the at least some of the sand pushed up and onto the berm by wave action. By September, after an extended period of calm conditions during summer, the low tide terrace accreted up to $0.5 \mathrm{~m}$ and the berm had built seaward. The lower elevation of the berm in September compared to February is likely due to the beach being graded with a bulldozer and the sediment pushed seaward, accounting for some of the deposition on the berm face. This is a common practice at Hampton Beach in summer. In contrast, the beach elevation profile at $\mathrm{HB} 02$ shows little change on the lower beach between the February and September profiles. However, similar to HB01, it is apparent that the beach had been graded over the summer, evidenced by the berm and backshore being lower in September than February. It is important to note that the sampling at $\mathrm{HBO} 1$ and $\mathrm{HBO} 2$ was completed before the major winter storms occurred in February 2017. Examination of mean beach elevation at HBO2 measured during a related study (Ward et al., 2021b) indicates the beach was lower after the February storms. Thus, it may be that HBO1 and HBO2 were sampled before the beach had significantly eroded. However, stations $\mathrm{HBO}$ and HBO4 were sampled after the storms and may have reflected greater erosion, but loss of the late summer profiles precludes this determination. 

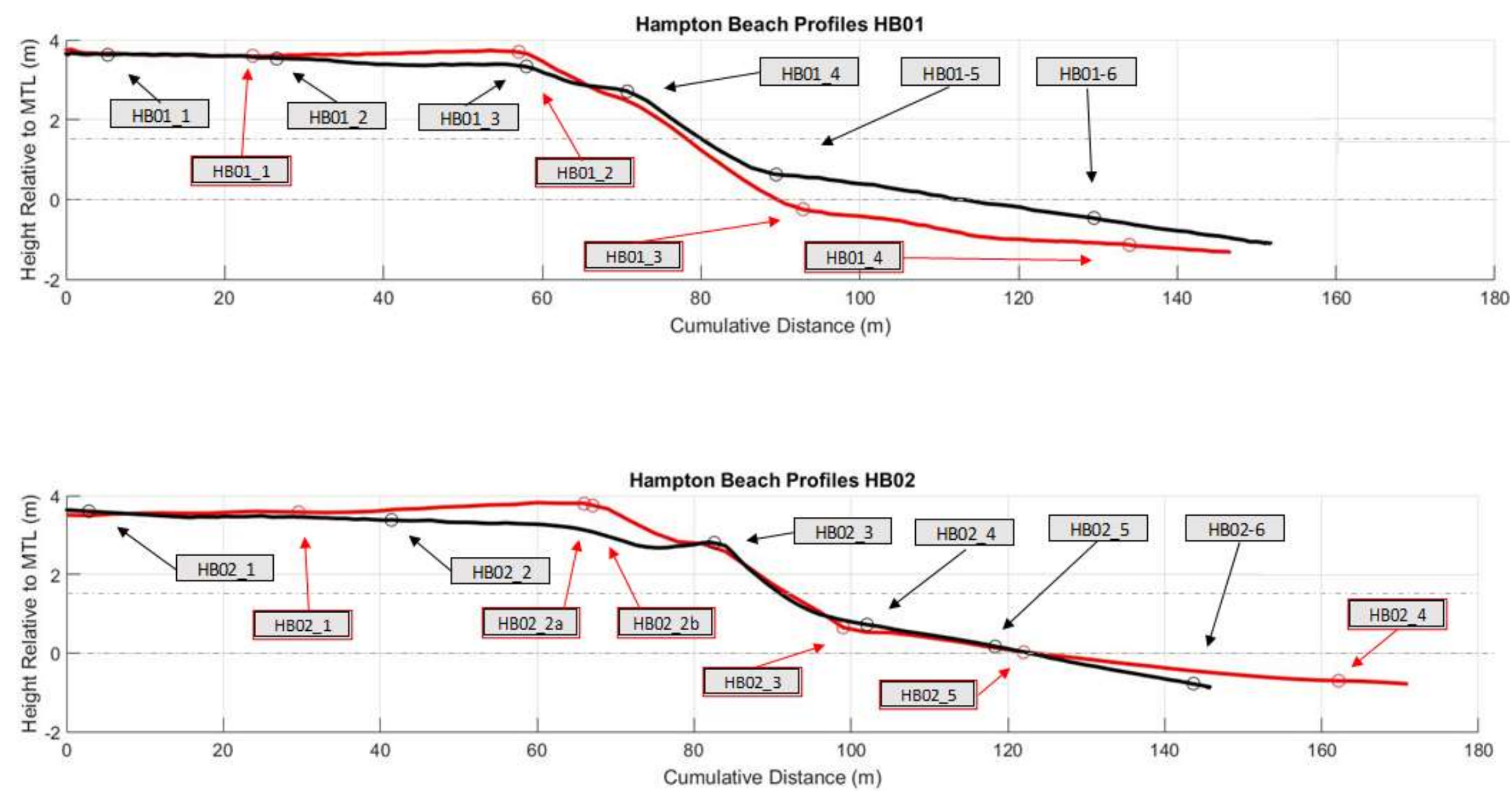

Figure HB-6a. Beach profiles and sediment sample locations from winter and late summer 2017 for stations HBO1 and HB02 at Hampton Beach, NH. Profile HB01 was run and sediment sampled on February 2 (red line/circles/boxes) and on September 17 (black line/circles/boxes). Profile HBO2 was run on April 11 (red) and on September 17 (black). 


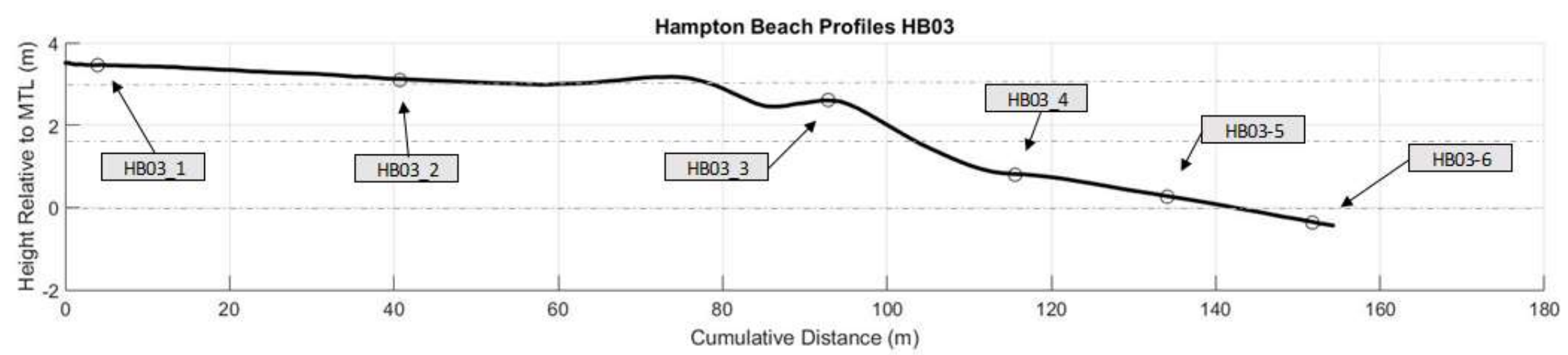

Figure HB-6b. Beach profile and sediment sample locations from late summer 2017 for station HBO3 at Hampton Beach, NH. The profile was run and sediment sampled on September 18 (black line/circles/boxes). 
Beach Sediments. Although Hampton Beach did not appear to be significantly eroded according to the elevation profiles, the sediment composition clearly changed from the first sampling in February and March (following the winter erosional period) to the September sampling (following the summer accretional period) (Figure HB-7). In February the sediments varied from slightly granuley fine sand to sandy granule gravel with most samples being either slightly granuley medium sand or slightly granuley coarse sand. In September the sediments ranged from slightly granuley fine sand to slightly pebbly medium sand with most samples being slightly granuley medium sand (Table HB-1). Although this is a subtle shift, there was a corresponding small fining of the pooled samples from each station in February compared to September (Figure HB-8 and Table HB-2). The increase in phi size ranged from 0.3 to 1.1. There was also a general fining of the grain size from February to September when comparing samples grouped by elevation into upper tidal beach, mid tidal beach, and lower tidal beach. The upper tidal beach increased by $0.5 \mathrm{phi}$, the mid tidal beach increased by $1.3 \mathrm{phi}$, and the lower tidal beach increased by 0.3 phi (Figure HB-9 and Table HB-3).
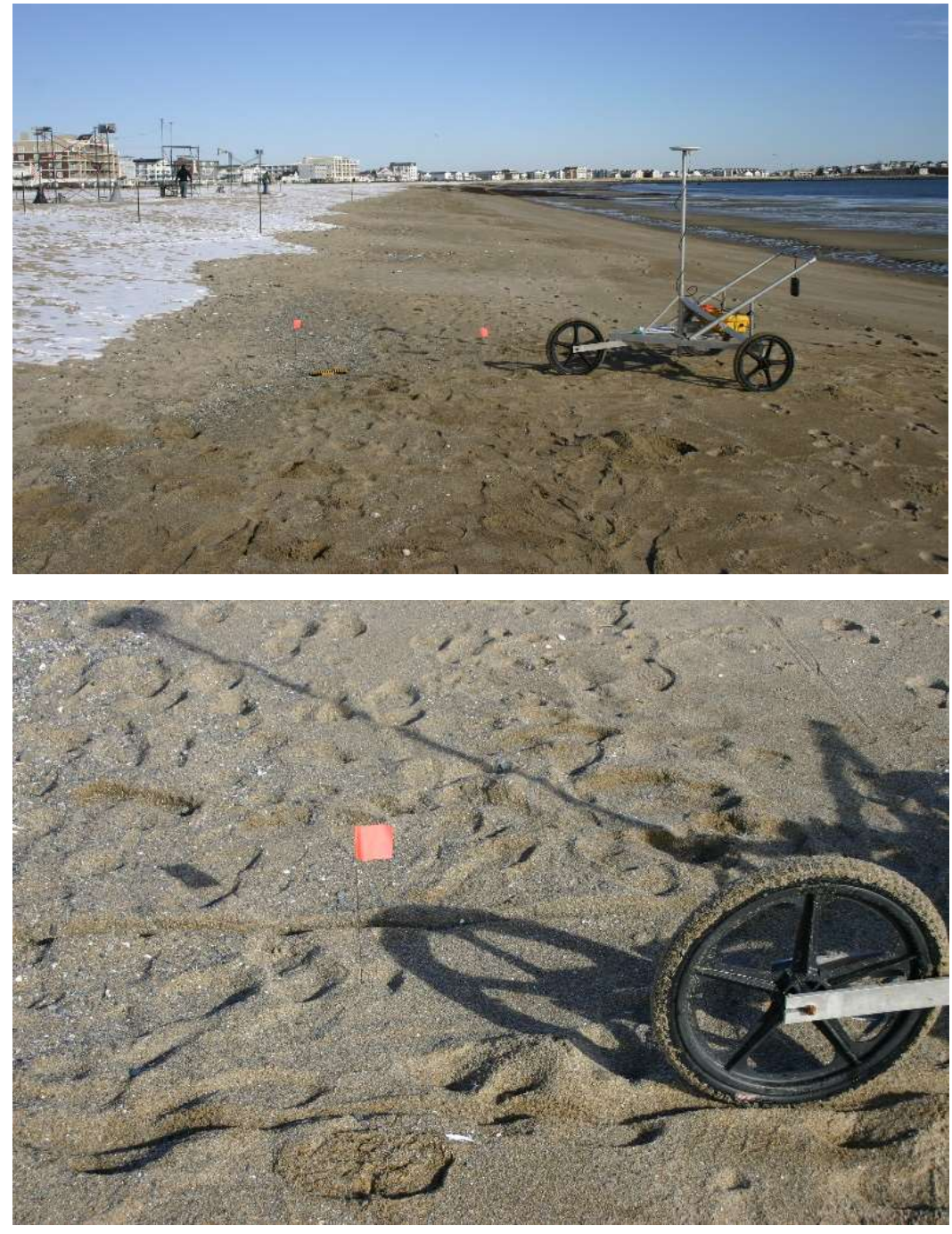

Figure $\mathrm{HB}-7$. Station $\mathrm{HBO} 2$ on February 3, 2017 looking north from the berm crest. The sediment sampling station is shown up close by the red flag in the lower photograph. The sediment was coarser overall in February than September at Hampton Beach. Very coarse sand to granule occurred on the berm crest. 
Table HB-1. Grain size statistics for samples collected at Hampton Beach, NH. More complete summaries of the samples are given in Appendix E.

\begin{tabular}{|c|c|c|c|c|c|c|c|c|c|c|c|c|c|c|c|c|c|c|c|c|c|}
\hline $\begin{array}{c}\text { Sample } \\
\text { ID }\end{array}$ & $\begin{array}{l}\text { Latitude } \\
\text { WGS84 }\end{array}$ & $\begin{array}{c}\text { Longitude } \\
\text { WGS84 }\end{array}$ & $\begin{array}{c}\text { Sample } \\
\text { Collected }\end{array}$ & $\begin{array}{c}\text { Sample } \\
\text { Wt. (gms) }\end{array}$ & $\begin{array}{l}\text { Morphologic } \\
\text { Feature }\end{array}$ & Sediment & $\begin{array}{c}\text { Sediment } \\
\text { Classification }\end{array}$ & Sorting & $\begin{array}{c}\text { Gravel } \\
\%\end{array}$ & $\begin{array}{c}\text { Pebble } \\
\%\end{array}$ & $\begin{array}{c}\text { Granule } \\
\%\end{array}$ & $\begin{array}{c}\text { Sand } \\
\%\end{array}$ & $\begin{array}{c}\text { Mud } \\
\%\end{array}$ & $\begin{array}{l}\text { Mode } \\
\text { Abbrev. }\end{array}$ & $\begin{array}{l}\text { Mode } \\
1 \text { (phi) }\end{array}$ & $\begin{array}{l}\text { Mode } \\
2 \text { (phi) }\end{array}$ & $\begin{array}{c}D_{10} \\
\text { (phi) }\end{array}$ & $\begin{array}{c}D_{50} \\
\text { (phi) }\end{array}$ & $\begin{array}{c}\text { Mean } \\
\text { (phi) }\end{array}$ & $\begin{array}{c}\text { Sorting } \\
\text { (phi) }\end{array}$ & $\begin{array}{c}\text { Skew- } \\
\text { ness }\end{array}$ \\
\hline HB01-1 & 42.912997 & -70.808562 & 2-Feb-17 & $1,005.6$ & Backshore: Mid & Sl. Granular Medium Sand & Medium Sand & MS & 0.35 & 0.10 & 0.25 & 99.49 & 0.16 & U & 1.25 & N/A & 0.09 & 1.04 & 1.03 & 0.75 & 0.00 \\
\hline HB01-2 & 912864 & .808144 & -Feb-17 & 203.2 & Berm Crest & Sl. Granular Coarse Sand & Coarse Sand & MS & 0.47 & 0.06 & 0.47 & 99.52 & .01 & 4 & 0.75 & N/A & -0.31 & 0.58 & 0.60 & 13 & .08 \\
\hline HB01-3 & 912764 & 0.807821 & 2-Feb-17 & $3,081.1$ & Berm Toe & SI. Granular V. Coarse Sand & V. Coarse Sand & MWS & 0.59 & 0.01 & 0.59 & 99.39 & 0.02 & $u$ & 0.24 & $\mathrm{~N} / \mathrm{A}$ & -0.86 & -0.31 & -0.27 & 54 & 0.22 \\
\hline HB01-4 & .912612 & 0.807332 & 2-Feb-17 & 180.0 & LTT: Lower & SI. Granular Coarse Sand & Coarse Sand & MWS & 0.65 & 0.00 & 0.65 & 99.34 & 0.01 & u & 0.75 & $\mathrm{~N} / \mathrm{A}$ & 0.03 & 0.86 & 0.84 & 166 & -0.04 \\
\hline HB01-1 & 42.913053 & -70.808745 & 17-Sep-17 & 3241.5 & re: Near Seawall & SI. Granular Medium Sand & Medium Sand & MS & 29 & 14 & 0.15 & 99.42 & 29 & ᄂ & 75 & N/A & 0.43 & 1.42 & 1.39 & 75 & -0.05 \\
\hline HB01-2 & 42.912980 & -70.808505 & $17-$ Sep-17 & 2429.4 & ckshore: Mid & SI. Granular Medium Sand & Medium Sand & MS & 0.42 & 07 & 35 & 99.31 & 0.27 & u & 25 & N/A & 0.06 & 1.16 & 1.10 & 80 & -0.09 \\
\hline HB01-3 & 42.912815 & -70.807993 & -Sep-17 & 168.1 & rm: Spring & SI. Granular Coarse Sand & Coarse Sand & MWS & 0.23 & 01 & .22 & 99.72 & 0.05 & 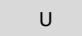 & 25 & N/A & -0.11 & 0.87 & 0.82 & .70 & -0.09 \\
\hline HB01-4 & 42.912759 & -70.807817 & $17-S e p-17$ & 261.4 & Berm: Neap & SI. Granular Medium Sand & Medium Sand & MWS & 0.02 & 00 & .02 & 99.96 & 0.02 & . & 75 & N/A & 0.59 & 1.49 & 1.43 & 63 & -0.13 \\
\hline HB01-5 & 42.912743 & -70.807804 & $17-$ Sep-17 & 60.3 & Landward & SI. Granular Coarse Sand & Coarse Sand & PS & 3.52 & 63 & 89 & 96.46 & 0.02 & u & 25 & N/A & -0.57 & 0.70 & 0.88 & 23 & 0.18 \\
\hline HB01-6 & 912609 & -70.807349 & -17 & 74.2 & T: Swash & SI. Granular Medium Sand & Mediu & & م8 & & 71 & 99.18 & 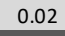 & 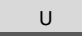 & & N/A & -0.20 & 1.32 & 1.29 & 13 & 0 \\
\hline HBO2-1 & .908963 & -70.810203 & 3-Feb-17 & 42.2 & kshore: Mid & Granular Medium Sand & edium Sand & MWS & 0.14 & 0.05 & 0.09 & 99.67 & 0.1 & u & 1.25 & N/A & 0.19 & 1.12 & 1.1 & 69 & -0. \\
\hline HBO2-2a & .908884 & 0.809677 & 3-Feb-17 & 312.5 & -m Crest; LHTS & Sandy Granule Gravel & Granule & PS & 45.89 & 23.92 & 21.97 & 54.09 & 0.0 & U & 174 & V/A & -2.87 & -0.88 & -1.02 & 1.36 & -0.11 \\
\hline $\mathrm{HBO2-2b}$ & 908881 & -70.809661 & 3-Feb-17 & 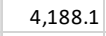 & t: Neap & rse Sand & Sand & MS & 60 & 0.46 & 13 & 97.37 & 0.0 & 4 & .24 & N/A & -0.73 & 0.18 & .27 & .80 & 0.16 \\
\hline HBO2-3 & 908849 & -70.809437 & 3-Feb-17 & $3,470.6$ & rm Runnel; LT & SI. Granular Coarse Sand & Coarse Sand & PS & 4.16 & 1.6 & 51 & 95.84 & 0.0 & $u$ & 0.25 & N/A & -0.59 & 0.57 & 0.64 & 1.00 & 0.08 \\
\hline HBO2-4 & 908826 & 0.809287 & 3-Feb-17 & $4,256.8$ & T: Mid & SI. Granular Coarse Sand & Coarse Sand & MS & 64 & 0.45 & 19 & 98.33 & 0.0 & $u$ & 1.25 & N/A & -0.34 & 0.73 & .71 & 0.80 & -0.0 \\
\hline HBO2-5 & 908773 & 0.808924 & 3-Feb-17 & 0.5 & LTT: Lower & y Medium Sand & Sand & MS & 2.40 & 0.87 & 1.52 & 97.60 & 0.00 & 4 & .25 & N/A & -0.21 & 0.94 & .89 & 0.78 & -0.13 \\
\hline HBO2-1 & 908993 & 0.810533 & $17-$ Sep-17 & 2813.1 & e: Near Seawall & um Sand & Medil & MWS & 0.30 & & 10 & 99.56 & 0.14 & 1 & 25 & $\mathrm{~N} / \mathrm{t}$ & 0.51 & 1.36 & 1.32 & 0.65 & -0.0 \\
\hline $\mathrm{HBO2-2}$ & 42.908961 & -70.810056 & $17-$ Sep-17 & 2307.1 & ckshore: Mid & SI. Granular Medium Sand & Medium Sand & MWS & 0.07 & 0.01 & 06 & 99.85 & 0.08 & $u$ & 1.25 & N/A & 0.44 & 1.29 & 1.26 & 63 & -0.0 \\
\hline HBO2-3 & 42.908873 & -70.809577 & $17-S e p-17$ & 2609.1 & Berm Crest & Medium Sand & Medium Sand & MWS & 0.01 & 0.00 & 01 & 99.98 & 0.01 & 4 & 1.75 & $\mathrm{~N} / \mathrm{t}$ & 0.66 & 1.53 & 1.48 & 0.59 & -0.1 \\
\hline HBO2-4 & .908843 & 0.809382 & -Sep-17 & 25.0 & $\mathrm{~m}$ Toe & SI. Granular Fine Sand & Sand & MWS & 2.03 & 1.36 & 73 & 97.95 & 0.0 & 1 & .24 & N/A & 1.52 & 2.20 & 2.19 & 0.56 & -0.11 \\
\hline HBO2-5 & 42.908807 & -70.809135 & -Sep-17 & 4268.3 & LTT: Mid & SI. Granular Fine Sand & Medium Sand & MS & 0.35 & 0.08 & .27 & 99.63 & 0.02 & $u$ & .24 & N/A & 0.56 & 2.03 & 1.90 & .88 & -0.27 \\
\hline HBO2-6 & 908783 & -70.808826 & Sep-17 & 02.9 & Т: Swash & Granular Medium Sand & Medium Sand & & 50 & & 10 & 98.48 & 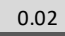 & u & & N/A & -0.02 & 1.36 & 1.38 & 09 & -0.0 \\
\hline HBO3-1 & & 88 & eb-17 & 2 & re: Mid & ranular Medium Sand & Sand & MWS & 3 & & 02 & 99.81 & 0.1 & ( & & N/ & 0.65 & 1.5 & .52 & & -0.04 \\
\hline HBO3-2 & 905509 & 0.810512 & Feb-17 & 85.0 & rm Crest & Medium Sand & Medium Sand & MWS & 0 & 0.0 & 01 & 99.93 & 0.0 & 1 & & $N / A$ & 0.63 & 1.45 & .42 & & -0.06 \\
\hline HBO3-3 & 905498 & 0.810196 & -Feb-17 & 98.3 & erm Toe & . Pebbly Medium Sand & Coarse Sand & MWS & 1. & 0.8 & 35 & 98.83 & 0.0 & 1 & 1.2 & $\mathrm{~N} / \mathrm{A}$ & 0.13 & 1.01 & 0.95 & 50 & -0.1 \\
\hline HBO3-4 & 905468 & 0.809390 & Feb-17 & 633.0 & T: Mid & Sl. Granular Medium Sand & arse Sand & MS & 2.39 & 0.83 & 56 & 97.59 & 0.0 & 4 & 1.25 & N/A & -0.13 & 1.07 & 0.98 & 0.78 & -0.2 \\
\hline HBO3-1 & 905535 & 0.811160 & Sep-17 & 05.4 & ckshore: Near Seawall & Iy Medium Sand & Sand & MWS & 1 & & 0 & 99.90 & 0.0 & 1 & & N/A & 0.94 & 1.63 & 1.61 & 3 & -0.06 \\
\hline НВО3-2 & 42.905520 & -70.810714 & $17-S e p-17$ & 2689.3 & ckshore: Mid & Sl. Granular Medium Sand & Medium Sand & MWs & 0.01 & 0.00 & 01 & 99.86 & 0.13 & 4 & 15 & N/A & 0.74 & 1.57 & 1.56 & 61 & 0.00 \\
\hline HBO3-3 & 42.905496 & -70.810079 & -Sep-17 & 2250.3 & Berm Crest & SI. Granular Medium Sand & Medium Sand & MWS & 12 & 0.02 & 11 & 99.87 & 0.01 & $\mathrm{c}$ & 75 & N/A & 0.61 & 1.58 & 1.53 & 67 & -0.14 \\
\hline HBO3-4 & 42.905484 & -70.809800 & -Sep-17 & 3596.5 & erm Toe & SI. Granular Medium Sand & Medium Sand & MS & 73 & 36 & 38 & 99.26 & 0.01 & $\mathrm{c}$ & 75 & N/A & 0.54 & 1.72 & 1.70 & .87 & -0.08 \\
\hline HBO3-5 & .905475 & -70.809570 & -Sep-17 & 85.7 & п: Mid & SI. Granular Medium Sand & Medium Sand & MS & 48 & .08 & 40 & 99.51 & 0.01 & ᄂ & 75 & N/A & 0.58 & 1.74 & 1.70 & .81 & -0.11 \\
\hline HBO3-6 & .905470 & 0.809348 & Sep-17 & 129.6 & LтT: Swash & SI. Granular Coarse Sand & Coarse Sand & PS & 3.88 & 1.77 & 2.11 & 96.10 & 0.02 & $u$ & 25 & N/A & -0.43 & 0.88 & 0.86 & 1.02 & -0.03 \\
\hline $4 s-1$ & & & $r-17$ & 4 & ; Ed & Sand & and & $\mathrm{N}$ & & & & 99.93 & 0.0 & & & $\mathrm{~N} / \mathrm{A}$ & 1.50 & 2. & 1.16 & & 0. \\
\hline $44-2$ & & 9 & & & & Sand & nd & MWS & 4 & & & 95.15 & 0.0 & 1 & & $\mathrm{~N} / \mathrm{A}$ & 8 & 98 & 99 & 69 & -0.08 \\
\hline $5-3$ & & 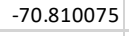 & & & & & & & & & & .07 & & & & /A & 1 & 91 & 83 & & -0.24 \\
\hline & & & & & & & & & & & & & & & & V/A & & Do & 96 & & 13 \\
\hline HBO4s-5 & 899850 & -70.809063 & Mar-17 & 34.0 & Lower & dium Sand & edium Sand & MWS & 0.26 & 0.19 & .07 & 99.71 & 0.03 & U & 1.7 & $\mathrm{~N} / \mathrm{t}$ & 0.75 & 1.73 & 1.72 & 0.70 & -0. \\
\hline
\end{tabular}



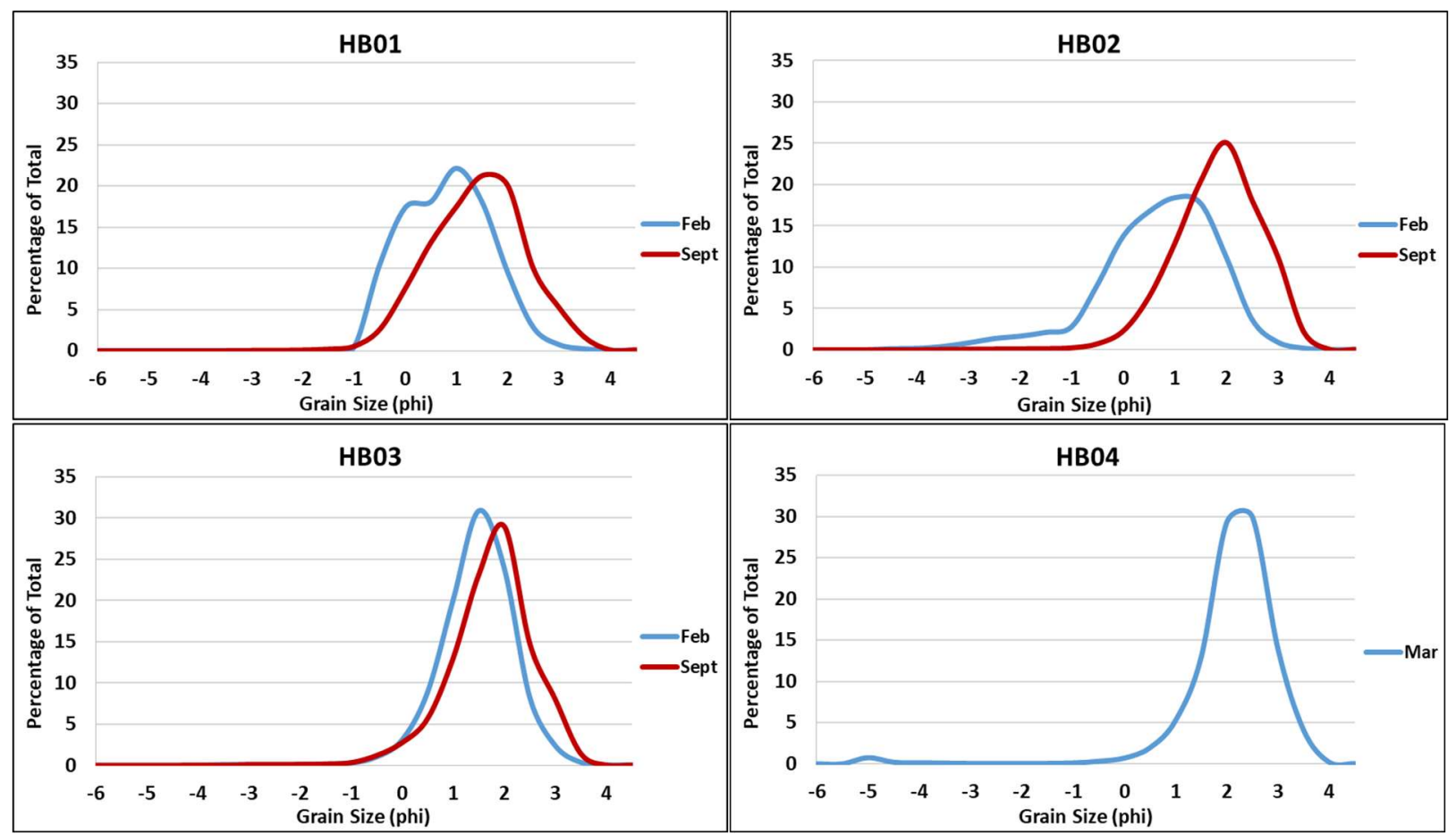

Figure HB-8. Average grain size distributions for all stations at Hampton Beach, NH in February-March (blue) and September (red) 2017, pooled for a station for each time period.

Table HB-2. Comparison of average grain size statistics for each of the cross-beach transects at Hampton Beach, NH. The average for each beach and season (winter erosive beach and summer accretional beach) is based on pooling all data from that station ( $n$ ).

\begin{tabular}{|c|c|c|c|c|c|c|c|}
\hline & \multicolumn{2}{|c|}{ HB01 } & \multicolumn{2}{|c|}{ HBO2 } & \multicolumn{2}{|c|}{ HBO3 } & \multirow{2}{*}{$\begin{array}{l}\text { HB04 } \\
\text { Winter }\end{array}$} \\
\hline & Winter & Summer & Winter & Summer & Winter & Summer & \\
\hline & $n=4$ & $n=6$ & $n=6$ & $n=6$ & $n=4$ & $n=6$ & $n=5$ \\
\hline Gravel \% & 0.5 & 0.9 & 9.5 & 0.7 & 0.9 & 0.9 & 1.4 \\
\hline Pebble \% & 0.0 & 0.2 & 4.6 & 0.3 & 0.4 & 0.4 & 1.3 \\
\hline Granule \% & 0.5 & 0.7 & 4.9 & 0.4 & 0.5 & 0.5 & 0.2 \\
\hline Sand \% & 99.4 & 99.0 & 90.5 & 99.2 & 99.0 & 99.1 & 98.5 \\
\hline Mud \% & 0.1 & 0.1 & 0.0 & 0.0 & 0.1 & 0.0 & 0.0 \\
\hline Mode 1 (phi) & 0.7 & 1.2 & 0.7 & 1.7 & 1.2 & 1.7 & 2.2 \\
\hline$D_{10}(p h i)$ & -0.5 & -0.1 & -1.0 & 0.5 & 0.3 & 0.4 & 1.0 \\
\hline$D_{10}(\mathrm{~mm})$ & 1.4 & 1.0 & 2.0 & 0.7 & 0.8 & 0.7 & 0.5 \\
\hline $\mathrm{D}_{50}$ median (phi) & 0.6 & 1.2 & 0.6 & 1.6 & 1.3 & 1.6 & 2.0 \\
\hline$D_{50}$ median $(\mathrm{mm})$ & 0.7 & 0.4 & 0.7 & 0.3 & 0.4 & 0.3 & 0.3 \\
\hline Mean (phi) & 0.6 & 1.1 & 0.5 & 1.6 & 1.2 & 1.5 & 1.9 \\
\hline Mean $(\mathrm{mm})$ & 0.68 & 0.45 & 0.71 & 0.33 & 0.43 & 0.35 & 0.26 \\
\hline Sorting (phi) & 0.85 & 0.93 & 1.11 & 0.84 & 0.70 & 0.81 & 0.70 \\
\hline Skewness (phi) & -0.02 & -0.06 & -0.17 & -0.09 & -0.06 & -0.10 & -0.14 \\
\hline Kurtosis (phi) & 0.88 & 0.98 & 1.09 & 1.01 & 1.03 & 1.18 & 1.20 \\
\hline
\end{tabular}



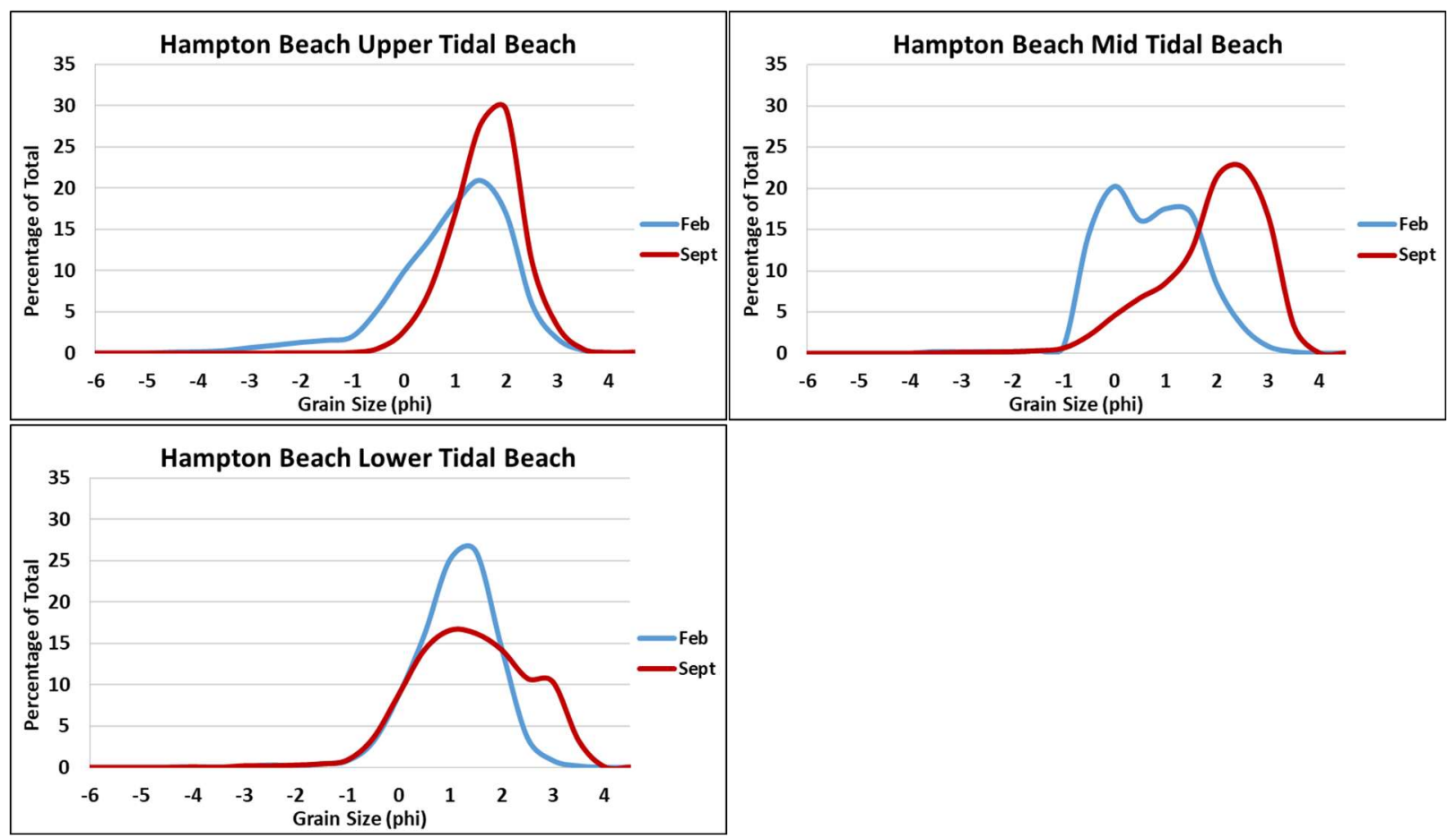

Figure HB-9. Average grain size distributions for stations HBO1, HBO2 and HBO3 in February (blue) and September (red) 2017, pooled by elevation for each time period. Station HBO4 was not included in averaging because it was not re-sampled in September.

Table HB-3. Comparison of average grain size statistics for Hampton Beach, NH sediment samples grouped by elevation into Upper Tidal Beach (UTB), Mid Tidal Beach (MTB), and Lower tidal Beach (LTB), and also separated into late winter (erosive beach) and late summer (accretional beach).

\begin{tabular}{|r|rr|rr|rr|}
\cline { 2 - 7 } & \multicolumn{2}{c|}{ UTB } & \multicolumn{2}{c|}{ MTB } & \multicolumn{2}{c|}{ LTB } \\
& Winter & Summer & Winter & Summer & Winter & Summer \\
\cline { 2 - 7 } Gravel \% & $\mathrm{n}=7$ & $\mathrm{n}=10$ & $\mathrm{n}=3$ & $\mathrm{n}=5$ & $\mathrm{n}=4$ & $\mathrm{n}=3$ \\
\hline Pebble \% & 7.1 & 0.1 & 2.0 & 1.4 & 1.8 & 2.1 \\
Granule \% & 3.5 & 0.0 & 0.8 & 0.5 & 0.5 & 0.8 \\
Sand \% & 3.6 & 0.1 & 1.2 & 0.9 & 1.2 & 1.3 \\
Mud \% & 92.8 & 99.7 & 98.0 & 98.6 & 98.2 & 97.9 \\
Mode 1 (phi) & 0.1 & 0.1 & 0.0 & 0.0 & 0.0 & 0.0 \\
D 10 (phi) & 1.2 & 1.7 & -0.2 & 2.2 & 1.2 & 1.2 \\
D10 (mm) & -0.7 & 0.4 & -0.7 & 0.1 & -0.2 & -0.2 \\
D50 median (phi) & 1.6 & 0.7 & 1.6 & 0.9 & 1.1 & 1.2 \\
D $_{50}$ median (mm) & 0.9 & 1.4 & 0.4 & 1.8 & 0.9 & 1.1 \\
Mean (phi) & 0.5 & 0.4 & 0.8 & 0.3 & 0.5 & 0.5 \\
Mean (mm) & 0.8 & 1.3 & 0.4 & 1.7 & 0.9 & 1.2 \\
Sorting (phi) & 0.58 & 0.39 & 0.74 & 0.32 & 0.55 & 0.44 \\
Skewness (phi) & 1.09 & 0.69 & 0.91 & 1.01 & 0.75 & 1.11 \\
Kurtosis (phi) & -0.21 & -0.12 & 0.07 & -0.28 & -0.10 & 0.04 \\
& 1.10 & 1.04 & 0.83 & 1.03 & 0.98 & 0.89 \\
\hline
\end{tabular}




\section{Seabrook Beach}

Seabrook Beach, $\mathrm{NH}$ is the northern $2.3 \mathrm{~km}$ of a barrier island that extends $7.8 \mathrm{~km}$ from Hampton Inlet to the entrance to the Merrimack River (Figure SB-1). Salisbury Beach, Massachusetts forms the rest of the barrier. The northern half of Seabrook Beach is relatively wide ( $0.7 \mathrm{~km}$ at the inlet) in comparison to the barrier further south ( $0.3 \mathrm{~km}$ wide at the NH-MA border). This is at least partially the result of being the updrift end of the barrier, which tends to be wider. Examination of aerial photographs indicates that large overwash deposits occur on the landward side of the barrier, suggesting that in the past it was inundated and sand was pushed into the backbarrier.

Unlike almost all other beaches in $\mathrm{NH}$, the Seabrook-Salisbury barrier island has a large dune system that begins $\sim 0.8 \mathrm{~km}$ south of the jetty at Hampton Inlet and extends nearly $3.5 \mathrm{~km}$ southward to the Merrimack River (Figures SB-1 and SB-2). The Seabrook Beach dune system varies in width from 50 to $150 \mathrm{~m}$. They were restored in 1993 and 1994 by the town of Seabrook (who also owns the dunes) to replace the natural dunes that were removed or damaged in the past. In this area the houses are set back from the beach and are afforded protection from storm surges and overwash by the dunes. The $0.8 \mathrm{~km}$ of beach north of the dunes to the southern jetty at Hampton Inlet is comprised of private homes, most with some sort of seawall separating the homes from the beach (Figure SB-3).

North of the dunes, Seabrook Beach typically has a wide backshore landward of a distinct berm, a steep berm face, and a wide flat lower beach or low tide terrace with bedrock outcrops (Figures SB-4 and SB-5). The barrier island is wider here than further south due to the effects of the jetty, offshore bedrock outcrops, and the ebb tidal delta or shoals. These factors dampen wave energy from the northeast and cause wave refraction and drift reversal, allowing the beach to build higher and wider via sand deposition. The backshore is narrower in front of the dune system (Figure SB-6), but the beach still has a distinctive berm, steep beach face, and a flat lower beach or low tide terrace. However, after stormy periods and erosion, the beach remains steep, but it narrows and has a minimal or no low tide terrace. Additionally, small pebbles and granular sediments, as well as shell fragments, become exposed.

Presently, Seabrook Beach (like Hampton Beach) has a relatively large volume of sand and higher elevation compared to NH beaches north of Great Boars Head. The cause of this accumulation is not clear, although it is undoubtedly related to local geology and glacial deposits, as well as wave refraction associated with Hampton Inlet. However, another source of sediment to Hampton Beach and Seabrook Beach is beach nourishment. Due to the need for Hampton Harbor and Seabrook Harbor to be dredged for navigation purposes, sand is periodically placed on Seabrook Beach and Hampton Beach. This occurred as recently as 2012 with $\sim 92,000 \mathrm{~m}^{3}$ of sand placed on Seabrook Beach, and again in 2019 with $\sim 91,750 \mathrm{~m}^{3}$ (Figure SB-7). 


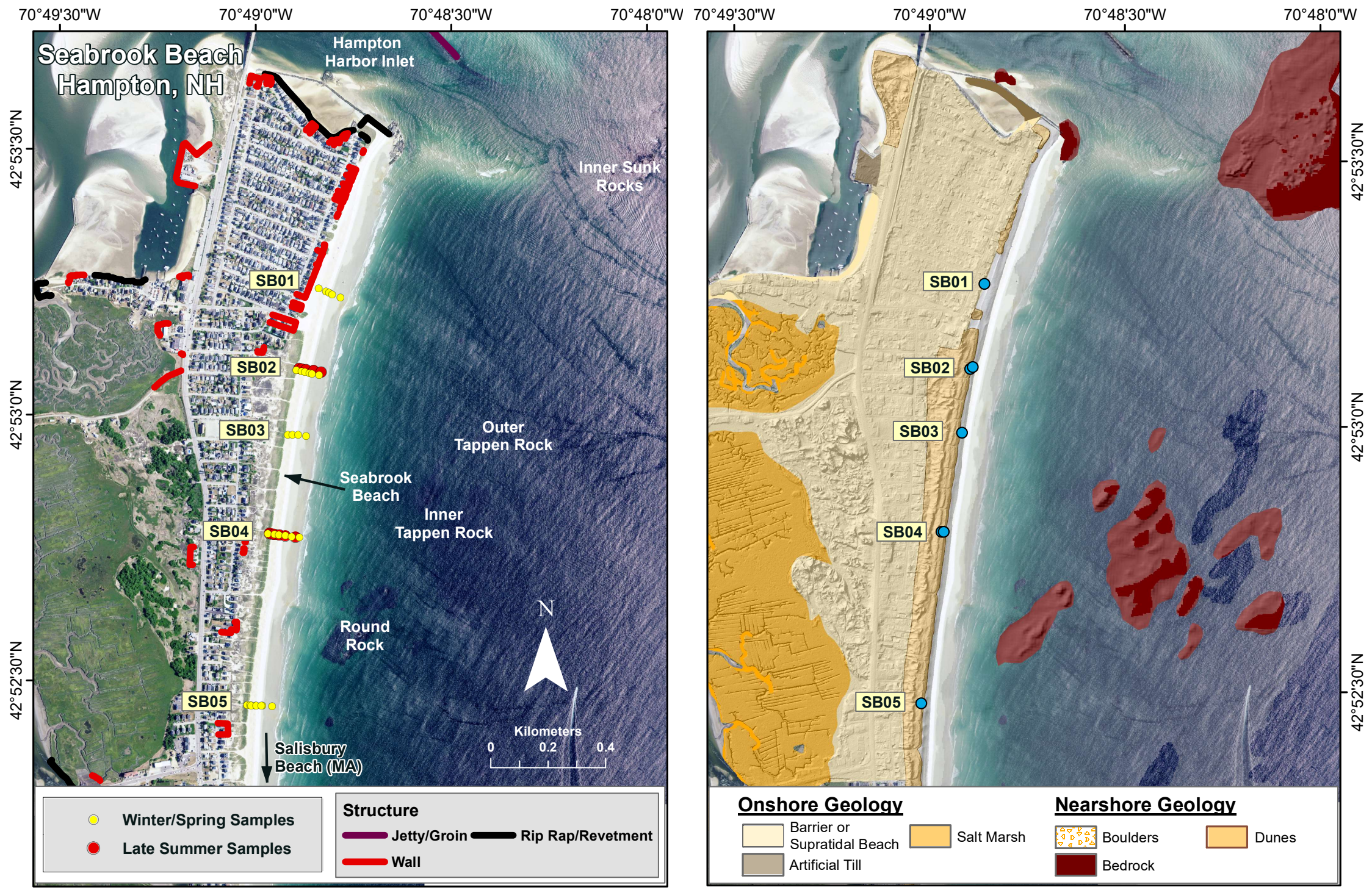

Figure SB-1. Station locations and shoreline structures (from Blondin, 2016) (left) and surficial geology of the upland (modified from NHGS digital series) and nearshore shelf (from Ward et al., 2021a) (right) for Seabrook Beach, Seabrook, NH. The nearshore seafloor not mapped (satellite imagery) is predominantly sand (right). 

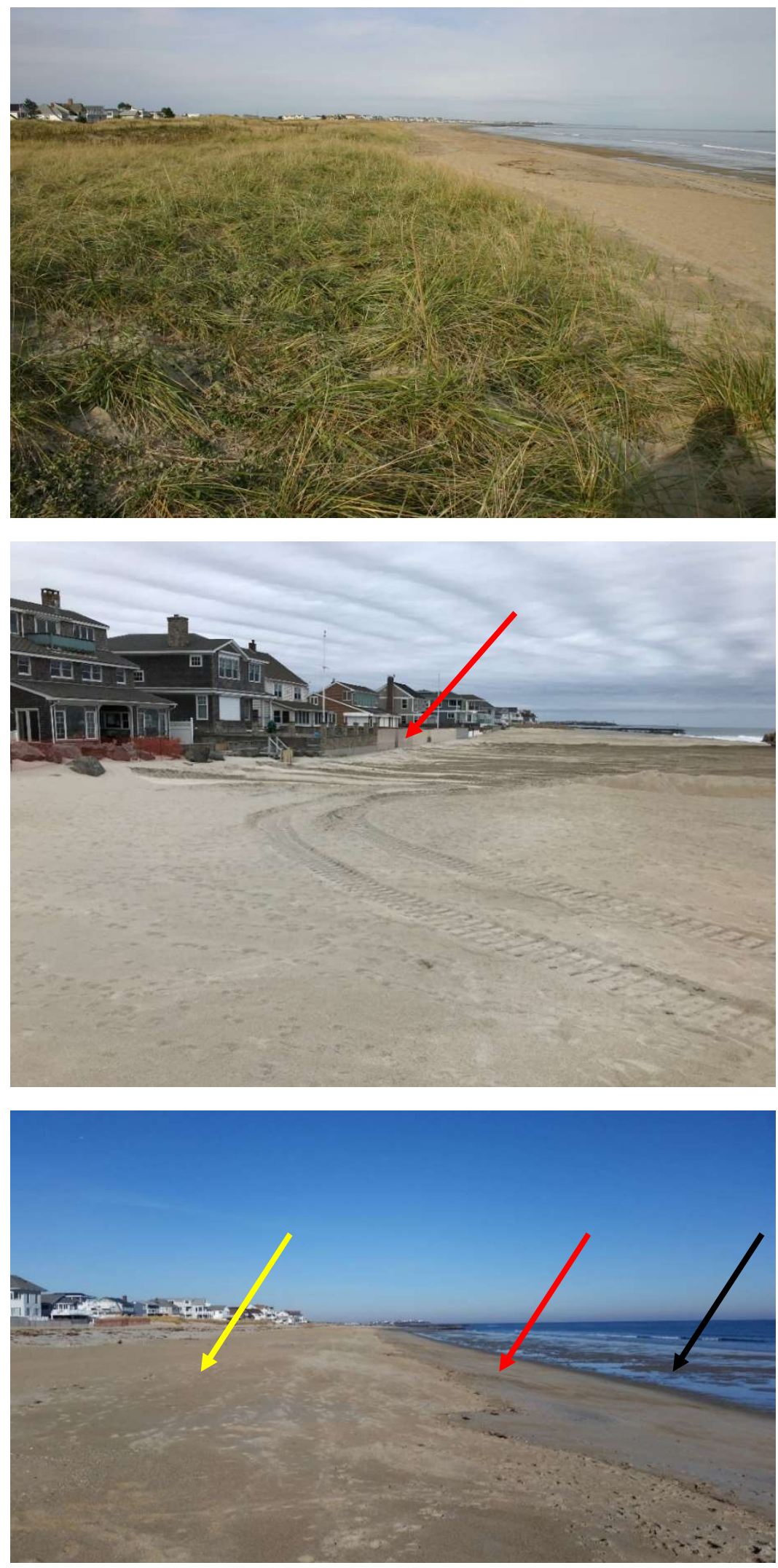

Figure SB-2. The photograph is looking north from station SB04 on November 1, 2017 and shows the wellestablished, extensive dune system.
Figure SB-3. Homes north of the major dunes on Seabrook Beach are typically protected by a seawall (arrow) as shown in this photograph from February 4, 2020. Sand dredged from Hampton and Seabrook Harbor was placed on the beach in late fall 2019.
Figure SB-4. Seabrook Beach looking north on December 6, 2015. Note the wide backshore (yellow arrow), steep berm face (red arrow), and wide lower beach or low tide terrace (black arrow). 

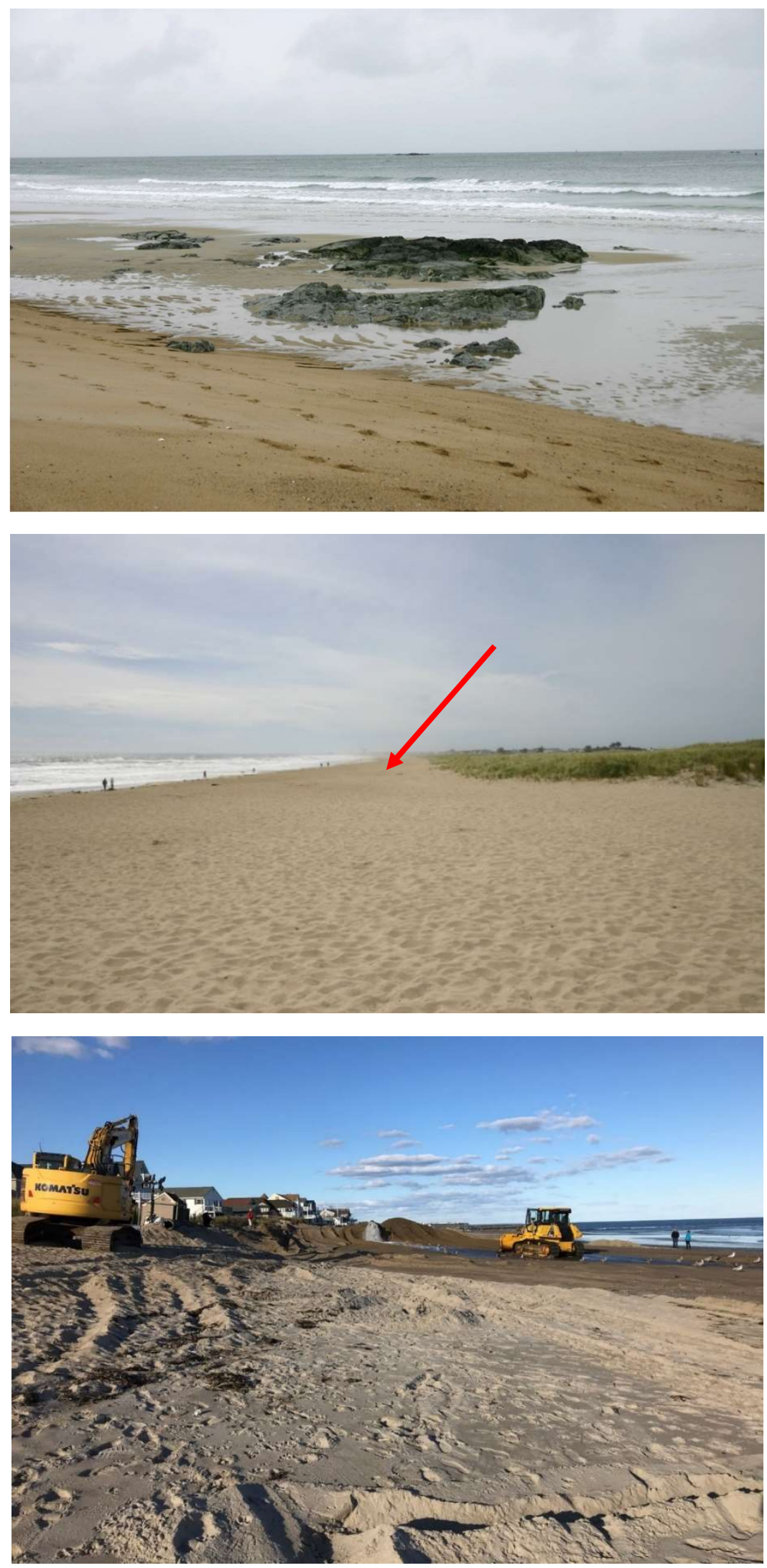

Figure SB-5. Bedrock outcropping on Seabrook Beach close to station SBO1 on March 10, 2017.

Figure SB-6. Seabrook Beach on September 5, 2016 looking south from near station SBO2. Note the upper beach or backshore tends to be narrower (arrow) than the beach to the north.

Figure SB-7. Beach nourishment on Seabrook Beach on October 26, 2019. The sand was pumped onto the beach and then distributed by a power shovel, bulldozer, and ultimately natural processes. 
Field Work. Elevation profiles at Seabrook Beach were measured and sediment samples collected in 2017 on March 10 (SB01 and SB02), March 18 (SB04), and March 20 (SB05) following the winter erosional period. Station SBO3 was sampled later in the spring on May 2 but still had erosional characteristics. Station SB05 was re-sampled also on May 2 because the March 20 sampling occurred during a neap tide and the lower beach was not exposed. Two of the stations were sampled again in the fall on September 18 (SB02 and SB04) to assess how the sediment population changed following an extended period of accretion. Unfortunately, stations SB01, SB03, and SB05 were was not sampled in the fall due to an early storm which eroded the beach. Since the purpose of the fall sampling period was to assess the beach after a long period of accretion, the early fall storm negated this possibility.

Beach Elevation Profiles. The beach profiles at Seabrook Beach (Figures SB-8a and SB-8b) in the area of the dunes are usually relatively steep with a narrow backshore, a distinctive berm, and a wide low tide terrace. The elevation profile at SB02 had an erosional profile on March 10 as shown by the elevation of the low tide terrace (Figure SB-8a). Apparently, sediment from the lower beach was eroded and transported to the upper beach, as the elevation was high on the backshore. At the end of the summer on September 18 the low tide terrace and mid beach at station SB02 had significantly accreted with up to $\sim 1.5 \mathrm{~m}$ of deposition, while the upper beach was lower. The reason for this loss of elevation is not clear, but it is likely the sand was redistributed by a bulldozer or some other mechanical means. This has been observed in the past at Seabrook Beach where the upper beach is graded and sand pushed seaward. Similar patterns were seen at station SB04. In March, station SB04 was eroded on the mid and lower beach as expected, and those areas had recovered by September (Figures SB-8b and SB-9). However, the upper profile at SB04 in March showed accretion on the upper beach which, similar to SB02, is likely related to scouring of the lower beach, causing the upper beach and dunes to be overwashed. This was clearly visible in the field as the foredune grasses were covered with new sand deposits (Figure SB-10). However, by September, the sand that was deposited at the landward edge of the profile appears to be lower by $\sim 0.5$ $\mathrm{m}$, likely due to mechanical manipulation. 

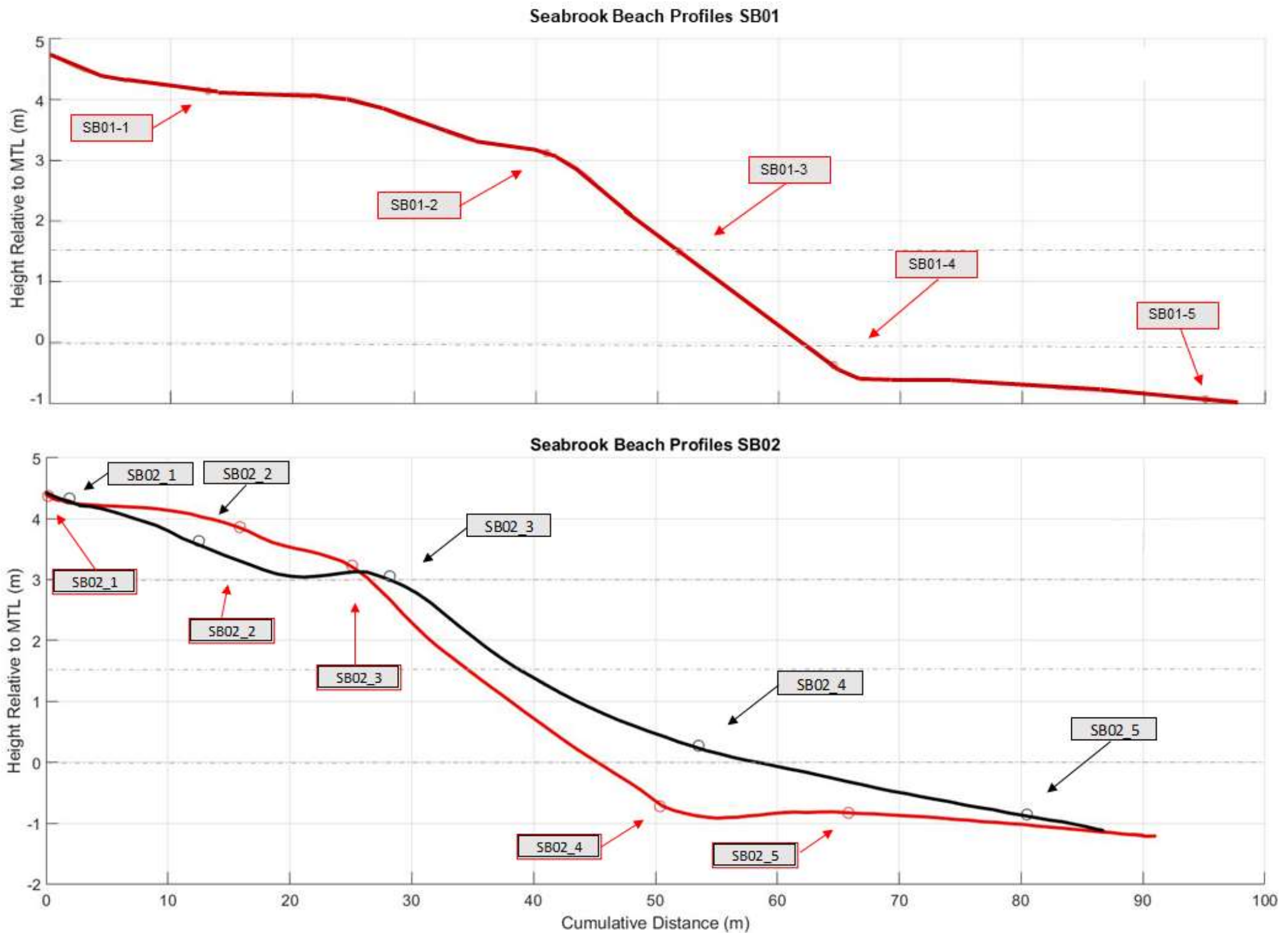

Figure SB-8a. Beach profiles and sediment sample locations from winter and late summer 2017 for stations SB01 and SB02 at Seabrook Beach, NH. Profile SB01 was run and sediment sampled on March 10 (red line/circles/boxes). Profile SBO2 was run on March 10 (red line/circles/boxes) and on September 18 (black). 
Seabrook Beach Profiles SB03
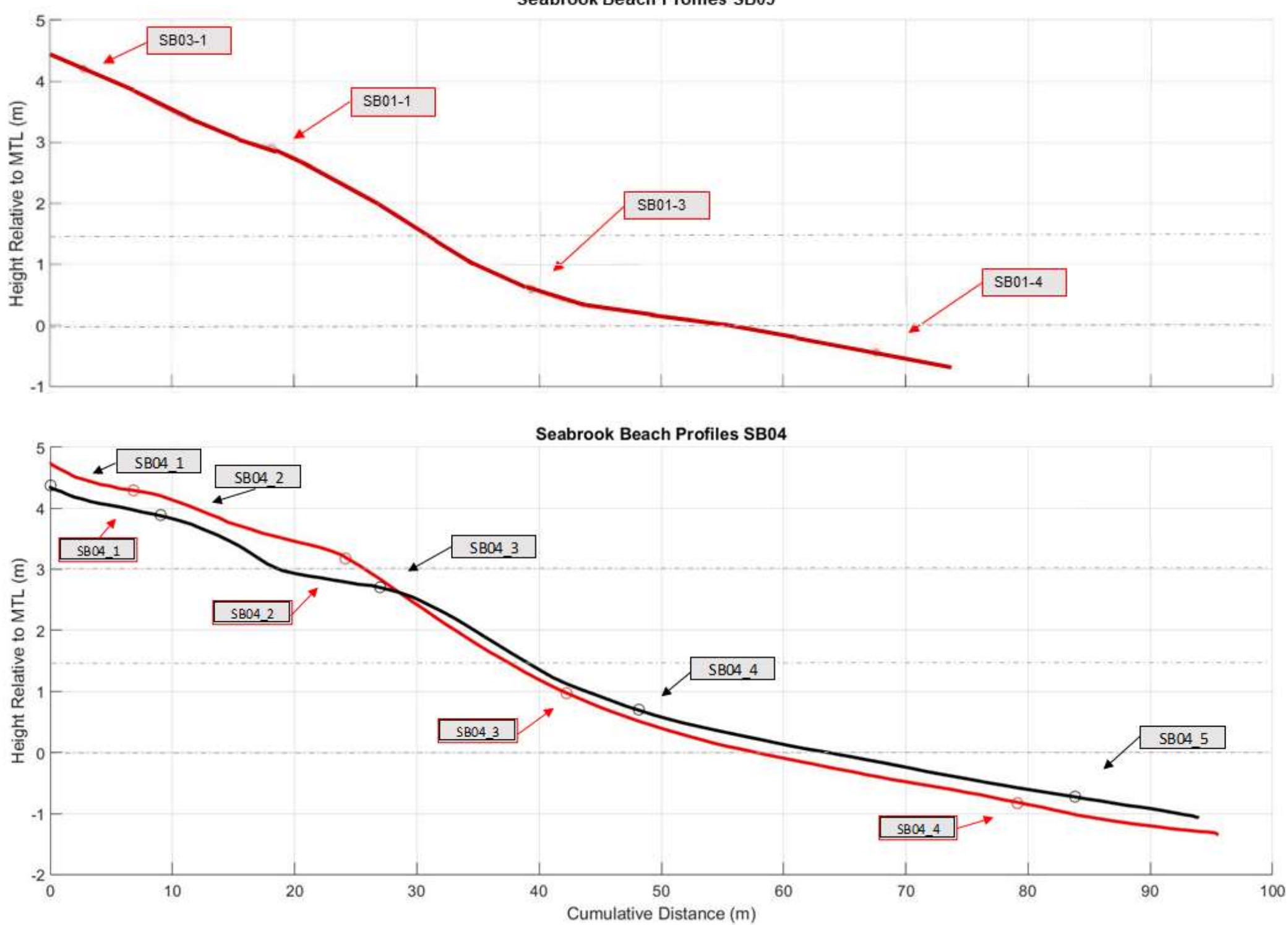

Figure SB-8b. Beach profiles and sediment sample locations from winter and late summer 2017 for stations SB03 and SB04 at Seabrook Beach, NH. Profile SBO3 was run and sediment sampled on May 2 (red line/circles/boxes). Profile SBO4 was run on March 18 (red line/boxes) and on September 18 (black line/circles/boxes). 

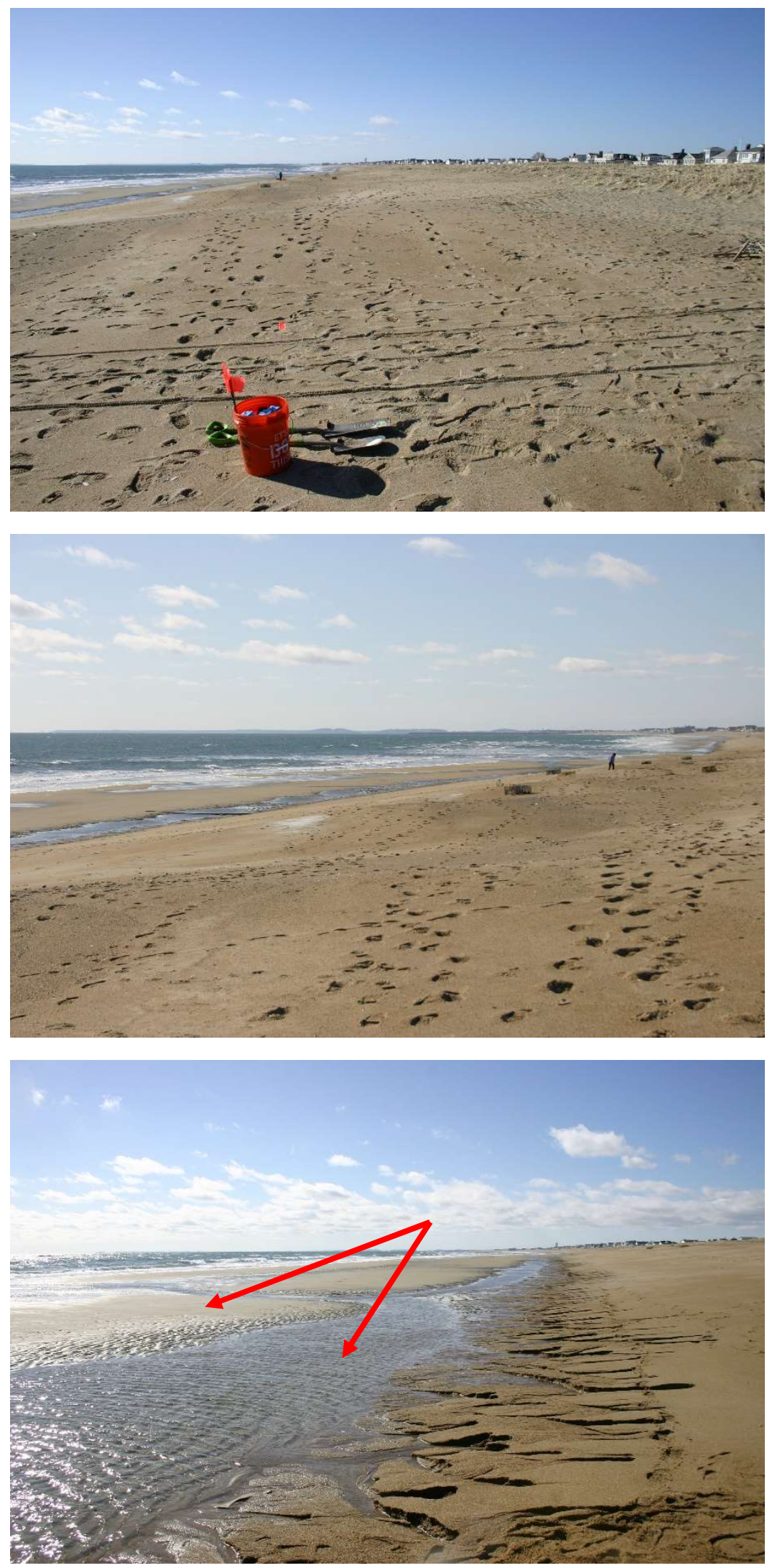

Figure SB-9. Seabrook Beach looking south from station SBO4 on March 18, 2017. During winter storms, sand was scoured from the lower and mid beach and transported to the upper beach (top photograph) and into the dunes (see Figure SB-10). Large cusps had developed on the berm (middle photograph), while the lower beach had been eroded (bottom photograph). However, a large ridge and runnel is present on the lower beach (arrows) indicating the beach was recovering. 


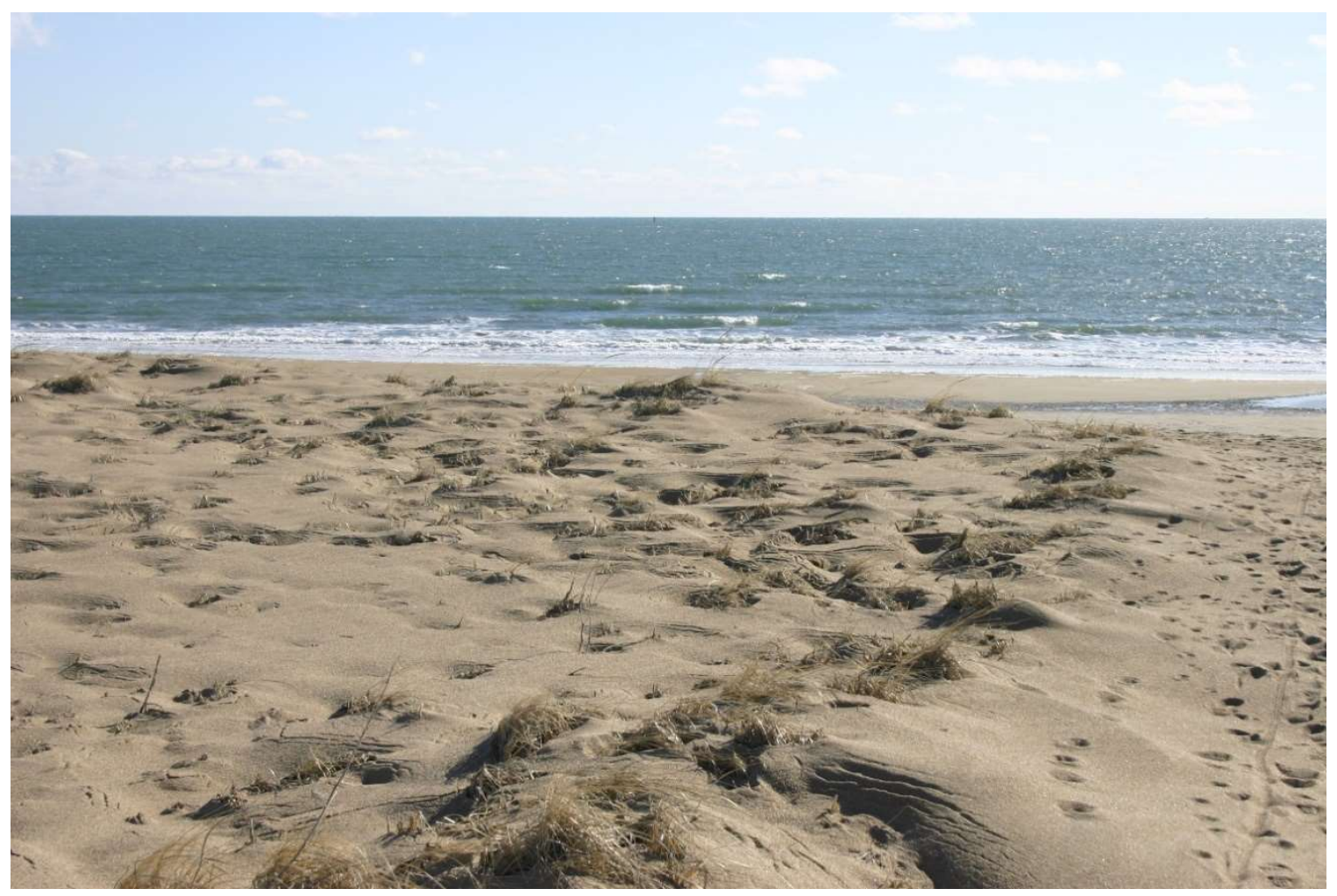

Figure SB-10. Sand overwash deposits in the dunes at station SB04 on March 18, 2017 at Seabrook Beach, NH.

Beach Sediments. The sediments on Seabrook Beach in March and May ranged from slightly granuley medium to very coarse sand (Table SB-1). In the fall the sediments ranged from slightly granuley fine to coarse sand reflecting the deposition of finer sediment over the summer months. This is even more apparent when looking at the station averages for March versus September (Table SB-2). The mean grain size at station SB02 increased by 0.9 phi and SB04 increased by 0.3 phi. Figure SB-11 shows this trend in the histograms of the grain size distribution. Comparison of the station averages also reveals that the alongshore variation between stations is small. Therefore, the samples for SB02 and SB04 which were sampled in the winter and the fall were pooled by elevation. The mean elevation for the upper tidal beach increased by $0.6 \mathrm{phi}$, the mid tidal beach by $2.0 \mathrm{phi}$, and the lower tidal beach increased by 0.9 phi (Table SB-3). This fining is reflected in the grain size distribution, with the September samples being finer and better sorted at all three elevations (Figure SB-12). 
Table SB-1. Grain size statistics for all samples collected at Seabrook Beach, NH in 2017. More complete summaries are given in Appendix E.

\begin{tabular}{|c|c|c|c|c|c|c|c|c|c|c|c|c|c|c|c|c|c|c|c|c|c|}
\hline $\begin{array}{l}\text { Sample } \\
\text { ID }\end{array}$ & $\begin{array}{l}\text { Latitude } \\
\text { WGS84 }\end{array}$ & $\begin{array}{l}\text { Longitude } \\
\text { WGS84 }\end{array}$ & \begin{tabular}{|c|} 
Sample \\
Collected
\end{tabular} & $\begin{array}{c}\text { Sample } \\
\text { Wt. (gms) }\end{array}$ & $\begin{array}{l}\text { Morphologic } \\
\text { Feature }\end{array}$ & Name & $\begin{array}{c}\text { Sediment } \\
\text { Classification }\end{array}$ & Sorting & $\begin{array}{c}\text { Gravel } \\
\%\end{array}$ & $\begin{array}{c}\text { Pebble } \\
\%\end{array}$ & $\begin{array}{c}\text { Granule } \\
\%\end{array}$ & Sand $\%$ & $\begin{array}{c}\text { Mud } \\
\%\end{array}$ & $\begin{array}{l}\text { Mode } \\
\text { Abbrev. }\end{array}$ & $\begin{array}{l}\text { Mode } \\
1 \text { (phi) }\end{array}$ & $\begin{array}{l}\text { Mode } \\
2 \text { (phi) }\end{array}$ & $\begin{array}{c}D_{10} \\
\text { (phi) }\end{array}$ & $\begin{array}{c}\mathrm{D}_{50} \\
\text { (phi) }\end{array}$ & $\begin{array}{c}\text { Mean } \\
\text { (phi) }\end{array}$ & $\begin{array}{c}\text { Sorting } \\
\text { (phi) }\end{array}$ & $\begin{array}{l}\text { Skew- } \\
\text { ness }\end{array}$ \\
\hline SB01-1 & 42.887482 & -70.813685 & 10-Mar-17 & $3,226.2$ & Backshore: Mid & 1. Granular Medium Sand & Medium Sand & MWS & 0.04 & 0.00 & 0.03 & 99.87 & 0.09 & $u$ & 1.25 & N/A & 0.36 & 1.25 & 1.23 & 0.65 & -0.04 \\
\hline SB01-2 & 87391 & .813368 & 10-Mar-17 & 76.3 & Berm Crest; LHTS; Cusps & SI. Granular Coarse Sand & Coarse Sand & MWS & .75 & 0.02 & 0.73 & 99.22 & 0.03 & u & 0.25 & N/A & -0.43 & 0.24 & 0.26 & .58 & 0.05 \\
\hline SB01-3 & 42.887354 & 0.813243 & 10-Mar-17 & 880.7 & Berm Face: Mid & Granular Very Coarse Sand & V. Coarse Sand & MWS & 7.38 & 1.17 & 6.21 & 92.61 & 0.01 & $\mathrm{U}$ & -0.24 & N/A & -0.94 & -0.16 & 0.17 & 65 & 0.00 \\
\hline SB01-4 & 42.887313 & -70.813098 & 10-Mar-17 & 072.3 & Berm Toe & Granular Very Coarse Sand & V. Coarse Sand & MWS & 14.81 & 2.30 & 12.51 & 85.18 & 0.01 & $u$ & -0.74 & N/A & -1.25 & -0.53 & 0.52 & 0.56 & .04 \\
\hline SB01-5 & 887213 & 0.812750 & 10-Mar-17 & 991.7 & LT; Swash & Sl. Granular Medium Sand & Medium Sand & MS & 48 & 0.12 & 0.36 & 99.48 & 0.04 & $u$ & 1.25 & N/A & 0.34 & 1.31 & 1.29 & 0.71 & -0.07 \\
\hline SB02-1 & 42.884902 & -70.814562 & 10-Mar-17 & 522.5 & Dunes: Frontal; Fringe & Coarse Sand & Coarse Sand & MWS & .00 & 0.00 & 0.00 & 9.97 & 0.03 & & 1.25 & N/A & 0.14 & 1.00 & 0.98 & 0.63 & -0.02 \\
\hline SBO2-2 & 42.884868 & -70.814337 & 10-Mar-17 & 188.9 & Backshore: Mid & SI. Granular Coarse Sand & Coarse Sand & MWS & 0.22 & 0.01 & 0.21 & 99.77 & 0.01 & $u$ & .75 & $\mathrm{~N} / \mathrm{A}$ & -0.24 & 0.52 & 0.50 & .54 & -0.05 \\
\hline SBO2-3 & 42.884850 & 0.814192 & 10-Mar-17 & 4,22 & Berm Crest; LHTS; Cusps & SI. Granular Coarse Sand & Coarse Sand & MWS & 1.74 & 0.03 & 1.71 & 98.25 & 0.01 & $u$ & 25 & N/A & -0.64 & 0.10 & 0.12 & 0 & 0.00 \\
\hline SBO2-4 & 42.884822 & -70.814001 & 10-Mar-17 & $5,039.3$ & Berm Face: Mid & Granular Very Coarse Sand & V. Coarse Sand & MWS & 8.74 & 0.73 & 8.01 & 91.25 & 0.01 & u & -0.24 & $\mathrm{~N} / \mathrm{A}$ & -0.97 & -0.21 & -0.22 & 64 & 0.00 \\
\hline SBO2-5 & 884806 & -70.813890 & 10-Mar-17 & 640.5 & Berm Toe & Granular Very Coarse Sand & V. Coarse Sand & MWS & 14.32 & 1.67 & 12.64 & 85.67 & 0.01 & $u$ & .74 & N/A & -1.21 & -0.54 & .53 & .51 & 0.03 \\
\hline SBO2-6 & 42.884766 & -70.813586 & 10-Mar-17 & $2,594.5$ & T; Mid & SI. Granular Medium Sand & Medium Sand & MWS & 0.27 & 0.01 & 26 & 99.70 & 0.03 & $u$ & .25 & $\mathrm{~N} / \mathrm{A}$ & 0.50 & 1.26 & .23 & .58 & -0.13 \\
\hline SB02-1 & 42.884958 & -70.814448 & 18-Sep-17 & 2631.4 & ore: Edge of Dunes & SI. Granular Coarse Sand & Coarse Sand & MS & 0.17 & 0.02 & 0.15 & 99.80 & 0.03 & ᄂ & .75 & N/A & -0.10 & 0.86 & 0.85 & 0.72 & -0.03 \\
\hline SB02-2 & 42.884948 & -70.814321 & 18-Sep-17 & 2786.4 & Backshore: Mid & SI. Granular Coarse Sand & Sand & MS & 1.63 & 0.05 & 1.57 & 98.34 & 0.03 & u & 25 & N/A & -0.67 & 0.27 & 0.33 & .81 & 0.13 \\
\hline SB02-3 & 42.884931 & -70.814131 & 18-Sep-17 & 2457.2 & Berm Crest & SI. Granular Medium Sand & Medium Sand & Mws & 0.20 & 0.01 & 0.19 & 99.79 & 0.01 & $u$ & .25 & N/A & 1.25 & 0.64 & 1.25 & 0.64 & -0.13 \\
\hline SB02-4 & 42.884901 & -70.813823 & 18-Sep-17 & 72.6 & Berm Toe & SI. Granular Fine Sand & Medium Sand & MS & 1.03 & 06 & 0.98 & 98.96 & 0.01 & u & .24 & N/A & .25 & 1.85 & 1.67 & 189 & -0.34 \\
\hline SB02-5 & 42.884870 & -70.813496 & 18-Sep-17 & 84.5 & Т: Mid & Granular Medium Sand & Medium Sand & PS & 1.86 & .07 & 1.78 & 98.13 & 0.01 & u & .75 & N/A & 0.32 & 1.59 & 1.34 & 10 & -0.32 \\
\hline SB03-1 & 882888 & 0.814862 & 2-May-17 & 92.3 & hore; Near Dunes & Granular Coarse Sand & parse Sand & MWS & 04 & 00 & 64 & 9.32 & .04 & & .25 & J/A & -0.3 & 41 & .44 & 1.67 & .11 \\
\hline SBO3-2 & 42.882880 & -70.814674 & 2-May-17 & 769.6 & Berm Crest; LHTS & SI. Granular Coarse Sand & Coarse Sand & MS & 0.14 & 0.00 & 0.14 & 99.83 & 0.03 & $\mathrm{c}$ & 0.25 & N/A & -0.3 & 0.46 & 0.54 & 0.76 & 0.18 \\
\hline SBO3-3 & 42.882870 & -70.814414 & 2-May-17 & $2,971.6$ & Berm Toe & Granular Very Coarse Sand & Coarse Sand & MS & 7.04 & 0.41 & 6.64 & 92.95 & 0.01 & u & -0.24 & N/A & -0.9 & 0.13 & 0.24 & 0.98 & 0.15 \\
\hline SB03-4 & 42.882854 & -70.814070 & 2-May-17 & $2,479.6$ & LTT; Lower & SI. Granular Medium Sand & Coarse Sand & PS & 2.69 & 0.10 & 2.60 & 97.30 & 0.01 & B & 1.75 & -0.24 & -0.66 & 0.91 & 0.79 & 1.06 & -0.14 \\
\hline SB04-1 & 42.879766 & -70.815632 & 18-Mar-17 & 56.4 & Ine; Overwash & . Granular Medium Sand & Medium Sand & M & .05 & 0.0 & 0.0 & 9.92 & 0.03 & & 1.7 & N/A & -0.6 & 1.07 & 1.0 & $1.82-3$ & -0.09 \\
\hline SB04-2 & 42.879740 & -70.815330 & 18-Mar-17 & 372.4 & ckshore: Mid & SI. Granular Coarse Sand & Coarse Sand & MS & 3.57 & 0.12 & 3.45 & 96.40 & 0.03 & $u$ & 0.24 & N/A & -0.7 & 0.22 & 0.25 & 0.81 & 0.06 \\
\hline SBO4-3 & 42.879727 & -70.815144 & 18-Mar-17 & $2,853.7$ & $m$ Crest & SI. Granular Coarse Sand & Coarse Sand & MS & 10 & 0.04 & 55 & 8.90 & oo & $\mathrm{c}$ & 24 & /A & - & 23 & 34 & 78 & .19 \\
\hline SB04-4 & 879707 & -70.814867 & 18-Mar & 562.9 & $\mathrm{~m}$ Toe & Granular Very Coarse Sand & V. Coarse Sand & MS & 0 & 0.54 & 9.16 & 90.30 & 0.00 & u & -0.74 & N/A & -1.0 & -0.38 & 0.28 & 73 & 0.25 \\
\hline SB04-5 & 879687 & -70.814604 & 18-Mar-17 & $2,426.8$ & T: Mid & SI. Granular Medium Sand & Medium Sand & Ms & 0.69 & 0.03 & 0.66 & 99.29 & 0.02 & 4 & 75 & N/A & 0.1 & 1.29 & 1.24 & 0 & -0.13 \\
\hline SB04-6 & 42.879663 & -70.814284 & 18-Mar-17 & 2,48 & T: Swash & Sl. Granular Medium Sand & Medium Sand & MWS & 17 & 0. & .44 & 99.52 & 0.01 & $u$ & .75 & N/A & 0.37 & .41 & .34 & 69 & -0.21 \\
\hline-0.5 :Dune & 42.879767 & -70.815555 & 18-Sep-17 & 3374.9 & Dune & SI. Granular Coarse Sand & Coarse Sand & MS & 13 & 0.00 & 0.13 & 99.85 & 0.02 & $\mathrm{c}$ & .25 & N/A & -0.18 & 0.87 & 0.86 & .77 & -0.04 \\
\hline SB04-1 & 42.879750 & -70.815455 & 18-Sep-17 & 3 & ckshore: Edge of Dunes & SI. Granular Coarse Sand & Coarse Sand & M & 0.24 & 01 & 0.23 & 99.72 & 0.04 & u & .75 & N/A & -0.16 & 0.78 & .80 & 74 & 0.02 \\
\hline SB04-2 & 42.879743 & -70.815347 & 18-Sep-17 & & ckshore: Mid & Sl. Granular Coa & Sand & W & 9 & 0.05 & 2.14 & 97.79 & 0.02 & $u$ & -0.24 & N/A & -0.72 & 15 & .29 & 86 & 0.24 \\
\hline SB04-3 & 42.879726 & -70.815130 & 18-Sep-17 & 60.7 & Berm Crest & Medium Sand & Medium Sand & ws & 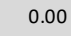 & 0.00 & 0.00 & 100.00 & 0.00 & u & 75 & N/A & 1.29 & .86 & 90 & 44 & 0.06 \\
\hline SB04-4 & 42.879705 & -70.814870 & 18-Sep-17 & 47.4 & m Toe & SI. Granular Fine Sand & Medium Sand & MS & 15 & 0.00 & 0.15 & 99.83 & 0.02 & u & .24 & N/A & 0.59 & 2.00 & 1.84 & 0.77 & -0.35 \\
\hline SB04-5 & 42.879672 & -70.814436 & 18-Sep-17 & 71.5 & ᄂTा: Lower & SI. Granular Fine Sand & Medium Sand & MS & 0.73 & 0.06 & 0.67 & 99.26 & 0.01 & u & 24 & N/A & 0.19 & .87 & .72 & 1.96 & 0.30 \\
\hline SB05-1 & 42.874376 & -70.816350 & 20-Mar-17 & & erwash & Granular Medium Sand & Medium Sand & MS & & & 27 & (2) & 04 & $u$ & 13 & J/A & -0.19 & 14 & .03 & (5) & -0.18 \\
\hline SB05-2 & 42.874374 & -70.816217 & 20-Mar-17 & $3,334.3$ & Backshore: Mid & SI. Granular Coarse Sand & Coarse Sand & MS & 0.96 & 0.15 & 0.80 & 99.00 & 0.04 & $u$ & .75 & N/A & -0.21 & 0.82 & 0.82 & .76 & -0.02 \\
\hline SB05-3 & 42.874371 & -70.815990 & 20-Mar-17 & $3,162.0$ & Berm Crest & SI. Granular Coarse Sand & Coarse Sand & MS & 2.37 & 0.15 & 2.22 & 97.62 & 0.01 & & .24 & $\mathrm{~N} / \mathrm{A}$ & 0.61 & 0.28 & .31 & .72 & 0.04 \\
\hline SB05-4 & 42.874370 & -70.815701 & 20-Mar-17 & $4,982.9$ & $n$ Toe: Water Covering LTT & Granular Very Coarse Sand & 1. Coarse Sand & PS & 17.30 & 5.27 & 12.03 & 82.70 & 0.00 & 4 & -0.24 & N/A & -1.48 & -0.12 & 0.04 & .09 & 0.02 \\
\hline-1 & 4369 & 99 & $2-$ & & ckshore: Near Dunes & ular Coarse Sand & and & MWs & 2 & 0.06 & 0. & 08 & - & & $0.2 .+2>$ & A & -0.43 & 29 & 32 & 65 & 09 \\
\hline SB05-2 & 42.874367 & -70.815956 & 2-May-17 & 79.7 & Berm Crest; Cusps; LHTS SI & SI. Granular Very Co & e Sand & MS & 45 & 12 & 33 & 6.55 & 00 & u & 24 & A & -0.80 & 32 & 40 & 96 & 1.12 \\
\hline 305-3 & 74367 & -70.815735 & 2-May-17 & $2,462.7$ & $\mathrm{~m}$ Toe & Granular Very Co & Sand & PS & 12.30 & 1.45 & 10.85 & 87.68 & 0.02 & u & -0.74 & N/A & -1.15 & -0.16 & 0.14 & 1.13 & 0.31 \\
\hline SB05-4 & 42.874359 & -70.815284 & 2-May-17 & $2,729.2$ & LT; Lower & SI. Granular Fine Sand & Medium Sand & MS & 0.56 & 0.08 & 0.48 & 99.44 & 0.00 & U & 2.24 & N/A & 0.69 & 1.93 & 1.85 & 0.78 & -0.26 \\
\hline
\end{tabular}



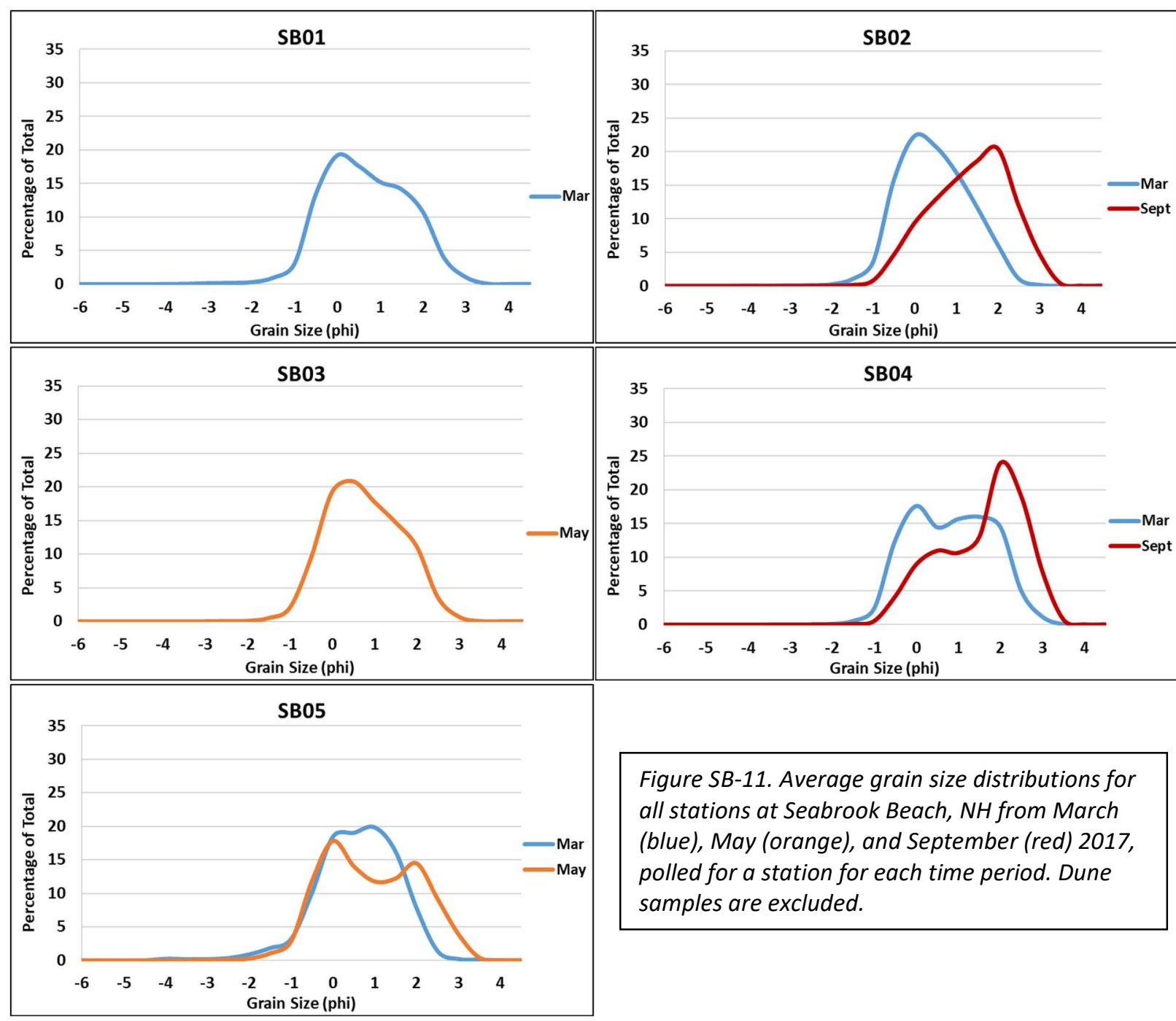

Figure SB-11. Average grain size distributions for all stations at Seabrook Beach, NH from March (blue), May (orange), and September (red) 2017, polled for a station for each time period. Dune samples are excluded.

Table SB-2. Comparison of average grain size statistics for each of the cross-beach transects at Seabrook Beach, NH. The average for each beach and season (winter erosive beach and summer accretional beach) is based on pooling all data from that station ( $n$ ).

\begin{tabular}{|c|c|c|c|c|c|c|c|c|}
\hline & \multirow{2}{*}{\begin{tabular}{c|} 
SB01 \\
Winter
\end{tabular}} & \multicolumn{2}{|c|}{ SB02 } & \multirow{2}{*}{$\begin{array}{c}\text { SB03 } \\
\text { Winter (May) }\end{array}$} & \multicolumn{2}{|c|}{ SB04 } & \multicolumn{2}{|c|}{ SB05 } \\
\hline & & Winter & Summer & & Winter & Summer & Winter (Mar) & Winter (May) \\
\hline & $n=5$ & $n=5$ & $n=5$ & $n=4$ & $n=4$ & $n=5$ & $n=3$ & $n=4$ \\
\hline Gravel \% & 4.7 & 5.1 & 1.0 & 2.6 & 3.1 & 0.7 & 6.9 & 4.3 \\
\hline Pebble \% & 0.7 & 0.5 & 0.0 & 0.1 & 0.2 & 0.0 & 1.9 & 0.4 \\
\hline Granule \% & 4.0 & 4.6 & 0.9 & 2.5 & 3.0 & 0.6 & 5.0 & 3.9 \\
\hline Sand \% & 95.3 & 94.9 & 99.0 & 97.4 & 96.9 & 99.3 & 93.1 & 95.7 \\
\hline Mud \% & 0.0 & 0.0 & 0.0 & 0.0 & 0.0 & 0.0 & 0.0 & 0.0 \\
\hline Mode 1 (phi) & -0.2 & -0.2 & 1.7 & 0.2 & -0.2 & 1.7 & 0.7 & -0.2 \\
\hline $\mathrm{D}_{10}$ (phi) & -0.8 & -0.8 & -0.3 & -0.6 & -0.7 & -0.2 & -0.8 & -0.8 \\
\hline $\mathrm{D}_{10}(\mathrm{~mm})$ & 1.7 & 1.8 & 1.2 & 1.5 & 1.6 & 1.2 & 1.8 & 1.7 \\
\hline $\mathrm{D}_{50}$ median (phi) & 0.4 & 0.2 & 1.2 & 0.4 & 0.6 & 1.5 & 0.4 & 0.6 \\
\hline$D_{50}$ median $(\mathrm{mm})$ & 0.8 & 0.9 & 0.4 & 0.7 & 0.7 & 0.3 & 0.8 & 0.7 \\
\hline Mean (phi) & 0.4 & 0.2 & 1.1 & 0.5 & 0.6 & 1.3 & 0.4 & 0.7 \\
\hline Mean $(\mathrm{mm})$ & 0.75 & 0.86 & 0.47 & 0.70 & 0.67 & 0.40 & 0.77 & 0.63 \\
\hline Sorting (phi) & 0.97 & 0.85 & 0.96 & 0.89 & 0.99 & 1.03 & 0.92 & 1.12 \\
\hline Skewness (phi) & 0.10 & 0.11 & -0.13 & 0.09 & 0.02 & -0.28 & -0.04 & 0.10 \\
\hline Kurtosis (phi) & 0.83 & 0.91 & 0.88 & 0.87 & 0.78 & 0.84 & 0.97 & 0.76 \\
\hline
\end{tabular}



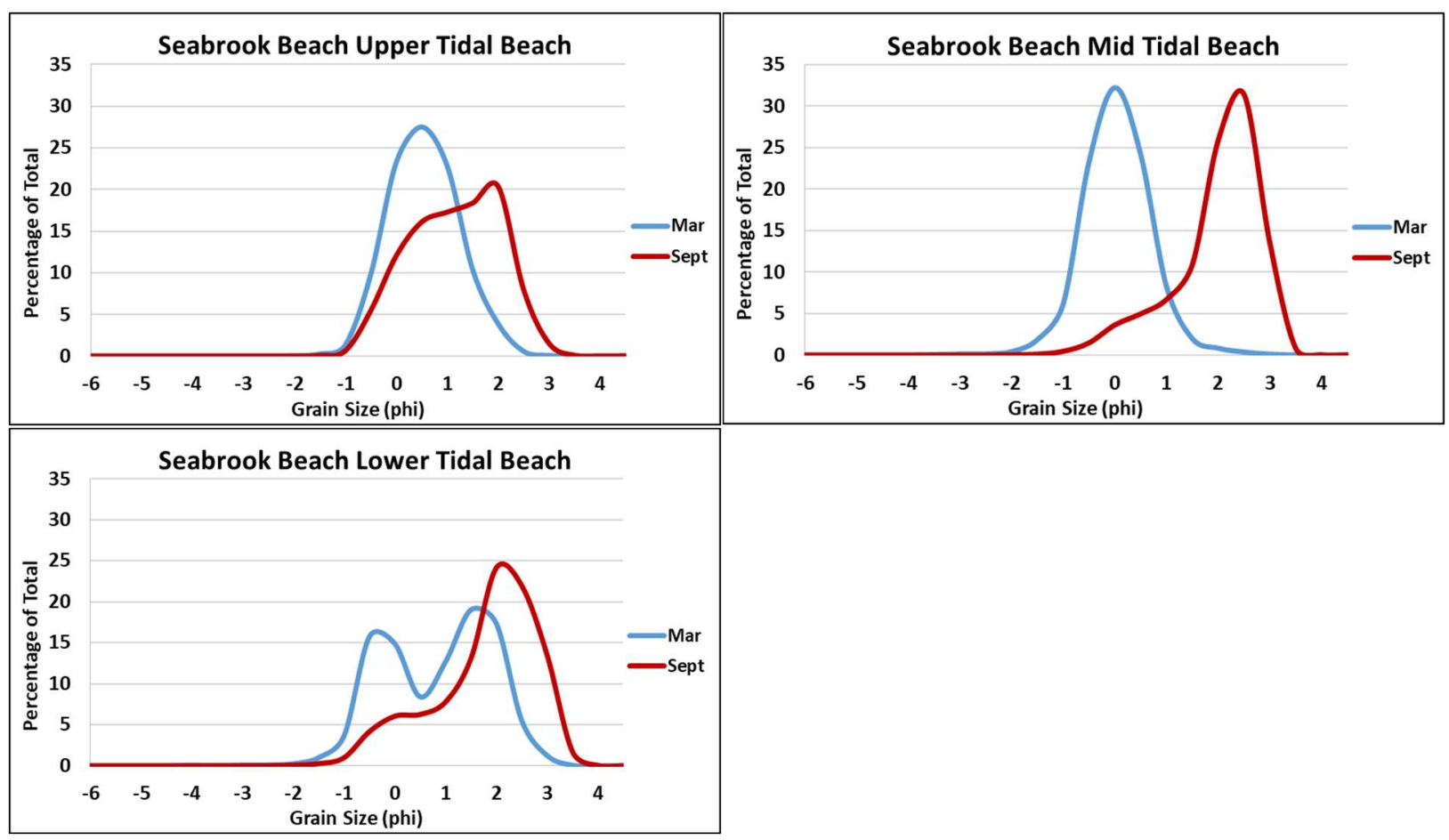

Figure SB-12. Average grain size distributions for stations SB02 and SB04 in March (blue) and September (red) 2017, pooled by elevation for each time period.

Table SB-3. Comparison of average grain size statistics for Seabrook Beach, NH sediment samples grouped by elevation into Upper Tidal Beach (UTB), Mid Tidal Beach (MTB), and Lower tidal Beach (LTB), and also separated into late winter (erosive beach) and late summer (accretional beach). Dune samples are excluded.

\begin{tabular}{|r|rr|rr|rr|}
\cline { 2 - 7 } \multicolumn{1}{c|}{} & \multicolumn{2}{c|}{ UTB } & \multicolumn{2}{c|}{ MTB } & \multicolumn{2}{c|}{ LTB } \\
& Winter & Summer & Winter & Summer & Winter & Summer \\
\cline { 2 - 7 } & $\mathrm{n}=4$ & $\mathrm{n}=6$ & $\mathrm{n}=1$ & $\mathrm{n}=2$ & $\mathrm{n}=5$ & $\mathrm{n}=2$ \\
\hline Gravel \% & 1.7 & 0.7 & 8.7 & 0.6 & 5.1 & 1.3 \\
Pebble \% & 0.1 & 0.0 & 0.7 & 0.0 & 0.5 & 0.1 \\
Granule \% & 1.6 & 0.7 & 8.0 & 0.6 & 4.6 & 1.2 \\
Sand \% & 98.3 & 99.2 & 91.3 & 99.4 & 94.9 & 98.7 \\
Mud \% & 0.0 & 0.0 & 0.0 & 0.0 & 0.0 & 0.0 \\
Mode 1 (phi) & 0.2 & 1.7 & -0.2 & 2.2 & 1.2 & 1.7 \\
$\mathbf{D}_{10}$ (phi) & -0.6 & -0.3 & -1.0 & 0.4 & -0.8 & -0.1 \\
$\mathbf{D}_{10}$ (mm) & 1.5 & 1.3 & 2.0 & 0.7 & 1.8 & 1.1 \\
$\mathbf{D}_{50}$ median (phi) & 0.3 & 1.0 & -0.2 & 1.9 & 0.7 & 1.7 \\
$\mathbf{D}_{50}$ median (mm) & 0.8 & 0.5 & 1.2 & 0.3 & 0.6 & 0.3 \\
Mean (phi) & 0.3 & 0.9 & -0.2 & 1.8 & 0.6 & 1.5 \\
Mean (mm) & 0.82 & 0.54 & 1.16 & 0.30 & 0.66 & 0.35 \\
Sorting (phi) & 0.69 & 0.92 & 0.64 & 0.83 & 1.07 & 1.04 \\
Skewness (phi) & 0.04 & -0.08 & 0.00 & -0.34 & -0.13 & -0.32 \\
Kurtosis (phi) & 0.96 & 0.83 & 1.04 & 1.24 & 0.71 & 1.08 \\
\hline
\end{tabular}




\section{Chapter 7: Summary}

Seasonal changes in sediment grain size statistics were determined in 2017 at seven major beaches along the New Hampshire coast representing the breadth of morphologic and sedimentologic types. Included were Wallis Sands, Foss Beach, Jenness Beach, North Hampton Beach, North Beach, Hampton Beach, and Seabrook Beach. Each beach was sampled along multiple transects as well as at multiple locations along those transects in late winter - early spring (to represent erosional conditions following winter storms) and again in late summer (after an extended period of calm and accretional conditions). The samples were collected along shore-normal transects from seawalls or foredunes to the low tide swash. An elevation profile was measured at each transect during both sampling periods to verify the condition of the beach (whether it was eroded or in equilibrium) and to determine the position of sediment samples with respect to beach morphology. In total, 28 elevation profiles were measured and 140 sediment samples collected at cross-shore transects in late winter - early spring. In late summer 22 elevation profiles were rerun and 97 sediment samples were collected. Unfortunately, six stations were not rerun due to a late summer storm which eroded the beach.

The results for each beach reported here includes a description of the beach and surrounding geology, beach elevation profiles, sediment grain size statistics and size distribution, and a comparison of the average grain size statistics between stations and between seasons. The average grain size statistics were examined using two approaches: first, by averaging the data by station and comparing the late winter early spring versus the late summer sampling periods; and two, by pooling all of the sample statistics by elevation and examining the upper tidal beach, mid tidal beach, and lower tidal beach for each time period. The first comparison was made for all stations where the sediment samples were available for both late winter - early spring and late summer periods. If the variability between stations was relatively small, the samples for all of the stations were also grouped by elevation and the seasonal comparison made to assess changes in grain size from the upper to the lower beach. At several beaches, the variability in sediment grain size was too extreme to pool samples by elevation.

The results of this study provide a baseline for the sediment grain size characteristics of the major beaches along the NH Atlantic coast in both their equilibrium (or accretional) condition after an extended calm period, as well as after an extended period of erosion. All beaches sampled following the summer accretional period had gained elevation and showed a decrease in grain size related to the deposition of fine to medium sand that migrated onshore, often in ridge and runnel systems. The bimodal beaches tended to show the largest change in grain size overall due to scattered pebbles or pebble lag deposits being buried by a sandy accretional wedge. 


\section{References}

Ashtech, 1998, Precise Differential Navigation and Surveying, PNAV: Magellan Corporation.

Balco, G., and Schaefer, J.M., 2006, Cosmogenic-nuclide and varve chronologies for the deglaciation of southern New England: Quaternary Geology volume 1, pp. 15-28.

Bennett, D.S., Chormann, F.H., Jr., Koteff, C., and Wunsch, D.R., 2004, Conversion of surficial geologic maps to digital format in the Seacoast Region of New Hampshire: Digital Mapping Techniques '04-Workshop Proceedings, Portland, Oregon, May 16-19, 2004, U.S. Geological Survey OpenFile Report 2004-1451, 220 pp. (NHGS surficial geology digital map series;

https://www.granit.unh.edu/ , accessed January 2021

Bennett, D.S., Lyons, J.B., Wittkop, C.A., and Dicken, C.L., 2006, Bedrock geologic map of New Hampshire, a digital representation of Lyons and others 1997 map and ancillary files: U.S. Geological Survey Data Series 215, 1 CD-ROM.

Betts, A.K., 2011, Seasonal climate transitions in New England: Weather, volume 66, number 9, pp. 245248.

Birch, F.S., 1984, A geophysical study of sedimentary deposits on the inner continental shelf of New Hampshire: Northeastern Geology, volume 6, number 4, pp. 207-221.

Birch, F.S., 1988, Sediments of the inner continental shelf: first- and second-year projects in New Hampshire: M.C. Hunt, D.C. Radcliff, S. Doenges and C. Condon (eds.), Proceedings of the First Symposium on the Studies Related to Continental Margins - A Summary of Year-One and YearTwo Activities, p. 242-251, U.S. Department of Interior, Minerals Management Service Continental Margins Program and Association of American State Geologists Continental Margins Committee.

Blondin, H., 2016, New Hampshire Inventory of Tidal Shoreline Protection Structures: New Hampshire Coastal Program No. R-WD-16-09, New Hampshire Department of Environmental Services, Portsmouth, New Hampshire.

Blott, S.J., and Pye, K., 2001, Gradistat: A grain size distribution and statistics package for the analysis of unconsolidated sediments: Earth Surface Processes and Landforms, volume 26, number 11, pp. 1237-1248. DOI: 10.1002/esp.261, Accessed March 1, 2020: http://www.kpal.co.uk/gradistat.html.

Bradley, E., 1964, Geology and Ground-Water Resources of Southeastern New Hampshire: USGS WaterSupply Paper 1695, 80 pp. http://doi.org/10.3133/wsp1695.

Donnelly, J.P., Smith Bryant, S., Butler, J., Dowling, J., Fan, L., Hausmann, N., Newby, P., Shuman, B., Stern, J., Westover, K., and Webb III, T., 2001, 700 yr sedimentary record of intense hurricane landfalls in southern New England: GSA Bulletin, volume 113, number 6, pp. 714-727. https://doi.org/10.1130/0016-7606(2001)113<0714:YSROIH>2.0.CO;2

FGDC (Federal Geographic Data Committee, Marine and Coastal Spatial Data Subcommittee), 2012, Coastal and Marine Ecological Classification Standard: FGDC-STD-018-2012, Washington, DC, 343 pp., https://www.fgdc.gov/standards/projects/cmecs-folder/CMECS Version 062012 FINAL.pdf 
Folk, R.L., 1954, The distinction between grain size and mineral composition in sedimentary-rock nomenclature: The Journal of Geology, volume 62, number 4, pp. 344-359.

Folk, R.L., 1980, Petrology of Sedimentary Rocks: Hemphill Publishing Company, Austin, TX. 182 pp.

Fucella, J.E. and Dolan, R., 1996, Magnitude of subaerial beach disturbance during Northeast Storms: Journal of Coastal Research, volume 12, pp. 420-429.

Goldthwait, J.W., Goldthwait, L., and Goldthwait, R.P., 1925, The Geology of New Hampshire: New Hampshire Academy of Science Handbook Number 1, 86 p.

Haddad, T.C. and Pilkey, O.H., 1998, Summary of the New England beach nourishment experience (19351996): Journal of Coastal Research, volume 14, pp. 1395-1404.

Hapke, C.J., Himmelstoss, E.A., Kratzmann, M.G., List, J.H., and Thieler, E.R., 2010, National Assessment of Shoreline Change: Historical Shoreline Change along the New England and Mid-Atlantic Coasts: USGS Open-File Report No. 2010-1118, 56 pp.

Harrison, W. and Lyon, C.J., 1963, Sea-level and crustal movements along the New England-Acadian Shore 4,500-3,000 B.P.: The Journal of Geology, volume 71, pp. 96-108.

Himmelstoss, E.A., Kratzmann, M.G., Hapke, C., Thieler, E.R., and List, J., 2010, The National Assessment of Shoreline Change: A GIS Compilation of Vector Shorelines and Associated Shoreline Change Data for the New England and Mid-Atlantic Coasts: USGS Open-File Report 2010-1119. https://doi.org/10.3133/ofr20101119

Huang, H., Winter, J.M., and Osterberg, E.C., 2018, Mechanisms of abrupt extreme precipitation change over the northeastern United States: Journal of Geophysical Research: Atmospheres, volume 123, pp. 7179-7192. https://doi.org/10.1029/2017JD028136

IPCC, 2014, Climate Change 2014: Synthesis Report. Contribution of Working Groups I, II and III to the Fifth Assessment Report of the Intergovernmental Panel on Climate Change [Core Writing Team, R.K. Pachauri and L.A. Meyer (eds.)], IPCC, Genève, Switzerland, 151 pp.

Keene, H.W., 1970, Salt Marsh Evolution and Postglacial Submergence in New Hampshire. Unpublished MS Thesis, University of New Hampshire, Durham, 87 pp.

Keene, H.W., 1971, Postglacial submergence and salt marsh evolution in New Hampshire, Maritime Sediments, volume 7, pp. 64-68.

Kelley, J.T., Belknap, D.F., and Claesso, S., 2010, Drowned coastal deposits with associated archaeological remains from a sea-level "slowstand": Northwestern Gulf of Maine, USA: Geology, volume 38, pp. 695-698.

Kirshen, P., Wake, C., Huber, M., Knuuti, K., and Stampone, M., 2014, Sea-level Rise, Storm Surges, and Extreme Precipitation in Coastal New Hampshire: Analysis of Past and Projected Future Trends: Science and Technical Advisory Panel, New Hampshire Coastal Risks and Hazards Commission (No. RSA 483-E)

Kottek, M., Grieser, J., Beck, C., Rudolf, B., and Rubel, F., 2006, World map of the Köppen-Geiger climate classification updated: Meteorologische Zeitschrift, volume 15, pp. 259-263. http://doi.10.1127/0941-948/2006/0130 
Leo, M.E., 2000, The Geomorphology, Sedimentology, and Storm Response of Beaches along the Glaciated Coast of the Western Gulf of Maine (New Hampshire and Southwestern Maine): Unpublished MS Thesis, University of New Hampshire, Durham. 123 pp. plus CD.

Lyon, C.J. and Harrison, W., 1960, Rates of submergence of coastal New England and Acadia: Science, volume 132, pp. 295-296.

Lyons, J.B., Bothner, W.A., Moench, R.H., and Thompson, J.B. Jr., 1997, Bedrock Geologic Map of New Hampshire: New Hampshire Department of Environmental Services and the United States Geological Survey, scale 1:1250,000.

Massachusetts Department of Environmental Protection, 2007, Beach Nourishment: MassDEP's Guide to Best Management Practices for Projects in Massachusetts. Boston, MA, $31 \mathrm{pp}$. http://archives.lib.state.ma.us/2452/264126

McKenna, L.A., 2013, Patterns of Bedform Migration and Mean Tidal Currents in Hampton Harbor Inlet, New Hampshire, USA: Unpublished MS Thesis, University of New Hampshire, Durham, 106 pp.

McPherran, K.A., 2017, Seasonal Changes in Geomorphology and Sediment Volume of New Hampshire Beaches: Insights into a Highly-Engineered, Paraglacial, Bedrock Influenced Mixed Sand and Gravel Coastal System: Unpublished MS Thesis, University of New Hampshire, Durham, 149 pp. https://scholars.unh.edu/thesis/1105

Moore, R.B., 1978, Evidence indicative of former grounding-lines in the Great Bay Region of New Hampshire: Unpublished MS Thesis, University of New Hampshire, Durham. 149 pp.

Museum of Natural History Staff, 1996, Natural History of Nova Scotia, Volume 1: Climate. Nova Scotia Museum. https://ojs.library.dal.ca/NSM/issue/view/349

NOAA CO-OPS (National Oceanic and Atmospheric Administration, Center for Operational Oceanographic Products and Services). Tides \& Currents. URL https://tidesandcurrents.noaa.gov/; Accessed January 2020.

NOAA NDBC (National Oceanic and Atmospheric Administration, National Data Buoy Center). URL https://www.ndbc.noaa.gov/ ; Accessed January 2020.

NOAA NOS (National Oceanic and Atmospheric Administration, National Ocean Service), Vertical Datum Transformation. URL https://vdatum.noaa.gov/ ; Accessed January 2020.

NOAA NWS (National Oceanic and Atmospheric Administration, National Weather Service). National Weather Service Forecast Office Gray/Portland, NOWData- NOAA Online Weather Data. URL https://w2.weather.gov/climate/xmacis.php?wfo=gyx ; Accessed January 2020.

NERA (New England Regional Assessment Group), 2001, Preparing for a Changing Climate: The Potential Consequences of Climate Variability and Change, New England Regional Overview: U.S. Global Change Research Program, 96 pp., University of New Hampshire.

New Hampshire Coastal Risk and Hazards Commission, 2016, Preparing New Hampshire for Projected Storm Surge, Sea-Level Rise and Extreme Precipitation. URL http://www.nhcrhc.org/wpcontent/uploads/2016-CRHC-final-report.pdf

Novotny, R., 1969, The Geology of the Seacoast Region of New Hampshire: NH Dept. of Natural Resources, Concord, NH, 46 pp. 
Oldale, R.N, Colman S.M., and Jones, J., 1993, Radiocarbon ages from two submerged strandline features in the Western Gulf of Maine and a sea-level curve for the northeastern Massachusetts coastal region: Quaternary Research, volume 40, pp. 38-45. https://doi.org/10.1006/ares.1993.1054

Olson, N.F., and Chormann, R., 2016, New Hampshire beaches: Shoreline Movement and Volumetric Change: BOEM/New Hampshire Cooperative Agreement (Contract M14ACO0010) Technical Report, BOEM Marine Minerals Branch.

Redfield, A.C. and Rubin, M., 1962, The age of salt marsh peat and its relation to recent changes in sea level at Barnstable, Massachusetts: Proceedings of the National Academy of Science (PNAS), volume 48 , pp. 1728-1735. https://doi.org./10.1073/pnas.48.10.1728

Rockingham Planning Commission (RPC), 1986, Assessment, Impact and Control of Shoreline Change along New Hampshire's Tidal Shoreline Update: 156 Water Street, Exeter, NH. 151 pp.

Sallenger, A.H. Jr., Doran, K.S., and Howd, P.A., 2012, Hotspot of accelerated sea-level rise on the Atlantic coast of North America: Nature Climate Change, volume 2, pp. 884-888.

Sargent, F.E. and Bottin, R.R. Jr., 1989., Case Histories of Corps Breakwater and Jetty Structures: Report 7, New England Division, Waterways Experiment Station, U.S. Department of Army Corps of Engineers, Vicksburg, MS, 106 pp.

Sinclair, S.N., Licciardi, J.M., Campbell, S.W., and Madore, B.M., 2018, Character and origin of De Geer moraines in the Seacoast region of New Hampshire, USA: Journal of Quaternary Science, volume 33, number 2, pp. 225-237, ISSN 0267-8179, http://doi.10.1002/jqs.3017.

Thieler, E.R., Himmelstoss, E.A., Zichichi, J.L., and Ergul, A., 2009, Digital Shoreline Analysis System (DSAS) version 4.0- An ArcGIS extension for calculating shoreline change: USGS Open-File Report 2008-1278.

Tuttle, S.D., 1960, Evolution of the New Hampshire shoreline: Bulletin of the Geological Society of America, volume 71, pp. 1211-1222.

USACE (United States Army Corps of Engineers), 1954, Hampton Beach, NH: Beach Erosion Control Study: 83 Congress, $2^{\text {nd }}$ Session, H Doc 325.30 pp., plus plates.

USACE (United States Army Corps of Engineers), 1962, Shore of the State of New Hampshire, Beach Erosion Control Study: 87/2, H Doc 416, 156 pp, plus plates.

USACE (United States Army Corps of Engineers), New England District, 1977, Beach Erosion Control Report for North Beach - Town of Hampton and Foss Beach - Town of Rye, NH: TC 423.N43 N864., 47 pp., plus plates.

USACE (United States Army Corps of Engineers), 2016a, Hampton Beach Shore and Bank Protection Project [WWW Document]: U.S. Army Corps of Engineers, URL www.nae.usace.army.mil/Missions/Civil-Works/Shore-Bank-Protection/NewHampshire/Hampton/

USACE (United States Army Corps of Engineers), 2016b, Wallis Sands State Beach Shore and Bank Protection Project [WWW Document]: U.S. Army Corps of Engineers. URL www.nae.usace.army.mil/Missions/Civil-Works/Shore-Bank-Protection/New-Hampshire/Wallis$\underline{\text { Sands/ }}$ 
Venti, N., Mabee, S.B., and Woodruff, J.D., 2016, Sand Resource Assessment at Critical Beaches on the Massachusetts Coast: Bureau of Ocean Energy Management Cooperative Agreement M14AC00006 with the Massachusetts Geological Survey/University of Massachusetts Amherst, Technical Report, 18pp. https://www.boem.gov/sites/default/files/mm-research/2021-05/MA-BOEMFinal-Summary-Report-opt.pdf

Wake, C., Burakowski, E., Kelsey, E., Hayhoe, K., Stoner, A., Watson, C., and Douglas, E., 2011, Climate Change in the Piscataqua/Great Bay Region: Past, Present, and Future: Carbon Solutions New England, University of New Hampshire, Durham, NH, pp. 54.

Ward, L.G. and Adams, J.R., 2001, A Preliminary Assessment of Tidal Flooding along the New Hampshire Coast: Past, Present and Future: New Hampshire Office of Emergency Management and the Office of State Planning Coastal Program, $2 \frac{1}{2}$ Beacon Street, Concord, NH. 56 pp. (UNH CMB/JEL Report Series Number 54). https://scholars.unh.edu/faculty pubs/649/

Ward, L.G., Zaprowski, B.J., Trainer, K.D., and Davis, P.T., 2008, Stratigraphy, pollen history and geochronology of tidal marshes in a Gulf of Maine estuarine system: climatic and relative sea level impacts: Marine Geology, volume 256, pp. 1-17.

https://doi.org/10.1016/j.margeo.2008.08.004

Ward, L.G., McPherran, K.A., McAvoy, Z.S., and Vallee-Anziani, M., 2016, New Hampshire Beaches: Sediment Characterization: BOEM/New Hampshire Cooperative Agreement (Contract M14ACO0010) Technical Report, BOEM Marine Minerals Branch, 381 Elden Street, Herndon, VA, 20170, 37 pp. https://dx.doi.org/10.34051/p/2021.29

Ward, L.G., McAvoy, Z.S., Vallee-Anziani, M., and Morrison, R.C., 2021a, Surficial Geology of the Continental Shelf off New Hampshire: Morphologic Features and Surficial Sediment: BOEM/New Hampshire Cooperative Agreement (Contract M14ACO0010) Technical Report, Department of Interior, Bureau of Ocean Energy Management, Marine Minerals Division, 45600 Woodland Road, Sterling, VA, 20166, 184pp. https://dx.doi.org/10.34051/p/2021.31

Ward, L.G., Morrison, R.C., Eberhardt, A.L., Costello, W.J., McAvoy, Z.S., and Mandeville, C.P., 2021. Erosion and Accretion Trends of New Hampshire Beaches from December 2016 to March 2020: Results of the Volunteer Beach Profile Monitoring Program. New Hampshire Sea Grant and University of New Hampshire Extension Technical Report, Durham, NH 03824. 420 pp. https://dx.doi.org/10.34051/p/2021.34

Wentworth, C.K., 1922, A scale of grade and class terms for clastic sediments: Journal of Geology 30: 377-392. 


\section{Appendix A: Glossary of Terms}

Note: The definitions presented here are frequently modified or simplified to describe concepts or calculations presented specifically for this study.

Accrete, Accretion, Accretional: Addition of sediment and an increase in elevation on a beach.

Attached Barrier: Elongated sand ridge built by waves, currents, and winds that rises above the high-tide level and extends generally parallel with the upland. Separated from the upland by a lagoon or marsh and attached to the mainland or a headland at both ends.

Back-barrier: Area of land between a barrier island, barrier spit, or attached barrier (barrier beach) and the mainland.

Backshore: Upper or landward zone of the beach lying between the high-water line for mean spring tides and the upland. Acted upon by waves or covered by water only during exceptionally severe storms or unusually high tides. It is essentially horizontal or slopes landward and is divided from the foreshore by the crest of the most seaward berm. Usually dry under normal conditions.

Barrier Island: Elongated sand ridge built by waves, currents, and winds that rises above the high-tide level and extends generally parallel to the upland. Separated from the upland by a lagoon or marsh. It is unattached to the mainland.

Barrier Spit: Elongated sand ridge built by waves, currents, and winds that rises above the high-tide level and extends generally parallel to the upland. Separated from the upland by a lagoon or marsh. It is attached to the mainland or a headland at one end.

Beach Fill, Beach Nourishment: Sediment placed on a beach.

Beach Profile or Beach Elevation Profile: Elevation of the beach running perpendicular to the shoreline.

Bedrock: General term for the rock that is part of the crust. It is not unattached (like boulders are). Can be buried by sediment or exposed.

Berm: Low, nearly horizontal upper beach generally bounded on the seaward side by an increase in slope towards the sea (berm crest). Many beaches have no berms, other have one or several.

Berm (Neap Tide Berm): Berm crest elevation controlled by neap tide conditions.

Berm (Spring Tide Berm): Berm crest elevation controlled by spring tide conditions.

Berm (Storm Berm): Berm crest elevation controlled by storm conditions.

Berm Crest: Seaward or outer limit or edge, and generally the highest part, of a berm on a beach.

Berm Face: Seaward-sloping beach starting at the berm crest and extending to the low tide terrace or where the beach becomes noticeably flatter.

Berm Toe: Base of the berm, usually where the berm ends and the low tide terrace begins; often scoured; often has coarser sediments than the berm of the low tide terrace. 
Cusps: Rhythmic topography usually formed at berm crest. Has an arc pattern, usually coarser sediment on horns and finer sediment in embayments.

Cusp Horn: High area of cusp. Horns can be composed of sand and/or pebble and cobbles.

Cusp Embayment: Low area between cusp horns.

Cusp Wavelength: Average distance between cusp horns.

Datum: Reference system or an approximation of the Earth's surface against which positional measurements can be made (e.g., latitude, longitude, and elevation). See geodetic datum.

Depth of Closure: Seaward limit of sediment transport along a cross-section of the beach. Seaward limit of normal transport of sediment associated with beach.

Diurnal Tide: One high tide and one low tide every lunar day.

Downcut Limit: Critical elevation below which there is little to no vertical erosion.

Downdrift: The alongshore direction off the dominant sediment transport direction.

Drumlin: A low, smoothly rounded, elongated and oval hill, mound, or ridge of compact glacial till, built under the glacial ice and shaped by its flow. The longer axis is parallel to the direction of movement of the ice. Composed of a large range of sediment from boulders to mud.

Dune: Accumulations of sand deposited primarily by the wind at the landward edge of a beach. Can be bare or covered with vegetation. Provides a barrier to water and sand sweeping inland. Acts as a natural storage site for sand.

Dune Grass: Grass growing in the dunes.

Ellipsoid: A flattened sphere used to represent the geometric model of the Earth (e.g. the Earth is not completely round and is slightly flattened at the poles); a mathematical model of the Earth to represent horizontal positions on maps and charts (versus the topographic or actual visible surface of the Earth).

Emery Method: A simple method for measuring the profile of a beach by using two graduated rods, whose alignment and reading of the intersection with the horizon allow for the determination of differences in level along the profile.

Equilibrium Beach Profile: Cross section of the beach that is stable with the dominant wave conditions and sediment grain size.

Erode (for beaches): To remove sediment by the action of current, waves, or wind.

Erosional (for beaches): A trend or condition where sediment is being eroded by currents, waves, or wind.

Esker: A long, low, narrow, sinuous, steep-sided ridge or mound composed of irregularly stratified sand and gravel that was deposited by a subglacial stream or in an ice tunnel. Eskers, unlike drumlins, are stratified accumulations of sand and gravel. 
Foreshore: The gradually seaward-sloping zone of the beach between high tide and low tide. Usually lying between the crest of the most seaward berm on the backshore (the upper limit of wave swash at high tide) and the ordinary low-water mark. Also called intertidal.

Foredune or Foredune Ridge: A coastal dune or dune ridge oriented parallel to the shoreline at the landward margin of the beach or along the shoreward face of a beach ridge. Usually stabilized by vegetation. The most seaward dune ridge.

Geodetic Datum: Provides a reference surface (such as sea level) from which all locations on Earth can be defined with coordinates; system developed to assist surveyors, navigators, and to create maps by translating Earth's three-dimensional surface to two-dimensional coordinates.

Geoid: The true zero surface of the Earth for measuring elevations defined by Earth's gravity. The geoid surface must be modeled. Mean sea level is a close approximation.

Geometric Datum: Coordinate system for collection of positions relative to an ellipsoid model of the Earth.

GNSS (Global Navigation Satellite System): A general term describing any satellite constellation that provides positioning, navigation, and timing on a global basis. GPS is the most prevalent GNSS.

Groin (Groyne): An engineering structure that is usually a low, narrow wall constructed of timber, stone, concrete, or steel. Usually extending roughly perpendicular to the shoreline and designed to protect the shore from erosion and to trap sediment.

Hot Spot (with Respect to Coastal Erosion): Shoreline where erosion is significantly greater than nearby areas.

Hot Spot (with Respect to Sea-Level Rise): Coastal area where the rate of sea-level rise is higher than the general overall trends for the region.

Horizontal Datum: Coordinate system for positions on Earth (e.g., latitude and longitude).

IGS08: Geodetic datum used by surveyors, engineers, and mapping professionals to measure locations and elevations on the Earth's surface throughout the world. Referenced to an ellipsoid.

Intertidal: Area of a beach between high water and low water. Also called foreshore.

Jetty: An engineering structure extending seaward at the edge of a river or inlet designed to stabilize the location or stop migration. It is often built in pairs on either side of a harbor entrance or at the mouth of a river.

Lag Deposits: Coarse-grained material that is left after currents, waves or wind have winnowed or eroded the finer material.

Littoral Zone: The area of beach between the high-water line and the offshore that is impacted by waves and sediment transport.

Longshore Sediment Transport or Drift: The transportation of sediment along the coast parallel to the shoreline by waves. 
Low Tide Terrace: A relatively horizontal or flat area of the beach extending from the seaward base of the berm to the low tide line. Usually remains wet.

Maximum Average Elevation Profile: The single beach elevation profile for a station that has the highest overall elevations. It is determined from the average profile elevation for a standard profile length for that beach.

MHW (Mean High Water): Average height of all the high water recorded at a given location over a 19year period (epoch) or a computed equivalent period.

MHHW (Mean Higher High Water): Average height of all the highest high water levels recorded at a given location over a 19-year period (epoch) or a computed equivalent period.

MLLW (Mean Lower Low Water): Average height of all the lower low water levels recorded at a given location over a 19-year period (epoch) or a computed equivalent period.

MLW (Mean Low Water): Average height of all the low water levels recorded at a given location over a 19-year period (epoch) or a computed equivalent period.

MSL (Mean Sea Level): Average water levels for all stages of the tide over a 19-year period (epoch) at a given location.

MTL (Mean Tidal Level): The arithmetic average of mean high water and mean low water.

MTR (Mean Tidal Range): The difference in height between mean high water (MHW) and mean low water (MLW).

MWL (Mean Water Level): Average water levels for all stages of the tide over a 19-year period (epoch) at a given location.

Megaclasts: Larger clasts (fragments of rock). Usually refers to cobbles and boulders.

Megaclast Platform: Flat or gently sloping surface composed of megaclasts.

Mid Tide Beach: Average elevation of beach at mid tide (the tide midway between high tide and low tide).

Minimum Average Elevation Profiles: The single elevation profile for a location (station) on a beach that has the lowest mean elevation. It is determined by averaging all the elevation measurements for a station for a standard profile length for that site.

Mixed Semidiurnal Tides: Two high and two low tides of different range every lunar day.

Morphology: The external structure and form of landforms.

NAD83 (North American Datum of 1983): Geodetic datum used by surveyors, engineers, and mapping professionals to measure locations (latitude and longitude) and elevations of the Earth's surface in the United States. Referenced to an ellipsoid.

NAVD88 (North American Vertical Datum of 1988): Vertical datum used by surveyors, engineers, and mapping professionals to measure and relate elevations to the Earth's surface. 
Neap Tide: A tide occurring at the first and third quarters of the moon when the gravitational pull of the sun opposes (or is at right angles to) that of the moon, and having an unusually small or reduced tide range (usually $10-30 \%$ less than the mean range).

Overwash: Flow of water and sediment over a coastal dune, beach crest, or engineering structure during storm events or other situations with high water.

Platforms (Pebble/Cobble/Boulder): Flat or gently sloping surface composed of megaclasts.

Projection: System of mathematics and geometry to transfer locations on the Earth onto a flat piece of paper (a map).

Ramp (Sand, Gravel, Cobble): Low gradient slope that extends seaward from a seawall or some type of engineering structure. The ramp is likely formed by the erosion of the lower beach during stormy periods and storm surge, along with wave run-up, pushing sand up against the seawall. The ramp can be composed of sand and/or gravel.

Ridge: Sand or dune ridge located inland from the modern beach due to the seaward building of the beach.

Ridge and Runnel: The ridge is a sand bar moving landward across the intertidal beach being moved by wave bores and swash. If no storms occur, the ridge will continue to migrate landward and weld onto the berm. It is a major mechanism for the natural recovery of a beach following an erosional period. The Runnel is a trough-like area at the landward edge of the ridge. It carries the water drainage off the beach as the tide retreats and is flooded as the tide advances.

Riprap: Rock debris used to stop erosion from waves or currents.

\section{Runnel: See Ridge and Runnel}

Runnel Outlet: Channel through the ridge draining water from the runnel.

Seawall: Engineering or man-made structure built at the landward edge of the beach primarily to prevent erosion and other damage to the upland by wave action.

Sediment: Fragmental material that originates from breaking down rocks by physical weathering (e.g. sand, gravel, silt, mud).

Semidiurnal Tide: Two high tides and low tides nearly equal in range every lunar day.

Shoaling (Sediment): Buildup of sediment due to deposition.

Shoaling (Waves): Alteration of a wave as it proceeds from deep water into shallow water. There is an initial decrease in height of the incoming wave, followed by an increase in height until it breaks.

Shore-normal: A line at a right angle or perpendicular to the coast or upland.

Significant wave height: Average height of the highest one-third of all waves for a period of time.

Spring Tide: Larger than average tides that occur twice each month at or near the times of new moon and full moon when the gravitational pull of the sun reinforces that of the moon. 
Standard Elevation Profile Length or Standard Profile Length: Profile length chosen to calculate all volume parameters or mean elevation for an individual beach station. The minimum length that captures most of the profiles determined from reviewing all the profiles from that station from all dates.

Storm Surge: An abnormal rise of water level along an open coast during a storm caused primarily by onshore wind stress and by lower atmospheric pressure. Forces water to be piled up against the coast causing flooding.

Subaerial Beach: The upper portion of a beach that is not under water at low tide.

Subsidence: Sinking of the Earth's crust relative to the surrounding area.

Swash: Rush of water up onto the beach following the breaking of a wave.

Swash (Last High Tide Swash): Landward extent of the last high tide, marked by foam, wrack, shells, and other debris forming a line on the beach.

Swash (Low Tide Swash): Area of swash at low tide.

Swash Zone: Sloping part of the beach that is alternately covered and uncovered by the uprush of waves.

Sweep Zone: Envelope encompassing the entire horizontal and vertical area occupied by all of the beach elevation profiles measured at a station when plotted together. It defines the highest and lowest elevations (extremes) of all points on the profile transect that have occurred during the entire period the profile has been monitored. An upper or lower boundary is rarely defined by a single profile from a given day. This definition is adapted for this study from the coastal literature which includes the intertidal beach and subtidal nearshore to the depth of closure.

Tidal Datum: Standard elevation framework used to track local water levels as measured by a tidal gauging station.

Tidal Inlet: An inlet through a barrier beach which water flows alternately landward with the rising tide and seaward with the falling tide.

Till or Glacial Till: Unsorted and unstratified sediment deposited by a glacier. Generally unconsolidated, deposited directly by and underneath a glacier without subsequent reworking by water from the glacier, and consisting of a heterogeneous mixture of clay, sand, gravel, and boulders varying widely in size and shape.

Uplift: Rising of the Earth's crust relative to the surrounding area.

Vertical Datum: Measures elevation above a reference surface.

Washover Deposit: Sediment deposited by overwash.

Water Line: Intersection of ocean water with the beach.

WGS84 (World Geodetic System 1984): Geodetic datum used by surveyors, engineers, and mapping professionals to measure locations (latitude and longitude) and elevations to the Earth's surface throughout the world. Referenced to an ellipsoid. 


\section{Appendix B: Complete Storm History}

Storm history of the New Hampshire coast from December 2016 to March 2020. Wind data was calculated from the buoy at the Isles of Shoals, $\mathrm{NH}$ (Station IOSN3; $42.967 \mathrm{~N} 70.623 \mathrm{~W}$ ) and wave data was calculated from the Jeffreys Ledge buoy (Station 44098; 42.798 N 70.168 W) (NOAA NDBC, accessed March 2020). Storm details have been downloaded from NOAA's Storm Events Database (NOAA NCEI, accessed March 2020). Times are in UTC. Average wind speed was calculated by averaging over a chosen period when winds were highest (generally when above $10 \mathrm{~m} / \mathrm{s}$ ), and which corresponded to the known storm dates. Wind gust range was calculated by finding the maximum and minimum wind gust from the chosen period. Average significant wave height was calculated by averaging over a chosen period when waves were highest (generally when above $2 \mathrm{~m}$ ), and which corresponded to the known storm dates. Peak significant wave heights were calculated by averaging the period of the highest waves.

Definitions of terms used in here are given below (from NOAA NDBC, accessed March 2020):

- Significant wave height $(\mathrm{Hs})$ : average height of the highest one third of all wave heights during a 20-minute sampling period, reported every half hour

- Wave direction: the direction from which the waves at the dominant period are coming, and is reported every half hour

- Wind speed: averaged over a two-minute period (because Isles of Shoals is a land station) and is reported hourly

- Wind direction: averaged over a two-minute period and reported every hour

- Wind gust: the peak 5 or 8 second gust speed measured during the two-minute period, and is reported every hour 


\begin{tabular}{|c|c|c|c|c|c|c|c|c|c|c|c|}
\hline \multicolumn{4}{|c|}{2016 - 2017} & \multicolumn{3}{|c|}{$\begin{array}{c}\text { Wind } \\
\text { (Isles of Shoals Station IOSN3) }\end{array}$} & \multicolumn{5}{|c|}{$\begin{array}{c}\text { Waves } \\
\text { (Jeffrey's Ledge Station 44098) }\end{array}$} \\
\hline Dates & Name & Type & Snow & $\begin{array}{l}\text { Average Wind } \\
\text { Speed }\end{array}$ & Wind Gust Range & Wind Direction & $\begin{array}{c}\text { Peak Wave } \\
\text { Hs (Significant Wave Height) } \\
\end{array}$ & $\begin{array}{c}\text { Average } \\
\text { Hs (Significant Wave Height) } \\
\end{array}$ & $\begin{array}{c}\text { Range } \\
\text { Hs }\end{array}$ & $\begin{array}{c}\text { Average } \\
\text { Ts }\end{array}$ & \begin{tabular}{|c|}
$\begin{array}{c}\text { Dominant } \\
\text { Ts }\end{array}$ \\
\end{tabular} \\
\hline \multirow[t]{2}{*}{ Dec 28-30 } & Fortis & Winter Storm & $<2^{\prime \prime}(<5 \mathrm{~cm})$ & $13.8 \mathrm{~m} / \mathrm{s}(30.9 \mathrm{mph})$ & $8.9-19.0 \mathrm{~m} / \mathrm{s}(19.9-42.5 \mathrm{mph})$ & SSE, then WSW & $3.4 \mathrm{~m}(\mathrm{SE})$ & $2.8 \mathrm{~m}(\mathrm{SE}$, then $\mathrm{W})$ & $2.1-3.7 \mathrm{~m}$ & $5.6 \mathrm{~s}$ & $6.5 \mathrm{~s}$ \\
\hline & & & & Dec $29(18: 00)$ to Dec 31 & $1(06: 00)$ & & Dec $30(00: 00$ to $04: 00)$ & Dec $29(22: 00)$ to Dec $30(17: 00)$ & & & \\
\hline \multirow[t]{2}{*}{$\operatorname{Jan} 3-5$} & & & & $13.4 \mathrm{~m} / \mathrm{s}(30 \mathrm{mph})$ & $8.0-21.8 \mathrm{~m} / \mathrm{s}(17.9-48.8 \mathrm{mph})$ & ENE, then W & $4.8 \mathrm{~m}$ (ESE) & $4.0 \mathrm{~m}$ (ESE) & $2.2-5.3 \mathrm{~m}$ & $7.5 \mathrm{~s}$ & $9.7 \mathrm{~s}$ \\
\hline & & & & $\operatorname{Jan} 3(08: 00)$ to $\operatorname{Jan} 4(09$ & $9: 00)$, and $\operatorname{Jan} 4(22: 00)$ to $\operatorname{Jan} 5(20: 00)$ & & $\operatorname{Jan} 4(02: 00$ to $10: 00)$ & $\operatorname{Jan} 3(18: 00)$ to $\operatorname{Jan} 4(16: 00)$ & & & \\
\hline \multirow[t]{2}{*}{$\operatorname{Jan} 7-8$} & Helena & Nor'easter & & $11.4 \mathrm{~m} / \mathrm{s}(25.5 \mathrm{mph})$ & $8.1-17.7 \mathrm{~m} / \mathrm{s}(18.1-39.6 \mathrm{mph})$ & NNE, then NNW & $3.1 \mathrm{~m}(\mathrm{E})$ & $2.8 \mathrm{~m}(\mathrm{E})$ & $2.0-3.2 \mathrm{~m}$ & $6.5 \mathrm{~s}$ & $8.7 \mathrm{~s}$ \\
\hline & & & & $\operatorname{Jan} 7(13: 00)$ to $\operatorname{Jan} 8(09$ & 9:00) & & $\operatorname{Jan} 8(03: 00$ to $12: 00)$ & $\operatorname{Jan} 7(22: 00)$ to $\operatorname{Jan} 8(21: 00)$ & & & \\
\hline \multirow[t]{2}{*}{$\operatorname{Jan} 17-19$} & Jupiter & Winter Storm & 5-8" $(13-20 \mathrm{~cm})$ & $10.8 \mathrm{~m} / \mathrm{s}(24.1 \mathrm{mph})$ & $9.3-14.5 \mathrm{~m} / \mathrm{s}(20.8-32.4 \mathrm{mph})$ & ENE & \multirow{2}{*}{\multicolumn{5}{|c|}{ (data not available) }} \\
\hline & & & & $\tan 17(22: 00)$ to $\operatorname{Jan} 19$ & (05:00) & & & & & & \\
\hline \multirow[t]{2}{*}{ Feb 5-7 } & Maya & Winter Storm & $6^{\prime \prime}(15 \mathrm{~cm})$ & $11.6 \mathrm{~m} / \mathrm{s}(26.0 \mathrm{mph})$ & $10.4-17.6 \mathrm{~m} / \mathrm{s}(23.2-39.4 \mathrm{mph})$ & WsW & (no peak) & $1.6 \mathrm{~m}$ (WSW) & $1.3-2.1 \mathrm{~m}$ & $4.3 \mathrm{~s}$ & $5.2 \mathrm{~s}$ \\
\hline & & & & Feb $5(14: 00)$ to Feb 6 (1 & 11:00) & & & Feb $5(15: 00)$ to Feb $6(17: 00)$ & & & \\
\hline \multirow[t]{2}{*}{ Feb 7-9 } & Niko & Nor'easter & $10-15^{\prime \prime}(25-38 \mathrm{~cm})$ & $13.6 \mathrm{~m} / \mathrm{s}(30.4 \mathrm{mph})$ & $8.0-18.7 \mathrm{~m} / \mathrm{s}(17.9-41.8 \mathrm{mph})$ & ENE & $4.0 \mathrm{~m}$ (WSW) & $3.1 \mathrm{~m}$ (WSW) & $2.0-4.6 \mathrm{~m}$ & $6.7 \mathrm{~s}$ & $8.4 \mathrm{~s}$ \\
\hline & & & & Feb $7(13: 00)$ to Feb $8(0$ & 06:00) & & Feb 8 (01:00 to 7:00) & Feb $7(16: 00)$ to Feb $8(16: 00)$ & & & \\
\hline \multirow{2}{*}{ Feb 9-10 } & & & & $14.1 \mathrm{~m} / \mathrm{s}(31.5 \mathrm{mph})$ & $10.9-22.8 \mathrm{~m} / \mathrm{s}(24.4-51.0 \mathrm{mph})$ & NE, then WNW & $4.2 \mathrm{~m}$ (NE) & $3.4 \mathrm{~m}(\mathrm{NE}$, then $\mathrm{WNW})$ & $2.1-4.8 \mathrm{~m}$ & $6.2 \mathrm{~s}$ & $7.7 \mathrm{~s}$ \\
\hline & & & & Feb $9(09: 00)$ to Feb 10( & $(20: 00)$ & & Feb $9(22: 00)$ to Feb $10(04: 00)$ & Feb $9(12: 00)$ to Feb $10(13: 00)$ & & & \\
\hline \multirow[t]{2}{*}{ Feb 12-13 } & Orson & Winter Storm & 6-16" $(15-41 \mathrm{~cm})$ & $14.0 \mathrm{~m} / \mathrm{s}(31.4 \mathrm{mph})$ & $11.9-18.4 \mathrm{~m} / \mathrm{s}(26.6-41.2 \mathrm{mph})$ & ENE, then NNW & $4.5 \mathrm{~m}(\mathrm{E})$ & $3.6 \mathrm{~m}(\mathrm{E})$ & $2.5-5.2 \mathrm{~m}$ & $6.9 \mathrm{~s}$ & $9.9 \mathrm{~s}$ \\
\hline & & & & Feb $12(18: 00)$ to Feb 14 & $4(02: 00)$ & & Feb $13(06: 00)$ to Feb $14(04: 00)$ & Feb $12(06: 00)$ to Feb $14(13: 00)$ & & & \\
\hline \multirow[t]{2}{*}{ Feb 15-16 } & Pluto & Winter Storm & & $10.3 \mathrm{~m} / \mathrm{s}(23.0 \mathrm{mph})$ & $7.4-14.7 \mathrm{~m} / \mathrm{s}(16.6-32.9 \mathrm{mph})$ & SSE, then $\mathrm{E}$ & $3.0 \mathrm{~m}(\mathrm{E})$ & $2.8 \mathrm{~m}(\mathrm{E})$ & $2.3-3.3 \mathrm{~m}$ & $6.4 \mathrm{~s}$ & $8.9 \mathrm{~s}$ \\
\hline & & & & Feb 15 (09-22:00), and Fe & Feb 16 (04-13:00) & & Feb 16 (11:00 to 15:00) & Feb 16 (06:00 to 19:00) & & & \\
\hline \multirow[t]{2}{*}{ Mar 14-15 } & Stella & Nor'easter & 12-20" $(30-51 \mathrm{~cm})$ & $19.5 \mathrm{~m} / \mathrm{s}(43.7 \mathrm{mph})$ & $10.5-30.7 \mathrm{~m} / \mathrm{s}(23.5-68.7 \mathrm{mph})$ & $\mid \mathrm{NE}$ & $6.3 \mathrm{~m}$ (ESE) & $4.6 \mathrm{~m}$ (ESE) & $2.9-7.1 \mathrm{~m}$ & $8.2 \mathrm{~s}$ & $12.0 \mathrm{~s}$ \\
\hline & & & & Mar 14 (13:00) to Mar 15 & $5(04: 00)$ & & Mar 14 (20:00) to Mar 15 (02:00) & Mar 14 (17:00) to Mar 15(23:00) & & & \\
\hline \multirow[t]{2}{*}{ Mar 19-21 } & & & & $10.1 \mathrm{~m} / \mathrm{s}(22.6 \mathrm{mph})$ & $6.9-15.4 \mathrm{~m} / \mathrm{s}(15.4-34.4 \mathrm{mph})$ & $\mathrm{NE}$, then variable & $3.8 \mathrm{~m}$ (ESE) & $3.1 \mathrm{~m}$ (ESE) & $1.9-4.1 \mathrm{~m}$ & $6.9 \mathrm{~s}$ & $9.5 \mathrm{~s}$ \\
\hline & & & & Mar $19(05: 00)$ to Mar 20 & $0(17: 00)$ & & Mar 20 (06:00 to 15:00) & Mar 19 (12:00) to Mar $21(03: 00)$ & & & \\
\hline \multirow[t]{2}{*}{ Mar 31-Apr 2} & Theseus & Winter Storm & $6 "(15 \mathrm{~cm})$ & $12.5 \mathrm{~m} / \mathrm{s}(27.9 \mathrm{mph})$ & $8.8-20.0 \mathrm{~m} / \mathrm{s}(19.7-44.7 \mathrm{mph})$ & $\mathrm{NE}$ & $4.1 \mathrm{~m}$ (ESE) & $3.3 \mathrm{~m}$ (ESE) & $2.0-4.6 \mathrm{~m}$ & $7.0 \mathrm{~s}$ & $9.0 \mathrm{~s}$ \\
\hline & & & & April 1 (00:00) to April 2 & $2(05: 00)$ & & April 1(13:00) to April 2 (01:00) & April 1 (07:00) to April 2 (17:00) & & & \\
\hline \multirow[t]{2}{*}{ May 14-15 } & & & & $11.7 \mathrm{~m} / \mathrm{s}(26.2 \mathrm{mph})$ & $7.8-19.5 \mathrm{~m} / \mathrm{s}(17.4-43.6 \mathrm{mph})$ & NNE, then WNW & $3.1 \mathrm{~m}(\mathrm{E})$ & $2.6 \mathrm{~m}(\mathrm{E})$ & $2.0-3.3 \mathrm{~m}$ & $5.9 \mathrm{~s}$ & $8.4 \mathrm{~s}$ \\
\hline & & & & Mar 14 (07:00) to Mar 15 & $5(23: 00)$ & & May 14 (19:00 to 23:00) & May $14(09: 00)$ to May $15(16: 00)$ & & & \\
\hline \multirow[t]{2}{*}{ May 25} & & Coastal Flood & & $12.3 \mathrm{~m} / \mathrm{s}(27.6 \mathrm{mph})$ & $6.4-21.5 \mathrm{~m} / \mathrm{s}(14.3-48.1 \mathrm{mph})$ & $\mathrm{NE}$ & $2.6 \mathrm{~m}(\mathrm{E})$ & $2.2 \mathrm{~m}(\mathrm{E})$ & $1.4-2.9 \mathrm{~m}$ & $5.9 \mathrm{~s}$ & $7.5 \mathrm{~s}$ \\
\hline & & Storm surge: 0 . & $35 \mathrm{~m}$ & May $25(13: 00)$ to May 26 & $66(18: 00)$ & & May $25(22: 00)$ to May $26(06: 00)$ & May $25(18: 00)$ to May $27(01: 00)$ & & & \\
\hline \multirow[t]{2}{*}{ Jun 5-7 } & & & & $12.2 \mathrm{~m} / \mathrm{s}(27.3 \mathrm{mph})$ & $8.5-18.1 \mathrm{~m} / \mathrm{s}(19.0-40.5 \mathrm{mph})$ & $\mathrm{NE}$ & $3.7 \mathrm{~m}(\mathrm{E})$ & $2.9 \mathrm{~m}(\mathrm{E})$ & $2.0-4.0 \mathrm{~m}$ & $6.7 \mathrm{~s}$ & $8.5 \mathrm{~s}$ \\
\hline & & & & June $5(18: 00)$ to June 6 & $5(19: 00)$ & & June $6(14: 00$ to $19: 00)$ & June $6(04: 00)$ to June $7(11: 00)$ & & & \\
\hline \multirow[t]{2}{*}{ Sept 19-22 } & Jose & Hurricane & & $11.1 \mathrm{~m} / \mathrm{s}(24.9 \mathrm{mph})$ & $7.4-18.7 \mathrm{~m} / \mathrm{s}(16.6-41.8 \mathrm{mph})$ & NNE & $4.2 \mathrm{~m}(\mathrm{E})$ & $3.6 \mathrm{~m}(\mathrm{E})$ & $2.8-4.6 \mathrm{~m}$ & $7.0 \mathrm{~s}$ & $9.3 \mathrm{~s}$ \\
\hline & & & & Sept $19(11: 00)$ to Sept 2 & $23(08: 00)$ & & Sept 22 (07-10:00, 19-22:00) & Sept $21(12: 00)$ to Sept $23(01: 00)$ & & & \\
\hline \multirow[t]{2}{*}{ Oct 29-30 } & Philippe & Tropical Storm & & $16.4 \mathrm{~m} / \mathrm{s}(36.6 \mathrm{mph})$ & $10.9-35.0 \mathrm{~m} / \mathrm{s}(24.4-78.3 \mathrm{mph})$ & ESE, then SW & $4.9 \mathrm{~m}(\mathrm{SE})$ & $3.9 \mathrm{~m}(\mathrm{SE})$ & $2.4-5.6 \mathrm{~m}$ & $7.6 \mathrm{~s}$ & $10.7 \mathrm{~s}$ \\
\hline & & & & Oct $29(18: 00)$ to Oct 30 ( & $(22: 00)$ & & Oct 30 (09:00 to 19:00) & Oct $30(03: 00)$ to Oct $31(08: 00)$ & & & \\
\hline \multirow[t]{2}{*}{ Dec 5-6 } & & & & $13.5 \mathrm{~m} / \mathrm{s}(30.2 \mathrm{mph})$ & $7.2-21.2 \mathrm{~m} / \mathrm{s}(16.1-47.4 \mathrm{mph})$ & $\mathrm{s}$ & $3.4 \mathrm{~m}(\mathrm{SE})$ & $2.8 \mathrm{~m}(\mathrm{SE})$ & $2.0-3.8 \mathrm{~m}$ & $6.0 \mathrm{~s}$ & $7.3 \mathrm{~s}$ \\
\hline & & & & $\operatorname{Dec} 5(13: 00)$ to $\operatorname{Dec} 6(1$ & 12:00) & & Dec $6(05: 00$ to 08:00) & Dec $5(18: 00)$ to $\operatorname{Dec} 6(14: 00)$ & & & \\
\hline Dec 23-24 & Dylan & Winter Storm & $1-4 "(3-10 \mathrm{~cm})$ & $8.2 \mathrm{~m} / \mathrm{s}(18.4 \mathrm{mph})$ & $5.8-13.6 \mathrm{~m} / \mathrm{s}(13.0-30.4 \mathrm{mph})$ & WNW & (no peak) & $1.9 \mathrm{~m}$ (ESE, then WNW) & $1.6-2.3 \mathrm{~m}$ & $5.4 \mathrm{~s}$ & $6.9 \mathrm{~s}$ \\
\hline & & & & Dec $23(20: 00)$ to Dec 24 & $4(18: 00)$ & & & Dec $23(02: 00)$ to Dec 24 (12:00) & & & \\
\hline Dec 25-26 & & & & $13.4 \mathrm{~m} / \mathrm{s}(30.0 \mathrm{mph})$ & $9.9-20.3 \mathrm{~m} / \mathrm{s}(22.1-45.4 \mathrm{mph})$ & NE, then WSW & $3.9 \mathrm{~m}$ (ENE) & $2.9 \mathrm{~m}$ (ENE, then WSW) & $1.9-4.4 \mathrm{~m}$ & $5.8 \mathrm{~s}$ & $7.3 \mathrm{~s}$ \\
\hline & & & & Dec $25(01: 00)$ to $\operatorname{Dec} 26$ & $6(20: 00)$ & & Dec 25 (13:00 to 18:00) & Dec $25(06: 00)$ to Dec $26(12: 00)$ & & & \\
\hline
\end{tabular}




\begin{tabular}{|c|c|c|c|c|c|c|c|c|c|c|c|}
\hline \multicolumn{4}{|l|}{2018} & \multicolumn{3}{|c|}{$\begin{array}{c}\text { Wind } \\
\text { (Isles of Shoals Station IOSN3) }\end{array}$} & \multicolumn{5}{|c|}{$\begin{array}{c}\text { Waves } \\
\text { (Jeffrey's Ledge Station 44098) }\end{array}$} \\
\hline Dates & Name & Type & Snow & $\begin{array}{l}\text { Average Wind } \\
\text { Speed }\end{array}$ & Wind Gust Range & Wind Direction & $\begin{array}{c}\text { Peak Wave } \\
\text { Hs (Significant Wave Height) } \\
\end{array}$ & $\begin{array}{c}\text { Average } \\
\text { Hs (Significant Wave Height) } \\
\end{array}$ & $\begin{array}{c}\text { Range } \\
\text { Hs }\end{array}$ & $\begin{array}{c}\text { Average } \\
\text { Ts }\end{array}$ & \begin{tabular}{|c|} 
Dominant \\
Ts
\end{tabular} \\
\hline $\operatorname{Jan} 3-5$ & Grayson & Nor'easter & $10-15^{\prime \prime}(25-38 \mathrm{~cm})$ & $16.65 \mathrm{~m} / \mathrm{s}(37.2 \mathrm{mph})$ & $13.5-27.9 \mathrm{~m} / \mathrm{s}(30.2-62.4 \mathrm{mph})$ & $\mathrm{NE}$, then WNW & $6.3 \mathrm{~m}$ (ENE) & $5.0 \mathrm{~m}(\mathrm{ENE})$ & $3.0-7.8 \mathrm{~m}$ & $7.5 \mathrm{~s}$ & $10.3 \mathrm{~s}$ \\
\hline & \multicolumn{3}{|c|}{ Storm surge: $0.85 \mathrm{~m}$} & \multicolumn{3}{|c|}{$\operatorname{Jan} 4(11: 00)$ to $\operatorname{Jan} 7(13: 00)$} & $\operatorname{Jan} 4(19: 00)$ to $\operatorname{Jan} 5(00: 00)$ & \multicolumn{4}{|l|}{$\operatorname{Jan} 4(14: 00)$ to Jan $5(11: 00)$} \\
\hline \multirow[t]{2}{*}{$\operatorname{an} 12-16$} & & & & $11.8 \mathrm{~m} / \mathrm{s}(26.4 \mathrm{mph})$ & $7.4-19.9 \mathrm{~m} / \mathrm{s}(16.6-44.5 \mathrm{mph})$ & S, WNW, then NNE & $3.5 \mathrm{~m}(\mathrm{SSE}), 3.2 \mathrm{~m}(\mathrm{E})$ & $2.7 \mathrm{~m}$ (SSE, then $\mathrm{E})$ & $1.9-3.8 \mathrm{~m}$ & $6.8 \mathrm{~s}$ & $9.1 \mathrm{~s}$ \\
\hline & & & & \multicolumn{3}{|c|}{$\operatorname{Jan} 12(15: 00)$ to Jan $15(03: 00)$, Jan $15(02: 00)$ to Jan $16(07: 00)$} & \multicolumn{5}{|c|}{\begin{tabular}{|l|l|l}
$\operatorname{Jan} 13(13-16: 00), \operatorname{Jan} 16(06-08: 00)$ & $\operatorname{Jan} 13(04-21: 00), \operatorname{Jan} 15(17: 00)$ to $\operatorname{Jan} 16(22: 00)$ \\
\end{tabular}} \\
\hline $\operatorname{Jan} 17-18$ & Inga & Winter Storm & $4-8^{\prime \prime}(10-20 \mathrm{~cm})$ & \multicolumn{3}{|c|}{ Low winds recorded at Isles of Shoals } & \multicolumn{5}{|c|}{ Low waves recorded at Jeffrey's Ledge } \\
\hline \multirow[t]{2}{*}{$\tan 29-31$} & & & & $11.7 \mathrm{~m} / \mathrm{s}(26.2 \mathrm{mph})$ & $9.4-16.9 \mathrm{~m} / \mathrm{s}(21.0-37.8 \mathrm{mph})$ & NNE, then variable & $4.2 \mathrm{~m}(\mathrm{E})$ & $3.4 \mathrm{~m}(\mathrm{E})$ & $2.3-4.5 \mathrm{~m}$ & $6.8 \mathrm{~s}$ & $9.5 \mathrm{~s}$ \\
\hline & & & & $\tan 29(10: 00)$ to $\tan 30$ & $(21: 00)$ & & $\tan 30(16: 00$ to $22: 00)$ & $\operatorname{Jan} 30(01: 00)$ to $\operatorname{Jan} 31(09: 00)$ & & & \\
\hline \multirow[t]{2}{*}{ Feb 7-9 } & Liam & Winter Storm & 5-12" $(13-30 \mathrm{~cm})$ & $10.85 \mathrm{~m} / \mathrm{s}(24.3 \mathrm{mph})$ & $7.5-15.6 \mathrm{~m} / \mathrm{s}(16.8-34.9 \mathrm{mph})$ & WNW & $2.2 \mathrm{~m}(\mathrm{NW})$ & $1.8 \mathrm{~m}$ (ESE, then NW) & $1.4-2.4 \mathrm{~m}$ & $4.9 \mathrm{~s}$ & $6.0 \mathrm{~s}$ \\
\hline & & & & Feb 8 from 05:00 to $15: 00$ & & & Feb $8(06: 00$ to $10: 00)$ & Feb $7(20: 00)$ to Feb $8(16: 00)$ & & & \\
\hline \multirow[t]{2}{*}{ Feb 16-18 } & Noah & Winter Storm & $6-9 "(15-23 \mathrm{~cm})$ & $10.8 \mathrm{~m} / \mathrm{s}(24.2 \mathrm{mph})$ & $7.1-15.9 \mathrm{~m} / \mathrm{s}(15.9-35.6 \mathrm{mph})$ & SW, NW, then SSE & $2.1 \mathrm{~m}$ (variable winds) & $1.7 \mathrm{~m}$ (variable winds) & $1.1-2.2 \mathrm{~m}$ & $4.8 \mathrm{~s}$ & $5.9 \mathrm{~s}$ \\
\hline & & & & Feb $15(20: 00)$ to Feb 16 & $(04: 00)$, Feb $17(00-13: 00)$, Feb $18(00-0$ & 5::00) & Feb $17(05-06: 00)$, Feb 18 (10-12:00) & Feb 17 (00:00-08:00), Feb 18 (06:00 & $0-21: 00)$ & & \\
\hline \multirow[t]{2}{*}{ Mar 1-4 } & Riley & Nor'easter & Flooding & $16.24 \mathrm{~m} / \mathrm{s}(36.3 \mathrm{mph})$ & $10.0-28.3 \mathrm{~m} / \mathrm{s}(22.4-64.3 \mathrm{mph})$ & NNE & $7.2 \mathrm{~m}(\mathrm{E})$ & $5.9 \mathrm{~m}(\mathrm{E})$ & $4.0-8.4 \mathrm{~m}$ & $9.5 \mathrm{~s}$ & $13.5 \mathrm{~s}$ \\
\hline & & Storm surge: 0 . & $99 \mathrm{~m}$ & Mar $2(01: 00)$ to Mar 4 (1. & 5:00) & & Mar 3 (01:00 to 10:00) & $\operatorname{Mar} 2$ (16:00) to Mar $5(01: 00)$ & & & \\
\hline \multirow[t]{2}{*}{ Mar 6-9 } & Quinn & Nor'easter & $10-18 "(25-46 \mathrm{~cm})$ & $14.63 \mathrm{~m} / \mathrm{s}(32.7 \mathrm{mph})$ & $8.6-23.9 \mathrm{~m} / \mathrm{s}(19.2-53.5 \mathrm{mph})$ & NE, then NNW & $6.6 \mathrm{~m}(\mathrm{E})$ & $5.1 \mathrm{~m}(\mathrm{E})$ & $3.0-7.4 \mathrm{~m}$ & $8.1 \mathrm{~s}$ & $10.4 \mathrm{~s}$ \\
\hline & & & & Mar 7 (06:00) to Mar 8 (1 & & & Mar 8 (06:00 to 12:00) & $\operatorname{Mar} 7(22: 00)$ to $\operatorname{Mar} 8(20: 00)$ & & & \\
\hline \multirow[t]{2}{*}{ Mar 12-14 } & Skylar & Nor'easter & $24 "(61 \mathrm{~cm})$ & $15.59 \mathrm{~m} / \mathrm{s}(34.9 \mathrm{mph})$ & $7.9-23.7 \mathrm{~m} / \mathrm{s}(17.7-53.0 \mathrm{mph})$ & $\mathrm{NE}$, then WNW & $6.5 \mathrm{~m}(\mathrm{E})$ & $5.1 \mathrm{~m}(\mathrm{E})$ & $2.9-7.6 \mathrm{~m}$ & $8.3 \mathrm{~s}$ & $11.9 \mathrm{~s}$ \\
\hline & oastal floo & ga at Hampton a & id Rye) & Mar $12(21: 00)$ to March & $14(02: 00)$ & & Mar $13(16: 00)$ to March 14 (02:00) & Mar $13(06: 00)$ to March $14(16: 00)$ & & & \\
\hline \multirow[t]{2}{*}{ Mar 21-23 } & & & & $12.5 \mathrm{~m} / \mathrm{s}(28 \mathrm{mph})$ & $7.8-18.5 \mathrm{~m} / \mathrm{s}(17.4-41.2 \mathrm{mph})$ & NNE, then NNW & $5.1 \mathrm{~m}(\mathrm{E})$ & $4.0 \mathrm{~m}(\mathrm{E})$ & $2.5-5.2 \mathrm{~m}$ & $7.5 \mathrm{~s}$ & $10.2 \mathrm{~s}$ \\
\hline & & & & Mar $21(06: 00)$ to Mar 22 & $(17: 00)$ & & Mar 22 (11:00 to 16:00) & Mar $21(22: 00)$ to Mar $23(03: 00)$ & & & \\
\hline \multirow[t]{2}{*}{ Apr 15-17 } & & & & $13.8 \mathrm{~m} / \mathrm{s}(30.9 \mathrm{mph})$ & $11.8-21.3 \mathrm{~m} / \mathrm{s}(26.4-47.6 \mathrm{mph})$ & ENE & $5.1 \mathrm{~m}(\mathrm{E})$ & $4.0 \mathrm{~m}(\mathrm{E})$ & $2.8-5.5 \mathrm{~m}$ & $7.2 \mathrm{~s}$ & $9.5 \mathrm{~s}$ \\
\hline & & & & Apr 15 (06:00) to Apr 17 ( & (03:00) & & Apr 16 (18:00 to 22:00) & Apr 16 (07:00) to Apr 17 (11:00) & & & \\
\hline Sept 18 & Florence & Hurricane & & & w winds recorded at Isles of Sho & & & ow waves recorded at Jeffrey's & 's Ledge & & \\
\hline Oct 12 & Michael & Hurricane & & & w winds recorded at Isles of Sho & & & ow waves recorded at Jeffrey's & 's Ledge & & \\
\hline \multirow[t]{2}{*}{ Oct 27-28 } & & & & $17.2 \mathrm{~m} / \mathrm{s}(38.5 \mathrm{mph})$ & $10.8-28.9 \mathrm{~m} / \mathrm{s}(24.2-64.6 \mathrm{mph})$ & & $6.2 \mathrm{~m}$ (ESE) & $4.5 \mathrm{~m}$ (ESE) & $2.6-6.5 \mathrm{~m}$ & $8.1 \mathrm{~s}$ & $10.3 \mathrm{~s}$ \\
\hline & & & & Oct $27(09: 00)$ to Oct $28(1$ & $11: 00)$ & & Oct $27(22: 00)$ to Oct $28(03: 00)$ & Oct $27(16: 00)$ to Oct $28(19: 00)$ & & & \\
\hline \multirow[t]{2}{*}{ Nov 10-11 } & & & & $13.3 \mathrm{~m} / \mathrm{s}(29.8 \mathrm{mph})$ & $9.1-19.7 \mathrm{~m} / \mathrm{s}(20.4-44.1 \mathrm{mph})$ & ENE, then W & $3.9 \mathrm{~m}(\mathrm{E})$ & $2.9 \mathrm{~m}(\mathrm{E}$, then $\mathrm{W})$ & $2.0-4.1 \mathrm{~m}$ & $6.0 \mathrm{~s}$ & $7.5 \mathrm{~s}$ \\
\hline & & & & Nov $10(00: 00)$ to Nov 11 & $(16: 00)$ & & Nov 10 (08:00 to 12:00) & Nov $10(03: 00)$ to Nov $11(07: 00)$ & & & \\
\hline \multirow[t]{2}{*}{ Nov 15-16 } & Avery & Winter Storm & 5-8" (13-20 cm) & $17.1 \mathrm{~m} / \mathrm{s}(38.3 \mathrm{mph})$ & $14.4-22.0 \mathrm{~m} / \mathrm{s}(32.2-49.2 \mathrm{mph})$ & ENE & & lata not available) & & & \\
\hline & & & & Nov 16 from 05:00 to $18: 0$ & & & & & & & \\
\hline \multirow[t]{2}{*}{ Nov 20} & & Snow Storm & $3-8 "(8-20 \mathrm{~cm})$ & $10.4 \mathrm{~m} / \mathrm{s}(23.3 \mathrm{mph})$ & $9.4-13.5 \mathrm{~m} / \mathrm{s}(21.0-30.2 \mathrm{mph})$ & NE, then NNW & & (data not available) & & & \\
\hline & & & & Nov 20 from 10:00 to $23: 0$ & & & & (adta nol dvallidole) & & & \\
\hline \multirow[t]{2}{*}{ Nov 27} & & Coastal Flood & & $15.7 \mathrm{~m} / \mathrm{s}(35.1 \mathrm{mph})$ & $11.7-21.6 \mathrm{~m} / \mathrm{s}(26.2-48.3 \mathrm{mph})$ & ENE, then $S$ & $5.6 \mathrm{~m}(\mathrm{E})$ & $3.8 \mathrm{~m}(\mathrm{E})$ & $2.5-6.2 \mathrm{~m}$ & $7.1 \mathrm{~s}$ & $10.1 \mathrm{~s}$ \\
\hline & & & & Nov $26(22: 00)$ to Nov 27 & $(16: 00)$ & & Nov 27 (10:00 to $14: 00)$ & Nov $26(22: 00)$ to Nov $28(02: 00)$ & & & \\
\hline Dec 16-19 & & & & $12.7 \mathrm{~m} / \mathrm{s}(28.4 \mathrm{mph})$ & $9.0-23.2 \mathrm{~m} / \mathrm{s}(20.1-51.9 \mathrm{mph})$ & WNW & $3.6 \mathrm{~m}$ (ESE) & $2.9 \mathrm{~m}(\mathrm{ESE}$, then $\mathrm{NW})$ & $1.9-4.1 \mathrm{~m}$ & $6.1 \mathrm{~s}$ & $8.1 \mathrm{~s}$ \\
\hline & & & & Dec $17(20: 00)$ to Dec 19 & $(10: 00)$ & & Dec 17 (07:00 to 13:00) & Dec $16(21: 00)$ to Dec $18(23: 00)$ & & & \\
\hline Dec 21-23 & & & & $12.5 \mathrm{~m} / \mathrm{s}(28.0 \mathrm{mph})$ & $8.3-21.3 \mathrm{~m} / \mathrm{s}(18.6-47.6 \mathrm{mph})$ & SSE, then WNW & $3.1 \mathrm{~m}(\mathrm{SE})$ & $2.4 \mathrm{~m}$ (SE, then variable) & $1.2-3.3 \mathrm{~m}$ & $6.1 \mathrm{~s}$ & $9.2 \mathrm{~s}$ \\
\hline & & & & Dec $21(13: 00)$ to $\operatorname{Dec} 23$ & $(21: 00)$ & & Dec 21 (19:00 to 22:00) & Dec $21(13: 00)$ to Dec $23(19: 00)$ & & & \\
\hline
\end{tabular}




\section{Appendix C: Relationship Between Grain Size, Phi Size, Wentworth}

Classification and Gradistat Classification

\begin{tabular}{|c|c|c|c|c|}
\hline Size & Size & Size & $\begin{array}{c}\text { Wentworth Size } \\
\text { Class }\end{array}$ & $\begin{array}{c}\text { Gradistat } \\
\text { Modified Class }\end{array}$ \\
\hline$>-10.0 \phi$ & $>1024 \mathrm{~mm}$ & -------- & Boulder Gravel & Very Large Boulder \\
\hline-9.0 to $-10.0 \phi$ & 512 to $1024 \mathrm{~mm}$ & -------- & Boulder Gravel & Large Boulder \\
\hline-8.0 to $-9.0 \phi$ & 256 to $512 \mathrm{~mm}$ & ------- & Boulder Gravel & Medium Boulder \\
\hline-7.0 to $-8.0 \phi$ & 128 to $256 \mathrm{~mm}$ & ------- & Cobble Gravel & Small Boulder \\
\hline-6.0 to $-7.0 \phi$ & 64 to $128 \mathrm{~mm}$ & ------- & Cobble Gravel & Very Small Boulder \\
\hline-5.0 to $-6.0 \phi$ & 32 to $64 \mathrm{~mm}$ & -------- & Pebble Gravel & Very Coarse Gravel \\
\hline-4.0 to $-5.0 \phi$ & 16 to $32 \mathrm{~mm}$ & -------- & Pebble Gravel & Coarse Gravel \\
\hline-3.0 to $-4.0 \phi$ & 8.0 to $16 \mathrm{~mm}$ & -------- & Pebble Gravel & Medium Gravel \\
\hline-2.0 to $-3.0 \phi$ & 4.0 to $8.0 \mathrm{~mm}$ & -------- & Pebble Gravel & Fine Gravel \\
\hline-1.0 to $-2.0 \phi$ & 2.0 to $4.0 \mathrm{~mm}$ & -------- & Granule Gravel & Very Fine Gravel \\
\hline 0.0 to $-1.0 \phi$ & 1.0 to $2.0 \mathrm{~mm}$ & --------- & Very Coarse Sand & Very Coarse Sand \\
\hline 1.0 to $0.0 \phi$ & 0.5 to $1.0 \mathrm{~mm}$ & -------- & Coarse Sand & Coarse Sand \\
\hline 2.0 to $1.0 \phi$ & 0.25 to $0.5 \mathrm{~mm}$ & $500 \mu$ & Medium Sand & Medium Sand \\
\hline 3.0 to $2.0 \phi$ & 0.125 to $0.25 \mathrm{~mm}$ & $250 \mu$ & Fine Sand & Fine Sand \\
\hline 4.0 to $3.0 \phi$ & 0.0625 to $.125 \mathrm{~mm}$ & $125 \mu$ & Very Fine Sand & Very Fine Sand \\
\hline 5.0 to $4.0 \phi$ & 0.031 to $.0625 \mathrm{~mm}$ & $63 \mu$ & Coarse Silt & Very Coarse Silt \\
\hline 6.0 to $5.0 \phi$ & 0.0156 to $0.031 \mathrm{~mm}$ & $31 \mu$ & Medium Silt & Coarse Silt \\
\hline 7.0 to $6.0 \phi$ & 0.0078 to $0.0156 \mathrm{~mm}$ & $15.6 \mu$ & Fine Silt & Medium Silt \\
\hline 8.0 to $7.0 \phi$ & 0.0039 to $0.0078 \mathrm{~mm}$ & $7.8 \mu$ & Very Fine Silt & Fine Silt \\
\hline 9.0 to $8.0 \phi$ & 0.0002 to $0.0039 \mathrm{~mm}$ & $3.9 \mu$ & Clay & Very Fine Silt \\
\hline$<9.0 \phi$ & $<0.0002 \mathrm{~mm}$ & $2.0 \mu$ & Clay & Clay \\
\hline $14.0 \phi$ & $0.00006 \mathrm{~mm}$ & $0.06 \mu$ & Clay & Clay \\
\hline
\end{tabular}




\section{Appendix D: CMECS Substrate Classification (FGDC, 2012)}

\begin{tabular}{|c|c|c|c|c|}
\hline $\begin{array}{l}\text { Substrate } \\
\text { Origin }\end{array}$ & $\begin{array}{l}\text { Substrate } \\
\text { Class }\end{array}$ & $\begin{array}{l}\text { Substrate } \\
\text { Subclass }\end{array}$ & $\begin{array}{l}\text { Substrate } \\
\text { Group }\end{array}$ & $\begin{array}{l}\text { Substrate } \\
\text { Subgroup }\end{array}$ \\
\hline \multirow{29}{*}{$\begin{array}{l}\text { Geologic } \\
\text { Substrate }\end{array}$} & Rock Substrate & Bedrock & & \\
\hline & \multirow{28}{*}{$\begin{array}{c}\text { Unconsolidated } \\
\text { Mineral } \\
\text { Substrate }\end{array}$} & \multirow{10}{*}{$\begin{array}{c}\text { Coarse } \\
\text { Unconsolidated } \\
\text { Substrate }\end{array}$} & \multirow{4}{*}{ Gravel } & Boulder \\
\hline & & & & Cobble \\
\hline & & & & Pebble \\
\hline & & & & Granule \\
\hline & & & \multirow{3}{*}{ Gravel Mixes } & Sandy Gravel \\
\hline & & & & Muddy Sandy Gravel \\
\hline & & & & Muddy Gravel \\
\hline & & & \multirow{3}{*}{ Gravelly } & Gravelly Sand \\
\hline & & & & Gravelly Muddy Sand \\
\hline & & & & Gravelly Mud \\
\hline & & \multirow{18}{*}{$\begin{array}{c}\text { Fine } \\
\text { Unconsolidated } \\
\text { Substrate }\end{array}$} & \multirow{4}{*}{ Slightly Gravelly } & Slightly Gravelly Sand \\
\hline & & & & Slightly Gravelly Muddy Sand \\
\hline & & & & Slightly Gravelly Sandy Mud \\
\hline & & & & Slightly Gravelly Mud \\
\hline & & & \multirow{5}{*}{ Sand } & Very Coarse Sand \\
\hline & & & & Coarse Sand \\
\hline & & & & Medium Sand \\
\hline & & & & Fine Sand \\
\hline & & & & Very Fine Sand \\
\hline & & & \multirow{3}{*}{ Muddy Sand } & Silty Sand \\
\hline & & & & Silty-Clayey Sand \\
\hline & & & & Clayey Sand \\
\hline & & & \multirow{3}{*}{ Sandy Mud } & Sandy Silt \\
\hline & & & & Sandy Silt-Clay \\
\hline & & & & Sandy Clay \\
\hline & & & \multirow{3}{*}{ Mud } & Silt \\
\hline & & & & Silt-Clay \\
\hline & & & & Clay \\
\hline
\end{tabular}




\section{Appendix E: Complete Grain Size Data for Beach Sediment Samples}

Sediment grain size data from seven major New Hampshire beaches is presented here. In total, 140 sediment samples were collected at cross-shore transects in late winter - early spring following an extended period of beach erosion, and 97 sediment samples were collected in late summer/early fall following an extended period of accretion. This appendix provides complete descriptions for each sample including identification, station and sample characteristics, sediment classifications, grain size statistics, and grain size distribution. The methods used for extracting the samples and grain size analyses are given in this report in Chapter 5: Methods. The sediment grain size classifications include: CMECS (Coastal and Marine Ecological Classification Standard; FGDC, 2012); Gradistat (Blot and Pye, 2001); and Wentworth (Wentworth, 1922; described in Folk, 1954, 1980). Statistics are based on the phi scale and include the graphic mean, sorting, skewness, and kurtosis (Folk, 1980). Each of the seven beaches is given its own section, and in each section (a) refers to the winter/spring 2017 sampling period and (b) refers to the late summer/early fall 2017 sampling period. Data for each beach and sampling period is separated by transect and spread across four pages, with each sample identified in the first column by the Sample ID.

The database is also available as a Microsoft Excel file at the UNH Scholars Repository (https://scholars.unh.edu/). PDF "single sample summaries" of each sample are also available in this online database (not included in the report due to the size), which include field photographs of the beach and sediment sample, laboratory photographs of the samples where available, location information, collection information, and selected sediment classifications, grain size statistics, and grain size distribution:

Ward, L.G., Corcoran, N.W., McAvoy, Z.S., and Morrison, R.C., 2021, New Hampshire Atlantic Beaches: 2017 Field Campaign Database - Field and Sample Photographs and Sediment Data: University of New Hampshire Center for Coastal and Ocean Mapping/Joint Hydrographic Center. UNH Scholars Repository. https://dx.doi.org/10.34051/d/2021.6 
Section 1(a): Wallis Sands (Winter/Spring 2017 Sampling Period) 
Wallis Sands Beach (Winter Sampling), Rye, New Hampshire: Identification, Location, and Description

\begin{tabular}{|c|c|c|c|c|c|c|c|c|c|c|c|c|c|}
\hline Sample ID & Global Sample ID & $\begin{array}{l}\text { Latitude } \\
\text { WGS84 }\end{array}$ & $\begin{array}{c}\text { Longitude } \\
\text { WGS84 } \\
\end{array}$ & $\begin{array}{l}\text { Relative } \\
\text { Position } \\
\text { Accuracy } \\
\end{array}$ & $\begin{array}{c}\text { Elevation } \\
(\mathrm{m}) \\
\text { NAVD88 } \\
\end{array}$ & $\begin{array}{c}\text { Elevation } \\
(\mathrm{m}) \\
\text { MTL } \\
\end{array}$ & $\begin{array}{l}\text { Relative } \\
\text { Elevation }\end{array}$ & $\begin{array}{l}\text { Relative } \\
\text { Location }\end{array}$ & $\begin{array}{c}\text { Sample } \\
\text { Collected }\end{array}$ & $\begin{array}{l}\text { Core } \\
\text { Length } \\
\text { (cm) } \\
\end{array}$ & $\begin{array}{c}\text { Collected } \\
\text { Sample } \\
\text { Wt. (gm) } \\
\end{array}$ & $\begin{array}{c}\text { Processed } \\
\text { Sample } \\
\text { Wt. (gm) } \\
\end{array}$ & $\begin{array}{l}\text { Morphologic } \\
\text { Feature }\end{array}$ \\
\hline WS01-1 & NHC_D20170222_WS01-1 & 43.027640 & -70.728328 & 1 & 1.92 & 2.03 & UTB & UB & 22-Feb-17 & 25 & $2,563.0$ & $2,555.5$ & S. Ramp or Berm \\
\hline WS01-2 & NHC_D20170222_WS01-2 & 43.027534 & -70.728175 & 1 & 1.14 & 1.25 & MTB & UB & 22 -Feb-17 & 20 & $3,646.5$ & $3,656.1$ & LTT: Landward \\
\hline WS01-3 & NHC_D20170222_WS01-3 & 43.027400 & -70.727988 & 1 & 0.49 & 0.60 & MTB & $\mathrm{MB}$ & $22-$ Feb-17 & 27 & $4,050.3$ & $4,144.9$ & LTT: Mid \\
\hline WS01-4 & NHC_D20170222_WS01-4 & 43.026983 & -70.727395 & 1 & -0.97 & -0.86 & LTB & LB & 22-Feb-17 & 27 & $4,501.3$ & $4,544.4$ & LT; Swash Zone \\
\hline WSO2-nr1 & NHC D20170223_WS02-nr1 & 43.024916 & -70.730610 & 1 & 1.78 & 1.89 & UTB & UB & 23-Feb-17 & Est. 25 & $2,841.7$ & $2,847.4$ & $\begin{array}{c}\text { S. Ramp or Berm; } \\
\text { G. Patch }\end{array}$ \\
\hline WSO2-1 & NHC_D20170223_WS02-1 & 43.024792 & -70.730806 & 1 & 2.67 & 2.79 & UTB & UB & 23-Feb-17 & 25 & $4,715.6$ & $4,831.7$ & S. Ramp or Berm \\
\hline WSO2-2 & NHC_D20170223_WS02-2 & 43.024749 & -70.730699 & 1 & 1.60 & 1.71 & UTB & UB & 23-Feb-17 & 22 & $4,886.8$ & $4,882.8$ & S. Ramp or Berm \\
\hline WSO2-3 & NHC_D20170223_WS02-3 & 43.024704 & -70.730588 & 1 & 0.53 & 0.65 & MTB & UB & 23-Feb-17 & 23 & $9,117.3$ & $9,241.1$ & $\begin{array}{c}\text { S. Ramp or Berm } \\
\text { Toe } \\
\end{array}$ \\
\hline WSO2-4 & NHC D20170223 WSO2-4 & 43.024693 & -70.730554 & 1 & 0.08 & 0.19 & $\mathrm{MW}$ & UB & 23-Feb-17 & Est. 25 & $19,112.3$ & $19,189.6$ & Berm Toe Runnel \\
\hline WSO2-5 & NHC_D20170223_WS02_5 & 43.024606 & -70.730338 & 1 & 0.14 & 0.25 & MTB & $\mathrm{MB}$ & 23-Feb-17 & 25 & $4,022.6$ & $4,126.1$ & $\begin{array}{c}\text { LT; Landward to } \\
\text { Mid }\end{array}$ \\
\hline WSO2-6 & NHC_D20170223_WS02-6 & 43.024516 & -70.730112 & 1 & -0.20 & -0.09 & LTB & $\mathrm{MB}$ & 23-Feb-17 & 25 & $4,214.0$ & $4,351.4$ & $\llcorner\pi$ ¿Mid \\
\hline WSO2-7 & NHC_D20170223_WS02-7 & 43.024429 & -70.729894 & 1 & -0.67 & -0.55 & LTB & LB & 23-Feb-17 & 25 & $4,583.5$ & $4,578.8$ & LTT; Swash Zone \\
\hline WS03-1 & NHC_D20170307_WS03-1 & 43.022884 & -70.731868 & 1 & 2.73 & 2.84 & UTB & UB & 7-Mar-17 & 27 & $3,872.0$ & $3,891.4$ & S. Ramp or Berm \\
\hline WS03-2 & NHC D20170307_WS03-2 & 43.022844 & -70.731715 & 1 & 1.63 & 1.74 & UTB & UB & 7-Mar-17 & 29 & $4,020.8$ & $4,004.0$ & S. Ramp or Berm \\
\hline WSO3-3 & NHC D20170307_WS03-3 & 43.022799 & -70.731540 & 1 & 0.41 & 0.52 & UTB & UB & 7-Mar-17 & 28 & $8,521.9$ & $8,529.6$ & LTT; Landward \\
\hline WSO3-4 & NHC_D20170307_WS03-4 & 43.022707 & -70.731179 & 1 & -0.12 & -0.01 & MTB & $\mathrm{MB}$ & 7-Mar-17 & 25 & $4,399.0$ & $4,388.8$ & LTT; Mid \\
\hline WS03-5 & NHC_D20170307_WS03-5 & 43.022542 & -70.730492 & 1 & -1.24 & -1.13 & LTB & $L B$ & 7-Mar-17 & 25 & $3,170.8$ & $3,174.4$ & LIT; Swash Zone \\
\hline WS05-1 & NHC_D20170308_WS05-1 & 43.020671 & -70.732412 & 2 & $\mathrm{~N} / \mathrm{A}$ & $\mathrm{N} / \mathrm{A}$ & N/A & N/A & 8-Mar-17 & 27 & $4,589.3$ & $4,570.8$ & S. Ramp \\
\hline WS05-2 & NHC_D20170308_WS05-2 & 43.020692 & -70.732166 & 2 & $\mathrm{~N} / \mathrm{A}$ & $\mathrm{N} / \mathrm{A}$ & N/A & $\mathrm{N} / \mathrm{A}$ & 8-Mar-17 & 28 & $4,066.6$ & $4,101.7$ & $\begin{array}{l}\text { S. Ramp Toe; Edge } \\
\text { of } L T\end{array}$ \\
\hline WSO5-3 & NHC D20170308_WS05-3 & 43.020642 & -70.731830 & 2 & N/A & $\mathrm{N} / \mathrm{A}$ & N/A & N/A & 8-Mar-17 & 27 & $4,443.8$ & $4,436.0$ & $\llcorner T \pi ; \mathrm{Mid}$ \\
\hline WS05-4 & NHC_D20170308_WS05-4 & 43.020617 & -70.731348 & 2 & $\mathrm{~N} / \mathrm{A}$ & $\mathrm{N} / \mathrm{A}$ & N/A & N/A & 8-Mar-17 & 29 & $4,109.5$ & $4,115.2$ & LTT; Swash Zone \\
\hline WS05-1 & NHC_D20170504_WS05-1 & 43.020677 & -70.732452 & 1 & 2.35 & 2.46 & UTB & UB & 4-May-17 & 28 & $2,775.5$ & $2,776.9$ & $\begin{array}{l}\text { S. Ramp; Near } \\
\text { Seawall }\end{array}$ \\
\hline WS05-2 & NHC_D20170504_WS05-2 & 43.020673 & -70.732341 & 1 & 1.50 & 1.61 & UTB & UB & 4-May-17 & 27 & $3,308.9$ & $3,296.7$ & S. Ramp \\
\hline WS05-3 & NHC D20170504_WS05-3 & 43.020669 & -70.732279 & 1 & 0.97 & 1.08 & MTB & UB & 4-May-17 & 28 & $4,252.9$ & $4,254.9$ & $\begin{array}{c}\text { S. Ramp Toe; Edge } \\
\text { of Runnel }\end{array}$ \\
\hline WS05-4 & NHC_D20170504_WS05-4 & 43.020663 & -70.732167 & 1 & 0.78 & 0.89 & MTB & UB & 4-May-17 & 30 & $3,028.0$ & $3,028.3$ & LTT; Landward \\
\hline WS05-5 & NHC_D20170504_WS05-5 & 43.020611 & -70.731455 & 1 & -0.69 & -0.58 & LTB & LB & 4-May-17 & 29 & $3,038.4$ & $2,956.8$ & LT; Seaward \\
\hline
\end{tabular}




\begin{tabular}{|c|c|c|c|c|c|c|c|c|}
\hline Sample ID & $\begin{array}{l}\text { CMECS Substrate } \\
\text { Component } \\
\text { Group (Specific) }\end{array}$ & $\begin{array}{l}\text { CMECS Substrate } \\
\text { Component Subgroup } \\
\text { (Specific) }\end{array}$ & $\begin{array}{l}\text { Textural Group from } \\
\text { \%GSM (Gradistat) }\end{array}$ & $\begin{array}{l}\text { Sediment Name from } \\
\text { \%GSM } \\
\text { and Mode (Gradistat) }\end{array}$ & $\begin{array}{l}\text { Sediment Name from } \\
\text { \%GSM and Mode } \\
\text { (Wentworth Scale) }\end{array}$ & $\begin{array}{l}\text { Sediment Classification } \\
\text { from Mean Phi } \\
\text { (Gradistat) }\end{array}$ & $\begin{array}{l}\text { Sediment } \\
\text { Classification } \\
\text { from Mean Phi } \\
\text { (Wentworth) }\end{array}$ & Sorting (Gradistat) \\
\hline & & Slightly Granuley Fine & & Slightly Very Fine Gravelly & Slightly Granular Fine & & & \\
\hline WS01-1 & Slightly Granuley & Sand & Slightly Gravelly Sand & Fine Sand & Sand & Medium Sand & Medium Sand & Moderately Well Sorted \\
\hline WS01-2 & Slightly Pebbly & $\begin{array}{l}\text { Slightly Pebbly Fine } \\
\text { Sand }\end{array}$ & Slightly Gravelly Sand & $\begin{array}{l}\text { Slightly Coarse Gravelly } \\
\text { Fine Sand }\end{array}$ & $\begin{array}{l}\text { Slightly Pebbly Fine } \\
\text { Sand }\end{array}$ & Fine Sand & Fine Sand & Moderately Well Sorted \\
\hline WS01-3 & Slightly Granuley & $\begin{array}{l}\text { Slightly Granuley Fine } \\
\text { Sand }\end{array}$ & Slightly Gravelly Sand & $\begin{array}{l}\text { Slightly Very Fine Gravelly } \\
\text { Fine Sand }\end{array}$ & $\begin{array}{l}\text { Slightly Granular Fine } \\
\text { Sand }\end{array}$ & Medium Sand & Medium Sand & Moderately Sorted \\
\hline WS01-4 & Slightly Granuley & $\begin{array}{l}\text { Slightly Granuley Fine } \\
\text { Sand }\end{array}$ & Slightly Gravelly Sand & $\begin{array}{l}\text { Slightly Very Fine Gravelly } \\
\text { Fine Sand }\end{array}$ & $\begin{array}{l}\text { Slightly Granular Fine } \\
\text { Sand }\end{array}$ & Medium Sand & Medium Sand & Moderately Sorted \\
\hline WS02-nr1 & Gravel & Pebble Gravel & Gravel & Medium Gravel & Pebble Gravel & Medium Gravel & Pebble Gravel & Poorly Sorted \\
\hline WSO2-1 & Slightly Granuley & $\begin{array}{l}\text { Slightly Granuley } \\
\text { Medium Sand }\end{array}$ & Slightly Gravelly Sand & $\begin{array}{l}\text { Slightly Very Fine Gravelly } \\
\text { Medium Sand }\end{array}$ & $\begin{array}{l}\text { Slightly Granular } \\
\text { Medium Sand }\end{array}$ & Medium Sand & Medium Sand & Moderately Sorted \\
\hline WSO2-2 & Granuley & Granuley Coarse Sand & Gravelly Sand & $\begin{array}{l}\text { Very Fine Gravelly Coarse } \\
\text { Sand }\end{array}$ & Granular Coarse Sand & Very Coarse Sand & Very Coarse Sand & Poorly Sorted \\
\hline WSO2-3 & Pebble Mixes & Sandy Pebble Gravel & Sandy Gravel & Sandy Fine Gravel & Sandy Pebble Gravel & Very Fine Gravel & Granule Gravel & Poorly Sorted \\
\hline WSO2-4 & Granule Mixes & Sandy Granule Gravel & Sandy Gravel & Sandy Very Fine Gravel & Sandy Granule Gravel & Very Coarse Sand & Very Coarse Sand & Very Poorly Sorted \\
\hline WSO2-5 & Slightly Granuley & $\begin{array}{l}\text { Slightly Granuley } \\
\text { Medium Sand }\end{array}$ & Slightly Gravelly Sand & $\begin{array}{l}\text { Slightly Very Fine Gravelly } \\
\text { Medium Sand }\end{array}$ & $\begin{array}{l}\text { Slightly Granular } \\
\text { Medium Sand }\end{array}$ & Medium Sand & Medium Sand & Moderately Sorted \\
\hline WSO2-6 & Pebbly & Pebbly Medium Sand & Gravelly Sand & $\begin{array}{l}\text { Coarse Gravelly Medium } \\
\text { Sand }\end{array}$ & Pebbly Medium Sand & Medium Sand & Medium Sand & Poorly Sorted \\
\hline WSO2-7 & Slightly Granuley & $\begin{array}{l}\text { Slightly Granuley } \\
\text { Medium Sand }\end{array}$ & Slightly Gravelly Sand & $\begin{array}{l}\text { Slightly Very Fine Gravelly } \\
\text { Medium Sand }\end{array}$ & $\begin{array}{l}\text { Slightly Granular } \\
\text { Medium Sand }\end{array}$ & Medium Sand & Medium Sand & Moderately Sorted \\
\hline WS03-1 & Slightly Granuley & $\begin{array}{l}\text { Slightly Granuley } \\
\text { Medium Sand }\end{array}$ & Slightly Gravelly Sand & $\begin{array}{l}\text { Slightly Very Fine Gravelly } \\
\text { Medium Sand }\end{array}$ & $\begin{array}{l}\text { Slightly Granular } \\
\text { Medium Sand }\end{array}$ & Medium Sand & Medium Sand & Moderately Well Sorted \\
\hline WSO3-2 & Slightly Pebbly & $\begin{array}{l}\text { Slightly Pebbly Medium } \\
\text { Sand }\end{array}$ & Slightly Gravelly Sand & $\begin{array}{l}\text { Slightly Fine Gravelly } \\
\text { Medium Sand }\end{array}$ & $\begin{array}{l}\text { Slightly Pebbly Medium } \\
\text { Sand }\end{array}$ & Medium Sand & Medium Sand & Moderately Well Sorted \\
\hline WSO3-3 & Granuley & Granuley Medium Sand & Gravelly Sand & $\begin{array}{l}\text { Very Fine Gravelly Medium } \\
\text { Sand }\end{array}$ & Granular Medium Sand & Coarse Sand & Coarse Sand & Poorly Sorted \\
\hline WSO3-4 & Slightly Granuley & $\begin{array}{l}\text { Slightly Granuley Fine } \\
\text { Sand }\end{array}$ & Slightly Gravelly Sand & $\begin{array}{l}\text { Slightly Very Fine Gravelly } \\
\text { Fine Sand }\end{array}$ & $\begin{array}{l}\text { Slightly Granular Fine } \\
\text { Sand }\end{array}$ & Medium Sand & Medium Sand & Moderately Sorted \\
\hline WS03-5 & Granuley & Granuley Medium Sand & Gravelly Sand & $\begin{array}{l}\text { Very Fine Gravelly Medium } \\
\text { Sand }\end{array}$ & Granular Medium Sand & Medium Sand & Medium Sand & Poorly Sorted \\
\hline WS05-1 & Slightly Pebbly & $\begin{array}{l}\text { Slightly Pebbly Medium } \\
\text { Sand }\end{array}$ & Slightly Gravelly Sand & $\begin{array}{l}\text { Slightly Coarse Gravelly } \\
\text { Medium Sand }\end{array}$ & $\begin{array}{l}\text { Slightly Pebbly Medium } \\
\text { Sand }\end{array}$ & Medium Sand & Medium Sand & Moderately Sorted \\
\hline WSO5-2 & Granuley & Granuley Medium Sand & Gravelly Sand & $\begin{array}{l}\text { Very Fine Gravelly Medium } \\
\text { Sand }\end{array}$ & Granular Medium Sand & Medium Sand & Medium Sand & Poorly Sorted \\
\hline WS05-3 & Slightly Pebbly & $\begin{array}{l}\text { Slightly Pebbly Medium } \\
\text { Sand }\end{array}$ & Slightly Gravelly Sand & $\begin{array}{l}\text { Slightly Medium Gravelly } \\
\text { Medium Sand }\end{array}$ & $\begin{array}{l}\text { Slightly Pebbly Medium } \\
\text { Sand }\end{array}$ & Medium Sand & Medium Sand & Moderately Well Sorted \\
\hline WS05-4 & Slightly Granuley & $\begin{array}{l}\text { Slightly Granuley } \\
\text { Medium Sand }\end{array}$ & Slightly Gravelly Sand & $\begin{array}{l}\text { Slightly Very Fine Gravelly } \\
\text { Medium Sand }\end{array}$ & $\begin{array}{l}\text { Slightly Granular } \\
\text { Medium Sand }\end{array}$ & Medium Sand & Medium Sand & Moderately Well Sorted \\
\hline WS05-1 & Slightly Granuley & $\begin{array}{l}\text { Slightly Granuley } \\
\text { Medium Sand }\end{array}$ & Slightly Gravelly Sand & $\begin{array}{l}\text { Slightly Very Fine Gravelly } \\
\text { Medium Sand }\end{array}$ & $\begin{array}{l}\text { Slightly Granular } \\
\text { Medium Sand }\end{array}$ & Medium Sand & Medium Sand & Moderately Well Sorted \\
\hline WSO5-2 & Pebbly & Pebbly Medium Sand & Gravelly Sand & $\begin{array}{l}\text { Coarse Gravelly Medium } \\
\text { Sand }\end{array}$ & Pebbly Medium Sand & Medium Sand & Medium Sand & Poorly Sorted \\
\hline WS05-3 & Granuley & Granuley Coarse Sand & Gravelly Sand & $\begin{array}{l}\text { Very Fine Gravelly Coarse } \\
\text { Sand }\end{array}$ & Granular Coarse Sand & Coarse Sand & Coarse Sand & Poorly Sorted \\
\hline WS05-4 & Slightly Granuley & $\begin{array}{l}\text { Slightly Granuley } \\
\text { Medium Sand }\end{array}$ & Slightly Gravelly Sand & $\begin{array}{l}\text { Slightly Very Fine Gravelly } \\
\text { Medium Sand }\end{array}$ & $\begin{array}{l}\text { Slightly Granular } \\
\text { Medium Sand }\end{array}$ & Medium Sand & Medium Sand & Moderately Well Sorted \\
\hline WSO5-5 & Slightly Granuley & $\begin{array}{l}\text { Slightly Granuley Fine } \\
\text { Sand }\end{array}$ & Slightly Gravelly Sand & $\begin{array}{l}\text { Slightly Very Fine Gravelly } \\
\text { Fine Sand }\end{array}$ & $\begin{array}{l}\text { Slightly Granular Fine } \\
\text { Sand }\end{array}$ & Medium Sand & Medium Sand & Moderately Sorted \\
\hline
\end{tabular}




\begin{tabular}{|c|c|c|c|c|c|c|c|c|c|c|c|c|c|c|c|c|c|}
\hline Sample ID & Gravel \% & Pebble \% & Granule \% & Sand $\%$ & Mud \% & Modes & $\begin{array}{c}\text { Mode } 1 \\
\text { (phi) }\end{array}$ & $\begin{array}{c}\text { Mode } 2 \\
\text { (phi) }\end{array}$ & $\begin{array}{c}\mathrm{D}_{10} \\
\text { (phi) }\end{array}$ & $\begin{array}{c}D_{10} \\
(\mathrm{~mm}) \\
\end{array}$ & $\begin{array}{r}D_{50} \\
\text { (phi) }\end{array}$ & $\begin{array}{r}D_{50} \\
(\mathrm{~mm}) \\
\end{array}$ & $\begin{array}{c}\text { Mean Size } \\
\text { (phi) }\end{array}$ & $\begin{array}{l}\text { Mean Size } \\
(\mathrm{mm})\end{array}$ & $\begin{array}{c}\text { Sorting } \\
\text { (phi) }\end{array}$ & Skewness & Kurtosis \\
\hline WSO1-1 & 0.34 & 0.08 & 0.26 & 99.62 & 0.04 & $u$ & 2.24 & N/A & 1.11 & 0.46 & 2.04 & 0.24 & 1.97 & 0.26 & 0.58 & -0.23 & 1.20 \\
\hline WSO1-2 & 1.23 & 1.15 & 0.08 & 98.76 & 0.01 & U & 2.24 & $\mathrm{~N} / \mathrm{A}$ & 1.15 & 0.45 & 2.12 & 0.23 & 2.06 & 0.24 & 0.61 & -0.20 & 1.16 \\
\hline WS01-3 & 2.36 & 1.43 & 0.94 & 97.60 & 0.04 & $u$ & 2.24 & $\mathrm{~N} / \mathrm{A}$ & 0.56 & 0.68 & 2.19 & 0.22 & 1.98 & 0.25 & 0.90 & -0.42 & 1.16 \\
\hline WS01-4 & 0.98 & 0.33 & 0.66 & 99.00 & 0.02 & $u$ & 2.24 & $\mathrm{~N} / \mathrm{A}$ & 0.54 & 0.69 & 1.93 & 0.26 & 1.78 & 0.29 & 0.87 & -0.27 & 0.96 \\
\hline WS02-nr1 & 99.10 & 89.77 & 9.34 & 0.89 & 0.01 & u & -3.74 & N/A & -4.84 & 28.54 & -3.61 & 12.24 & -3.54 & 11.65 & 1.09 & 0.14 & 0.94 \\
\hline WSO2-1 & 1.57 & 0.62 & 0.96 & 98.40 & 0.03 & $u$ & 0.75 & N/A & 0.11 & 0.93 & 1.15 & 0.45 & 1.16 & 0.45 & 0.81 & -0.05 & 1.05 \\
\hline WSO2-2 & 17.51 & 10.77 & 6.74 & 82.47 & 0.02 & $u$ & 0.25 & $\mathrm{~N} / \mathrm{A}$ & -2.17 & 4.49 & 0.03 & 0.98 & -0.05 & 1.03 & 1.39 & -0.20 & 1.62 \\
\hline WSO2-3 & 75.78 & 51.46 & 24.32 & 24.21 & 0.01 & u & -2.24 & $\mathrm{~N} / \mathrm{A}$ & -3.43 & 10.79 & -2.04 & 4.10 & -1.84 & 3.59 & 1.40 & 0.21 & 1.13 \\
\hline WSO2-4 & 42.07 & 28.62 & 13.45 & 57.92 & 0.01 & $B$ & 0.75 & -5.74 & -4.24 & 18.95 & -0.43 & 1.35 & -0.91 & 1.87 & 2.12 & -0.38 & 0.94 \\
\hline WSO2-5 & 2.61 & 0.99 & 1.63 & 97.37 & 0.02 & $u$ & 2.24 & N/A & 0.11 & 0.92 & 1.71 & 0.31 & 1.56 & 0.34 & 0.97 & -0.33 & 1.17 \\
\hline WSO2-6 & 9.06 & 6.78 & 2.27 & 90.93 & 0.01 & B & 1.75 & -0.74 & -0.87 & 1.83 & 2.39 & 0.19 & 1.24 & 0.42 & 1.47 & -0.49 & 1.72 \\
\hline WSO2-7 & 2.14 & 0.76 & 1.39 & 97.84 & 0.02 & U & 1.75 & $\mathrm{~N} / \mathrm{A}$ & 0.34 & 0.79 & 1.63 & 0.32 & 1.54 & 0.34 & 0.86 & -0.21 & 1.06 \\
\hline WSO3-1 & 0.07 & 0.01 & 0.06 & 99.93 & 0.00 & $\mathrm{u}$ & 1.25 & N/A & 0.38 & 0.77 & 1.12 & 0.46 & 1.15 & 0.45 & 0.61 & 0.06 & 0.99 \\
\hline WSO3-2 & 0.08 & 0.05 & 0.03 & 99.92 & 0.00 & u & 1.75 & $\mathrm{~N} / \mathrm{A}$ & 0.70 & 0.61 & 1.61 & 0.33 & 1.57 & 0.34 & 0.61 & -0.11 & 0.91 \\
\hline WSO3-3 & 15.68 & 8.67 & 7.01 & 84.31 & 0.01 & $B$ & 2.24 & 0.75 & -1.79 & 3.45 & 0.83 & 0.56 & 0.66 & 0.63 & 1.59 & -0.28 & 1.03 \\
\hline WSO3-4 & 3.21 & 1.87 & 1.34 & 96.78 & 0.01 & U & 2.24 & $\mathrm{~N} / \mathrm{A}$ & 0.54 & 0.69 & 1.83 & 0.28 & 1.70 & 0.31 & 0.85 & -0.31 & 1.18 \\
\hline WSO3-5 & 5.86 & 2.85 & 3.01 & 94.13 & 0.01 & U & 2.24 & N/A & -0.19 & 1.14 & 1.62 & 0.32 & 1.46 & 0.36 & 1.11 & -0.34 & 1.22 \\
\hline WS05-1 & 2.87 & 2.60 & 0.26 & 97.12 & 0.01 & U & 1.75 & $\mathrm{~N} / \mathrm{A}$ & 0.52 & 0.70 & 1.66 & 0.32 & 1.56 & 0.34 & 0.74 & -0.26 & 1.00 \\
\hline WS05-2 & 5.42 & 3.84 & 1.58 & 94.56 & 0.02 & U & 2.24 & N/A & 0.08 & 0.95 & 1.49 & 0.36 & 1.40 & 0.38 & 1.02 & -0.29 & 1.19 \\
\hline WS05-3 & 1.03 & 0.72 & 0.31 & 98.96 & 0.01 & U & 1.75 & $\mathrm{~N} / \mathrm{A}$ & 0.81 & 0.57 & 1.82 & 0.28 & 1.75 & 0.30 & 0.64 & -0.19 & 1.06 \\
\hline WS05-4 & 0.63 & 0.40 & 0.23 & 99.36 & 0.01 & U & 2.24 & $\mathrm{~N} / \mathrm{A}$ & 0.93 & 0.53 & 1.87 & 0.27 & 1.81 & 0.29 & 0.64 & -0.18 & 1.12 \\
\hline WSO5-1 & 0.05 & 0.00 & 0.05 & 99.94 & 0.01 & U & 1.75 & $\mathrm{~N} / \mathrm{A}$ & 0.66 & 0.63 & 1.59 & 0.33 & 1.52 & 0.35 & 0.61 & -0.16 & 1.03 \\
\hline WS05-2 & 6.32 & 5.22 & 1.10 & 93.67 & 0.01 & $\mathrm{U}$ & 1.75 & N/A & -0.11 & 1.08 & 1.40 & 0.38 & 1.29 & 0.41 & 1.16 & -0.37 & 1.56 \\
\hline WSO5-3 & 13.33 & 9.02 & 4.31 & 86.66 & 0.01 & $u$ & 0.75 & $\mathrm{~N} / \mathrm{A}$ & -1.77 & 3.41 & 0.83 & 0.56 & 0.69 & 0.62 & 1.41 & -0.31 & 1.52 \\
\hline WS05-4 & 1.25 & 0.67 & 0.58 & 98.74 & 0.01 & U & 1.75 & N/A & 0.58 & 0.67 & 1.55 & 0.34 & 1.51 & 0.35 & 0.70 & -0.13 & 1.01 \\
\hline WS05-5 & 0.73 & 0.18 & 0.56 & 99.26 & 0.01 & U & 2.24 & N/A & 0.50 & 0.71 & 1.83 & 0.28 & 1.68 & 0.31 & 0.87 & -0.24 & 0.85 \\
\hline
\end{tabular}




\section{Wallis Sands Beach (Winter Sampling), Rye, New Hampshire: Grain Size Distribution}

\begin{tabular}{|c|c|c|c|c|c|c|c|c|c|c|c|c|c|c|c|c|c|c|c|c|c|}
\hline Sample ID & $\begin{array}{c}\text { Class \% } \\
\text { phi } \\
-5.5 \\
\end{array}$ & $\begin{array}{c}\text { Class \% } \\
\text { phi } \\
-5.0 \\
\end{array}$ & $\begin{array}{c}\text { Class \% } \\
\text { phi } \\
-4.5 \\
\end{array}$ & $\begin{array}{c}\text { Class \% } \\
\text { phi } \\
-4.0 \\
\end{array}$ & $\begin{array}{c}\text { Class \% } \\
\text { phi } \\
-3.5 \\
\end{array}$ & $\begin{array}{c}\text { Class \% } \\
\text { phi } \\
-3.0 \\
\end{array}$ & $\begin{array}{c}\text { Class \% } \\
\text { phi } \\
-2.5 \\
\end{array}$ & $\begin{array}{c}\text { Class \% } \\
\text { phi } \\
-2.0 \\
\end{array}$ & $\begin{array}{c}\text { Class \% } \\
\text { phi } \\
-1.5 \\
\end{array}$ & $\begin{array}{c}\text { Class \% } \\
\text { phi } \\
-1.0 \\
\end{array}$ & $\begin{array}{c}\text { Class \% } \\
\text { phi } \\
-0.5 \\
\end{array}$ & $\begin{array}{c}\text { Class \% } \\
\text { phi } \\
0.0 \\
\end{array}$ & $\begin{array}{c}\text { Class \% } \\
\text { phi } \\
0.5 \\
\end{array}$ & $\begin{array}{c}\text { Class \% } \\
\text { phi } \\
1.0 \\
\end{array}$ & $\begin{array}{c}\text { Class \% } \\
\text { phi } \\
1.5 \\
\end{array}$ & $\begin{array}{c}\text { Class \% } \\
\text { phi } \\
2.0 \\
\end{array}$ & $\begin{array}{c}\text { Class \% } \\
\text { phi } \\
2.5 \\
\end{array}$ & $\begin{array}{c}\text { Class \% } \\
\text { phi } \\
\mathbf{3 . 0} \\
\end{array}$ & $\begin{array}{c}\text { Class \% } \\
\text { phi } \\
3.5 \\
\end{array}$ & $\begin{array}{c}\text { Class \% } \\
\text { phi } \\
4.0 \\
\end{array}$ & $\begin{array}{c}\text { Class } \% \\
\text { phi } \\
>4.0 \\
\end{array}$ \\
\hline WS01-1 & 0.00 & 0.00 & 0.00 & 0.00 & 0.00 & 0.01 & 0.01 & 0.06 & 0.11 & 0.14 & 0.29 & 0.75 & 1.56 & 4.83 & 9.98 & 29.09 & 38.64 & 13.67 & 0.79 & 0.03 & 0.04 \\
\hline WS01-2 & 0.00 & 0.00 & 0.00 & 0.78 & 0.29 & 0.04 & 0.02 & 0.02 & 0.03 & 0.05 & 0.06 & 0.17 & 0.74 & 4.90 & 9.40 & 23.74 & 38.80 & 19.70 & 1.23 & 0.02 & 0.01 \\
\hline WS01-3 & 0.00 & 0.00 & 0.00 & 0.46 & 0.37 & 0.09 & 0.16 & 0.34 & 0.45 & 0.49 & 0.95 & 1.90 & 3.89 & 6.99 & 7.44 & 14.89 & 29.17 & 29.58 & 2.75 & 0.04 & 0.04 \\
\hline WS01-4 & 0.00 & 0.00 & 0.00 & 0.00 & 0.00 & 0.09 & 0.08 & 0.15 & 0.24 & 0.42 & 0.88 & 2.15 & 5.11 & 10.97 & 13.15 & 19.65 & 26.87 & 18.05 & 2.14 & 0.03 & 0.02 \\
\hline WS02-nr 1 & 0.00 & 5.53 & 15.45 & 13.94 & 20.10 & 16.72 & 10.44 & 7.58 & 6.56 & 2.78 & 0.58 & 0.14 & 0.07 & 0.04 & 0.02 & 0.02 & 0.01 & 0.00 & 0.00 & 0.00 & 0.01 \\
\hline WSO2-1 & 0.00 & 0.00 & 0.00 & 0.14 & 0.17 & 0.11 & 0.05 & 0.16 & 0.41 & 0.55 & 2.94 & 2.99 & 10.98 & 24.70 & 23.09 & 19.78 & 11.17 & 2.61 & 0.13 & 0.02 & 0.03 \\
\hline WSO2-2 & 0.00 & 1.12 & 1.05 & 1.56 & 1.42 & 1.53 & 1.87 & 2.21 & 2.85 & 3.89 & 12.88 & 18.51 & 19.90 & 15.01 & 6.45 & 4.82 & 3.95 & 0.92 & 0.03 & 0.01 & 0.01 \\
\hline WSO2-3 & 0.00 & 1.43 & 0.99 & 1.47 & 5.06 & 9.29 & 14.05 & 19.17 & 16.69 & 7.63 & 6.90 & 5.84 & 4.52 & 3.14 & 1.61 & 1.19 & 0.83 & 0.16 & 0.01 & 0.00 & 0.01 \\
\hline WSO2-4 & 4.54 & 2.71 & 1.76 & 1.99 & 3.35 & 3.83 & 4.62 & 5.81 & 7.09 & 6.37 & 7.12 & 7.00 & 10.64 & 17.56 & 10.19 & 3.72 & 1.34 & 0.33 & 0.02 & 0.00 & 0.01 \\
\hline WSO2-5 & 0.00 & 0.00 & 0.00 & 0.00 & 0.07 & 0.23 & 0.18 & 0.50 & 0.82 & 0.80 & 3.93 & 2.30 & 5.04 & 11.11 & 14.44 & 24.63 & 25.81 & 9.62 & 0.48 & 0.01 & 0.01 \\
\hline WSO2-6 & 0.00 & 0.00 & 2.42 & 1.33 & 1.17 & 0.57 & 0.54 & 0.76 & 1.12 & 1.15 & 3.78 & 3.25 & 6.36 & 12.04 & 15.41 & 23.86 & 20.00 & 5.99 & 0.23 & 0.01 & 0.01 \\
\hline WSO2-7 & 0.00 & 0.00 & 0.00 & 0.00 & 0.05 & 0.14 & 0.16 & 0.40 & 0.60 & 0.79 & 1.34 & 2.46 & 5.87 & 12.98 & 18.12 & 26.18 & 21.89 & 8.54 & 0.46 & 0.01 & 0.02 \\
\hline WS03-1 & 0.00 & 0.00 & 0.00 & 0.00 & 0.00 & 0.00 & 0.00 & 0.01 & 0.02 & 0.05 & 0.22 & 1.63 & 10.50 & 30.00 & 30.47 & 19.84 & 5.88 & 1.32 & 0.07 & 0.01 & 0.00 \\
\hline WSO3-2 & 0.00 & 0.00 & 0.00 & 0.00 & 0.00 & 0.00 & 0.02 & 0.02 & 0.01 & 0.02 & 0.00 & 0.40 & 3.60 & 14.36 & 24.22 & 32.91 & 21.24 & 3.13 & 0.04 & 0.01 & 0.00 \\
\hline WSO3-3 & 0.00 & 1.65 & 1.07 & 0.11 & 0.83 & 1.21 & 1.65 & 2.15 & 3.20 & 3.80 & 6.57 & 8.67 & 10.83 & 12.45 & 10.90 & 15.28 & 15.03 & 4.46 & 0.11 & 0.01 & 0.01 \\
\hline WSO3-4 & 0.00 & 0.00 & 0.00 & 0.00 & 0.33 & 0.27 & 0.64 & 0.64 & 0.70 & 0.64 & 1.12 & 1.38 & 3.41 & 9.73 & 14.60 & 25.05 & 29.20 & 11.84 & 0.45 & 0.01 & 0.01 \\
\hline WSO3-5 & 0.00 & 0.00 & 0.00 & 0.00 & 0.72 & 0.36 & 0.81 & 0.96 & 1.50 & 1.51 & 2.23 & 3.17 & 5.96 & 11.97 & 15.37 & 21.42 & 23.18 & 10.26 & 0.56 & 0.01 & 0.01 \\
\hline WS05-1 & 0.00 & 0.00 & 1.38 & 0.27 & 0.47 & 0.26 & 0.09 & 0.13 & 0.13 & 0.14 & 0.37 & 0.95 & 5.18 & 12.70 & 17.69 & 31.66 & 23.50 & 4.51 & 0.56 & 0.02 & 0.01 \\
\hline WS05-2 & 0.00 & 0.00 & 0.61 & 0.75 & 0.38 & 0.75 & 0.60 & 0.73 & 0.78 & 0.80 & 1.22 & 2.14 & 7.51 & 17.68 & 16.35 & 22.22 & 21.62 & 5.43 & 0.40 & 0.00 & 0.02 \\
\hline WS05-3 & 0.00 & 0.00 & 0.00 & 0.00 & 0.19 & 0.22 & 0.16 & 0.15 & 0.15 & 0.16 & 0.23 & 0.74 & 2.69 & 8.64 & 15.60 & 32.70 & 30.58 & 7.51 & 0.27 & 0.01 & 0.01 \\
\hline WS05-4 & 0.00 & 0.00 & 0.00 & 0.00 & 0.00 & 0.17 & 0.11 & 0.11 & 0.13 & 0.10 & 0.41 & 0.76 & 2.21 & 7.02 & 15.20 & 31.95 & 31.68 & 9.78 & 0.34 & 0.02 & 0.01 \\
\hline WS05-1 & 0.00 & 0.00 & 0.00 & 0.00 & 0.00 & 0.00 & 0.00 & 0.00 & 0.01 & 0.04 & 0.21 & 1.07 & 4.34 & 13.51 & 23.84 & 37.48 & 15.76 & 3.57 & 0.17 & 0.01 & 0.01 \\
\hline WS05-2 & 0.00 & 0.00 & 0.40 & 2.39 & 1.21 & 0.47 & 0.34 & 0.41 & 0.52 & 0.58 & 1.44 & 2.93 & 7.92 & 15.99 & 18.92 & 25.25 & 17.75 & 3.39 & 0.08 & 0.01 & 0.01 \\
\hline WS05-3 & 0.00 & 0.00 & 1.08 & 1.49 & 1.09 & 1.43 & 1.84 & 2.09 & 2.19 & 2.12 & 3.21 & 6.45 & 13.51 & 20.36 & 17.68 & 14.70 & 8.89 & 1.82 & 0.05 & 0.00 & 0.01 \\
\hline WSO5-4 & 0.00 & 0.00 & 0.00 & 0.00 & 0.00 & 0.14 & 0.34 & 0.19 & 0.31 & 0.27 & 0.55 & 1.35 & 4.48 & 14.56 & 24.69 & 29.49 & 18.59 & 4.87 & 0.16 & 0.01 & 0.01 \\
\hline WS05-5 & 0.00 & 0.00 & 0.00 & 0.00 & 0.00 & 0.04 & 0.06 & 0.07 & 0.26 & 0.30 & 0.87 & 1.85 & 6.37 & 14.73 & 13.55 & 17.94 & 26.69 & 16.26 & 1.00 & 0.01 & 0.01 \\
\hline
\end{tabular}


Section 1(b): Wallis Sands (Summer/Fall 2017 Sampling Period) 
Wallis Sands Beach (Summer Sampling), Rye, New Hampshire: Identification, Location, and Description

\begin{tabular}{|c|c|c|c|c|c|c|c|c|c|c|c|c|c|}
\hline Sample ID & Global Sample ID & $\begin{array}{c}\text { Latitude } \\
\text { WGS84 } \\
\end{array}$ & $\begin{array}{c}\text { Longitude } \\
\text { WGS84 } \\
\end{array}$ & $\begin{array}{l}\text { Relative } \\
\text { Position } \\
\text { Accuracy } \\
\end{array}$ & $\begin{array}{c}\begin{array}{c}\text { Elevation } \\
\text { (m) }\end{array} \\
\text { NAVD88 } \\
\end{array}$ & $\begin{array}{c}\text { Elevation } \\
\text { (m) } \\
\text { MTL }\end{array}$ & $\begin{array}{c}\text { Relative } \\
\text { Elevation }\end{array}$ & $\begin{array}{l}\text { Relative } \\
\text { Location } \\
\end{array}$ & $\begin{array}{c}\text { Sample } \\
\text { Collected }\end{array}$ & $\begin{array}{c}\text { Core } \\
\text { Length } \\
(\mathrm{cm}) \\
\end{array}$ & $\begin{array}{c}\text { Collected } \\
\text { Sample } \\
\text { Wt. (gm) } \\
\end{array}$ & $\begin{array}{c}\text { Processed } \\
\text { Sample } \\
\text { Wt. (gm) } \\
\end{array}$ & $\begin{array}{c}\text { Morphologic } \\
\text { Feature }\end{array}$ \\
\hline WS01-1 & NHC_D20170905_WS01-1 & 43.027680 & -70.728386 & 1 & 2.69 & 2.80 & UTB & UB & 5-Sep-17 & 25 & $2,798.3$ & $2,790.0$ & S. Ramp \\
\hline WS01-2 & NHC_D20170905_WS01-2 & 43.027563 & -70.728218 & 1 & 1.80 & 1.91 & UTB & UB & 5-Sep-17 & 27 & $2,371.3$ & $2,371.7$ & S. Ramp; LHTS \\
\hline WS01-3 & NHC_D20170905_WS01-3 & 43.027420 & -70.728016 & 1 & 0.83 & 0.94 & MTB & $\mathrm{MB}$ & 5-Sep-17 & 28 & $2,801.8$ & $2,800.3$ & LT; Mid \\
\hline WS01-4 & NHC_D20170905_WS01-4 & 43.027153 & -70.727633 & 1 & -0.17 & -0.06 & LTB & LB & 5-Sep-17 & 28 & $2,862.0$ & $2,767.5$ & LT; Lower \\
\hline WSO2-1 & NHC_D20170905_WS02-1 & 43.024799 & -70.730819 & 1 & 3.02 & 3.13 & UTB & UB & 5-Sep-17 & 28 & $2,366.0$ & $2,367.6$ & $\begin{array}{c}\text { S. Ramp; } \\
\text { Backshore }\end{array}$ \\
\hline WSO2-2 & NHC_D20170905_WS02-2 & 43.024760 & -70.730721 & 1 & 2.20 & 2.31 & UTB & UB & 5-Sep-17 & 27 & $2,512.9$ & $2,509.9$ & Berm Crest; LHTS \\
\hline WSO2-3 & NHC_D20170905_WS02-3 & 43.024683 & -70.730527 & 1 & 0.89 & 1.00 & MTB & UB & 5-Sep-17 & 26 & $2,906.6$ & $2,856.1$ & Berm Toe; $L T$ \\
\hline WSO2-4 & NHC_D20170905_WS02-4 & 43.024494 & -70.730056 & 1 & 0.11 & 0.22 & MTB & $\mathrm{MB}$ & 5-Sep-17 & 28 & $2,862.9$ & $2,909.6$ & $\mathrm{LT} ; \mathrm{Mid}$ \\
\hline WSO2-5 & NHC_D20170905_WS02-5 & 43.024339 & -70.729667 & 1 & -0.86 & -0.75 & LTB & LB & 5-Sep-17 & 29 & $3,270.9$ & $3,274.3$ & LTT; Swash Zone \\
\hline WS03-1 & NHC_D20170906_WS03-1 & 43.022880 & -70.731864 & 1 & 3.09 & 3.20 & UTB & UB & 6-Sep-17 & 29 & $2,249.6$ & $2,245.8$ & $\begin{array}{c}\text { S. Ramp; } \\
\text { Backshore }\end{array}$ \\
\hline WSO3-2 & NHC_D20170907_WS03-2 & 43.022854 & -70.731760 & 1 & 2.46 & 2.57 & UTB & UB & 7-Sep-17 & 30 & $1,958.7$ & $1,970.2$ & Berm Crest; LHTS \\
\hline WSO3-3 & NHC_D20170907_WS03-3 & 43.022814 & -70.731598 & 1 & 1.11 & 1.22 & MTB & UB & 7-Sep-17 & 28 & $9,594.7$ & $9,694.3$ & LTT; Berm Toe \\
\hline WSO3-4 & NHC_D20170907_WS03-4 & 43.022725 & -70.731244 & 1 & 0.27 & 0.39 & MTB & $\mathrm{MB}$ & 7-Sep-17 & 27 & $3,004.4$ & $3,001.5$ & LTT; Mid \\
\hline WS05-1 & NHC_D20170907_WS05-1 & 43.020674 & -70.732422 & 1 & 2.23 & 2.34 & UTB & UB & 7-Sep-17 & 28 & $2,295.5$ & $2,293.6$ & S. Ramp; LHTS \\
\hline WS05-2 & NHC_D20170907_WS05-2 & 43.020660 & -70.732155 & 1 & 0.90 & 1.01 & MTB & UB & 7-Sep-17 & 27 & $2,777.2$ & $2,715.7$ & $\mathrm{LT}$; Landward \\
\hline WS05-3 & NHC_D20170907_WS05-3 & 43.020641 & -70.731794 & 1 & 0.13 & 0.24 & MTB & $\mathrm{MB}$ & 7-Sep-17 & 28 & $3,519.8$ & $3,512.9$ & $\mathrm{LT} ; \mathrm{Mid}$ \\
\hline WS05-4 & NHC_D20170907_WS05-4 & 43.020604 & -70.731201 & 1 & -0.92 & -0.81 & LTB & $\mathrm{LB}$ & 7-Sep-17 & 28 & $2,179.7$ & $2,186.0$ & LT; Swash Zone \\
\hline
\end{tabular}




\begin{tabular}{|c|c|c|c|c|c|c|c|c|}
\hline Sample ID & $\begin{array}{l}\text { CMECS Substrate } \\
\text { Component } \\
\text { Group (Specific) } \\
\end{array}$ & $\begin{array}{l}\text { CMECS Substrate } \\
\text { Component Subgroup } \\
\text { (Specific) }\end{array}$ & $\begin{array}{l}\text { Textural Group from } \\
\text { \%GSM (Gradistat) }\end{array}$ & $\begin{array}{l}\text { Sediment Name from } \\
\% G S M \\
\text { and Mode (Gradistat) }\end{array}$ & $\begin{array}{l}\text { Sediment Name from } \\
\text { \%GSM and Mode } \\
\text { (Wentworth Scale) }\end{array}$ & $\begin{array}{l}\text { Sediment Classification } \\
\text { from Mean Phi } \\
\text { (Gradistat) }\end{array}$ & $\begin{array}{l}\text { Sediment } \\
\text { Classification } \\
\text { from Mean Phi } \\
\text { (Wentworth) }\end{array}$ & Sorting (Gradistat) \\
\hline WS01-1 & Slightly Granuley & $\begin{array}{l}\text { Slightly Granuley Fine } \\
\text { Sand }\end{array}$ & Slightly Gravelly Sand & $\begin{array}{l}\text { Slightly Very Fine Gravelly } \\
\text { Fine Sand }\end{array}$ & $\begin{array}{l}\text { Slightly Granular Fine } \\
\text { Sand }\end{array}$ & Fine Sand & Fine Sand & Moderately Well Sorted \\
\hline WS01-2 & Slightly Granuley & $\begin{array}{l}\text { Slightly Granuley Fine } \\
\text { Sand }\end{array}$ & Slightly Gravelly Sand & $\begin{array}{l}\text { Slightly Very Fine Gravelly } \\
\text { Fine Sand }\end{array}$ & $\begin{array}{l}\text { Slightly Granular Fine } \\
\text { Sand }\end{array}$ & Fine Sand & Fine Sand & Well Sorted \\
\hline WS01-3 & Slightly Granuley & $\begin{array}{l}\text { Slightly Granuley Fine } \\
\text { Sand }\end{array}$ & Slightly Gravelly Sand & $\begin{array}{l}\text { Slightly Very Fine Gravelly } \\
\text { Fine Sand }\end{array}$ & $\begin{array}{l}\text { Slightly Granular Fine } \\
\text { Sand }\end{array}$ & Fine Sand & Fine Sand & Moderately Well Sorted \\
\hline WS01-4 & Slightly Granuley & $\begin{array}{l}\text { Slightly Granuley Fine } \\
\text { Sand }\end{array}$ & Slightly Gravelly Sand & $\begin{array}{l}\text { Slightly Very Fine Gravelly } \\
\text { Fine Sand }\end{array}$ & $\begin{array}{l}\text { Slightly Granular Fine } \\
\text { Sand }\end{array}$ & Fine Sand & Fine Sand & Moderately Sorted \\
\hline WSO2-1 & Slightly Granuley & $\begin{array}{l}\text { Slightly Granuley } \\
\text { Medium Sand }\end{array}$ & Slightly Gravelly Sand & $\begin{array}{l}\text { Slightly Very Fine Gravelly } \\
\text { Medium Sand }\end{array}$ & $\begin{array}{l}\text { Slightly Granular } \\
\text { Medium Sand }\end{array}$ & Medium Sand & Medium Sand & Moderately Well Sorted \\
\hline WSO2-2 & Slightly Granuley & $\begin{array}{l}\text { Slightly Granuley } \\
\text { Medium Sand }\end{array}$ & Slightly Gravelly Sand & $\begin{array}{l}\text { Slightly Very Fine Gravelly } \\
\text { Medium Sand }\end{array}$ & $\begin{array}{l}\text { Slightly Granular } \\
\text { Medium Sand }\end{array}$ & Medium Sand & Medium Sand & Moderately Well Sorted \\
\hline WSO2-3 & Slightly Pebbly & $\begin{array}{l}\text { Slightly Pebbly Medium } \\
\text { Sand }\end{array}$ & Slightly Gravelly Sand & $\begin{array}{l}\text { Slightly Medium Gravelly } \\
\text { Fine Sand }\end{array}$ & $\begin{array}{l}\text { Slightly Pebbly Medium } \\
\text { Sand }\end{array}$ & Fine Sand & Fine Sand & Moderately Well Sorted \\
\hline WSO2-4 & Slightly Granuley & $\begin{array}{l}\text { Slightly Granuley Fine } \\
\text { Sand }\end{array}$ & Slightly Gravelly Sand & $\begin{array}{l}\text { Slightly Very Fine Gravelly } \\
\text { Fine Sand }\end{array}$ & $\begin{array}{l}\text { Slightly Granular Fine } \\
\text { Sand }\end{array}$ & Medium Sand & Medium Sand & Moderately Sorted \\
\hline WSO2-5 & Slightly Granuley & $\begin{array}{l}\text { Slightly Granuley } \\
\text { Medium Sand }\end{array}$ & Slightly Gravelly Sand & $\begin{array}{l}\text { Slightly Very Fine Gravelly } \\
\text { Medium Sand }\end{array}$ & $\begin{array}{l}\text { Slightly Granular } \\
\text { Medium Sand }\end{array}$ & Medium Sand & Medium Sand & Moderately Sorted \\
\hline WS03-1 & Slightly Granuley & $\begin{array}{l}\text { Slightly Granuley } \\
\text { Medium Sand }\end{array}$ & Slightly Gravelly Sand & $\begin{array}{l}\text { Slightly Very Fine Gravelly } \\
\text { Medium Sand }\end{array}$ & $\begin{array}{l}\text { Slightly Granular } \\
\text { Medium Sand }\end{array}$ & Medium Sand & Medium Sand & Moderately Well Sorted \\
\hline WS03-2 & Slightly Pebbly & $\begin{array}{l}\text { Slightly Pebbly Medium } \\
\text { Sand }\end{array}$ & Slightly Gravelly Sand & $\begin{array}{l}\text { Slightly Medium Gravelly } \\
\text { Fine Sand }\end{array}$ & $\begin{array}{l}\text { Slightly Pebbly Medium } \\
\text { Sand }\end{array}$ & Medium Sand & Medium Sand & Well Sorted \\
\hline WS03-3 & Granule Mixes & Sandy Granule Gravel & Sandy Gravel & Sandy Very Fine Gravel & Sandy Granule Gravel & Coarse Sand & Coarse Sand & Very Poorly Sorted \\
\hline WS03-4 & Slightly Granuley & $\begin{array}{l}\text { Slightly Granuley Fine } \\
\text { Sand }\end{array}$ & Slightly Gravelly Sand & $\begin{array}{l}\text { Slightly Very Fine Gravelly } \\
\text { Fine Sand }\end{array}$ & $\begin{array}{l}\text { Slightly Granular Fine } \\
\text { Sand }\end{array}$ & Fine Sand & Fine Sand & Moderately Well Sorted \\
\hline WS05-1 & Slightly Granuley & $\begin{array}{l}\text { Slightly Granuley Fine } \\
\text { Sand }\end{array}$ & Slightly Gravelly Sand & $\begin{array}{l}\text { Slightly Very Fine Gravelly } \\
\text { Fine Sand }\end{array}$ & $\begin{array}{l}\text { Slightly Granular Fine } \\
\text { Sand }\end{array}$ & Medium Sand & Medium Sand & Moderately Well Sorted \\
\hline WS05-2 & Slightly Granuley & $\begin{array}{l}\text { Slightly Granuley Fine } \\
\text { Sand }\end{array}$ & Slightly Gravelly Sand & $\begin{array}{l}\text { Slightly Very Fine Gravelly } \\
\text { Fine Sand }\end{array}$ & $\begin{array}{l}\text { Slightly Granular Fine } \\
\text { Sand }\end{array}$ & Medium Sand & Medium Sand & Moderately Well Sorted \\
\hline WS05-3 & Slightly Granuley & $\begin{array}{l}\text { Slightly Granuley Fine } \\
\text { Sand }\end{array}$ & Slightly Gravelly Sand & $\begin{array}{l}\text { Slightly Very Fine Gravelly } \\
\text { Fine Sand }\end{array}$ & $\begin{array}{l}\text { Slightly Granular Fine } \\
\text { Sand }\end{array}$ & Medium Sand & Medium Sand & Moderately Sorted \\
\hline WS05-4 & Slightly Granuley & $\begin{array}{l}\text { Slightly Granuley Fine } \\
\text { Sand }\end{array}$ & Slightly Gravelly Sand & $\begin{array}{l}\text { Slightly Very Fine Gravelly } \\
\text { Fine Sand }\end{array}$ & $\begin{array}{l}\text { Slightly Granular Fine } \\
\text { Sand }\end{array}$ & Medium Sand & Medium Sand & Moderately Well Sorted \\
\hline
\end{tabular}


Wallis Sands Beach (Summer Sampling), Rye, New Hampshire: Grain Size Statistics

\begin{tabular}{|c|c|c|c|c|c|c|c|c|c|c|c|c|c|c|c|c|c|}
\hline Sample ID & Gravel \% & Pebble \% & Granule \% & Sand $\%$ & Mud \% & Modes & $\begin{array}{c}\text { Mode } 1 \\
\text { (phi) }\end{array}$ & $\begin{array}{c}\text { Mode } 2 \\
\text { (phi) }\end{array}$ & $\begin{array}{c}\mathrm{D}_{10} \\
\text { (phi) }\end{array}$ & $\begin{array}{r}D_{10} \\
(\mathrm{~mm})\end{array}$ & $\begin{array}{l}\mathrm{D}_{50} \\
\text { (phi) }\end{array}$ & $\begin{array}{r}D_{50} \\
(\mathrm{~mm}) \\
\end{array}$ & $\begin{array}{c}\text { Mean Size } \\
\text { (phi) }\end{array}$ & $\begin{array}{c}\text { Mean Size } \\
(\mathrm{mm})\end{array}$ & $\begin{array}{c}\text { Sorting } \\
\text { (phi) }\end{array}$ & Skewness & Kurtosis \\
\hline WS01-1 & 0.68 & 0.29 & 0.40 & 99.24 & 0.08 & $u$ & 2.24 & N/A & 1.19 & 0.44 & 2.10 & 0.23 & 2.05 & 0.24 & 0.58 & -0.22 & 1.24 \\
\hline WS01-2 & 0.01 & 0.00 & 0.01 & 99.96 & 0.03 & $u$ & 2.24 & N/A & 1.84 & 0.28 & 2.34 & 0.20 & 2.38 & 0.19 & 0.39 & 0.05 & 0.98 \\
\hline WS01-3 & 0.49 & 0.09 & 0.40 & 99.48 & 0.03 & $u$ & 2.24 & N/A & 1.10 & 0.47 & 2.22 & 0.22 & 2.15 & 0.23 & 0.66 & -0.26 & 1.12 \\
\hline WS01-4 & 0.89 & 0.22 & 0.67 & 99.08 & 0.03 & $U$ & 2.24 & N/A & 0.91 & 0.53 & 2.18 & 0.22 & 2.06 & 0.24 & 0.75 & -0.31 & 1.15 \\
\hline WSO2-1 & 0.22 & 0.02 & 0.20 & 99.76 & 0.02 & $\mathrm{U}$ & 0.75 & N/A & 0.23 & 0.85 & 1.07 & 0.48 & 1.12 & 0.46 & 0.67 & 0.08 & 1.00 \\
\hline WSO2-2 & 0.06 & 0.01 & 0.04 & 99.92 & 0.02 & U & 2.24 & N/A & 1.04 & 0.49 & 1.92 & 0.26 & 1.84 & 0.28 & 0.59 & -0.22 & 1.06 \\
\hline WSO2-3 & 0.22 & 0.18 & 0.04 & 99.76 & 0.02 & $u$ & 2.24 & N/A & 1.52 & 0.35 & 2.26 & 0.21 & 2.23 & 0.21 & 0.53 & -0.15 & 1.18 \\
\hline WSO2-4 & 1.17 & 0.25 & 0.92 & 98.81 & 0.02 & $u$ & 2.24 & N/A & 0.38 & 0.77 & 1.73 & 0.30 & 1.60 & 0.33 & 0.86 & -0.23 & 0.90 \\
\hline WSO2-5 & 0.65 & 0.10 & 0.55 & 99.33 & 0.02 & $u$ & 2.24 & N/A & 0.44 & 0.74 & 2.56 & 0.17 & 1.55 & 0.34 & 0.84 & -0.11 & 0.84 \\
\hline WSO3-1 & 0.02 & 0.00 & 0.02 & 99.96 & 0.02 & u & 1.75 & N/A & 0.58 & 0.67 & 1.43 & 0.37 & 1.41 & 0.38 & 0.64 & -0.05 & 0.90 \\
\hline WSO3-2 & 0.18 & 0.13 & 0.04 & 99.80 & 0.02 & $u$ & 2.24 & N/A & 1.28 & 0.41 & 2.03 & 0.25 & 1.98 & 0.25 & 0.48 & -0.13 & 1.05 \\
\hline WSO3-3 & 31.52 & 18.59 & 12.93 & 68.47 & 0.01 & B & 2.24 & -0.74 & -2.73 & 6.62 & 0.47 & 0.72 & 0.23 & 0.85 & 2.09 & -0.19 & 0.67 \\
\hline WSO3-4 & 0.17 & 0.03 & 0.14 & 99.81 & 0.02 & $u$ & 2.24 & N/A & 1.15 & 0.45 & 2.17 & 0.22 & 2.11 & 0.23 & 0.62 & -0.23 & 1.21 \\
\hline WS05-1 & 0.06 & 0.01 & 0.05 & 99.93 & 0.01 & u & 2.24 & N/A & 1.10 & 0.47 & 1.95 & 0.26 & 1.88 & 0.27 & 0.56 & -0.19 & 1.09 \\
\hline WSO5-2 & 0.54 & 0.34 & 0.19 & 99.43 & 0.03 & $u$ & 2.24 & $\mathrm{~N} / \mathrm{A}$ & 0.93 & 0.52 & 2.06 & 0.24 & 1.93 & 0.26 & 0.68 & -0.29 & 1.09 \\
\hline WS05-3 & 0.99 & 0.56 & 0.43 & 98.99 & 0.02 & $U$ & 2.24 & N/A & 0.68 & 0.63 & 1.82 & 0.28 & 1.72 & 0.30 & 0.74 & -0.18 & 0.92 \\
\hline WS05-4 & 0.32 & 0.10 & 0.23 & 99.67 & 0.01 & U & 2.24 & N/A & 0.96 & 0.51 & 2.05 & 0.24 & 1.94 & 0.26 & 0.68 & -0.25 & 1.06 \\
\hline
\end{tabular}


Wallis Sands Beach (Summer Sampling), Rye, New Hampshire: Grain Size Distribution

\begin{tabular}{|c|c|c|c|c|c|c|c|c|c|c|c|c|c|c|c|c|c|c|c|c|c|}
\hline Sample ID & $\begin{array}{c}\text { Class \% } \\
\text { phi } \\
-5.5 \\
\end{array}$ & $\begin{array}{c}\text { Class \% } \\
\text { phi } \\
-5.0\end{array}$ & $\begin{array}{c}\text { Class \% } \\
\text { phi } \\
-4.5\end{array}$ & $\begin{array}{c}\text { Class \% } \\
\text { phi } \\
-4.0 \\
\end{array}$ & $\begin{array}{c}\text { Class \% } \\
\text { phi } \\
-3.5 \\
\end{array}$ & $\begin{array}{c}\text { Class \% } \\
\text { phi } \\
-3.0\end{array}$ & $\begin{array}{c}\text { Class \% } \\
\text { phi } \\
-2.5 \\
\end{array}$ & $\begin{array}{c}\text { Class \% } \\
\text { phi } \\
-2.0 \\
\end{array}$ & $\begin{array}{c}\text { Class \% } \\
\text { phi } \\
-1.5\end{array}$ & $\begin{array}{c}\text { Class \% } \\
\text { phi } \\
-1.0\end{array}$ & $\begin{array}{c}\text { Class \% } \\
\text { phi } \\
-0.5 \\
\end{array}$ & $\begin{array}{c}\text { Class \% } \\
\text { phi } \\
0.0 \\
\end{array}$ & $\begin{array}{c}\text { Class \% } \\
\text { phi } \\
0.5 \\
\end{array}$ & $\begin{array}{c}\text { Class \% } \\
\text { phi } \\
1.0 \\
\end{array}$ & $\begin{array}{c}\text { Class \% } \\
\text { phi } \\
1.5 \\
\end{array}$ & $\begin{array}{c}\text { Class \% } \\
\text { phi } \\
2.0 \\
\end{array}$ & $\begin{array}{c}\text { Class \% } \\
\text { phi } \\
2.5 \\
\end{array}$ & $\begin{array}{c}\text { Class \% } \\
\text { phi } \\
3.0 \\
\end{array}$ & $\begin{array}{c}\text { Class \% } \\
\text { phi } \\
3.5 \\
\end{array}$ & $\begin{array}{c}\text { Class \% } \\
\text { phi } \\
4.0 \\
\end{array}$ & $\begin{array}{c}\text { Class } \% \\
\text { phi } \\
>4.0 \\
\end{array}$ \\
\hline WS01-1 & 0.00 & 0.00 & 0.00 & 0.00 & 0.00 & 0.12 & 0.06 & 0.10 & 0.18 & 0.22 & 0.40 & 0.68 & 1.36 & 3.50 & 8.62 & 25.80 & 41.48 & 15.84 & 1.48 & 0.07 & 0.08 \\
\hline WS01-2 & 0.00 & 0.00 & 0.00 & 0.00 & 0.00 & 0.00 & 0.00 & 0.00 & 0.00 & 0.01 & 0.00 & 0.01 & 0.02 & 0.03 & 0.65 & 13.74 & 48.99 & 33.57 & 2.90 & 0.04 & 0.03 \\
\hline WS01-3 & 0.00 & 0.00 & 0.00 & 0.00 & 0.00 & 0.00 & 0.03 & 0.06 & 0.16 & 0.23 & 0.51 & 0.95 & 1.81 & 4.64 & 7.55 & 17.04 & 37.34 & 26.92 & 2.67 & 0.05 & 0.03 \\
\hline WS01-4 & 0.00 & 0.00 & 0.00 & 0.00 & 0.00 & 0.07 & 0.02 & 0.13 & 0.27 & 0.40 & 0.67 & 1.31 & 2.61 & 5.47 & 9.25 & 17.05 & 34.11 & 25.56 & 2.99 & 0.06 & 0.03 \\
\hline WSO2-1 & 0.00 & 0.00 & 0.00 & 0.00 & 0.00 & 0.00 & 0.00 & 0.02 & 0.06 & 0.14 & 0.69 & 3.25 & 12.52 & 29.36 & 26.88 & 17.58 & 8.13 & 1.30 & 0.05 & 0.01 & 0.02 \\
\hline WSO2-2 & 0.00 & 0.00 & 0.00 & 0.00 & 0.00 & 0.00 & 0.00 & 0.01 & 0.02 & 0.02 & 0.10 & 0.34 & 1.43 & 6.88 & 15.83 & 29.88 & 37.04 & 8.32 & 0.05 & 0.05 & 0.02 \\
\hline WSO2-3 & 0.00 & 0.00 & 0.00 & 0.00 & 0.13 & 0.05 & 0.00 & 0.00 & 0.03 & 0.01 & 0.01 & 0.03 & 0.22 & 1.97 & 6.64 & 17.14 & 43.33 & 28.15 & 2.25 & 0.03 & 0.02 \\
\hline WSO2-4 & 0.00 & 0.00 & 0.00 & 0.00 & 0.00 & 0.02 & 0.06 & 0.17 & 0.31 & 0.61 & 0.95 & 2.68 & 6.76 & 13.91 & 14.86 & 20.92 & 26.73 & 11.38 & 0.62 & 0.02 & 0.02 \\
\hline WSO2-5 & 0.00 & 0.00 & 0.00 & 0.00 & 0.00 & 0.00 & 0.02 & 0.08 & 0.17 & 0.38 & 0.41 & 2.13 & 7.68 & 17.39 & 17.35 & 19.33 & 23.30 & 11.05 & 0.68 & 0.01 & 0.02 \\
\hline WSO3-1 & 0.00 & 0.00 & 0.00 & 0.00 & 0.00 & 0.00 & 0.00 & 0.00 & 0.00 & 0.02 & 0.07 & 0.63 & 5.69 & 20.17 & 26.96 & 28.16 & 16.11 & 2.10 & 0.06 & 0.01 & 0.02 \\
\hline WSO3-2 & 0.00 & 0.00 & 0.00 & 0.00 & 0.13 & 0.00 & 0.00 & 0.00 & 0.01 & 0.03 & 0.08 & 0.04 & 0.33 & 2.66 & 11.72 & 32.78 & 41.43 & 10.34 & 0.39 & 0.05 & 0.02 \\
\hline WSO3-3 & 0.00 & 0.00 & 0.47 & 0.69 & 2.17 & 3.77 & 5.47 & 6.03 & 6.70 & 6.23 & 7.00 & 5.88 & 5.93 & 5.33 & 3.12 & 6.46 & 20.23 & 13.66 & 0.84 & 0.02 & 0.01 \\
\hline WSO3-4 & 0.00 & 0.00 & 0.00 & 0.00 & 0.00 & 0.00 & 0.00 & 0.03 & 0.05 & 0.09 & 0.24 & 0.51 & 1.88 & 4.64 & 8.59 & 19.97 & 40.16 & 22.36 & 1.44 & 0.02 & 0.02 \\
\hline WS05-1 & 0.00 & 0.00 & 0.00 & 0.00 & 0.00 & 0.00 & 0.00 & 0.01 & 0.03 & 0.02 & 0.02 & 0.04 & 0.92 & 6.33 & 13.54 & 32.41 & 37.61 & 8.79 & 0.28 & 0.01 & 0.01 \\
\hline WSO5-2 & 0.00 & 0.00 & 0.00 & 0.00 & 0.16 & 0.00 & 0.09 & 0.10 & 0.10 & 0.09 & 0.15 & 0.52 & 2.09 & 7.72 & 12.50 & 21.97 & 36.53 & 17.21 & 0.71 & 0.01 & 0.03 \\
\hline WS05-3 & 0.00 & 0.00 & 0.00 & 0.00 & 0.06 & 0.19 & 0.13 & 0.17 & 0.22 & 0.21 & 0.31 & 0.87 & 3.38 & 12.23 & 17.48 & 23.05 & 28.64 & 12.39 & 0.61 & 0.01 & 0.02 \\
\hline WS05-4 & 0.00 & 0.00 & 0.00 & 0.00 & 0.00 & 0.00 & 0.04 & 0.05 & 0.11 & 0.11 & 0.17 & 0.45 & 1.84 & 7.82 & 13.39 & 22.04 & 35.04 & 17.38 & 1.52 & 0.02 & 0.01 \\
\hline
\end{tabular}


Section 2(a): Foss Beach (Winter/Spring 2017 Sampling Period) 
Foss Beach (Winter Sampling), Rye, New Hampshire: Identification, Location, and Description

\begin{tabular}{|c|c|c|c|c|c|c|c|c|c|c|c|c|c|}
\hline Sample ID & Global Sample ID & $\begin{array}{l}\text { Latitude } \\
\text { WGS84 } \\
\end{array}$ & $\begin{array}{c}\text { Longitude } \\
\text { WGS84 }\end{array}$ & $\begin{array}{l}\text { Relative } \\
\text { Position } \\
\text { Accuracy } \\
\end{array}$ & $\begin{array}{c}\begin{array}{c}\text { Elevation } \\
(\mathrm{m})\end{array} \\
\text { NAVD88 } \\
\end{array}$ & $\begin{array}{c}\text { Elevation } \\
(\mathrm{m}) \\
\text { MTL } \\
\end{array}$ & $\begin{array}{c}\text { Relative } \\
\text { Elevation }\end{array}$ & $\begin{array}{l}\text { Relative } \\
\text { Location }\end{array}$ & $\begin{array}{l}\text { Sample } \\
\text { Collected }\end{array}$ & $\begin{array}{c}\text { Core } \\
\text { Length } \\
\text { (cm) } \\
\end{array}$ & $\begin{array}{c}\text { Collected } \\
\text { Sample } \\
\text { Wt. (gm) }\end{array}$ & $\begin{array}{c}\text { Processed } \\
\text { Sample } \\
\text { Wt. (gm) }\end{array}$ & $\begin{array}{l}\text { Morphologic } \\
\text { Feature }\end{array}$ \\
\hline FB01-1A & NHC D20170409 FB01-1A & 43.010404 & -70.741635 & 1 & 1.07 & 1.18 & MTB & UB & 9-Apr-17 & 16 & $20,071.0$ & $20,075.4$ & $\begin{array}{c}\text { Anth. Berm Toe: } \\
\text { Cusp Horn }\end{array}$ \\
\hline FB01-1B & NHC_D20170409_FB01-1B & 43.010390 & -70.741647 & 1 & 1.14 & 1.26 & MTB & UB & 9-Apr-17 & 5 & $24,057.0$ & $24,101.4$ & $\begin{array}{l}\text { Anth. Berm Toe: } \\
\text { Cusp Trough }\end{array}$ \\
\hline FB01-2 & NHC_D20170409_FB01-2 & 43.010346 & -70.741532 & 1 & 0.17 & 0.29 & MTB & UB & 9-Apr-17 & 27 & $5,750.8$ & $5,858.2$ & LTT: Landward \\
\hline FB01-3 & NHC_D20170409_FB01-3 & 43.010194 & -70.741271 & 1 & -0.53 & -0.41 & LTB & $\mathrm{MB}$ & 9-Apr-17 & 26 & $5,502.5$ & $5,474.4$ & LTT:Mid \\
\hline FB01-4 & NHC_D20170409_FB01-4 & 43.010051 & -70.741022 & 1 & -1.42 & -1.30 & LTB & $\mathrm{LB}$ & 9-Apr-17 & 26 & $5,126.5$ & $5,173.6$ & LTT: Swash Zone \\
\hline $\mathrm{FBO2-3}$ & NHC D20170409 FB02-3 & 43.007819 & -70.743638 & 1 & -0.53 & -0.41 & UTB & $\mathrm{MB}$ & 9-Apr-17 & 28 & $2,990.4$ & $2,987.3$ & LTT: Landward \\
\hline $\mathrm{FB} 02-4$ & NHC_D20170409_FB02-4 & 43.007734 & -70.743424 & 1 & -1.03 & -0.92 & LTB & LB & 9-Apr-17 & 27 & $3,430.2$ & $3,502.4$ & LTT: Mid \\
\hline FB02-5 & NHC_D20170409_FB02-5 & 43.007667 & -70.743254 & 1 & -1.37 & -1.25 & LTB & $\mathrm{LB}$ & 9-Apr-17 & 27 & $4,879.5$ & $5,039.0$ & LTT: Swash Zone \\
\hline FB03-1 & NHC_D20170409_FB03-1 & 43.005768 & -70.744772 & 1 & 0.98 & 1.10 & UTB & UB & 10-Apr-17 & $\sim 5 \mathrm{~cm}$ & $14,916.2$ & $15,022.6$ & S./G. Ramp: Upper \\
\hline FB03-2 & NHC_D20170409_FB03-2 & 43.005748 & -70.744631 & 1 & -0.35 & -0.24 & MTB & UB & 10-Apr-17 & $\sim 5 \mathrm{~cm}$ & $14,303.5$ & $14,312.5$ & S./G. Ramp: Mid \\
\hline FB03-3 & NHC_D20170410_FB03-3 & 43.005725 & -70.744481 & 1 & -1.25 & -1.14 & LTB & $\mathrm{MB}$ & 10-Apr-17 & 10 & $13,039.0$ & $13,108.7$ & $\begin{array}{c}\text { S./G. Ramp: Lower; } \\
\text { Upper LTT }\end{array}$ \\
\hline FB03-4 & NHC D20170410 FB03-4 & 43.005711 & -70.744381 & 1 & -1.41 & -1.30 & LTB & $\mathrm{MB}$ & 10-Apr-17 & 18 & $8,187.7$ & $8,149.0$ & $\begin{array}{c}\text { Thin S. Ridge Over } \\
\text { C./B. Field: Start }\end{array}$ \\
\hline FB03-5 & NHC_D20170410_FB03-5 & 43.005707 & -70.744344 & 1 & -1.53 & -1.41 & LTB & LB & 10-Apr-17 & 18 & $1,528.5$ & $1,533.5$ & $\begin{array}{l}\text { Thin S. Ridge Over } \\
\text { C./B. Field: Mid }\end{array}$ \\
\hline FB03-6 & NHC_D20170410_FB03-6 & 43.005721 & -70.744426 & 1 & -0.70 & -0.58 & LTB & $\mathrm{LB}$ & 10-Apr-17 & 24 & $3,202.6$ & $3,197.8$ & $\begin{array}{c}\text { Thin S. Ridge Over } \\
\text { C/BF: Swash }\end{array}$ \\
\hline FB04-1 & NHC_D20170410_FB04-1 & 43.003387 & -70.744998 & 1 & 0.41 & 0.53 & MTB & UB & 10-Apr-17 & 10 & $22,948.6$ & $22,977.2$ & S/G. Ramp: Upper \\
\hline $\mathrm{FBO4-2}$ & NHC_D20170410_FB04-2 & 43.003405 & -70.744829 & 1 & -0.51 & -0.40 & LTB & UB & 10-Apr-17 & 25 & $5,219.0$ & $5,263.1$ & S/G. Ramp: Mid \\
\hline FB04-3 & NHC_D20170410_FB04-3 & 43.003425 & -70.744635 & 1 & -1.29 & -1.17 & LTB & $\mathrm{MB}$ & 10-Apr-17 & 24 & $3,333.2$ & $3,348.2$ & $\begin{array}{l}\text { S./G. Ramp: Lower } \\
\text { Bound. to C./B. }\end{array}$ \\
\hline FB04-4 & NHC_D20170410_FB04-4 & 43.003453 & -70.7443552 & 1 & -1.51 & -1.40 & LTB & $\mathrm{LB}$ & 10-Apr-17 & 23 & $2,491.7$ & $2,476.6$ & $\begin{array}{c}\text { Water Line - Low } \\
\text { Tide } \\
\end{array}$ \\
\hline
\end{tabular}




\begin{tabular}{|c|c|c|c|c|c|c|c|c|}
\hline Sample ID & $\begin{array}{l}\text { CMECS Substrate } \\
\text { Component } \\
\text { Group (Specific) }\end{array}$ & $\begin{array}{l}\text { CMECS Substrate } \\
\text { Component Subgroup } \\
\text { (Specific) }\end{array}$ & $\begin{array}{l}\text { Textural Group from } \\
\text { \%GSM (Gradistat) }\end{array}$ & $\begin{array}{l}\text { Sediment Name from } \\
\text { \%GSM } \\
\text { and Mode (Gradistat) }\end{array}$ & $\begin{array}{l}\text { Sediment Name from } \\
\text { \%GSM and Mode } \\
\text { (Wentworth Scale) }\end{array}$ & $\begin{array}{l}\text { Sediment Classification } \\
\text { from Mean Phi } \\
\text { (Gradistat) }\end{array}$ & $\begin{array}{l}\text { Sediment } \\
\text { Classification } \\
\text { from Mean Phi } \\
\text { (Wentworth) }\end{array}$ & Sorting (Gradistat) \\
\hline FB01-1A & Pebble Mixes & Sandy Pebble Gravel & Sandy Gravel & Sandy Medium Gravel & Sandy Pebble Gravel & Very Coarse Sand & Very Coarse Sand & Very Poorly Sorted \\
\hline FB01-1B & Gravel & Pebble Gravel & Gravel & Medium Gravel & Pebble Gravel & Medium Gravel & Pebble Gravel & Poorly Sorted \\
\hline FB01-2 & Granule Mixes & Sandy Granule Gravel & Sandy Gravel & Sandy Very Fine Gravel & Sandy Granule Gravel & Very Coarse Sand & Very Coarse Sand & Very Poorly Sorted \\
\hline FB01-3 & Granule Mixes & Sandy Granule Gravel & Sandy Gravel & Sandy Very Fine Gravel & Sandy Granule Gravel & Very Coarse Sand & Very Coarse Sand & Very Poorly Sorted \\
\hline FB01-4 & Granuley & Granuley Fine Sand & Gravelly Sand & $\begin{array}{l}\text { Very Fine Gravelly Fine } \\
\text { Sand }\end{array}$ & Granular Fine Sand & Medium Sand & Medium Sand & Poorly Sorted \\
\hline $\mathrm{FBO2-3}$ & Pebbly & Pebbly Fine Sand & Gravelly Sand & Medium Gravelly Fine Sand & Pebbly Fine Sand & Fine Sand & Fine Sand & Moderately Sorted \\
\hline $\mathrm{FBO2-4}$ & Granuley & Granuley Fine Sand & Gravelly Sand & $\begin{array}{l}\text { Very Fine Gravelly Fine } \\
\text { Sand }\end{array}$ & Granular Fine Sand & Medium Sand & Medium Sand & Poorly Sorted \\
\hline $\mathrm{FBO2-5}$ & Granuley & Granuley Fine Sand & Gravelly Sand & $\begin{array}{l}\text { Very Fine Gravelly Fine } \\
\text { Sand }\end{array}$ & Granular Fine Sand & Medium Sand & Medium Sand & Poorly Sorted \\
\hline FB03-1 & Gravel & Pebble Gravel & Gravel & Coarse Gravel & Pebble Gravel & Coarse Gravel & Pebble Gravel & Moderately Sorted \\
\hline FB03-2 & Gravel & Pebble Gravel & Gravel & Medium Gravel & Pebble Gravel & Fine Gravel & Pebble Gravel & Poorly Sorted \\
\hline $\mathrm{FBO3-3}$ & Pebble Mixes & Sandy Pebble Gravel & Sandy Gravel & Sandy Medium Gravel & Sandy Pebble Gravel & Fine Gravel & Pebble Gravel & Very Poorly Sorted \\
\hline $\mathrm{FBO3-4}$ & Pebble Mixes & Sandy Pebble Gravel & Sandy Gravel & Sandy Fine Gravel & Sandy Pebble Gravel & Coarse Sand & Coarse Sand & Very Poorly Sorted \\
\hline $\mathrm{FB} 03-5$ & Slightly Granuley & $\begin{array}{l}\text { Slightly Granuley Fine } \\
\text { Sand }\end{array}$ & Slightly Gravelly Sand & $\begin{array}{l}\text { Slightly Very Fine Gravelly } \\
\text { Fine Sand }\end{array}$ & $\begin{array}{l}\text { Slightly Granular Fine } \\
\text { Sand }\end{array}$ & Fine Sand & Fine Sand & Very Well Sorted \\
\hline FB03-6 & Slightly Granuley & $\begin{array}{l}\text { Slightly Granuley Fine } \\
\text { Sand }\end{array}$ & Slightly Gravelly Sand & $\begin{array}{l}\text { Slightly Very Fine Gravelly } \\
\text { Fine Sand }\end{array}$ & $\begin{array}{l}\text { Slightly Granular Fine } \\
\text { Sand }\end{array}$ & Fine Sand & Fine Sand & Well Sorted \\
\hline FB04-1 & Pebble Mixes & Sandy Pebble Gravel & Sandy Gravel & Sandy Coarse Gravel & Sandy Pebble Gravel & Fine Gravel & Pebble Gravel & Very Poorly Sorted \\
\hline FBO4-2 & Pebbly & Pebbly Fine Sand & Gravelly Sand & Fine Gravelly Fine Sand & Pebbly Fine Sand & Coarse Sand & Coarse Sand & Very Poorly Sorted \\
\hline FB04-3 & Slightly Pebbly & $\begin{array}{l}\text { Slightly Pebbly Fine } \\
\text { Sand }\end{array}$ & Slightly Gravelly Sand & $\begin{array}{l}\text { Slightly Fine Gravelly Fine } \\
\text { Sand }\end{array}$ & $\begin{array}{l}\text { Slightly Pebbly Fine } \\
\text { Sand }\end{array}$ & Fine Sand & Fine Sand & Well Sorted \\
\hline FB04-4 & Slightly Granuley & $\begin{array}{l}\text { Slightly Granuley Fine } \\
\text { Sand }\end{array}$ & Slightly Gravelly Sand & $\begin{array}{l}\text { Slightly Very Fine Gravelly } \\
\text { Fine Sand }\end{array}$ & $\begin{array}{l}\text { Slightly Granular Fine } \\
\text { Sand }\end{array}$ & Fine Sand & Fine Sand & Very Well Sorted \\
\hline
\end{tabular}




\begin{tabular}{|c|c|c|c|c|c|c|c|c|c|c|c|c|c|c|c|c|c|}
\hline Sample ID & Gravel \% & Pebble \% & Granule \% & Sand $\%$ & Mud \% & Modes & $\begin{array}{c}\text { Mode } 1 \\
\text { (phi) }\end{array}$ & $\begin{array}{c}\text { Mode } 2 \\
\text { (phi) }\end{array}$ & $\begin{array}{r}\mathrm{D}_{10} \\
\text { (phi) }\end{array}$ & $\begin{array}{c}\mathrm{D}_{10} \\
(\mathrm{~mm})\end{array}$ & $\begin{array}{c}D_{50} \\
\text { (phi) }\end{array}$ & $\begin{array}{c}D_{50} \\
(\mathrm{~mm})\end{array}$ & $\begin{array}{c}\text { Mean Size } \\
\text { (phi) }\end{array}$ & $\begin{array}{c}\text { Mean Size } \\
(\mathrm{mm})\end{array}$ & $\begin{array}{c}\text { Sorting } \\
\text { (phi) }\end{array}$ & Skewness & Kurtosis \\
\hline FB01-1A & 32.28 & 25.15 & 7.13 & 67.71 & 0.01 & B & 0.75 & -3.24 & -3.67 & 12.76 & 0.11 & 0.93 & -0.52 & 1.43 & 2.11 & -0.38 & 0.87 \\
\hline FB01-1B & 88.35 & 84.72 & 3.63 & 11.63 & 0.02 & B & -3.74 & 2.24 & -4.94 & 30.63 & -3.61 & 12.24 & -3.44 & 10.83 & 1.74 & 0.36 & 1.96 \\
\hline FB01-2 & 46.37 & 27.41 & 18.96 & 53.62 & 0.01 & B & 2.24 & -0.74 & -3.43 & 10.78 & -0.82 & 1.77 & -0.51 & 1.43 & 2.23 & 0.13 & 0.72 \\
\hline FB01-3 & 37.99 & 21.92 & 16.07 & 62.00 & 0.01 & $\mathrm{~B}$ & 2.24 & -1.74 & -2.81 & 7.02 & -0.12 & 1.09 & -0.10 & 1.07 & 2.04 & -0.02 & 0.65 \\
\hline FB01-4 & 16.02 & 9.51 & 6.51 & 83.96 & 0.02 & U & 2.74 & $\mathrm{~N} / \mathrm{A}$ & -1.93 & 3.80 & 2.25 & 0.21 & 1.34 & 0.39 & 1.81 & -0.73 & 1.36 \\
\hline FBO2-3 & 5.19 & 4.42 & 0.77 & 94.78 & 0.03 & u & 2.24 & N/A & 1.57 & 0.34 & 2.37 & 0.19 & 2.37 & 0.19 & 0.87 & -0.36 & 2.89 \\
\hline FBO2-4 & 20.86 & 11.64 & 9.22 & 79.12 & 0.02 & U & 2.24 & $\mathrm{~N} / \mathrm{A}$ & -2.19 & 4.56 & 2.10 & 0.23 & 1.09 & 0.47 & 1.94 & -0.71 & 0.78 \\
\hline FBO2-5 & 19.18 & 11.11 & 8.07 & 80.80 & 0.02 & B & 2.24 & -0.24 & -2.15 & 4.45 & 1.83 & 0.28 & 1.03 & 0.49 & 1.90 & -0.61 & 0.83 \\
\hline FB03-1 & 99.80 & 99.69 & 0.10 & 0.20 & 0.00 & U & -4.73 & $\mathrm{~N} / \mathrm{A}$ & -5.53 & 46.32 & -4.51 & 22.82 & -4.47 & 22.22 & 0.84 & 0.07 & 0.92 \\
\hline FBO3-2 & 92.90 & 78.21 & 14.70 & 7.10 & 0.00 & U & -3.24 & $\mathrm{~N} / \mathrm{A}$ & -4.10 & 17.12 & -2.96 & 7.80 & -2.85 & 7.20 & 1.29 & 0.27 & 1.41 \\
\hline FB03-3 & 75.46 & 66.91 & 8.55 & 24.53 & 0.01 & B & -3.24 & 2.24 & -5.22 & 37.16 & -3.11 & 8.60 & -2.04 & 4.11 & 2.86 & 0.43 & 1.06 \\
\hline FBO3-4 & 30.22 & 21.60 & 8.62 & 69.75 & 0.03 & B & 2.74 & -2.24 & -3.04 & 8.20 & 2.33 & 0.20 & 0.89 & 0.54 & 2.34 & -0.81 & 0.62 \\
\hline FBO3-5 & 0.45 & 0.12 & 0.33 & 99.50 & 0.05 & U & 2.74 & $\mathrm{~N} / \mathrm{A}$ & 2.12 & 0.23 & 2.64 & 0.16 & 2.60 & 0.16 & 0.34 & -0.15 & 0.99 \\
\hline FBO3-6 & 0.02 & 0.00 & 0.02 & 99.96 & 0.02 & u & 2.74 & N/A & 2.04 & 0.24 & 2.54 & 0.17 & 2.52 & 0.17 & 0.36 & -0.15 & 0.84 \\
\hline FB04-1 & 77.64 & 70.71 & 6.93 & 22.35 & 0.01 & B & -4.73 & 2.24 & -5.36 & 40.95 & -3.56 & 11.82 & -2.31 & 4.96 & 2.93 & 0.52 & 1.01 \\
\hline FBO4-2 & 26.64 & 19.38 & 7.25 & 73.32 & 0.04 & u & 2.24 & N/A & -3.05 & 8.29 & 2.19 & 0.22 & 0.86 & 0.55 & 2.32 & -0.77 & 0.71 \\
\hline FBO4-3 & 2.72 & 1.84 & 0.88 & 97.17 & 0.11 & U & 2.74 & N/A & 2.08 & 0.24 & 2.67 & 0.16 & 2.62 & 0.16 & 0.42 & -0.17 & 1.24 \\
\hline FBO4-4 & 0.12 & 0.03 & 0.10 & 99.85 & 0.03 & U & 2.74 & N/A & 2.05 & 0.24 & 2.50 & 0.18 & 2.50 & 0.18 & 0.34 & -0.04 & 0.77 \\
\hline
\end{tabular}


Foss Beach (Winter Sampling), Rye, New Hampshire: Grain Size Distribution

\begin{tabular}{|c|c|c|c|c|c|c|c|c|c|c|c|c|c|c|c|c|c|c|c|c|c|}
\hline Sample ID & $\begin{array}{c}\text { Class \% } \\
\text { phi } \\
-5.5 \\
\end{array}$ & $\begin{array}{c}\text { Class \% } \\
\text { phi } \\
-5.0 \\
\end{array}$ & $\begin{array}{c}\text { Class \% } \\
\text { phi } \\
-4.5 \\
\end{array}$ & $\begin{array}{c}\text { Class \% } \\
\text { phi } \\
-4.0 \\
\end{array}$ & $\begin{array}{c}\text { Class \% } \\
\text { phi } \\
-3.5 \\
\end{array}$ & $\begin{array}{c}\text { Class \% } \\
\text { phi } \\
-3.0 \\
\end{array}$ & $\begin{array}{c}\text { Class \% } \\
\text { phi } \\
-2.5 \\
\end{array}$ & $\begin{array}{c}\text { Class \% } \\
\text { phi } \\
-2.0 \\
\end{array}$ & $\begin{array}{c}\text { Class \% } \\
\text { phi } \\
-1.5 \\
\end{array}$ & $\begin{array}{c}\text { Class \% } \\
\text { phi } \\
-1.0 \\
\end{array}$ & $\begin{array}{c}\text { Class \% } \\
\text { phi } \\
-0.5 \\
\end{array}$ & $\begin{array}{c}\text { Class \% } \\
\text { phi } \\
0.0 \\
\end{array}$ & $\begin{array}{c}\text { Class \% } \\
\text { phi } \\
0.5 \\
\end{array}$ & $\begin{array}{c}\text { Class \% } \\
\text { phi } \\
1.0 \\
\end{array}$ & $\begin{array}{c}\text { Class \% } \\
\text { phi } \\
1.5 \\
\end{array}$ & $\begin{array}{c}\text { Class \% } \\
\text { phi } \\
2.0 \\
\end{array}$ & $\begin{array}{c}\text { Class \% } \\
\text { phi } \\
2.5 \\
\end{array}$ & $\begin{array}{c}\text { Class \% } \\
\text { phi } \\
3.0 \\
\end{array}$ & $\begin{array}{c}\text { Class \% } \\
\text { phi } \\
3.5 \\
\end{array}$ & $\begin{array}{c}\text { Class \% } \\
\text { phi } \\
4.0 \\
\end{array}$ & $\begin{array}{c}\text { Class \% } \\
\text { phi } \\
>4.0 \\
\end{array}$ \\
\hline FB01-1A & 0.62 & 0.46 & 1.92 & 3.65 & 5.29 & 5.25 & 4.23 & 3.73 & 3.56 & 3.58 & 5.96 & 8.95 & 12.75 & 15.30 & 9.74 & 8.08 & 5.53 & 1.36 & 0.04 & 0.00 & 0.01 \\
\hline FB01-1B & 4.15 & 5.09 & 9.26 & 16.41 & 20.11 & 16.03 & 9.10 & 4.58 & 2.38 & 1.25 & 1.07 & 0.79 & 0.82 & 1.11 & 1.17 & 2.32 & 3.10 & 1.19 & 0.06 & 0.01 & 0.02 \\
\hline FBO1-2 & 0.00 & 0.00 & 0.41 & 2.73 & 5.11 & 5.95 & 6.09 & 7.11 & 9.46 & 9.50 & 10.46 & 7.01 & 4.60 & 3.33 & 3.04 & 5.87 & 11.63 & 7.28 & 0.41 & 0.02 & 0.01 \\
\hline FB01-3 & 0.00 & 0.00 & 0.00 & 0.53 & 2.22 & 4.81 & 6.67 & 7.69 & 8.65 & 7.41 & 7.73 & 5.73 & 4.52 & 4.80 & 5.56 & 10.93 & 15.37 & 7.03 & 0.33 & 0.01 & 0.01 \\
\hline FB01-4 & 0.00 & 0.00 & 0.00 & 0.00 & 1.20 & 2.47 & 2.69 & 3.16 & 3.42 & 3.08 & 3.32 & 2.52 & 1.75 & 1.62 & 2.07 & 7.61 & 29.12 & 32.97 & 2.93 & 0.05 & 0.02 \\
\hline $\mathrm{FBO2-3}$ & 0.00 & 0.00 & 0.00 & 1.28 & 1.04 & 0.88 & 0.71 & 0.51 & 0.46 & 0.31 & 0.39 & 0.30 & 0.40 & 0.65 & 1.65 & 8.97 & 42.00 & 37.48 & 2.89 & 0.06 & 0.03 \\
\hline $\mathrm{FBO2-4}$ & 0.00 & 0.00 & 0.00 & 0.00 & 1.35 & 2.70 & 3.37 & 4.22 & 4.78 & 4.44 & 4.55 & 3.25 & 2.01 & 1.64 & 2.48 & 9.28 & 29.50 & 24.19 & 2.18 & 0.05 & 0.02 \\
\hline FB02-5 & 0.00 & 0.00 & 0.67 & 0.29 & 1.52 & 2.13 & 2.98 & 3.52 & 4.11 & 3.96 & 5.66 & 5.78 & 5.73 & 4.76 & 3.66 & 7.92 & 24.27 & 21.05 & 1.93 & 0.03 & 0.02 \\
\hline FB03-1 & 10.94 & 16.45 & 23.88 & 19.12 & 16.52 & 9.65 & 2.57 & 0.56 & 0.08 & 0.02 & 0.02 & 0.01 & 0.01 & 0.00 & 0.01 & 0.03 & 0.06 & 0.07 & 0.01 & 0.00 & 0.00 \\
\hline FB03-2 & 2.20 & 0.00 & 2.89 & 6.15 & 16.64 & 20.96 & 16.21 & 13.15 & 10.85 & 3.84 & 0.87 & 0.57 & 0.66 & 0.76 & 0.83 & 1.55 & 1.45 & 0.38 & 0.02 & 0.01 & 0.00 \\
\hline FB03-3 & 7.99 & 3.74 & 8.63 & 8.63 & 11.05 & 12.70 & 8.35 & 5.81 & 4.86 & 3.69 & 2.92 & 1.61 & 0.86 & 0.70 & 0.95 & 3.30 & 8.63 & 5.32 & 0.22 & 0.02 & 0.01 \\
\hline FB03-4 & 0.00 & 2.96 & 0.00 & 0.93 & 1.81 & 4.63 & 5.58 & 5.69 & 5.25 & 3.37 & 2.43 & 0.51 & 0.18 & 0.24 & 0.39 & 1.92 & 20.52 & 39.96 & 3.56 & 0.04 & 0.03 \\
\hline FBO3-5 & 0.00 & 0.00 & 0.00 & 0.00 & 0.00 & 0.00 & 0.04 & 0.08 & 0.17 & 0.15 & 0.14 & 0.03 & 0.12 & 0.22 & 0.32 & 1.93 & 26.29 & 63.42 & 6.91 & 0.11 & 0.05 \\
\hline FB03-6 & 0.00 & 0.00 & 0.00 & 0.00 & 0.00 & 0.00 & 0.00 & 0.00 & 0.01 & 0.01 & 0.02 & 0.08 & 0.16 & 0.18 & 0.54 & 5.57 & 36.90 & 51.52 & 4.90 & 0.09 & 0.02 \\
\hline FBO4-1 & 6.86 & 11.88 & 12.11 & 10.97 & 9.64 & 8.29 & 5.95 & 5.03 & 4.17 & 2.75 & 2.08 & 0.85 & 0.36 & 0.38 & 0.83 & 3.95 & 9.76 & 3.92 & 0.20 & 0.01 & 0.01 \\
\hline FBO4-2 & 0.00 & 0.00 & 2.32 & 1.46 & 2.91 & 3.70 & 4.80 & 4.20 & 4.36 & 2.89 & 1.81 & 0.62 & 0.29 & 0.39 & 1.01 & 7.24 & 29.71 & 28.37 & 3.77 & 0.12 & 0.04 \\
\hline FBO4-3 & 0.00 & 0.00 & 0.00 & 0.00 & 0.00 & 0.83 & 0.44 & 0.56 & 0.54 & 0.34 & 0.27 & 0.05 & 0.05 & 0.08 & 0.30 & 2.62 & 22.88 & 57.48 & 12.82 & 0.60 & 0.11 \\
\hline FB04-4 & 0.00 & 0.00 & 0.00 & 0.00 & 0.00 & 0.00 & 0.01 & 0.02 & 0.08 & 0.02 & 0.02 & 0.01 & 0.04 & 0.15 & 0.39 & 4.72 & 41.91 & 48.66 & 3.85 & 0.09 & 0.03 \\
\hline
\end{tabular}


Section 2(b): Foss Beach (Summer/Fall 2017 Sampling Period) 
Foss Beach (Summer Sampling), Rye, New Hampshire: Identification, Location, and Description

\begin{tabular}{|c|c|c|c|c|c|c|c|c|c|c|c|c|c|}
\hline Sample ID & Global Sample ID & $\begin{array}{l}\text { Latitude } \\
\text { WGS84 }\end{array}$ & $\begin{array}{l}\text { Longitude } \\
\text { WGS84 }\end{array}$ & $\begin{array}{l}\text { Relative } \\
\text { Position } \\
\text { Accuracy }\end{array}$ & $\begin{array}{l}\text { Elevation } \\
\text { (m) } \\
\text { NAVD88 }\end{array}$ & $\begin{array}{c}\text { Elevation } \\
(\mathrm{m}) \\
\text { MTL }\end{array}$ & $\begin{array}{c}\text { Relative } \\
\text { Elevation }\end{array}$ & $\begin{array}{l}\text { Relative } \\
\text { Location }\end{array}$ & $\begin{array}{c}\text { Sample } \\
\text { Collected }\end{array}$ & $\begin{array}{l}\text { Core } \\
\text { Length } \\
(\mathrm{cm})\end{array}$ & $\begin{array}{c}\text { Collected } \\
\text { Sample } \\
\text { Wt. (gm) }\end{array}$ & $\begin{array}{c}\text { Processed } \\
\text { Sample } \\
\text { Wt. (gm) }\end{array}$ & $\begin{array}{l}\text { Morphologic } \\
\text { Feature }\end{array}$ \\
\hline FBO1-1 & NHC D20170915 FB01-1 & 43.010407 & -70.741639 & 1 & 1.25 & 1.36 & MW & UB & 15 -Sep-17 & 20 & $2,867.9$ & $2,874.0$ & G. Ramp: Base \\
\hline FBO1-2 & NHC_D20170915_FB01-2 & 43.010370 & -70.741579 & 1 & 0.56 & 0.68 & MW & UB & 15-Sep-17 & 29 & $7,067.7$ & $7,090.2$ & Berm: Backshore \\
\hline FB01-3 & NHC_D20170915_FB01-3 & 43.010292 & -70.741458 & 1 & 0.26 & 0.37 & $\mathrm{MW}$ & UB & 15 -Sep-17 & 28 & $7,989.3$ & $8,001.6$ & LTT:Mid \\
\hline FB01-4 & NHC_D20170915_FB01-4 & 43.010114 & -70.741180 & 1 & -0.87 & -0.76 & $\mathrm{LW}$ & $\mathrm{LB}$ & $15-$ Sep-17 & 28 & $5,787.1$ & $5,744.9$ & LTT:Swash \\
\hline FBO2-2 & NHC_D20170915_FB02-2 & 43.007890 & -70.743799 & 1 & 0.61 & 0.72 & MTB & UB & $15-$ Sep-17 & 24 & $2,200.7$ & $2,190.7$ & $\begin{array}{l}\text { Foreshore: Upper } \\
\text { Base of G. Ramp }\end{array}$ \\
\hline FBO2-3 & NHC_D20170915_FB02-3 & 43.007809 & -70.743572 & 1 & -0.12 & -0.01 & LTB & $\mathrm{MB}$ & 15 -Sep-17 & 29 & $6,832.3$ & $6,851.6$ & LTT: Mid \\
\hline FBO2-4 & NHC_D20170915_FB02-4 & 43.007702 & -70.743272 & 1 & -0.98 & -0.86 & LTB & LB & 15 -Sep-17 & 29 & $6,288.6$ & $6,280.9$ & LTT: Lower \\
\hline FB03-2 & NHC D20170915_FB03-2 & 43.005768 & -70.744776 & 1 & 1.04 & 1.15 & MTB & UB & 15 -Sep-17 & 27 & $2,931.6$ & $2,926.0$ & $\begin{array}{l}\text { Foreshore: Upper } \\
\text { Base of G. Ramp }\end{array}$ \\
\hline FBO3-3 & NHC_D20170915_FB03-3 & 43.005738 & -70.744546 & 1 & -0.13 & -0.01 & LTB & $\mathrm{MB}$ & 15 -Sep-17 & 27 & $7,089.2$ & $7,108.6$ & LTT: Mid \\
\hline FBO3-4 & NHC_D20170915_FB03-4 & 43.005700 & -70.744259 & 1 & -1.00 & -0.89 & LTB & $\angle B$ & 15-Sep-17 & 28 & $3,322.4$ & $3,313.9$ & LTT: Lower \\
\hline
\end{tabular}

Foss Beach (Summer Sampling), Rye, New Hampshire: Sediment Classifications

\begin{tabular}{|c|c|c|c|c|c|c|c|c|}
\hline Sample ID & $\begin{array}{l}\text { CMECS Substrate } \\
\text { Component } \\
\text { Group (Specific) }\end{array}$ & $\begin{array}{l}\text { CMECS Substrate } \\
\text { Component Subgroup } \\
\text { (Specific) }\end{array}$ & $\begin{array}{l}\text { Textural Group from } \\
\% \text { GSM (Gradistat) }\end{array}$ & $\begin{array}{l}\text { Sediment Name from } \\
\text { \%GSM } \\
\text { and Mode (Gradistat) }\end{array}$ & $\begin{array}{l}\text { Sediment Name from } \\
\text { \%GSM and Mode } \\
\text { (Wentworth Scale) }\end{array}$ & $\begin{array}{l}\text { Sediment Classification } \\
\text { from Mean Phi } \\
\text { (Gradistat) }\end{array}$ & $\begin{array}{l}\text { Sediment } \\
\text { Classification } \\
\text { from Mean Phi } \\
\text { (Wentworth) } \\
\end{array}$ & Sorting (Gradistat) \\
\hline FB01-1 & Pebble Mixes & Sandy Pebble Gravel & Sandy Gravel & Sandy Medium Gravel & Sandy Pebble Gravel & Very Fine Gravel & Granule Gravel & Very Poorly Sorted \\
\hline FB01-2 & Pebble Mixes & Sandy Pebble Gravel & Sandy Gravel & Sandy Medium Gravel & Sandy Pebble Gravel & Very Coarse Sand & Very Coarse Sand & Very Poorly Sorted \\
\hline FB01-3 & Pebbly & Pebbly Fine Sand & Gravelly Sand & Medium Gravelly Fine Sand & Pebbly Fine Sand & Medium Sand & Medium Sand & Very Poorly Sorted \\
\hline FB01-4 & Granuley & Granuley Fine Sand & Gravelly Sand & $\begin{array}{l}\text { Very Fine Gravelly Fine } \\
\text { Sand }\end{array}$ & Granular Fine Sand & Medium Sand & Medium Sand & Poorly Sorted \\
\hline FBO2-2 & Slightly Pebbly & $\begin{array}{l}\text { Slightly Pebbly Fine } \\
\text { Sand }\end{array}$ & Slightly Gravelly Sand & $\begin{array}{l}\text { Slightly Medium Gravelly } \\
\text { Fine Sand }\end{array}$ & $\begin{array}{l}\text { Slightly Pebbly Fine } \\
\text { Sand }\end{array}$ & Fine Sand & Fine Sand & Well Sorted \\
\hline FBO2-3 & Pebbly & Pebbly Fine Sand & Gravelly Sand & Coarse Gravelly Fine Sand & Pebbly Fine Sand & Fine Sand & Fine Sand & Poorly Sorted \\
\hline FBO2-4 & Pebbly & Pebbly Fine Sand & Gravelly Sand & Medium Gravelly Fine Sand & Pebbly Fine Sand & Coarse Sand & Coarse Sand & Very Poorly Sorted \\
\hline FBO3-2 & Slightly Granuley & $\begin{array}{l}\text { Slightly Granuley Fine } \\
\text { Sand }\end{array}$ & Slightly Gravelly Sand & $\begin{array}{l}\text { Slightly Very Fine Gravelly } \\
\text { Fine Sand }\end{array}$ & $\begin{array}{l}\text { Slightly Granular Fine } \\
\text { Sand }\end{array}$ & Fine Sand & Fine Sand & Well Sorted \\
\hline FBO3-3 & Pebbly & Pebbly Fine Sand & Gravelly Sand & $\begin{array}{l}\text { Very Coarse Gravelly Fine } \\
\text { Sand }\end{array}$ & Pebbly Fine Sand & Coarse Sand & Coarse Sand & Very Poorly Sorted \\
\hline FB03-4 & Slightly Pebbly & $\begin{array}{l}\text { Slightly Pebbly Fine } \\
\text { Sand }\end{array}$ & Slightly Gravelly Sand & $\begin{array}{l}\text { Slightly Coarse Gravelly } \\
\text { Fine Sand }\end{array}$ & $\begin{array}{l}\text { Slightly Pebbly Fine } \\
\text { Sand }\end{array}$ & Fine Sand & Fine Sand & Well Sorted \\
\hline
\end{tabular}


Foss Beach (Summer Sampling), Rye, New Hampshire: Grain Size Statistics

\begin{tabular}{|c|c|c|c|c|c|c|c|c|c|c|c|c|c|c|c|c|c|}
\hline Sample ID & Gravel \% & Pebble \% & Granule \% & Sand $\%$ & Mud \% & Modes & $\begin{array}{c}\text { Mode } 1 \\
\text { (phi) }\end{array}$ & $\begin{array}{c}\text { Mode } 2 \\
\text { (phi) }\end{array}$ & $\begin{array}{c}D_{10} \\
\text { (phi) }\end{array}$ & $\begin{array}{c}D_{10} \\
(\mathrm{~mm})\end{array}$ & $\begin{array}{c}\mathrm{D}_{50} \\
\text { (phi) }\end{array}$ & $\begin{array}{c}D_{50} \\
(\mathrm{~mm})\end{array}$ & $\begin{array}{c}\text { Mean Size } \\
\text { (phi) }\end{array}$ & $\begin{array}{c}\text { Mean Size } \\
(\mathrm{mm})\end{array}$ & $\begin{array}{c}\text { Sorting } \\
\text { (phi) }\end{array}$ & Skewness & Kurtosis \\
\hline FB01-1 & 61.79 & 51.78 & 10.01 & 38.20 & 0.01 & B & -3.74 & 2.24 & -4.76 & 27.18 & -2.15 & 4.45 & -1.58 & 2.99 & 2.56 & 0.25 & 0.77 \\
\hline FB01-2 & 46.57 & 37.48 & 9.09 & 53.39 & 0.04 & B & 2.24 & -3.24 & -4.22 & 18.66 & -0.38 & 1.30 & -0.54 & 1.46 & 2.67 & -0.12 & 0.60 \\
\hline FB01-3 & 18.27 & 14.94 & 3.34 & 81.70 & 0.03 & $u$ & 2.24 & $\mathrm{~N} / \mathrm{A}$ & -3.02 & 8.13 & 2.13 & 0.23 & 1.04 & 0.49 & 2.11 & -0.75 & 1.68 \\
\hline FBO1-4 & 21.19 & 12.49 & 8.70 & 78.76 & 0.05 & $U$ & 2.24 & $\mathrm{~N} / \mathrm{A}$ & -2.29 & 4.90 & 2.03 & 0.24 & 1.03 & 0.49 & 1.98 & -0.69 & 0.80 \\
\hline $\mathrm{FBO2-2}$ & 0.25 & 0.25 & 0.00 & 99.73 & 0.02 & $U$ & 2.24 & N/A & 2.05 & 0.24 & 2.49 & 0.18 & 2.50 & 0.18 & 0.37 & 0.06 & 0.85 \\
\hline $\mathrm{FBO2-3}$ & 13.08 & 11.85 & 1.23 & 86.48 & 0.44 & $u$ & 2.74 & $\mathrm{~N} / \mathrm{A}$ & -3.00 & 8.00 & 2.42 & 0.19 & 2.12 & 0.23 & 1.54 & -0.65 & 3.99 \\
\hline FBO2-4 & 25.84 & 21.10 & 4.75 & 74.12 & 0.04 & B & 2.74 & -3.74 & -3.61 & 12.17 & 2.03 & 0.25 & 0.62 & 0.65 & 2.51 & -0.74 & 0.78 \\
\hline FB03-2 & 1.18 & 0.33 & 0.85 & 98.79 & 0.03 & $u$ & 2.24 & $\mathrm{~N} / \mathrm{A}$ & 1.65 & 0.32 & 2.28 & 0.21 & 2.31 & 0.20 & 0.48 & -0.11 & 1.61 \\
\hline FB03-3 & 29.78 & 26.24 & 3.54 & 70.19 & 0.03 & B & 2.24 & -5.73 & -4.73 & 26.52 & 2.12 & 0.23 & 0.30 & 0.81 & 2.97 & -0.82 & 0.74 \\
\hline FBO3-4 & 0.91 & 0.76 & 0.15 & 99.04 & 0.05 & $u$ & 2.74 & N/A & 2.05 & 0.24 & 2.55 & 0.17 & 2.53 & 0.17 & 0.40 & -0.03 & 0.93 \\
\hline
\end{tabular}

Foss Beach (Summer Sampling), Rye, New Hampshire: Grain Size Distribution

\begin{tabular}{|c|c|c|c|c|c|c|c|c|c|c|c|c|c|c|c|c|c|c|c|c|c|}
\hline Sample ID & $\begin{array}{c}\text { Class \% } \\
\text { phi } \\
-5.5 \\
\end{array}$ & $\begin{array}{c}\text { Class \% } \\
\text { phi } \\
-5.0 \\
\end{array}$ & $\begin{array}{c}\text { Class \% } \\
\text { phi } \\
-4.5 \\
\end{array}$ & $\begin{array}{c}\text { Class \% } \\
\text { phi } \\
-4.0 \\
\end{array}$ & $\begin{array}{c}\text { Class \% } \\
\text { phi } \\
-3.5 \\
\end{array}$ & $\begin{array}{c}\text { Class \% } \\
\text { phi } \\
-3.0 \\
\end{array}$ & $\begin{array}{c}\text { Class \% } \\
\text { phi } \\
-2.5 \\
\end{array}$ & $\begin{array}{c}\text { Class \% } \\
\text { phi } \\
-2.0 \\
\end{array}$ & $\begin{array}{c}\text { Class \% } \\
\text { phi } \\
-1.5 \\
\end{array}$ & $\begin{array}{c}\text { Class \% } \\
\text { phi } \\
-1.0 \\
\end{array}$ & $\begin{array}{c}\text { Class \% } \\
\text { phi } \\
-0.5 \\
\end{array}$ & $\begin{array}{c}\text { Class \% } \\
\text { phi } \\
0.0 \\
\end{array}$ & $\begin{array}{c}\text { Class \% } \\
\text { phi } \\
0.5 \\
\end{array}$ & $\begin{array}{c}\text { Class \% } \\
\text { phi } \\
1.0 \\
\end{array}$ & $\begin{array}{c}\text { Class \% } \\
\text { phi } \\
1.5 \\
\end{array}$ & $\begin{array}{c}\text { Class \% } \\
\text { phi } \\
2.0 \\
\end{array}$ & $\begin{array}{c}\text { Class \% } \\
\text { phi } \\
2.5 \\
\end{array}$ & $\begin{array}{c}\text { Class \% } \\
\text { phi } \\
\mathbf{3 . 0} \\
\end{array}$ & $\begin{array}{c}\text { Class \% } \\
\text { phi } \\
3.5 \\
\end{array}$ & $\begin{array}{c}\text { Class \% } \\
\text { phi } \\
4.0 \\
\end{array}$ & $\begin{array}{c}\text { Class } \% \\
\text { phi } \\
>4.0 \\
\end{array}$ \\
\hline FB01-1 & 0.00 & 9.68 & 0.74 & 6.76 & 11.91 & 9.97 & 7.12 & 5.60 & 5.38 & 4.63 & 4.43 & 4.86 & 4.88 & 4.45 & 3.47 & 4.61 & 7.16 & 4.01 & 0.31 & 0.02 & 0.01 \\
\hline FBO1-2 & 0.00 & 3.20 & 4.74 & 3.80 & 6.41 & 7.04 & 6.24 & 6.06 & 5.13 & 3.96 & 2.96 & 2.09 & 1.98 & 2.46 & 2.86 & 7.21 & 20.86 & 11.53 & 1.36 & 0.07 & 0.04 \\
\hline FBO1-3 & 0.00 & 0.00 & 1.12 & 2.23 & 3.20 & 3.62 & 2.58 & 2.19 & 1.89 & 1.45 & 1.81 & 1.50 & 1.59 & 2.54 & 4.13 & 11.21 & 33.38 & 23.15 & 2.31 & 0.07 & 0.03 \\
\hline FB01-4 & 0.00 & 0.00 & 0.00 & 0.75 & 1.36 & 2.84 & 3.44 & 4.11 & 5.04 & 3.66 & 4.33 & 4.28 & 3.75 & 3.57 & 3.54 & 7.62 & 26.49 & 22.38 & 2.71 & 0.09 & 0.05 \\
\hline FBO2-2 & 0.00 & 0.00 & 0.00 & 0.00 & 0.25 & 0.00 & 0.00 & 0.00 & 0.00 & 0.00 & 0.00 & 0.01 & 0.01 & 0.06 & 0.36 & 4.83 & 43.23 & 44.33 & 6.72 & 0.19 & 0.02 \\
\hline FBO2-3 & 0.00 & 0.00 & 2.08 & 3.48 & 2.85 & 1.59 & 1.02 & 0.83 & 0.65 & 0.58 & 0.66 & 0.61 & 0.64 & 0.77 & 1.36 & 6.62 & 29.54 & 39.81 & 6.27 & 0.20 & 0.44 \\
\hline FBO2-4 & 0.00 & 1.73 & 1.52 & 2.78 & 5.18 & 4.41 & 2.90 & 2.58 & 2.50 & 2.25 & 1.57 & 2.35 & 3.21 & 4.81 & 4.40 & 6.61 & 21.50 & 24.83 & 4.60 & 0.23 & 0.04 \\
\hline FBO3-2 & 0.00 & 0.00 & 0.00 & 0.00 & 0.00 & 0.03 & 0.10 & 0.20 & 0.32 & 0.53 & 0.88 & 0.90 & 0.81 & 0.99 & 1.86 & 11.13 & 53.90 & 26.72 & 1.54 & 0.05 & 0.03 \\
\hline FBO3-3 & 8.70 & 0.00 & 2.58 & 4.35 & 2.98 & 3.33 & 2.26 & 2.04 & 1.86 & 1.68 & 1.60 & 1.27 & 0.82 & 0.66 & 1.07 & 6.76 & 30.85 & 24.54 & 2.55 & 0.06 & 0.03 \\
\hline-4 & 0.00 & 0.00 & 0.00 & 0.51 & 0.12 & 0.07 & 0.03 & 0.04 & 0.07 & 0.08 & 0.17 & 0.12 & 0.13 & 0.18 & 0.40 & 3.92 & 36.93 & 48.41 & 8.54 & 0.25 & 0.05 \\
\hline
\end{tabular}


Section 3(a): Jenness Beach (Winter/Spring 2017 Sampling Period) 


\begin{tabular}{|c|c|c|c|c|c|c|c|c|c|c|c|c|c|}
\hline Sample ID & Global Sample ID & $\begin{array}{l}\text { Latitude } \\
\text { WGS84 } \\
\end{array}$ & $\begin{array}{c}\text { Longitude } \\
\text { WGS84 }\end{array}$ & $\begin{array}{l}\text { Relative } \\
\text { Position } \\
\text { Accuracy } \\
\end{array}$ & $\begin{array}{c}\begin{array}{c}\text { Elevation } \\
(\mathrm{m})\end{array} \\
\text { NAVD88 } \\
\end{array}$ & $\begin{array}{c}\text { Elevation } \\
(\mathrm{m}) \\
\text { MTL } \\
\end{array}$ & $\begin{array}{c}\text { Relative } \\
\text { Elevation } \\
\end{array}$ & $\begin{array}{l}\text { Relative } \\
\text { Location }\end{array}$ & $\begin{array}{c}\text { Sample } \\
\text { Collected }\end{array}$ & $\begin{array}{c}\text { Core } \\
\text { Length } \\
\text { (cm) } \\
\end{array}$ & $\begin{array}{c}\text { Collected } \\
\text { Sample } \\
\text { Wt. (gm) } \\
\end{array}$ & $\begin{array}{c}\text { Processed } \\
\text { Sample } \\
\text { Wt. (gm) }\end{array}$ & $\begin{array}{c}\text { Morphologic } \\
\text { Feature }\end{array}$ \\
\hline JBO1-1 & NHC D20170328 JB01-1 & 42.988705 & -70.760126 & 1 & 2.38 & 2.50 & UTB & UB & 28-Mar-17 & 24 & $14,751.0$ & $14,753.7$ & S. Ramp; LHTS \\
\hline JBO1-2 & NHC_D20170328_JB01-2 & 42.988624 & -70.759929 & 1 & 1.08 & 1.20 & MTB & UB & 28-Mar-17 & Est. 20 & $16,064.5$ & $15,217.3$ & S.-P. Ramp: Lower \\
\hline JB01-3 & NHC_D20170328_JB01-3 & 42.988511 & -70.759652 & 1 & 0.28 & 0.40 & MTB & $\mathrm{MB}$ & 28-Mar-17 & 25 & $6,257.0$ & $6,307.2$ & LTT; Upper \\
\hline JB01-4 & NHC_D20170328_JB01-4 & 42.988352 & -70.759260 & 1 & -0.51 & -0.39 & LTB & $\mathrm{LB}$ & 28-Mar-17 & 24 & $4,448.7$ & $4,469.6$ & $\mathrm{LT} ; \mathrm{Mid}$ \\
\hline JBO2-1 & NHC_D20170328_JB02-1 & 42.985737 & -70.762319 & 1 & 2.28 & 2.40 & UTB & UB & 28-Mar-17 & 25 & $2,850.2$ & $2,838.9$ & S. Ramp; LHTS \\
\hline JBO2-2 & NHC_D20170328_JB02-2 & 42.985639 & -70.761995 & 1 & 1.01 & 1.13 & MTB & UB & 28-Mar-17 & $\mathrm{N} / \mathrm{A}$ & $19,525.8$ & $19,165.9$ & $\begin{array}{l}\text { S. Ramp: Bound. } \\
\text { with LTT }\end{array}$ \\
\hline JBO2-3 & NHC_D20170328_JB02-3 & 42.985485 & -70.761503 & 1 & -0.07 & 0.05 & MTB & $\mathrm{MB}$ & 28-Mar-17 & 23 & $10,381.1$ & $10,398.6$ & LTT; Mid \\
\hline JBO2-4 & NHC_D20170328_JB02-4 & 42.985264 & -70.760780 & 1 & -1.17 & -1.04 & LTB & $\mathrm{LB}$ & 28-Mar-17 & 26 & $3,779.6$ & $3,788.8$ & LTT; Lower \\
\hline JBO3-1 & NHC_D20170329_JB03-1 & 42.982856 & -70.763455 & 1 & 1.23 & 1.35 & $\mathrm{MW}$ & UB & 29-Mar-17 & N/A & $16,145.1$ & $16,158.1$ & G. Ramp \\
\hline $\mathrm{JBO3-2}$ & NHC_D20170329_JB03-2 & 42.982844 & -70.763397 & 1 & 0.81 & 0.93 & $\mathrm{MW}$ & UB & 29-Mar-17 & 20 & $16,159.5$ & $16,147.6$ & Start LTT - Low Tide \\
\hline $\mathrm{JBO3-3}$ & NHC_D20170329_JB03-3 & 42.982734 & -70.762795 & 1 & -0.23 & -0.11 & $\mathrm{LW}$ & $\mathrm{MB}$ & 29-Mar-17 & 25 & $6,627.1$ & $6,621.6$ & Mid LTT - Low Tide \\
\hline JBO3-4 & NHC_D20170329_JB03-4 & 42.982581 & -70.762037 & 1 & -1.19 & -1.07 & LW & LB & 29-Mar-17 & 25 & $3,656.8$ & $3,657.7$ & $\begin{array}{c}\text { Water Line - Low } \\
\text { Tide }\end{array}$ \\
\hline JBO4-1 & NHC_D20170329_JB04-1 & 42.980488 & -70.764507 & 1 & 1.80 & 1.93 & $\mathrm{HW}$ & UB & 29-Mar-17 & N/A & $15,479.5$ & $15,508.8$ & G. Ramp \\
\hline JB04-2 & NHC_D20170329_JB04-2 & 42.980456 & -70.764327 & 1 & 0.77 & 0.90 & MW & UB & 29-Mar-17 & $\mathrm{N} / \mathrm{A}$ & $11,899.6$ & $11,882.7$ & Start LT - Low Tide \\
\hline JBO4-3 & NHC_D20170329_JB04-3 & 42.980306 & -70.763425 & 1 & -0.70 & -0.58 & $\mathrm{LW}$ & $\mathrm{MB}$ & 29-Mar-17 & 25 & $3,672.6$ & $3,667.7$ & Mid LTT - Low Tide \\
\hline JBO4-4 & NHC_D20170329_JB04-4 & 42.980163 & -70.762623 & 1 & -1.59 & -1.47 & LW & LB & 29-Mar-17 & 24 & $3,567.5$ & $3,570.5$ & $\begin{array}{c}\text { Water Line - Low } \\
\text { Tide }\end{array}$ \\
\hline
\end{tabular}




\begin{tabular}{|c|c|c|c|c|c|c|c|c|}
\hline Sample ID & $\begin{array}{l}\text { CMECS Substrate } \\
\text { Component } \\
\text { Group (Specific) }\end{array}$ & $\begin{array}{l}\text { CMECS Substrate } \\
\text { Component Subgroup } \\
\text { (Specific) }\end{array}$ & $\begin{array}{l}\text { Textural Group from } \\
\text { \%GSM (Gradistat) }\end{array}$ & $\begin{array}{l}\text { Sediment Name from } \\
\text { \%GSM } \\
\text { and Mode (Gradistat) }\end{array}$ & $\begin{array}{l}\text { Sediment Name from } \\
\text { \%GSM and Mode } \\
\text { (Wentworth Scale) }\end{array}$ & $\begin{array}{l}\text { Sediment Classification } \\
\text { from Mean Phi } \\
\text { (Gradistat) }\end{array}$ & $\begin{array}{l}\text { Sediment } \\
\text { Classification } \\
\text { from Mean Phi } \\
\text { (Wentworth) }\end{array}$ & Sorting (Gradistat) \\
\hline JB01-1 & Pebbly & Pebbly Medium Sand & Gravelly Sand & $\begin{array}{l}\text { Very Coarse Gravelly } \\
\text { Medium Sand }\end{array}$ & Pebbly Medium Sand & Coarse Sand & Coarse Sand & Very Poorly Sorted \\
\hline JB01-2 & Pebble Mixes & Sandy Pebble Gravel & Sandy Gravel & Sandy Medium Gravel & Sandy Pebble Gravel & Very Fine Gravel & Granule Gravel & Very Poorly Sorted \\
\hline JB01-3 & Granuley & Granuley Fine Sand & Gravelly Sand & $\begin{array}{l}\text { Very Fine Gravelly Fine } \\
\text { Sand }\end{array}$ & Granular Fine Sand & Coarse Sand & Coarse Sand & Very Poorly Sorted \\
\hline JB01-4 & Granuley & Granuley Fine Sand & Gravelly Sand & $\begin{array}{l}\text { Very Fine Gravelly Fine } \\
\text { Sand }\end{array}$ & Granular Fine Sand & Medium Sand & Medium Sand & Poorly Sorted \\
\hline JBO2-1 & Slightly Pebbly & $\begin{array}{l}\text { Slightly Pebbly Medium } \\
\text { Sand }\end{array}$ & Slightly Gravelly Sand & $\begin{array}{l}\text { Slightly Medium Gravelly } \\
\text { Medium Sand }\end{array}$ & $\begin{array}{l}\text { Slightly Pebbly Medium } \\
\text { Sand }\end{array}$ & Medium Sand & Medium Sand & Moderately Well Sorted \\
\hline $\mathrm{JBO2}-2$ & Pebble Mixes & Sandy Pebble Gravel & Sandy Gravel & Sandy Coarse Gravel & Sandy Pebble Gravel & Very Coarse Sand & Very Coarse Sand & Very Poorly Sorted \\
\hline JBO2-3 & Pebbly & Pebbly Medium Sand & Gravelly Sand & $\begin{array}{l}\text { Medium Gravelly Medium } \\
\text { Sand }\end{array}$ & Pebbly Medium Sand & Coarse Sand & Coarse Sand & Very Poorly Sorted \\
\hline JBO2-4 & Slightly Granuley & $\begin{array}{l}\text { Slightly Granuley Fine } \\
\text { Sand }\end{array}$ & Slightly Gravelly Sand & $\begin{array}{l}\text { Slightly Very Fine Gravelly } \\
\text { Fine Sand }\end{array}$ & $\begin{array}{l}\text { Slightly Granular Fine } \\
\text { Sand }\end{array}$ & Medium Sand & Medium Sand & Poorly Sorted \\
\hline $\mathrm{JB} 03-1$ & Gravel & Pebble Gravel & Gravel & Medium Gravel & Pebble Gravel & Medium Gravel & Pebble Gravel & Poorly Sorted \\
\hline JB03-2 & Pebbly & Pebbly Fine Sand & Gravelly Sand & Medium Gravelly Fine Sand & Pebbly Fine Sand & Coarse Sand & Coarse Sand & Very Poorly Sorted \\
\hline JBO3-3 & Pebbly & Pebbly Fine Sand & Gravelly Sand & Medium Gravelly Fine Sand & Pebbly Fine Sand & Medium Sand & Medium Sand & Poorly Sorted \\
\hline JB03-4 & Pebbly & Pebbly Fine Sand & Gravelly Sand & Medium Gravelly Fine Sand & Pebbly Fine Sand & Coarse Sand & Coarse Sand & Very Poorly Sorted \\
\hline JB04-1 & Pebble Mixes & Sandy Pebble Gravel & Sandy Gravel & Sandy Medium Gravel & Sandy Pebble Gravel & Very Fine Gravel & Granule Gravel & Very Poorly Sorted \\
\hline JBO4-2 & Pebble Mixes & Sandy Pebble Gravel & Sandy Gravel & Sandy Medium Gravel & Sandy Pebble Gravel & Coarse Sand & Coarse Sand & Very Poorly Sorted \\
\hline JB04-3 & Pebbly & Pebbly Fine Sand & Gravelly Sand & $\begin{array}{l}\text { Very Coarse Gravelly Fine } \\
\text { Sand }\end{array}$ & Pebbly Fine Sand & Fine Sand & Fine Sand & Poorly Sorted \\
\hline JB04-4 & Pebbly & Pebbly Fine Sand & Gravelly Sand & $\begin{array}{l}\text { Very Coarse Gravelly Fine } \\
\text { Sand }\end{array}$ & Pebbly Fine Sand & Fine Sand & Fine Sand & Poorly Sorted \\
\hline
\end{tabular}




\begin{tabular}{|c|c|c|c|c|c|c|c|c|c|c|c|c|c|c|c|c|c|}
\hline Sample ID & Gravel \% & Pebble \% & Granule \% & Sand \% & Mud \% & Modes & $\begin{array}{c}\text { Mode } 1 \\
\text { (phi) }\end{array}$ & $\begin{array}{c}\text { Mode } 2 \\
\text { (phi) }\end{array}$ & $\begin{array}{r}\mathrm{D}_{10} \\
\text { (phi) }\end{array}$ & $\begin{array}{r}D_{10} \\
(\mathrm{~mm}) \\
\end{array}$ & $\begin{array}{r}D_{50} \\
\text { (phi) }\end{array}$ & $\begin{array}{r}D_{50} \\
(\mathrm{~mm}) \\
\end{array}$ & $\begin{array}{c}\text { Mean Size } \\
\text { (phi) }\end{array}$ & $\begin{array}{c}\text { Mean Size } \\
(\mathrm{mm})\end{array}$ & $\begin{array}{c}\text { Sorting } \\
\text { (phi) }\end{array}$ & Skewness & Kurtosis \\
\hline JB01-1 & 16.62 & 16.15 & 0.47 & 83.36 & 0.02 & B & 1.75 & -5.74 & -5.56 & 47.04 & 1.41 & 0.38 & 0.36 & 0.78 & 2.41 & -0.71 & 2.50 \\
\hline JB01-2 & 50.08 & 41.58 & 8.49 & 49.90 & 0.02 & B & 1.75 & -3.24 & -4.92 & 30.21 & -1.01 & 2.01 & -1.22 & 2.34 & 2.69 & -0.12 & 0.67 \\
\hline JB01-3 & 29.58 & 18.13 & 11.45 & 70.40 & 0.02 & U & 2.24 & N/A & -2.93 & 7.60 & 0.46 & 0.73 & 0.13 & 0.91 & 2.05 & -0.26 & 0.84 \\
\hline JB01-4 & 14.14 & 7.96 & 6.18 & 85.81 & 0.05 & u & 2.24 & N/A & -1.65 & 3.15 & 1.42 & 0.37 & 1.08 & 0.47 & 1.67 & -0.38 & 1.03 \\
\hline JB02-1 & 0.08 & 0.07 & 0.01 & 99.90 & 0.02 & U & 1.75 & N/A & 1.16 & 0.45 & 1.84 & 0.28 & 1.84 & 0.28 & 0.53 & 0.05 & 1.02 \\
\hline JBO2-2 & 43.79 & 40.48 & 3.31 & 56.18 & 0.03 & B & 1.75 & -4.73 & -4.89 & 29.75 & 0.54 & 0.69 & -0.63 & 1.55 & 2.82 & -0.51 & 0.59 \\
\hline JBO2-3 & 26.81 & 22.28 & 4.54 & 73.16 & 0.03 & B & 1.25 & -3.74 & -3.79 & 13.83 & 1.02 & 0.49 & 0.08 & 0.95 & 2.44 & -0.53 & 0.91 \\
\hline JBO2-4 & 2.87 & 1.55 & 1.32 & 97.09 & 0.04 & U & 2.74 & N/A & 0.54 & 0.69 & 2.20 & 0.22 & 1.99 & 0.25 & 1.03 & -0.35 & 0.95 \\
\hline JB03-1 & 86.19 & 83.63 & 2.57 & 13.80 & 0.01 & u & -3.74 & N/A & -4.75 & 26.84 & -3.59 & 12.05 & -3.32 & 9.95 & 1.72 & 0.46 & 2.19 \\
\hline JB03-2 & 23.69 & 22.48 & 1.21 & 76.28 & 0.03 & B & 2.24 & -3.24 & -3.58 & 11.99 & 2.16 & 0.22 & 0.62 & 0.65 & 2.52 & -0.79 & 2.00 \\
\hline JB03-3 & 14.78 & 13.62 & 1.16 & 85.19 & 0.03 & U & 2.24 & N/A & -3.18 & 9.04 & 2.15 & 0.23 & 1.74 & 0.30 & 1.62 & -0.65 & 3.08 \\
\hline JB03-4 & 22.50 & 18.75 & 3.75 & 77.47 & 0.03 & U & 2.24 & $\mathrm{~N} / \mathrm{A}$ & -3.58 & 11.93 & 1.92 & 0.26 & 0.69 & 0.62 & 2.39 & -0.71 & 1.03 \\
\hline JB04-1 & 63.59 & 56.63 & 6.96 & 36.37 & 0.04 & B & -4.24 & 1.75 & -4.53 & 23.13 & -2.59 & 6.00 & -1.74 & 3.35 & 2.58 & 0.39 & 0.61 \\
\hline JBO4-2 & 34.75 & 32.87 & 1.88 & 65.21 & 0.04 & B & 2.24 & -3.24 & -4.03 & 16.35 & 1.95 & 0.26 & 0.30 & 0.81 & 2.65 & -0.78 & 0.57 \\
\hline JB04-3 & 12.99 & 11.16 & 1.83 & 86.97 & 0.04 & U & 2.74 & N/A & -2.46 & 5.49 & 2.44 & 0.18 & 2.12 & 0.23 & 1.60 & -0.65 & 3.33 \\
\hline JB04-4 & 5.49 & 4.47 & 1.03 & 94.48 & 0.03 & $u$ & 2.74 & N/A & 1.31 & 0.40 & 2.49 & 0.18 & 2.38 & 0.19 & 1.01 & -0.48 & 2.68 \\
\hline
\end{tabular}


Jenness Beach (Winter Sampling), New Hampshire: Grain Size Distribution

\begin{tabular}{|c|c|c|c|c|c|c|c|c|c|c|c|c|c|c|c|c|c|c|c|c|c|}
\hline Sample ID & $\begin{array}{c}\text { Class \% } \\
\text { phi } \\
-5.5 \\
\end{array}$ & $\begin{array}{c}\text { Class \% } \\
\text { phi } \\
-5.0 \\
\end{array}$ & $\begin{array}{c}\text { Class \% } \\
\text { phi } \\
-4.5 \\
\end{array}$ & $\begin{array}{c}\text { Class \% } \\
\text { phi } \\
-4.0 \\
\end{array}$ & $\begin{array}{c}\text { Class \% } \\
\text { phi } \\
-3.5 \\
\end{array}$ & $\begin{array}{c}\text { Class \% } \\
\text { phi } \\
-3.0 \\
\end{array}$ & $\begin{array}{c}\text { Class \% } \\
\text { phi } \\
-2.5 \\
\end{array}$ & $\begin{array}{c}\text { Class \% } \\
\text { phi } \\
-2.0 \\
\end{array}$ & $\begin{array}{c}\text { Class \% } \\
\text { phi } \\
-1.5 \\
\end{array}$ & $\begin{array}{c}\text { Class \% } \\
\text { phi } \\
-1.0 \\
\end{array}$ & $\begin{array}{c}\text { Class \% } \\
\text { phi } \\
-0.5 \\
\end{array}$ & $\begin{array}{c}\text { Class \% } \\
\text { phi } \\
0.0 \\
\end{array}$ & $\begin{array}{c}\text { Class \% } \\
\text { phi } \\
0.5 \\
\end{array}$ & $\begin{array}{c}\text { Class \% } \\
\text { phi } \\
1.0 \\
\end{array}$ & $\begin{array}{c}\text { Class \% } \\
\text { phi } \\
1.5 \\
\end{array}$ & $\begin{array}{c}\text { Class \% } \\
\text { phi } \\
2.0 \\
\end{array}$ & $\begin{array}{c}\text { Class \% } \\
\text { phi } \\
2.5 \\
\end{array}$ & $\begin{array}{c}\text { Class \% } \\
\text { phi } \\
3.0 \\
\end{array}$ & $\begin{array}{c}\text { Class \% } \\
\text { phi } \\
3.5 \\
\end{array}$ & $\begin{array}{c}\text { Class \% } \\
\text { phi } \\
4.0 \\
\end{array}$ & $\begin{array}{c}\text { Class \% } \\
\text { phi } \\
>4.0 \\
\end{array}$ \\
\hline JB01-1 & 11.52 & 1.64 & 1.25 & 0.54 & 0.48 & 0.37 & 0.21 & 0.14 & 0.20 & 0.27 & 0.69 & 1.66 & 4.17 & 10.69 & 19.45 & 25.22 & 16.93 & 4.24 & 0.29 & 0.02 & 0.02 \\
\hline JBO1-2 & 4.03 & 5.25 & 5.83 & 3.76 & 5.88 & 6.24 & 5.56 & 5.02 & 4.67 & 3.82 & 4.20 & 4.20 & 4.93 & 7.36 & 8.81 & 10.23 & 7.80 & 2.21 & 0.15 & 0.02 & 0.02 \\
\hline JB01-3 & 0.00 & 0.00 & 0.68 & 2.11 & 3.43 & 3.23 & 3.79 & 4.88 & 5.83 & 5.62 & 7.01 & 6.51 & 7.39 & 10.28 & 10.16 & 9.18 & 11.83 & 7.54 & 0.47 & 0.03 & 0.02 \\
\hline JB01-4 & 0.00 & 0.00 & 0.00 & 0.11 & 1.23 & 1.85 & 2.32 & 2.44 & 3.03 & 3.15 & 3.96 & 5.07 & 6.35 & 10.21 & 12.01 & 11.54 & 17.05 & 17.56 & 2.02 & 0.04 & 0.05 \\
\hline JBO2-1 & 0.00 & 0.00 & 0.00 & 0.00 & 0.07 & 0.00 & 0.00 & 0.00 & 0.00 & 0.01 & 0.02 & 0.02 & 0.21 & 3.25 & 20.15 & 38.92 & 26.94 & 8.94 & 1.39 & 0.07 & 0.02 \\
\hline $\mathrm{JBO2-2}$ & 2.61 & 6.21 & 7.04 & 6.40 & 6.28 & 5.30 & 3.73 & 2.91 & 1.95 & 1.35 & 1.30 & 1.51 & 2.70 & 7.44 & 12.64 & 13.76 & 10.50 & 5.85 & 0.48 & 0.02 & 0.03 \\
\hline $\mathrm{JB} 02-3$ & 0.00 & 2.85 & 3.00 & 2.40 & 4.29 & 3.68 & 3.05 & 3.01 & 2.43 & 2.10 & 2.65 & 3.48 & 5.73 & 10.85 & 13.99 & 13.87 & 12.66 & 9.22 & 0.67 & 0.03 & 0.03 \\
\hline JBO2-4 & 0.00 & 0.00 & 0.00 & 0.00 & 0.26 & 0.33 & 0.50 & 0.46 & 0.67 & 0.65 & 1.07 & 1.74 & 3.56 & 9.06 & 12.57 & 12.25 & 16.07 & 30.81 & 9.67 & 0.29 & 0.04 \\
\hline JB03-1 & 1.56 & 3.83 & 9.81 & 15.44 & 24.39 & 17.67 & 7.62 & 3.31 & 1.75 & 0.81 & 0.51 & 0.29 & 0.31 & 0.90 & 2.30 & 3.79 & 3.34 & 2.04 & 0.29 & 0.02 & 0.01 \\
\hline JB03-2 & 0.00 & 0.48 & 2.19 & 3.56 & 4.67 & 5.47 & 3.88 & 2.23 & 0.88 & 0.33 & 0.21 & 0.15 & 0.16 & 0.50 & 2.18 & 11.47 & 34.26 & 24.51 & 2.74 & 0.10 & 0.03 \\
\hline $\mathrm{JB} 03-3$ & 0.00 & 0.00 & 1.65 & 3.19 & 3.65 & 2.38 & 1.63 & 1.12 & 0.71 & 0.44 & 0.42 & 0.35 & 0.55 & 1.66 & 4.91 & 16.42 & 35.39 & 23.76 & 1.66 & 0.06 & 0.03 \\
\hline JB03-4 & 0.00 & 1.90 & 0.61 & 3.91 & 4.35 & 2.98 & 2.60 & 2.40 & 2.12 & 1.62 & 2.05 & 1.55 & 1.96 & 3.81 & 6.74 & 13.54 & 22.51 & 22.47 & 2.76 & 0.09 & 0.03 \\
\hline JBO4-1 & 1.99 & 2.58 & 6.00 & 12.29 & 11.22 & 10.20 & 7.12 & 5.24 & 4.03 & 2.93 & 2.58 & 2.20 & 2.40 & 4.19 & 6.71 & 8.50 & 6.39 & 2.91 & 0.44 & 0.04 & 0.04 \\
\hline JB04-2 & 1.75 & 0.00 & 3.76 & 4.80 & 6.85 & 7.64 & 5.35 & 2.73 & 1.32 & 0.55 & 0.36 & 0.21 & 0.23 & 0.62 & 2.69 & 12.36 & 30.90 & 16.36 & 1.41 & 0.07 & 0.04 \\
\hline JBO4-3 & 0.00 & 3.43 & 0.68 & 1.70 & 1.11 & 1.77 & 1.23 & 1.24 & 1.10 & 0.72 & 0.75 & 0.54 & 0.55 & 1.09 & 2.71 & 8.60 & 24.72 & 38.89 & 8.81 & 0.32 & 0.04 \\
\hline JB04-4 & 0.00 & 2.27 & 0.00 & 0.30 & 0.10 & 0.69 & 0.45 & 0.65 & 0.61 & 0.42 & 0.57 & 0.36 & 0.61 & 1.16 & 2.92 & 9.72 & 28.12 & 42.14 & 8.59 & 0.29 & 0.03 \\
\hline
\end{tabular}


Section 3(b): Jenness Beach (Summer/Fall 2017 Sampling Period) 


\begin{tabular}{|c|c|c|c|c|c|c|c|c|c|c|c|c|c|}
\hline Sample ID & Global Sample ID & $\begin{array}{l}\text { Latitude } \\
\text { WGS84 } \\
\end{array}$ & $\begin{array}{c}\text { Longitude } \\
\text { WGS84 }\end{array}$ & $\begin{array}{l}\text { Relative } \\
\text { Position } \\
\text { Accuracy } \\
\end{array}$ & $\begin{array}{c}\begin{array}{c}\text { Elevation } \\
(\mathrm{m})\end{array} \\
\text { NAVD88 } \\
\end{array}$ & $\begin{array}{c}\text { Elevation } \\
(\mathrm{m}) \\
\text { MTL } \\
\end{array}$ & $\begin{array}{c}\text { Relative } \\
\text { Elevation } \\
\end{array}$ & $\begin{array}{l}\text { Relative } \\
\text { Location }\end{array}$ & $\begin{array}{l}\text { Sample } \\
\text { Collected } \\
\end{array}$ & $\begin{array}{c}\text { Core } \\
\text { Length } \\
\text { (cm) } \\
\end{array}$ & $\begin{array}{c}\text { Collected } \\
\text { Sample } \\
\text { Wt. (gm) } \\
\end{array}$ & $\begin{array}{c}\text { Processed } \\
\text { Sample } \\
\text { Wt. (gm) }\end{array}$ & $\begin{array}{l}\text { Morphologic } \\
\text { Feature }\end{array}$ \\
\hline JB01-1 & NHC D20170909 JB01-1 & 42.988702 & -70.760122 & 1 & 2.30 & 2.42 & UTB & UB & 9-Sep-17 & 29 & $2,638.9$ & $2,635.4$ & S. Ramp; LHTS \\
\hline JB01-2 & NHC_D20170909_JB01-2 & 42.988638 & -70.759962 & 1 & 1.33 & 1.45 & MTB & UB & 9-Sep-17 & 29 & $15,845.7$ & $15,864.2$ & S. Ramp; Lower \\
\hline JB01-3 & NHC_D20170909_JB01-3 & 42.988599 & -70.759867 & 1 & 0.94 & 1.06 & MTB & UB & 9-Sep-17 & 29 & $4,963.7$ & $4,985.2$ & LTT: Upper \\
\hline JB01-4 & NHC_D20170909_JB01-4 & 42.988385 & -70.759338 & 1 & -0.03 & 0.09 & MTB & $\mathrm{MB}$ & 9-Sep-17 & 28 & $3,156.1$ & $3,141.2$ & LTT:Mid \\
\hline JB01-5 & NHC_D20170909_JB01-5 & 42.988184 & -70.758851 & 1 & -0.96 & -0.84 & $\mathrm{LW}$ & $\mathrm{LB}$ & 9-Sep-17 & 28 & $2,835.0$ & $2,825.0$ & LTT: Lower \\
\hline $\mathrm{JBO2-1}$ & NHC_D20170909_JB02-1 & 42.985748 & -70.762356 & 1 & 2.59 & 2.71 & UTB & UB & 9-Sep-17 & 29 & $2,765.8$ & $2,763.0$ & S. Ramp \\
\hline JBO2-2 & NHC_D20170909_JB02-2 & 42.985700 & -70.762202 & 1 & 2.10 & 2.22 & UTB & UB & 9-Sep-17 & 27 & $2,370.7$ & $2,365.2$ & Berm Crest; LHTS \\
\hline JB02-3 & NHC_D20170909_JB02-3 & 42.985626 & -70.761961 & 1 & 1.06 & 1.18 & MTB & UB & 9-Sep-17 & 28 & $5,339.7$ & $5,340.2$ & Berm Toe; $L T$ \\
\hline JBO2-4 & NHC D20170909_JB02-4 & 42.985449 & -70.761375 & 1 & 0.05 & 0.17 & MTB & $\mathrm{MB}$ & 9-Sep-17 & 29 & $3,419.3$ & $3,415.3$ & LTT:Mid \\
\hline JB02-5 & NHC_D20170909_JB02-5 & 42.985254 & -70.760734 & 1 & -1.24 & -1.12 & LTB & $\mathrm{LB}$ & 9-Sep-17 & 29 & 4,393.9 & $4,390.8$ & LTT: Lower \\
\hline JB03-1 & NHC D20170909_JB03-1 & 42.982855 & -70.763449 & 1 & 1.75 & 1.87 & UTB & UB & 11 -Sep-17 & 29 & $2,719.9$ & $2,725.7$ & S. Ramp; LHTS \\
\hline JB03-2 & NHC_D20170909_JB03-2 & 42.982827 & -70.763307 & 1 & 1.01 & 1.13 & MTB & UB & 11-Sep-17 & 27 & $5,623.0$ & $5,623.0$ & $\begin{array}{c}\text { S. Ramp Toe; } \Pi \text { : } \\
\text { Upper }\end{array}$ \\
\hline $\mathrm{JBO3}-3$ & NHC_D20170909_JB03-3 & 42.982768 & -70.763013 & 1 & 0.48 & 0.60 & MTB & UB & 11-Sep-17 & 28 & $3,143.2$ & $3,146.0$ & LTT: Upper to Mid \\
\hline JB03-4 & NHC_D20170909_JB03-4 & 42.982653 & -70.762443 & 1 & -0.37 & -0.24 & LTB & $\mathrm{MB}$ & 11-Sep-17 & 26 & $4,050.8$ & $4,044.9$ & LTT:Mid \\
\hline JB03-5 & NHC_D20170909_JB03-5 & 42.982538 & -70.761872 & 1 & -1.22 & -1.10 & LTB & LB & 11-Sep-17 & 27 & $4,191.9$ & $4,196.1$ & LTT: Lower \\
\hline JBO4-1 & NHC_D20170909JBO4-1 & 42.980508 & -70.764479 & 1 & 2.03 & 2.15 & UTB & UB & $11-$ Sep-17 & 28 & $2,453.0$ & $2,751.3$ & $\begin{array}{c}\text { S. Ramp: } \\
\text { Landward; LHTS }\end{array}$ \\
\hline JBO4-2 & NHC_D20170909_JB04-2 & 42.980475 & -70.764279 & 1 & 0.92 & 1.04 & MTB & UB & 11-Sep-17 & 28 & $4,888.5$ & $4,900.3$ & $\begin{array}{c}\text { S. Ramp Toe; LT: } \\
\text { Upper }\end{array}$ \\
\hline JB04-3 & NHC D20170909 JB04-3 & 42.980426 & -70.764001 & 1 & 0.40 & 0.52 & MTB & UB & 11-Sep-17 & 27 & $3,119.1$ & $3,118.5$ & LTT: Upper to Mid \\
\hline JBO4-4 & NHC_D20170909_JB04-4 & 42.980338 & -70.763493 & 1 & -0.25 & -0.13 & LTB & $\mathrm{MB}$ & 11 -Sep-17 & 28 & $3,430.2$ & $3,430.9$ & LTT: Mid to Lower \\
\hline JBO4-5 & NHC_D20170909_JB04-5 & 42.980223 & -70.762853 & 1 & -1.26 & -1.14 & LTB & LB & 11-Sep-17 & 27 & $3,383.6$ & 3,373.1 & LTT: Lower \\
\hline
\end{tabular}




\begin{tabular}{|c|c|c|c|c|c|c|c|c|}
\hline Sample ID & $\begin{array}{l}\text { CMECS Substrate } \\
\text { Component } \\
\text { Group (Specific) }\end{array}$ & $\begin{array}{l}\text { CMECS Substrate } \\
\text { Component Subgroup } \\
\text { (Specific) }\end{array}$ & $\begin{array}{l}\text { Textural Group from } \\
\text { \%GSM (Gradistat) }\end{array}$ & $\begin{array}{l}\text { Sediment Name from } \\
\text { \%GSM } \\
\text { and Mode (Gradistat) }\end{array}$ & $\begin{array}{l}\text { Sediment Name from } \\
\text { \%GSM and Mode } \\
\text { (Wentworth Scale) }\end{array}$ & $\begin{array}{l}\text { Sediment Classification } \\
\text { from Mean Phi } \\
\text { (Gradistat) }\end{array}$ & $\begin{array}{l}\text { Sediment } \\
\text { Classification } \\
\text { from Mean Phi } \\
\text { (Wentworth) }\end{array}$ & Sorting (Gradistat) \\
\hline JB01-1 & Slightly Pebbly & $\begin{array}{l}\text { Slightly Pebbly Fine } \\
\text { Sand }\end{array}$ & Slightly Gravelly Sand & $\begin{array}{l}\text { Slightly Coarse Gravelly } \\
\text { Fine Sand }\end{array}$ & $\begin{array}{l}\text { Slightly Pebbly Fine } \\
\text { Sand }\end{array}$ & Fine Sand & Fine Sand & Moderately Sorted \\
\hline JB01-2 & Pebbly & Pebbly Fine Sand & Gravelly Sand & Medium Gravelly Fine Sand & Pebbly Fine Sand & Coarse Sand & Coarse Sand & Very Poorly Sorted \\
\hline JB01-3 & Pebble Mixes & Sandy Pebble Gravel & Sandy Gravel & Sandy Fine Gravel & Sandy Pebble Gravel & Very Coarse Sand & Very Coarse Sand & Very Poorly Sorted \\
\hline JB01-4 & Slightly Granuley & $\begin{array}{l}\text { Slightly Granuley Fine } \\
\text { Sand }\end{array}$ & Slightly Gravelly Sand & $\begin{array}{l}\text { Slightly Very Fine Gravelly } \\
\text { Fine Sand }\end{array}$ & $\begin{array}{l}\text { Slightly Granular Fine } \\
\text { Sand }\end{array}$ & Fine Sand & Fine Sand & Moderately Sorted \\
\hline JB01-5 & Slightly Granuley & $\begin{array}{l}\text { Slightly Granuley Fine } \\
\text { Sand }\end{array}$ & Slightly Gravelly Sand & $\begin{array}{l}\text { Slightly Very Fine Gravelly } \\
\text { Fine Sand }\end{array}$ & $\begin{array}{l}\text { Slightly Granular Fine } \\
\text { Sand }\end{array}$ & Fine Sand & Fine Sand & Poorly Sorted \\
\hline $\mathrm{JBO2}-1$ & Slightly Granuley & $\begin{array}{l}\text { Slightly Granuley } \\
\text { Medium Sand }\end{array}$ & Slightly Gravelly Sand & $\begin{array}{l}\text { Slightly Very Fine Gravelly } \\
\text { Medium Sand }\end{array}$ & $\begin{array}{l}\text { Slightly Granular } \\
\text { Medium Sand }\end{array}$ & Medium Sand & Medium Sand & Moderately Well Sorted \\
\hline $\mathrm{JBO2-2}$ & Slightly Pebbly & $\begin{array}{l}\text { Slightly Pebbly Fine } \\
\text { Sand }\end{array}$ & Slightly Gravelly Sand & $\begin{array}{l}\text { Slightly Medium Gravelly } \\
\text { Fine Sand }\end{array}$ & $\begin{array}{l}\text { Slightly Pebbly Fine } \\
\text { Sand }\end{array}$ & Fine Sand & Fine Sand & Well Sorted \\
\hline JBO2-3 & Pebble Mixes & Sandy Pebble Gravel & Sandy Gravel & Sandy Medium Gravel & Sandy Pebble Gravel & Very Coarse Sand & Very Coarse Sand & Very Poorly Sorted \\
\hline $\mathrm{JBO2}-4$ & Slightly Pebbly & $\begin{array}{l}\text { Slightly Pebbly Fine } \\
\text { Sand }\end{array}$ & Slightly Gravelly Sand & $\begin{array}{l}\text { Slightly Coarse Gravelly } \\
\text { Fine Sand }\end{array}$ & $\begin{array}{l}\text { Slightly Pebbly Fine } \\
\text { Sand }\end{array}$ & Fine Sand & Fine Sand & Moderately Sorted \\
\hline JBO2-5 & Granuley & Granuley Fine Sand & Gravelly Sand & $\begin{array}{l}\text { Very Fine Gravelly Fine } \\
\text { Sand }\end{array}$ & Granular Fine Sand & Medium Sand & Medium Sand & Poorly Sorted \\
\hline JB03-1 & Slightly Pebbly & $\begin{array}{l}\text { Slightly Pebbly Fine } \\
\text { Sand }\end{array}$ & Slightly Gravelly Sand & $\begin{array}{l}\text { Slightly Coarse Gravelly } \\
\text { Fine Sand }\end{array}$ & $\begin{array}{l}\text { Slightly Pebbly Fine } \\
\text { Sand }\end{array}$ & Fine Sand & Fine Sand & Well Sorted \\
\hline JBO3-2 & Slightly Pebbly & $\begin{array}{l}\text { Slightly Pebbly Fine } \\
\text { Sand }\end{array}$ & Slightly Gravelly Sand & $\begin{array}{l}\text { Slightly Fine Gravelly Fine } \\
\text { Sand }\end{array}$ & $\begin{array}{l}\text { Slightly Pebbly Fine } \\
\text { Sand }\end{array}$ & Fine Sand & Fine Sand & Moderately Sorted \\
\hline JB03-3 & Slightly Granuley & $\begin{array}{l}\text { Slightly Granuley Fine } \\
\text { Sand }\end{array}$ & Slightly Gravelly Sand & $\begin{array}{l}\text { Slightly Very Fine Gravelly } \\
\text { Fine Sand }\end{array}$ & $\begin{array}{l}\text { Slightly Granular Fine } \\
\text { Sand }\end{array}$ & Fine Sand & Fine Sand & Well Sorted \\
\hline JBO3-4 & Slightly Pebbly & $\begin{array}{l}\text { Slightly Pebbly Fine } \\
\text { Sand }\end{array}$ & Slightly Gravelly Sand & $\begin{array}{l}\text { Slightly Medium Gravelly } \\
\text { Fine Sand }\end{array}$ & $\begin{array}{l}\text { Slightly Pebbly Fine } \\
\text { Sand }\end{array}$ & Fine Sand & Fine Sand & Moderately Well Sorted \\
\hline JB03-5 & Pebbly & Pebbly Fine Sand & Gravelly Sand & Medium Gravelly Fine Sand & Pebbly Fine Sand & Fine Sand & Fine Sand & Moderately Sorted \\
\hline JB04-1 & Slightly Pebbly & $\begin{array}{l}\text { Slightly Pebbly Fine } \\
\text { Sand }\end{array}$ & Slightly Gravelly Sand & $\begin{array}{l}\text { Slightly Coarse Gravelly } \\
\text { Fine Sand }\end{array}$ & $\begin{array}{l}\text { Slightly Pebbly Fine } \\
\text { Sand }\end{array}$ & Fine Sand & Fine Sand & Well Sorted \\
\hline JB04-2 & Pebbly & Pebbly Fine Sand & Gravelly Sand & Coarse Gravelly Fine Sand & Pebbly Fine Sand & Fine Sand & Fine Sand & Poorly Sorted \\
\hline JB04-3 & Slightly Pebbly & $\begin{array}{l}\text { Slightly Pebbly Fine } \\
\text { Sand }\end{array}$ & Slightly Gravelly Sand & $\begin{array}{l}\text { Slightly Medium Gravelly } \\
\text { Fine Sand }\end{array}$ & $\begin{array}{l}\text { Slightly Pebbly Fine } \\
\text { Sand }\end{array}$ & Fine Sand & Fine Sand & Well Sorted \\
\hline JBO4-4 & Slightly Pebbly & $\begin{array}{l}\text { Slightly Pebbly Fine } \\
\text { Sand }\end{array}$ & Slightly Gravelly Sand & $\begin{array}{l}\text { Slightly Fine Gravelly Fine } \\
\text { Sand }\end{array}$ & $\begin{array}{l}\text { Slightly Pebbly Fine } \\
\text { Sand }\end{array}$ & Fine Sand & Fine Sand & Moderately Well Sorted \\
\hline JBO4-5 & Slightly Pebbly & $\begin{array}{l}\text { Slightly Pebbly Fine } \\
\text { Sand }\end{array}$ & Slightly Gravelly Sand & $\begin{array}{l}\text { Slightly Fine Gravelly Fine } \\
\text { Sand }\end{array}$ & $\begin{array}{l}\text { Slightly Pebbly Fine } \\
\text { Sand }\end{array}$ & Fine Sand & Fine Sand & Moderately Sorted \\
\hline
\end{tabular}




\begin{tabular}{|c|c|c|c|c|c|c|c|c|c|c|c|c|c|c|c|c|c|}
\hline Sample ID & Gravel \% & Pebble \% & Granule \% & Sand \% & Mud \% & Modes & $\begin{array}{c}\text { Mode } 1 \\
\text { (phi) }\end{array}$ & $\begin{array}{c}\text { Mode } 2 \\
\text { (phi) }\end{array}$ & $\begin{array}{r}D_{10} \\
\text { (phi) }\end{array}$ & $\begin{array}{c}D_{10} \\
(\mathrm{~mm})\end{array}$ & $\begin{array}{c}D_{50} \\
\text { (phi) }\end{array}$ & $\begin{array}{c}D_{50} \\
(\mathrm{~mm})\end{array}$ & $\begin{array}{c}\text { Mean Size } \\
\text { (phi) }\end{array}$ & $\begin{array}{c}\text { Mean Size } \\
(\mathrm{mm})\end{array}$ & $\begin{array}{c}\text { Sorting } \\
\text { (phi) }\end{array}$ & Skewness & Kurtosis \\
\hline JB01-1 & 1.66 & 1.57 & 0.09 & 98.33 & 0.01 & U & 2.74 & N/A & 1.05 & 0.48 & 2.12 & 0.23 & 2.06 & 0.24 & 0.73 & -0.18 & 0.89 \\
\hline JB01-2 & 27.52 & 22.69 & 4.84 & 72.45 & 0.03 & B & 2.74 & -3.24 & -3.84 & 14.35 & 1.35 & 0.39 & 0.37 & 0.77 & 2.64 & -0.53 & 0.77 \\
\hline JB01-3 & 35.86 & 27.30 & 8.57 & 64.11 & 0.03 & $\mathrm{~B}$ & 2.74 & -3.24 & -3.64 & 12.47 & 0.32 & 0.80 & -0.04 & 1.03 & 2.54 & -0.23 & 0.68 \\
\hline JB01-4 & 1.92 & 0.65 & 1.27 & 98.04 & 0.04 & u & 2.74 & N/A & 0.87 & 0.55 & 2.53 & 0.17 & 2.26 & 0.21 & 0.86 & -0.52 & 1.29 \\
\hline JB01-5 & 4.04 & 1.50 & 2.54 & 95.92 & 0.04 & $u$ & 2.74 & N/A & 0.09 & 0.94 & 2.51 & 0.18 & 2.07 & 0.24 & 1.19 & -0.59 & 1.09 \\
\hline JB02-1 & 0.03 & 0.00 & 0.03 & 99.93 & 0.04 & U & 1.75 & N/A & 1.23 & 0.43 & 1.97 & 0.26 & 1.97 & 0.26 & 0.54 & 0.01 & 1.02 \\
\hline $\mathrm{JB} 02-2$ & 0.09 & 0.07 & 0.01 & 99.85 & 0.06 & $U$ & 2.74 & N/A & 2.03 & 0.25 & 2.54 & 0.17 & 2.52 & 0.17 & 0.40 & -0.15 & 0.94 \\
\hline $\mathrm{JB} 02-3$ & 32.75 & 31.10 & 1.64 & 67.22 & 0.03 & B & 2.74 & -3.24 & -4.36 & 20.58 & 1.10 & 0.47 & -0.01 & 1.01 & 2.80 & -0.52 & 0.59 \\
\hline JBO2-4 & 4.41 & 3.54 & 0.87 & 95.55 & 0.04 & u & 2.74 & N/A & 1.06 & 0.48 & 2.43 & 0.19 & 2.29 & 0.21 & 0.88 & -0.47 & 1.90 \\
\hline $\mathrm{JBO2-5}$ & 9.29 & 5.28 & 4.01 & 90.69 & 0.02 & $U$ & 2.74 & N/A & -0.85 & 1.81 & 1.93 & 0.26 & 1.61 & 0.33 & 1.43 & -0.47 & 1.15 \\
\hline JB03-1 & 0.31 & 0.31 & 0.00 & 99.66 & 0.03 & U & 2.24 & N/A & 1.88 & 0.27 & 2.40 & 0.19 & 2.43 & 0.19 & 0.41 & -0.02 & 0.96 \\
\hline JBO3-2 & 3.60 & 2.80 & 0.80 & 96.35 & 0.05 & u & 2.74 & N/A & 1.38 & 0.38 & 2.56 & 0.17 & 2.43 & 0.19 & 0.72 & -0.44 & 1.64 \\
\hline JB03-3 & 0.18 & 0.08 & 0.10 & 99.79 & 0.03 & $U$ & 2.74 & N/A & 1.81 & 0.28 & 2.51 & 0.18 & 2.48 & 0.18 & 0.46 & -0.15 & 1.02 \\
\hline JB03-4 & 1.29 & 0.90 & 0.39 & 98.69 & 0.02 & u & 2.74 & N/A & 1.66 & 0.32 & 2.48 & 0.18 & 2.44 & 0.18 & 0.53 & -0.20 & 1.17 \\
\hline JB03-5 & 5.30 & 4.10 & 1.20 & 94.68 & 0.02 & U & 2.74 & N/A & 1.09 & 0.47 & 2.36 & 0.20 & 2.26 & 0.21 & 1.00 & -0.43 & 2.16 \\
\hline JB04-1 & 0.29 & 0.28 & 0.01 & 99.69 & 0.02 & $U$ & 2.24 & N/A & 1.75 & 0.30 & 2.38 & 0.19 & 2.41 & 0.19 & 0.43 & -0.04 & 0.98 \\
\hline JBO4-2 & 5.66 & 5.59 & 0.07 & 94.31 & 0.03 & u & 2.74 & N/A & 1.69 & 0.31 & 2.59 & 0.17 & 2.53 & 0.17 & 1.26 & -0.51 & 4.42 \\
\hline $\mathrm{JB} 04-3$ & 0.85 & 0.66 & 0.19 & 99.12 & 0.03 & $u$ & 2.74 & N/A & 1.78 & 0.29 & 2.54 & 0.17 & 2.49 & 0.18 & 0.46 & -0.21 & 1.03 \\
\hline JBO4-4 & 0.96 & 0.62 & 0.34 & 99.01 & 0.03 & u & 2.74 & N/A & 1.66 & 0.32 & 2.46 & 0.18 & 2.43 & 0.19 & 0.52 & -0.17 & 1.14 \\
\hline JB04-5 & 4.86 & 3.64 & 1.22 & 95.11 & 0.03 & u & 2.24 & N/A & 1.04 & 0.49 & 2.25 & 0.21 & 2.19 & 0.22 & 0.93 & -0.37 & 1.75 \\
\hline
\end{tabular}


Jenness Beach (Summer Sampling), New Hampshire: Grain Size Distribution

\begin{tabular}{|c|c|c|c|c|c|c|c|c|c|c|c|c|c|c|c|c|c|c|c|c|c|}
\hline Sample ID & $\begin{array}{c}\text { Class \% } \\
\text { phi } \\
-5.5 \\
\end{array}$ & $\begin{array}{c}\text { Class \% } \\
\text { phi } \\
-5.0 \\
\end{array}$ & $\begin{array}{c}\text { Class \% } \\
\text { phi } \\
-4.5 \\
\end{array}$ & $\begin{array}{c}\text { Class \% } \\
\text { phi } \\
-4.0 \\
\end{array}$ & $\begin{array}{c}\text { Class \% } \\
\text { phi } \\
-3.5 \\
\end{array}$ & $\begin{array}{c}\text { Class \% } \\
\text { phi } \\
-3.0 \\
\end{array}$ & $\begin{array}{c}\text { Class \% } \\
\text { phi } \\
-2.5 \\
\end{array}$ & $\begin{array}{c}\text { Class \% } \\
\text { phi } \\
-2.0 \\
\end{array}$ & $\begin{array}{c}\text { Class \% } \\
\text { phi } \\
-1.5 \\
\end{array}$ & $\begin{array}{c}\text { Class \% } \\
\text { phi } \\
-1.0 \\
\end{array}$ & $\begin{array}{c}\text { Class \% } \\
\text { phi } \\
-0.5 \\
\end{array}$ & $\begin{array}{c}\text { Class \% } \\
\text { phi } \\
0.0 \\
\end{array}$ & $\begin{array}{c}\text { Class \% } \\
\text { phi } \\
0.5 \\
\end{array}$ & $\begin{array}{c}\text { Class \% } \\
\text { phi } \\
1.0 \\
\end{array}$ & $\begin{array}{c}\text { Class \% } \\
\text { phi } \\
1.5 \\
\end{array}$ & $\begin{array}{c}\text { Class \% } \\
\text { phi } \\
2.0 \\
\end{array}$ & $\begin{array}{c}\text { Class \% } \\
\text { phi } \\
2.5 \\
\end{array}$ & $\begin{array}{c}\text { Class \% } \\
\text { phi } \\
\mathbf{3 . 0} \\
\end{array}$ & $\begin{array}{c}\text { Class \% } \\
\text { phi } \\
3.5 \\
\end{array}$ & $\begin{array}{c}\text { Class \% } \\
\text { phi } \\
4.0 \\
\end{array}$ & $\begin{array}{c}\text { Class \% } \\
\text { phi } \\
>4.0 \\
\end{array}$ \\
\hline JB01-1 & 0.00 & 0.00 & 1.52 & 0.00 & 0.00 & 0.05 & 0.00 & 0.00 & 0.02 & 0.07 & 0.06 & 0.27 & 1.19 & 5.46 & 13.53 & 22.40 & 21.88 & 29.21 & 4.27 & 0.05 & 0.01 \\
\hline JB01-2 & 0.81 & 2.58 & 3.17 & 2.41 & 3.42 & 3.84 & 3.52 & 2.96 & 2.61 & 2.22 & 2.77 & 3.75 & 4.85 & 6.08 & 7.09 & 5.99 & 10.27 & 25.17 & 6.33 & 0.14 & 0.03 \\
\hline JB01-3 & 3.32 & 0.00 & 1.08 & 2.23 & 4.82 & 5.39 & 5.27 & 5.19 & 4.48 & 4.08 & 5.09 & 4.77 & 6.66 & 7.90 & 6.14 & 5.16 & 7.32 & 16.27 & 4.74 & 0.05 & 0.03 \\
\hline JB01-4 & 0.00 & 0.00 & 0.00 & 0.00 & 0.00 & 0.07 & 0.28 & 0.30 & 0.50 & 0.77 & 0.66 & 1.41 & 2.31 & 4.94 & 7.40 & 8.78 & 18.13 & 44.82 & 9.39 & 0.20 & 0.04 \\
\hline JB01-5 & 0.00 & 0.00 & 0.00 & 0.00 & 0.26 & 0.14 & 0.37 & 0.73 & 1.09 & 1.45 & 2.26 & 2.93 & 4.12 & 6.15 & 8.31 & 7.96 & 11.38 & 37.41 & 15.05 & 0.33 & 0.04 \\
\hline $\mathrm{JB} 02-1$ & 0.00 & 0.00 & 0.00 & 0.00 & 0.00 & 0.00 & 0.00 & 0.00 & 0.01 & 0.02 & 0.05 & 0.18 & 0.38 & 2.68 & 14.16 & 34.48 & 31.42 & 13.97 & 2.49 & 0.12 & 0.04 \\
\hline $\mathrm{JB} 02-2$ & 0.00 & 0.00 & 0.00 & 0.00 & 0.00 & 0.07 & 0.00 & 0.00 & 0.01 & 0.01 & 0.01 & 0.05 & 0.12 & 0.30 & 1.10 & 6.47 & 35.01 & 50.84 & 5.80 & 0.15 & 0.06 \\
\hline $\mathrm{JB} 02-3$ & 0.00 & 4.20 & 4.63 & 4.66 & 6.06 & 6.11 & 3.50 & 1.94 & 1.04 & 0.60 & 0.75 & 1.31 & 3.62 & 9.58 & 10.31 & 7.31 & 10.93 & 20.16 & 3.17 & 0.08 & 0.03 \\
\hline $\mathrm{JBO2}-4$ & 0.00 & 0.00 & 1.42 & 0.00 & 0.19 & 0.73 & 0.54 & 0.66 & 0.45 & 0.42 & 0.59 & 0.65 & 1.09 & 2.63 & 5.32 & 10.64 & 27.41 & 40.78 & 6.30 & 0.14 & 0.04 \\
\hline JB02-5 & 0.00 & 0.00 & 0.00 & 0.00 & 0.86 & 0.91 & 1.67 & 1.84 & 1.99 & 2.01 & 2.49 & 2.96 & 4.77 & 9.35 & 11.51 & 11.24 & 17.32 & 26.26 & 4.69 & 0.11 & 0.02 \\
\hline JB03-1 & 0.00 & 0.00 & 0.00 & 0.31 & 0.00 & 0.00 & 0.00 & 0.00 & 0.00 & 0.00 & 0.00 & 0.02 & 0.03 & 0.24 & 1.83 & 9.89 & 44.30 & 39.04 & 4.14 & 0.17 & 0.03 \\
\hline JB03-2 & 0.00 & 0.00 & 0.33 & 0.64 & 0.34 & 0.44 & 0.49 & 0.56 & 0.43 & 0.37 & 0.34 & 0.50 & 0.76 & 1.79 & 3.89 & 8.59 & 22.27 & 48.64 & 9.43 & 0.13 & 0.05 \\
\hline JB03-3 & 0.00 & 0.00 & 0.00 & 0.00 & 0.00 & 0.05 & 0.01 & 0.02 & 0.05 & 0.05 & 0.03 & 0.11 & 0.23 & 0.66 & 2.24 & 10.42 & 32.78 & 46.07 & 7.12 & 0.12 & 0.03 \\
\hline JB03-4 & 0.00 & 0.00 & 0.00 & 0.00 & 0.35 & 0.17 & 0.14 & 0.23 & 0.21 & 0.18 & 0.30 & 0.26 & 0.39 & 1.06 & 3.29 & 10.36 & 32.41 & 42.99 & 7.46 & 0.17 & 0.02 \\
\hline JB03-5 & 0.00 & 0.00 & 0.00 & 0.00 & 0.88 & 1.31 & 0.93 & 0.97 & 0.70 & 0.51 & 0.30 & 0.48 & 0.84 & 2.18 & 5.18 & 13.51 & 29.60 & 35.59 & 6.77 & 0.23 & 0.02 \\
\hline JB04-1 & 0.00 & 0.00 & 0.00 & 0.26 & 0.00 & 0.02 & 0.00 & 0.00 & 0.00 & 0.01 & 0.01 & 0.02 & 0.11 & 0.67 & 2.94 & 11.81 & 42.33 & 37.65 & 4.01 & 0.15 & 0.02 \\
\hline JB04-2 & 0.00 & 0.00 & 3.18 & 0.90 & 1.13 & 0.22 & 0.10 & 0.06 & 0.04 & 0.03 & 0.02 & 0.06 & 0.13 & 0.46 & 1.34 & 5.99 & 24.98 & 50.96 & 10.07 & 0.30 & 0.03 \\
\hline $\mathrm{JB} 04-3$ & 0.00 & 0.00 & 0.00 & 0.00 & 0.37 & 0.07 & 0.10 & 0.12 & 0.09 & 0.09 & 0.07 & 0.08 & 0.20 & 0.51 & 2.22 & 10.60 & 29.10 & 49.04 & 7.21 & 0.10 & 0.03 \\
\hline $\mathrm{JB} 04-4$ & 0.00 & 0.00 & 0.00 & 0.00 & 0.12 & 0.10 & 0.20 & 0.19 & 0.17 & 0.16 & 0.10 & 0.24 & 0.41 & 1.15 & 3.52 & 10.72 & 33.75 & 41.86 & 7.03 & 0.23 & 0.03 \\
\hline JB04-5 & 0.00 & 0.00 & 0.00 & 0.57 & 0.45 & 1.07 & 0.83 & 0.72 & 0.66 & 0.56 & 0.47 & 0.60 & 1.03 & 2.48 & 6.68 & 17.56 & 30.36 & 30.13 & 5.66 & 0.15 & 0.03 \\
\hline
\end{tabular}


Section 4(a): North Hampton Beach (Winter/Spring 2017 Sampling Period) 


\begin{tabular}{|c|c|c|c|c|c|c|c|c|c|c|c|c|c|}
\hline Sample ID & Global Sample ID & $\begin{array}{l}\text { Latitude } \\
\text { WGS84 } \\
\end{array}$ & $\begin{array}{c}\text { Longitude } \\
\text { WGS84 }\end{array}$ & $\begin{array}{l}\text { Relative } \\
\text { Position } \\
\text { Accuracy }\end{array}$ & $\begin{array}{c}\begin{array}{c}\text { Elevation } \\
(m)\end{array} \\
\text { NAVD88 }\end{array}$ & $\begin{array}{c}\text { Elevation } \\
(\mathrm{m}) \\
\text { MTL }\end{array}$ & $\begin{array}{c}\text { Relative } \\
\text { Elevation } \\
\end{array}$ & $\begin{array}{l}\text { Relative } \\
\text { Location } \\
\end{array}$ & $\begin{array}{l}\text { Sample } \\
\text { Collected }\end{array}$ & $\begin{array}{c}\text { Core } \\
\text { Length } \\
\text { (cm) }\end{array}$ & $\begin{array}{c}\text { Collected } \\
\text { Sample } \\
\text { Wt. (gm) }\end{array}$ & $\begin{array}{c}\text { Processed } \\
\text { Sample } \\
\text { Wt. (gm) }\end{array}$ & $\begin{array}{l}\text { Morphologic } \\
\text { Feature }\end{array}$ \\
\hline NHB01-1 & NHC D20170331_NHB01-1 & 42.955679 & -70.781161 & 1 & 2.16 & 2.29 & UTB & UB & 31-Mar-17 & 23 & $4,014.9$ & $4,009.1$ & $\begin{array}{c}\text { Sand at Base of C.- } \\
\text { B. Ramp } \\
\end{array}$ \\
\hline NHBO1-2 & NHC_D20170331_NHB01-2 & 42.955598 & -70.780998 & 1 & 0.91 & 1.03 & MTB & $\mathrm{MB}$ & 31-Mar-17 & 30 & $17,816.4$ & $17,829.4$ & LTT: Upper \\
\hline NHBO1-3 & NHC_D20170331_NHB01-3 & 42.955468 & -70.780733 & 1 & -0.33 & -0.20 & LTB & LB & 31-Mar-17 & 27 & $6,019.0$ & $6,014.7$ & LTT: Mid \\
\hline NHB01-4 & NHC_D20170331_NHB01-4 & 42.955353 & -70.780493 & 1 & -1.30 & -1.18 & LTB & $\mathrm{LB}$ & 31-Mar-17 & 27 & $4,441.5$ & $4,442.0$ & LTT: Swash \\
\hline NHB02-05 & NHC_D20170331_NHB02-05 & 42.952370 & -70.784663 & 2 & N/A & N/A & UTB & UB & 31-Mar-17 & 22 & $2,808.7$ & $2,816.3$ & Dune \\
\hline $\mathrm{NHBO2-1}$ & NHC D20170331 NHB02-1 & 42.952257 & -70.784540 & 1 & 2.76 & 2.88 & UTB & UB & 31-Mar-17 & 24 & $3,053.2$ & $3,047.3$ & $\begin{array}{l}\text { S.-G. Ramp: } \\
\text { Landward }\end{array}$ \\
\hline NHBO2-2 & NHC_D20170331_NHB02-2 & 42.952201 & -70.784457 & 1 & 2.50 & 2.62 & UTB & UB & 31-Mar-17 & 5 & $15,781.9$ & $15,795.7$ & S.-G. Ramp: Mid \\
\hline $\mathrm{NHBO2-3}$ & NHC_D20170331_NHB02-3 & 42.952169 & -70.784405 & 1 & 2.23 & 2.36 & UTB & UB & 31-Mar-17 & 30 & $7,439.5$ & $7,511.8$ & $\begin{array}{c}\text { S.-G. Ramp: } \\
\text { Seaward Edge }\end{array}$ \\
\hline $\mathrm{NHBO2-4}$ & NHC_D20170331_NHB02-4 & 42.952027 & -70.784186 & 1 & 0.54 & 0.67 & MTB & $\mathrm{MB}$ & 31-Mar-17 & 30 & $15,118.5$ & $15,119.6$ & LTT: Upper \\
\hline $\mathrm{NHBO2-5}$ & NHC_D20170331_NHB02-5 & 42.951873 & -70.783945 & 1 & -0.86 & -0.73 & LTB & $\mathrm{LB}$ & 31-Mar-17 & 22 & $6,938.2$ & $6,962.5$ & LTT: Mid \\
\hline NHBO2-6 & NHC_D20170331_NHB02-6 & 42.951731 & -70.783728 & 1 & -1.79 & -1.66 & LTB & $\mathrm{LB}$ & 31-Mar-17 & 28 & $6,519.3$ & $6,541.7$ & LTT: Swash \\
\hline NHBO3-1 & NHC_D20170330_NHB03-1 & 42.950556 & -70.785688 & 1 & 2.00 & 2.13 & UTB & UB & 30-Mar-17 & 30 & $21,663.2$ & $21,671.5$ & $\begin{array}{c}\text { S.-G. Ramp; Gravel } \\
\text { Cusp }\end{array}$ \\
\hline NHBO3-2 & NHC_D20170330_NHB03-2 & 42.950541 & -70.785614 & 1 & 1.70 & 1.83 & UTB & UB & 30-Mar-17 & 30 & $17,929.2$ & $17,991.6$ & $\begin{array}{c}\text { S.-G. Ramp; Base of } \\
\text { Cusp } \\
\end{array}$ \\
\hline $\mathrm{NHBO3-3}$ & NHC_D20170330_NHB03-3 & 42.950473 & -70.785252 & 1 & -0.84 & -0.71 & LTB & $\mathrm{MB}$ & 30-Mar-17 & 25 & $5,329.5$ & $5,344.2$ & $\begin{array}{c}\text { S. Ramp; Start of } \\
\mathrm{LT}\end{array}$ \\
\hline NHBO3-4 & NHC_D20170330_NHB03-4 & 42.950357 & -70.784633 & 1 & -1.87 & -1.74 & LTB & LB & 30-Mar-17 & 26 & $3,042.2$ & $3,044.3$ & LTT: Swash \\
\hline
\end{tabular}


North Hampton Beach (Winter Sampling), North Hampton, New Hampshire: Sediment Classifications

\begin{tabular}{|c|c|c|c|c|c|c|c|c|}
\hline Sample ID & $\begin{array}{l}\text { CMECS Substrate } \\
\text { Component } \\
\text { Group (Specific) }\end{array}$ & $\begin{array}{l}\text { CMECS Substrate } \\
\text { Component Subgroup } \\
\text { (Specific) }\end{array}$ & $\begin{array}{l}\text { Textural Group from } \\
\text { \%GSM (Gradistat) }\end{array}$ & $\begin{array}{l}\text { Sediment Name from } \\
\text { \%GSM } \\
\text { and Mode (Gradistat) }\end{array}$ & $\begin{array}{l}\text { Sediment Name from } \\
\text { \%GSM and Mode } \\
\text { (Wentworth Scale) }\end{array}$ & $\begin{array}{l}\text { Sediment Classification } \\
\text { from Mean Phi } \\
\text { (Gradistat) }\end{array}$ & $\begin{array}{l}\text { Sediment } \\
\text { Classification } \\
\text { from Mean Phi } \\
\text { (Wentworth) }\end{array}$ & Sorting (Gradistat) \\
\hline NHB01-1 & Pebbly & Pebbly Medium Sand & Gravelly Sand & $\begin{array}{l}\text { Medium Gravelly Medium } \\
\text { Sand }\end{array}$ & Pebbly Medium Sand & Medium Sand & Medium Sand & Poorly Sorted \\
\hline NHB01-2 & Pebble Mixes & Sandy Pebble Gravel & Sandy Gravel & Sandy Medium Gravel & Sandy Pebble Gravel & Very Fine Gravel & Granule Gravel & Very Poorly Sorted \\
\hline NHB01-3 & Pebbly & Pebbly Medium Sand & Gravelly Sand & $\begin{array}{l}\text { Medium Gravelly Medium } \\
\text { Sand }\end{array}$ & Pebbly Medium Sand & Coarse Sand & Coarse Sand & Very Poorly Sorted \\
\hline NHB01-4 & Pebbly & Pebbly Medium Sand & Gravelly Sand & Fine Gravelly Medium Sand & Pebbly Medium Sand & Medium Sand & Medium Sand & Poorly Sorted \\
\hline NHB02-05 & Medium Sand & Medium Sand & Sand & Medium Sand & Medium Sand & Medium Sand & Medium Sand & Moderately Well Sorted \\
\hline $\mathrm{NHBO2-1}$ & Slightly Granuley & $\begin{array}{l}\text { Slightly Granuley } \\
\text { Medium Sand }\end{array}$ & Slightly Gravelly Sand & $\begin{array}{l}\text { Slightly Very Fine Gravelly } \\
\text { Medium Sand }\end{array}$ & $\begin{array}{l}\text { Slightly Granular } \\
\text { Medium Sand }\end{array}$ & Medium Sand & Medium Sand & Moderately Well Sorted \\
\hline $\mathrm{NHBO2-2}$ & Gravel & Pebble Gravel & Gravel & Very Coarse Gravel & Pebble Gravel & Medium Gravel & Pebble Gravel & Very Poorly Sorted \\
\hline NHBO2-3 & Pebbly & Pebbly Medium Sand & Gravelly Sand & $\begin{array}{l}\text { Coarse Gravelly Medium } \\
\text { Sand }\end{array}$ & Pebbly Medium Sand & Very Coarse Sand & Very Coarse Sand & Very Poorly Sorted \\
\hline NHBO2-4 & Pebble Mixes & Sandy Pebble Gravel & Sandy Gravel & Sandy Medium Gravel & Sandy Pebble Gravel & Very Coarse Sand & Very Coarse Sand & Very Poorly Sorted \\
\hline NHBO2-5 & Pebble Mixes & Sandy Pebble Gravel & Sandy Gravel & Sandy Medium Gravel & Sandy Pebble Gravel & Very Fine Gravel & Granule Gravel & Very Poorly Sorted \\
\hline NHB02-6 & Pebbly & Pebbly Medium Sand & Gravelly Sand & $\begin{array}{l}\text { Very Coarse Gravelly } \\
\text { Medium Sand }\end{array}$ & Pebbly Medium Sand & Very Coarse Sand & Very Coarse Sand & Very Poorly Sorted \\
\hline NHB03-1 & Pebble Mixes & Sandy Pebble Gravel & Sandy Gravel & Sandy Medium Gravel & Sandy Pebble Gravel & Fine Gravel & Pebble Gravel & Very Poorly Sorted \\
\hline NHBO3-2 & Gravel & Pebble Gravel & Gravel & Coarse Gravel & Pebble Gravel & Medium Gravel & Pebble Gravel & Very Poorly Sorted \\
\hline NHBO3-3 & Granuley & $\begin{array}{l}\text { Granuley Medium Sand } \\
\text { Slightly Pebbly Medium }\end{array}$ & Gravelly Sand & $\begin{array}{l}\text { Very Fine Gravelly Medium } \\
\text { Sand } \\
\text { Slightly Coarse Gravelly }\end{array}$ & $\begin{array}{l}\text { Granular Medium Sand } \\
\text { Slightly Pebbly Medium }\end{array}$ & Coarse Sand & Coarse Sand & Poorly Sorted \\
\hline NHBO3-4 & Slightly Pebbly & Sand & Slightly Gravelly Sand & Medium Sand & Sand & Medium Sand & Medium Sand & Moderately Well Sorted \\
\hline
\end{tabular}


North Hampton Beach (Winter Sampling), North Hampton, New Hampshire: Grain Size Statistics

\begin{tabular}{|c|c|c|c|c|c|c|c|c|c|c|c|c|c|c|c|c|c|}
\hline Sample ID & Gravel \% & Pebble \% & Granule \% & Sand \% & Mud \% & Modes & $\begin{array}{c}\text { Mode } 1 \\
\text { (phi) }\end{array}$ & $\begin{array}{c}\text { Mode } 2 \\
\text { (phi) }\end{array}$ & $\begin{array}{c}D_{10} \\
\text { (phi) }\end{array}$ & $\begin{array}{c}D_{10} \\
(\mathrm{~mm})\end{array}$ & $\begin{array}{r}D_{50} \\
\text { (phi) }\end{array}$ & $\begin{array}{c}\begin{array}{c}D_{50} \\
(\mathrm{~mm})\end{array} \\
\end{array}$ & $\begin{array}{c}\begin{array}{c}\text { Mean Size } \\
\text { (phi) }\end{array} \\
\end{array}$ & $\begin{array}{c}\begin{array}{c}\text { Mean Size } \\
(\mathrm{mm})\end{array} \\
\end{array}$ & $\begin{array}{c}\text { Sorting } \\
\text { (phi) }\end{array}$ & Skewness & Kurtosis \\
\hline NHB01-1 & 7.17 & 6.54 & 0.63 & 92.82 & 0.01 & $u$ & 1.75 & $\mathrm{~N} / \mathrm{A}$ & 0.51 & 0.70 & 1.67 & 0.31 & 1.61 & 0.33 & 1.13 & -0.45 & 3.29 \\
\hline NHB01-2 & 48.68 & 41.12 & 7.55 & 51.31 & 0.01 & B & 1.75 & -3.74 & -4.93 & 30.57 & -0.80 & 1.74 & -1.08 & 2.12 & 2.74 & -0.16 & 0.61 \\
\hline NHB01-3 & 21.86 & 17.90 & 3.97 & 78.12 & 0.02 & U & 1.75 & $\mathrm{~N} / \mathrm{A}$ & -3.45 & 10.93 & 1.70 & 0.31 & 0.55 & 0.68 & 2.27 & -0.74 & 1.39 \\
\hline NHB01-4 & 12.61 & 8.71 & 3.89 & 87.34 & 0.05 & U & 1.75 & N/A & -1.70 & 3.26 & 1.79 & 0.29 & 1.37 & 0.39 & 1.42 & -0.61 & 2.53 \\
\hline NHB02-05 & 0.00 & 0.00 & 0.00 & 99.98 & 0.02 & $u$ & 1.75 & N/A & 0.63 & 0.65 & 1.46 & 0.36 & 1.43 & 0.37 & 0.61 & -0.03 & 0.99 \\
\hline NHBO2-1 & 0.14 & 0.03 & 0.11 & 99.84 & 0.02 & U & 1.25 & $\mathrm{~N} / \mathrm{A}$ & 0.55 & 0.68 & 1.26 & 0.42 & 1.26 & 0.42 & 0.59 & 0.02 & 1.04 \\
\hline NHBO2-2 & 84.17 & 83.40 & 0.78 & 15.82 & 0.01 & B & -5.23 & 0.75 & -5.75 & 53.64 & -4.84 & 28.64 & -3.88 & 14.77 & 2.17 & 0.68 & 2.12 \\
\hline NHBO2-3 & 29.33 & 28.84 & 0.48 & 70.66 & 0.01 & B & 1.75 & -4.73 & -5.23 & 37.43 & 1.50 & 0.35 & -0.43 & 1.35 & 2.91 & -0.82 & 0.57 \\
\hline NHBO2-4 & 43.59 & 40.05 & 3.54 & 56.40 & 0.01 & B & 1.75 & -3.74 & -4.87 & 29.15 & 0.53 & 0.69 & -0.68 & 1.60 & 2.70 & -0.58 & 0.60 \\
\hline NHBO2-5 & 51.69 & 42.32 & 9.37 & 48.29 & 0.02 & B & 1.75 & -5.23 & -5.02 & 32.37 & -1.19 & 2.29 & -1.27 & 2.42 & 2.65 & -0.07 & 0.66 \\
\hline NHBO2-6 & 27.05 & 20.02 & 7.03 & 72.94 & 0.01 & B & 1.75 & -5.73 & -4.67 & 25.45 & 0.53 & 0.69 & -0.17 & 1.13 & 2.37 & -0.50 & 1.12 \\
\hline NHBO3-1 & 71.15 & 63.72 & 7.43 & 28.84 & 0.01 & B & -3.74 & 1.75 & -4.89 & 29.70 & -3.19 & 9.10 & -2.23 & 4.69 & 2.46 & 0.45 & 0.79 \\
\hline NHBO3-2 & 82.60 & 71.25 & 11.35 & 17.39 & 0.01 & B & -4.73 & -2.24 & -5.31 & 39.75 & -3.67 & 12.75 & -3.20 & 9.22 & 2.13 & 0.41 & 0.92 \\
\hline NHBO3-3 & 19.49 & 10.57 & 8.93 & 80.50 & 0.01 & $u$ & 1.75 & N/A & -2.13 & 4.36 & 1.06 & 0.48 & 0.55 & 0.68 & 1.71 & -0.51 & 1.02 \\
\hline NHBO3-4 & 1.26 & 0.91 & 0.35 & 98.73 & 0.01 & U & 1.75 & $\mathrm{~N} / \mathrm{A}$ & 1.04 & 0.49 & 1.72 & 0.30 & 1.70 & 0.31 & 0.52 & -0.12 & 1.19 \\
\hline
\end{tabular}


North Hampton Beach (Winter Sampling), North Hampton, New Hampshire: Grain Size Distribution

\begin{tabular}{|c|c|c|c|c|c|c|c|c|c|c|c|c|c|c|c|c|c|c|c|c|c|}
\hline Sample ID & $\begin{array}{c}\text { Class \% } \\
\text { phi } \\
-5.5 \\
\end{array}$ & $\begin{array}{c}\text { Class \% } \\
\text { phi } \\
-5.0\end{array}$ & $\begin{array}{c}\text { Class \% } \\
\text { phi } \\
-4.5\end{array}$ & $\begin{array}{c}\text { Class \% } \\
\text { phi } \\
-4.0 \\
\end{array}$ & $\begin{array}{c}\text { Class \% } \\
\text { phi } \\
-3.5 \\
\end{array}$ & $\begin{array}{c}\text { Class \% } \\
\text { phi } \\
-3.0\end{array}$ & $\begin{array}{c}\text { Class \% } \\
\text { phi } \\
-2.5 \\
\end{array}$ & $\begin{array}{c}\text { Class \% } \\
\text { phi } \\
-2.0 \\
\end{array}$ & $\begin{array}{c}\text { Class \% } \\
\text { phi } \\
-1.5\end{array}$ & $\begin{array}{c}\text { Class \% } \\
\text { phi } \\
-1.0 \\
\end{array}$ & $\begin{array}{c}\text { Class \% } \\
\text { phi } \\
-0.5 \\
\end{array}$ & $\begin{array}{c}\text { Class \% } \\
\text { phi } \\
0.0 \\
\end{array}$ & $\begin{array}{c}\text { Class \% } \\
\text { phi } \\
0.5 \\
\end{array}$ & $\begin{array}{c}\text { Class \% } \\
\text { phi } \\
1.0 \\
\end{array}$ & $\begin{array}{c}\text { Class \% } \\
\text { phi } \\
1.5 \\
\end{array}$ & $\begin{array}{c}\text { Class \% } \\
\text { phi } \\
2.0 \\
\end{array}$ & $\begin{array}{c}\text { Class \% } \\
\text { phi } \\
2.5 \\
\end{array}$ & $\begin{array}{c}\text { Class \% } \\
\text { phi } \\
3.0 \\
\end{array}$ & $\begin{array}{c}\text { Class \% } \\
\text { phi } \\
3.5 \\
\end{array}$ & $\begin{array}{c}\text { Class \% } \\
\text { phi } \\
4.0 \\
\end{array}$ & $\begin{array}{c}\text { Class } \% \\
\text { phi } \\
>4.0 \\
\end{array}$ \\
\hline NHBO1-1 & 0.00 & 0.00 & 0.91 & 1.56 & 1.82 & 1.31 & 0.65 & 0.30 & 0.31 & 0.32 & 0.65 & 0.70 & 1.31 & 4.99 & 19.98 & 44.42 & 18.54 & 2.10 & 0.13 & 0.01 & 0.01 \\
\hline NHBO1-2 & 3.45 & 6.10 & 5.15 & 5.31 & 6.21 & 5.85 & 4.76 & 4.29 & 4.05 & 3.50 & 3.44 & 2.73 & 2.86 & 4.91 & 8.14 & 15.83 & 11.26 & 1.99 & 0.12 & 0.01 & 0.01 \\
\hline NHBO1-3 & 0.00 & 1.35 & 4.43 & 1.11 & 2.88 & 3.09 & 2.49 & 2.54 & 2.27 & 1.70 & 1.86 & 1.23 & 1.30 & 3.03 & 8.74 & 28.82 & 25.70 & 6.79 & 0.62 & 0.03 & 0.02 \\
\hline NHBO1-4 & 0.00 & 0.00 & 0.91 & 0.19 & 0.87 & 2.15 & 2.28 & 2.31 & 2.22 & 1.67 & 2.33 & 1.11 & 0.99 & 2.38 & 9.47 & 35.62 & 28.04 & 6.60 & 0.75 & 0.06 & 0.05 \\
\hline NHB02-05 & 0.00 & 0.00 & 0.00 & 0.00 & 0.00 & 0.00 & 0.00 & 0.00 & 0.00 & 0.00 & 0.07 & 0.67 & 4.64 & 17.28 & 29.51 & 30.77 & 12.67 & 4.20 & 0.16 & 0.01 & 0.02 \\
\hline NHBO2-1 & 0.00 & 0.00 & 0.00 & 0.00 & 0.00 & 0.00 & 0.02 & 0.01 & 0.05 & 0.06 & 0.27 & 1.19 & 5.64 & 23.52 & 37.23 & 23.25 & 6.88 & 1.83 & 0.05 & 0.01 & 0.02 \\
\hline $\mathrm{NHBO}_{2}-2$ & 20.92 & 23.59 & 19.67 & 11.82 & 4.83 & 1.58 & 0.60 & 0.38 & 0.35 & 0.42 & 0.83 & 1.41 & 2.46 & 4.59 & 4.31 & 1.84 & 0.32 & 0.05 & 0.01 & 0.00 & 0.01 \\
\hline NHBO2-3 & 7.65 & 4.54 & 10.19 & 2.13 & 2.11 & 1.23 & 0.67 & 0.34 & 0.25 & 0.24 & 0.26 & 0.52 & 1.23 & 4.42 & 13.63 & 35.51 & 13.44 & 1.59 & 0.05 & 0.01 & 0.01 \\
\hline NHBO2-4 & 5.40 & 3.33 & 5.54 & 6.16 & 6.79 & 6.11 & 3.90 & 2.80 & 2.09 & 1.45 & 1.43 & 1.63 & 2.82 & 7.49 & 14.98 & 20.54 & 6.72 & 0.74 & 0.04 & 0.01 & 0.01 \\
\hline NHBO2-5 & 3.88 & 6.63 & 3.08 & 6.02 & 6.46 & 6.22 & 5.10 & 4.93 & 5.12 & 4.25 & 4.56 & 3.73 & 4.20 & 7.35 & 8.68 & 11.48 & 6.52 & 1.65 & 0.11 & 0.02 & 0.02 \\
\hline NHBO2-6 & 5.79 & 2.73 & 2.36 & 1.69 & 1.24 & 1.78 & 1.99 & 2.44 & 3.27 & 3.77 & 6.12 & 7.87 & 8.27 & 9.58 & 12.27 & 18.54 & 8.66 & 1.50 & 0.10 & 0.01 & 0.01 \\
\hline NHBO3-1 & 4.47 & 4.32 & 7.04 & 13.64 & 15.13 & 8.77 & 5.55 & 4.80 & 4.19 & 3.24 & 3.31 & 2.68 & 2.74 & 4.33 & 6.24 & 7.11 & 2.21 & 0.19 & 0.02 & 0.01 & 0.01 \\
\hline NHBO3-2 & 4.48 & 15.87 & 15.72 & 9.15 & 7.51 & 5.28 & 5.97 & 7.29 & 6.52 & 4.83 & 4.03 & 1.92 & 1.49 & 2.02 & 2.76 & 3.54 & 1.41 & 0.17 & 0.02 & 0.01 & 0.01 \\
\hline NHBO3-3 & 0.00 & 3.32 & 0.42 & 0.67 & 0.68 & 1.45 & 1.83 & 2.20 & 3.92 & 5.01 & 7.20 & 6.94 & 6.26 & 8.48 & 13.73 & 24.77 & 11.68 & 1.37 & 0.05 & 0.01 & 0.01 \\
\hline $\mathrm{NHBO3}_{-4}$ & 0.00 & 0.00 & 0.68 & 0.00 & 0.00 & 0.07 & 0.03 & 0.13 & 0.20 & 0.15 & 0.27 & 0.31 & 0.93 & 5.66 & 20.86 & 46.20 & 20.89 & 3.44 & 0.15 & 0.01 & 0.01 \\
\hline
\end{tabular}


Section 4(b): North Hampton Beach (Summer/Fall 2017 Sampling Period) 
North Hampton Beach (Summer Sampling), North Hampton, New Hampshire: Identification, Location, and Description

\begin{tabular}{|c|c|c|c|c|c|c|c|c|c|c|c|c|c|}
\hline Sample ID & Global Sample ID & $\begin{array}{l}\text { Latitude } \\
\text { WGS84 } \\
\end{array}$ & $\begin{array}{c}\text { Longitude } \\
\text { WGS84 }\end{array}$ & $\begin{array}{l}\text { Relative } \\
\text { Position } \\
\text { Accuracy } \\
\end{array}$ & $\begin{array}{c}\begin{array}{c}\text { Elevation } \\
(m)\end{array} \\
\text { NAVD88 }\end{array}$ & $\begin{array}{c}\text { Elevation } \\
\text { (m) } \\
\text { MTL }\end{array}$ & $\begin{array}{l}\text { Relative } \\
\text { Elevation }\end{array}$ & $\begin{array}{l}\text { Relative } \\
\text { Location }\end{array}$ & $\begin{array}{l}\text { Sample } \\
\text { Collected }\end{array}$ & $\begin{array}{c}\text { Core } \\
\text { Length } \\
\text { (cm) }\end{array}$ & $\begin{array}{c}\text { Collected } \\
\text { Sample } \\
\text { Wt. (gm) }\end{array}$ & $\begin{array}{c}\text { Processed } \\
\text { Sample } \\
\text { Wt. (gm) }\end{array}$ & $\begin{array}{l}\text { Morphologic } \\
\text { Feature }\end{array}$ \\
\hline NHB01-2 & NHC D20170913 NHB01-2 & 42.955690 & -70.781211 & 1 & 2.61 & 2.73 & UTB & UB & 13-Sep-17 & 15 & $1,802.5$ & $1,795.0$ & $\begin{array}{c}\text { Berm; Sand Over } \\
\text { Cobble }\end{array}$ \\
\hline NHB01-3 & NHC_D20170913_NHB01-3 & 42.955632 & -70.781100 & 1 & 2.37 & 2.50 & UTB & UB & 13-Sep-17 & 28 & $2,449.3$ & $2,450.2$ & $\begin{array}{c}\text { Berm Crest; Last HT } \\
\text { Swash } \\
\end{array}$ \\
\hline NHB01-4 & NHC_D20170913_NHB01-4 & 42.955564 & -70.780964 & 1 & 1.29 & 1.42 & MTB & $\mathrm{MB}$ & 13-Sep-17 & 29 & $2,679.7$ & $2,665.3$ & Berm Face \\
\hline NHB01-5 & NHC_D20170913_NHB01-5 & 42.955461 & -70.780761 & 1 & -0.29 & -0.17 & LTB & $\mathrm{LB}$ & 13-Sep-17 & 28 & $8,358.8$ & $8,376.4$ & LTT: Mid \\
\hline NHB02-1 & NHC_D20170913_NHB02-1 & 42.952330 & -70.7843955 & 1 & 2.89 & 3.02 & UTB & UB & 13-Sep-17 & 9 & $1,169.1$ & $1,163.4$ & $\begin{array}{c}\text { Backshore: Edge of } \\
\text { C. Ramp }\end{array}$ \\
\hline NHBO2-2 & NHC D20170913 NHB02-2 & 42.952186 & -70.784171 & 1 & 2.42 & 2.55 & UTB & UB & 13-Sep-17 & 28 & $2,855.4$ & $2,877.4$ & Berm Crest \\
\hline NHBO2-3 & NHC_D20170913_NHB02-3 & 42.952073 & -70.784002 & 1 & 0.57 & 0.70 & MTB & MB & 13-Sep-17 & 26 & $4,652.9$ & $4,642.9$ & LTT: Landward \\
\hline NHBO2-4 & NHC_D20170913_NHB02-4 & 42.951860 & -70.783679 & 1 & -0.86 & -0.73 & LTB & $\mathrm{LB}$ & 13-Sep-17 & 27 & $5,956.2$ & $5,947.0$ & LTT: Swash \\
\hline NHB03-1 & NHC_D20170914_NHB03-1 & 42.950567 & -70.785743 & 1 & 2.65 & 2.78 & UTB & UB & 14-Sep-17 & 28 & $2,458.6$ & $2,461.8$ & Backshore \\
\hline NHBO3-2 & NHC_D20170914_NHB03-2 & 42.950550 & -70.785652 & 1 & 2.64 & 2.76 & UTB & UB & 14-Sep-17 & 29 & $2,514.4$ & $2,499.7$ & Berm Crest \\
\hline NHB03-3 & NHC_D20170914_NHB03-3 & 42.950511 & -70.785458 & 1 & 0.73 & 0.86 & MTB & $\mathrm{MB}$ & 14-Sep-17 & 26 & $2,985.7$ & $2,981.5$ & LTT:Mid \\
\hline NHBO3-4 & NHC_D20170914_NHB03-4 & 42.950436 & -70.785092 & 1 & -0.47 & -0.34 & LTB & LB & 14-Sep-17 & 28 & $4,405.8$ & $4,402.3$ & LTT: Swash \\
\hline
\end{tabular}


North Hampton Beach (Summer Sampling), North Hampton, New Hampshire: Sediment Classifications

\begin{tabular}{|c|c|c|c|c|c|c|c|c|}
\hline Sample ID & $\begin{array}{l}\text { CMECS Substrate } \\
\text { Component } \\
\text { Group (Specific) } \\
\end{array}$ & $\begin{array}{l}\text { CMECS Substrate } \\
\text { Component Subgroup } \\
\text { (Specific) }\end{array}$ & $\begin{array}{l}\text { Textural Group from } \\
\text { \%GSM (Gradistat) }\end{array}$ & $\begin{array}{l}\text { Sediment Name from } \\
\% \text { GSM } \\
\text { and Mode (Gradistat) }\end{array}$ & $\begin{array}{l}\text { Sediment Name from } \\
\text { \%GSM and Mode } \\
\text { (Wentworth Scale) }\end{array}$ & $\begin{array}{l}\text { Sediment Classification } \\
\text { from Mean Phi } \\
\text { (Gradistat) }\end{array}$ & $\begin{array}{l}\text { Sediment } \\
\text { Classification } \\
\text { from Mean Phi } \\
\text { (Wentworth) }\end{array}$ & Sorting (Gradistat) \\
\hline NHB01-2 & Medium Sand & Medium Sand & Sand & Medium Sand & Medium Sand & Medium Sand & Medium Sand & Well Sorted \\
\hline NHB01-3 & Slightly Granuley & $\begin{array}{l}\text { Slightly Granuley } \\
\text { Medium Sand }\end{array}$ & Slightly Gravelly Sand & $\begin{array}{l}\text { Slightly Very Fine Gravelly } \\
\text { Medium Sand }\end{array}$ & $\begin{array}{l}\text { Slightly Granular } \\
\text { Medium Sand }\end{array}$ & Medium Sand & Medium Sand & Well Sorted \\
\hline NHB01-4 & Slightly Granuley & $\begin{array}{l}\text { Slightly Granuley } \\
\text { Medium Sand }\end{array}$ & Slightly Gravelly Sand & $\begin{array}{l}\text { Slightly Very Fine Gravelly } \\
\text { Medium Sand }\end{array}$ & $\begin{array}{l}\text { Slightly Granular } \\
\text { Medium Sand }\end{array}$ & Medium Sand & Medium Sand & Moderately Well Sorted \\
\hline NHB01-5 & Pebble Mixes & Sandy Pebble Gravel & Sandy Gravel & Sandy Medium Gravel & Sandy Pebble Gravel & Very Fine Gravel & Granule Gravel & Very Poorly Sorted \\
\hline NHBO2-1 & Pebbly & Pebbly Medium Sand & Gravelly Sand & $\begin{array}{l}\text { Coarse Gravelly Medium } \\
\text { Sand }\end{array}$ & Pebbly Medium Sand & Coarse Sand & Coarse Sand & Poorly Sorted \\
\hline NHBO2-2 & Sand & Medium Sand & Sand & Well Sorted Medium Sand & Medium Sand & Medium Sand & Medium Sand & Well Sorted \\
\hline NHBO2-3 & Pebbly & Pebbly Medium Sand & Gravelly Sand & $\begin{array}{l}\text { Coarse Gravelly Medium } \\
\text { Sand }\end{array}$ & Pebbly Medium Sand & Medium Sand & Medium Sand & Poorly Sorted \\
\hline $\mathrm{NHBO2-4}$ & Pebbly & Pebbly Medium Sand & Gravelly Sand & $\begin{array}{l}\text { Medium Gravelly Medium } \\
\text { Sand }\end{array}$ & Pebbly Medium Sand & Medium Sand & Medium Sand & Poorly Sorted \\
\hline NHBO3-1 & Slightly Granuley & $\begin{array}{l}\text { Slightly Granuley } \\
\text { Medium Sand }\end{array}$ & Slightly Gravelly Sand & $\begin{array}{l}\text { Slightly Very Fine Gravelly } \\
\text { Medium Sand }\end{array}$ & $\begin{array}{l}\text { Slightly Granular } \\
\text { Medium Sand }\end{array}$ & Medium Sand & Medium Sand & Moderately Well Sorted \\
\hline NHBO3-2 & Slightly Granuley & $\begin{array}{l}\text { Slightly Granuley } \\
\text { Medium Sand }\end{array}$ & Slightly Gravelly Sand & $\begin{array}{l}\text { Slightly Very Fine Gravelly } \\
\text { Medium Sand }\end{array}$ & $\begin{array}{l}\text { Slightly Granular } \\
\text { Medium Sand }\end{array}$ & Medium Sand & Medium Sand & Well Sorted \\
\hline NHBO3-3 & Pebbly & Pebbly Medium Sand & Gravelly Sand & $\begin{array}{l}\text { Coarse Gravelly Medium } \\
\text { Sand }\end{array}$ & Pebbly Medium Sand & Medium Sand & Medium Sand & Poorly Sorted \\
\hline NHB03-4 & Pebbly & Pebbly Medium Sand & Gravelly Sand & $\begin{array}{l}\text { Coarse Gravelly Medium } \\
\text { Sand }\end{array}$ & Pebbly Medium Sand & Coarse Sand & Coarse Sand & Poorly Sorted \\
\hline
\end{tabular}


North Hampton Beach (Summer Sampling), North Hampton, New Hampshire: Grain Size Statistics

\begin{tabular}{|c|c|c|c|c|c|c|c|c|c|c|c|c|c|c|c|c|c|}
\hline Sample ID & Gravel \% & Pebble \% & Granule \% & Sand $\%$ & Mud \% & Modes & $\begin{array}{c}\text { Mode } 1 \\
\text { (phi) }\end{array}$ & $\begin{array}{c}\text { Mode } 2 \\
\text { (phi) }\end{array}$ & $\begin{array}{c}\mathrm{D}_{10} \\
\text { (phi) }\end{array}$ & $\begin{array}{c}\mathrm{D}_{10} \\
(\mathrm{~mm}) \\
\end{array}$ & $\begin{array}{r}D_{50} \\
\text { (phi) }\end{array}$ & $\begin{array}{r}D_{50} \\
(\mathrm{~mm}) \\
\end{array}$ & $\begin{array}{c}\text { Mean Size } \\
\text { (phi) }\end{array}$ & $\begin{array}{c}\text { Mean Size } \\
(\mathrm{mm})\end{array}$ & $\begin{array}{c}\text { Sorting } \\
\text { (phi) }\end{array}$ & Skewness & Kurtosis \\
\hline NHBO1-2 & 0.00 & 0.00 & 0.00 & 99.98 & 0.02 & U & 1.75 & N/A & 1.39 & 0.38 & 1.92 & 0.26 & 1.94 & 0.26 & 0.45 & 0.06 & 1.04 \\
\hline NHBO1-3 & 0.20 & 0.09 & 0.11 & 99.78 & 0.02 & U & 1.75 & N/A & 1.20 & 0.44 & 1.85 & 0.28 & 1.87 & 0.27 & 0.47 & 0.00 & 1.08 \\
\hline NHBO1-4 & 1.33 & 0.76 & 0.57 & 98.66 & 0.01 & u & 1.75 & N/A & 0.95 & 0.52 & 1.79 & 0.29 & 1.76 & 0.30 & 0.61 & -0.15 & 1.17 \\
\hline NHB01-5 & 60.22 & 52.69 & 7.54 & 39.75 & 0.03 & B & 1.75 & -3.24 & -4.76 & 27.19 & -2.23 & 4.70 & -1.51 & 2.86 & 2.78 & 0.28 & 0.60 \\
\hline NHBO2-1 & 11.00 & 10.74 & 0.26 & 88.98 & 0.02 & B & 1.25 & -4.73 & -4.50 & 22.61 & 1.00 & 0.50 & 0.92 & 0.53 & 1.42 & -0.42 & 3.03 \\
\hline NHBO2-2 & 0.00 & 0.00 & 0.00 & 99.98 & 0.02 & U & 1.75 & N/A & 1.26 & 0.42 & 1.82 & 0.28 & 1.86 & 0.28 & 0.44 & 0.07 & 1.08 \\
\hline NHBO2-3 & 11.27 & 9.24 & 2.03 & 88.71 & 0.02 & $U$ & 1.75 & N/A & -1.62 & 3.08 & 1.75 & 0.30 & 1.56 & 0.34 & 1.47 & -0.52 & 2.95 \\
\hline NHBO2-4 & 8.90 & 6.75 & 2.15 & 91.09 & 0.01 & U & 1.75 & $\mathrm{~N} / \mathrm{A}$ & -0.48 & 1.40 & 1.62 & 0.32 & 1.46 & 0.36 & 1.27 & -0.46 & 2.29 \\
\hline NHBO3-1 & 0.32 & 0.01 & 0.31 & 99.67 & 0.01 & U & 1.25 & N/A & 0.43 & 0.74 & 1.32 & 0.40 & 1.28 & 0.41 & 0.65 & -0.11 & 0.99 \\
\hline $\mathrm{NHBO3-2}$ & 0.02 & 0.00 & 0.02 & 99.97 & 0.01 & U & 1.75 & N/A & 1.02 & 0.49 & 1.68 & 0.31 & 1.65 & 0.32 & 0.50 & -0.12 & 1.14 \\
\hline NHBO3-3 & 9.49 & 9.24 & 0.24 & 90.49 & 0.02 & $u$ & 2.24 & N/A & 0.50 & 0.71 & 1.90 & 0.27 & 1.81 & 0.28 & 1.41 & -0.49 & 4.15 \\
\hline NHBO3-4 & 15.48 & 12.16 & 3.32 & 84.51 & 0.01 & U & 1.75 & N/A & -2.66 & 6.33 & 1.54 & 0.34 & 0.93 & 0.53 & 1.75 & -0.68 & 1.93 \\
\hline
\end{tabular}




\begin{tabular}{|c|c|c|c|c|c|c|c|c|c|c|c|c|c|c|c|c|c|c|c|c|c|}
\hline Sample ID & $\begin{array}{c}\text { Class \% } \\
\text { phi } \\
-5.5 \\
\end{array}$ & $\begin{array}{c}\text { Class \% } \\
\text { phi } \\
-5.0\end{array}$ & $\begin{array}{c}\text { Class \% } \\
\text { phi } \\
-4.5\end{array}$ & $\begin{array}{c}\text { Class \% } \\
\text { phi } \\
-4.0 \\
\end{array}$ & $\begin{array}{c}\text { Class \% } \\
\text { phi } \\
-3.5 \\
\end{array}$ & $\begin{array}{c}\text { Class \% } \\
\text { phi } \\
-3.0\end{array}$ & $\begin{array}{c}\text { Class \% } \\
\text { phi } \\
-2.5 \\
\end{array}$ & $\begin{array}{c}\text { Class \% } \\
\text { phi } \\
-2.0 \\
\end{array}$ & $\begin{array}{c}\text { Class \% } \\
\text { phi } \\
-1.5\end{array}$ & $\begin{array}{c}\text { Class \% } \\
\text { phi } \\
-1.0 \\
\end{array}$ & $\begin{array}{c}\text { Class \% } \\
\text { phi } \\
-0.5 \\
\end{array}$ & $\begin{array}{c}\text { Class \% } \\
\text { phi } \\
0.0\end{array}$ & $\begin{array}{c}\text { Class \% } \\
\text { phi } \\
0.5 \\
\end{array}$ & $\begin{array}{c}\text { Class \% } \\
\text { phi } \\
1.0 \\
\end{array}$ & $\begin{array}{c}\text { Class \% } \\
\text { phi } \\
1.5 \\
\end{array}$ & $\begin{array}{c}\text { Class \% } \\
\text { phi } \\
2.0 \\
\end{array}$ & $\begin{array}{c}\text { Class \% } \\
\text { phi } \\
2.5 \\
\end{array}$ & $\begin{array}{c}\text { Class \% } \\
\text { phi } \\
3.0 \\
\end{array}$ & $\begin{array}{c}\text { Class \% } \\
\text { phi } \\
3.5 \\
\end{array}$ & $\begin{array}{c}\text { Class \% } \\
\text { phi } \\
4.0 \\
\end{array}$ & $\begin{array}{c}\text { Class } \% \\
\text { phi } \\
>4.0 \\
\end{array}$ \\
\hline NHBO1-2 & 0.00 & 0.00 & 0.00 & 0.00 & 0.00 & 0.00 & 0.00 & 0.00 & 0.00 & 0.00 & 0.00 & 0.00 & 0.07 & 1.33 & 10.98 & 44.61 & 34.01 & 8.32 & 0.64 & 0.02 & 0.02 \\
\hline NHB01-3 & 0.00 & 0.00 & 0.00 & 0.00 & 0.00 & 0.05 & 0.02 & 0.02 & 0.04 & 0.07 & 0.23 & 0.41 & 0.82 & 3.02 & 13.37 & 45.04 & 29.94 & 6.48 & 0.46 & 0.02 & 0.02 \\
\hline NHBO1-4 & 0.00 & 0.00 & 0.00 & 0.00 & 0.14 & 0.19 & 0.21 & 0.22 & 0.26 & 0.32 & 0.28 & 0.98 & 1.91 & 6.13 & 16.55 & 38.45 & 27.38 & 6.48 & 0.48 & 0.02 & 0.01 \\
\hline NHB01-5 & 4.15 & 3.33 & 5.83 & 6.99 & 10.00 & 9.66 & 7.14 & 5.59 & 4.23 & 3.31 & 2.70 & 1.62 & 1.22 & 1.72 & 4.01 & 12.76 & 9.63 & 4.93 & 1.10 & 0.06 & 0.03 \\
\hline NHBO2-1 & 0.00 & 0.00 & 10.29 & 0.00 & 0.32 & 0.00 & 0.02 & 0.12 & 0.09 & 0.17 & 0.55 & 2.55 & 9.58 & 26.17 & 28.52 & 16.32 & 4.19 & 0.98 & 0.11 & 0.02 & 0.02 \\
\hline NHBO2-2 & 0.00 & 0.00 & 0.00 & 0.00 & 0.00 & 0.00 & 0.00 & 0.00 & 0.00 & 0.00 & 0.00 & 0.00 & 0.11 & 1.72 & 15.46 & 50.14 & 26.31 & 5.69 & 0.54 & 0.01 & 0.02 \\
\hline $\mathrm{NHBO}_{2}-3$ & 0.00 & 1.50 & 2.76 & 0.84 & 0.89 & 1.04 & 1.05 & 1.15 & 1.04 & 0.99 & 1.12 & 0.99 & 1.71 & 4.57 & 12.41 & 35.09 & 23.30 & 8.67 & 0.83 & 0.02 & 0.02 \\
\hline $\mathrm{NHBO}_{2}-4$ & 0.00 & 0.00 & 1.01 & 1.23 & 1.08 & 1.47 & 0.96 & 0.99 & 1.08 & 1.07 & 1.08 & 1.82 & 3.87 & 8.87 & 16.96 & 33.48 & 18.11 & 6.32 & 0.55 & 0.02 & 0.01 \\
\hline NHBO3-1 & 0.00 & 0.00 & 0.00 & 0.00 & 0.00 & 0.00 & 0.00 & 0.01 & 0.09 & 0.22 & 0.83 & 2.20 & 7.56 & 19.87 & 29.43 & 29.69 & 8.98 & 1.04 & 0.06 & 0.01 & 0.01 \\
\hline NHBO3-2 & 0.00 & 0.00 & 0.00 & 0.00 & 0.00 & 0.00 & 0.00 & 0.00 & 0.01 & 0.01 & 0.01 & 0.14 & 1.23 & 7.57 & 23.32 & 47.84 & 16.68 & 2.96 & 0.22 & 0.00 & 0.01 \\
\hline NHBO3-3 & 0.00 & 1.64 & 4.23 & 1.45 & 0.45 & 0.69 & 0.56 & 0.23 & 0.14 & 0.10 & 0.09 & 0.07 & 0.30 & 2.70 & 9.92 & 34.33 & 34.28 & 8.38 & 0.42 & 0.01 & 0.02 \\
\hline NHBO3-4 & 0.00 & 1.44 & 1.37 & 3.40 & 0.96 & 1.77 & 1.61 & 1.61 & 1.68 & 1.64 & 2.14 & 2.52 & 4.40 & 7.92 & 14.17 & 33.48 & 16.30 & 3.35 & 0.22 & 0.01 & 0.01 \\
\hline
\end{tabular}


Section 5(a): North Beach (Winter/Spring 2017 Sampling Period) 
North Beach (Winter Sampling), Hampton, New Hampshire: Identification, Location, and Description

\begin{tabular}{|c|c|c|c|c|c|c|c|c|c|c|c|c|c|}
\hline Sample ID & Global Sample ID & $\begin{array}{l}\text { Latitude } \\
\text { WGS84 }\end{array}$ & $\begin{array}{c}\text { Longitude } \\
\text { WGS84 }\end{array}$ & $\begin{array}{l}\text { Relative } \\
\text { Position } \\
\text { Accuracy }\end{array}$ & $\begin{array}{c}\text { Elevation } \\
(m) \\
\text { NAVD88 }\end{array}$ & $\begin{array}{c}\text { Elevation } \\
\text { (m) } \\
\text { MTL }\end{array}$ & $\begin{array}{l}\text { Relative } \\
\text { Elevation }\end{array}$ & $\begin{array}{l}\text { Relative } \\
\text { Location }\end{array}$ & $\begin{array}{c}\text { Sample } \\
\text { Collected }\end{array}$ & $\begin{array}{l}\text { Core } \\
\text { Length } \\
\text { (cm) }\end{array}$ & $\begin{array}{l}\text { Collected } \\
\text { Sample } \\
\text { Wt. (gm) }\end{array}$ & $\begin{array}{c}\text { Processed } \\
\text { Sample } \\
\text { Wt. }(\mathrm{gm})\end{array}$ & $\begin{array}{l}\text { Morphologic } \\
\text { Feature }\end{array}$ \\
\hline NB01-1A & NHC D20170424 NB01-1A & 42.939459 & -70.794499 & 1 & 1.01 & 1.14 & MTB & UB & 24-Apr-17 & 28 & $3,101.7$ & $3,117.1$ & S. Ramp \\
\hline NB01-1B Top & NHC D20170424 NB01-1B Top & 42.939519 & -70.794515 & 1 & 1.32 & 1.45 & MTB & UB & 24-Apr-17 & Est. 20 & $6,823.0$ & $6,872.0$ & Top of G. Cusp \\
\hline NB01-1B_Bottom & NHC_D20170424_NB01-1B_Bottom & 42.939519 & -70.794515 & 1 & 1.32 & 1.45 & MTB & UB & 24-Apr-17 & Est. 20 & $7,342.4$ & $7,359.3$ & Bottom of G. Cusp \\
\hline NBO1-2 & NHC_D20170424_NB01-2 & 42.939402 & -70.794269 & 1 & -0.08 & 0.05 & MTB & $\mathrm{MB}$ & 24-Apr-17 & 30 & $12,021.1$ & $12,137.8$ & $\begin{array}{c}\text { S. Ramp Base -LTT } \\
\text { Bound. }\end{array}$ \\
\hline NB01-3 & NHC_D20170424_NB01-3 & 42.939279 & -70.793785 & 1 & -1.30 & -1.18 & LTB & $\mathrm{LB}$ & 24-Apr-17 & 27 & $2,741.6$ & $2,747.7$ & LTT: Lower \\
\hline NBO2-1 & NHC D20170411 NB02-1 & 42.934344 & -70.796565 & 1 & 0.42 & 0.55 & MTB & UB & 11-Apr-17 & 15 & $18,666.5$ & $18,688.9$ & S.-P. Ramp \\
\hline NBO2-2 & NHC_D20170411_NB02-2 & 42.934309 & -70.796354 & 1 & -0.77 & -0.64 & LTB & $\mathrm{MB}$ & 11-Apr-17 & 22 & $15,564.3$ & $15,609.2$ & $\begin{array}{l}\text { S. Ramp - LTT } \\
\text { Boundary }\end{array}$ \\
\hline NBO2-3 & NHC D20170411_NB02-3 & 42.934273 & -70.796137 & 1 & -1.09 & -0.96 & LTB & $\mathrm{MB}$ & 11-Apr-17 & 27 & $3,367.6$ & $3,373.9$ & LT: Upper; Ridge \\
\hline NBO2-4 & NHC_D20170411_NB02-4 & 42.934233 & -70.795881 & 1 & -1.15 & -1.02 & LTB & LB & 11-Apr-17 & 27 & $2,382.5$ & $2,381.6$ & LTT: Upper \\
\hline NB03-1 & NHC_D20170411_NB03-1 & 42.928573 & -70.798077 & 1 & 0.30 & 0.43 & MTB & UB & 11-Apr-17 & 28 & $17,157.1$ & $17,250.6$ & S. Ramp: Upper \\
\hline NBO3-2 & NHC_D20170411_NB03-2 & 42.928563 & -70.797962 & 1 & -0.75 & -0.62 & LTB & UB & 11-Apr-17 & 20 & $11,148.0$ & $11,178.0$ & $\begin{array}{l}\text { S. Ramp: Lower; } \\
\text { Bound. to Runnel }\end{array}$ \\
\hline NBO3-3 & NHC D20170411 NB03-3 & 42.928552 & -70.797833 & 1 & -1.08 & -0.95 & LTB & UB & 11-Apr-17 & 25 & $4,386.8$ & $4,398.7$ & LTT: Upper; Ridge \\
\hline NBO3-4 & NHC_D20170411_NB03-4 & 42.928531 & -70.797600 & 1 & -0.99 & -0.86 & LTB & $\mathrm{MB}$ & 11-Apr-17 & 27 & $2,790.6$ & $2,792.7$ & LTT: Mid; Ridge \\
\hline NBO3-5 & NHC_D20170411_NB03-5 & 42.928511 & -70.797369 & 1 & -1.36 & -1.23 & LTB & LB & 11-Apr-17 & 28 & $2,837.2$ & $2,840.9$ & LTT: Swash \\
\hline NB04-1 & NHC_D20170424_NB04-1 & 42.925031 & -70.798758 & 1 & 1.93 & 2.06 & MTB & UB & 24-Apr-17 & 10 & $15,447.7$ & $15,446.3$ & G. Ramp \\
\hline NBO4-2 & NHC_D20170424_NB04-2 & 42.925034 & -70.798595 & 1 & 0.60 & 0.73 & MTB & $\mathrm{MB}$ & 24-Apr-17 & 9 & $19,054.1$ & $19,065.9$ & S.-P. Ramp: Lower \\
\hline NBO4-3 & NHC_D20170424_NB04-3 & 42.925042 & -70.798099 & 1 & -0.48 & -0.35 & LTB & LB & 24-Apr-17 & 28 & $10,405.3$ & $10,409.4$ & LTT:Mid \\
\hline NBO4-4 & NHC D20170424 NB04-4 & 42.925048 & -70.797708 & 1 & -1.17 & -1.03 & LTB & LB & 24-Apr-17 & 27 & $5,595.4$ & $5,587.6$ & LTT: Swash \\
\hline
\end{tabular}


North Beach (Winter Sampling), Hampton, New Hampshire: Sediment Classifications

\begin{tabular}{|c|c|c|c|c|c|c|c|c|}
\hline Sample ID & $\begin{array}{l}\text { CMECS Substrate } \\
\text { Component } \\
\text { Group (Specific) }\end{array}$ & $\begin{array}{l}\text { CMECS Substrate } \\
\text { Component Subgroup } \\
\text { (Specific) }\end{array}$ & $\begin{array}{l}\text { Textural Group from } \\
\text { \%GSM (Gradistat) }\end{array}$ & $\begin{array}{l}\text { Sediment Name from } \\
\text { \%GSM } \\
\text { and Mode (Gradistat) }\end{array}$ & $\begin{array}{l}\text { Sediment Name from } \\
\text { \%GSM and Mode } \\
\text { (Wentworth Scale) }\end{array}$ & $\begin{array}{l}\text { Sediment Classification } \\
\text { from Mean Phi } \\
\text { (Gradistat) }\end{array}$ & $\begin{array}{l}\text { Sediment } \\
\text { Classification } \\
\text { from Mean Phi } \\
\text { (Wentworth) }\end{array}$ & Sorting (Gradistat) \\
\hline NB01-1A & Granuley & Granuley Coarse Sand & Gravelly Sand & $\begin{array}{l}\text { Very Fine Gravelly Coarse } \\
\text { Sand }\end{array}$ & Granular Coarse Sand & Coarse Sand & Coarse Sand & Poorly Sorted \\
\hline NB01-1B_Top & Gravel & Pebble Gravel & Gravel & Fine Gravel & Pebble Gravel & Fine Gravel & Pebble Gravel & Moderately Sorted \\
\hline NB01-1B_Bottom & Gravel & Pebble Gravel & Gravel & Fine Gravel & Pebble Gravel & Fine Gravel & Pebble Gravel & Moderately Well Sorted \\
\hline NB01-2 & Granule Mixes & Sandy Granule Gravel & Sandy Gravel & Sandy Very Fine Gravel & Sandy Granule Gravel & Very Coarse Sand & Very Coarse Sand & Very Poorly Sorted \\
\hline NBO1-3 & Granuley & Granuley Fine Sand & Gravelly Sand & $\begin{array}{l}\text { Very Fine Gravelly Fine } \\
\text { Sand }\end{array}$ & Granular Fine Sand & Medium Sand & Medium Sand & Poorly Sorted \\
\hline NBO2-1 & Pebble Mixes & Sandy Pebble Gravel & Sandy Gravel & Sandy Coarse Gravel & Sandy Pebble Gravel & Fine Gravel & Pebble Gravel & Very Poorly Sorted \\
\hline NBO2-2 & Pebbly & Pebbly Fine Sand & Gravelly Sand & Medium Gravelly Fine Sand & Pebbly Fine Sand & Coarse Sand & Coarse Sand & Very Poorly Sorted \\
\hline NBO2-3 & Slightly Granuley & $\begin{array}{l}\text { Slightly Granuley Fine } \\
\text { Sand }\end{array}$ & Slightly Gravelly Sand & $\begin{array}{l}\text { Slightly Very Fine Gravelly } \\
\text { Fine Sand }\end{array}$ & $\begin{array}{l}\text { Slightly Granular Fine } \\
\text { Sand }\end{array}$ & Medium Sand & Medium Sand & Moderately Sorted \\
\hline NBO2-4 & Granuley & Granuley Fine Sand & Gravelly Sand & $\begin{array}{l}\text { Very Fine Gravelly Fine } \\
\text { Sand }\end{array}$ & Granular Fine Sand & Medium Sand & Medium Sand & Moderately Sorted \\
\hline NB03-1 & Granule Mixes & Sandy Granule Gravel & Sandy Gravel & Sandy Very Fine Gravel & Sandy Granule Gravel & Very Fine Gravel & Granule Gravel & Very Poorly Sorted \\
\hline NBO3-2 & Gravel & Pebble Gravel & Gravel & Fine Gravel & Pebble Gravel & Fine Gravel & Pebble Gravel & Poorly Sorted \\
\hline NBO3-3 & Granuley & Granuley Fine Sand & Gravelly Sand & $\begin{array}{l}\text { Very Fine Gravelly Fine } \\
\text { Sand }\end{array}$ & Granular Fine Sand & Medium Sand & Medium Sand & Poorly Sorted \\
\hline NBO3-4 & Pebbly & Pebbly Fine Sand & Gravelly Sand & Fine Gravelly Fine Sand & Pebbly Fine Sand & Fine Sand & Fine Sand & Moderately Sorted \\
\hline NBO3-5 & Pebbly & Pebbly Fine Sand & Gravelly Sand & Coarse Gravelly Fine Sand & Pebbly Fine Sand & Medium Sand & Medium Sand & Poorly Sorted \\
\hline NBO4-1 & Gravel & Pebble Gravel & Gravel & Coarse Gravel & Pebble Gravel & Coarse Gravel & Pebble Gravel & Well Sorted \\
\hline NBO4-2 & Pebble Mixes & Sandy Pebble Gravel & Sandy Gravel & Sandy Medium Gravel & Sandy Pebble Gravel & Very Fine Gravel & Granule Gravel & Very Poorly Sorted \\
\hline NBO4-3 & Pebbly & Pebbly Fine Sand & Gravelly Sand & Medium Gravelly Fine Sand & Pebbly Fine Sand & Coarse Sand & Coarse Sand & Very Poorly Sorted \\
\hline NBO4-4 & Pebbly & Pebbly Fine Sand & Gravelly Sand & Medium Gravelly Fine Sand & Pebbly Fine Sand & Medium Sand & Medium Sand & Poorly Sorted \\
\hline
\end{tabular}




\begin{tabular}{|c|c|c|c|c|c|c|c|c|c|c|c|c|c|c|c|c|c|}
\hline Sample ID & Gravel \% & Pebble \% & Granule \% & Sand $\%$ & Mud \% & Modes & $\begin{array}{c}\text { Mode } 1 \\
\text { (phi) }\end{array}$ & $\begin{array}{c}\text { Mode } 2 \\
\text { (phi) }\end{array}$ & $\begin{array}{r}\mathrm{D}_{10} \\
\text { (phi) }\end{array}$ & $\begin{array}{r}D_{10} \\
(\mathrm{~mm}) \\
\end{array}$ & $\begin{array}{r}\mathrm{D}_{50} \\
\text { (phi) }\end{array}$ & $\begin{array}{r}D_{50} \\
(\mathrm{~mm}) \\
\end{array}$ & $\begin{array}{c}\text { Mean Size } \\
\text { (phi) }\end{array}$ & $\begin{array}{c}\text { Mean Size } \\
(\mathrm{mm})\end{array}$ & $\begin{array}{c}\text { Sorting } \\
\text { (phi) }\end{array}$ & Skewness & Kurtosis \\
\hline NB01-1A & 12.65 & 6.66 & 5.99 & 87.34 & 0.01 & $u$ & 0.75 & $\mathrm{~N} / \mathrm{A}$ & -1.35 & 2.55 & 0.26 & 0.84 & 0.20 & 0.87 & 1.18 & -0.18 & 1.37 \\
\hline NB01-1B_Top & 92.75 & 74.22 & 18.53 & 7.25 & 0.00 & $u$ & -2.24 & $\mathrm{~N} / \mathrm{A}$ & -3.38 & 10.42 & -2.45 & 5.45 & -2.42 & 5.36 & 0.87 & 0.14 & 1.38 \\
\hline NB01-1B_Bottom & 96.49 & 57.04 & 39.44 & 3.51 & 0.00 & $u$ & -1.24 & N/A & -2.92 & 7.58 & -2.12 & 4.35 & -2.13 & 4.37 & 0.64 & -0.01 & 0.95 \\
\hline NB01-2 & 35.11 & 21.22 & 13.89 & 64.88 & 0.01 & B & 2.24 & -0.74 & -3.06 & 8.35 & -0.21 & 1.16 & -0.20 & 1.15 & 2.05 & -0.06 & 0.74 \\
\hline NB01-3 & 6.09 & 2.62 & 3.47 & 93.88 & 0.03 & U & 2.24 & $\mathrm{~N} / \mathrm{A}$ & -0.49 & 1.40 & 1.83 & 0.28 & 1.49 & 0.36 & 1.24 & -0.45 & 1.09 \\
\hline NB02-1 & 73.14 & 69.03 & 4.11 & 26.84 & 0.02 & B & -5.23 & 2.24 & -5.42 & 42.81 & -3.99 & 15.90 & -2.48 & 5.60 & 2.96 & 0.61 & 0.70 \\
\hline NBO2-2 & 26.74 & 20.43 & 6.31 & 73.23 & 0.03 & $\mathrm{u}$ & 2.24 & N/A & -3.76 & 13.52 & 1.89 & 0.27 & 0.55 & 0.68 & 2.45 & -0.75 & 0.84 \\
\hline NBO2-3 & 4.43 & 2.19 & 2.25 & 95.47 & 0.10 & $u$ & 2.24 & N/A & 0.70 & 0.61 & 2.11 & 0.23 & 1.99 & 0.25 & 0.91 & -0.40 & 1.82 \\
\hline NBO2-4 & 6.04 & 3.71 & 2.33 & 93.93 & 0.03 & $\mathrm{u}$ & 2.24 & N/A & 0.35 & 0.78 & 2.02 & 0.25 & 1.86 & 0.28 & 1.00 & -0.48 & 2.15 \\
\hline NB03-1 & 57.57 & 38.96 & 18.61 & 42.42 & 0.01 & $\mathrm{~B}$ & -0.74 & -3.24 & -4.62 & 24.52 & -1.41 & 2.65 & -1.41 & 2.67 & 2.37 & -0.05 & 0.91 \\
\hline NB03-2 & 89.30 & 66.28 & 23.02 & 10.69 & 0.01 & u & -2.24 & N/A & -3.86 & 14.50 & -2.44 & 5.42 & -2.44 & 5.44 & 1.46 & 0.20 & 1.62 \\
\hline NBO3-3 & 9.77 & 6.12 & 3.65 & 90.19 & 0.04 & $\mathrm{U}$ & 2.24 & N/A & -0.94 & 1.91 & 2.09 & 0.24 & 1.86 & 0.27 & 1.18 & -0.56 & 2.60 \\
\hline NB03-4 & 5.78 & 3.67 & 2.11 & 94.20 & 0.02 & u & 2.24 & N/A & 1.03 & 0.49 & 2.12 & 0.23 & 2.05 & 0.24 & 0.89 & -0.43 & 2.58 \\
\hline NBO3-5 & 9.42 & 6.86 & 2.56 & 90.57 & 0.01 & U & 2.24 & N/A & -0.77 & 1.71 & 1.97 & 0.26 & 1.81 & 0.28 & 1.19 & -0.52 & 2.91 \\
\hline NB04-1 & 97.88 & 97.85 & 0.03 & 2.12 & 0.00 & $u$ & -4.73 & $\mathrm{~N} / \mathrm{A}$ & -5.61 & 48.95 & -4.97 & 31.24 & -4.98 & 31.51 & 0.50 & 0.00 & 1.02 \\
\hline NBO4-2 & 63.88 & 57.46 & 6.42 & 36.09 & 0.03 & B & 2.24 & -4.24 & -4.63 & 24.72 & -2.74 & 6.69 & -1.71 & 3.27 & 2.68 & 0.45 & 0.55 \\
\hline NBO4-3 & 22.88 & 18.73 & 4.15 & 77.09 & 0.03 & U & 2.24 & N/A & -3.28 & 9.69 & 1.76 & 0.29 & 0.55 & 0.68 & 2.17 & -0.75 & 1.11 \\
\hline NBO4-4 & 13.91 & 11.31 & 2.60 & 86.07 & 0.02 & U & 2.24 & N/A & -2.40 & 5.27 & 1.98 & 0.25 & 1.52 & 0.35 & 1.49 & -0.69 & 3.29 \\
\hline
\end{tabular}




\begin{tabular}{|c|c|c|c|c|c|c|c|c|c|c|c|c|c|c|c|c|c|c|c|c|c|}
\hline Sample ID & $\begin{array}{c}\text { Class \% } \\
\text { phi } \\
-5.5 \\
\end{array}$ & $\begin{array}{c}\text { Class \% } \\
\text { phi } \\
-5.0 \\
\end{array}$ & $\begin{array}{c}\text { Class \% } \\
\text { phi } \\
-4.5 \\
\end{array}$ & $\begin{array}{c}\text { Class \% } \\
\text { phi } \\
-4.0 \\
\end{array}$ & $\begin{array}{c}\text { Class \% } \\
\text { phi } \\
-3.5 \\
\end{array}$ & $\begin{array}{c}\text { Class \% } \\
\text { phi } \\
-3.0 \\
\end{array}$ & $\begin{array}{c}\text { Class \% } \\
\text { phi } \\
-2.5 \\
\end{array}$ & $\begin{array}{c}\text { Class \% } \\
\text { phi } \\
-2.0 \\
\end{array}$ & $\begin{array}{c}\text { Class \% } \\
\text { phi } \\
-1.5 \\
\end{array}$ & $\begin{array}{c}\text { Class \% } \\
\text { phi } \\
-1.0 \\
\end{array}$ & $\begin{array}{c}\text { Class \% } \\
\text { phi } \\
-0.5 \\
\end{array}$ & $\begin{array}{c}\text { Class \% } \\
\text { phi } \\
0.0 \\
\end{array}$ & $\begin{array}{c}\text { Class \% } \\
\text { phi } \\
0.5 \\
\end{array}$ & $\begin{array}{c}\text { Class \% } \\
\text { phi } \\
1.0 \\
\end{array}$ & $\begin{array}{c}\text { Class \% } \\
\text { phi } \\
1.5 \\
\end{array}$ & $\begin{array}{c}\text { Class \% } \\
\text { phi } \\
2.0 \\
\end{array}$ & $\begin{array}{c}\text { Class \% } \\
\text { phi } \\
2.5 \\
\end{array}$ & $\begin{array}{c}\text { Class \% } \\
\text { phi } \\
3.0 \\
\end{array}$ & $\begin{array}{c}\text { Class \% } \\
\text { phi } \\
3.5 \\
\end{array}$ & $\begin{array}{c}\text { Class \% } \\
\text { phi } \\
4.0 \\
\end{array}$ & $\begin{array}{c}\text { Class \% } \\
\text { phi } \\
>4.0 \\
\end{array}$ \\
\hline NB01-1A & 0.00 & 0.00 & 1.02 & 1.16 & 0.47 & 1.10 & 1.52 & 1.40 & 2.32 & 3.67 & 10.96 & 16.48 & 19.03 & 20.70 & 10.62 & 6.58 & 2.56 & 0.38 & 0.03 & 0.00 & 0.01 \\
\hline NB01-1B_Top & 0.00 & 0.00 & 0.00 & 1.54 & 5.39 & 14.33 & 26.64 & 26.32 & 14.14 & 4.39 & 2.18 & 1.24 & 1.08 & 1.22 & 0.73 & 0.41 & 0.28 & 0.10 & 0.01 & 0.00 & 0.00 \\
\hline NB01-1B_Bottom & 0.00 & 0.00 & 0.62 & 0.29 & 0.93 & 4.89 & 21.79 & 28.52 & 26.96 & 12.48 & 1.59 & 0.43 & 0.28 & 0.31 & 0.22 & 0.26 & 0.29 & 0.11 & 0.01 & 0.00 & 0.00 \\
\hline NB01-2 & 0.00 & 0.00 & 0.55 & 1.69 & 3.92 & 4.40 & 5.02 & 5.65 & 6.65 & 7.23 & 9.75 & 9.09 & 5.97 & 5.58 & 6.07 & 11.02 & 12.97 & 4.20 & 0.22 & 0.01 & 0.01 \\
\hline NB01-3 & 0.00 & 0.00 & 0.00 & 0.00 & 0.38 & 0.78 & 0.65 & 0.82 & 1.46 & 2.01 & 3.91 & 4.83 & 5.38 & 8.38 & 10.61 & 16.28 & 26.76 & 15.52 & 2.16 & 0.04 & 0.03 \\
\hline NBO2-1 & 7.77 & 15.93 & 12.98 & 13.17 & 8.78 & 4.77 & 3.05 & 2.58 & 2.39 & 1.73 & 1.39 & 0.80 & 0.68 & 1.17 & 2.59 & 7.86 & 9.78 & 2.41 & 0.12 & 0.02 & 0.02 \\
\hline NBO2-2 & 0.00 & 2.27 & 3.07 & 3.00 & 3.50 & 3.00 & 2.60 & 2.99 & 3.34 & 2.96 & 3.12 & 2.09 & 1.64 & 2.08 & 3.91 & 13.33 & 29.63 & 16.14 & 1.24 & 0.04 & 0.03 \\
\hline NBO2-3 & 0.00 & 0.00 & 0.00 & 0.00 & 0.16 & 0.59 & 0.67 & 0.78 & 1.13 & 1.11 & 1.17 & 1.23 & 1.62 & 3.75 & 7.94 & 21.68 & 35.98 & 19.46 & 2.55 & 0.09 & 0.10 \\
\hline NBO2-4 & 0.00 & 0.00 & 0.00 & 0.25 & 0.91 & 0.87 & 0.66 & 1.02 & 1.20 & 1.13 & 1.38 & 1.38 & 1.67 & 3.87 & 9.04 & 25.20 & 35.74 & 14.22 & 1.38 & 0.04 & 0.03 \\
\hline NBO3-1 & 4.30 & 3.35 & 3.20 & 4.60 & 5.22 & 5.37 & 5.67 & 7.25 & 9.56 & 9.05 & 9.72 & 5.93 & 4.35 & 5.05 & 6.25 & 6.81 & 3.55 & 0.72 & 0.03 & 0.00 & 0.01 \\
\hline NBO3-2 & 0.00 & 0.00 & 2.62 & 4.59 & 10.13 & 14.10 & 16.87 & 17.97 & 15.48 & 7.54 & 2.47 & 0.64 & 0.31 & 0.36 & 0.76 & 2.46 & 2.96 & 0.68 & 0.04 & 0.01 & 0.01 \\
\hline NBO3-3 & 0.00 & 0.00 & 0.00 & 0.35 & 0.75 & 1.59 & 1.52 & 1.91 & 1.92 & 1.73 & 1.79 & 1.31 & 1.16 & 2.12 & 5.49 & 21.28 & 38.94 & 16.70 & 1.35 & 0.05 & 0.04 \\
\hline NBO3-4 & 0.00 & 0.00 & 0.00 & 0.00 & 0.10 & 1.19 & 1.18 & 1.20 & 1.13 & 0.98 & 0.99 & 0.76 & 0.71 & 1.43 & 5.21 & 23.46 & 44.54 & 15.82 & 1.25 & 0.04 & 0.02 \\
\hline NB03-5 & 0.00 & 0.00 & 1.68 & 0.91 & 1.03 & 0.79 & 1.29 & 1.17 & 1.39 & 1.17 & 1.29 & 0.89 & 1.11 & 2.57 & 8.19 & 28.25 & 35.91 & 11.47 & 0.86 & 0.03 & 0.01 \\
\hline NB04-1 & 13.33 & 35.75 & 37.07 & 10.36 & 1.09 & 0.19 & 0.04 & 0.01 & 0.02 & 0.02 & 0.03 & 0.05 & 0.10 & 0.27 & 0.54 & 0.72 & 0.32 & 0.07 & 0.01 & 0.00 & 0.00 \\
\hline NBO4-2 & 0.65 & 3.50 & 8.22 & 12.70 & 12.82 & 9.23 & 5.76 & 4.58 & 3.73 & 2.69 & 2.34 & 1.69 & 1.48 & 2.20 & 3.58 & 9.54 & 12.70 & 2.43 & 0.12 & 0.01 & 0.03 \\
\hline NBO4-3 & 0.00 & 0.00 & 2.52 & 1.47 & 4.20 & 4.22 & 3.38 & 2.95 & 2.43 & 1.72 & 1.49 & 1.09 & 1.14 & 2.26 & 6.95 & 26.78 & 31.10 & 5.86 & 0.41 & 0.01 & 0.03 \\
\hline NBO4-4 & 0.00 & 0.00 & 0.59 & 1.39 & 2.73 & 2.82 & 2.19 & 1.60 & 1.52 & 1.08 & 1.04 & 0.77 & 0.78 & 1.59 & 5.67 & 27.38 & 39.70 & 8.59 & 0.51 & 0.03 & 0.02 \\
\hline
\end{tabular}


Section 5(b): North Beach (Summer/Fall 2017 Sampling Period) 
North Beach (Summer Sampling), Hampton, New Hampshire: Identification, Location, and Description

\begin{tabular}{|c|c|c|c|c|c|c|c|c|c|c|c|c|c|}
\hline Sample ID & Global Sample ID & $\begin{array}{c}\text { Latitude } \\
\text { WGS84 }\end{array}$ & $\begin{array}{c}\text { Longitude } \\
\text { WGS84 }\end{array}$ & $\begin{array}{l}\text { Relative } \\
\text { Position } \\
\text { Accuracy }\end{array}$ & $\begin{array}{c}\text { Elevation } \\
\text { (m) } \\
\text { NAVD88 }\end{array}$ & $\begin{array}{c}\text { Elevation } \\
(\mathrm{m}) \\
\text { MTL }\end{array}$ & $\begin{array}{c}\text { Relative } \\
\text { Elevation }\end{array}$ & $\begin{array}{l}\text { Relative } \\
\text { Location }\end{array}$ & $\begin{array}{l}\text { Sample } \\
\text { Collected }\end{array}$ & $\begin{array}{l}\text { Core } \\
\text { Length } \\
\text { (cm) }\end{array}$ & $\begin{array}{c}\text { Collected } \\
\text { Sample } \\
\text { Wt. (gm) }\end{array}$ & $\begin{array}{c}\text { Processed } \\
\text { Sample } \\
\text { Wt. (gm) }\end{array}$ & $\begin{array}{c}\text { Morphologic } \\
\text { Feature }\end{array}$ \\
\hline NB01-1 & NHC_D20170919_NB01-1 & 42.939449 & -70.794467 & 1 & 0.87 & 1.00 & MTB & UB & 19-Sep-17 & 20 & $16,752.2$ & $16,712.4$ & S. Ramp: Upper \\
\hline NB01-2 & NHC_D20170919_NB01-2 & 42.939394 & -70.794261 & 1 & 0.32 & 0.45 & MTB & $\mathrm{MB}$ & 19-Sep-17 & 29 & $6,818.5$ & $6,796.2$ & LTT: Upper \\
\hline NB01-3 & NHC_D20170919_NB01-3 & 42.939321 & -70.793980 & 1 & -0.31 & -0.18 & LTB & LB & 19-Sep-17 & 28 & $5,651.1$ & $5,645.8$ & LTT: Swash \\
\hline NB02-1 & NHC_D20170919_NB02-1 & 42.934334 & -70.796505 & 1 & 0.23 & 0.37 & MTB & UB & 19-Sep-17 & 18 & $13,429.4$ & $13,468.4$ & LTT: Upper \\
\hline NBO2-3 & NHC_D20170919_NB02-3 & 42.934291 & -70.796237 & 1 & -0.19 & -0.06 & LTB & $\mathrm{MB}$ & 19-Sep-17 & 28 & $5,401.3$ & $5,391.6$ & LTT:Mid \\
\hline NB02-4 & NHC_D20170919_NB02-4 & 42.934236 & -70.795912 & 1 & -0.64 & -0.51 & LTB & $\mathrm{LB}$ & 19-Sep-17 & 29 & $3,218.0$ & $3,200.0$ & LTT: Lower \\
\hline NB03-1 & NHC D20170919 NB03-1 & 42.928572 & -70.798080 & 1 & 0.68 & 0.81 & MTB & UB & 19-Sep-17 & 18 & $12,793.8$ & $12,786.9$ & LTT: Upper \\
\hline NB03-2 & NHC_D20170919_NB03-2 & 42.928551 & -70.797828 & 1 & 0.06 & 0.20 & МTB & UB & 19-Sep-17 & 28 & $5,279.6$ & $5,238.5$ & LTT: Mid \\
\hline NBO3-3 & NHC_D20170919_NB03-3 & 42.928527 & -70.797559 & 1 & -0.75 & -0.61 & LTB & $\mathrm{MB}$ & 19-Sep-17 & 28 & $7,651.0$ & $7,631.3$ & LTT: Swash \\
\hline
\end{tabular}

North Beach (Summer Sampling), Hampton, New Hampshire: Sediment Classifications

\begin{tabular}{|c|c|c|c|c|c|c|c|c|}
\hline Sample ID & $\begin{array}{l}\text { CMECS Substrate } \\
\text { Component } \\
\text { Group (Specific) }\end{array}$ & $\begin{array}{l}\text { CMECS Substrate } \\
\text { Component Subgroup } \\
\text { (Specific) }\end{array}$ & $\begin{array}{l}\text { Textural Group from } \\
\text { \%GSM (Gradistat) }\end{array}$ & $\begin{array}{l}\text { Sediment Name from } \\
\text { \%GSM } \\
\text { and Mode (Gradistat) }\end{array}$ & $\begin{array}{l}\text { Sediment Name from } \\
\text { \%GSM and Mode } \\
\text { (Wentworth Scale) }\end{array}$ & $\begin{array}{l}\text { Sediment Classification } \\
\text { from Mean Phi } \\
\text { (Gradistat) }\end{array}$ & $\begin{array}{l}\text { Sediment } \\
\text { Classification } \\
\text { from Mean Phi } \\
\text { (Wentworth) } \\
\end{array}$ & Sorting (Gradistat) \\
\hline NB01-1 & Pebble Mixes & Sandy Pebble Gravel & Sandy Gravel & Sandy Coarse Gravel & Sandy Pebble Gravel & Very Coarse Sand & Very Coarse Sand & Very Poorly Sorted \\
\hline NB01-2 & Pebbly & Pebbly Fine Sand & Gravelly Sand & Medium Gravelly Fine Sand & Pebbly Fine Sand & Medium Sand & Medium Sand & Poorly Sorted \\
\hline NB01-3 & Slightly Granuley & $\begin{array}{l}\text { Slightly Granuley Fine } \\
\text { Sand }\end{array}$ & Slightly Gravelly Sand & $\begin{array}{l}\text { Slightly Very Fine Gravelly } \\
\text { Fine Sand }\end{array}$ & $\begin{array}{l}\text { Slightly Granular Fine } \\
\text { Sand }\end{array}$ & Medium Sand & Medium Sand & Moderately Sorted \\
\hline NBO2-1 & Pebbly & Pebbly Fine Sand & Gravelly Sand & Coarse Gravelly Fine Sand & Pebbly Fine Sand & Coarse Sand & Coarse Sand & Very Poorly Sorted \\
\hline NBO2-3 & Pebbly & Pebbly Fine Sand & Gravelly Sand & $\begin{array}{l}\text { Very Coarse Gravelly Fine } \\
\text { Sand }\end{array}$ & Pebbly Fine Sand & Fine Sand & Fine Sand & Poorly Sorted \\
\hline NBO2-4 & Slightly Granuley & $\begin{array}{l}\text { Slightly Granuley Fine } \\
\text { Sand }\end{array}$ & Slightly Gravelly Sand & $\begin{array}{l}\text { Slightly Very Fine Gravelly } \\
\text { Fine Sand }\end{array}$ & $\begin{array}{l}\text { Slightly Granular Fine } \\
\text { Sand }\end{array}$ & Medium Sand & Medium Sand & Moderately Sorted \\
\hline NB03-1 & Pebble Mixes & Sandy Pebble Gravel & Sandy Gravel & Sandy Medium Gravel & Sandy Pebble Gravel & Very Coarse Sand & Very Coarse Sand & Very Poorly Sorted \\
\hline NBO3-2 & Slightly Pebbly & $\begin{array}{l}\text { Slightly Pebbly Fine } \\
\text { Sand }\end{array}$ & Slightly Gravelly Sand & $\begin{array}{l}\text { Slightly Coarse Gravelly } \\
\text { Fine Sand }\end{array}$ & $\begin{array}{l}\text { Slightly Pebbly Fine } \\
\text { Sand }\end{array}$ & Medium Sand & Medium Sand & Moderately Sorted \\
\hline NBO3-3 & Pebbly & Pebbly Fine Sand & Gravelly Sand & Fine Gravelly Fine Sand & Pebbly Fine Sand & Medium Sand & Medium Sand & Poorly Sorted \\
\hline
\end{tabular}


North Beach (Summer Sampling), Hampton, New Hampshire: Grain Size Statistics

\begin{tabular}{|c|c|c|c|c|c|c|c|c|c|c|c|c|c|c|c|c|c|}
\hline Sample ID & Gravel \% & Pebble \% & Granule \% & Sand $\%$ & Mud \% & Modes & $\begin{array}{c}\text { Mode } 1 \\
\text { (phi) }\end{array}$ & $\begin{array}{c}\text { Mode } 2 \\
\text { (phi) }\end{array}$ & $\begin{array}{r}D_{10} \\
\text { (phi) }\end{array}$ & $\begin{array}{r}\mathrm{D}_{10} \\
(\mathrm{~mm}) \\
\end{array}$ & $\begin{array}{r}\mathrm{D}_{50} \\
\text { (phi) }\end{array}$ & $\begin{array}{r}D_{50} \\
(\mathrm{~mm}) \\
\end{array}$ & $\begin{array}{c}\text { Mean Size } \\
\text { (phi) }\end{array}$ & $\begin{array}{c}\text { Mean Size } \\
(\mathrm{mm})\end{array}$ & $\begin{array}{c}\text { Sorting } \\
\text { (phi) }\end{array}$ & Skewness & Kurtosis \\
\hline NB01-1 & 42.28 & 37.64 & 4.64 & 57.71 & 0.01 & $B$ & 2.24 & -4.73 & -4.84 & 28.57 & 0.43 & 0.74 & -0.53 & 1.44 & 2.92 & -0.42 & 0.58 \\
\hline NB01-2 & 12.07 & 9.77 & 2.30 & 87.90 & 0.03 & $u$ & 2.24 & N/A & -1.89 & 3.71 & 2.05 & 0.24 & 1.59 & 0.33 & 1.67 & -0.61 & 1.99 \\
\hline NB01-3 & 2.56 & 1.29 & 1.27 & 97.42 & 0.02 & u & 2.24 & N/A & 0.55 & 0.68 & 2.10 & 0.23 & 1.96 & 0.26 & 0.89 & -0.36 & 1.49 \\
\hline NBO2-1 & 27.77 & 25.88 & 1.89 & 72.21 & 0.02 & $\mathrm{~B}$ & 2.24 & -4.73 & -4.45 & 21.86 & 2.12 & 0.23 & 0.31 & 0.81 & 2.84 & -0.80 & 0.67 \\
\hline NBO2-3 & 5.99 & 4.75 & 1.23 & 93.99 & 0.02 & $u$ & 2.24 & N/A & 1.07 & 0.48 & 2.16 & 0.22 & 2.13 & 0.23 & 1.00 & -0.38 & 2.72 \\
\hline NBO2-4 & 0.68 & 0.36 & 0.32 & 99.30 & 0.02 & U & 2.24 & N/A & 0.72 & 0.61 & 1.94 & 0.26 & 1.88 & 0.27 & 0.80 & -0.18 & 1.12 \\
\hline NB03-1 & 50.82 & 44.60 & 6.23 & 49.17 & 0.01 & B & 2.24 & -3.24 & -4.17 & 17.95 & -1.19 & 2.28 & -0.90 & 1.86 & 2.60 & 0.10 & 0.55 \\
\hline NB03-2 & 4.77 & 3.77 & 1.00 & 95.22 & 0.01 & $u$ & 2.24 & $\mathrm{~N} / \mathrm{A}$ & 1.21 & 0.43 & 2.02 & 0.25 & 1.99 & 0.25 & 0.74 & -0.33 & 2.16 \\
\hline NB03-3 & 11.14 & 7.20 & 3.95 & 88.84 & 0.02 & u & 2.24 & N/A & -1.29 & 2.45 & 1.97 & 0.26 & 1.66 & 0.32 & 1.26 & -0.59 & 2.74 \\
\hline
\end{tabular}

North Beach (Summer Sampling), Hampton, New Hampshire: Grain Size Distribution

\begin{tabular}{|c|c|c|c|c|c|c|c|c|c|c|c|c|c|c|c|c|c|c|c|c|c|}
\hline Sample ID & $\begin{array}{c}\text { Class \% } \\
\text { phi } \\
-5.5 \\
\end{array}$ & $\begin{array}{c}\text { Class \% } \\
\text { phi } \\
-5.0 \\
\end{array}$ & $\begin{array}{c}\text { Class \% } \\
\text { phi } \\
-4.5 \\
\end{array}$ & $\begin{array}{c}\text { Class \% } \\
\text { phi } \\
-4.0 \\
\end{array}$ & $\begin{array}{c}\text { Class \% } \\
\text { phi } \\
-3.5 \\
\end{array}$ & $\begin{array}{c}\text { Class \% } \\
\text { phi } \\
-3.0 \\
\end{array}$ & $\begin{array}{c}\text { Class \% } \\
\text { phi } \\
-2.5 \\
\end{array}$ & $\begin{array}{c}\text { Class \% } \\
\text { phi } \\
-2.0 \\
\end{array}$ & $\begin{array}{c}\text { Class \% } \\
\text { phi } \\
-1.5 \\
\end{array}$ & $\begin{array}{c}\text { Class \% } \\
\text { phi } \\
-1.0 \\
\end{array}$ & $\begin{array}{c}\text { Class \% } \\
\text { phi } \\
-0.5\end{array}$ & $\begin{array}{c}\text { Class \% } \\
\text { phi } \\
0.0\end{array}$ & $\begin{array}{c}\text { Class \% } \\
\text { phi } \\
0.5\end{array}$ & $\begin{array}{c}\text { Class \% } \\
\text { phi } \\
1.0\end{array}$ & $\begin{array}{c}\text { Class \% } \\
\text { phi } \\
1.5\end{array}$ & $\begin{array}{c}\text { Class \% } \\
\text { phi } \\
2.0 \\
\end{array}$ & $\begin{array}{c}\text { Class \% } \\
\text { phi } \\
2.5\end{array}$ & $\begin{array}{c}\text { Class \% } \\
\text { phi } \\
3.0\end{array}$ & $\begin{array}{c}\text { Class \% } \\
\text { phi } \\
3.5\end{array}$ & $\begin{array}{c}\text { Class \% } \\
\text { phi } \\
4.0\end{array}$ & $\begin{array}{c}\text { Class \% } \\
\text { phi } \\
>4.0\end{array}$ \\
\hline NB01-1 & 2.80 & 5.20 & 6.96 & 4.91 & 6.12 & 5.10 & 3.62 & 2.93 & 2.45 & 2.19 & 2.79 & 2.61 & 2.66 & 2.54 & 2.77 & 11.64 & 21.10 & 10.15 & 1.41 & 0.02 & 0.01 \\
\hline NB01-2 & 0.00 & 0.00 & 0.29 & 2.60 & 2.51 & 1.79 & 1.41 & 1.17 & 1.09 & 1.22 & 1.83 & 2.04 & 3.10 & 4.39 & 5.95 & 17.56 & 27.67 & 20.27 & 4.99 & 0.10 & 0.03 \\
\hline NB01-3 & 0.00 & 0.00 & 0.00 & 0.16 & 0.00 & 0.29 & 0.47 & 0.37 & 0.54 & 0.73 & 1.64 & 1.91 & 3.30 & 5.16 & 7.41 & 21.33 & 32.59 & 20.21 & 3.81 & 0.06 & 0.02 \\
\hline NBO2-1 & 0.00 & 3.38 & 6.21 & 5.65 & 4.29 & 2.96 & 1.82 & 1.58 & 1.09 & 0.80 & 0.65 & 0.28 & 0.19 & 0.29 & 1.02 & 11.20 & 32.77 & 21.78 & 3.96 & 0.06 & 0.02 \\
\hline NBO2-3 & 0.00 & 2.46 & 0.00 & 0.00 & 0.50 & 0.49 & 0.74 & 0.56 & 0.61 & 0.62 & 0.61 & 0.52 & 0.71 & 1.49 & 4.46 & 22.65 & 39.73 & 20.72 & 3.06 & 0.04 & 0.02 \\
\hline NBO2-4 & 0.00 & 0.00 & 0.00 & 0.00 & 0.00 & 0.16 & 0.08 & 0.12 & 0.11 & 0.21 & 0.71 & 1.73 & 3.81 & 6.88 & 13.15 & 26.41 & 25.24 & 18.40 & 2.94 & 0.04 & 0.02 \\
\hline NBO3-1 & 0.00 & 1.78 & 4.35 & 5.89 & 9.19 & 9.55 & 7.65 & 6.20 & 4.09 & 2.14 & 0.98 & 0.29 & 0.17 & 0.23 & 1.82 & 16.51 & 22.82 & 5.88 & 0.47 & 0.01 & 0.01 \\
\hline NBO3-2 & 0.00 & 0.00 & 1.04 & 0.45 & 0.43 & 0.37 & 0.80 & 0.69 & 0.60 & 0.40 & 0.33 & 0.32 & 0.54 & 1.31 & 6.28 & 35.16 & 40.40 & 10.20 & 0.67 & 0.01 & 0.01 \\
\hline NBO3-3 & 0.00 & 0.00 & 0.00 & 0.29 & 1.09 & 1.73 & 1.87 & 2.21 & 2.04 & 1.91 & 1.64 & 1.37 & 1.41 & 2.27 & 5.89 & 28.00 & 35.47 & 11.80 & 0.96 & 0.02 & 0.02 \\
\hline
\end{tabular}


Section 6(a): Hampton Beach (Winter/Spring 2017 Sampling Period) 
Hampton Beach (Winter Sampling), Hampton, New Hampshire: Identification, Location, and Description

\begin{tabular}{|c|c|c|c|c|c|c|c|c|c|c|c|c|c|}
\hline Sample ID & Global Sample ID & $\begin{array}{c}\text { Latitude } \\
\text { WGS84 }\end{array}$ & $\begin{array}{l}\text { Longitude } \\
\text { WGS84 }\end{array}$ & $\begin{array}{l}\text { Relative } \\
\text { Position } \\
\text { Accuracy }\end{array}$ & $\begin{array}{c}\text { Elevation } \\
(\mathrm{m}) \\
\text { NAVD88 }\end{array}$ & $\begin{array}{c}\text { Elevation } \\
\text { (m) } \\
\text { MTL }\end{array}$ & $\begin{array}{c}\text { Relative } \\
\text { Elevation }\end{array}$ & $\begin{array}{l}\text { Relative } \\
\text { Location }\end{array}$ & $\begin{array}{c}\text { Sample } \\
\text { Collected }\end{array}$ & $\begin{array}{l}\text { Core } \\
\text { Length } \\
\text { (cm) }\end{array}$ & $\begin{array}{c}\text { Collected } \\
\text { Sample } \\
\text { Wt. (gm) }\end{array}$ & $\begin{array}{c}\text { Processed } \\
\text { Sample } \\
\text { Wt. }(\mathrm{gm})\end{array}$ & $\begin{array}{l}\text { Morphologic } \\
\text { Feature }\end{array}$ \\
\hline HB01-1 & NHC D20170202 HB01-1 & 42.912997 & -70.808562 & 1 & 3.38 & 3.52 & STB & $\mathrm{BS} / \mathrm{UB}$ & 2-Feb-17 & 25 & $1,005.6$ & $1,005.3$ & Backshore: Mid \\
\hline HB01-2 & NHC_D20170202_HB01-2 & 42.912864 & -70.808144 & 1 & 3.38 & 3.51 & STB & UB & 2-Feb-17 & 25 & 203.2 & 202.8 & Berm Crest \\
\hline HBO1-3 & NHC_D20170202_HB01-3 & 42.912764 & -70.807821 & 1 & 0.04 & 0.18 & MTB & $\mathrm{MB}$ & 2-Feb-17 & 25 & $3,081.1$ & $3,082.3$ & Berm Toe \\
\hline HB01-4 & NHC_D20170202_HB01-4 & 42.912612 & -70.807332 & 1 & -1.30 & -1.16 & LTB & LB & 2-Feb-17 & 25 & 180.0 & 179.6 & LTT: Lower \\
\hline HBO2-1 & NHC_D20170203_HB02-1 & 42.908963 & -70.810203 & 1 & 3.22 & 3.36 & STB & BS & 3-Feb-17 & 28 & $2,542.2$ & $2,537.4$ & Backshore: Mid \\
\hline $\mathrm{HBO2}-2 \mathrm{a}$ & NHC D20170203 HB02-2a & 42.908884 & -70.809677 & 1 & 2.34 & 2.47 & STB & UB & 3-Feb-17 & 5 & $4,312.5$ & $4,335.5$ & Berm Crest; LHTS \\
\hline $\mathrm{HBO} 2-2 \mathrm{~b}$ & NHC_D20170203_HB02-2b & 42.908881 & -70.809661 & 1 & 2.31 & 2.44 & sW & UB & 3-Feb-17 & 28 & $4,188.1$ & $4,196.0$ & Berm Crest: Neap \\
\hline $\mathrm{HB} 02-3$ & NHC_D20170203_HB02-3 & 42.908849 & -70.809437 & 1 & 0.04 & 0.17 & MTB & $\mathrm{MB}$ & 3-Feb-17 & 28 & $3,470.6$ & $3,427.3$ & Berm Runnel; LTT \\
\hline HBO2-4 & NHC_D20170203_HB02-4 & 42.908826 & -70.809287 & 1 & -0.22 & -0.09 & LTB & $\mathrm{LB}$ & 3-Feb-17 & 28 & $4,256.8$ & $4,256.2$ & LTT: Mid \\
\hline HBO2-5 & NHC_D20170203_HB02-5 & 42.908773 & -70.808924 & 1 & -1.14 & -1.00 & LTB & LB & 3-Feb-17 & 28 & 330.5 & 330.8 & LTT: Lower \\
\hline HBO3-1 & NHC_D20170221_HB03-1 & 42.905527 & -70.810888 & 1 & 3.05 & 3.18 & STB & UB & 21-Feb-17 & 26 & $3,984.2$ & $3,964.9$ & Backshore: Mid \\
\hline $\mathrm{HBO3-2}$ & NHC D20170221 HB03-2 & 42.905509 & -70.810512 & 1 & 2.94 & 3.07 & UTB & UB & 21-Feb-17 & 26 & $3,785.0$ & $3,781.9$ & Berm Crest \\
\hline HBO3-3 & NHC_D20170221_HB03-3 & 42.905498 & -70.810196 & 1 & 1.30 & 1.44 & MTB & $\mathrm{MB}$ & 21-Feb-17 & 26 & $4,198.3$ & $4,193.5$ & Berm Toe \\
\hline HBO3-4 & NHC_D20170221_HB03-4 & 42.905468 & -70.809390 & 1 & -0.45 & -0.32 & LTB & $\mathrm{LB}$ & 21-Feb-17 & 26 & $2,633.0$ & $2,629.5$ & LTT: Mid \\
\hline HBO4s-1 & NHC_D20170308_HB04s-1 & 42.900096 & -70.811336 & 1 & 4.10 & 4.24 & STB & UB & 8-Mar-17 & 29 & 233.4 & 233.2 & $\begin{array}{c}\text { Backshore; Edge of } \\
\text { Dunes }\end{array}$ \\
\hline HBO4s-2 & NHC_D20170308_HB04s-2 & 42.900045 & -70.810849 & 1 & 2.05 & 2.18 & UTB & UB & 8-Mar-17 & 29 & $7,673.8$ & $7,666.6$ & S. Ramp; LHTS \\
\hline HBO4s-3 & NHC_D20170308_HB04s-3 & 42.899962 & -70.810075 & 1 & 0.17 & 0.30 & LTB & $\mathrm{MB}$ & 8-Mar-17 & 30 & $3,818.3$ & $3,817.2$ & LTT: Upper \\
\hline HBO4s-4 & NHC_D20170308_HB04s-4 & 42.899907 & -70.809570 & 1 & -0.59 & -0.46 & LTB & LB & 8-Mar-17 & 28 & $3,170.7$ & $3,156.8$ & LTT: Mid \\
\hline HBO4s-5 & NHC_D20170308_HB04s-5 & 42.899850 & -70.809063 & 1 & -1.07 & -0.94 & LTB & LB & 8-Mar-17 & 26 & $3,534.0$ & $3,526.0$ & LTT: Lower \\
\hline
\end{tabular}




\begin{tabular}{|c|c|c|c|c|c|c|c|c|}
\hline Sample ID & $\begin{array}{l}\text { CMECS Substrate } \\
\text { Component } \\
\text { Group (Specific) }\end{array}$ & $\begin{array}{l}\text { CMECS Substrate } \\
\text { Component Subgroup } \\
\text { (Specific) }\end{array}$ & $\begin{array}{l}\text { Textural Group from } \\
\text { \%GSM (Gradistat) }\end{array}$ & $\begin{array}{l}\text { Sediment Name from } \\
\text { \%GSM } \\
\text { and Mode (Gradistat) }\end{array}$ & $\begin{array}{l}\text { Sediment Name from } \\
\text { \%GSM and Mode } \\
\text { (Wentworth Scale) }\end{array}$ & $\begin{array}{l}\text { Sediment Classification } \\
\text { from Mean Phi } \\
\text { (Gradistat) }\end{array}$ & $\begin{array}{l}\text { Sediment } \\
\text { Classification } \\
\text { from Mean Phi } \\
\text { (Wentworth) }\end{array}$ & Sorting (Gradistat) \\
\hline HB01-1 & Slightly Granuley & $\begin{array}{l}\text { Slightly Granuley } \\
\text { Medium Sand }\end{array}$ & Slightly Gravelly Sand & $\begin{array}{l}\text { Slightly Very Fine Gravelly } \\
\text { Medium Sand }\end{array}$ & $\begin{array}{l}\text { Slightly Granular } \\
\text { Medium Sand }\end{array}$ & Medium Sand & Medium Sand & Moderately Sorted \\
\hline HB01-2 & Slightly Granuley & $\begin{array}{l}\text { Slightly Granuley } \\
\text { Coarse Sand }\end{array}$ & Slightly Gravelly Sand & $\begin{array}{l}\text { Slightly Very Fine Gravelly } \\
\text { Coarse Sand }\end{array}$ & $\begin{array}{l}\text { Slightly Granular Coarse } \\
\text { Sand }\end{array}$ & Coarse Sand & Coarse Sand & Moderately Sorted \\
\hline HB01-3 & Slightly Granuley & $\begin{array}{l}\text { Slightly Granuley Very } \\
\text { Coarse Sand }\end{array}$ & Slightly Gravelly Sand & $\begin{array}{l}\text { Slightly Very Fine Gravelly } \\
\text { Very Coarse Sand }\end{array}$ & $\begin{array}{l}\text { Slightly Granular Very } \\
\text { Coarse Sand }\end{array}$ & Very Coarse Sand & Very Coarse Sand & Moderately Well Sorted \\
\hline HB01-4 & Slightly Granuley & $\begin{array}{l}\text { Slightly Granuley } \\
\text { Coarse Sand } \\
\end{array}$ & Slightly Gravelly Sand & $\begin{array}{l}\text { Slightly Very Fine Gravelly } \\
\text { Coarse Sand } \\
\end{array}$ & $\begin{array}{l}\text { Slightly Granular Coarse } \\
\text { Sand }\end{array}$ & Coarse Sand & Coarse Sand & Moderately Well Sorted \\
\hline HB02-1 & Slightly Granuley & $\begin{array}{l}\text { Slightly Granuley } \\
\text { Medium Sand }\end{array}$ & Slightly Gravelly Sand & $\begin{array}{l}\text { Slightly Very Fine Gravelly } \\
\text { Medium Sand }\end{array}$ & $\begin{array}{l}\text { Slightly Granular } \\
\text { Medium Sand }\end{array}$ & Medium Sand & Medium Sand & Moderately Well Sorted \\
\hline HBO2-2a & Granule Mixes & Sandy Granule Gravel & Sandy Gravel & Sandy Very Fine Gravel & Sandy Granule Gravel & Very Fine Gravel & Granule Gravel & Poorly Sorted \\
\hline HBO2-2b & Slightly Granuley & $\begin{array}{l}\text { Slightly Granuley } \\
\text { Coarse Sand }\end{array}$ & Slightly Gravelly Sand & $\begin{array}{l}\text { Slightly Very Fine Gravelly } \\
\text { Coarse Sand }\end{array}$ & $\begin{array}{l}\text { Slightly Granular Coarse } \\
\text { Sand }\end{array}$ & Coarse Sand & Coarse Sand & Moderately Sorted \\
\hline $\mathrm{HB} 02-3$ & Slightly Granuley & $\begin{array}{l}\text { Slightly Granuley } \\
\text { Coarse Sand }\end{array}$ & Slightly Gravelly Sand & $\begin{array}{l}\text { Slightly Very Fine Gravelly } \\
\text { Coarse Sand }\end{array}$ & $\begin{array}{l}\text { Slightly Granular Coarse } \\
\text { Sand }\end{array}$ & Coarse Sand & Coarse Sand & Poorly Sorted \\
\hline HBO2-4 & Slightly Granuley & $\begin{array}{l}\text { Slightly Granuley } \\
\text { Coarse Sand }\end{array}$ & Slightly Gravelly Sand & $\begin{array}{l}\text { Slightly Very Fine Gravelly } \\
\text { Coarse Sand }\end{array}$ & $\begin{array}{l}\text { Slightly Granular Coarse } \\
\text { Sand }\end{array}$ & Coarse Sand & Coarse Sand & Moderately Sorted \\
\hline HBO2-5 & Slightly Pebbly & $\begin{array}{l}\text { Slightly Pebbly Medium } \\
\text { Sand }\end{array}$ & Slightly Gravelly Sand & $\begin{array}{l}\text { Slightly Fine Gravelly } \\
\text { Medium Sand }\end{array}$ & $\begin{array}{l}\text { Slightly Pebbly Medium } \\
\text { Sand }\end{array}$ & Coarse Sand & Coarse Sand & Moderately Sorted \\
\hline HB03-1 & Slightly Granuley & $\begin{array}{l}\text { Slightly Granuley } \\
\text { Medium Sand }\end{array}$ & Slightly Gravelly Sand & $\begin{array}{l}\text { Slightly Very Fine Gravelly } \\
\text { Medium Sand }\end{array}$ & $\begin{array}{l}\text { Slightly Granular } \\
\text { Medium Sand }\end{array}$ & Medium Sand & Medium Sand & Moderately Well Sorted \\
\hline HB03-2 & Sand & Medium Sand & Medium Sand & Medium Sand & Medium Sand & Medium Sand & Medium Sand & Moderately Well Sorted \\
\hline HBO3-3 & Slightly Pebbly & $\begin{array}{l}\text { Slightly Pebbly Medium } \\
\text { Sand }\end{array}$ & Slightly Gravelly Sand & $\begin{array}{l}\text { Slightly Medium Gravelly } \\
\text { Medium Sand }\end{array}$ & $\begin{array}{l}\text { Slightly Pebbly Medium } \\
\text { Sand }\end{array}$ & Coarse Sand & Coarse Sand & Moderately Well Sorted \\
\hline HBO3-4 & Slightly Granuley & $\begin{array}{l}\text { Slightly Granuley } \\
\text { Medium Sand }\end{array}$ & Slightly Gravelly Sand & $\begin{array}{l}\text { Slightly Very Fine Gravelly } \\
\text { Medium Sand }\end{array}$ & $\begin{array}{l}\text { Slightly Granular } \\
\text { Medium Sand }\end{array}$ & Coarse Sand & Coarse Sand & Moderately Sorted \\
\hline HB04s-1 & Slightly Granuley & $\begin{array}{l}\text { Slightly Granuley Fine } \\
\text { Sand }\end{array}$ & Slightly Gravelly Sand & $\begin{array}{l}\text { Slightly Very Fine Gravelly } \\
\text { Fine Sand }\end{array}$ & $\begin{array}{l}\text { Slightly Granular Fine } \\
\text { Sand }\end{array}$ & Fine Sand & Fine Sand & Moderately Well Sorted \\
\hline HBO4s-2 & Slightly Pebbly & $\begin{array}{l}\text { Slightly Pebbly Medium } \\
\text { Sand }\end{array}$ & Slightly Gravelly Sand & $\begin{array}{l}\text { Slightly Very Coarse } \\
\text { Gravelly Medium Sand }\end{array}$ & $\begin{array}{l}\text { Slightly Pebbly Medium } \\
\text { Sand }\end{array}$ & Medium Sand & Medium Sand & Moderately Well Sorted \\
\hline HBO4s-3 & Slightly Granuley & $\begin{array}{l}\text { Slightly Granuley Fine } \\
\text { Sand }\end{array}$ & Slightly Gravelly Sand & $\begin{array}{l}\text { Slightly Very Fine Gravelly } \\
\text { Fine Sand }\end{array}$ & $\begin{array}{l}\text { Slightly Granular Fine } \\
\text { Sand }\end{array}$ & Medium Sand & Medium Sand & Moderately Sorted \\
\hline HBO4s-4 & Slightly Granuley & $\begin{array}{l}\text { Slightly Granuley Fine } \\
\text { Sand }\end{array}$ & Slightly Gravelly Sand & $\begin{array}{l}\text { Slightly Very Fine Gravelly } \\
\text { Fine Sand }\end{array}$ & $\begin{array}{l}\text { Slightly Granular Fine } \\
\text { Sand }\end{array}$ & Medium Sand & Medium Sand & Moderately Well Sorted \\
\hline HBO4s-5 & Slightly Pebbly & $\begin{array}{l}\text { Slightly Pebbly Medium } \\
\text { Sand }\end{array}$ & Slightly Gravelly Sand & $\begin{array}{l}\text { Slightly Medium Gravelly } \\
\text { Medium Sand }\end{array}$ & $\begin{array}{l}\text { Slightly Pebbly Medium } \\
\text { Sand }\end{array}$ & Medium Sand & Medium Sand & Moderately Well Sorted \\
\hline
\end{tabular}




\begin{tabular}{|c|c|c|c|c|c|c|c|c|c|c|c|c|c|c|c|c|c|}
\hline Sample ID & Gravel \% & Pebble \% & Granule \% & Sand $\%$ & Mud \% & Modes & $\begin{array}{c}\text { Mode } 1 \\
\text { (phi) }\end{array}$ & $\begin{array}{c}\text { Mode } 2 \\
\text { (phi) }\end{array}$ & $\begin{array}{r}D_{10} \\
\text { (phi) }\end{array}$ & $\begin{array}{c}\mathrm{D}_{10} \\
(\mathrm{~mm}) \\
\end{array}$ & $\begin{array}{r}\mathrm{D}_{50} \\
\text { (phi) }\end{array}$ & $\begin{array}{r}D_{50} \\
(\mathrm{~mm})\end{array}$ & $\begin{array}{c}\text { Mean Size } \\
\text { (phi) }\end{array}$ & $\begin{array}{c}\text { Mean Size } \\
(\mathrm{mm})\end{array}$ & $\begin{array}{c}\text { Sorting } \\
\text { (phi) }\end{array}$ & Skewness & Kurtosis \\
\hline HB01-1 & 0.35 & 0.10 & 0.25 & 99.49 & 0.16 & u & 1.25 & N/A & 0.09 & 0.94 & 1.04 & 0.49 & 1.03 & 0.49 & 0.75 & 0.00 & 1.03 \\
\hline HBO1-2 & 0.47 & 0.00 & 0.47 & 99.52 & 0.01 & U & 0.75 & N/A & -0.31 & 1.24 & 0.58 & 0.67 & 0.60 & 0.66 & 0.73 & 0.08 & 0.93 \\
\hline HB01-3 & 0.59 & 0.01 & 0.59 & 99.39 & 0.02 & U & -0.24 & $\mathrm{~N} / \mathrm{A}$ & -0.86 & 1.82 & -0.31 & 1.24 & -0.27 & 1.21 & 0.54 & 0.22 & 1.19 \\
\hline HB01-4 & 0.65 & 0.00 & 0.65 & 99.34 & 0.01 & U & 0.75 & N/A & 0.03 & 0.98 & 0.86 & 0.55 & 0.84 & 0.56 & 0.66 & -0.04 & 1.10 \\
\hline HBO2-1 & 0.14 & 0.05 & 0.09 & 99.67 & 0.19 & U & 1.25 & N/A & 0.19 & 0.88 & 1.12 & 0.46 & 1.11 & 0.46 & 0.69 & -0.01 & 0.98 \\
\hline HBO2-2a & 45.89 & 23.92 & 21.97 & 54.09 & 0.02 & u & -0.74 & N/A & -2.87 & 7.30 & -0.88 & 1.84 & -1.02 & 2.02 & 1.36 & -0.11 & 1.03 \\
\hline HBO2-2b & 2.60 & 0.46 & 2.13 & 97.37 & 0.03 & U & -0.24 & $\mathrm{~N} / \mathrm{A}$ & -0.73 & 1.65 & 0.18 & 0.88 & 0.27 & 0.83 & 0.80 & 0.16 & 0.95 \\
\hline HBO2-3 & 4.16 & 1.66 & 2.51 & 95.84 & 0.00 & u & 0.25 & N/A & -0.59 & 1.51 & 0.57 & 0.67 & 0.64 & 0.64 & 1.00 & 0.08 & 0.94 \\
\hline HBO2-4 & 1.64 & 0.45 & 1.19 & 98.33 & 0.03 & $u$ & 1.25 & N/A & -0.34 & 1.27 & 0.73 & 0.60 & 0.71 & 0.61 & 0.80 & -0.04 & 0.89 \\
\hline HBO2-5 & 2.40 & 0.87 & 1.52 & 97.60 & 0.00 & U & 1.25 & $\mathrm{~N} / \mathrm{A}$ & -0.21 & 1.16 & 0.94 & 0.52 & 0.89 & 0.54 & 0.78 & -0.13 & 1.02 \\
\hline HBO3-1 & 0.03 & 0.00 & 0.02 & 99.81 & 0.16 & u & 1.75 & N/A & 0.65 & 0.64 & 1.54 & 0.34 & 1.52 & 0.35 & 0.65 & -0.04 & 1.05 \\
\hline HBO3-2 & 0.01 & 0.00 & 0.01 & 99.93 & 0.06 & u & 1.75 & $\mathrm{~N} / \mathrm{A}$ & 0.63 & 0.65 & 1.45 & 0.37 & 1.42 & 0.37 & 0.59 & -0.06 & 1.04 \\
\hline HBO3-3 & 1.14 & 0.80 & 0.35 & 98.83 & 0.03 & $\mathrm{U}$ & 1.25 & N/A & 0.13 & 0.92 & 1.01 & 0.50 & 0.95 & 0.52 & 0.60 & -0.14 & 1.08 \\
\hline HBO3-4 & 2.39 & 0.83 & 1.56 & 97.59 & 0.02 & U & 1.25 & $\mathrm{~N} / \mathrm{A}$ & -0.13 & 1.10 & 1.07 & 0.48 & 0.98 & 0.51 & 0.78 & -0.20 & 1.12 \\
\hline HBO4s-1 & 0.05 & 0.00 & 0.05 & 99.93 & 0.02 & U & 2.24 & $\mathrm{~N} / \mathrm{A}$ & 1.50 & 0.35 & 2.15 & 0.23 & 2.16 & 0.22 & 0.58 & 0.01 & 1.19 \\
\hline HBO4s-2 & 4.84 & 4.84 & 0.00 & 95.15 & 0.01 & U & 1.75 & N/A & 1.18 & 0.44 & 1.98 & 0.25 & 1.99 & 0.25 & 0.69 & -0.08 & 1.64 \\
\hline HBO4s-3 & 1.90 & 1.30 & 0.61 & 98.07 & 0.03 & U & 2.24 & N/A & 0.61 & 0.65 & 1.91 & 0.27 & 1.83 & 0.28 & 0.81 & -0.24 & 1.15 \\
\hline HBO $4 \mathrm{~s}-4$ & 0.13 & 0.03 & 0.10 & 99.84 & 0.03 & U & 2.24 & N/A & 1.06 & 0.48 & 2.00 & 0.25 & 1.96 & 0.26 & 0.67 & -0.13 & 1.11 \\
\hline HBO4s -5 & 0.26 & 0.19 & 0.07 & 99.71 & 0.03 & U & 1.75 & N/A & 0.75 & 0.59 & 1.73 & 0.30 & 1.72 & 0.30 & 0.70 & -0.03 & 0.99 \\
\hline
\end{tabular}


Hampton Beach (Winter Sampling), Hampton, New Hampshire: Grain Size Distribution

\begin{tabular}{|c|c|c|c|c|c|c|c|c|c|c|c|c|c|c|c|c|c|c|c|c|c|}
\hline Sample ID & $\begin{array}{c}\text { Class \% } \\
\text { phi } \\
-5.5 \\
\end{array}$ & $\begin{array}{c}\text { Class \% } \\
\text { phi } \\
-5.0 \\
\end{array}$ & $\begin{array}{c}\text { Class \% } \\
\text { phi } \\
-4.5 \\
\end{array}$ & $\begin{array}{c}\text { Class \% } \\
\text { phi } \\
-4.0 \\
\end{array}$ & $\begin{array}{c}\text { Class \% } \\
\text { phi } \\
-3.5 \\
\end{array}$ & $\begin{array}{c}\text { Class \% } \\
\text { phi } \\
-3.0 \\
\end{array}$ & $\begin{array}{c}\text { Class \% } \\
\text { phi } \\
-2.5 \\
\end{array}$ & $\begin{array}{c}\text { Class \% } \\
\text { phi } \\
-2.0 \\
\end{array}$ & $\begin{array}{c}\text { Class \% } \\
\text { phi } \\
-1.5 \\
\end{array}$ & $\begin{array}{c}\text { Class \% } \\
\text { phi } \\
-1.0 \\
\end{array}$ & $\begin{array}{c}\text { Class \% } \\
\text { phi } \\
-0.5 \\
\end{array}$ & $\begin{array}{c}\text { Class \% } \\
\text { phi } \\
0.0 \\
\end{array}$ & $\begin{array}{c}\text { Class \% } \\
\text { phi } \\
0.5 \\
\end{array}$ & $\begin{array}{c}\text { Class \% } \\
\text { phi } \\
1.0 \\
\end{array}$ & $\begin{array}{c}\text { Class \% } \\
\text { phi } \\
1.5 \\
\end{array}$ & $\begin{array}{c}\text { Class \% } \\
\text { phi } \\
2.0 \\
\end{array}$ & $\begin{array}{c}\text { Class \% } \\
\text { phi } \\
2.5 \\
\end{array}$ & $\begin{array}{c}\text { Class \% } \\
\text { phi } \\
3.0 \\
\end{array}$ & $\begin{array}{c}\text { Class \% } \\
\text { phi } \\
3.5 \\
\end{array}$ & $\begin{array}{c}\text { Class \% } \\
\text { phi } \\
4.0 \\
\end{array}$ & $\begin{array}{c}\text { Class \% } \\
\text { phi } \\
>4.0 \\
\end{array}$ \\
\hline HB01-1 & 0.00 & 0.00 & 0.00 & 0.00 & 0.00 & 0.00 & 0.00 & 0.10 & 0.04 & 0.21 & 1.07 & 5.58 & 15.91 & 25.04 & 26.09 & 17.35 & 5.87 & 1.96 & 0.48 & 0.15 & 0.16 \\
\hline HB01-2 & 0.00 & 0.00 & 0.00 & 0.00 & 0.00 & 0.00 & 0.00 & 0.00 & 0.04 & 0.43 & 3.19 & 17.63 & 24.52 & 25.50 & 17.23 & 8.46 & 2.35 & 0.47 & 0.17 & 0.02 & 0.01 \\
\hline HB01-3 & 0.00 & 0.00 & 0.00 & 0.00 & 0.00 & 0.00 & 0.00 & 0.01 & 0.00 & 0.59 & 35.41 & 39.81 & 14.96 & 5.07 & 2.35 & 1.28 & 0.38 & 0.08 & 0.01 & 0.02 & 0.02 \\
\hline HB01-4 & 0.00 & 0.00 & 0.00 & 0.00 & 0.00 & 0.00 & 0.00 & 0.00 & 0.20 & 0.45 & 1.94 & 6.48 & 16.92 & 32.95 & 26.50 & 11.03 & 2.75 & 0.50 & 0.26 & 0.01 & 0.01 \\
\hline HBO2-1 & 0.00 & 0.00 & 0.00 & 0.00 & 0.00 & 0.00 & 0.01 & 0.04 & 0.02 & 0.07 & 0.71 & 3.93 & 13.71 & 24.14 & 29.35 & 20.06 & 5.53 & 1.66 & 0.42 & 0.17 & 0.19 \\
\hline HBO2-2a & 0.00 & 0.00 & 0.82 & 0.82 & 2.05 & 4.60 & 6.68 & 8.96 & 10.48 & 11.50 & 17.95 & 15.47 & 8.71 & 5.27 & 4.02 & 2.04 & 0.50 & 0.11 & 0.01 & 0.01 & 0.02 \\
\hline $\mathrm{HBO2-2b}$ & 0.00 & 0.00 & 0.00 & 0.26 & 0.07 & 0.02 & 0.03 & 0.08 & 0.31 & 1.82 & 13.93 & 24.67 & 23.73 & 16.36 & 11.49 & 5.69 & 1.28 & 0.20 & 0.02 & 0.01 & 0.03 \\
\hline $\mathrm{HB} 02-3$ & 0.00 & 0.00 & 0.00 & 0.00 & 0.28 & 0.30 & 0.52 & 0.55 & 0.87 & 1.64 & 7.36 & 16.41 & 19.36 & 18.55 & 13.85 & 10.75 & 7.34 & 1.80 & 0.41 & 0.01 & 0.00 \\
\hline HBO2-4 & 0.00 & 0.00 & 0.00 & 0.00 & 0.00 & 0.10 & 0.14 & 0.21 & 0.35 & 0.83 & 4.28 & 13.86 & 19.86 & 21.80 & 21.54 & 12.89 & 3.21 & 0.77 & 0.13 & 0.01 & 0.03 \\
\hline HBO2-5 & 0.00 & 0.00 & 0.00 & 0.00 & 0.00 & 0.00 & 0.79 & 0.08 & 0.63 & 0.89 & 3.04 & 8.16 & 15.02 & 24.38 & 26.12 & 15.67 & 4.03 & 0.94 & 0.22 & 0.01 & 0.00 \\
\hline HBO3-1 & 0.00 & 0.00 & 0.00 & 0.00 & 0.00 & 0.00 & 0.00 & 0.00 & 0.01 & 0.02 & 0.15 & 0.81 & 4.64 & 14.03 & 27.18 & 32.11 & 15.03 & 4.87 & 0.84 & 0.16 & 0.16 \\
\hline $\mathrm{HBO3}-2$ & 0.00 & 0.00 & 0.00 & 0.00 & 0.00 & 0.00 & 0.00 & 0.00 & 0.01 & 0.00 & 0.16 & 0.79 & 4.72 & 15.83 & 31.21 & 32.46 & 11.36 & 2.93 & 0.43 & 0.04 & 0.06 \\
\hline $\mathrm{HB} 03-3$ & 0.00 & 0.00 & 0.00 & 0.00 & 0.37 & 0.24 & 0.09 & 0.10 & 0.11 & 0.23 & 0.81 & 4.50 & 13.94 & 29.01 & 34.74 & 12.84 & 2.15 & 0.68 & 0.14 & 0.02 & 0.03 \\
\hline HBO3-4 & 0.00 & 0.00 & 0.00 & 0.00 & 0.06 & 0.15 & 0.28 & 0.34 & 0.59 & 0.97 & 3.01 & 6.35 & 12.44 & 21.55 & 30.41 & 18.24 & 4.40 & 1.08 & 0.11 & 0.01 & 0.02 \\
\hline HBO4s-1 & 0.00 & 0.00 & 0.00 & 0.00 & 0.00 & 0.00 & 0.00 & 0.00 & 0.02 & 0.03 & 0.03 & 0.13 & 0.52 & 1.86 & 7.06 & 27.85 & 39.04 & 16.24 & 6.80 & 0.40 & 0.02 \\
\hline HBO4s-2 & 0.00 & 3.73 & 0.96 & 0.15 & 0.00 & 0.00 & 0.00 & 0.00 & 0.00 & 0.00 & 0.03 & 0.02 & 0.22 & 1.45 & 9.67 & 34.86 & 32.46 & 8.76 & 7.36 & 0.33 & 0.01 \\
\hline HB04s-3 & 0.00 & 0.00 & 0.00 & 0.50 & 0.36 & 0.15 & 0.13 & 0.15 & 0.20 & 0.41 & 1.01 & 1.77 & 3.63 & 7.10 & 14.15 & 24.58 & 27.72 & 16.09 & 1.93 & 0.10 & 0.03 \\
\hline HBO4s-4 & 0.00 & 0.00 & 0.00 & 0.00 & 0.00 & 0.00 & 0.01 & 0.02 & 0.03 & 0.07 & 0.30 & 0.79 & 2.05 & 5.27 & 12.77 & 28.89 & 29.81 & 17.24 & 2.62 & 0.10 & 0.03 \\
\hline HB04s -5 & 0.00 & 0.00 & 0.00 & 0.00 & 0.07 & 0.09 & 0.00 & 0.03 & 0.03 & 0.04 & 0.20 & 0.77 & 3.32 & 10.58 & 20.99 & 30.35 & 20.73 & 11.13 & 1.60 & 0.04 & 0.03 \\
\hline
\end{tabular}


Section 6(b): Hampton Beach (Summer/Fall 2017 Sampling Period) 
Hampton Beach (Summer Sampling), Hampton, New Hampshire: Identification, Location, and Description

\begin{tabular}{|c|c|c|c|c|c|c|c|c|c|c|c|c|c|}
\hline Sample ID & Global Sample ID & $\begin{array}{l}\text { Latitude } \\
\text { WGS84 }\end{array}$ & $\begin{array}{l}\text { Longitude } \\
\text { WGS84 }\end{array}$ & $\begin{array}{l}\text { Relative } \\
\text { Position } \\
\text { Accuracy }\end{array}$ & $\begin{array}{c}\text { Elevation } \\
(m) \\
\text { NAVD88 }\end{array}$ & $\begin{array}{c}\text { Elevation } \\
(\mathrm{m}) \\
\text { MTL }\end{array}$ & $\begin{array}{l}\text { Relative } \\
\text { Elevation }\end{array}$ & $\begin{array}{l}\text { Relative } \\
\text { Location }\end{array}$ & $\begin{array}{c}\text { Sample } \\
\text { Collected }\end{array}$ & $\begin{array}{l}\text { Core } \\
\text { Length } \\
(\mathrm{cm})\end{array}$ & $\begin{array}{l}\text { Collected } \\
\text { Sample } \\
\text { Wt. (gm) }\end{array}$ & $\begin{array}{l}\text { Processed } \\
\text { Sample } \\
\text { Wt. (gm) }\end{array}$ & $\begin{array}{l}\text { Morphologic } \\
\text { Feature }\end{array}$ \\
\hline HBO1-1 & NHC D20170917 HB01-1 & 42.913053 & -70.808745 & 2 & $\mathrm{~N} / \mathrm{A}$ & $\mathrm{N} / \mathrm{A}$ & STB & UB; BS & $17-$ Sep-17 & 28 & $3,241.5$ & $3,236.0$ & $\begin{array}{c}\text { Backshore: Near } \\
\text { Seawall }\end{array}$ \\
\hline HB01-2 & NHC_D20170917_HB01-2 & 42.912980 & -70.808505 & 2 & $\mathrm{~N} / \mathrm{A}$ & $\mathrm{N} / \mathrm{A}$ & STB & UB; BS & 17-Sep-17 & 29 & $2,429.4$ & $2,432.7$ & Backshore: Mid \\
\hline HB01-3 & NHC_D20170917_HB01-3 & 42.912815 & -70.807993 & 1 & 2.41 & 2.54 & STB & UB & 17-Sep-17 & 28 & $3,168.1$ & $3,172.5$ & Berm: Spring \\
\hline $\mathrm{HB} 01-4$ & NHC_D20170917_HB01-4 & 42.912759 & -70.807817 & 1 & 0.54 & 0.67 & UTB & UB & 17-Sep-17 & 28 & $3,261.4$ & $3,250.8$ & Berm: Neap \\
\hline $\mathrm{HB} 01-5$ & NHC_D20170917_HB01-5 & 42.912743 & -70.807804 & 2 & N/A & $\mathrm{N} / \mathrm{A}$ & MTB & $\mathrm{MB}$ & 17-Sep-17 & 28 & $4,960.3$ & $5,012.6$ & LTT: Landward \\
\hline HB01-6 & NHC_D20170917_HB01-6 & 42.912609 & -70.807349 & 2 & N/A & $\mathrm{N} / \mathrm{A}$ & LTB & LB & 17 -Sep-17 & 28 & $4,074.2$ & $4,068.6$ & LTT: Swash \\
\hline HB02-1 & NHC_D20170917_HB02-1 & 42.908993 & -70.810533 & 2 & $\mathrm{~N} / \mathrm{A}$ & $\mathrm{N} / \mathrm{A}$ & STB & UB; BS & 17-Sep-17 & 28 & $2,813.1$ & $2,808.9$ & $\begin{array}{c}\text { Backshore: Near } \\
\text { Seawall }\end{array}$ \\
\hline $\mathrm{HBO2-2}$ & NHC_D20170917_HB02-2 & 42.908961 & -70.810056 & 2 & $\mathrm{~N} / \mathrm{A}$ & $\mathrm{N} / \mathrm{A}$ & STB & UB; BS & 17-Sep-17 & 29 & $2,307.1$ & $2,306.2$ & Backshore: Mid \\
\hline $\mathrm{HBO2}-3$ & NHC_D20170917_HB02-3 & 42.908873 & -70.809577 & 1 & 2.42 & 2.56 & UTB & UB & 17 -Sep-17 & 29 & $2,609.1$ & $2,605.2$ & Berm Crest \\
\hline $\mathrm{HBO2-4}$ & NHC_D20170917_HB02-4 & 42.908843 & -70.809382 & 1 & 0.76 & 0.89 & MTB & $\mathrm{MB}$ & 17-Sep-17 & 28 & $5,025.0$ & $4,984.4$ & Berm Toe \\
\hline HBO2-5 & NHC_D20170917_HB02-5 & 42.908807 & -70.809135 & 2 & $\mathrm{~N} / \mathrm{A}$ & $\mathrm{N} / \mathrm{A}$ & MTB & $\mathrm{LB}$ & 17 -Sep-17 & 30 & $4,268.3$ & $4,249.0$ & LTT:Mid \\
\hline $\mathrm{HBO2-6}$ & NHC_D20170917_HB02-6 & 42.908783 & -70.808826 & 2 & $\mathrm{~N} / \mathrm{A}$ & $\mathrm{N} / \mathrm{A}$ & LTB & LB & 17-Sep-17 & 29 & $3,602.9$ & $3,617.1$ & LTT: Swash \\
\hline HВ03-1 & NHC_D20170917_HB03-1 & 42.905535 & -70.811160 & 1 & 3.32 & 3.45 & STB & UB; BS & 17 -Sep-17 & 29 & $2,605.4$ & $2,589.8$ & $\begin{array}{c}\text { Backshore: Near } \\
\text { Seawall }\end{array}$ \\
\hline HBO3-2 & NHC_D20170917_HB03-2 & 42.905520 & -70.810714 & 1 & 2.98 & 3.11 & STB & UB; BS & 17-Sep-17 & 29 & $2,689.3$ & $2,681.7$ & Backshore: Mid \\
\hline HВ03-3 & NHC_D20170917_HB03-3 & 42.905496 & -70.810079 & 1 & 2.47 & 2.60 & UTB & UB & 17-Sep-17 & 29 & $2,250.3$ & $2,249.1$ & Berm Crest \\
\hline $\mathrm{HBO3-4}$ & NHC D20170917 HB03-4 & 42.905484 & -70.809800 & 1 & 0.71 & 0.84 & MTB & $\mathrm{MB}$ & 17-Sep-17 & 30 & $3,596.5$ & $3,580.1$ & Berm Toe \\
\hline HBO3-5 & NHC_D20170917_HB03-5 & 42.905475 & -70.809570 & 1 & 0.15 & 0.29 & MTB & LB & 17 -Sep-17 & 29 & $3,685.7$ & $3,673.4$ & LTT: Mid \\
\hline HB03-6 & NHC_D20170917_HB03-6 & 42.905470 & -70.809348 & 1 & -0.50 & -0.37 & LTB & LB & 17-Sep-17 & 27 & $4,129.6$ & $4,149.8$ & LTT: Swash \\
\hline
\end{tabular}




\begin{tabular}{|c|c|c|c|c|c|c|c|c|}
\hline Sample ID & $\begin{array}{l}\text { CMECS Substrate } \\
\text { Component } \\
\text { Group (Specific) }\end{array}$ & $\begin{array}{l}\text { CMECS Substrate } \\
\text { Component Subgroup } \\
\text { (Specific) }\end{array}$ & $\begin{array}{l}\text { Textural Group from } \\
\text { \%GSM (Gradistat) }\end{array}$ & $\begin{array}{l}\text { Sediment Name from } \\
\text { \%GSM } \\
\text { and Mode (Gradistat) }\end{array}$ & $\begin{array}{l}\text { Sediment Name from } \\
\text { \%GSM and Mode } \\
\text { (Wentworth Scale) }\end{array}$ & $\begin{array}{l}\text { Sediment Classification } \\
\text { from Mean Phi } \\
\text { (Gradistat) }\end{array}$ & $\begin{array}{l}\text { Sediment } \\
\text { Classification } \\
\text { from Mean Phi } \\
\text { (Wentworth) }\end{array}$ & Sorting (Gradistat) \\
\hline HB01-1 & Slightly Granuley & $\begin{array}{l}\text { Slightly Granuley } \\
\text { Medium Sand }\end{array}$ & Slightly Gravelly Sand & $\begin{array}{l}\text { Slightly Very Fine Gravelly } \\
\text { Medium Sand }\end{array}$ & $\begin{array}{l}\text { Slightly Granular } \\
\text { Medium Sand }\end{array}$ & Medium Sand & Medium Sand & Moderately Sorted \\
\hline HB01-2 & Slightly Granuley & $\begin{array}{l}\text { Slightly Granuley } \\
\text { Medium Sand }\end{array}$ & Slightly Gravelly Sand & $\begin{array}{l}\text { Slightly Very Fine Gravelly } \\
\text { Medium Sand }\end{array}$ & $\begin{array}{l}\text { Slightly Granular } \\
\text { Medium Sand }\end{array}$ & Medium Sand & Medium Sand & Moderately Sorted \\
\hline HB01-3 & Slightly Granuley & $\begin{array}{l}\text { Slightly Granuley } \\
\text { Coarse Sand }\end{array}$ & Slightly Gravelly Sand & $\begin{array}{l}\text { Slightly Very Fine Gravelly } \\
\text { Coarse Sand }\end{array}$ & $\begin{array}{l}\text { Slightly Granular Coarse } \\
\text { Sand }\end{array}$ & Coarse Sand & Coarse Sand & Moderately Well Sorted \\
\hline HB01-4 & Slightly Granuley & $\begin{array}{l}\text { Slightly Granuley } \\
\text { Medium Sand }\end{array}$ & Slightly Gravelly Sand & $\begin{array}{l}\text { Slightly Very Fine Gravelly } \\
\text { Medium Sand }\end{array}$ & $\begin{array}{l}\text { Slightly Granular } \\
\text { Medium Sand }\end{array}$ & Medium Sand & Medium Sand & Moderately Well Sorted \\
\hline HB01-5 & Slightly Granuley & $\begin{array}{l}\text { Slightly Granuley } \\
\text { Coarse Sand }\end{array}$ & Slightly Gravelly Sand & $\begin{array}{l}\text { Slightly Very Fine Gravelly } \\
\text { Coarse Sand }\end{array}$ & $\begin{array}{l}\text { Slightly Granular Coarse } \\
\text { Sand }\end{array}$ & Coarse Sand & Coarse Sand & Poorly Sorted \\
\hline HB01-6 & Slightly Granuley & $\begin{array}{l}\text { Slightly Granuley } \\
\text { Medium Sand }\end{array}$ & Slightly Gravelly Sand & $\begin{array}{l}\text { Slightly Very Fine Gravelly } \\
\text { Medium Sand }\end{array}$ & $\begin{array}{l}\text { Slightly Granular } \\
\text { Medium Sand }\end{array}$ & Medium Sand & Medium Sand & Poorly Sorted \\
\hline $\mathrm{HBO2-1}$ & Slightly Pebbly & $\begin{array}{l}\text { Slightly Pebbly Medium } \\
\text { Sand }\end{array}$ & Slightly Gravelly Sand & $\begin{array}{l}\text { Slightly Medium Gravelly } \\
\text { Medium Sand }\end{array}$ & $\begin{array}{l}\text { Slightly Pebbly Medium } \\
\text { Sand }\end{array}$ & Medium Sand & Medium Sand & Moderately Well Sorted \\
\hline HBO2-2 & Slightly Granuley & $\begin{array}{l}\text { Slightly Granuley } \\
\text { Medium Sand }\end{array}$ & Slightly Gravelly Sand & $\begin{array}{l}\text { Slightly Very Fine Gravelly } \\
\text { Medium Sand }\end{array}$ & $\begin{array}{l}\text { Slightly Granular } \\
\text { Medium Sand }\end{array}$ & Medium Sand & Medium Sand & Moderately Well Sorted \\
\hline HBO2-3 & Medium Sand & Medium Sand & Sand & Medium Sand & Medium Sand & Medium Sand & Medium Sand & Moderately Well Sorted \\
\hline HBO2-4 & Slightly Granuley & $\begin{array}{l}\text { Slightly Granuley Fine } \\
\text { Sand }\end{array}$ & Slightly Gravelly Sand & $\begin{array}{l}\text { Slightly Very Fine Gravelly } \\
\text { Fine Sand }\end{array}$ & $\begin{array}{l}\text { Slightly Granular Fine } \\
\text { Sand }\end{array}$ & Fine Sand & Fine Sand & Moderately Well Sorted \\
\hline HBO2-5 & Slightly Granuley & $\begin{array}{l}\text { Slightly Granuley Fine } \\
\text { Sand }\end{array}$ & Slightly Gravelly Sand & $\begin{array}{l}\text { Slightly Very Fine Gravelly } \\
\text { Fine Sand }\end{array}$ & $\begin{array}{l}\text { Slightly Granular Fine } \\
\text { Sand }\end{array}$ & Medium Sand & Medium Sand & Moderately Sorted \\
\hline $\mathrm{HBO2-6}$ & Slightly Granuley & $\begin{array}{l}\text { Slightly Granuley } \\
\text { Medium Sand }\end{array}$ & Slightly Gravelly Sand & $\begin{array}{l}\text { Slightly Very Fine Gravelly } \\
\text { Medium Sand }\end{array}$ & $\begin{array}{l}\text { Slightly Granular } \\
\text { Medium Sand }\end{array}$ & Medium Sand & Medium Sand & Poorly Sorted \\
\hline HBO3-1 & Slightly Pebbly & $\begin{array}{l}\text { Slightly Pebbly Medium } \\
\text { Sand }\end{array}$ & Slightly Gravelly Sand & $\begin{array}{l}\text { Slightly Fine Gravelly } \\
\text { Medium Sand }\end{array}$ & $\begin{array}{l}\text { Slightly Pebbly Medium } \\
\text { Sand }\end{array}$ & Medium Sand & Medium Sand & Moderately Well Sorted \\
\hline HBO3-2 & Slightly Granuley & $\begin{array}{l}\text { Slightly Granuley } \\
\text { Medium Sand }\end{array}$ & Slightly Gravelly Sand & $\begin{array}{l}\text { Slightly Very Fine Gravelly } \\
\text { Medium Sand }\end{array}$ & $\begin{array}{l}\text { Slightly Granular } \\
\text { Medium Sand }\end{array}$ & Medium Sand & Medium Sand & Moderately Well Sorted \\
\hline HBO3-3 & Slightly Granuley & $\begin{array}{l}\text { Slightly Granuley } \\
\text { Medium Sand }\end{array}$ & Slightly Gravelly Sand & $\begin{array}{l}\text { Slightly Very Fine Gravelly } \\
\text { Medium Sand }\end{array}$ & $\begin{array}{l}\text { Slightly Granular } \\
\text { Medium Sand }\end{array}$ & Medium Sand & Medium Sand & Moderately Well Sorted \\
\hline HBO3-4 & Slightly Granuley & $\begin{array}{l}\text { Slightly Granuley } \\
\text { Medium Sand }\end{array}$ & Slightly Gravelly Sand & $\begin{array}{l}\text { Slightly Very Fine Gravelly } \\
\text { Medium Sand }\end{array}$ & $\begin{array}{l}\text { Slightly Granular } \\
\text { Medium Sand }\end{array}$ & Medium Sand & Medium Sand & Moderately Sorted \\
\hline HBO3-5 & Slightly Granuley & $\begin{array}{l}\text { Slightly Granuley } \\
\text { Medium Sand }\end{array}$ & Slightly Gravelly Sand & $\begin{array}{l}\text { Slightly Very Fine Gravelly } \\
\text { Medium Sand }\end{array}$ & $\begin{array}{l}\text { Slightly Granular } \\
\text { Medium Sand }\end{array}$ & Medium Sand & Medium Sand & Moderately Sorted \\
\hline HBO3-6 & Slightly Granuley & $\begin{array}{l}\text { Slightly Granuley } \\
\text { Coarse Sand }\end{array}$ & Slightly Gravelly Sand & $\begin{array}{l}\text { Slightly Very Fine Gravelly } \\
\text { Coarse Sand }\end{array}$ & $\begin{array}{l}\text { Slightly Granular Coarse } \\
\text { Sand }\end{array}$ & Coarse Sand & Coarse Sand & Poorly Sorted \\
\hline
\end{tabular}


Hampton Beach (Summer Sampling), Hampton, New Hampshire: Grain Size Statistics

\begin{tabular}{|c|c|c|c|c|c|c|c|c|c|c|c|c|c|c|c|c|c|}
\hline Sample ID & Gravel \% & Pebble \% & Granule \% & Sand \% & Mud \% & Modes & $\begin{array}{c}\text { Mode } 1 \\
\text { (phi) }\end{array}$ & $\begin{array}{c}\text { Mode } 2 \\
\text { (phi) }\end{array}$ & $\begin{array}{c}\mathrm{D}_{10} \\
\text { (phi) }\end{array}$ & $\begin{array}{c}\mathrm{D}_{10} \\
(\mathrm{~mm}) \\
\end{array}$ & $\begin{array}{r}\mathrm{D}_{50} \\
\text { (phi) }\end{array}$ & $\begin{array}{r}\mathrm{D}_{50} \\
(\mathrm{~mm}) \\
\end{array}$ & $\begin{array}{c}\begin{array}{c}\text { Mean Size } \\
\text { (phi) }\end{array} \\
\end{array}$ & $\begin{array}{c}\text { Mean Size } \\
(\mathrm{mm})\end{array}$ & $\begin{array}{c}\text { Sorting } \\
\text { (phi) }\end{array}$ & Skewness & Kurtosis \\
\hline HB01-1 & 0.29 & 0.14 & 0.15 & 99.42 & 0.29 & $u$ & 1.75 & N/A & 0.43 & 0.74 & 1.42 & 0.37 & 1.39 & 0.38 & 0.75 & -0.05 & 1.05 \\
\hline HB01-2 & 0.42 & 0.07 & 0.35 & 99.31 & 0.27 & $u$ & 1.25 & N/A & 0.06 & 0.96 & 1.16 & 0.45 & 1.10 & 0.47 & 0.80 & -0.09 & 0.99 \\
\hline HB01-3 & 0.23 & 0.01 & 0.22 & 99.72 & 0.05 & U & 1.25 & N/A & -0.11 & 1.08 & 0.87 & 0.55 & 0.82 & 0.57 & 0.70 & -0.09 & 0.93 \\
\hline HB01-4 & 0.02 & 0.00 & 0.02 & 99.96 & 0.02 & $u$ & 1.75 & $\mathrm{~N} / \mathrm{A}$ & 0.59 & 0.66 & 1.49 & 0.35 & 1.43 & 0.37 & 0.63 & -0.13 & 1.00 \\
\hline HB01-5 & 3.52 & 0.63 & 2.89 & 96.46 & 0.02 & U & 0.25 & N/A & -0.57 & 1.48 & 0.70 & 0.62 & 0.88 & 0.54 & 1.23 & 0.18 & 0.79 \\
\hline HB01-6 & 0.80 & 0.09 & 0.71 & 99.18 & 0.02 & $u$ & 1.75 & N/A & -0.20 & 1.15 & 1.32 & 0.40 & 1.29 & 0.41 & 1.13 & -0.03 & 0.78 \\
\hline $\mathrm{HB} 02-1$ & 0.30 & 0.19 & 0.10 & 99.56 & 0.14 & $u$ & 1.25 & N/A & 0.51 & 0.70 & 1.36 & 0.39 & 1.32 & 0.40 & 0.65 & -0.08 & 1.06 \\
\hline $\mathrm{HBO2-2}$ & 0.07 & 0.01 & 0.06 & 99.85 & 0.08 & U & 1.25 & N/A & 0.44 & 0.74 & 1.29 & 0.41 & 1.26 & 0.42 & 0.63 & -0.08 & 1.04 \\
\hline $\mathrm{HBO2-3}$ & 0.01 & 0.00 & 0.01 & 99.98 & 0.01 & $u$ & 1.75 & N/A & 0.66 & 0.63 & 1.53 & 0.35 & 1.48 & 0.36 & 0.59 & -0.10 & 1.00 \\
\hline $\mathrm{HBO2-4}$ & 2.03 & 1.30 & 0.73 & 97.95 & 0.02 & U & 2.24 & N/A & 1.52 & 0.35 & 2.20 & 0.22 & 2.19 & 0.22 & 0.56 & -0.11 & 1.18 \\
\hline $\mathrm{HB} 02-5$ & 0.35 & 0.08 & 0.27 & 99.63 & 0.02 & $u$ & 2.24 & N/A & 0.56 & 0.68 & 2.03 & 0.25 & 1.90 & 0.27 & 0.88 & -0.27 & 1.01 \\
\hline $\mathrm{HBO2-6}$ & 1.50 & 0.40 & 1.10 & 98.48 & 0.02 & U & 0.75 & $\mathrm{~N} / \mathrm{A}$ & -0.02 & 1.01 & 1.36 & 0.39 & 1.38 & 0.38 & 1.09 & -0.01 & 0.82 \\
\hline HBO3-1 & 0.01 & 0.01 & 0.00 & 99.90 & 0.09 & $u$ & 1.75 & $\mathrm{~N} / \mathrm{A}$ & 0.94 & 0.52 & 1.63 & 0.32 & 1.61 & 0.33 & 0.53 & -0.06 & 1.05 \\
\hline $\mathrm{HB} 03-2$ & 0.01 & 0.00 & 0.01 & 99.86 & 0.13 & U & 1.75 & N/A & 0.74 & 0.60 & 1.57 & 0.34 & 1.56 & 0.34 & 0.61 & 0.00 & 1.05 \\
\hline HBO3-3 & 0.12 & 0.02 & 0.11 & 99.87 & 0.01 & U & 1.75 & N/A & 0.61 & 0.66 & 1.58 & 0.34 & 1.53 & 0.35 & 0.67 & -0.14 & 1.04 \\
\hline HB03-4 & 0.73 & 0.36 & 0.38 & 99.26 & 0.01 & $U$ & 1.75 & N/A & 0.54 & 0.69 & 1.72 & 0.30 & 1.70 & 0.31 & 0.87 & -0.08 & 0.96 \\
\hline HBO3-5 & 0.48 & 0.08 & 0.40 & 99.51 & 0.01 & $U$ & 1.75 & N/A & 0.58 & 0.67 & 1.74 & 0.30 & 1.70 & 0.31 & 0.81 & -0.11 & 1.10 \\
\hline HBO3-6 & 3.88 & 1.77 & 2.11 & 96.10 & 0.02 & U & 1.25 & N/A & -0.43 & 1.35 & 0.88 & 0.54 & 0.86 & 0.55 & 1.02 & -0.03 & 1.12 \\
\hline
\end{tabular}




\begin{tabular}{|c|c|c|c|c|c|c|c|c|c|c|c|c|c|c|c|c|c|c|c|c|c|}
\hline Sample ID & $\begin{array}{c}\text { Class \% } \\
\text { phi } \\
-5.5\end{array}$ & $\begin{array}{c}\text { Class \% } \\
\text { phi } \\
-5.0\end{array}$ & $\begin{array}{c}\text { Class \% } \\
\text { phi } \\
-4.5\end{array}$ & $\begin{array}{c}\text { Class \% } \\
\text { phi } \\
-4.0 \\
\end{array}$ & $\begin{array}{c}\text { Class \% } \\
\text { phi } \\
-3.5\end{array}$ & $\begin{array}{c}\text { Class \% } \\
\text { phi } \\
-3.0\end{array}$ & $\begin{array}{c}\text { Class \% } \\
\text { phi } \\
-2.5 \\
\end{array}$ & $\begin{array}{c}\text { Class \% } \\
\text { phi } \\
-2.0 \\
\end{array}$ & $\begin{array}{c}\text { Class \% } \\
\text { phi } \\
-1.5\end{array}$ & $\begin{array}{c}\text { Class \% } \\
\text { phi } \\
-1.0 \\
\end{array}$ & $\begin{array}{c}\text { Class \% } \\
\text { phi } \\
-0.5 \\
\end{array}$ & $\begin{array}{c}\text { Class \% } \\
\text { phi } \\
0.0 \\
\end{array}$ & $\begin{array}{c}\text { Class \% } \\
\text { phi } \\
0.5 \\
\end{array}$ & $\begin{array}{c}\text { Class \% } \\
\text { phi } \\
1.0 \\
\end{array}$ & $\begin{array}{c}\text { Class \% } \\
\text { phi } \\
1.5 \\
\end{array}$ & $\begin{array}{c}\text { Class \% } \\
\text { phi } \\
2.0 \\
\end{array}$ & $\begin{array}{c}\text { Class \% } \\
\text { phi } \\
2.5 \\
\end{array}$ & $\begin{array}{c}\text { Class \% } \\
\text { phi } \\
3.0 \\
\end{array}$ & $\begin{array}{c}\text { Class \% } \\
\text { phi } \\
3.5 \\
\end{array}$ & $\begin{array}{c}\text { Class \% } \\
\text { phi } \\
4.0 \\
\end{array}$ & $\begin{array}{c}\text { Class } \% \\
\text { phi } \\
>4.0 \\
\end{array}$ \\
\hline HB01-1 & 0.00 & 0.00 & 0.00 & 0.00 & 0.00 & 0.05 & 0.03 & 0.07 & 0.05 & 0.10 & 0.46 & 2.10 & 8.27 & 16.90 & 25.66 & 27.04 & 12.41 & 5.23 & 1.17 & 0.18 & 0.29 \\
\hline HB01-2 & 0.00 & 0.00 & 0.00 & 0.00 & 0.00 & 0.00 & 0.04 & 0.02 & 0.07 & 0.29 & 1.73 & 6.36 & 13.24 & 19.94 & 25.94 & 21.78 & 6.92 & 2.58 & 0.67 & 0.15 & 0.27 \\
\hline HB01-3 & 0.00 & 0.00 & 0.00 & 0.00 & 0.00 & 0.00 & 0.00 & 0.01 & 0.03 & 0.19 & 1.93 & 10.23 & 18.71 & 25.53 & 27.28 & 12.97 & 2.34 & 0.59 & 0.12 & 0.03 & 0.05 \\
\hline HB01-4 & 0.00 & 0.00 & 0.00 & 0.00 & 0.00 & 0.00 & 0.00 & 0.00 & 0.01 & 0.02 & 0.18 & 0.72 & 5.92 & 16.88 & 26.26 & 33.17 & 13.55 & 2.95 & 0.32 & 0.01 & 0.02 \\
\hline HB01-5 & 0.00 & 0.00 & 0.00 & 0.00 & 0.03 & 0.13 & 0.13 & 0.34 & 0.84 & 2.05 & 7.75 & 15.70 & 17.82 & 12.82 & 9.77 & 9.96 & 10.91 & 9.22 & 2.49 & 0.02 & 0.02 \\
\hline HB01-6 & 0.00 & 0.00 & 0.00 & 0.00 & 0.00 & 0.01 & 0.01 & 0.07 & 0.20 & 0.51 & 3.30 & 10.06 & 14.74 & 12.86 & 12.56 & 15.54 & 13.86 & 11.00 & 5.10 & 0.16 & 0.02 \\
\hline $\mathrm{HB} 02-1$ & 0.00 & 0.00 & 0.00 & 0.00 & 0.14 & 0.00 & 0.02 & 0.03 & 0.02 & 0.08 & 0.35 & 1.86 & 6.99 & 17.86 & 30.91 & 29.37 & 9.05 & 2.59 & 0.47 & 0.12 & 0.14 \\
\hline $\mathrm{HBO2-2}$ & 0.00 & 0.00 & 0.00 & 0.00 & 0.00 & 0.00 & 0.00 & 0.01 & 0.01 & 0.06 & 0.40 & 2.09 & 8.31 & 19.24 & 33.37 & 27.98 & 6.26 & 1.76 & 0.37 & 0.07 & 0.08 \\
\hline $\mathrm{HB} 02-3$ & 0.00 & 0.00 & 0.00 & 0.00 & 0.00 & 0.00 & 0.00 & 0.00 & 0.00 & 0.00 & 0.08 & 0.53 & 4.57 & 14.85 & 27.37 & 34.93 & 14.03 & 3.22 & 0.39 & 0.01 & 0.01 \\
\hline $\mathrm{HBO2}-4$ & 0.00 & 0.00 & 0.00 & 0.00 & 0.15 & 0.38 & 0.38 & 0.39 & 0.37 & 0.36 & 0.43 & 0.37 & 0.51 & 1.14 & 4.20 & 23.49 & 41.25 & 22.33 & 4.18 & 0.04 & 0.02 \\
\hline $\mathrm{HBO2-5}$ & 0.00 & 0.00 & 0.00 & 0.00 & 0.00 & 0.02 & 0.01 & 0.04 & 0.08 & 0.19 & 0.83 & 2.42 & 5.33 & 8.07 & 11.42 & 20.27 & 24.80 & 22.15 & 4.27 & 0.07 & 0.02 \\
\hline $\mathrm{HBO2-6}$ & 0.00 & 0.00 & 0.00 & 0.00 & 0.00 & 0.05 & 0.14 & 0.22 & 0.37 & 0.73 & 2.30 & 6.41 & 12.71 & 16.10 & 15.11 & 14.42 & 13.00 & 15.17 & 3.25 & 0.04 & 0.02 \\
\hline HB03-1 & 0.00 & 0.00 & 0.00 & 0.00 & 0.00 & 0.00 & 0.00 & 0.01 & 0.00 & 0.00 & 0.01 & 0.09 & 1.36 & 9.58 & 27.98 & 41.08 & 15.57 & 3.80 & 0.39 & 0.03 & 0.09 \\
\hline $\mathrm{HB} 03-2$ & 0.00 & 0.00 & 0.00 & 0.00 & 0.00 & 0.00 & 0.00 & 0.00 & 0.00 & 0.01 & 0.06 & 0.46 & 2.76 & 13.88 & 28.01 & 34.27 & 14.21 & 5.17 & 0.95 & 0.11 & 0.13 \\
\hline $\mathrm{HBO3-3}$ & 0.00 & 0.00 & 0.00 & 0.00 & 0.00 & 0.00 & 0.00 & 0.02 & 0.03 & 0.08 & 0.39 & 1.58 & 5.00 & 13.13 & 24.56 & 32.64 & 17.51 & 4.89 & 0.17 & 0.01 & 0.01 \\
\hline $\mathrm{HB} 03-4$ & 0.00 & 0.00 & 0.00 & 0.00 & 0.05 & 0.07 & 0.13 & 0.11 & 0.13 & 0.25 & 0.93 & 2.14 & 5.20 & 11.42 & 19.31 & 23.24 & 17.45 & 16.46 & 3.05 & 0.05 & 0.01 \\
\hline HBO3-5 & 0.00 & 0.00 & 0.00 & 0.00 & 0.00 & 0.00 & 0.03 & 0.05 & 0.14 & 0.26 & 0.90 & 2.34 & 4.74 & 9.30 & 17.86 & 30.07 & 18.54 & 12.98 & 2.73 & 0.04 & 0.01 \\
\hline $\mathrm{HBO3-6}$ & 0.00 & 0.00 & 0.00 & 0.22 & 0.03 & 0.56 & 0.40 & 0.57 & 0.70 & 1.41 & 4.94 & 9.96 & 15.17 & 20.81 & 20.98 & 12.73 & 5.44 & 4.77 & 1.28 & 0.03 & 0.02 \\
\hline
\end{tabular}


Section 7(a): Seabrook Beach (Winter/Spring 2017 Sampling Period) 


\begin{tabular}{|c|c|c|c|c|c|c|c|c|c|c|c|c|c|}
\hline Sample ID & Global Sample ID & $\begin{array}{l}\text { Latitude } \\
\text { WGS84 } \\
\end{array}$ & $\begin{array}{c}\text { Longitude } \\
\text { WGS84 }\end{array}$ & $\begin{array}{l}\text { Relative } \\
\text { Position } \\
\text { Accuracy } \\
\end{array}$ & $\begin{array}{c}\text { Elevation } \\
\text { (m) } \\
\text { NAVD88 } \\
\end{array}$ & $\begin{array}{c}\text { Elevation } \\
(\mathrm{m}) \\
\text { MTL } \\
\end{array}$ & $\begin{array}{c}\text { Relative } \\
\text { Elevation }\end{array}$ & $\begin{array}{l}\text { Relative } \\
\text { Location }\end{array}$ & $\begin{array}{l}\text { Sample } \\
\text { Collected }\end{array}$ & $\begin{array}{l}\text { Core } \\
\text { Length } \\
\text { (cm) } \\
\end{array}$ & $\begin{array}{c}\text { Collected } \\
\text { Sample } \\
\text { Wt. (gm) } \\
\end{array}$ & $\begin{array}{c}\text { Processed } \\
\text { Sample } \\
\text { Wt. (gm) } \\
\end{array}$ & $\begin{array}{l}\text { Morphologic } \\
\text { Feature } \\
\end{array}$ \\
\hline SB01-1 & NHC_D20170310_SB01-1 & 42.887482 & -70.813685 & 1 & 3.96 & 4.09 & STB & BS & 10-Mar-17 & 27 & $3,226.2$ & $3,214.7$ & Backshore: Mid \\
\hline SB01-2 & NHC_D20170310_SB01-2 & 42.887391 & -70.813368 & 1 & 2.93 & 3.07 & STB & UB & 10-Mar-17 & 28 & $2,976.3$ & $2,978.7$ & $\begin{array}{c}\text { Berm Crest; LHTS; } \\
\text { Cusps }\end{array}$ \\
\hline SB01-3 & NHC D20170310_SB01-3 & 42.887354 & -70.813243 & 1 & 1.31 & 1.45 & MTL & $\mathrm{MB}$ & 10-Mar-17 & 28 & $3,080.7$ & $3,066.4$ & Berm Face: Mid \\
\hline SB01-4 & NHC D20170310_SB01-4 & 42.887313 & -70.813098 & 1 & -0.56 & -0.42 & LTB & LB & 10-Mar-17 & 27 & $6,072.3$ & $5,986.8$ & Berm Toe \\
\hline SB01-5 & NHC_D20170310_SB01-5 & 42.887213 & -70.812750 & 1 & -1.14 & -1.00 & LTB & LB & 10-Mar-17 & 28 & $3,591.7$ & $3,593.3$ & LT; Swash \\
\hline SBO2-1 & NHC_D20170310_SB02-1 & 42.884902 & -70.814562 & 1 & 5.20 & 5.34 & STB & Dunes & 10-Mar-17 & 26 & $2,522.5$ & $2,518.4$ & $\begin{array}{l}\text { Dunes: Frontal; } \\
\text { Fringe }\end{array}$ \\
\hline $\mathrm{SB} 02-2$ & NHC D20170310 SB02-2 & 42.884868 & -70.814337 & 1 & 3.91 & 4.05 & STB & BS & 10-Mar-17 & 24 & $5,188.9$ & $5,163.7$ & Backshore: Mid \\
\hline SBO2-3 & NHC_D20170310_SB02-3 & 42.884850 & -70.814192 & 1 & 3.18 & 3.32 & STB & UB & 10-Mar-17 & 27 & $4,227.1$ & $4,210.1$ & $\begin{array}{c}\text { Berm Crest; } \text { LHTS; } \\
\text { Cusps }\end{array}$ \\
\hline SBO2-4 & NHC_D20170310_SB02-4 & 42.884822 & -70.814001 & 1 & 0.65 & 0.79 & MTB & $\mathrm{MB}$ & 10-Mar-17 & 27 & $5,039.3$ & $4,982.7$ & Berm Face: Mid \\
\hline SBO2-5 & NHC_D20170310_SB02-5 & 42.884806 & -70.813890 & 1 & -0.62 & -0.48 & LTB & LB & 10-Mar-17 & 26 & $4,640.5$ & $4,553.2$ & Berm Toe \\
\hline SBO2-6 & NHC D20170310 SB02-6 & 42.884766 & -70.813586 & 1 & -1.10 & -0.96 & LTB & LB & 10-Mar-17 & 29 & $2,594.5$ & $2,587.3$ & LT; Mid \\
\hline SBO3-1 & NHC_D20170502_SB03-1 & 42.882888 & -70.814862 & 1 & 3.98 & 4.12 & STB & BS & 2-May-17 & 27 & $2,992.3$ & $2,988.7$ & $\begin{array}{c}\text { Backshore; Near } \\
\text { Dunes }\end{array}$ \\
\hline SBO3-2 & NHC_D20170502_SB03-2 & 42.882880 & -70.814674 & 1 & 2.69 & 2.83 & UTB & UB & 2-May-17 & 27 & $2,769.6$ & $2,767.0$ & Berm Crest; LHTS \\
\hline SBO3-3 & NHC D20170502_SB03-3 & 42.882870 & -70.814414 & 1 & 0.39 & 0.52 & MTB & $\mathrm{MB}$ & 2-May-17 & 27 & $2,971.6$ & $2,939.1$ & Berm Toe \\
\hline SBO3-4 & NHC D20170502_SB03-4 & 42.882854 & -70.814070 & 1 & -0.66 & -0.53 & LTB & $L B$ & 2-May-17 & 27 & $2,479.6$ & $2,460.3$ & LT; Lower \\
\hline SB04-1 & NHC D20170318 SB04-1 & 42.879766 & -70.815632 & 1 & 4.92 & 5.06 & STB & Dunes & 18-Mar-17 & 25 & $2,956.4$ & $2,945.3$ & Dune; Overwash \\
\hline SB04-2 & NHC_D20170318_SB04-2 & 42.879740 & -70.815330 & 1 & 3.44 & 3.58 & STB & BS & 18-Mar-17 & 27 & $2,372.4$ & $2,359.8$ & Backshore: Mid \\
\hline SBO4-3 & NHC D20170318_SB04-3 & 42.879727 & -70.815144 & 1 & 2.14 & 2.28 & UTB & UB & 18-Mar-17 & 27 & $2,853.7$ & $2,845.2$ & Berm Crest \\
\hline SB04-4 & NHC_D20170318_SB04-4 & 42.879707 & -70.814867 & 1 & -0.72 & -0.58 & LTB & $M B$ & 18-Mar-17 & 27 & $2,662.9$ & $2,635.2$ & Berm Toe \\
\hline SB04-5 & NHC_D20170318_SB04-5 & 42.879687 & -70.814604 & 1 & -1.09 & -0.96 & LTB & $L B$ & 18-Mar-17 & 25 & $2,426.8$ & $2,416.7$ & LTT: Mid \\
\hline SB04-6 & NHC_D20170318_SB04-6 & 42.879663 & -70.814284 & 1 & -1.30 & -1.16 & LTB & LB & 18-Mar-17 & 27 & $2,489.1$ & $2,490.0$ & LTT: Swash \\
\hline SB05-1 & NHC D20170320 SB05-1 & 42.874376 & -70.816350 & 1 & 5.30 & 5.44 & STB & Dunes & 20-Mar-17 & 27 & $3,797.7$ & $3,788.3$ & Dune; Overwash \\
\hline SB05-2 & NHC D20170320_SB05-2 & 42.874374 & -70.816217 & 1 & 4.28 & 4.42 & STB & BS & 20-Mar-17 & 26 & $3,334.3$ & 3,324.4 & Backshore: Mid \\
\hline SB05-3 & NHC_D20170320_SB05-3 & 42.874371 & -70.815990 & 1 & 3.17 & 3.31 & STB & UB & 20-Mar-17 & 28 & $3,162.0$ & $3,149.2$ & Berm Crest \\
\hline SB05-4 & NHC_D20170320_SB05-4 & 42.874370 & -70.815701 & 1 & 0.07 & 0.21 & MTB & $\mathrm{MB}$ & 20-Mar-17 & 26 & $4,982.9$ & $5,002.5$ & $\begin{array}{c}\text { Berm Toe: Water } \\
\text { Covering LTT }\end{array}$ \\
\hline
\end{tabular}




\begin{tabular}{|c|c|c|c|c|c|c|c|c|}
\hline Sample ID & $\begin{array}{l}\text { CMECS Substrate } \\
\text { Component } \\
\text { Group (Specific) }\end{array}$ & $\begin{array}{l}\text { CMECS Substrate } \\
\text { Component Subgroup } \\
\text { (Specific) }\end{array}$ & $\begin{array}{l}\text { Textural Group from } \\
\% \text { GSM (Gradistat) }\end{array}$ & $\begin{array}{l}\text { Sediment Name from } \\
\text { \%GSM } \\
\text { and Mode (Gradistat) }\end{array}$ & $\begin{array}{l}\text { Sediment Name from } \\
\text { \%GSM and Mode } \\
\text { (Wentworth Scale) }\end{array}$ & $\begin{array}{l}\text { Sediment Classification } \\
\text { from Mean Phi } \\
\text { (Gradistat) }\end{array}$ & $\begin{array}{l}\text { Sediment } \\
\text { Classification } \\
\text { from Mean Phi } \\
\text { (Wentworth) }\end{array}$ & Sorting (Gradistat) \\
\hline SB01-1 & Slightly Granuley & $\begin{array}{l}\text { Slightly Granuley } \\
\text { Medium Sand }\end{array}$ & Slightly Gravelly Sand & $\begin{array}{l}\text { Slightly Very Fine Gravelly } \\
\text { Medium Sand }\end{array}$ & $\begin{array}{l}\text { Slightly Granular } \\
\text { Medium Sand }\end{array}$ & Medium Sand & Medium Sand & Moderately Well Sorted \\
\hline SB01-2 & Slightly Granuley & $\begin{array}{l}\text { Slightly Granuley } \\
\text { Coarse Sand }\end{array}$ & Slightly Gravelly Sand & $\begin{array}{l}\text { Slightly Very Fine Gravelly } \\
\text { Coarse Sand }\end{array}$ & $\begin{array}{l}\text { Slightly Granular Coarse } \\
\text { Sand }\end{array}$ & Coarse Sand & Coarse Sand & Moderately Well Sorted \\
\hline SB01-3 & Granuley & Granuley Coarse Sand & Gravelly Sand & $\begin{array}{l}\text { Very Fine Gravelly Very } \\
\text { Coarse Sand }\end{array}$ & $\begin{array}{l}\text { Granular Very Coarse } \\
\text { Sand }\end{array}$ & Very Coarse Sand & Very Coarse Sand & Moderately Well Sorted \\
\hline SB01-4 & Granuley & Granuley Coarse Sand & Gravelly Sand & $\begin{array}{l}\text { Very Fine Gravelly Very } \\
\text { Coarse Sand }\end{array}$ & $\begin{array}{l}\text { Granular Very Coarse } \\
\text { Sand }\end{array}$ & Very Coarse Sand & Very Coarse Sand & Moderately Well Sorted \\
\hline SB01-5 & Slightly Granuley & $\begin{array}{l}\text { Slightly Granuley } \\
\text { Medium Sand }\end{array}$ & Slightly Gravelly Sand & $\begin{array}{l}\text { Slightly Very Fine Gravelly } \\
\text { Medium Sand }\end{array}$ & $\begin{array}{l}\text { Slightly Granular } \\
\text { Medium Sand }\end{array}$ & Medium Sand & Medium Sand & Moderately Sorted \\
\hline SBO2-1 & Sand & Coarse Sand & Sand & Coarse Sand & Coarse Sand & Coarse Sand & Coarse Sand & Moderately Well Sorted \\
\hline SBO2-2 & Slightly Granuley & $\begin{array}{l}\text { Slightly Granuley } \\
\text { Coarse Sand }\end{array}$ & Slightly Gravelly Sand & $\begin{array}{l}\text { Slightly Very Fine Gravelly } \\
\text { Coarse Sand }\end{array}$ & $\begin{array}{l}\text { Slightly Granular Coarse } \\
\text { Sand }\end{array}$ & Coarse Sand & Coarse Sand & Moderately Well Sorted \\
\hline SBO2-3 & Slightly Granuley & $\begin{array}{l}\text { Slightly Granuley } \\
\text { Coarse Sand }\end{array}$ & Slightly Gravelly Sand & $\begin{array}{l}\text { Slightly Very Fine Gravelly } \\
\text { Coarse Sand }\end{array}$ & $\begin{array}{l}\text { Slightly Granular Coarse } \\
\text { Sand }\end{array}$ & Coarse Sand & Coarse Sand & Moderately Well Sorted \\
\hline SBO2-4 & Granuley & $\begin{array}{l}\text { Granuley Very Coarse } \\
\text { Sand }\end{array}$ & Gravelly Sand & $\begin{array}{l}\text { Very Fine Gravelly Very } \\
\text { Coarse Sand }\end{array}$ & $\begin{array}{l}\text { Granular Very Coarse } \\
\text { Sand }\end{array}$ & Very Coarse Sand & Very Coarse Sand & Moderately Well Sorted \\
\hline SBO2-5 & Granuley & $\begin{array}{l}\text { Granuley Very Coarse } \\
\text { Sand }\end{array}$ & Gravelly Sand & $\begin{array}{l}\text { Very Fine Gravelly Very } \\
\text { Coarse Sand }\end{array}$ & $\begin{array}{l}\text { Granular Very Coarse } \\
\text { Sand }\end{array}$ & Very Coarse Sand & Very Coarse Sand & Moderately Well Sorted \\
\hline$S B 02-6$ & Slightly Granuley & $\begin{array}{l}\text { Slightly Granuley } \\
\text { Medium Sand }\end{array}$ & Slightly Gravelly Sand & $\begin{array}{l}\text { Slightly Very Fine Gravelly } \\
\text { Medium Sand }\end{array}$ & $\begin{array}{l}\text { Slightly Granular } \\
\text { Medium Sand }\end{array}$ & Medium Sand & Medium Sand & Moderately Well Sorted \\
\hline SB03-1 & Slightly Granuley & $\begin{array}{l}\text { Slightly Granuley } \\
\text { Coarse Sand }\end{array}$ & Slightly Gravelly Sand & $\begin{array}{l}\text { Slightly Very Fine Gravelly } \\
\text { Coarse Sand }\end{array}$ & $\begin{array}{l}\text { Slightly Granular Coarse } \\
\text { Sand }\end{array}$ & Coarse Sand & Coarse Sand & Moderately Well Sorted \\
\hline SBO3-2 & Slightly Granuley & $\begin{array}{l}\text { Slightly Granuley } \\
\text { Coarse Sand }\end{array}$ & Slightly Gravelly Sand & $\begin{array}{l}\text { Slightly Very Fine Gravelly } \\
\text { Coarse Sand }\end{array}$ & $\begin{array}{l}\text { Slightly Granular Coarse } \\
\text { Sand }\end{array}$ & Coarse Sand & Coarse Sand & Moderately Sorted \\
\hline SB03-3 & Granuley & $\begin{array}{l}\text { Granuley Very Coarse } \\
\text { Sand }\end{array}$ & Gravelly Sand & $\begin{array}{l}\text { Very Fine Gravelly Very } \\
\text { Coarse Sand }\end{array}$ & $\begin{array}{l}\text { Granular Very Coarse } \\
\text { Sand }\end{array}$ & Coarse Sand & Coarse Sand & Moderately Sorted \\
\hline SBO3-4 & Slightly Granuley & $\begin{array}{l}\text { Slightly Granuley } \\
\text { Medium Sand }\end{array}$ & Slightly Gravelly Sand & $\begin{array}{l}\text { Slightly Very Fine Gravelly } \\
\text { Medium Sand }\end{array}$ & $\begin{array}{l}\text { Slightly Granular } \\
\text { Medium Sand }\end{array}$ & Coarse Sand & Coarse Sand & Poorly Sorted \\
\hline SB04-1 & Slightly Granuley & $\begin{array}{l}\text { Slightly Granuley } \\
\text { Medium Sand }\end{array}$ & Slightly Gravelly Sand & $\begin{array}{l}\text { Slightly Very Fine Gravelly } \\
\text { Medium Sand }\end{array}$ & $\begin{array}{l}\text { Slightly Granular } \\
\text { Medium Sand }\end{array}$ & Medium Sand & Medium Sand & Moderately Sorted \\
\hline SBO4-2 & Slightly Granuley & $\begin{array}{l}\text { Slightly Granuley } \\
\text { Coarse Sand }\end{array}$ & Slightly Gravelly Sand & $\begin{array}{l}\text { Slightly Very Fine Gravelly } \\
\text { Coarse Sand }\end{array}$ & $\begin{array}{l}\text { Slightly Granular Coarse } \\
\text { Sand }\end{array}$ & Coarse Sand & Coarse Sand & Moderately Sorted \\
\hline SBO4-3 & Slightly Granuley & $\begin{array}{l}\text { Slightly Granuley } \\
\text { Coarse Sand }\end{array}$ & Slightly Gravelly Sand & $\begin{array}{l}\text { Slightly Very Fine Gravelly } \\
\text { Coarse Sand }\end{array}$ & $\begin{array}{l}\text { Slightly Granular Coarse } \\
\text { Sand }\end{array}$ & Coarse Sand & Coarse Sand & Moderately Sorted \\
\hline SBO4-4 & Granuley & $\begin{array}{l}\text { Granuley Very Coarse } \\
\text { Sand }\end{array}$ & Gravelly Sand & $\begin{array}{l}\text { Very Fine Gravelly Very } \\
\text { Coarse Sand }\end{array}$ & $\begin{array}{l}\text { Granular Very Coarse } \\
\text { Sand }\end{array}$ & Very Coarse Sand & Very Coarse Sand & Moderately Sorted \\
\hline SBO4-5 & Slightly Granuley & $\begin{array}{l}\text { Slightly Granuley } \\
\text { Medium Sand }\end{array}$ & Slightly Gravelly Sand & $\begin{array}{l}\text { Slightly Very Fine Gravelly } \\
\text { Medium Sand }\end{array}$ & $\begin{array}{l}\text { Slightly Granular } \\
\text { Medium Sand }\end{array}$ & Medium Sand & Medium Sand & Moderately Sorted \\
\hline SB04-6 & Slightly Granuley & $\begin{array}{l}\text { Slightly Granuley } \\
\text { Medium Sand }\end{array}$ & Slightly Gravelly Sand & $\begin{array}{l}\text { Slightly Very Fine Gravelly } \\
\text { Medium Sand }\end{array}$ & $\begin{array}{l}\text { Slightly Granular } \\
\text { Medium Sand }\end{array}$ & Medium Sand & Medium Sand & Moderately Well Sorted \\
\hline SB05-1 & Slightly Granuley & $\begin{array}{l}\text { Slightly Granuley } \\
\text { Medium Sand }\end{array}$ & Slightly Gravelly Sand & $\begin{array}{l}\text { Slightly Very Fine Gravelly } \\
\text { Medium Sand }\end{array}$ & $\begin{array}{l}\text { Slightly Granular } \\
\text { Medium Sand }\end{array}$ & Medium Sand & Medium Sand & Moderately Sorted \\
\hline SB05-2 & Slightly Granuley & $\begin{array}{l}\text { Slightly Granuley } \\
\text { Coarse Sand }\end{array}$ & Slightly Gravelly Sand & $\begin{array}{l}\text { Slightly Very Fine Gravelly } \\
\text { Coarse Sand }\end{array}$ & $\begin{array}{l}\text { Slightly Granular Coarse } \\
\text { Sand }\end{array}$ & Coarse Sand & Coarse Sand & Moderately Sorted \\
\hline SBO5-3 & Slightly Granuley & $\begin{array}{l}\text { Slightly Granuley } \\
\text { Coarse Sand }\end{array}$ & Slightly Gravelly Sand & $\begin{array}{l}\text { Slightly Very Fine Gravelly } \\
\text { Coarse Sand }\end{array}$ & $\begin{array}{l}\text { Slightly Granular Coarse } \\
\text { Sand }\end{array}$ & Coarse Sand & Coarse Sand & Moderately Sorted \\
\hline SB05-4 & Granuley & $\begin{array}{l}\text { Granuley Very Coarse } \\
\text { Sand }\end{array}$ & Gravelly Sand & $\begin{array}{l}\text { Very Fine Gravelly Very } \\
\text { Coarse Sand }\end{array}$ & $\begin{array}{l}\text { Granular Very Coarse } \\
\text { Sand }\end{array}$ & Very Coarse Sand & Very Coarse Sand & Poorly Sorted \\
\hline
\end{tabular}


Seabrook Beach (Winter Sampling), Seabrook, New Hampshire: Grain Size Statistics

\begin{tabular}{|c|c|c|c|c|c|c|c|c|c|c|c|c|c|c|c|c|c|}
\hline Sample ID & Gravel\% & Pebble \% & Granule \% & Sand \% & Mud \% & Modes & $\begin{array}{c}\text { Mode } 1 \\
\text { (phi) }\end{array}$ & $\begin{array}{c}\text { Mode } 2 \\
\text { (phi) }\end{array}$ & $\begin{array}{r}\mathrm{D}_{10} \\
\text { (phi) }\end{array}$ & $\begin{array}{c}\mathrm{D}_{10} \\
(\mathrm{~mm})\end{array}$ & $\begin{array}{r}\mathrm{D}_{50} \\
\text { (phi) }\end{array}$ & $\begin{array}{c}D_{50} \\
(\mathrm{~mm})\end{array}$ & $\begin{array}{c}\text { Mean Size } \\
\text { (phi) }\end{array}$ & $\begin{array}{c}\text { Mean Size } \\
(\mathrm{mm})\end{array}$ & $\begin{array}{c}\text { Sorting } \\
\text { (phi) }\end{array}$ & Skewness & Kurtosis \\
\hline SB01-1 & 0.04 & 0.00 & 0.03 & 99.87 & 0.09 & u & 1.25 & $\mathrm{~N} / \mathrm{A}$ & 0.36 & 0.78 & 1.25 & 0.42 & 1.23 & 0.43 & 0.65 & -0.04 & 0.96 \\
\hline SB01-2 & 0.75 & 0.02 & 0.73 & 99.22 & 0.03 & $u$ & 0.25 & $\mathrm{~N} / \mathrm{A}$ & -0.43 & 1.34 & 0.24 & 0.84 & 0.26 & 0.84 & 0.58 & 0.05 & 1.02 \\
\hline SB01-3 & 7.38 & 1.17 & 6.21 & 92.61 & 0.01 & u & -0.24 & $\mathrm{~N} / \mathrm{A}$ & -0.94 & 1.91 & -0.16 & 1.12 & -0.17 & 1.12 & 0.65 & 0.00 & 1.08 \\
\hline SB01-4 & 14.81 & 2.30 & 12.51 & 85.18 & 0.01 & u & -0.74 & $\mathrm{~N} / \mathrm{A}$ & -1.25 & 2.37 & -0.53 & 1.44 & -0.52 & 1.43 & 0.56 & 0.04 & 1.26 \\
\hline SB01-5 & 0.48 & 0.12 & 0.36 & 99.48 & 0.04 & u & 1.25 & N/A & 0.34 & 0.79 & 1.31 & 0.40 & 1.29 & 0.41 & 0.71 & -0.07 & 1.04 \\
\hline SBO2-1 & 0.00 & 0.00 & 0.00 & 99.97 & 0.03 & u & 1.25 & $\mathrm{~N} / \mathrm{A}$ & 0.14 & 0.91 & 1.00 & 0.50 & 0.98 & 0.51 & 0.63 & -0.02 & 0.91 \\
\hline SBO2-2 & 0.22 & 0.01 & 0.21 & 99.77 & 0.01 & U & 0.75 & $\mathrm{~N} / \mathrm{A}$ & -0.24 & 1.18 & 0.52 & 0.70 & 0.50 & 0.71 & 0.54 & -0.05 & 0.99 \\
\hline $\mathrm{SB} 02-3$ & 1.74 & 0.03 & 1.71 & 98.25 & 0.01 & $u$ & 0.25 & $\mathrm{~N} / \mathrm{A}$ & -0.64 & 1.56 & 0.10 & 0.93 & 0.12 & 0.92 & 0.56 & 0.00 & 1.00 \\
\hline SBO2-4 & 8.74 & 0.73 & 8.01 & 91.25 & 0.01 & u & -0.24 & $\mathrm{~N} / \mathrm{A}$ & -0.97 & 1.96 & -0.21 & 1.16 & -0.22 & 1.16 & 0.64 & 0.00 & 1.04 \\
\hline SBO2-5 & 14.32 & 1.67 & 12.64 & 85.67 & 0.01 & u & -0.74 & N/A & -1.21 & 2.32 & -0.54 & 1.46 & -0.53 & 1.44 & 0.51 & 0.03 & 1.12 \\
\hline SBO2-6 & 0.27 & 0.01 & 0.26 & 99.70 & 0.03 & $u$ & 1.25 & $\mathrm{~N} / \mathrm{A}$ & 0.50 & 0.71 & 1.26 & 0.42 & 1.23 & 0.42 & 0.58 & -0.13 & 1.07 \\
\hline SBO3-1 & 0.64 & 0.00 & 0.64 & 99.32 & 0.04 & $u$ & 0.25 & $\mathrm{~N} / \mathrm{A}$ & -0.37 & 1.29 & 0.41 & 0.75 & 0.44 & 0.74 & 0.67 & 0.11 & 1.02 \\
\hline SBO3-2 & 0.14 & 0.00 & 0.14 & 99.83 & 0.03 & U & 0.25 & $\mathrm{~N} / \mathrm{A}$ & -0.36 & 1.28 & 0.46 & 0.73 & 0.54 & 0.69 & 0.76 & 0.18 & 0.84 \\
\hline SBO3-3 & 7.04 & 0.41 & 6.64 & 92.95 & 0.01 & U & -0.24 & N/A & -0.91 & 1.88 & 0.13 & 0.91 & 0.24 & 0.85 & 0.98 & 0.15 & 0.87 \\
\hline SBO3-4 & 2.69 & 0.10 & 2.60 & 97.30 & 0.01 & B & 1.75 & -0.24 & -0.66 & 1.58 & 0.91 & 0.53 & 0.79 & 0.58 & 1.06 & -0.14 & 0.74 \\
\hline SB04-1 & 0.05 & 0.00 & 0.05 & 99.92 & 0.03 & u & 1.75 & $\mathrm{~N} / \mathrm{A}$ & -0.08 & 1.05 & 1.07 & 0.48 & 1.02 & 0.49 & 0.82 & -0.09 & 0.85 \\
\hline SB04-2 & 3.57 & 0.12 & 3.45 & 96.40 & 0.03 & U & -0.24 & $\mathrm{~N} / \mathrm{A}$ & -0.79 & 1.72 & 0.22 & 0.86 & 0.25 & 0.84 & 0.81 & 0.06 & 0.87 \\
\hline SBO4-3 & 1.10 & 0.04 & 1.05 & 98.90 & 0.00 & U & -0.24 & N/A & -0.53 & 1.44 & 0.23 & 0.85 & 0.34 & 0.79 & 0.78 & 0.19 & 0.97 \\
\hline SBO4-4 & 9.70 & 0.54 & 9.16 & 90.30 & 0.00 & U & -0.74 & $\mathrm{~N} / \mathrm{A}$ & -1.00 & 1.99 & -0.38 & 1.30 & -0.28 & 1.21 & 0.73 & 0.25 & 1.28 \\
\hline SBO4-5 & 0.69 & 0.03 & 0.66 & 99.29 & 0.02 & U & 1.75 & $\mathrm{~N} / \mathrm{A}$ & 0.12 & 0.92 & 1.29 & 0.41 & 1.24 & 0.42 & 0.80 & -0.13 & 1.00 \\
\hline SB04-6 & 0.47 & 0.04 & 0.44 & 99.52 & 0.01 & u & 1.75 & $\mathrm{~N} / \mathrm{A}$ & 0.37 & 0.77 & 1.41 & 0.38 & 1.34 & 0.40 & 0.69 & -0.21 & 1.19 \\
\hline SB05-1 & 0.27 & 0.00 & 0.27 & 99.69 & 0.04 & U & 1.75 & $\mathrm{~N} / \mathrm{A}$ & -0.19 & 1.14 & 1.14 & 0.45 & 1.03 & 0.49 & 0.85 & -0.18 & 0.87 \\
\hline SBO5-2 & 0.96 & 0.15 & 0.80 & 99.00 & 0.04 & u & 0.75 & N/A & -0.21 & 1.16 & 0.82 & 0.57 & 0.82 & 0.57 & 0.76 & -0.02 & 0.90 \\
\hline SBO5-3 & 2.37 & 0.15 & 2.22 & 97.62 & 0.01 & U & -0.24 & N/A & -0.61 & 1.53 & 0.28 & 0.82 & 0.31 & 0.81 & 0.72 & 0.04 & 0.89 \\
\hline SB05-4 & 17.30 & 5.27 & 12.03 & 82.70 & 0.00 & u & -0.24 & N/A & -1.48 & 2.80 & -0.12 & 1.09 & -0.04 & 1.03 & 1.09 & 0.02 & 0.99 \\
\hline
\end{tabular}


Seabrook Beach (Winter Sampling), Seabrook, New Hampshire: Grain Size Distribution

\begin{tabular}{|c|c|c|c|c|c|c|c|c|c|c|c|c|c|c|c|c|c|c|c|c|c|}
\hline Sample ID & $\begin{array}{c}\text { Class \% } \\
\text { phi } \\
-5.5 \\
\end{array}$ & $\begin{array}{c}\text { Class \% } \\
\text { phi } \\
-5.0 \\
\end{array}$ & $\begin{array}{c}\text { Class \% } \\
\text { phi } \\
-4.5 \\
\end{array}$ & $\begin{array}{c}\text { Class \% } \\
\text { phi } \\
-4.0 \\
\end{array}$ & $\begin{array}{c}\text { Class \% } \\
\text { phi } \\
-3.5 \\
\end{array}$ & $\begin{array}{c}\text { Class \% } \\
\text { phi } \\
-3.0 \\
\end{array}$ & $\begin{array}{c}\text { Class \% } \\
\text { phi } \\
-2.5 \\
\end{array}$ & $\begin{array}{c}\text { Class \% } \\
\text { phi } \\
-2.0 \\
\end{array}$ & $\begin{array}{c}\text { Class \% } \\
\text { phi } \\
-1.5 \\
\end{array}$ & $\begin{array}{c}\text { Class \% } \\
\text { phi } \\
-1.0 \\
\end{array}$ & $\begin{array}{c}\text { Class \% } \\
\text { phi } \\
-0.5 \\
\end{array}$ & $\begin{array}{c}\text { Class \% } \\
\text { phi } \\
0.0 \\
\end{array}$ & $\begin{array}{c}\text { Class \% } \\
\text { phi } \\
0.5 \\
\end{array}$ & $\begin{array}{c}\text { Class \% } \\
\text { phi } \\
1.0 \\
\end{array}$ & $\begin{array}{c}\text { Class \% } \\
\text { phi } \\
1.5 \\
\end{array}$ & $\begin{array}{c}\text { Class \% } \\
\text { phi } \\
2.0 \\
\end{array}$ & $\begin{array}{c}\text { Class \% } \\
\text { phi } \\
2.5 \\
\end{array}$ & $\begin{array}{c}\text { Class \% } \\
\text { phi } \\
3.0 \\
\end{array}$ & $\begin{array}{c}\text { Class \% } \\
\text { phi } \\
3.5 \\
\end{array}$ & $\begin{array}{c}\text { Class \% } \\
\text { phi } \\
4.0 \\
\end{array}$ & $\begin{array}{c}\text { Class } \% \\
\text { phi } \\
>4.0 \\
\end{array}$ \\
\hline SB01-1 & 0.00 & 0.00 & 0.00 & 0.00 & 0.00 & 0.00 & 0.00 & 0.00 & 0.00 & 0.03 & 0.29 & 2.09 & 10.54 & 22.09 & 30.09 & 25.43 & 7.57 & 1.54 & 0.18 & 0.06 & 0.09 \\
\hline SB01-2 & 0.00 & 0.00 & 0.00 & 0.00 & 0.00 & 0.00 & 0.00 & 0.02 & 0.09 & 0.64 & 6.25 & 24.62 & 37.06 & 22.62 & 6.97 & 1.51 & 0.15 & 0.02 & 0.01 & 0.00 & 0.03 \\
\hline SB01-3 & 0.00 & 0.00 & 0.00 & 0.00 & 0.08 & 0.40 & 0.18 & 0.50 & 1.58 & 4.63 & 20.87 & 32.41 & 25.64 & 9.31 & 2.85 & 1.15 & 0.32 & 0.06 & 0.02 & 0.00 & 0.01 \\
\hline SB01-4 & 0.00 & 0.00 & 0.00 & 0.11 & 0.20 & 0.38 & 0.67 & 0.94 & 3.00 & 9.51 & 38.30 & 33.78 & 7.54 & 2.95 & 1.57 & 0.80 & 0.19 & 0.04 & 0.01 & 0.00 & 0.01 \\
\hline SB01-5 & 0.00 & 0.00 & 0.00 & 0.00 & 0.00 & 0.00 & 0.08 & 0.04 & 0.08 & 0.28 & 1.51 & 3.11 & 7.23 & 19.17 & 29.16 & 24.76 & 10.86 & 3.51 & 0.17 & 0.01 & 0.04 \\
\hline SBO2-1 & 0.00 & 0.00 & 0.00 & 0.00 & 0.00 & 0.00 & 0.00 & 0.00 & 0.00 & 0.00 & 0.39 & 4.66 & 17.02 & 28.19 & 28.73 & 17.61 & 2.93 & 0.37 & 0.04 & 0.01 & 0.03 \\
\hline SBO2-2 & 0.00 & 0.00 & 0.00 & 0.00 & 0.00 & 0.00 & 0.00 & 0.01 & 0.03 & 0.18 & 2.55 & 14.48 & 30.58 & 35.78 & 13.57 & 2.55 & 0.22 & 0.03 & 0.01 & 0.00 & 0.01 \\
\hline SBO2-3 & 0.00 & 0.00 & 0.00 & 0.00 & 0.00 & 0.00 & 0.00 & 0.02 & 0.30 & 1.41 & 11.75 & 29.50 & 33.94 & 18.32 & 3.92 & 0.68 & 0.09 & 0.03 & 0.01 & 0.00 & 0.01 \\
\hline SBO2-4 & 0.00 & 0.00 & 0.00 & 0.00 & 0.05 & 0.12 & 0.14 & 0.41 & 1.86 & 6.15 & 23.30 & 32.23 & 24.17 & 8.25 & 1.97 & 0.83 & 0.36 & 0.11 & 0.01 & 0.00 & 0.01 \\
\hline SBO2-5 & 0.00 & 0.00 & 0.00 & 0.25 & 0.06 & 0.29 & 0.32 & 0.76 & 2.83 & 9.81 & 40.28 & 33.17 & 9.13 & 2.37 & 0.48 & 0.17 & 0.04 & 0.02 & 0.01 & 0.00 & 0.01 \\
\hline SBO2-6 & 0.00 & 0.00 & 0.00 & 0.00 & 0.00 & 0.00 & 0.00 & 0.01 & 0.06 & 0.20 & 1.03 & 2.45 & 6.16 & 19.84 & 38.63 & 26.28 & 4.70 & 0.60 & 0.03 & 0.00 & 0.03 \\
\hline SB03-1 & 0.00 & 0.00 & 0.00 & 0.00 & 0.00 & 0.00 & 0.00 & 0.00 & 0.10 & 0.54 & 4.72 & 18.71 & 31.50 & 25.03 & 12.71 & 5.41 & 1.04 & 0.15 & 0.03 & 0.02 & 0.04 \\
\hline SBO3-2 & 0.00 & 0.00 & 0.00 & 0.00 & 0.00 & 0.00 & 0.00 & 0.00 & 0.01 & 0.13 & 4.29 & 21.59 & 25.94 & 19.08 & 16.31 & 10.40 & 2.06 & 0.15 & 0.01 & 0.00 & 0.03 \\
\hline SBO3-3 & 0.00 & 0.00 & 0.00 & 0.00 & 0.00 & 0.03 & 0.13 & 0.24 & 1.38 & 5.26 & 17.67 & 21.30 & 15.08 & 14.72 & 12.61 & 8.73 & 2.45 & 0.36 & 0.02 & 0.01 & 0.01 \\
\hline SB03-4 & 0.00 & 0.00 & 0.00 & 0.00 & 0.00 & 0.00 & 0.04 & 0.06 & 0.47 & 2.12 & 10.94 & 15.46 & 10.75 & 12.22 & 17.24 & 19.91 & 8.67 & 2.02 & 0.08 & 0.01 & 0.01 \\
\hline SBO4-1 & 0.00 & 0.00 & 0.00 & 0.00 & 0.00 & 0.00 & 0.00 & 0.00 & 0.00 & 0.04 & 1.61 & 9.87 & 16.06 & 19.33 & 21.08 & 22.65 & 8.07 & 1.15 & 0.08 & 0.02 & 0.03 \\
\hline SBO4-2 & 0.00 & 0.00 & 0.00 & 0.00 & 0.00 & 0.00 & 0.03 & 0.09 & 0.59 & 2.86 & 15.40 & 22.04 & 20.07 & 20.28 & 12.69 & 5.14 & 0.64 & 0.10 & 0.03 & 0.02 & 0.03 \\
\hline SBO4-3 & 0.00 & 0.00 & 0.00 & 0.00 & 0.00 & 0.02 & 0.00 & 0.02 & 0.11 & 0.94 & 9.74 & 27.15 & 25.43 & 16.80 & 11.23 & 7.07 & 1.33 & 0.14 & 0.01 & 0.01 & 0.00 \\
\hline SBO4-4 & 0.00 & 0.00 & 0.00 & 0.00 & 0.02 & 0.05 & 0.13 & 0.34 & 1.80 & 7.36 & 33.60 & 30.27 & 11.74 & 7.33 & 4.27 & 2.36 & 0.60 & 0.10 & 0.01 & 0.00 & 0.00 \\
\hline SBO4-5 & 0.00 & 0.00 & 0.00 & 0.00 & 0.00 & 0.00 & 0.00 & 0.03 & 0.15 & 0.51 & 2.21 & 4.83 & 9.40 & 19.31 & 23.12 & 25.00 & 11.69 & 3.60 & 0.12 & 0.01 & 0.02 \\
\hline SBO4-6 & 0.00 & 0.00 & 0.00 & 0.00 & 0.00 & 0.00 & 0.00 & 0.04 & 0.11 & 0.33 & 1.68 & 3.67 & 5.57 & 14.63 & 28.62 & 32.89 & 10.49 & 1.88 & 0.09 & 0.01 & 0.01 \\
\hline SB05-1 & 0.00 & 0.00 & 0.00 & 0.00 & 0.00 & 0.00 & 0.00 & 0.00 & 0.02 & 0.25 & 3.28 & 10.68 & 12.42 & 17.13 & 21.76 & 25.13 & 8.04 & 1.10 & 0.12 & 0.03 & 0.04 \\
\hline SB05-2 & 0.00 & 0.00 & 0.00 & 0.00 & 0.00 & 0.00 & 0.03 & 0.12 & 0.29 & 0.52 & 2.62 & 11.30 & 18.97 & 25.06 & 22.08 & 14.83 & 3.52 & 0.53 & 0.08 & 0.02 & 0.04 \\
\hline SBO5-3 & 0.00 & 0.00 & 0.00 & 0.00 & 0.00 & 0.00 & 0.04 & 0.12 & 0.51 & 1.71 & 10.10 & 23.89 & 24.15 & 21.52 & 14.26 & 3.47 & 0.18 & 0.03 & 0.01 & 0.01 & 0.01 \\
\hline SBO5-4 & 0.00 & 0.00 & 0.00 & 0.75 & 0.55 & 0.54 & 1.00 & 2.44 & 4.72 & 7.31 & 17.50 & 20.11 & 13.97 & 12.96 & 12.25 & 5.09 & 0.49 & 0.07 & 0.27 & 0.01 & 0.00 \\
\hline
\end{tabular}


Section 7(b): Seabrook Beach (Summer/Fall 2017 Sampling Period) 
Seabrook Beach (Summer Sampling), Seabrook, New Hampshire: Identification, Location, and Description

\begin{tabular}{|c|c|c|c|c|c|c|c|c|c|c|c|c|c|}
\hline Sample ID & Global Sample ID & $\begin{array}{l}\text { Latitude } \\
\text { WGS84 } \\
\end{array}$ & $\begin{array}{c}\text { Longitude } \\
\text { WGS84 }\end{array}$ & $\begin{array}{c}\text { Relative } \\
\text { Position } \\
\text { Accuracy } \\
\end{array}$ & $\begin{array}{c}\text { Elevation } \\
\text { (m) } \\
\text { NAVD88 }\end{array}$ & $\begin{array}{c}\text { Elevation } \\
\text { (m) } \\
\text { MTL } \\
\end{array}$ & $\begin{array}{c}\text { Relative } \\
\text { Elevation } \\
\end{array}$ & $\begin{array}{l}\text { Relative } \\
\text { Location } \\
\end{array}$ & $\begin{array}{c}\text { Sample } \\
\text { Collected } \\
\end{array}$ & $\begin{array}{c}\text { Core } \\
\text { Length } \\
(\mathrm{cm}) \\
\end{array}$ & $\begin{array}{l}\text { Collected } \\
\text { Sample } \\
\text { Wt. (gm) }\end{array}$ & $\begin{array}{c}\text { Processed } \\
\text { Sample } \\
\text { Wt. (gm) }\end{array}$ & $\begin{array}{c}\text { Morphologic } \\
\text { Feature }\end{array}$ \\
\hline SB02-1 & NHC D20170918 SB02-1 & 42.884958 & -70.814448 & 1 & 4.18 & 4.32 & STB & UB/BS & 18 -Sep-17 & 24 & $2,631.4$ & $2,637.5$ & $\begin{array}{c}\text { Backshore: Edge of } \\
\text { Dunes } \\
\end{array}$ \\
\hline SBO2-2 & NHC_D20170918_SB02-2 & 42.884948 & -70.814321 & 1 & 3.50 & 3.64 & STB & UB/BS & 18-Sep-17 & 27 & $2,786.4$ & $2,792.4$ & Backshore: Mid \\
\hline SB02-3 & NHC_D20170918_SB02-3 & 42.884931 & -70.814131 & 1 & 2.92 & 3.05 & UTB & UB & 18-Sep-17 & 29 & $2,457.2$ & $2,459.1$ & Berm Crest \\
\hline SBO2-4 & NHC_D20170918_SB02-4 & 42.884901 & -70.813823 & 1 & 0.14 & 0.28 & MTB & MB & 18-Sep-17 & 28 & $3,572.6$ & $3,555.4$ & Berm Toe \\
\hline $\mathrm{SB} 02-5$ & NHC_D20170918_SB02-5 & 42.884870 & -70.813496 & 1 & -1.00 & -0.86 & LTB & $\mathrm{LB}$ & 18-Sep-17 & 28 & $3,584.5$ & $3,585.5$ & LTT: Mid \\
\hline SB04-0.5:Dune & NHC D20170918 SB04-0.5:Dune & 42.879767 & -70.815555 & 2 & $\mathrm{~N} / \mathrm{A}$ & $\mathrm{N} / \mathrm{A}$ & STB & Dune & 18-Sep-17 & $\mathrm{N} / \mathrm{A}$ & $3,374.9$ & $3,373.0$ & Dune \\
\hline SB04-1 & NHC_D20170918_SB04-1 & 42.879750 & -70.815455 & 1 & 4.23 & 4.37 & STB & UB/BS & 18-Sep-17 & 26 & $2,352.3$ & $2,355.0$ & $\begin{array}{c}\text { Backshore: Edge of } \\
\text { Dunes }\end{array}$ \\
\hline SB04-2 & NHC_D20170918_SB04-2 & 42.879743 & -70.815347 & 1 & 3.75 & 3.89 & STB & UB/BS & 18-Sep-17 & 26 & $2,118.9$ & $2,124.0$ & Backshore: Mid \\
\hline SBO4-3 & NHC_D20170918_SB04-3 & 42.879726 & -70.815130 & 1 & 2.58 & 2.71 & UTB & UB & 18-Sep-17 & 28 & $1,960.7$ & $1,962.4$ & Berm Crest \\
\hline SB04-4 & NHC_D20170918_SB04-4 & 42.879705 & -70.814870 & 1 & 0.57 & 0.71 & MW & MB & 18-Sep-17 & 28 & $3,247.4$ & $3,227.7$ & Berm Toe \\
\hline SB04-5 & NHC_D20170918_SB04-5 & 42.879672 & -70.814436 & 1 & -0.87 & -0.73 & LW & $\mathrm{LB}$ & 18-Sep-17 & 27 & $3,371.5$ & $3,360.4$ & LTT: Lower \\
\hline SB05-1 & NHC_D20170502_SB05-1 & 42.874369 & -70.816169 & 1 & 6.01 & 6.15 & STB & BS & 2-May-17 & 26 & $1,994.0$ & $1,990.6$ & $\begin{array}{c}\text { Backshore: Near } \\
\text { Dunes }\end{array}$ \\
\hline SB05-2 & NHC_D20170502_SB05-2 & 42.874367 & -70.815956 & 1 & 4.90 & 5.04 & STB & UB & 2-May-17 & 25 & $2,179.7$ & $2,169.1$ & $\begin{array}{c}\text { Berm Crest; Cusps; } \\
\text { LHTS } \\
\end{array}$ \\
\hline SB05-3 & NHC_D20170502_SB05-3 & 42.874367 & -70.815735 & 1 & 2.68 & 2.82 & UTB & $\mathrm{MB}$ & 2-May-17 & 26 & $2,462.7$ & $2,432.1$ & Berm Toe \\
\hline SB05-4 & NHC_D20170502_SB05-4 & 42.874359 & -70.815284 & 1 & 0.88 & 1.02 & MTB & LB & 2-May-17 & 28 & $2,729.2$ & $2,719.1$ & LTT; Lower \\
\hline
\end{tabular}




\begin{tabular}{|c|c|c|c|c|c|c|c|c|}
\hline Sample ID & $\begin{array}{l}\text { CMECS Substrate } \\
\text { Component } \\
\text { Group (Specific) }\end{array}$ & $\begin{array}{l}\text { CMECS Substrate } \\
\text { Component Subgroup } \\
\text { (Specific) }\end{array}$ & $\begin{array}{l}\text { Textural Group from } \\
\text { \%GSM (Gradistat) }\end{array}$ & $\begin{array}{l}\text { Sediment Name from } \\
\text { \%GSM } \\
\text { and Mode (Gradistat) }\end{array}$ & $\begin{array}{l}\text { Sediment Name from } \\
\text { \%GSM and Mode } \\
\text { (Wentworth Scale) }\end{array}$ & $\begin{array}{l}\text { Sediment Classification } \\
\text { from Mean Phi } \\
\text { (Gradistat) }\end{array}$ & $\begin{array}{l}\text { Sediment } \\
\text { Classification } \\
\text { from Mean Phi } \\
\text { (Wentworth) }\end{array}$ & Sorting (Gradistat) \\
\hline SB02-1 & Slightly Granuley & $\begin{array}{l}\text { Slightly Granuley } \\
\text { Coarse Sand }\end{array}$ & Slightly Gravelly Sand & $\begin{array}{l}\text { Slightly Very Fine Gravelly } \\
\text { Coarse Sand }\end{array}$ & $\begin{array}{l}\text { Slightly Granular Coarse } \\
\text { Sand }\end{array}$ & Coarse Sand & Coarse Sand & Moderately Sorted \\
\hline SBO2-2 & Slightly Granuley & $\begin{array}{l}\text { Slightly Granuley } \\
\text { Coarse Sand }\end{array}$ & Slightly Gravelly Sand & $\begin{array}{l}\text { Slightly Very Fine Gravelly } \\
\text { Coarse Sand }\end{array}$ & $\begin{array}{l}\text { Slightly Granular Coarse } \\
\text { Sand }\end{array}$ & Coarse Sand & Coarse Sand & Moderately Sorted \\
\hline SBO2-3 & Slightly Granuley & $\begin{array}{l}\text { Slightly Granuley } \\
\text { Medium Sand }\end{array}$ & Slightly Gravelly Sand & $\begin{array}{l}\text { Slightly Very Fine Gravelly } \\
\text { Medium Sand }\end{array}$ & $\begin{array}{l}\text { Slightly Granular } \\
\text { Medium Sand }\end{array}$ & Medium Sand & Medium Sand & Moderately Well Sorted \\
\hline SBO2-4 & Slightly Granuley & $\begin{array}{l}\text { Slightly Granuley Fine } \\
\text { Sand }\end{array}$ & Slightly Gravelly Sand & $\begin{array}{l}\text { Slightly Very Fine Gravelly } \\
\text { Fine Sand }\end{array}$ & $\begin{array}{l}\text { Slightly Granular Fine } \\
\text { Sand }\end{array}$ & Medium Sand & Medium Sand & Moderately Sorted \\
\hline SB02-5 & Slightly Granuley & $\begin{array}{l}\text { Slightly Granuley } \\
\text { Medium Sand }\end{array}$ & Slightly Gravelly Sand & $\begin{array}{l}\text { Slightly Very Fine Gravelly } \\
\text { Medium Sand }\end{array}$ & $\begin{array}{l}\text { Slightly Granular } \\
\text { Medium Sand }\end{array}$ & Medium Sand & Medium Sand & Poorly Sorted \\
\hline SB04-0.5:Dune & Slightly Granuley & $\begin{array}{l}\text { Slightly Granuley } \\
\text { Coarse Sand }\end{array}$ & Slightly Gravelly Sand & $\begin{array}{l}\text { Slightly Very Fine Gravelly } \\
\text { Coarse Sand }\end{array}$ & $\begin{array}{l}\text { Slightly Granular Coarse } \\
\text { Sand }\end{array}$ & Coarse Sand & Coarse Sand & Moderately Sorted \\
\hline SB04-1 & Slightly Granuley & $\begin{array}{l}\text { Slightly Granuley } \\
\text { Coarse Sand }\end{array}$ & Slightly Gravelly Sand & $\begin{array}{l}\text { Slightly Very Fine Gravelly } \\
\text { Coarse Sand }\end{array}$ & $\begin{array}{l}\text { Slightly Granular Coarse } \\
\text { Sand }\end{array}$ & Coarse Sand & Coarse Sand & Moderately Sorted \\
\hline SB04-2 & Slightly Granuley & $\begin{array}{l}\text { Slightly Granuley } \\
\text { Coarse Sand }\end{array}$ & Slightly Gravelly Sand & $\begin{array}{l}\text { Slightly Very Fine Gravelly } \\
\text { Very Coarse Sand }\end{array}$ & $\begin{array}{l}\text { Slightly Granular Coarse } \\
\text { Sand }\end{array}$ & Coarse Sand & Coarse Sand & Moderately Sorted \\
\hline SB04-3 & Sand & Medium Sand & Sand & Medium Sand & Medium Sand & Medium Sand & Medium Sand & Well Sorted \\
\hline SB04-4 & Slightly Granuley & $\begin{array}{l}\text { Slightly Granuley Fine } \\
\text { Sand }\end{array}$ & Slightly Gravelly Sand & $\begin{array}{l}\text { Slightly Very Fine Gravelly } \\
\text { Fine Sand }\end{array}$ & $\begin{array}{l}\text { Slightly Granular Fine } \\
\text { Sand }\end{array}$ & Medium Sand & Medium Sand & Moderately Sorted \\
\hline SB04-5 & Slightly Granuley & $\begin{array}{l}\text { Slightly Granuley Fine } \\
\text { Sand }\end{array}$ & Slightly Gravelly Sand & $\begin{array}{l}\text { Slightly Very Fine Gravelly } \\
\text { Fine Sand }\end{array}$ & $\begin{array}{l}\text { Slightly Granular Fine } \\
\text { Sand }\end{array}$ & Medium Sand & Medium Sand & Moderately Sorted \\
\hline SB05-1 & Slightly Granuley & $\begin{array}{l}\text { Slightly Granuley } \\
\text { Coarse Sand }\end{array}$ & Slightly Gravelly Sand & $\begin{array}{l}\text { Slightly Very Fine Gravelly } \\
\text { Coarse Sand }\end{array}$ & $\begin{array}{l}\text { Slightly Granular Coarse } \\
\text { Sand }\end{array}$ & Coarse Sand & Coarse Sand & Moderately Well Sorted \\
\hline SB05-2 & Slightly Granuley & $\begin{array}{l}\text { Slightly Granuley Very } \\
\text { Coarse Sand }\end{array}$ & Slightly Gravelly Sand & $\begin{array}{l}\text { Slightly Very Fine Gravelly } \\
\text { Very Coarse Sand }\end{array}$ & $\begin{array}{l}\text { Slightly Granular Very } \\
\text { Coarse Sand }\end{array}$ & Coarse Sand & Coarse Sand & Moderately Sorted \\
\hline SB05-3 & Granuley & $\begin{array}{l}\text { Granuley Very Coarse } \\
\text { Sand } \\
\text { Sliaghtly Granuley Fine }\end{array}$ & Gravelly Sand & $\begin{array}{l}\text { Very Fine Gravelly Very } \\
\text { Coarse Sand } \\
\text { Slightly Very Fine Gravelly }\end{array}$ & $\begin{array}{l}\text { Granular Very Coarse } \\
\text { Sand } \\
\text { Slightly Granular Fine }\end{array}$ & Coarse Sand & Coarse Sand & Poorly Sorted \\
\hline SB05-4 & Slightly Granuley & Sand & Slightly Gravelly Sand & Fine Sand & Sand & Medium Sand & Medium Sand & Moderately Sorted \\
\hline
\end{tabular}


Seabrook Beach (Summer Sampling), Seabrook, New Hampshire: Grain Size Statistics

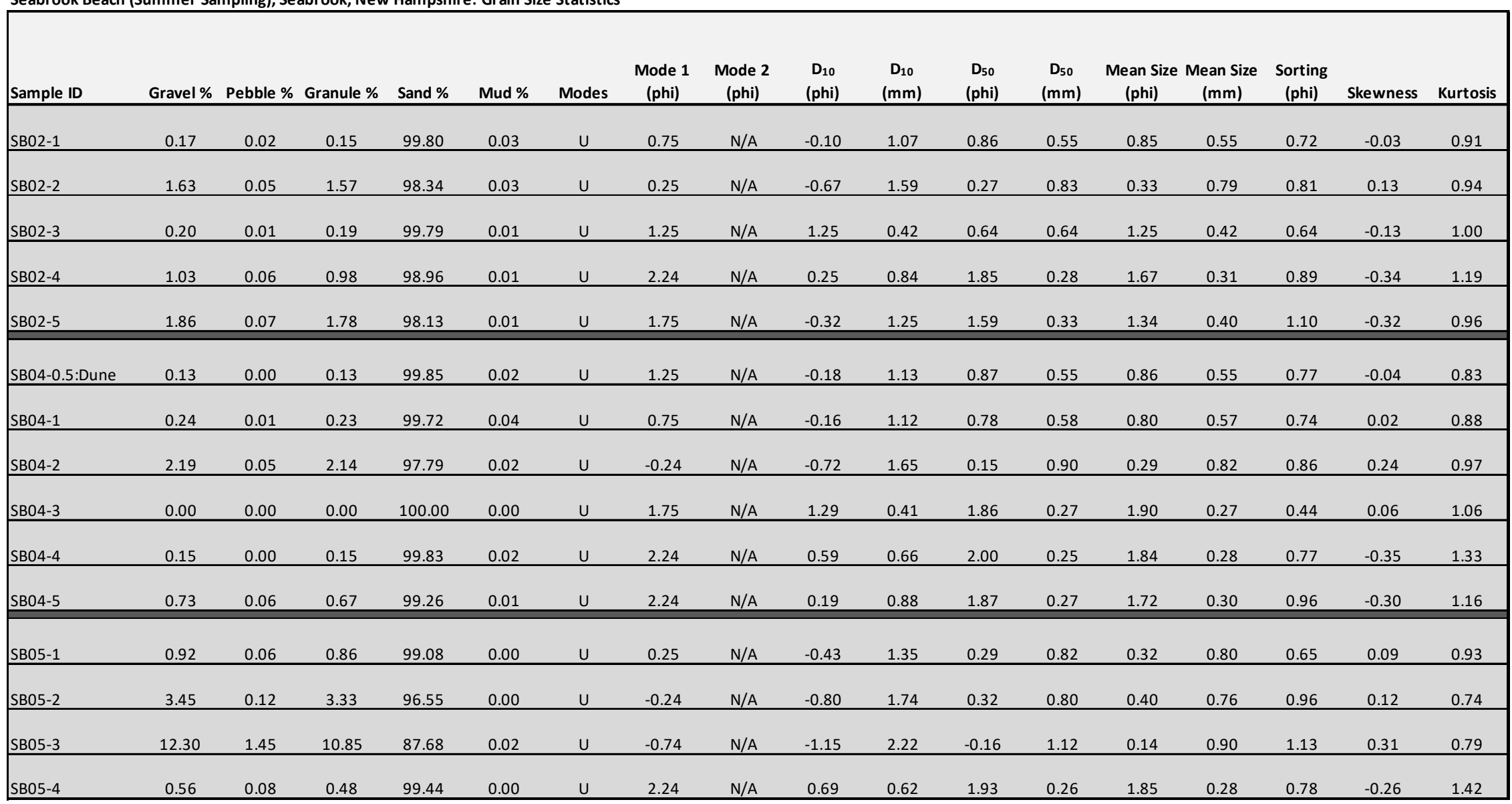




\begin{tabular}{|c|c|c|c|c|c|c|c|c|c|c|c|c|c|c|c|c|c|c|c|c|c|}
\hline Sample ID & $\begin{array}{c}\text { Class \% } \\
\text { phi } \\
-5.5 \\
\end{array}$ & $\begin{array}{c}\text { Class \% } \\
\text { phi } \\
-5.0 \\
\end{array}$ & $\begin{array}{c}\text { Class \% } \\
\text { phi } \\
-4.5 \\
\end{array}$ & $\begin{array}{c}\text { Class \% } \\
\text { phi } \\
-4.0 \\
\end{array}$ & $\begin{array}{c}\text { Class \% } \\
\text { phi } \\
-3.5 \\
\end{array}$ & $\begin{array}{c}\text { Class \% } \\
\text { phi } \\
-3.0 \\
\end{array}$ & $\begin{array}{c}\text { Class \% } \\
\text { phi } \\
-2.5 \\
\end{array}$ & $\begin{array}{c}\text { Class \% } \\
\text { phi } \\
-2.0 \\
\end{array}$ & $\begin{array}{c}\text { Class \% } \\
\text { phi } \\
-1.5 \\
\end{array}$ & $\begin{array}{c}\text { Class \% } \\
\text { phi } \\
-1.0 \\
\end{array}$ & $\begin{array}{c}\text { Class \% } \\
\text { phi } \\
-0.5 \\
\end{array}$ & $\begin{array}{c}\text { Class \% } \\
\text { phi } \\
0.0 \\
\end{array}$ & $\begin{array}{c}\text { Class \% } \\
\text { phi } \\
0.5 \\
\end{array}$ & $\begin{array}{c}\text { Class \% } \\
\text { phi } \\
1.0 \\
\end{array}$ & $\begin{array}{c}\text { Class \% } \\
\text { phi } \\
1.5 \\
\end{array}$ & $\begin{array}{c}\text { Class \% } \\
\text { phi } \\
2.0 \\
\end{array}$ & $\begin{array}{c}\text { Class \% } \\
\text { phi } \\
2.5 \\
\end{array}$ & $\begin{array}{c}\text { Class \% } \\
\text { phi } \\
3.0 \\
\end{array}$ & $\begin{array}{c}\text { Class \% } \\
\text { phi } \\
3.5 \\
\end{array}$ & $\begin{array}{c}\text { Class \% } \\
\text { phi } \\
4.0 \\
\end{array}$ & $\begin{array}{c}\text { Class \% } \\
\text { phi } \\
>4.0 \\
\end{array}$ \\
\hline SB02-1 & 0.00 & 0.00 & 0.00 & 0.00 & 0.00 & 0.00 & 0.00 & 0.02 & 0.02 & 0.14 & 1.94 & 9.85 & 19.60 & 25.64 & 23.84 & 15.20 & 3.14 & 0.48 & 0.08 & 0.02 & 0.03 \\
\hline SBO2-2 & 0.00 & 0.00 & 0.00 & 0.00 & 0.00 & 0.00 & 0.03 & 0.02 & 0.10 & 1.48 & 13.00 & 22.46 & 23.94 & 18.20 & 12.10 & 6.83 & 1.50 & 0.26 & 0.04 & 0.00 & 0.03 \\
\hline SB02-3 & 0.00 & 0.00 & 0.00 & 0.00 & 0.00 & 0.00 & 0.00 & 0.01 & 0.02 & 0.17 & 0.83 & 2.87 & 7.99 & 19.39 & 31.07 & 29.92 & 6.96 & 0.71 & 0.06 & 0.00 & 0.01 \\
\hline SBO2-4 & 0.00 & 0.00 & 0.00 & 0.00 & 0.00 & 0.00 & 0.00 & 0.06 & 0.20 & 0.77 & 1.97 & 4.31 & 5.23 & 7.31 & 11.77 & 26.46 & 28.99 & 12.18 & 0.73 & 0.01 & 0.01 \\
\hline SB02-5 & 0.00 & 0.00 & 0.00 & 0.00 & 0.00 & 0.00 & 0.00 & 0.07 & 0.35 & 1.44 & 5.49 & 7.62 & 7.48 & 8.88 & 14.28 & 23.87 & 19.08 & 10.30 & 1.09 & 0.04 & 0.01 \\
\hline SB04-0.5:Dune & 0.00 & 0.00 & 0.00 & 0.00 & 0.00 & 0.00 & 0.00 & 0.00 & 0.00 & 0.13 & 2.19 & 12.10 & 19.34 & 21.66 & 22.38 & 17.66 & 3.94 & 0.52 & 0.05 & 0.00 & 0.02 \\
\hline SB04-1 & 0.00 & 0.00 & 0.00 & 0.00 & 0.00 & 0.00 & 0.00 & 0.01 & 0.03 & 0.20 & 2.60 & 10.77 & 22.50 & 24.41 & 20.95 & 14.63 & 3.33 & 0.45 & 0.07 & 0.02 & 0.04 \\
\hline SB04-2 & 0.00 & 0.00 & 0.00 & 0.00 & 0.00 & 0.00 & 0.00 & 0.05 & 0.28 & 1.85 & 14.54 & 26.45 & 22.25 & 13.87 & 9.83 & 7.86 & 2.53 & 0.41 & 0.05 & 0.02 & 0.02 \\
\hline SB04-3 & 0.00 & 0.00 & 0.00 & 0.00 & 0.00 & 0.00 & 0.00 & 0.00 & 0.00 & 0.00 & 0.01 & 0.05 & 0.36 & 2.21 & 12.45 & 47.71 & 30.20 & 6.68 & 0.31 & 0.01 & 0.00 \\
\hline SB04-4 & 0.00 & 0.00 & 0.00 & 0.00 & 0.00 & 0.00 & 0.00 & 0.00 & 0.03 & 0.12 & 0.97 & 2.95 & 4.71 & 6.11 & 10.00 & 25.25 & 33.91 & 14.96 & 0.95 & 0.03 & 0.02 \\
\hline SB04-5 & 0.00 & 0.00 & 0.00 & 0.00 & 0.00 & 0.00 & 0.01 & 0.05 & 0.15 & 0.52 & 2.86 & 4.47 & 5.03 & 6.69 & 11.84 & 24.43 & 24.86 & 16.73 & 2.32 & 0.03 & 0.01 \\
\hline SB05-1 & 0.00 & 0.00 & 0.00 & 0.00 & 0.00 & 0.00 & 0.02 & 0.04 & 0.17 & 0.69 & 6.09 & 25.72 & 29.65 & 22.12 & 11.37 & 3.63 & 0.40 & 0.07 & 0.02 & 0.01 & 0.00 \\
\hline SB05-2 & 0.00 & 0.00 & 0.00 & 0.00 & 0.00 & 0.00 & 0.05 & 0.08 & 0.56 & 2.77 & 16.67 & 20.93 & 13.97 & 13.10 & 15.80 & 12.96 & 2.77 & 0.32 & 0.02 & 0.01 & 0.00 \\
\hline SB05-3 & 0.00 & 0.00 & 0.00 & 0.00 & 0.00 & 0.26 & 0.23 & 0.96 & 3.36 & 7.49 & 23.18 & 21.55 & 9.46 & 7.08 & 10.03 & 11.57 & 4.19 & 0.57 & 0.04 & 0.01 & 0.02 \\
\hline SB05-4 & 0.00 & 0.00 & 0.00 & 0.00 & 0.00 & 0.00 & 0.03 & 0.05 & 0.15 & 0.33 & 1.40 & 3.07 & 3.07 & 4.79 & 11.69 & 29.76 & 29.34 & 14.67 & 1.59 & 0.05 & 0.00 \\
\hline
\end{tabular}

